\title{
Soil and Slope Stability Study of Geomorphic Landform Profiles versus Approximate Original Contour for Valley Fill Designs
}

Harold Russell

West Virginia University

Follow this and additional works at: https://researchrepository.wvu.edu/etd

\section{Recommended Citation}

Russell, Harold, "Soil and Slope Stability Study of Geomorphic Landform Profiles versus Approximate Original Contour for Valley Fill Designs" (2012). Graduate Theses, Dissertations, and Problem Reports. 4914.

https://researchrepository.wvu.edu/etd/4914

This Thesis is protected by copyright and/or related rights. It has been brought to you by the The Research Repository @ WVU with permission from the rights-holder(s). You are free to use this Thesis in any way that is permitted by the copyright and related rights legislation that applies to your use. For other uses you must obtain permission from the rights-holder(s) directly, unless additional rights are indicated by a Creative Commons license in the record and/ or on the work itself. This Thesis has been accepted for inclusion in WVU Graduate Theses, Dissertations, and Problem Reports collection by an authorized administrator of The Research Repository @ WVU. For more information, please contact researchrepository@mail.wvu.edu. 


\title{
Soil and Slope Stability Study of Geomorphic Landform Profiles versus Approximate Original Contour for Valley Fill Designs
}

\author{
Harold Russell, EIT \\ Thesis submitted to the \\ Benjamin M. Statler College of Engineering and Mineral Resources \\ at West Virginia University \\ in partial fulfillment of the requirements \\ for the degree of \\ Master of Science \\ in \\ Civil and Environmental Engineering \\ John D. Quaranta, Ph.D., P.E., Chair \\ Hema Siriwardane, Ph.D., P.E. \\ Vladislav Kecojevic, Ph.D \\ Department of Civil and Environmental Engineering \\ Morgantown, West Virginia \\ 2012
}

KEYWORDS: Approximate original contour, geomorphic landform design, valley fill, slope stability analysis, soil testing 


\title{
ABSTRACT
}

\section{Soil and Slope Stability Study of Geomorphic Landform Profiles versus Approximate Original Contour for Valley Fill Designs}

\author{
Harold B. Russell
}

This report presents the findings of geotechnical testing on two material types retrieved from a surface mine site in Logan County, West Virginia, and investigates geomorphic landform design as an alternative in lieu of typical valley fill design and approximate original contour (AOC) surface mine reclamation design. Laboratory testing was carried out according to ASTM standard test methods. The scope of the testing performed involved grain size distribution analysis, hydrometer analysis, saturated shear strength testing under an insitu consolidation load, Atterberg limits including plastic and liquid limits, compaction at three predetermined compaction energies, and rigid wall permeameter hydraulic conductivity testing. Data was evaluated and analyzed to find to what degree the material particles moved under certain hydraulic gradients and if the particle movement affected the shear strength of the samples. The objectives of the testing were to understand the movement and behavior of small diameter soil particles at a valley fill and use the strength values as input parameters into several modules of GeoStudio $^{\mathrm{TM}}$ for numerical slope stability modeling.

The numerical modeling involved geomorphic design for a proposed valley fill in southern West Virginia using commercial software following the Geofluv® method. A comprehensive seepage and slope stability analysis was then developed using the SEEP/W, SIGMA/W, and SLOPE/W modules of GeoStudio2007TM for assessing the groundwater flow characteristics of the blasted, unweathered sandstone fill, an insitu load calculation, and the resultant limit equilibrium analysis of slope stability (static factor of safety). These analyses were performed for both the AOC and geomorphic fill designs.

The cumulative analysis for the geomorphic valley fill alternative design yielded the highest factors of safety. Most cases produced factors of safety over 2.0. The failure locations were sought out to produce the lowest factors of safety for the structure. None of the factors of safety modeled yielded factors of safety under 1.0 for the geomorphic design. The results imply that the geomorphic design can remain very stable when a range of hydrologic conditions and geometries are applied.

Regulations require that reclaimed slope factors of safety must remain above 1.5. The analyses performed showed that the AOC valley fill design could withstand insitu loads and produced slope angles under most hydrologic conditions analyzed. Elevated pore pressures tended to result at the toe of the slope, and decreased the factor of safety. The most critical scenario was a fully saturated toe which yielded a factor of safety of 0.50 .

If particle transport can occur and alter toe pore pressures, it is possible that some small slope failure may occur. The gradations that were found for the unweathered well graded sand with silt fill material showed that particle transport would not be a significant concern. The gradations that were found for the range of cases analyzed for the unweathered well graded sand with silt showed aggregation phenomena which could have implications on the long term stability of the earthen structures. 


\section{ACKNOWLEDGEMENTS}

I would like to gratefully acknowledge the enthusiastic supervision of Dr. John D. Quaranta, a great teacher and advisor who was abundantly helpful and offered invaluable assistance, support and guidance to accomplish this research project. His technical insight was of priceless value. I wish to thank Dr. Hema J. Siriwardane and Dr. Vlad Kecojevic for being in my advisory Committee.

I wish to thank Mr. Jeremi Stawovy, Mr. Nathan DePriest, and Ms. Allison Sears for assistance in laboratory testing and computer modeling.

I also wish to thank the engineers and staff members from Coal-Mac, Incorporated who provided support for the program.

I would like to dedicate this thesis to my wonderful grandparents, parents, brother, and my closest friends for the love, support and encouragement they have provided throughout my academic career. Additionally, I would like to recognize the contribution of the events, good and bad, over the course of my life thus far which have shaped me to take on a challenging career in civil engineering. 


\section{TABLE OF CONTENTS}

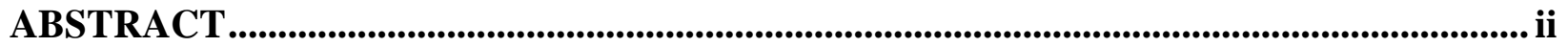

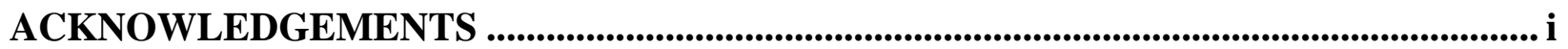

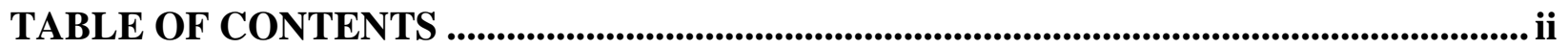

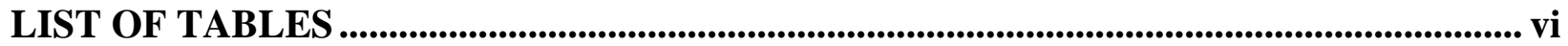

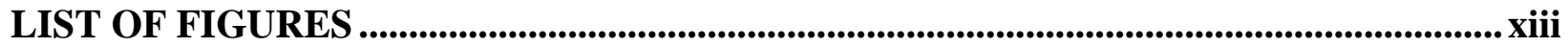

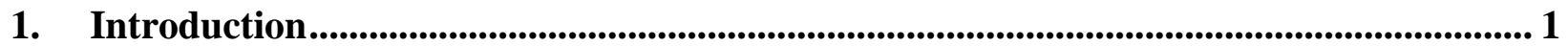

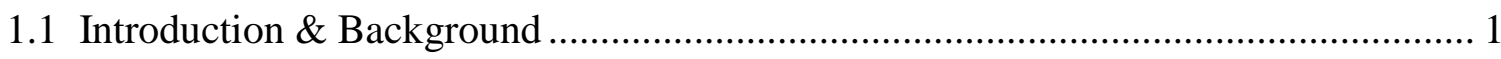

1.2 Research Purpose \& Objectives ....................................................................... 1

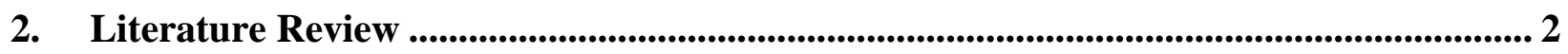

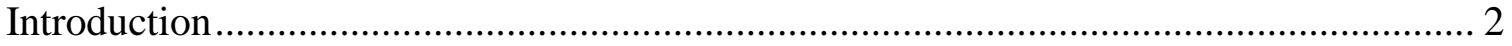

Regulatory Drivers Affecting Geomorphic Landform Design ................................... 3

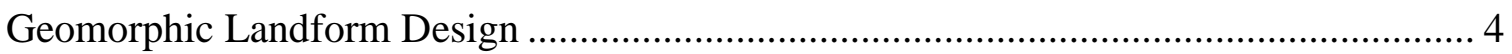

Geomorphic Landform Design of a Valley Fill Under Construction .............................. 5

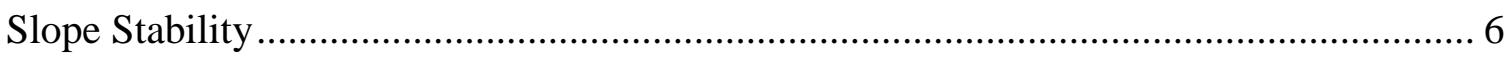

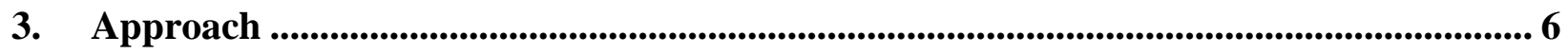

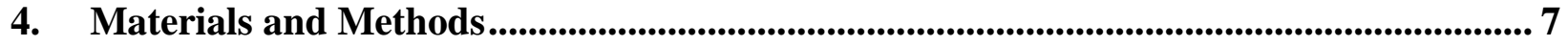

5. Material Properties and Results: Weathered Sandstone ......................................... 7

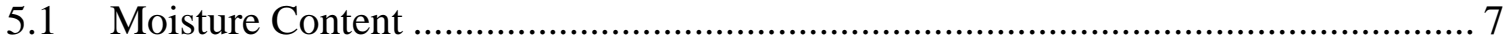

5.2 As Received Grain Size Distribution and Hydrometer Analysis .......................... 8

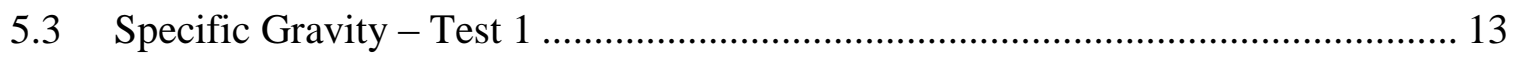

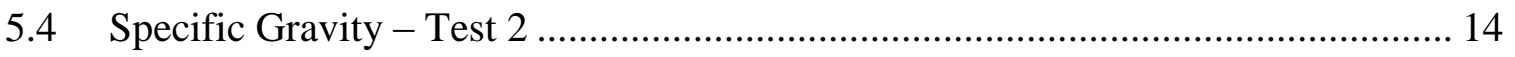

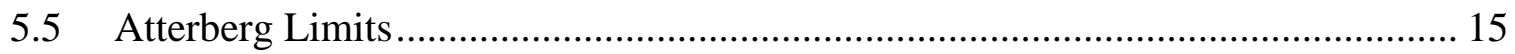

6. Material Properties: Unweathered Sandstone Overburden .................................. 16

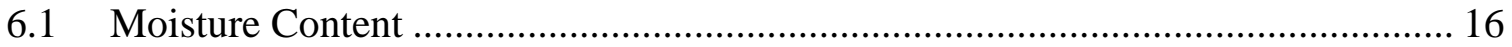

6.2 As Received Grain Size Distribution................................................................ 17

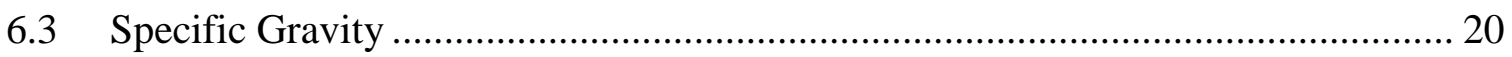

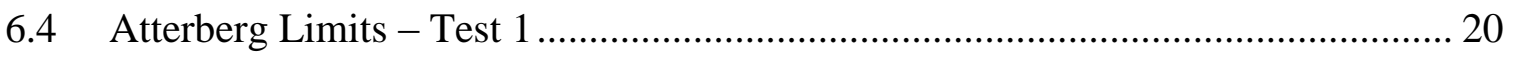

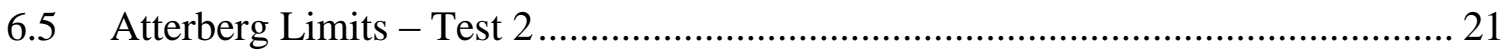

6.6 Weathered and Unweathered Sandstone Comparison ....................................... 23

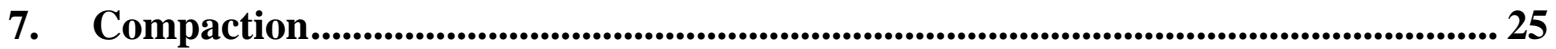

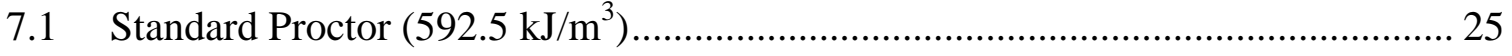


7.2 Proctor Compaction Energy at 34\%: 12 Blows/Layer, 2 Layers $\left(203.6 \mathrm{~kJ} / \mathrm{m}^{3}\right) \ldots .27$

7.3 Proctor Compaction Energy at 11\%: 4 Blows/Layer, 2 Layers $\left(67.85 \mathrm{~kJ} / \mathrm{m}^{3}\right)$...... 29

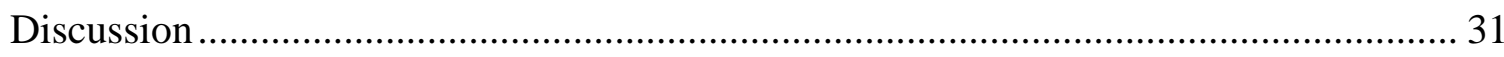

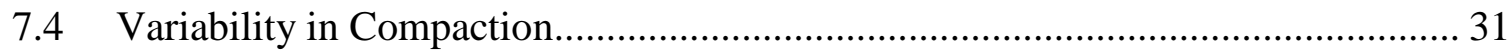

8. Strength Testing ...................................................................................................................... 33

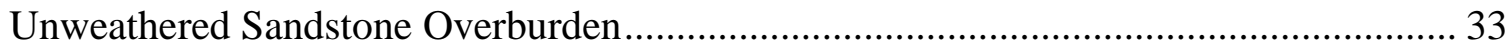

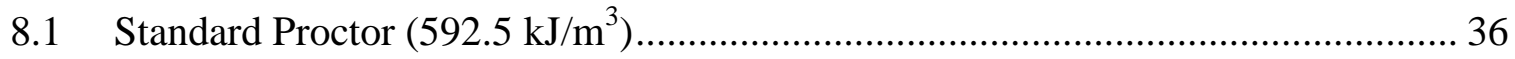

8.2 Proctor Compaction Energy at 34\%: 12 Blows/Layer, 2 Layers $\left(203.6 \mathrm{~kJ} / \mathrm{m}^{3}\right)$.... 40

8.3 Proctor Compaction Energy at 11\%: 4 Blows/Layer, 2 Layers $\left(67.85 \mathrm{~kJ} / \mathrm{m}^{3}\right) \ldots \ldots . .44$

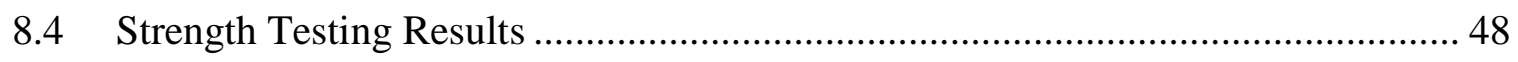

9. Pre-Permeability Grain Size Distribution ........................................................................... 49

9.1 Grain Size Distribution: Standard Proctor $\left(592.5 \mathrm{~kJ} / \mathrm{m}^{3}\right)$................................ 49

9.2 Grain Size Distribution: 34\% Proctor Compaction Energy $\left(203.6 \mathrm{~kJ} / \mathrm{m}^{3}\right) \ldots \ldots \ldots \ldots . .51$

9.3 Grain Size Distribution: 11\% Proctor Compaction Energy $\left(67.85 \mathrm{~kJ} / \mathrm{m}^{3}\right)$........... 53

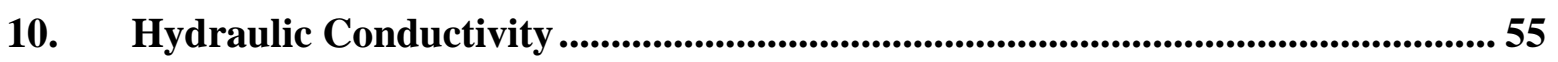

10.1 Hydraulic Conductivity: Standard Proctor $\left(592.5 \mathrm{~kJ} / \mathrm{m}^{3}\right)$................................ 55

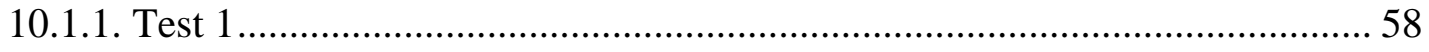

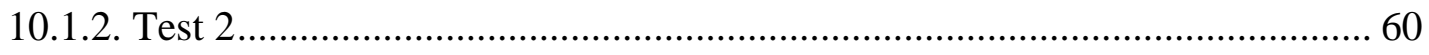

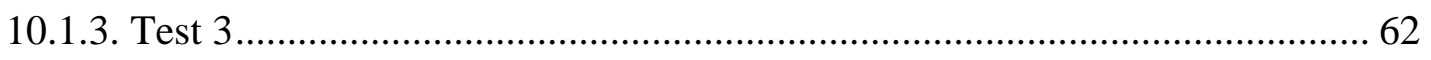

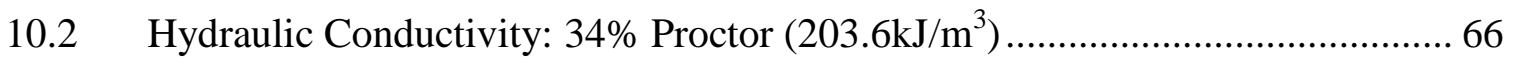

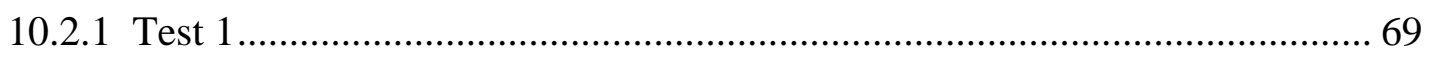

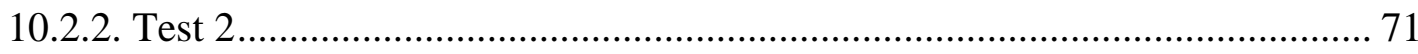

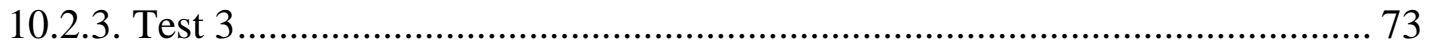

10.3 Hydraulic Conductivity: $11 \%$ Proctor $\left(67.85 \mathrm{~kJ} / \mathrm{m}^{3}\right)$................................... 77

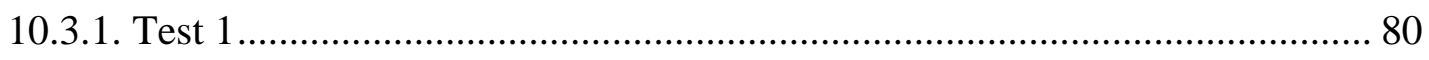

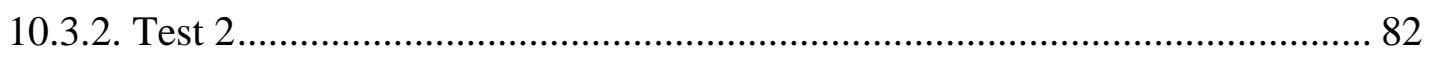

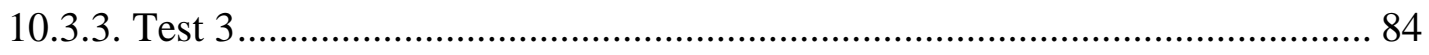

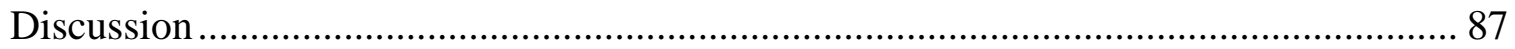

11. Post-Permeability Grain Size Distribution .................................................................... 88

11.1 Post-Permeability Grain Size Distribution: Standard Proctor $\left(592.5 \mathrm{~kJ} / \mathrm{m}^{3}\right)$...... 88

11.2 Post-Permeability Grain Size Distribution: $34 \%$ Proctor $\left(203.6 \mathrm{~kJ} / \mathrm{m}^{3}\right) \ldots \ldots \ldots \ldots . . .91$

11.3 Post-Permeability Grain Size Distribution: $11 \%$ Proctor $\left(67.85 \mathrm{~kJ} / \mathrm{m}^{3}\right) \ldots \ldots \ldots \ldots . .93$ 
11.3.1 Post-Permeability Grain Size Distribution: 11\% Proctor - Test 1 ................... 93

11.3.2 Post-Permeability Grain Size Distribution: $11 \%$ Proctor - Test 2 ................... 95

11.3.3 Post-Permeability Grain Size Distribution: 11\% Proctor - Test 3 ................... 97

12. Grading Envelopes and Particle Transport ..................................................99

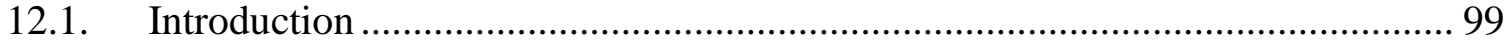

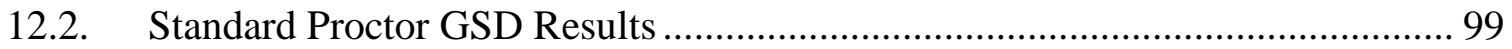

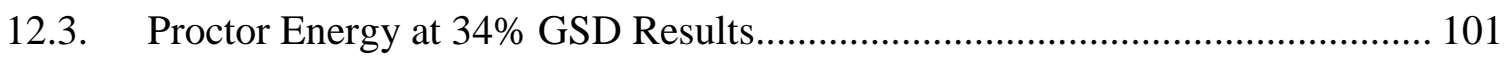

12.4. Proctor Energy at $11 \%$ GSD Results..................................................... 103

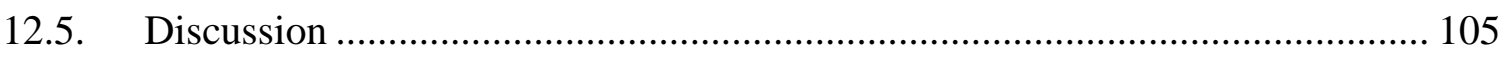

13. Numerical Modeling ….............................................................................................. 107

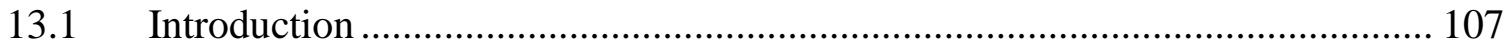

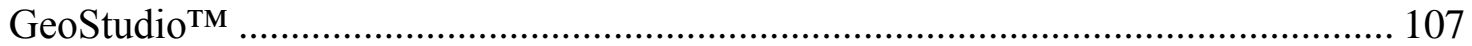

General Limit Equilibrium Theory and Method ................................................. 107

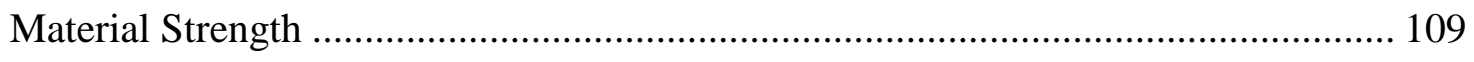

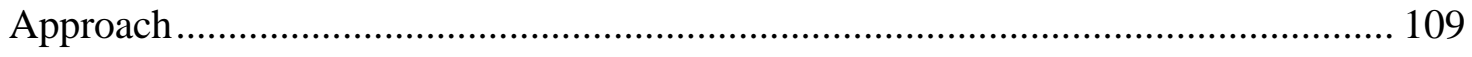

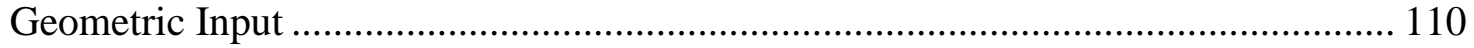

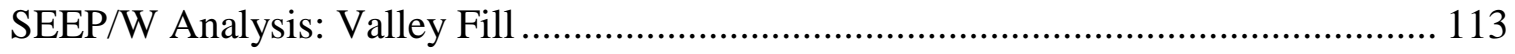

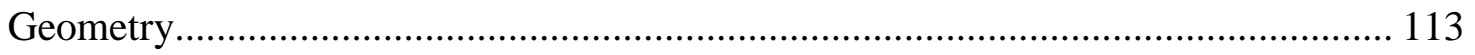

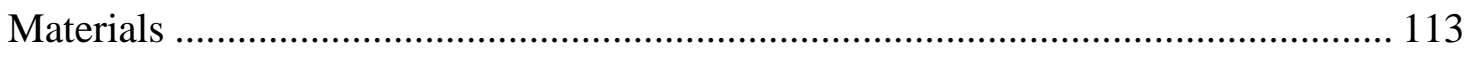

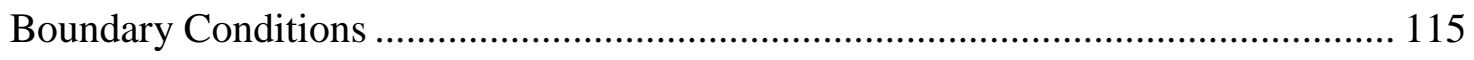

SEEP/W Analysis: Geomorphic Fill.......................................................................... 116

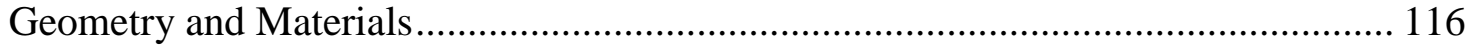

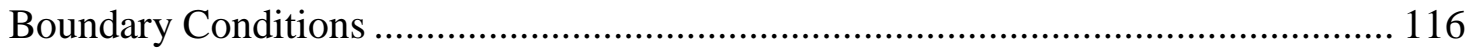

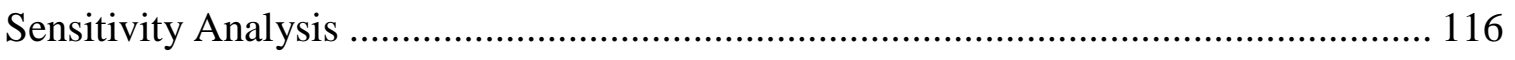

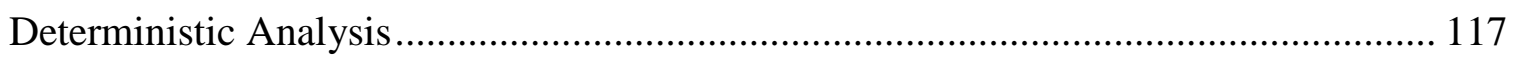

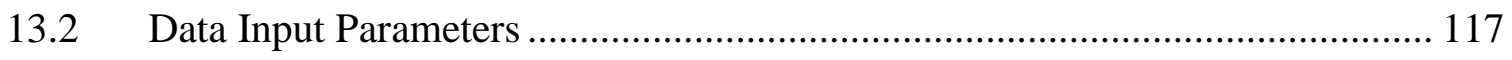

13.3 Stability Analysis: AOC Valley Fill Design ............................................ 121

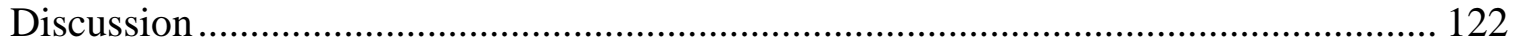

13.4 Stability Analysis: Geomorphic Valley Fill Alternative ................................ 123

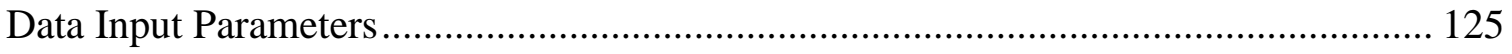

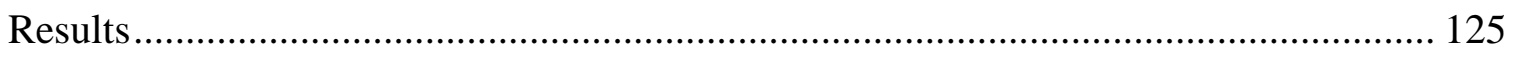

13.5 Cumulative Analysis: AOC Valley Fill Design ......................................... 127 


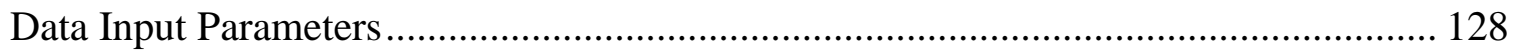

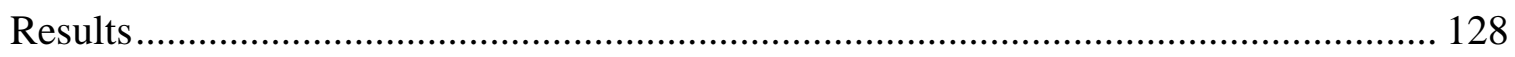

13.6 Cumulative Analysis: Geomorphic Valley Fill Alternative ............................. 130

Data Input Parameters ............................................................................................ 131

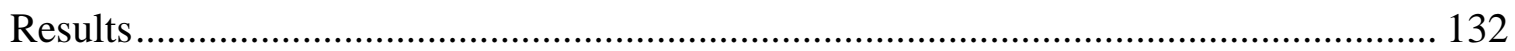

13.7 Geomorphic Design Critical Slope Analysis .................................................. 133

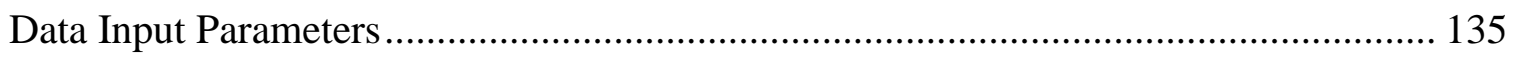

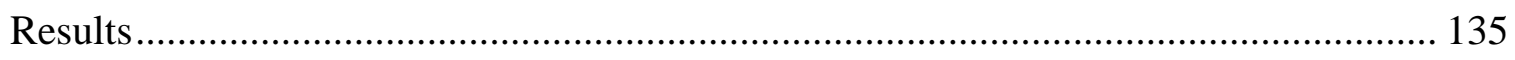

AOC Valley Fill and Geomorphic Alternative Profiles................................................ 137

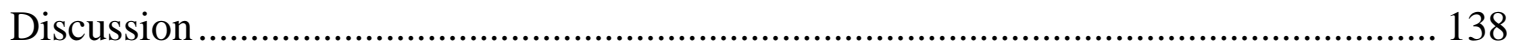

Summary and Comparison .................................................................................... 139

14. Conclusions and Practical Significance ................................................................... 143

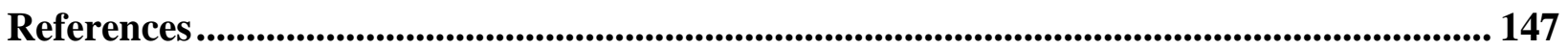

Appendices........................................................................................................................................... 150

Appendix I - Hydraulic Conductivity Data Tables …………………....................... 150

Appendix II - Compaction Data ………………………..................................... 190

Appendix III - Grain Size Distribution Testing Data.................................................. 196

Post-Permeability Grain Size Distribution Data .................................................... 196

Pre-Permeability Grain Size Distribution Data...................................................... 202

As-Received Grain Size Distribution Data: Weathered Sandstone Material.......... 208

As-Received Grain Size Distribution Data: Unweathered Sandstone Overburden 209

Appendix IV - Specific Gravity and Atterberg Limit Data.......................................... 211

Weathered Sandstone - Specific Gravity - Test 1 Data ........................................... 211

Weathered Sandstone - Atterberg Limit Data ....................................................... 213

Unweathered Sandstone - Specific Gravity Data ................................................... 214

Unweathered Sandstone - Atterberg Limit Data - Test 1 ...................................... 215

Unweathered Sandstone - Atterberg Limit Data - Test 2 …….............................. 215

Appendix V - Direct Shear Data ....................................................................... 217 


\section{LIST OF TABLES}

Table 5.1 Moisture Content Data .............................................................................. 8

Table 5.2 Average Moisture Content and Statistics.......................................................... 8

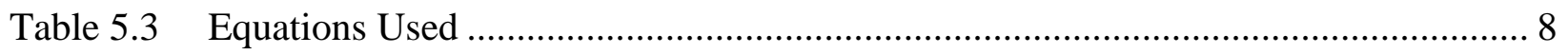

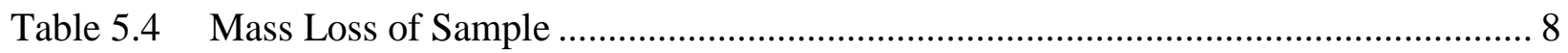

Table 5.5 Critical Index Values and Coefficients ............................................................. 9

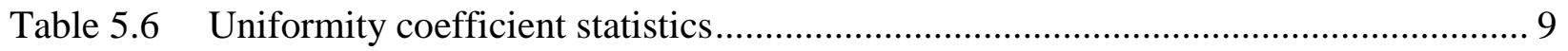

Table 5.7 Coefficient of gradation statistics ............................................................ 9

Table 5.8 Weathered Sandstone GW sample hydrometer data......................................... 11

Table 5.9 Hydrometer equations and definitions .......................................................... 11

Table 5.10 Test statistics for specific gravity of soil solids........................................... 13

Table 5.11 Test statistics for specific gravity at the test temperature .................................. 13

Table 5.12 Specific gravity equations and definitions .................................................... 13

Table 5.13 Test statistics for specific gravity of soil solids............................................. 14

Table 5.14 Test statistics for specific gravity at the test temperature.................................. 14

Table 5.15 Determination of plastic limit, liquid limit and plasticity index .......................... 15

Table 6.1 Moisture Content Data ..................................................................................... 16

Table 6.2 Average Moisture Content and Statistics......................................................... 16

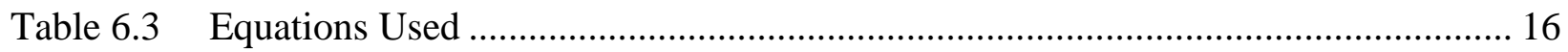

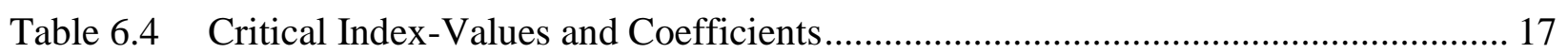

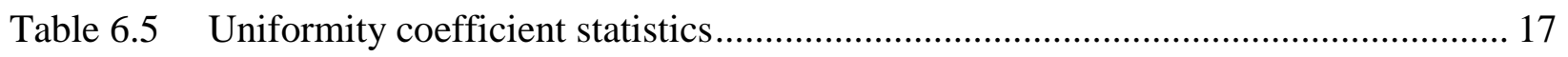

Table 6.6 Coefficient of gradation statistics ................................................................... 18

Table 6.7 Unweathered Sandstone SW-SM sample hydrometer data. ................................. 19

Table 6.8 Test statistics for specific gravity of soil solids............................................. 20

Table 6.9 Test statistics for specific gravity at the test temperature.................................... 20

Table 6.10 Determination of plastic limit, liquid limit and plasticity index ........................ 20

Table 6.11 Determination of plastic limit, liquid limit and plasticity index ......................... 22

Table 6.12 Soil Property summary table for unweathered and weathered sandstone.............. 23

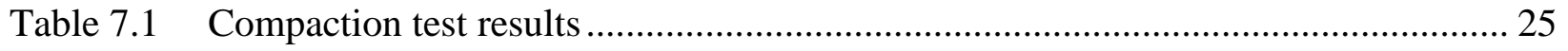

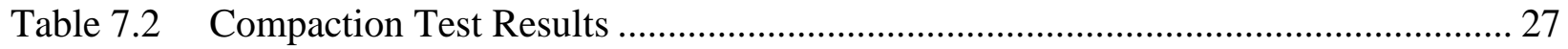




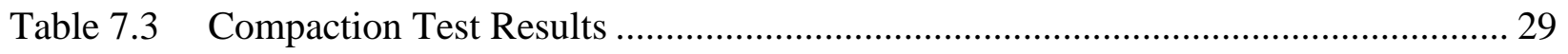

Table 8.1 Stress conditions for direct shear test depths (DS1, DS2, DS3) .......................... 35

Table 8.2 Direct shear peak data and calculated values .................................................. 37

Table 8.3 Direct shear peak data and calculated values .................................................. 41

Table 8.4 Direct shear peak data and calculated values ................................................. 45

Table 8.5 Friction angle results with shear stresses and normal stresses shown ................... 48

Table 9.1 Critical index values for the direct shear grain size distribution testing................. 49

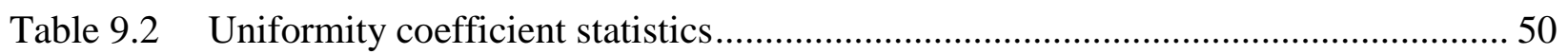

Table 9.3 Coefficient of gradation statistics .................................................................. 50

Table 9.4 Critical index values for the direct shear grain size distribution testing................ 51

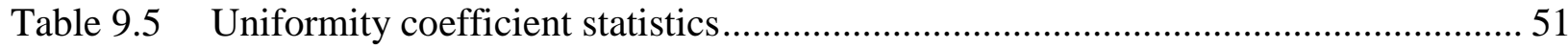

Table 9.6 Coefficient of gradation statistics ................................................................ 51

Table 9.7 Critical index values for the direct shear grain size distribution testing................ 53

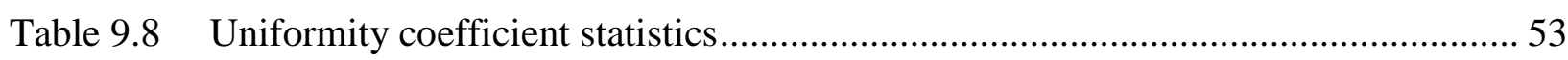

Table 9.9 Coefficient of gradation statistics ............................................................... 53

Table 10.1 Hydraulic conductivty standard proctor compaction energy specimen data......... 56

Table 10.2 Sample properties for the hydraulic conductivity specimen...............................58

Table 10.3 Sample characteristics for the hydraulic conductivity specimen .........................59

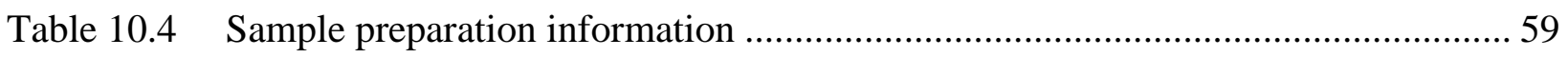

Table 10.5 Hydraulic gradient calculation information ................................................. 59

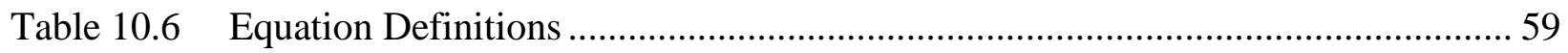

Table 10.7 Hydraulic conductivity results - Statistics (Last 5 data points)......................... 60

Table 10.8 Sample properties for the hydraulic conductivity specimen.............................. 60

Table 10.9 Sample characteristics for the hydraulic conductivity specimen ........................ 61

Table $10.10 \quad$ Sample preparation information................................................................ 61

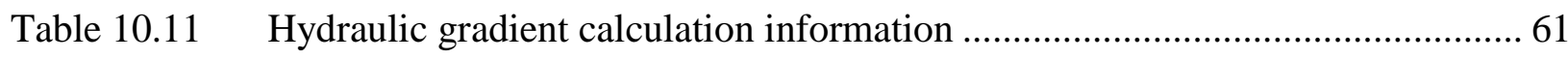

Table 10.12 Hydraulic conductivity results - Statistics (Last 5 data points) ...................... 61

Table 10.13 Sample properties for the hydraulic conductivity specimen ........................... 62

Table 10.14 Sample characteristics for the hydraulic conductivity specimen. .................... 63

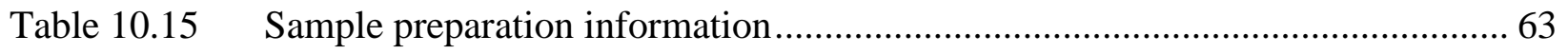

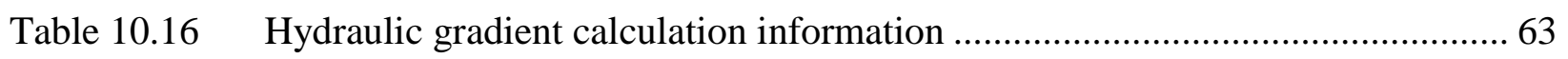

Table 10.17 Hydraulic conductivity results - Statistics (Last 5 data points) ....................... 64 


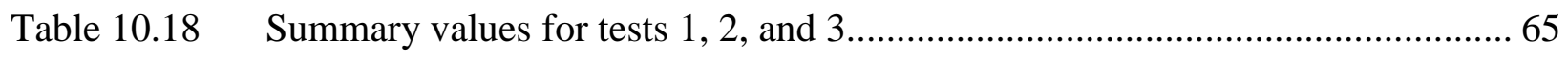

Table 10.19 Hydraulic conductivity 34\% Proctor compaction energy specimen data. ......... 67

Table 10.20 Sample characteristics for the hydraulic conductivity specimen ..................... 69

Table 10.21 Sample properties for the hydraulic conductivity specimen ........................... 69

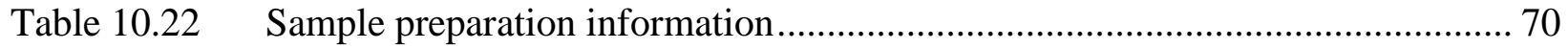

Table 10.23 Hydraulic gradient calculation information ................................................. 70

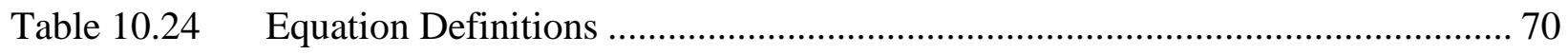

Table 10.25 Hydraulic conductivity results - Statistics (All test 1 data) ............................ 70

Table 10.26 Hydraulic conductivity results - Statistics (Last 5 data points) ........................ 70

Table 10.27 Sample characteristics for the hydraulic conductivity specimen .................... 71

Table 10.28 Sample properties for the hydraulic conductivity specimen ............................ 71

Table 10.29 Sample preparation information................................................................. 72

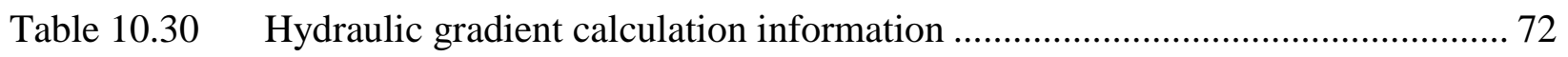

Table 10.31 Hydraulic conductivity results - Statistics (All test 2 data) ............................ 72

Table 10.32 Hydraulic conductivity results - Statistics (Last 5 data points) ....................... 72

Table 10.33 Sample characteristics for the hydraulic conductivity specimen ..................... 73

Table 10.34 Sample properties for the hydraulic conductivity specimen ........................... 73

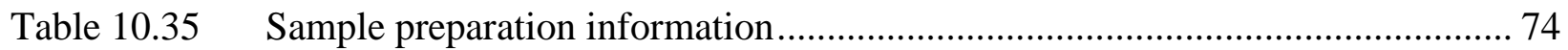

Table $10.36 \quad$ Hydraulic gradient calculation information ............................................... 74

Table 10.37 Hydraulic conductivity results - Statistics (All test 3 data) ............................ 74

Table 10.38 Hydraulic conductivity results - Statistics (Last 5 data points) ....................... 74

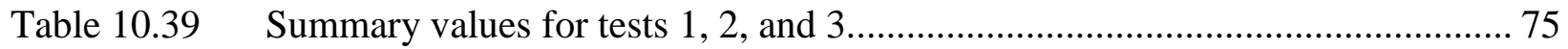

Table $10.40 \quad$ Hydraulic conductivity $11 \%$ Proctor compaction energy specimen data. ......... 78

Table 10.41 Sample characteristics for the hydraulic conductivity specimen ..................... 80

Table 10.42 Sample properties for the hydraulic conductivity specimen ........................... 80

Table $10.43 \quad$ Sample preparation information .............................................................. 81

Table $10.44 \quad$ Hydraulic gradient calculation information .............................................. 81

Table $10.45 \quad$ Hydraulic conductivity results - Statistics (All test 1 data) ............................ 81

Table 10.46 Hydraulic conductivity results - Statistics (Last 5 data points) ....................... 81

Table 10.47 Sample characteristics for the hydraulic conductivity specimen ..................... 82

Table 10.48 Sample properties for the hydraulic conductivity specimen ............................ 82

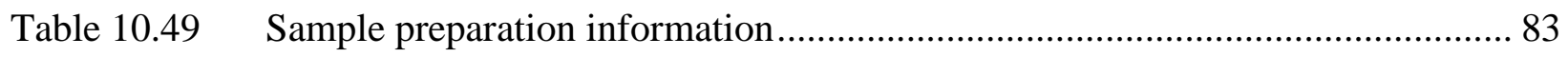




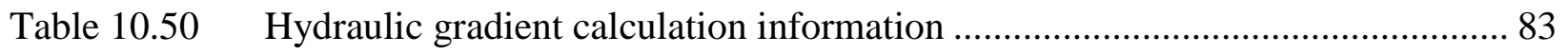

Table 10.51 Hydraulic conductivity results - Statistics (All test 1 data) ............................. 83

Table 10.52 Hydraulic conductivity results - Statistics (Last 5 data points) ....................... 83

Table 10.53 Sample characteristics for the hydraulic conductivity specimen ..................... 84

Table 10.54 Sample properties for the hydraulic conductivity specimen ............................ 84

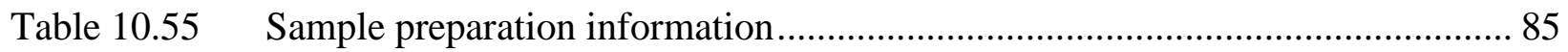

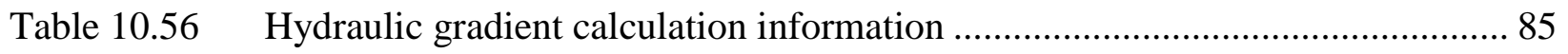

Table 10.57 Hydraulic conductivity results - Statistics (All test 1 data) ........................... 85

Table 10.58 Hydraulic conductivity results - Statistics (Last 5 data points) ........................ 85

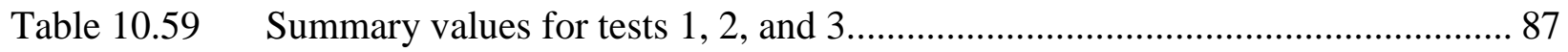

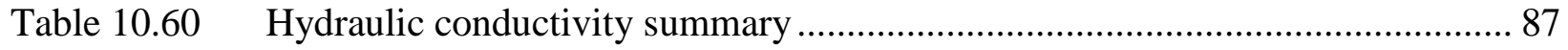

Table 11.1 Critical index values for the hydraulic conductivity grain size distribution testing. 89

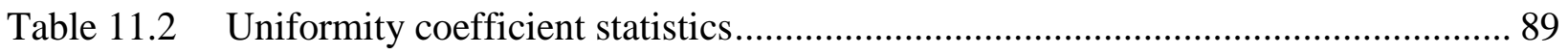

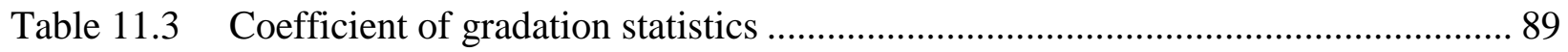

Table 11.4 Critical index values for the hydraulic conductivity grain size distribution testing. 91

Table 11.5 Uniformity coefficient statistics........................................................... 91

Table 11.6 Coefficient of gradation statistics ............................................................ 92

Table 11.7 Critical index values for the hydraulic conductivity grain size distribution testing 93

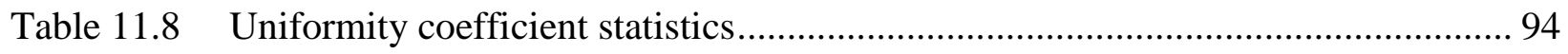

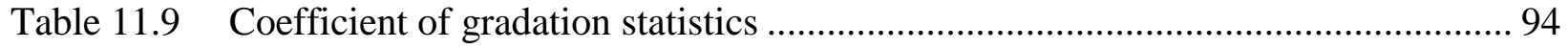

Table 11.10 Critical index values for the hydraulic conductivity grain size distribution testing. 95

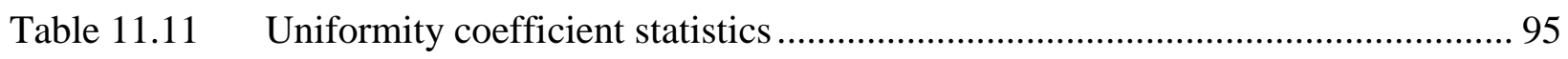

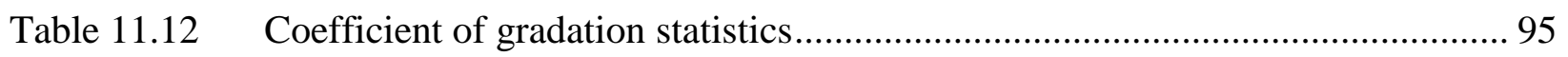

Table 11.13 Critical index values for the hydraulic conductivity grain size distribution testing. 97

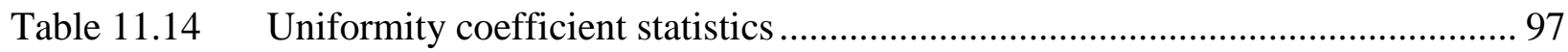

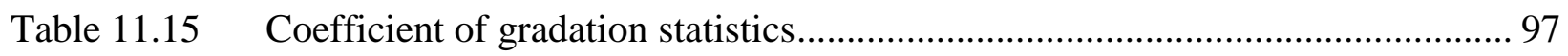

Table 12.1 Change in critical index summary table.................................................... 106

Table 13.1. Laboratory friction angle values .......................................................... 118

Table 13.2. Laboratory friction angle statistics for sensitivity model input ......................... 118 
Table 13.3. Laboratory dry unit weight $\left(\gamma_{\mathrm{d}}\right)$ values at predetermined compaction energies ... 118

Table 13.4. Laboratory dry unit weight $\left(\gamma_{\mathrm{d}}\right)$ statistics for sensitivity model input ................. 119

Table 13.5. Deterministic SLOPE/W material input values ............................................. 119

Table 13.6. Sensitivity SLOPE/W material input values .................................................. 120

Table 13.7. SIGMA/W material input values ................................................................. 120

Table 13.8. Deterministic critical factors of safety (FOS) for selected scenarios using AOC

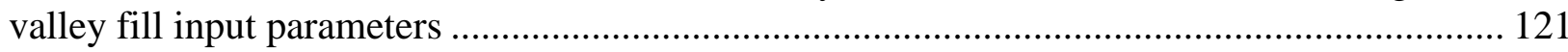

Table 13.9. Deterministic critical factors of safety for selected scenarios using laboratory value 121

Table 13.10. Sensitivity assessment: Critical factor of safety results for selected scenarios. 122

Table 13.11. Deterministic critical factors of safety for two piezometric scenarios............. 125

Table 13.12. Sensitivity critical factors of safety for two piezometric scenarios ................ 126

Table 13.13. Deterministic factor of safety results: Saturated Underdrain .......................... 128

Table 13.14. Deterministic factor of safety results: Unsaturated Underdrain..................... 129

Table 13.15. Sensitivity factor of safety results: Saturated Underdrain............................. 129

Table 13.16. Sensitivity factor of safety results: Unsaturated underdrain .......................... 129

Table 13.17. Deterministic critical factor of safety results for the geomorphic design valley fill alternative under an initial saturated underdrain condition................................................ 132

Table 13.18. Sensitivity critical factor of safety results for the geomorphic design valley fill alternative under an initial saturated undedrain condition ................................................... 132

Table 13.19. Deterministic critical factor of safety results for the geomorphic design valley fill alternative under an initial unsaturated underdrain condition............................................ 132

Table 13.20. Sensitivity critical factor of safety results for the geomorphic design valley fill alternative under an initial unsaturated undedrain condition ........................................... 133

Table 13.21. Sensitivity critical factor of safety results for the critical slope for two

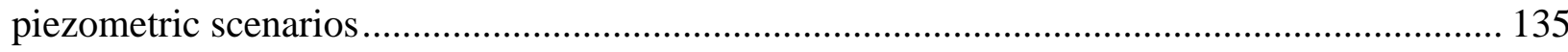

Table 13.22. Deterministic critical factor of safety results for the critical slope for two

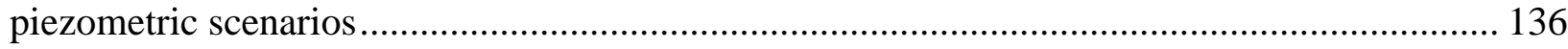

Table 13.23. Critical slip plane approximate exit point slope angles................................ 139

Table 13.24. AOC valley fill slope summary ............................................................ 141

Table 13.25. Geomorphic valley fill alternative slope summary .................................... 142

Hydraulic Conductivity: Test 1 - Standard Proctor Compaction $\left(592.5 \mathrm{~kJ} / \mathrm{m}^{3}\right)$.................. 150

Hydraulic Conductivity: Test 1 - Standard Proctor Compaction $\left(592.5 \mathrm{~kJ} / \mathrm{m}^{3}\right)$ : Continued...... 152

Hydraulic Conductivity: Test 1 - Standard Proctor Compaction $\left(592.5 \mathrm{~kJ} / \mathrm{m}^{3}\right)$ : Continued..... 154

Hydraulic Conductivity: Test 1 - Standard Proctor Compaction $\left(592.5 \mathrm{~kJ} / \mathrm{m}^{3}\right)$ : Continued...... 156 
Hydraulic Conductivity: Test 2 - Standard Proctor Compaction $\left(592.5 \mathrm{~kJ} / \mathrm{m}^{3}\right)$................... 158 Hydraulic Conductivity: Test 2 - Standard Proctor Compaction $\left(592.5 \mathrm{~kJ} / \mathrm{m}^{3}\right)$ : Continued ...... 160 Hydraulic Conductivity: Test 2 - Standard Proctor Compaction $\left(592.5 \mathrm{~kJ} / \mathrm{m}^{3}\right)$ : Continued ...... 161 Hydraulic Conductivity: Test 2 - Standard Proctor Compaction $\left(592.5 \mathrm{~kJ} / \mathrm{m}^{3}\right)$ : Continued ...... 163 Hydraulic Conductivity: Test 3- Standard Proctor Compaction $\left(592.5 \mathrm{~kJ} / \mathrm{m}^{3}\right)$...................... 164 Hydraulic Conductivity: Test 3- Standard Proctor Compaction $\left(592.5 \mathrm{~kJ} / \mathrm{m}^{3}\right)$ : Continued ....... 166 Hydraulic Conductivity: Test 3- Standard Proctor Compaction $\left(592.5 \mathrm{~kJ} / \mathrm{m}^{3}\right)$ : Continued ....... 168 Hydraulic Conductivity: Test 3- Standard Proctor Compaction $\left(592.5 \mathrm{~kJ} / \mathrm{m}^{3}\right)$ : Continued ...... 170 Hydraulic Conductivity: Test $1-34 \%$ Proctor Compaction $\left(203.6 \mathrm{~kJ} / \mathrm{m}^{3}\right)$......................... 172 Hydraulic Conductivity: Test $2-34 \%$ Proctor Compaction $\left(203.6 \mathrm{~kJ} / \mathrm{m}^{3}\right)$.......................... 176 Hydraulic Conductivity: Test $3-34 \%$ Proctor Compaction $\left(203.6 \mathrm{~kJ} / \mathrm{m}^{3}\right)$......................... 180 Hydraulic Conductivity: Test $1-11 \%$ Proctor Compaction $\left(67.85 \mathrm{~kJ} / \mathrm{m}^{3}\right)$......................... 184 Hydraulic Conductivity: Test $2-11 \%$ Proctor Compaction $\left(67.85 \mathrm{~kJ} / \mathrm{m}^{3}\right)$...................... 186 Hydraulic Conductivity: Test 3 - 11\% Proctor Compaction $\left(67.85 \mathrm{~kJ} / \mathrm{m}^{3}\right)$......................... 188

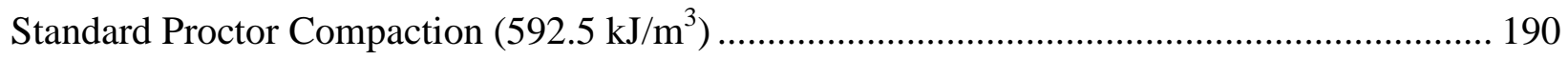

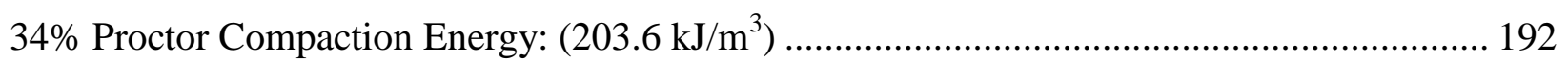

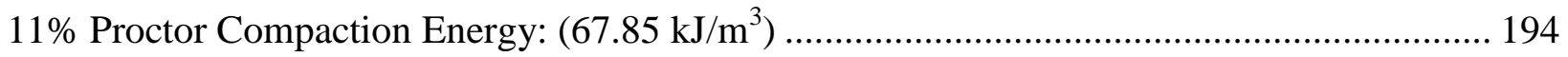

Standard Proctor Effort - Sieve analysis data for layer 1 and layer 2 ................................ 196

Standard Proctor Effort - Sieve analysis data for layer 3 ............................................... 197

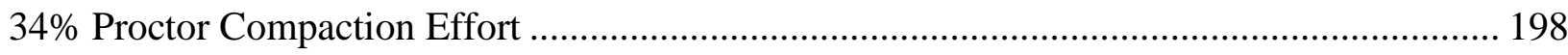

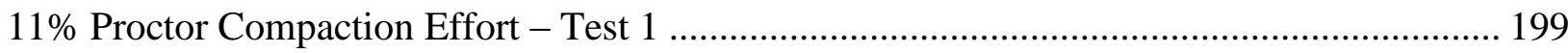

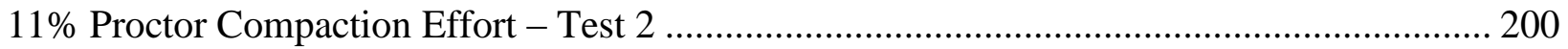

$11 \%$ Proctor Compaction Effort - Test 3 ................................................................... 201

Standard Proctor Compaction Effort - Sieve analysis data for layer 1 and layer 2................. 202

Standard Proctor Compaction Effort - Sieve analysis data for layer 3 ................................. 203

34\% Proctor Compaction Effort - Sieve analysis data for layer 1 and layer 2 ...................... 204

34\% Proctor Compaction Effort - Sieve analysis data for layer 3 ....................................... 205

11\% Proctor Compaction Effort - Sieve analysis data for layer 1 and layer 2 ..................... 206

11\% Proctor Compaction Effort - Sieve analysis data for layer 3 ....................................... 207

As Received Grain Size Distribution: Weathered Sandstone Material: Test 1, Test 2............. 208

As Received Grain Size Distribution: Unweathered Sandstone Overburden: Test 1, Test 2 ..... 209

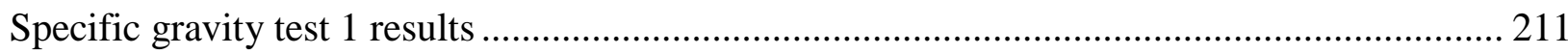


Water content for determining the dry mass of the test specimen..................................... 211

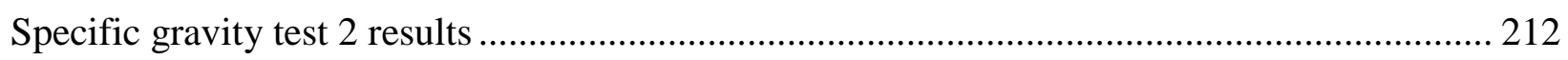

Water content for determining the dry mass of the test specimen ...................................... 212

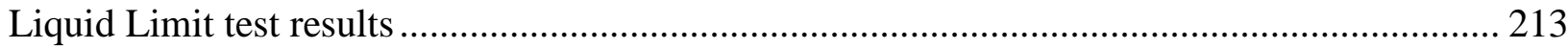

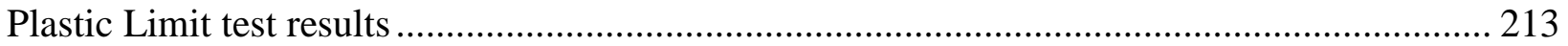

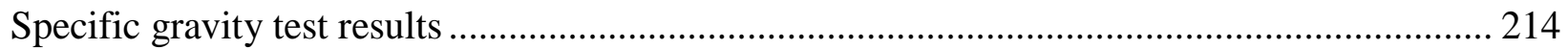

Moisture content for specific gravity test calculations .................................................. 214

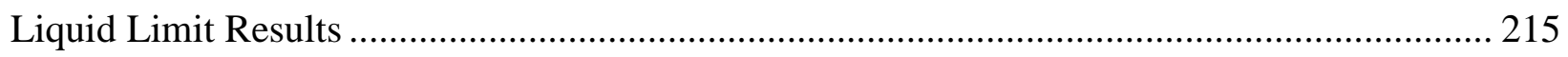

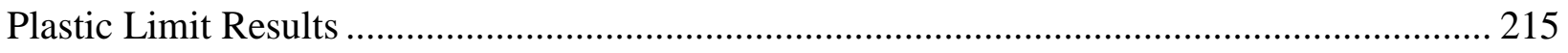

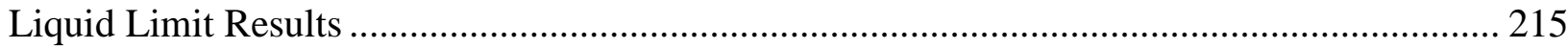

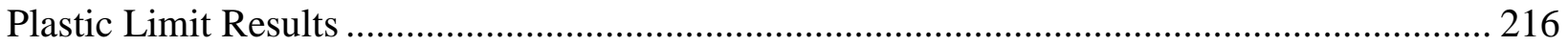

Unweathered Sandstone - Direct Shear Standard Proctor Compaction Data.......................... 217

Unweathered Sandstone - Direct Shear 34\% Proctor Compaction Data ............................... 218

Unweathered Sandstone - Direct Shear 11\% Proctor Compaction Data ................................ 219 


\section{LIST OF FIGURES}

Figure 1.1 Valley fill under construction with labeled design features................................ 5

Figure 5.1 Grain Size Distribution of two as received samples ......................................... 10

Figure 5.2 Grain size distribution graph including hydrometer data. ................................ 12

Figure 5.3 Liquid limit graph for the weathered sandstone material ................................ 15

Figure 6.1 Grain Size Distribution of two samples of unweathered sandstone overburden SW. 18

Figure 6.2 Grain size distribution including hydrometer data.......................................... 19

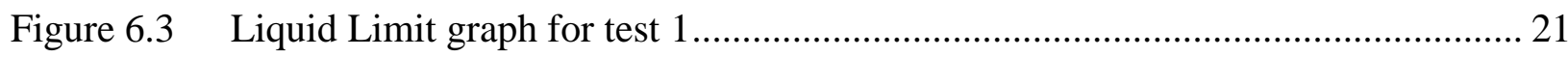

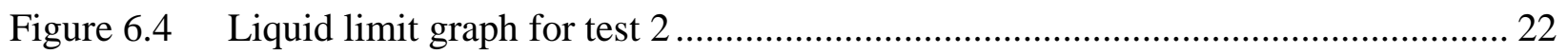

Figure 6.5 As received grain size distributions of weathered and unweathered sandstone ..... 24

Figure 7.1 Standard proctor curve with lines at 100\% and 90\% saturation.......................... 26

Figure $7.2 \quad 34 \%$ Proctor curve with lines at $100 \%$ and $90 \%$ saturation................................ 28

Figure $7.3 \quad 11 \%$ Proctor compaction curve with lines at $100 \%$ and $90 \%$ saturation.............. 30

Figure 7.4 Compaction curve compilation ...................................................................... 30

Figure 7.5 34\% Proctor compaction energy $\left(203.6 \mathrm{~kJ} / \mathrm{m}^{3}\right)$ : Variability in dry density........... 32

Figure $7.6 \quad 11 \%$ Proctor Compaction Energy $\left(67.85 \mathrm{~kJ} / \mathrm{m}^{3}\right)$ : Variability in dry density ......... 32

Figure 8.1 Shows the centerline and the points of evaluation on the valley fill under inspection

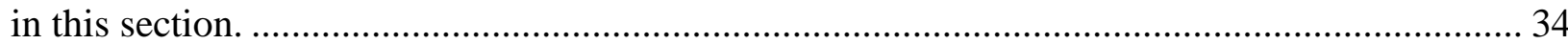

Figure 8.2 Slope profile of an AOC fill design illustrating determined stress evaluation points

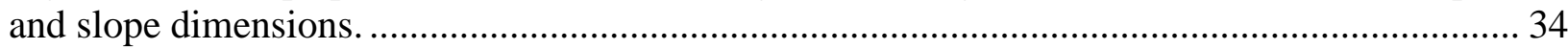

Figure 8.3 Comparison of the direct shear standard proctor compaction specimen and other

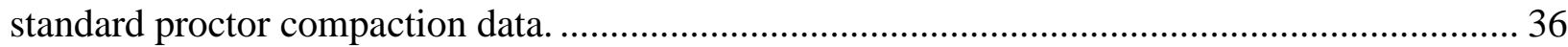

Figure 8.4 Shear stress versus normal stress plot of the standard proctor specimen .............. 37

Figure 8.5 Shear stress versus normal stress saturated and unsaturated conditions of the

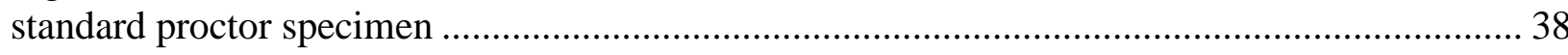

Figure 8.6 Shear stress versus horizontal displacement of test 1 (DS1) and test 2 (DS2)..... 38

Figure 8.7 Shear stress versus shear strain of test 1 (DS1) and test 2 (DS2) ...................... 39

Figure 8.8 Comparison of the direct shear 34\% Proctor compaction specimen and other 34\% Proctor compaction energy specimen data.

Figure 8.9 Shear stress versus normal stress plot of test 1 (DS31), test 2 (DS32), and test 3 (DS33) $\quad 41$ 
Figure 8.10 Shear stress versus normal stress saturated and unsaturated conditions of test 1 (DS31), test 2 (DS32), and test 3 (DS33)

Figure 8.11 Shear stress versus horizontal displacement of layer 1, layer 2, and layer 3..... 42

Figure 8.12 Shear stress versus shear strain of layer 1, layer 2, and layer 3..................... 43

Figure 8.13 Comparison of the direct shear 11\% Proctor compaction specimen and other $11 \%$ Proctor compaction data.

Figure 8.14 Shear stress versus normal stress plot of $11 \%$ Proctor compaction layer 1, layer 2, and layer $3 \quad 45$

Figure 8.15 Shear stress versus normal stress saturated and unsaturated conditions of test 1

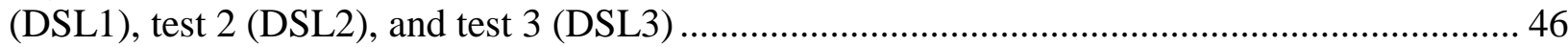

Figure 8.16 Shear stress versus horizontal displacement of layer 1, layer 2, and layer 3..... 46

Figure 8.17 Shear stress versus shear strain ........................................................... 47

Figure 9.1 Grain size distribution of layer 1, layer 2, layer 3. ........................................ 50

Figure 9.2 Grain size distribution of 34\% Proctor compaction effort: layer 1 (test1), layer 2

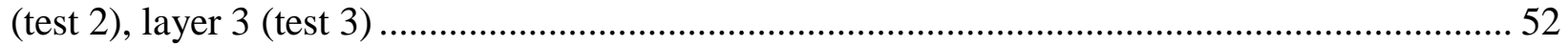

Figure 9.3 Grain size distribution of 11\% Proctor compaction effort: layer 1, layer 2, layer 354

Figure 10.1 Comparison of the hydraulic conductivity standard proctor compaction energy specimen and other standard proctor compaction energy compaction data. ............................. 57

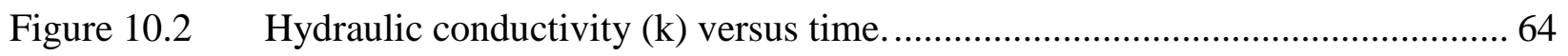

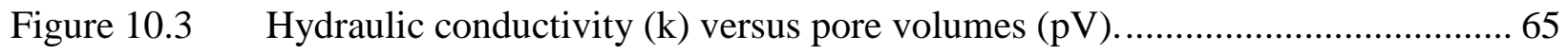

Figure 10.4 Comparison of the hydraulic conductivity 34\% Proctor compaction energy

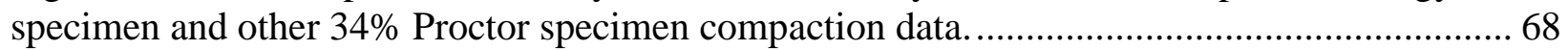

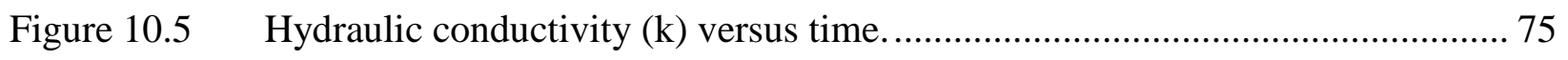

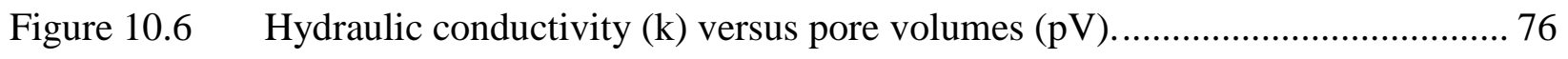

Figure 10.7 Comparison of the hydraulic conductivity $11 \%$ Proctor compaction energy specimen and other $11 \%$ Proctor compaction energy compaction data. .................................. 79

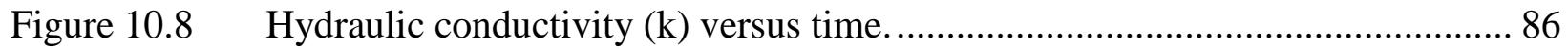

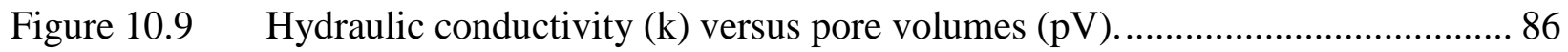

Figure 11.1 Grain size distribution of layer1, layer2, and layer3 of the hydraulic conductivity test specimen. 90

Figure 11.2 Grain size distribution of layer1, layer2, and layer3 of the hydraulic conductivity test specimen. 92

Figure 11.3 Grain size distribution of layer1, layer2, and layer3 of the hydraulic conductivity test specimen. 94

Figure 11.4 Grain size distribution of layer1, layer2, and layer3 of the hydraulic conductivity test specimen. 96 
Figure 11.5 Grain size distribution of layer1, layer2, and layer3 of the hydraulic conductivity test specimen. 98

Figure 12.1. Standard Proctor grain size distribution compilation .................................. 100

Figure 12.2. 34\% Proctor compaction energy grain size distribution compilation .............. 102

Figure 12.3. 11\% Proctor compaction energy grain size distribution compilation .............. 104

Figure 13.1. Slope profile used for valley fill modeling............................................... 111

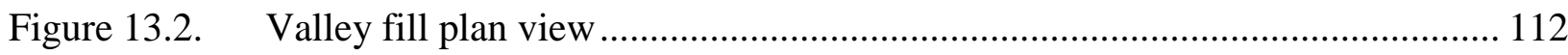

Figure 13.3. Actual modeled slope profile ............................................................. 113

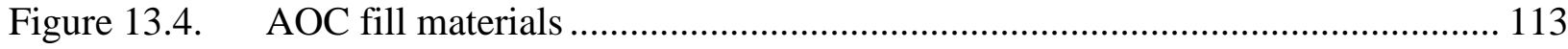

Figure 13.5. Fill conductivity function - AOC fill ................................................... 114

Figure 13.6. Fill water content function - AOC fill .............................................. 115

Figure 13.7. AOC fill boundary conditions .................................................................. 115

Figure 13.8. Geomorphic fill boundary conditions ....................................................... 116

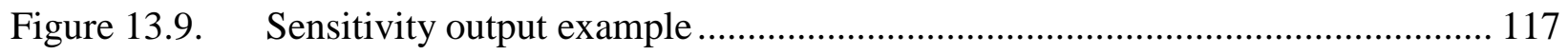

Figure 13.10. Geomorphic design contours superimposed on original ground contours ........ 123

Figure 13.11. Geomorphic design surface generated from a triangulated irregular network (TIN) $\quad 124$

Figure 13.12. Geomorphic valley fill alternative failure planes along centerline shown in Fig. $13.10 \quad 124$

Figure 13.13. Valley fill diagrams of results from a cumulative analysis of SEEP/W, SIGMA/W, and SLOPE/W from GeoStudio ${ }^{\text {TM }}$

Figure 13.14. Failure entry and exit locations for saturated underdrain - Deterministic analysis results $\quad 128$

Figure 13.15. Geomorphic valley fill alternative cumulative analysis results for unsaturated underdrain conditions

Figure 13.16. Critical slope profile with failure planes along centerline shown in Fig. 13.10.

Pieziometric line \#2 enabled - Deterministic analysis visual results .................................. 134

Figure 13.17. Direct shear information on as received testing ......................................... 137

Figure 13.18. Geomorphic profile for as received models .............................................. 138

Figure 13.19. AOC valley fill profile for as received models ........................................ 138 


\section{Introduction}

\subsection{Introduction \& Background}

Coal mining has long been a significant aspect of the state economies in the Appalachian region. Shallow coal seams can be retrieved by implementing a method of mining called surface mining. Surface mining involves removing overburden, extracting coal, and reclaiming the disturbed area. Federal law requires that all surface mine sites be reclaimed according to approximate original contour (AOC) design. In West Virginia, Kentucky, Tennessee, and south-western Virginia, pre-SMCRA state laws did not require elimination of high walls by complete backfilling. SMCRA was adopted into law in 1977 and since then much of central Appalachian surface mine land has been returned to AOC. Approximate original contour design and excess spoil disposal on surface mining sites in West Virginia are regulated by the state of West Virginia and the United States Federal Government. The Surface Mining Control and Reclamation Act of 1977 (SMCRA) establishes that surface mining sites must be returned to "approximate original contour," (AOC) and requires surface mining equipment operators to "...grade in order to restore the approximate original contour of the land with all high walls, spoil piles, and depressions eliminated..." [Sec. 515(b)3]. West Virginia has its own version of SMCRA called WVSCMRA which has primacy over SMCRA due to its unique steep sloped terrain. WVSCMRA has similar requirements when compared to SMCRA.

Since the terrain in Appalachia is unique to surface mining, it is thought that AOC may not always be an appropriate method of landform design (Superfesky, 2007). Fluvial geomorphic landform design is an alternative landform design method to AOC design. Fluvial geomorphology utilizes concepts that attempt to establish a nature-emulated landforms where erosive forces are in equilibrium with the land surface. This alternative earthwork design method has a great potential to increase the durability of reclamation earthwork designs and decrease the critical nature of some of the issues involved with AOC. One drawback about fluvial geomorphic design is that the software used to generate the design models do not incorporate slope stability analysis. In steep sloped Appalachian terrain, slope stability analysis can be a critical element of the design process. Slope stability analysis can be run quickly and effectively by many different versions of computer software. By integrating fluvial geomorphic design into surface mine reclamation, landform designers have the potential to create a more natural, less erosive, and more stable landform as opposed to AOC.

\subsection{Research Purpose \& Objectives}

The objective of this research was to sample and identify a surface mine spoil in southern West Virginia, characterize its associated physical properties as well as the strength aspects for appropriate input parameter key in into a slope stability software analysis tool to compare stability results of an AOC valley fill and a geomorphic landform design with regard to a factor of safety computed by the general limit equilibrium method. Laboratory values were used along with the surface mine permit documentation of the proposed slope geometry to validate, assess, and calibrate the models. A deterministic analysis method was then used along with the general limit equilibrium computational method in order to perform a risk assessment with regard to a factor of safety. The factor of safety output data was addressed to develop insights into risk assessment of the generated landform model compared to the AOC valley fill design. 
The unweathered sandstone overburden is a blasted rock material. Blasted rock material properties vary from naturally occurring soil particle properties. A blasted rock particle may be very small and may share the relative size or diameter of a weathered particle, but the two are significantly dissimilar. A blasted rock particle's affinity to retain water as well as its strength properties vary significantly. A naturally occurring particle whose location provided it to be exposed to weathering and chemical processes over time changes its characteristics, strength behavior, and geotechnical properties. A blasted rock particle has not participated in these processes. Geotechnical laboratory testing is necessary to establish design limitations. The blasted rock material plays a significant role in the unique design of valley fills. It is important to understand the grading envelopes that occur under varying compaction efforts. Small particles can be carried by water and create internal erosion or suffosion phenomena. In order for a valley fill to be durable, internal erosion processes must be slowed as much as possible. This can be done by constructing the valley fill at compaction efforts that reach a desired density condition without creating a significant volume of fine particles. Void spaces are created by internal erosion in the upper regions of the valley fill, and are filled in the lower regions. Lower regions that begin to hold large volumes of fine particles can result in increased pore pressures, and decrease the stability of the valley fill.

\section{Literature Review}

State and Federal regulations directing mine reclamation using the Approximate Original Contour approach have resulted in geotechnically stable designs of valley fills constructed using waste rock overburden. Environmental concerns at mountain top mining sites abound because of the loss of headwater stream length and increased flooding risk. One promising technique to lessen the impacts involves fluvial geomorphic landform design applied to the waste rock fill and slope profiles. Geomorphic designs have proven successful in semi-arid regions; however, this approach has not been adapted to eastern surface mining reclamation. Research results are presented using fluvial geomorphic design principles which show alternative valley fill design approaches for a mountain top mine site under construction in southern West Virginia. Features of the design are the channelizing of surface water from the rock fill flats and sloped faces, and directing the runoff to engineered perimeter channels.

\section{Introduction}

Concerns of detrimental environmental impacts originating from surface mining and valley fill construction are of constant debate, resulting in numerous lawsuits (e.g. Hasselman, 2002, Davis and Duffy, 2009) and scientific studies throughout Central Appalachia (Hartman et al., 2005; Pond et al., 2008; Ferrari et al, 2009). State and Federal regulations have been promulgated to control environmental impacts associated with surface mining and valley fill construction through the Surface Mining Control and Reclamation Act (SMCRA) and the Clean Water Act (CWA). West Virginia has primacy of the State's regulatory enforcement and thus must meet stringent regulatory standards for valley fill construction.

These regulations have resulted in geotechnically stable designs of valley fills with runoff management; however, major environmental concerns have resulted, specifically the loss of headwater stream length, increased flooding risk, and degraded water quality in downstream communities. The predicted headwater stream loss in WV is approximately 3,200 km by 2012 , thus impacting the ability of West Virginia to support high quality and unique aquatic species 
(USEPA, 2005). Studies have shown that streams below valley fills often have elevated conductivity levels, resulting from water contact with the overburden (Hartman et al., 2005, Pond et al., 2008). Additionally, changes in downstream thermal regime, chemistry, and sedimentation are potential impacts (USEPA, 2005). One promising innovative technique used to lessen impacts involves fluvial geomorphic landform design that incorporates mature landform shapes into the designs. These landform designs add variability and aid in establishing a site with a long-term hydrologic balance.

The objective of the research performed was to investigate alternative geomorphic design and reclamation approaches applied to surface mining methods in West Virginia. First, an overview of geomorphic landform design and associated regulations are presented, noting challenges associated with the application of the technique in West Virginia. Then, a conceptual geomorphic landform design of a valley-fill currently under construction is discussed.

\section{Regulatory Drivers Affecting Geomorphic Landform Design}

Challenges associated with implementing the landforming approach in the WV Central Appalachia Region extend beyond the complexity of designing and constructing mature landforms in steep terrain. Current, civil engineering based regulations for meeting Approximate Original Contour (AOC) and Surface Water Runoff Analysis (SWROA) do not readily support this nontraditional design approach, and perceived initial construction costs are greater than traditional designs (Michael et al., 2010).

Reclamation by approximate original contour (AOC) design is a practiced in the central Appalachian region of the United States. These promulgated design requirements were needed to provide standards and controls. Prior to the Surface Mining Control and Reclamation Act (SMCRA), adopted into law in 1977, non-designed earth moving practices resulted in spoil materials being deposited into valleys, hillsides, and over ephemeral streams without consideration of erosion, geotechnical stability, seepage, and hydrology. Generically termed "shoot-and-shove", the end results included slope washes, loss of topsoil, and stream siltation.

The approximate original contour design and excess spoil disposal on surface mining sites in West Virginia are regulated by the state of West Virginia and by the US Office of Surface Mining, Reclamation, and Enforcement (OSM) (WVDEP, 1999).

In West Virginia the AOC guidelines are promulgated by WVSMRR, CSR $\S 38$ which require slope profile configurations constructed by backfilling and grading of disturbed areas have a final profile which in effect closely resemble the general surface configuration of the land prior to mining (WVDEP, 1999). The post mining configuration is intended to ensure slope stability, control drainage, complement the drainage pattern of the surrounding terrain, and prevent stream sedimentation. These requirements are comprehensive covering the drainage pattern of the surrounding terrain, high walls, and spoil piles. The State does consider special circumstances and permits variances. In addition, the West Virginia Department of Environmental Protection (WVDEP) and the US Environmental Protection Agency (EPA) implement the Clean Water Act of 1972 through the National Pollution Discharge and Elimination System (NPDES) in order to provide requirements for drainage and sediment control requirements for the quality of the discharged runoff.

The AOC requirements result in the typically profiled slope shapes exhibiting uniform benches, planar slopes having unvarying contours with perimeter or center surface water ditches. The 
AOC guidelines have performed well and as intended, the reduction in environmental degradation of mountain streams and the stability of slopes have been the benefit. In West Virginia the revegetation efforts using select grasses and hardwoods have proven very effective in concealing the planar slope profiles and surface drainage structures. The effectiveness of post mine land use implemented by the mining industry has, to a large extent, been so successful that when the tree canopy matures the slopes appear natural.

The aesthetic and geotechnical safety benefits of the AOC requirements although are not able to balance trade-offs with the loss of streams and changes in watershed sizes. Under natural conditions, landforms develop a balance between erosive and resistance forces, resulting in a system in equilibrium with low erosion rates. The fluvial geomorphic landform design approach attempts to design landforms in this steady-state condition, considering long-term climatic conditions, soil types, slopes, and vegetation types (Toy and Chuse, 2005; Bugosh, 2009). The need to balance valley fill construction stability with surface hydrologic reclamation needs has opened the opportunity to introduce geomorphic design.

\section{Geomorphic Landform Design}

Compared to traditional designs, landforming appears natural, reduces long-term maintenance, requires fewer artificial elements, and supports long-term stability (Martin-Duque et al., 2009).

While this innovative design approach has been used with success in semi-arid regions of the U.S. (e.g. Toy and Chuse, 2005; Measles and Bugosh, 2007; Bugosh, 2009; Robson et al., 2009) and outside of the U.S. (e.g. Marin-Duque et al., 2009; Martin-Moreno et al., 2008), the approach has not been utilized in West Virginia surface mining design or reclamation.

The geomorphic landform design procedure builds a drainage network using a reference landform approach; a reference watershed must be identified and characterized. The following information is necessary to inform successful design (Toy and Chuse, 2005; Eckels and Bugosh, 2010): i) main channel slope and landform profile shape; ii) drainage density and area; and, iii) channel characteristics. Each of these design requirements is discussed separately below.

i) Main channel slope represents the watershed slope. As the main channel slope increases, the stream power and erosion potential increase (Toy and Chuse, 2005). Landform longitudinal profile shapes must also be considered as the concave shape differs among headwater and downstream locations. In mountainous terrain the nature of slope profiles develop into compound surface profiles. These profiles exhibit steep convex slopes at the head of the valley then progressively transition into a concave form gradually tapering to a uniform profile. The fluvial influence stream cutting and surfical erosion and the rill to gulley erosion all couple to effect the development of natural stream design. Valley fills end up as unique landforms, they do exhibit geotechnical stability; however, they are not suited, as currently regulated, to incorporate surface hydrologic features to enable stream replacement or development.

ii) Drainage density is measure of the average stream channel spacing and results from flow interactions with sediment and soil, topography, weather variables, and vegetation (Bugosh, 2004; Toy and Chuse, 2005). For a given reference landform, the drainage density describes the drainage network that can be supported without significant aggradation or erosion (Bugosh, 2004). The fluvial geomorphic design approach 
assumes a dendritic pattern, a configuration common for unconsolidated materials (Toy and Chuse, 2005; Eckels and Bugosh, 2010).

iii) Natural channels vary in characteristics with location in the watershed. Headwater streams are often steep ( $>4 \%$ slope) and relatively straight (sinuosity $=1.0-1.2)$, and down-stream channels have a lower gradient ( $<4 \%$ slope) and increased sinuosity $(>1.2$; Rosgen, 1996). Stream characteristics must be considered to designs systems that will properly manage both flow and sediment discharge: bankfull width, width to depth ratio, sinuosity, meander belt width, "A" channel reach length (the distance of one-half of a meander length in steep channels), and sinuosity (Eckels and Bugosh, 2010). Ridge to head of channel distance defines the length required to form concentrated flow, advising the channel head location in reference to the watershed boundary.

\section{Geomorphic Landform Design of a Valley Fill Under Construction}

The design tool Carlson Natural Regrade with GeoFluv® was used to apply the geomorphic landform design approach to a specific valley fill site currently under construction. The study site is in the southern WV coalfield region. The area is characterized by a system of steep-sloped ridges and valleys (Figure 1.1).

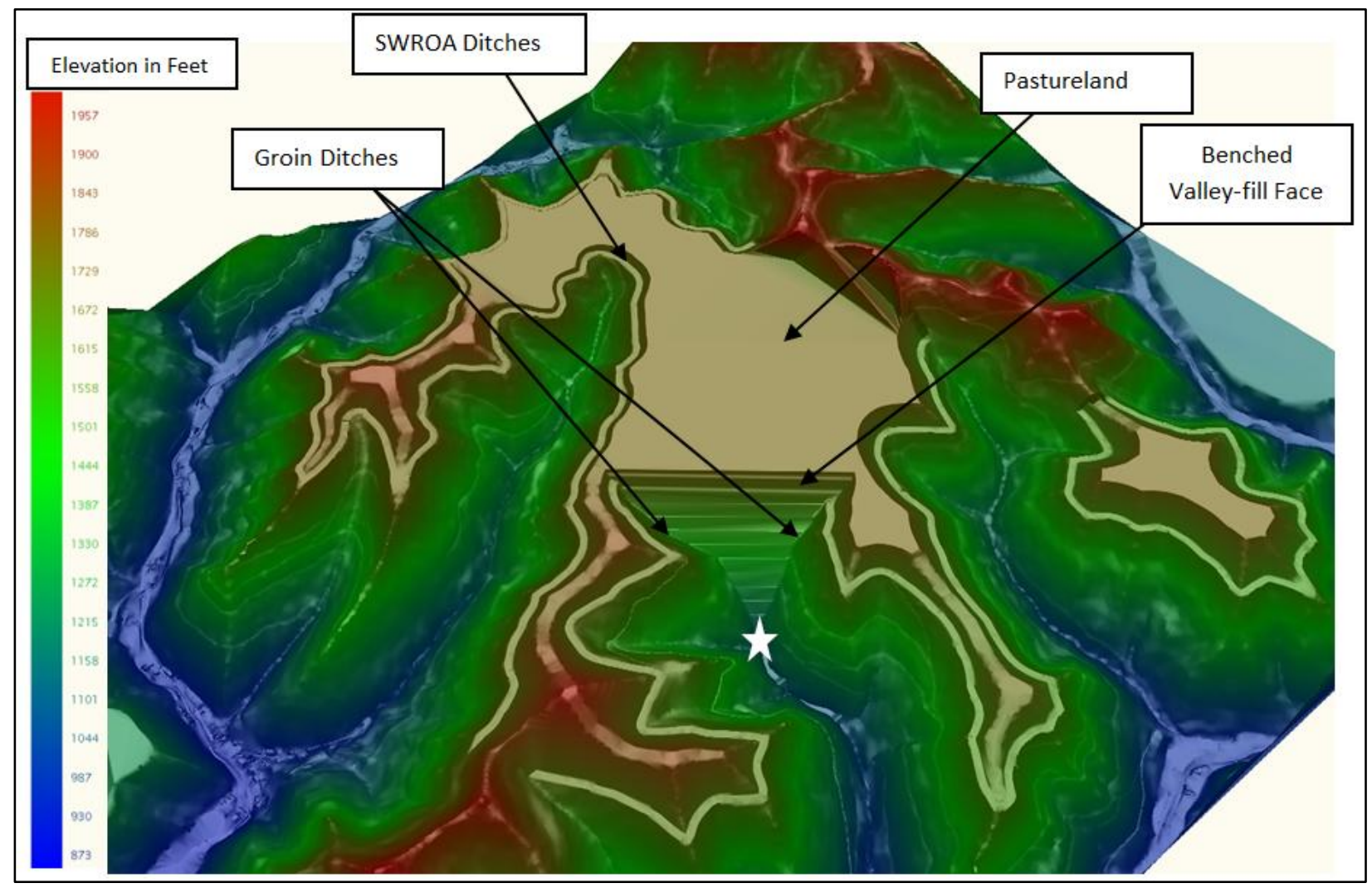

Figure 1.1 Valley fill under construction with labeled design features 


\section{Slope Stability}

GeoFluv® generated geomorphic landform designs do not analyze the stability of the slopes. It is critical that slope structures remain durable and do not fail when constructed with surface mine overburden for several reasons. If toxic mineralogy exist within the overburden, slope stability becomes an especially critical analysis that should be performed before construction begins. Slope structures have the capacity to encapsulate and contain ecologically destructive mineralogy. In steep sloped Appalachia, it is also especially critical to perform slope stability analysis to ensure the durability of the structure. In some cases, AOC or GeoFluv® designs may not be adequate for the stability of slopes. As slope angles increase, the factor of safety of a slope structure decreases, and the probability of failure increases. In Appalachia, it is not uncommon to find mountainous terrain with shear rock cliffs which cannot be reconstructed to AOC. Exceedingly steep slopes should not be built. Safety concerns may also arise when constructing steep slopes.

If adequate slope stability analysis is performed on GeoFluv® generated slopes which are associated with specified design limitation criteria, then the environmental, and societal benefit could result. Inevitably, all surface mined areas are contributors to large watersheds. Slope failure has the potential in many cases to introduce ecologically destructive mineralogy into the watershed, as well as sediment pollution. Sediment accumulation can alter stream beds and have great potential to result in a legion of significant erosion impacts, and can cause flooding. When taking these very realistic scenarios into account, it can easy be understood that slope failure can have a significant impact on the health and safety of downstream communities as well as the operators constructing the structures.

\section{Approach}

The approach taken for this study involved considering the design limitations of two types of soil retrieved from a surface mine site in southern West Virginia. The shear strength of the unweathered sandstone overburden material was determined via direct shear testing in order to have a better understanding of its geotechnical properties. During the course of the research effort, it was decided that only the unweathered sandstone material would be examined thoroughly for strength. The geotechnical values that were found via testing were input into GeoSlope software for modeling analysis.

Step\#1: Acquire physical and engineering properties of a cover material and a blasted fill material.

Step\#2: Assess the strength characteristics of the field soil as the primary material in the slope structures to be modeled.

Step\#3: Consider the grain size distribution of as received and pre-permeability specimens prepared at predetermined compaction energies in order to develop grading envelopes to better understand how the materials may degrade and create fine particles with transport potential when compacted in the field during slope construction.

Step\#4: Evaluate the pre-and-post-permeability grain size distributions to determine particle movement behavior

Step \#5: Utilize GeoSlope® software modules SIGMA/W, SEEP/W, and SLOPE/W to model the valley fill under inspection and determine the stability of the structure using general limit 
equilibrium and sensitivity analysis as well as insitu stress calculations involving hydraulic parameters generated with a 10 years of infiltration with a set hydraulic conductivity.

\section{Materials and Methods}

The materials selected for this research included a blasted, weathered sandstone material and a blasted, unweathered sandstone material retrieved from a surface mine site in Logan County, West Virginia on the hot, dry day of June $7^{\text {th }} 2011$. The materials will be simply referred to as "weathered sandstone," and "unweathered sandstone." The samples were obtained from the disturbed area at an active surface mine reclamation site where piles of end dumped material were allotted some time to be exposed to surface conditions. The samples were obtained prior to any leveling or compaction effort. The geotechnical material physical and engineering property tests were performed according the ASTM standard test methods and included: Moisture content (D-2216), Sieve/hydrometer (D-422), Specific Gravity (D-854), Atterberg Limits (D-4318), Standard Proctor (D-698), Soil Classification-USCS (D-2487), Direct Shear (D-3080), and Hydraulic Conductivity (D-5856). Many of the specimen labels incorporate the terms "brown" and "gray," but will be referred to in the text as "weathered sandstone" and "unweathered sandstone," respectively. The results of the experimental testing are reported in the following sections. The laboratory tests included duplicate and triplicate specimen testing for precision. Most test data is presented in the appendices. The results are reported in Chapter 5 through Chapter 12.

\section{Material Properties and Results: Weathered Sandstone}

The objective of the testing performed is to discover the geotechnical properties and gradations of a weathered sandstone sampled at a nearby site to the unweathered sandstone overburden material discussed in other sections. The results of this laboratory testing will be compared to the unweathered sandstone overburden to determine whether or not their properties vary significantly enough to be included as input parameters in the numerical slope stability modeling. The test methods and associated results are shown in the following text. The material under inspection in this section was classified using the United Soil Classification System (USCS) ASTM D 2487. After assessment, the weathered sandstone material was classified to be a well graded gravel $(\mathrm{GW})$.

\subsection{Moisture Content}

Testing was performed according to ASTM standard test method D 2216-05. The sampling was performed on a hot, dry day; however, the moisture content was measured in the laboratory after the specimens acclimated to the indoor climate. The coefficient of variation was found to be 0.017, which implies little variability in the results of the testing. The average moisture content was found to be $8.07 \%$. Table 5.1, Table 5.2, and Table 5.3 present the results for the triplicate specimen testing. 
Table 5.1 Moisture Content Data

\begin{tabular}{|l|r|r|r|}
\hline \multicolumn{1}{|c|}{ Test Number } & \multicolumn{1}{c|}{1} & \multicolumn{1}{c|}{2} & \multicolumn{1}{c|}{3} \\
\hline Empty Container, $\mathbf{M}_{\mathrm{c},(\mathrm{g})}$ & 17.41 & 17.3 & 18.77 \\
\hline Container + Wet Sample, $\mathrm{M}_{\mathrm{cms}},(\mathrm{g})$ & 73.92 & 80.97 & 80.85 \\
\hline Container + Dry Sample, $\mathrm{M}_{\mathrm{cds}},(\mathrm{g})$ & 69.63 & 76.29 & 76.22 \\
\hline Moisture content w $(\%)$ & $\mathbf{8 . 2 2}$ & $\mathbf{7 . 9 3}$ & $\mathbf{8 . 0 6}$ \\
\hline
\end{tabular}

Table 5.2 Average Moisture Content and Statistics

\begin{tabular}{|l|l|}
\hline Average Moisture Content (\%): & $\mathbf{8 . 0 7 0}$ \\
\hline Sample Standard Deviation (s) & 0.141 \\
\hline Coefficient of Variation (COV) & 0.017 \\
\hline
\end{tabular}

Table 5.3 Equations Used

\begin{tabular}{|l|}
\hline$M_{\mathrm{w}}=$ mass of water $=\mathrm{M}_{\mathrm{cms}}-\mathrm{M}_{\mathrm{cds}}$ \\
\hline $\mathrm{M}_{\mathrm{s}}=$ mass of dry sample $=\mathrm{M}_{\mathrm{cds}}-\mathrm{M}_{\mathrm{c}}$ \\
\hline $\mathrm{w} \%=\left(\mathrm{M}_{\mathrm{w}} / \mathrm{M}_{\mathrm{s}}\right) \times 100$ \\
\hline
\end{tabular}

\subsection{As Received Grain Size Distribution and Hydrometer Analysis}

Sieve analysis was performed according to ASTM D 422-63. A duplicate test was performed to ensure accuracy in the data. The objective of this testing was to obtain appropriate data in order to classify the material, and understand its original as received grain size distribution. The as received grain size distribution results were a critical element in the understanding of material changes that can occur during construction under different compaction energies. A hydrometer test was run for the particles passing the \#200 sieve. For the first test the critical indices were $\mathrm{D}_{90}=24, \mathrm{D}_{60}=9, \mathrm{D}_{50}=6.3, \mathrm{D}_{30}=2.00, \mathrm{D}_{25}=1.3, \mathrm{D}_{10}=.22(\mathrm{~mm})$. The uniformity coefficient $\left(\mathrm{C}_{\mathrm{u}}\right)$ was 40.91 and the coefficient of gradation $\left(\mathrm{C}_{\mathrm{c}}\right)$ was 2.02 . For the second test the critical indices were $\mathrm{D}_{90}=33, \mathrm{D}_{60}=6.9, \mathrm{D}_{50}=6.2, \mathrm{D}_{30}=1.7, \mathrm{D}_{25}=1.3, \mathrm{D}_{10}=0.29(\mathrm{~mm})$. The uniformity coefficient $\left(\mathrm{C}_{\mathrm{u}}\right)$ was 23.79 and the coefficient of gradation $\left(\mathrm{C}_{\mathrm{c}}\right)$ was 1.44 . Some variability occurred in the data as represented by the coefficient of variation at 0.374 for the uniformity coefficient and 0.235 for the coefficient of gradation. The variation is likely the result of clodding of the particles due to the presence of moisture. The data does follow the same trend approximately. The hydrometer analysis illustrated the presence of few fine particles relative to the sample size. The results are shown in Table 5.4 through Table 5.9, Figure 5.1 and Figure 5.2. Table 5.8 shows data according to ASTM D-422 tables and associated values.

Table 5.4 Mass Loss of Sample

\begin{tabular}{|c|r|r|}
\hline As Received & \multicolumn{1}{|c|}{ Test 1 } & \multicolumn{1}{|c|}{ Test 2 } \\
\hline Mass of Sample & 500 & 500 \\
\hline Mass Loss $(\%)$ & 0.28 & 0.23 \\
\hline
\end{tabular}


Table 5.5 Critical Index Values and Coefficients

\begin{tabular}{|c|r|r|}
\hline \multicolumn{2}{|c|}{ Results } & \\
\hline Critical Indices & Test 1 & Test 2 \\
\hline $\mathrm{D}_{90}$ & 24.00 & 33.00 \\
\hline $\mathrm{D}_{60}$ & 9.00 & 6.90 \\
\hline $\mathrm{D}_{50}$ & 6.30 & 6.20 \\
\hline $\mathrm{D}_{30}$ & 2.00 & 1.70 \\
\hline $\mathrm{D}_{25}$ & 1.30 & 1.30 \\
\hline $\mathrm{D}_{10}$ & 0.22 & 0.29 \\
\hline Uniformity Coefficient, $\mathbf{C}_{\mathbf{u}}$ & $\mathbf{4 0 . 9 1}$ & $\mathbf{2 3 . 7 9}$ \\
\hline Coefficient of Gradation, $\mathbf{C}_{\mathbf{c}}$ & $\mathbf{2 . 0 2}$ & $\mathbf{1 . 4 4}$ \\
\hline
\end{tabular}

Table 5.6 Uniformity coefficient statistics

\begin{tabular}{|l|r|}
\hline \multicolumn{2}{|c|}{ Uniformity Coefficient, $\mathbf{C}_{\mathbf{u}}$} \\
\hline Average Uniformity Coefficient & 32.351 \\
\hline Sample Standard Deviation (s) & 12.103 \\
\hline Coefficient of Variation (COV) & 0.374 \\
\hline
\end{tabular}

Table 5.7 Coefficient of gradation statistics

\begin{tabular}{|l|l|}
\hline \multicolumn{2}{|c|}{ Coefficient of Gradation, $\mathbf{C}_{\mathbf{c}}$} \\
\hline Average Coefficient of Gradation & 1.732 \\
\hline Sample Standard Deviation (s) & 0.407 \\
\hline Coefficient of Variation (COV) & 0.235 \\
\hline
\end{tabular}




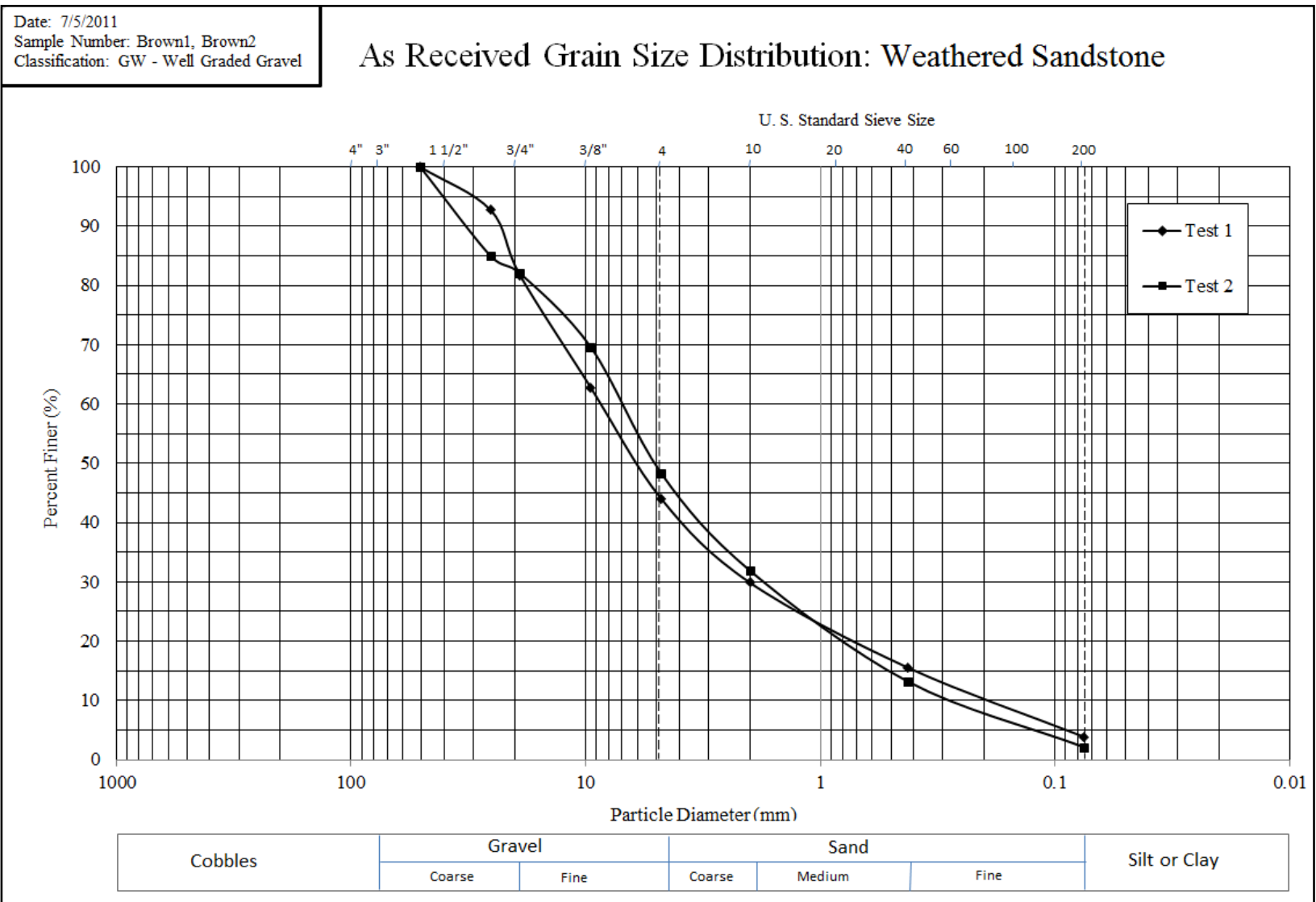

Figure 5.1 Grain Size Distribution of two as received samples 
Table 5.8 Weathered Sandstone GW sample hydrometer data.

\begin{tabular}{|c|c|c|c|c|c|c|c|c|}
\hline \multicolumn{2}{|c|}{ Hydrometer No.: } & $\begin{array}{c}\text { Sample } \\
\text { Moist Mass, } \\
\mathrm{g}\end{array}$ & \multicolumn{2}{|c|}{$\begin{array}{c}\text { Moisture Content } \\
\qquad, \mathrm{w} \%\end{array}$} & \multicolumn{2}{|c|}{$\begin{array}{l}\text { Sample Dry } \\
\text { Mass, g }\end{array}$} & \multicolumn{2}{|c|}{$\mathrm{G}_{\mathrm{s}}$} \\
\hline \multicolumn{2}{|c|}{$152 \mathrm{H}$} & 100 & \multicolumn{2}{|c|}{8.07} & \multicolumn{2}{|c|}{91.93} & \multicolumn{2}{|c|}{2.75} \\
\hline $\begin{array}{c}\text { Elapsed } \\
\text { Time, }(\mathrm{T}) \\
\min \end{array}$ & $\begin{array}{c}\text { Hydrometer } \\
\text { Reading }\end{array}$ & $\begin{array}{c}\text { Actual } \\
\text { Hydrometer } \\
\text { Reading, R }\end{array}$ & $\underset{{ }^{\circ} \mathrm{C}}{\mathrm{Temp}}$ & $\frac{\mathrm{K}}{(\mathrm{Table} 3)}$ & $\begin{array}{c}\mathrm{a} \\
(\text { Table1) }\end{array}$ & $\begin{array}{l}\% \\
\text { Finer, } \\
\text { P }\end{array}$ & $\begin{array}{l}\text { Effective } \\
\text { Depth, } \\
\text { (L) cm } \\
\text { (Table 2) }\end{array}$ & $\begin{array}{l}\text { Particle } \\
\text { Diameter, } \\
\text { (D) } \mathrm{mm}\end{array}$ \\
\hline 2 & 63 & 63 & 22 & 0.01249 & 0.98 & 67.2 & 8.1 & 0.0251 \\
\hline 5 & 60 & 60 & 22 & 0.01249 & 0.98 & 64 & 8.9 & 0.0167 \\
\hline 15 & 52 & 52 & 22 & 0.01249 & 0.98 & 55.4 & 9.9 & 0.0101 \\
\hline 30 & 46 & 46 & 22 & 0.01249 & 0.98 & 49 & 10.6 & 0.0074 \\
\hline 60 & 41 & 41 & 22 & 0.01249 & 0.98 & 43.7 & 11.1 & 0.0054 \\
\hline 250 & 29 & 29 & 22 & 0.01249 & 0.98 & 30.9 & 12.2 & 0.0028 \\
\hline 1440 & 20 & 20 & 22 & 0.01249 & 0.98 & 21.3 & 13.3 & 0.0012 \\
\hline
\end{tabular}

Table 5.9 Hydrometer equations and definitions

\begin{tabular}{|c|c|}
\hline 151H: & $\mathrm{P}=\left[(100,000 / \mathrm{W}) \times\left(\mathrm{G} /\left(\mathrm{G}-\mathrm{G}_{1}\right)\right]\right)\left(\mathrm{R}-\mathrm{G}_{1}\right)$ \\
\hline 152H: & $\mathrm{P}=(\mathrm{Ra} / \mathrm{W}) \times 100$ \\
\hline a & Correction factor to be applied to the reading of hydrometer $152 \mathrm{H}$. \\
\hline $\mathrm{P}$ & $\begin{array}{l}\text { Percentage of soil remaining in suspension at the level at which the hydrometer } \\
\text { measures the density of the suspension. }\end{array}$ \\
\hline $\mathrm{R}$ & Hydrometer reading with composite correction applied \\
\hline $\mathrm{W}$ & Oven-dry mass of soil in a total test sample represented by mass of soil dispersed (g) \\
\hline G & Specific gravity of the soil particles \\
\hline $\mathrm{G}_{1}$ & Specific gravity of the liquid in which soil particles are suspended. \\
\hline $\mathrm{K}$ & $\begin{array}{l}\text { Constant depending on the temperature of the suspension and the specific gravity of } \\
\text { the soil particles }\end{array}$ \\
\hline $\mathrm{L}$ & $\begin{array}{l}\text { Distance from the surface of the suspension to the level at which the density of the } \\
\text { suspension is being measured }\end{array}$ \\
\hline $\mathrm{T}$ & Interval of time from beginning of sedimentation to the taking of the reading, min. \\
\hline $\mathrm{D}$ & Diameter of particle, $\mathrm{mm}$. \\
\hline Note: & $\begin{array}{l}\text { Meniscus correction is the difference between the hydrometer reading and zero for } \\
152 \mathrm{H} \text { hydrometer }(7.3)\end{array}$ \\
\hline$D=K \sqrt{2}$ & \\
\hline
\end{tabular}




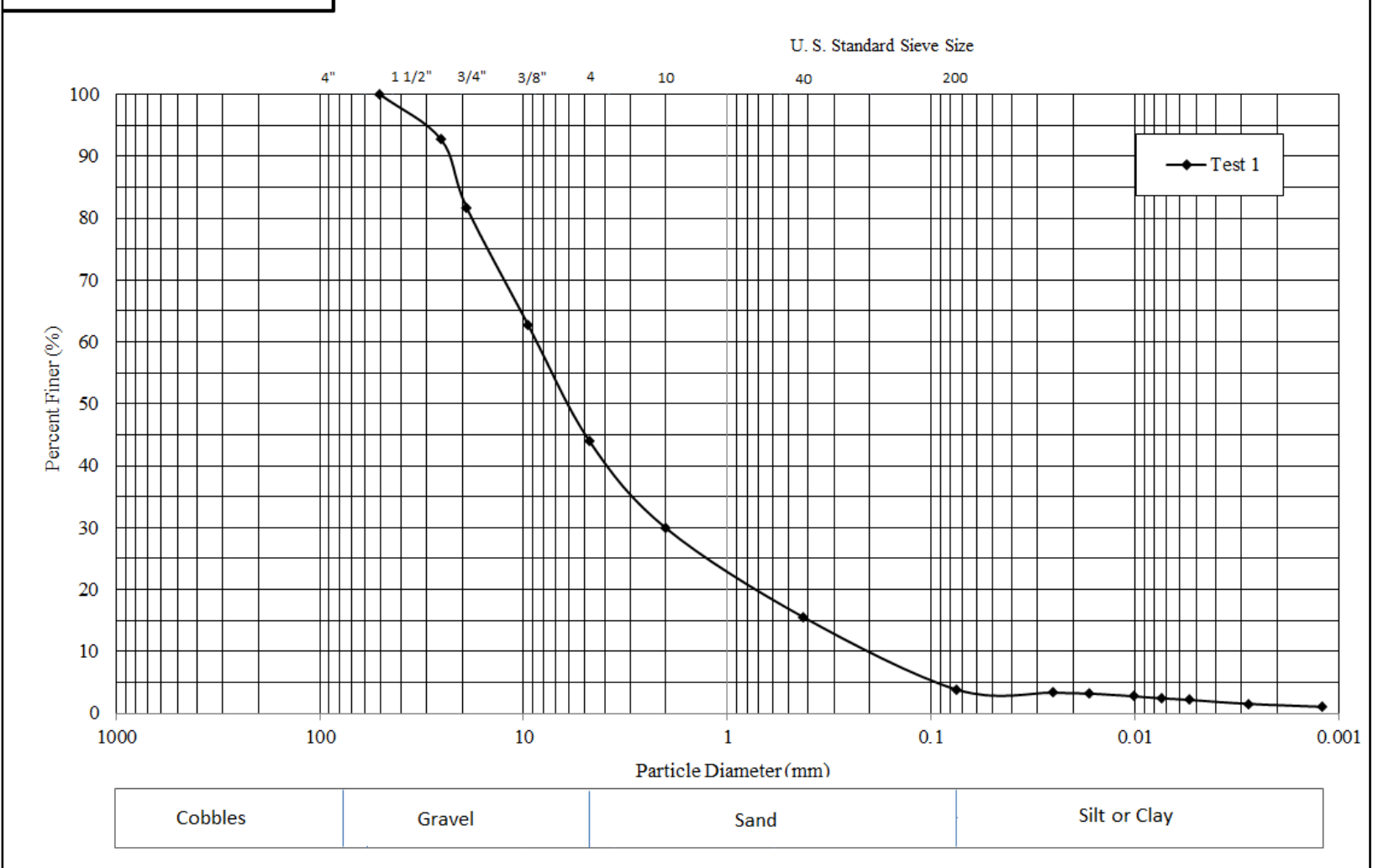

Figure 5.2 Grain size distribution graph including hydrometer data. 


\subsection{Specific Gravity - Test 1}

Specific gravity testing was performed according to ASTM standard test method D 854. Three tests were run in order to ensure the accuracy of the data. The objective of the specific gravity testing was to obtain knowledge about the physical characteristics of the material. For the first test, the specific gravity was found to be 2.81 . For the duplicate test, the specific gravity was found to be 2.75. The high precision of the tests is represented by the coefficient of variation of 0.014. The results for the first test are shown in Table 5.10 through Table 5.12 . Table 5.12 shows the equations used and the associated definitions. The data for this test are presented in appendix IV.

Table 5.10 Test statistics for specific gravity of soil solids.

\begin{tabular}{|l|l|}
\hline Average Specific Gravity, $\mathbf{G}_{\mathbf{t}}$ : & $\mathbf{2 . 8 1 0}$ \\
\hline Sample Standard Deviation for $\mathrm{G}_{\mathrm{t}}(\mathrm{s})$ & 0.041 \\
\hline Coefficient of Variation for $\mathrm{G}_{\mathrm{t}}(\mathrm{COV})$ & 0.014 \\
\hline
\end{tabular}

Table 5.11 Test statistics for specific gravity at the test temperature.

\begin{tabular}{|l|l|}
\hline Avg. Specific Gravity at Test Temp, $\mathbf{G}_{\mathrm{tt}}$ : & $\mathbf{2 . 8 1 0}$ \\
\hline Sample Standard Deviation for $\mathrm{G}_{\mathrm{tt}},(\mathrm{s})$ & 0.041 \\
\hline Coefficient of Variation for $\mathrm{G}_{\mathrm{tt}}(\mathrm{COV})$ & 0.014 \\
\hline
\end{tabular}

Table 5.12 Specific gravity equations and definitions

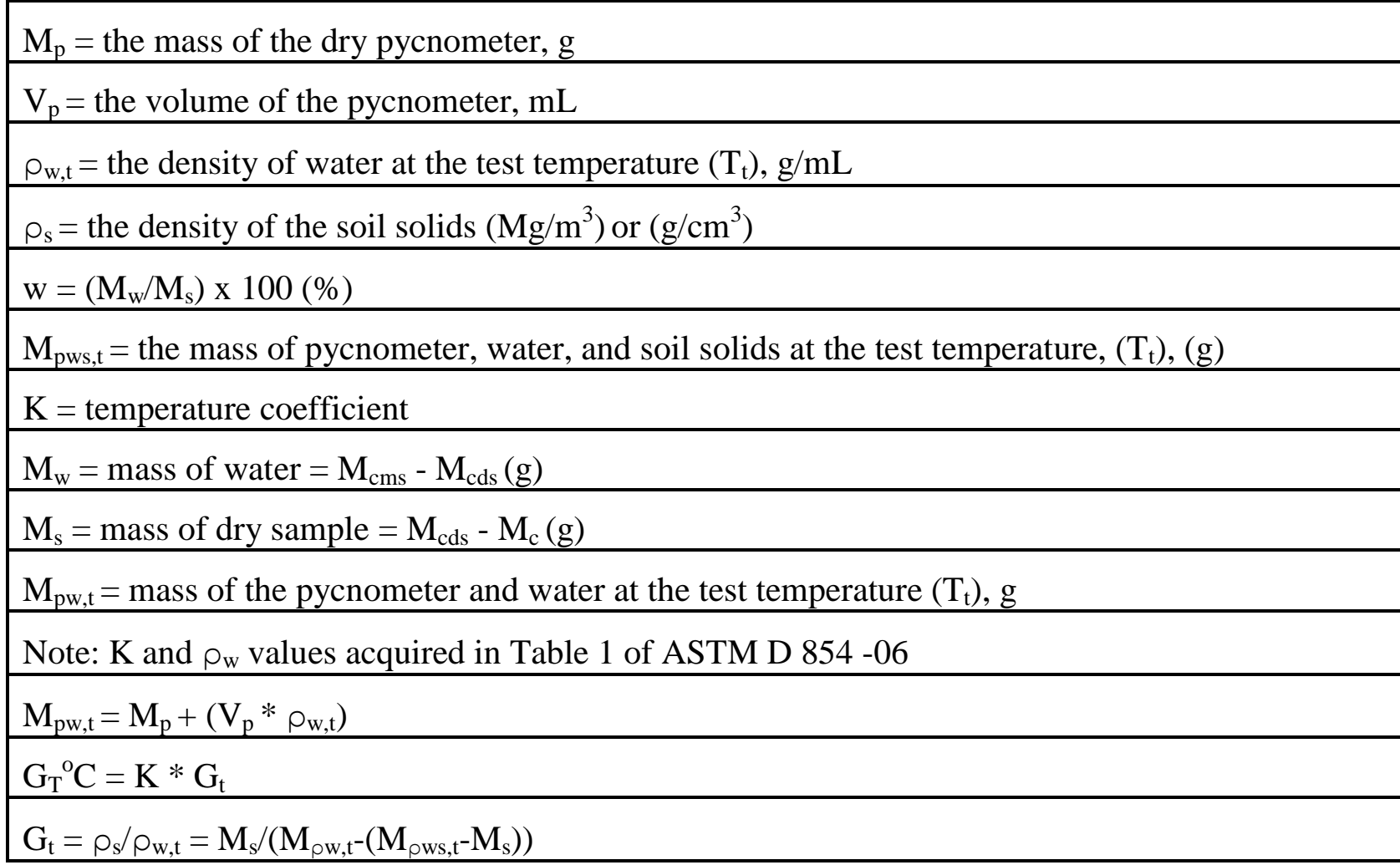




\subsection{Specific Gravity - Test 2}

Specific gravity testing was performed according to ASTM standard test method D 854. Three tests were run in order to ensure the accuracy of the data. The objective of the specific gravity testing was to obtain knowledge about the physical characteristics of the material. This duplicate test was performed to achieve high precision for the specific gravity testing of the weathered sandstone. The coefficient of variation of the data was found to be 0.002 ; implying little variation in the results. The average specific gravity was found to be 2.75 . The data is located in appendix IV. The results for the duplicate specific gravity test are shown in Table 5.13 and Table 5.14.

Table 5.13 Test statistics for specific gravity of soil solids.

\begin{tabular}{|l|r|}
\hline Average Specific Gravity, $\mathbf{G}_{\mathbf{t}}$ : & $\mathbf{2 . 7 5}$ \\
\hline Sample Standard Deviation for $\mathrm{G}_{\mathrm{t}}, \mathrm{s}$ & 0.004 \\
\hline Coefficient of Variation for $\mathrm{G}_{\mathrm{t}}(\mathrm{COV})$ & 0.002 \\
\hline
\end{tabular}

Table 5.14 Test statistics for specific gravity at the test temperature.

\begin{tabular}{|l|r|}
\hline Avg. Specific Gravity at Test Temp, $\mathbf{G}_{\mathbf{t t}}$ : & $\mathbf{2 . 7 5}$ \\
\hline Sample Standard Deviation for $\mathrm{G}_{\mathrm{tt}},(\mathrm{s})$ & 0.004 \\
\hline Coefficient of Variation for $\mathrm{G}_{\mathrm{tt}}(\mathrm{COV})$ & 0.002 \\
\hline
\end{tabular}




\subsection{Atterberg Limits}

Atterberg limit tests including the plastic limit and liquid limit tests were performed on the weathered sandstone material according to ASTM standard test method D 4318. The objective of the testing was to determine the liquid limit, plastic limit, and plasticity index of the material. The liquid limit of the material was found to be 26.2. The plastic limit was found to be 22.4 with a plasticity index of 3.8. The test results are presented in the following Table 5.15 and Figure 5.3 .

Table 5.15 Determination of plastic limit, liquid limit and plasticity index

\begin{tabular}{|r|r|}
\hline Plastic Limit: & 22.4 \\
\hline Liquid Limit: & 26.2 \\
\hline Plasticity Index: & 3.8 \\
\hline
\end{tabular}

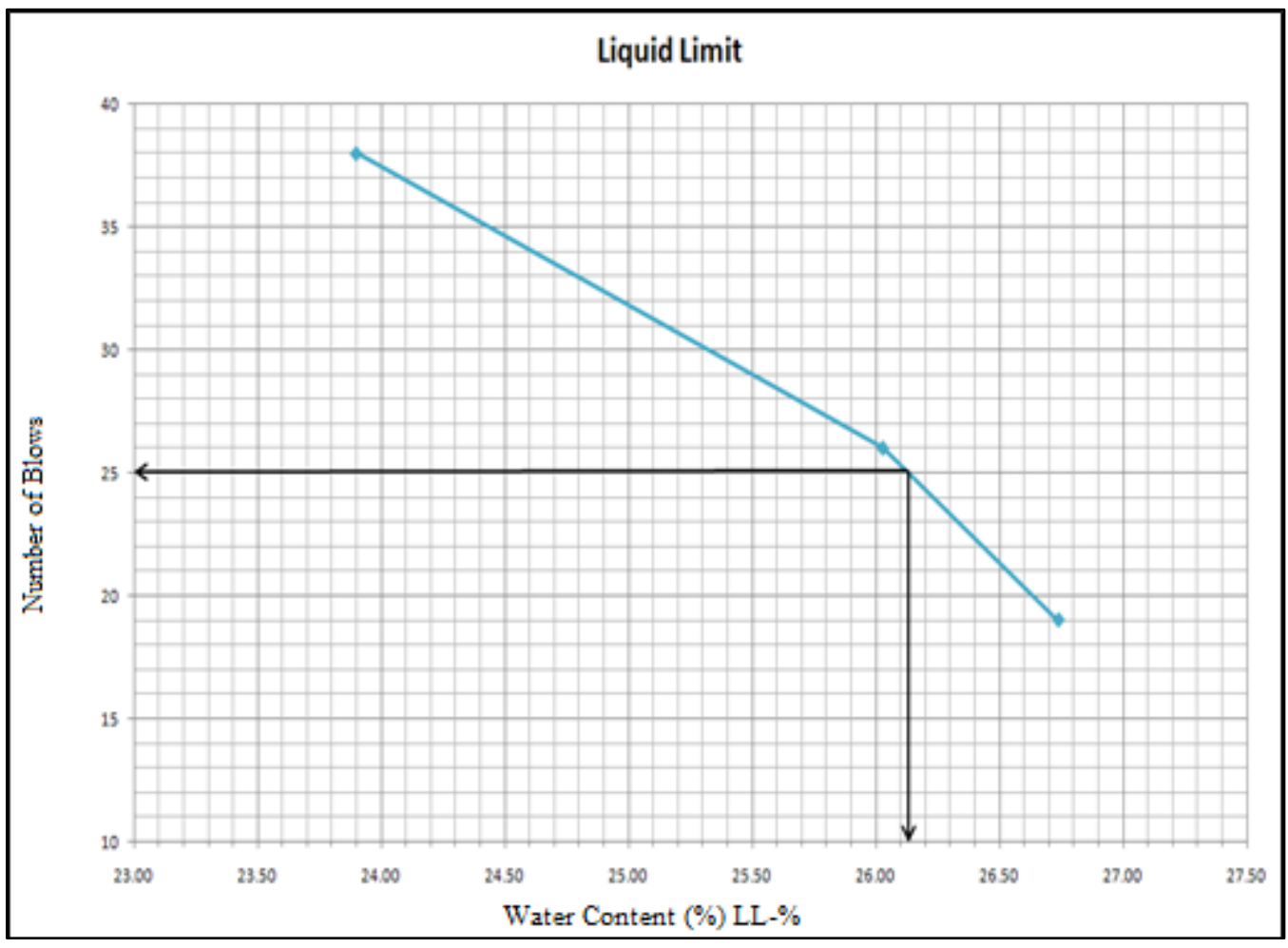

Figure 5.3 Liquid limit graph for the weathered sandstone material 


\section{Material Properties: Unweathered Sandstone Overburden}

The unweathered sandstone overburden was sampled at a surface mine site in southern West Virginia. The sampling site was the same as for the weathered sandstone material. The unweathered sandstone overburden was a blasted sandstone material. The material was classified using the United Soil Classification System (USCS) - ASTM D 2487. After assessment, the unweathered sandstone material was classified to be a well graded sand (SW). In accordance with ASTM test methods, the material was sieved between the \#4 and \#200 sieves. The sieved gradation was classified as a SW-SM material or a well graded sand with silt.

\subsection{Moisture Content}

Testing was performed according to ASTM standard test method D 2216-05. The sampling was performed on a hot, dry day; however, the moisture content was measured in the laboratory after the specimens acclimated to the indoor climate. There was little variation in the results. The coefficient of variation was found to be 0.052 , implying high precision in the data. Table 6.1 and Table 6.2 present the results for the triplicate specimen testing. Table 6.3 shows the equations used for the calculations.

Table 6.1 Moisture Content Data

\begin{tabular}{|l|r|r|r|}
\hline \multicolumn{1}{|c|}{ Test Number } & \multicolumn{1}{c|}{1} & \multicolumn{1}{c|}{2} & \multicolumn{1}{c|}{3} \\
\hline Empty Container, $\mathrm{M}_{\mathrm{c},}(\mathrm{g})$ & 16.89 & 21.79 & 30.03 \\
\hline Container + Wet Sample, $\mathrm{M}_{\mathrm{cms}},(\mathrm{g})$ & 70.86 & 74.82 & 100.21 \\
\hline Container + Dry Sample, $\mathrm{M}_{\mathrm{cds}},(\mathrm{g})$ & 69.37 & 73.33 & 98.42 \\
\hline Moisture content w $(\%)$ & $\mathbf{2 . 8 4}$ & $\mathbf{2 . 8 9}$ & $\mathbf{2 . 6 2}$ \\
\hline
\end{tabular}

Table 6.2 Average Moisture Content and Statistics

\begin{tabular}{|l|r|}
\hline Average Moisture Content (\%): & $\mathbf{2 . 7 8}$ \\
\hline Sample Standard Deviation (s) & 0.145 \\
\hline Coefficient of Variation (COV) & 0.052 \\
\hline
\end{tabular}

Table 6.3 Equations Used

\begin{tabular}{|l|}
\hline$M_{w}=$ mass of water $=M_{c m s}-M_{c d s}$ \\
\hline$M_{s}=$ mass of dry sample $=M_{c d s}-M_{c}$ \\
\hline $\mathrm{w}=\left(M_{\mathrm{w}} / M_{\mathrm{s}}\right) \times 100$ \\
\hline
\end{tabular}




\subsection{As Received Grain Size Distribution}

Sieve analysis was performed according to ASTM D 422-63. A duplicate test was performed to ensure accuracy in the data. The objective of this testing was to obtain appropriate data in order to classify the material, and understand its original as received grain size distribution. The as received grain size distribution results were a critical element in the understanding of material changes that can occur during construction under different compaction energies. For the first test the critical indices were $\mathrm{D}_{90}=12, \mathrm{D}_{60}=2.7, \mathrm{D}_{50}=1.6, \mathrm{D}_{30}=0.55, \mathrm{D}_{25}=0.40, \mathrm{D}_{10}=0.13(\mathrm{~mm})$. The uniformity coefficient $\left(\mathrm{C}_{\mathrm{u}}\right)$ was 20.77 and the coefficient of gradation $\left(\mathrm{C}_{\mathrm{c}}\right)$ was 0.86 . For the second test the critical indices were $\mathrm{D}_{90}=10.7, \mathrm{D}_{60}=3.0, \mathrm{D}_{50}=1.6, \mathrm{D}_{30}=0.55, \mathrm{D}_{25}=0.39, \mathrm{D}_{10}$ $=0.12(\mathrm{~mm})$. The uniformity coefficient $\left(\mathrm{C}_{\mathrm{u}}\right)$ was 25.00 and the coefficient of gradation $\left(\mathrm{C}_{\mathrm{c}}\right)$ was 0.84. The data approximately followed the same trend along their curves. The precision of the data is shown by a coefficient of variation for the uniformity coefficient of 0.131 , and a coefficient of variation for the coefficient of gradation of 0.018 . The hydrometere analysis illustrated that there are few fines in the sample relative to the sample size. The results are shown in Table 6.4 through Table 6.7, Figure 6.1 and Figure 6.2.

Table 6.4 Critical Index-Values and Coefficients

\begin{tabular}{|c|r|r|}
\hline \multicolumn{2}{|c|}{ Results } \\
\hline Critical Indices & Test 1 & Test 2 \\
\hline $\mathrm{D}_{90}$ & 12 & 10.7 \\
\hline $\mathrm{D}_{60}$ & 2.7 & 3 \\
\hline $\mathrm{D}_{50}$ & 1.6 & 1.6 \\
\hline $\mathrm{D}_{30}$ & 0.55 & 0.55 \\
\hline $\mathrm{D}_{25}$ & 0.4 & 0.39 \\
\hline $\mathrm{D}_{10}$ & 0.13 & 0.12 \\
\hline Uniformity Coefficient, $\mathbf{C}_{\mathbf{u}}$ & $\mathbf{2 0 . 7 7}$ & $\mathbf{2 5}$ \\
\hline Coefficient of Gradation, $\mathbf{C}_{\boldsymbol{c}}$ & $\mathbf{0 . 8 6}$ & $\mathbf{0 . 8 4}$ \\
\hline
\end{tabular}

Table 6.5 Uniformity coefficient statistics

\begin{tabular}{|l|r|}
\hline \multicolumn{2}{|c|}{ Uniformity Coefficient, $\mathbf{C}_{\mathbf{u}}$} \\
\hline Average Uniformity Coefficient & 22.885 \\
\hline Sample Standard Deviation (s) & 2.992 \\
\hline Coefficient of Variation (COV) & 0.131 \\
\hline
\end{tabular}


Table 6.6 Coefficient of gradation statistics

\begin{tabular}{|l|l|}
\hline \multicolumn{2}{|c|}{ Coefficient of Gradation, $\mathbf{C}_{\mathbf{c}}$} \\
\hline Average Coefficient of Gradation (\%) & 0.851 \\
\hline Sample Standard Deviation (s) & 0.015 \\
\hline Coefficient of Variation (COV) & 0.018 \\
\hline
\end{tabular}

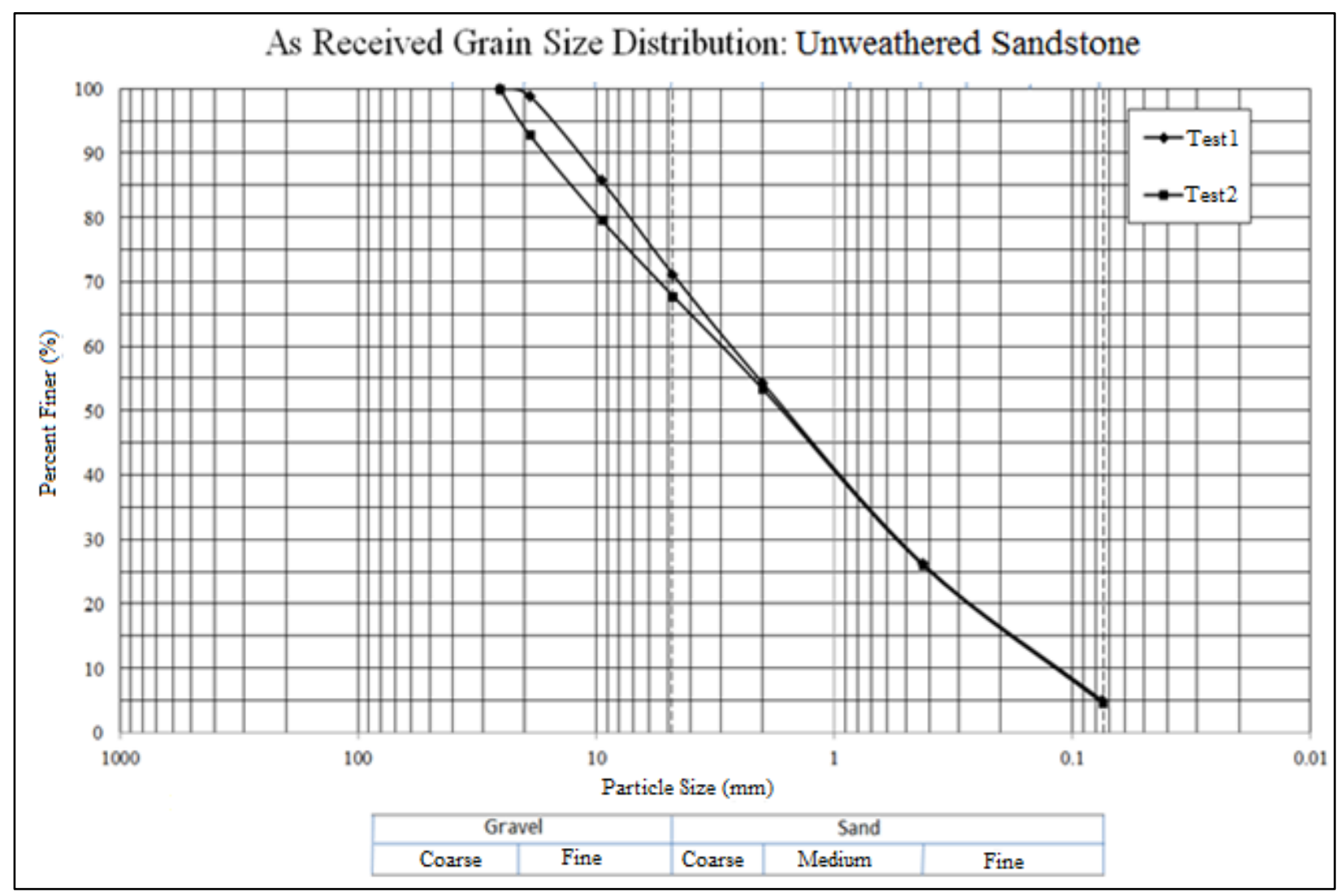

Figure 6.1 Grain Size Distribution of two samples of unweathered sandstone overburden SW. 
Table 6.7 Unweathered Sandstone SW-SM sample hydrometer data.

\begin{tabular}{|c|c|c|c|c|c|c|c|c|}
\hline \multicolumn{2}{|c|}{ Hydrometer No.: } & \multicolumn{2}{|c|}{$\mathrm{G}_{\mathrm{s}}$} & \multicolumn{2}{c|}{$\begin{array}{c}\text { Sample Moist } \\
\text { Mass, g }\end{array}$} & $\begin{array}{c}\text { Moisture } \\
\text { Content } \\
\mathrm{w} \%\end{array}$ & Sample Dry Mass, g \\
\hline \multicolumn{2}{|c|}{$152 \mathrm{H}$} & \multicolumn{2}{|c|}{2.75} & \multicolumn{2}{c|}{100} & 2.78 & \multicolumn{2}{c|}{97.22} \\
\hline $\begin{array}{c}\text { Elapsed } \\
\text { Time, } \\
(\mathrm{T}) \text { min }\end{array}$ & $\begin{array}{c}\text { Hydrometer } \\
\text { Reading }\end{array}$ & $\begin{array}{c}\text { Actual } \\
\text { Hydrometer } \\
\text { Reading, R }\end{array}$ & $\begin{array}{c}\text { Temp, } \\
{ }^{\circ} \mathrm{C}\end{array}$ & $\begin{array}{c}\mathrm{K} \\
(\mathrm{Table3})\end{array}$ & $\begin{array}{c}\mathrm{a} \\
(\mathrm{Table} 1)\end{array}$ & $\begin{array}{c}\text { \% Finer, } \\
\mathrm{P}\end{array}$ & $\begin{array}{c}\text { Effective } \\
\text { Depth, } \\
\text { (L) cm } \\
\text { (Table 2) }\end{array}$ & $\begin{array}{c}\text { Particle } \\
\text { (D) mm }\end{array}$ \\
\hline 2 & 60 & 60 & 22 & 0.01294 & 0.98 & 60.5 & 6.5 & 0.0233 \\
\hline 5 & 56 & 56 & 22 & 0.01294 & 0.98 & 56.4 & 7.1 & 0.0154 \\
\hline 15 & 46 & 46 & 22 & 0.01294 & 0.98 & 46.4 & 8.8 & 0.0099 \\
\hline 30 & 40 & 40 & 22 & 0.01294 & 0.98 & 40.3 & 9.7 & 0.0074 \\
\hline 60 & 36 & 36 & 22 & 0.01294 & 0.98 & 36.3 & 10.4 & 0.0054 \\
\hline 250 & 26 & 26 & 22 & 0.01294 & 0.98 & 26.2 & 12 & 0.0028 \\
\hline 1440 & 18 & 18 & 22 & 0.01294 & 0.98 & 18.1 & 13.3 & 0.0012 \\
\hline
\end{tabular}

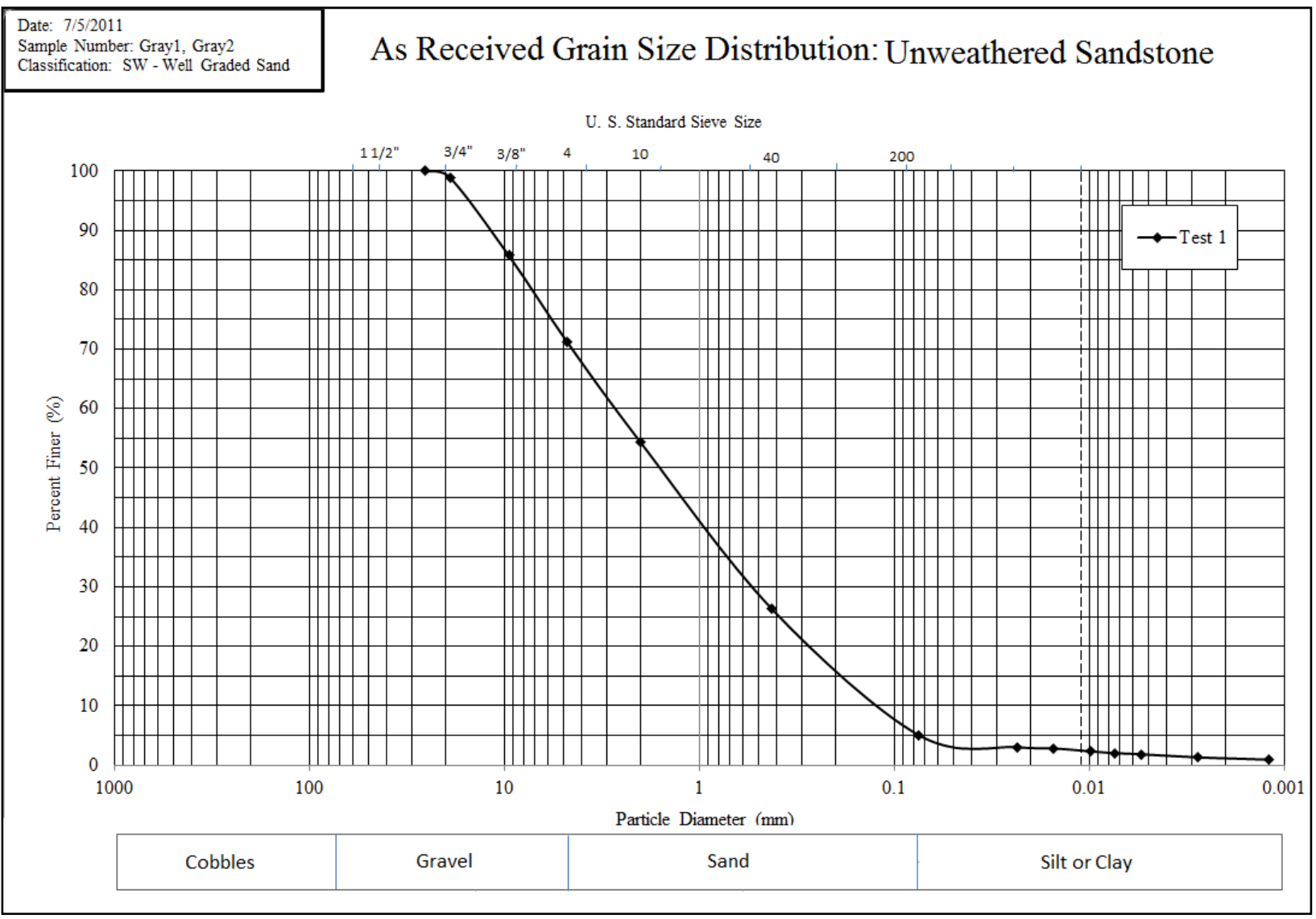

Figure 6.2 Grain size distribution including hydrometer data. 


\subsection{Specific Gravity}

Specific gravity testing was performed according to ASTM standard test method D 854. The objective of the specific gravity testing was to obtain knowledge about the physical characteristics of the material. The specific gravity was found to be 2.69 . The precision of the testing was reflected by the coefficient of variation. The coefficient of variation was found for the specific gravity and the specific gravity at the test temperature to be 0.029 . The test data are shown in Table 6.8 and Table 6.9.

Table 6.8 Test statistics for specific gravity of soil solids.

\begin{tabular}{|l|r|}
\hline Average Specific Gravity, $\mathbf{G}_{\mathbf{t}}$ & 2.690 \\
\hline Sample Standard Deviation for $\mathbf{G}_{\mathbf{t}}, \mathbf{S}$ & 0.078 \\
\hline Coefficient of Variation for $\mathbf{G}_{\mathbf{t}}(\mathbf{C O V})$ & 0.029 \\
\hline
\end{tabular}

Table 6.9 Test statistics for specific gravity at the test temperature.

\begin{tabular}{|l|r|}
\hline Avg. Specific Gravity at Test Temp, $\mathbf{G}_{\mathbf{t t}}:$ & 2.690 \\
\hline Sample Standard Deviation for $\mathbf{G}_{\mathbf{t t}}, \mathbf{S}$ & 0.078 \\
\hline Coefficient of Variation for $\mathbf{G}_{\mathbf{t t}}(\mathbf{C O V})$ & 0.029 \\
\hline
\end{tabular}

\subsection{Atterberg Limits - Test 1}

Atterberg limit tests included the plastic limit and liquid limit test. The tests were performed on the unweathered sandstone material according to ASTM standard test method D 4318. A duplicate test was performed in order to ensure accuracy in the data. The objective of the testing was to determine the liquid limit, plastic limit, and plasticity index of the material. For the first test the liquid limit of the material was found to be 19.3. The plastic limit was found to be 16.3 with a plasticity index of 3.1 which indicates that the material is slightly plastic (PL 1-5) (Das, 2006). For the second test the liquid limit of the material was found to be 19.1. The plastic limit was found to be 16.5 with a plasticity index of 2.6. The test results are presented in Table 6.10 and Figure 6.3. The data is presented in Appendix IV

Table 6.10 Determination of plastic limit, liquid limit and plasticity index

\begin{tabular}{|r|r|}
\hline Plastic Limit: & 16.3 \\
\hline Liquid Limit: & 19.3 \\
\hline Plasticity Index: & 3.1 \\
\hline
\end{tabular}




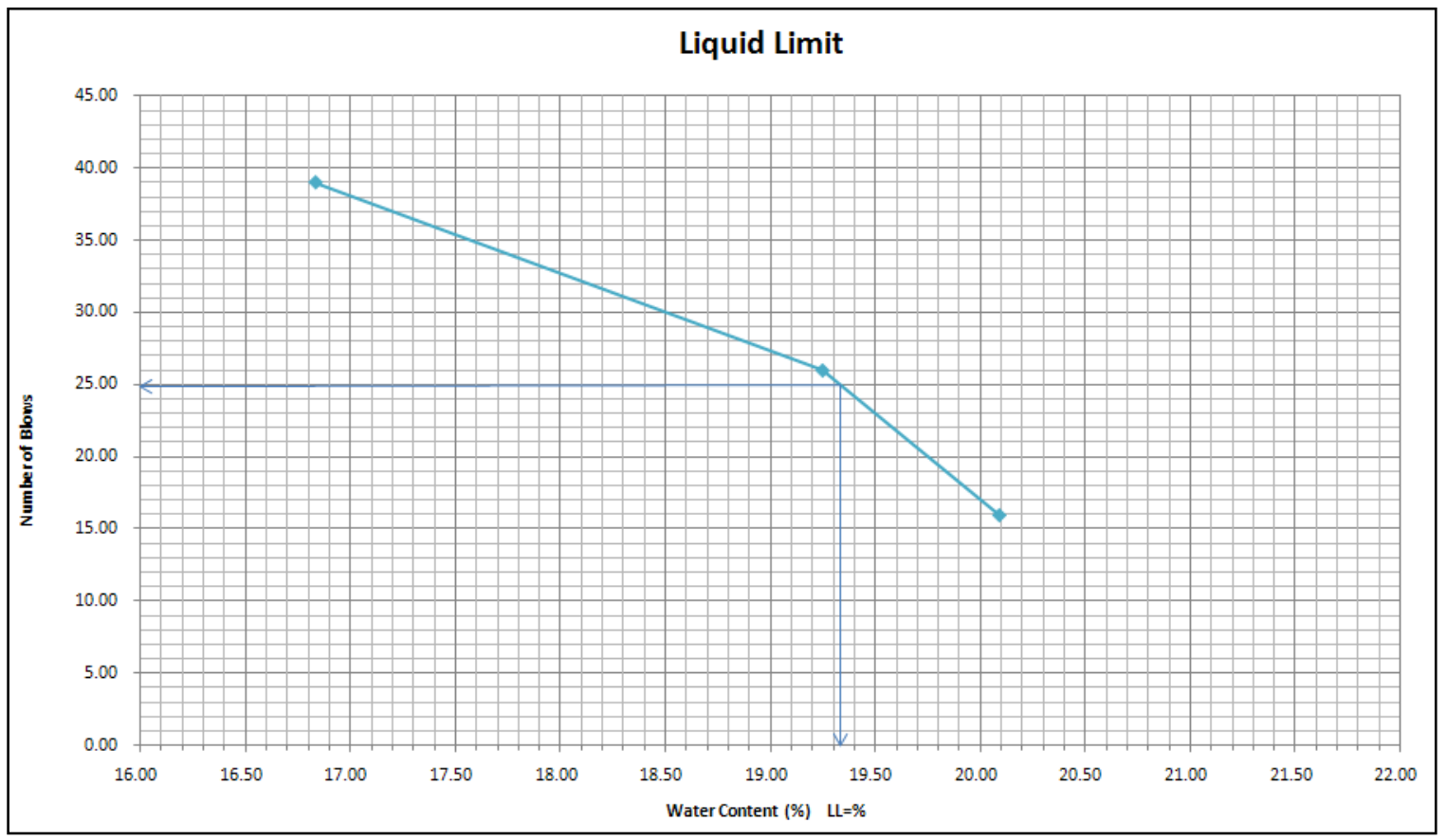

Figure 6.3 Liquid Limit graph for test 1

\subsection{Atterberg Limits - Test 2}

Atterberg limit tests included the plastic limit and liquid limit test. The tests were performed on the unweathered sandstone material according to ASTM standard test method D 4318. This duplicate test was performed in order to ensure accuracy in the data. The objective of the testing was to determine the liquid limit, plastic limit, and plasticity index of the material. For this duplicate test, the liquid limit of the material was found to be 19.1. The plastic limit was found to be 16.5 with a plasticity index of 2.6 which indicates that the soil is slightly plastic (PL 1-5) (Das, 2006). The test results for the Atterberg Limits are shown in Table 6.11 and Figure 6.4. The data is presented in Appendix IV. 
Table 6.11 Determination of plastic limit, liquid limit and plasticity index

\begin{tabular}{|r|r|}
\hline Plastic Limit: & 16.5 \\
\hline Liquid Limit: & 19.1 \\
\hline Plasticity Index: & 2.6 \\
\hline
\end{tabular}

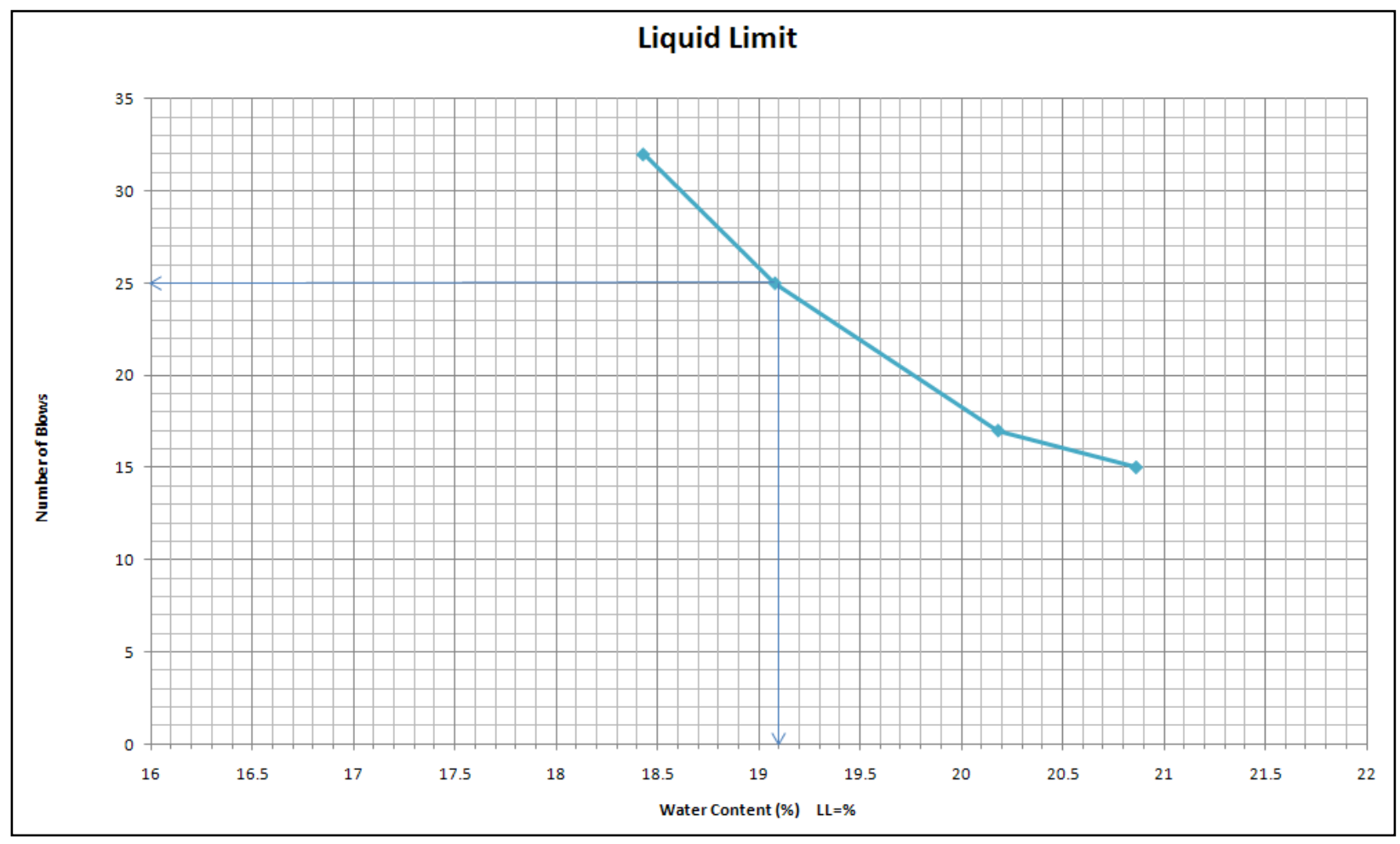

Figure 6.4 Liquid limit graph for test 2 


\subsection{Weathered and Unweathered Sandstone Comparison}

The two materials "unweathered sandstone" and "weathered sandstone" were tested for their individual geotechnical material properties and as received grain size distributions. The results show that the materials are somewhat different. The weathered and the unweathered sandstone are both slightly plastic soils (Das, 2006). The grain size analysis illustrates that the gradations do vary. No strength testing was performed for the weathered material, and it was not included in the numerical modeling of the slopes. Since most of the volume of a landform design typically consists of overburden material, only the weathered sandstone was used for input into the numerical models. A summary of the material properties and as received grain size distributions are shown in Table 6.12 and Figure 6.5. It is important to note that the Atterberg limits test method was for the material passing a \#40 sieve. The unweathered material was reclassified as a well graded sand with silt or SW-SM, as the more coarse particles were separated for the laboratory testing.

Table 6.12 Soil Property summary table for unweathered and weathered sandstone

\begin{tabular}{|c|c|c|}
\hline Soil Property Summary & $\begin{array}{c}\text { Unweathered } \\
\text { Sandstone }\end{array}$ & $\begin{array}{l}\text { Weathered } \\
\text { Sandstone }\end{array}$ \\
\hline Soil Classification & SW & GW \\
\hline $\begin{array}{l}\text { As Received Moisture } \\
\text { Content, w }(\%)\end{array}$ & 2.78 & 8.07 \\
\hline \multicolumn{3}{|c|}{ As Received GSD } \\
\hline \multicolumn{3}{|l|}{ Test 1} \\
\hline $\mathrm{C}_{\mathrm{u}}(\mathrm{mm})$ & 20.77 & 40.91 \\
\hline $\mathrm{C}_{\mathrm{c}}(\mathrm{mm})$ & 0.86 & 2.02 \\
\hline \multicolumn{3}{|l|}{ Test 2} \\
\hline $\mathrm{C}_{\mathrm{u}}(\mathrm{mm})$ & 25 & 23.79 \\
\hline $\mathrm{C}_{\mathrm{c}}(\mathrm{mm})$ & 0.84 & 1.44 \\
\hline Specific Gravity, $\mathbf{G}_{\mathrm{s}}$ & 2.69 & 2.81 \\
\hline \multicolumn{3}{|c|}{ Atterberg Limits - Passing \#40 Sieve } \\
\hline LL & 19.3 & 22.4 \\
\hline PL & 16.3 & 26.2 \\
\hline $\mathrm{PI}$ & 3.1 & 3.8 \\
\hline
\end{tabular}




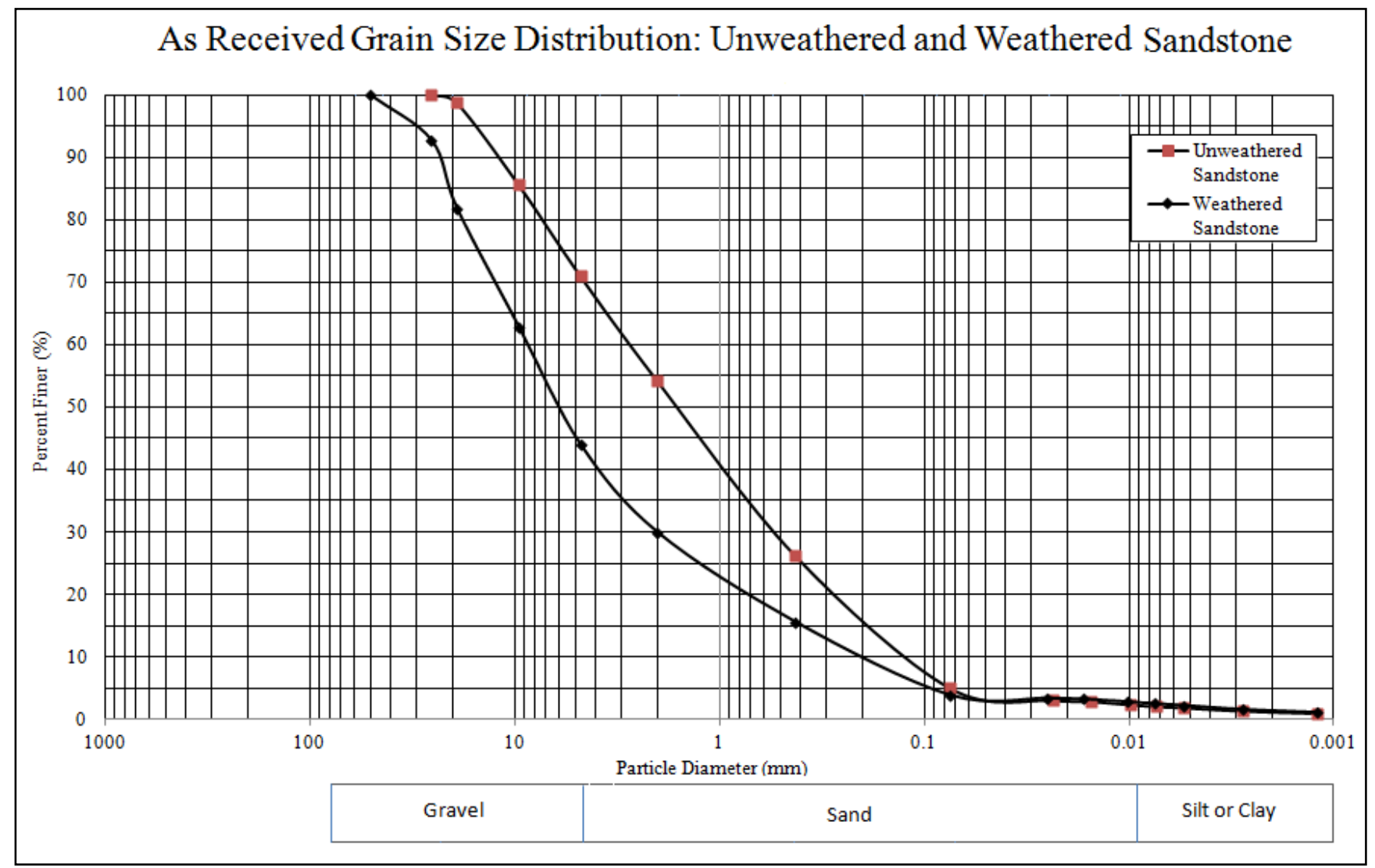

Figure 6.5 As received grain size distributions of weathered and unweathered sandstone 


\section{Compaction}

Compaction testing was performed to find the maximum dry density of the unweathered sandstone overburden material at three predetermined compaction energies. The tests were run at a standard proctor compaction effort (energy applied $=592.5 \mathrm{~kJ} / \mathrm{m}^{3}$ ), at a $34 \%$ Proctor effort (energy applied $\left.=203.6 \mathrm{~kJ} / \mathrm{m}^{3}\right)$, and at an $11 \%$ Proctor compaction effort $\left(67.85 \mathrm{~kJ} / \mathrm{m}^{3}\right)$.

Multiple water contents were used for the testing for the optimization of each test. The objective of the compaction testing was to find the optimum and minimum dry density of the material at the compaction energies listed above. The compaction testing data are presented in this chapter.

\subsection{Standard Proctor $\left(592.5 \mathrm{~kJ} / \mathrm{m}^{3}\right)$}

The testing described in this section were run at a standard proctor compaction effort (energy applied $=592.5 \mathrm{~kJ} / \mathrm{m}^{3}$ ). Four water contents were tested. The water contents were calculated to be $4.12 \%, 9.94 \%, 11.54 \%$, and $12.86 \%$. The optimum dry density of the material was found to be $18.75 \mathrm{kN} / \mathrm{m}^{3}$ at a water content of $10.75 \%$. The data are shown in Table 7.1 and Figure 7.1.

\section{Table 7.1 Compaction test results}

\begin{tabular}{|l|r|r|r|r|}
\hline Test Calculations & Test 1 & \multicolumn{1}{c|}{ Test 2 } & \multicolumn{1}{c|}{ Test 3 } & Test 4 \\
\hline Specific Gravity of Soil, $\mathrm{G}_{\mathrm{s}}$ & 2.69 & 2.69 & 2.69 & 2.69 \\
\hline Dry Unit Weight of Compacted Specimen $\left(\mathrm{KN} / \mathrm{m}^{3}\right), \gamma_{\mathrm{d}}$ & 16.65 & 18.51 & 18.54 & 13.92 \\
\hline Dry Unit Weight at $\mathrm{S}=1.0\left(\mathrm{KN} / \mathrm{m}^{3}\right), \gamma_{\mathrm{d}}$ & 19.57 & 20.09 & 20.78 & 23.71 \\
\hline Dry Unit Weight at $\mathrm{S}=0.9\left(\mathrm{KN} / \mathrm{m}^{3}\right), \gamma_{\mathrm{d}}$ & 19.03 & 19.58 & 20.3 & 23.45 \\
\hline Degree of Saturation $(\%), \mathrm{S}=\mathrm{G}_{\mathrm{s}}{ }^{*} \mathrm{w} / \mathrm{e}$ & 0.59 & 0.73 & 0.64 & 0.12 \\
\hline Saturated Water Content, $\mathrm{w}_{\mathrm{sat}}(\%)$ & 21.62 & 15.71 & 15.64 & 33.14 \\
\hline Water Content, $\mathrm{W}=(\mathrm{Mw} / \mathrm{Ms}) \times 100(\%)$ & 12.86 & 11.54 & 9.94 & 4.12 \\
\hline
\end{tabular}




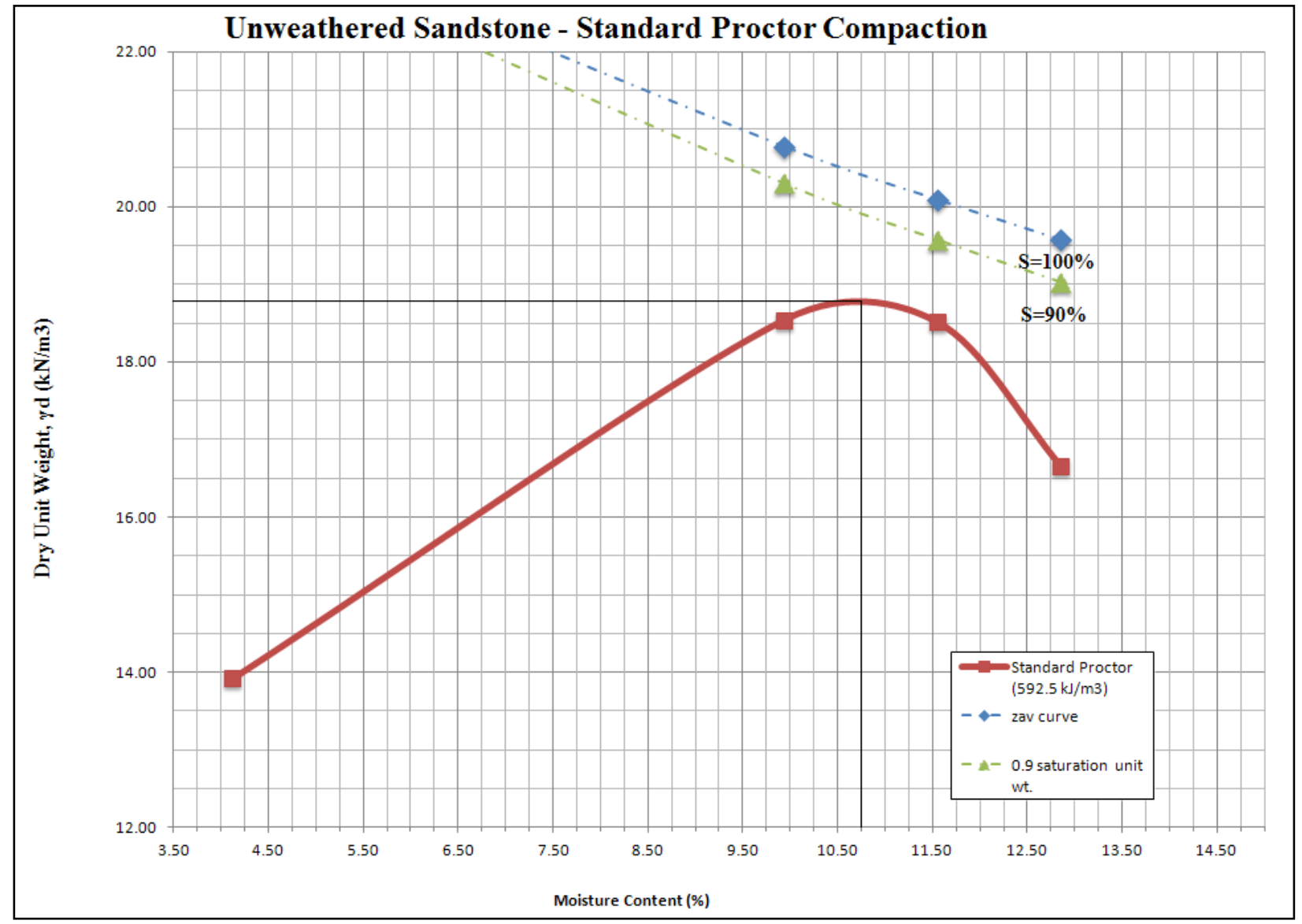

Figure 7.1 Standard proctor curve with lines at $100 \%$ and $90 \%$ saturation. 


\subsection{Proctor Compaction Energy at 34\%: 12 Blows/Layer, 2 Layers (203.6 $\mathbf{k J} / \mathbf{m}^{3}$ )}

The testing described in this section were run at 34\% Proctor compaction effort (energy applied $=203.6 \mathrm{~kJ} / \mathrm{m}^{3}$ ). The test applied 12 blows of a 5 pound compaction hammer to 2 layers of material in a typical compaction mold. The volume of the compaction mold is given in the data below. Seven water contents were tested. The water contents were calculated to be $7.45 \%$, $9.57 \%, 11.20 \%, 12.73 \%, 12.85 \%, 15.73 \%$, and $17.97 \%$. The optimum dry density of the material was found to be $18.1 \mathrm{kN} / \mathrm{m}^{3}$ at a water content of $14.5 \%$. The data are shown in Table 7.2 and Figure 7.2.

\section{Table $7.2 \quad$ Compaction Test Results}

\begin{tabular}{|l|r|r|r|r|r|r|r|}
\hline Test Calculations & \multicolumn{1}{|c|}{$\begin{array}{c}\text { Test } \\
\mathbf{1}\end{array}$} & $\begin{array}{c}\text { Test } \\
\mathbf{2}\end{array}$ & $\begin{array}{c}\text { Test } \\
\mathbf{3}\end{array}$ & $\begin{array}{c}\text { Test } \\
\mathbf{4}\end{array}$ & $\begin{array}{c}\text { Test } \\
\mathbf{5}\end{array}$ & $\begin{array}{c}\text { Test } \\
\mathbf{6}\end{array}$ & $\begin{array}{c}\text { Test } \\
\mathbf{7}\end{array}$ \\
\hline Specific Gravity of Soil, $\mathrm{G}_{\mathrm{s}}$ & 2.69 & 2.69 & 2.69 & 2.69 & 2.69 & 2.69 & 2.69 \\
\hline Dry Unit Weight of Compacted Specimen $\left(\mathrm{KN} / \mathrm{m}^{3}\right), \gamma_{d}$ & 16.11 & 16.21 & 16.48 & 17.98 & 17.94 & 17.8 & 14.37 \\
\hline Dry Unit Weight at $\mathrm{S}=1.0\left(\mathrm{KN} / \mathrm{m}^{3}\right), \gamma_{d}$ & 21.94 & 20.95 & 20.24 & 19.57 & 19.62 & 18.51 & 17.75 \\
\hline Dry Unit Weight at $\mathrm{S}=0.9\left(\mathrm{KN} / \mathrm{m}^{3}\right), \gamma_{d}$ & 21.54 & 20.48 & 19.73 & 19.03 & 19.08 & 17.91 & 17.13 \\
\hline Degree of Saturation $(\%), \mathrm{S}_{\mathrm{f}} \mathrm{G}_{\mathrm{s}}{ }^{*} \mathrm{w} / \mathrm{e}$ & 0.32 & 0.41 & 0.5 & 0.74 & 0.73 & 0.88 & 0.58 \\
\hline Saturated Water Content, $\mathrm{W}_{\mathrm{sat}}(\%)$ & 23.58 & 23.22 & 22.22 & 17.28 & 17.39 & 17.84 & 30.96 \\
\hline Water Content, $(\%) \mathrm{W}=\left(\mathrm{M}_{\mathrm{w}} / \mathrm{M}_{\mathrm{s}}\right) \mathrm{x} 100$ & 7.45 & 9.57 & 11.2 & 12.85 & 12.73 & 15.73 & 17.97 \\
\hline
\end{tabular}




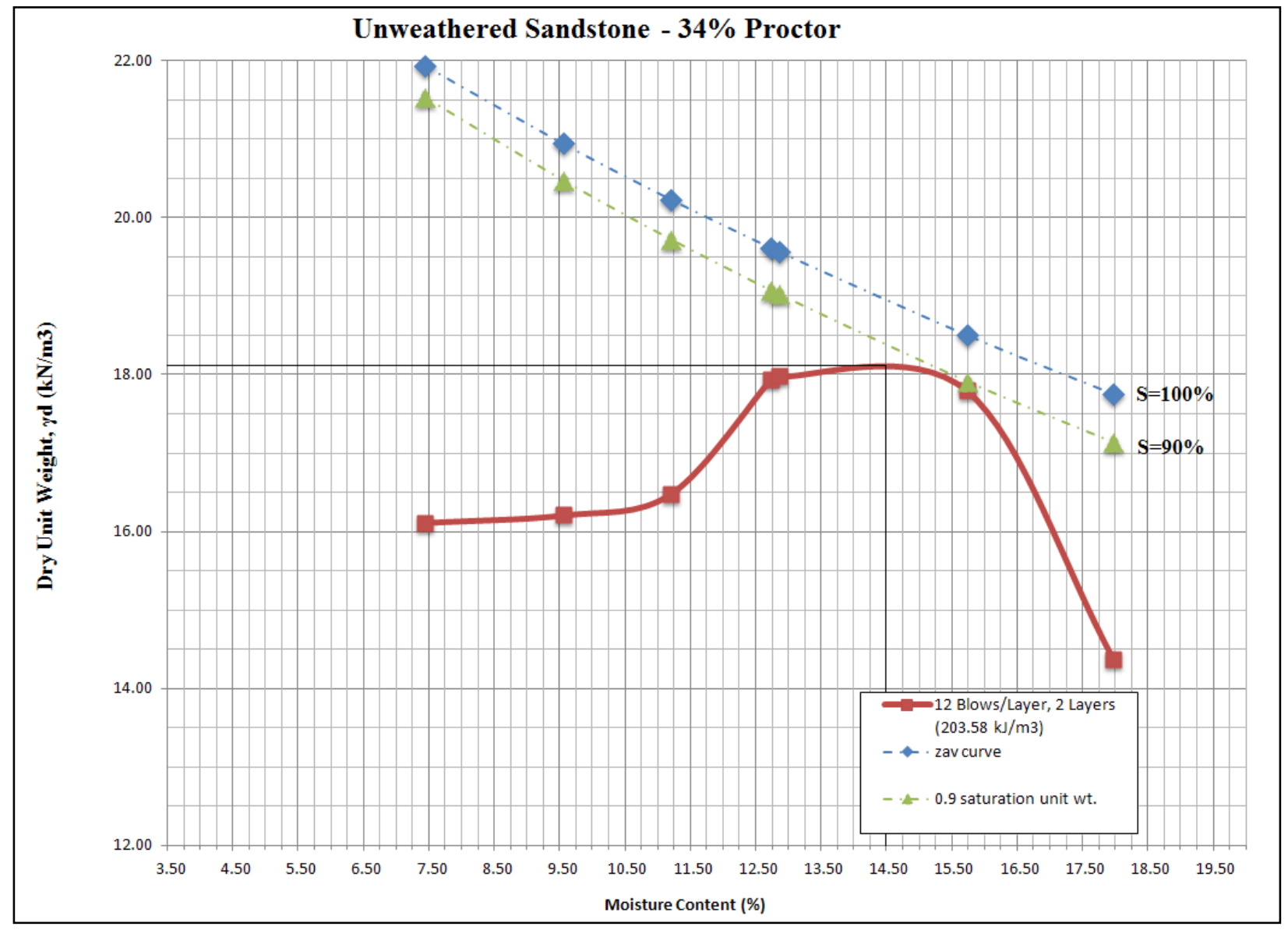

Figure $7.2 \quad 34 \%$ Proctor curve with lines at $100 \%$ and $90 \%$ saturation. 


\subsection{Proctor Compaction Energy at 11\%: 4 Blows/Layer, 2 Layers $(67.85$ $\mathrm{kJ} / \mathbf{m}^{3}$ )}

The testing described in this section were run at an $11 \%$ Proctor compaction effort (energy applied $=67.85 \mathrm{~kJ} / \mathrm{m}^{3}$ ). The test applied 4 blows of a 5 pound compaction hammer to 2 layers of material in a typical compaction mold. The volume of the compaction mold is given in the data below. Seven water contents were tested. The water contents were calculated to be $4.36 \%$, $9.78 \%, 11.60 \%, 11.65 \%, 15.47 \%, 16.89 \%$, and $17.45 \%$. The optimum dry density of the material was found to be $17.6 \mathrm{kN} / \mathrm{m}^{3}$ at a water content of $16.89 \%$. The minimum dry density was found to be $14.9 \mathrm{kN} / \mathrm{m}^{3}$ at a corresponding water content of $9.75 \%$. The minimum dry density was used to find design limitations in hydraulic conductivity. The hydraulic conductivity testing that was performed is described later in this document. The data for the $11 \%$ Proctor compaction effort tests are shown in Table 7.3 and Figure 7.3.

Table 7.3 Compaction Test Results

\begin{tabular}{|l|c|c|c|c|c|c|c|}
\hline \multicolumn{1}{|c|}{ Test Calculations } & $\begin{array}{c}\text { Test } \\
1\end{array}$ & $\begin{array}{c}\text { Test } \\
2\end{array}$ & $\begin{array}{c}\text { Test } \\
3\end{array}$ & $\begin{array}{c}\text { Test } \\
4\end{array}$ & $\begin{array}{c}\text { Test } \\
5\end{array}$ & $\begin{array}{c}\text { Test } \\
6\end{array}$ & $\begin{array}{c}\text { Test } \\
7\end{array}$ \\
\hline Specific Gravity of Soil, $\mathrm{G}_{\mathrm{s}}$ & 2.69 & 2.69 & 2.69 & 2.69 & 2.69 & 2.69 & 2.69 \\
\hline $\begin{array}{l}\text { Dry Unit Weight of Compacted Specimen }\left(\mathrm{KN} / \mathrm{m}^{3}\right), \\
\text { Үd }\end{array}$ & 15.39 & 16.9 & 15.2 & 14.93 & 15.07 & 17.6 & 16.55 \\
\hline Dry Unit Weight at $\mathrm{S}=1.0\left(\mathrm{KN} / \mathrm{m}^{3}\right), \gamma_{\mathrm{d}}$ & 23.57 & 18.6 & 20.07 & 20.85 & 20.05 & 18.11 & 17.92 \\
\hline Dry Unit Weight at $\mathrm{S}=0.9\left(\mathrm{KN} / \mathrm{m}^{3}\right), \gamma_{\mathrm{d}}$ & 23.3 & 18.01 & 19.55 & 20.38 & 19.53 & 17.5 & 17.31 \\
\hline Degree of Saturation $(\%), \mathrm{S}=\mathrm{G}_{\mathrm{s}}{ }^{*} \mathrm{w} / \mathrm{e}$ & 0.16 & 0.75 & 0.43 & 0.34 & 0.42 & 0.92 & 0.79 \\
\hline Saturated Water Content, $\mathrm{w}_{\mathrm{sat}}(\%)$ & 26.45 & 20.74 & 27.22 & 28.41 & 27.79 & 18.46 & 21.97 \\
\hline Water Content, $(\%) \mathrm{W}=\left(\mathrm{M}_{\mathrm{w}} / \mathrm{M}_{\mathrm{s}}\right) \mathrm{x} 100$ & 4.36 & 15.47 & 11.6 & 9.78 & 11.65 & 16.89 & 17.45 \\
\hline
\end{tabular}




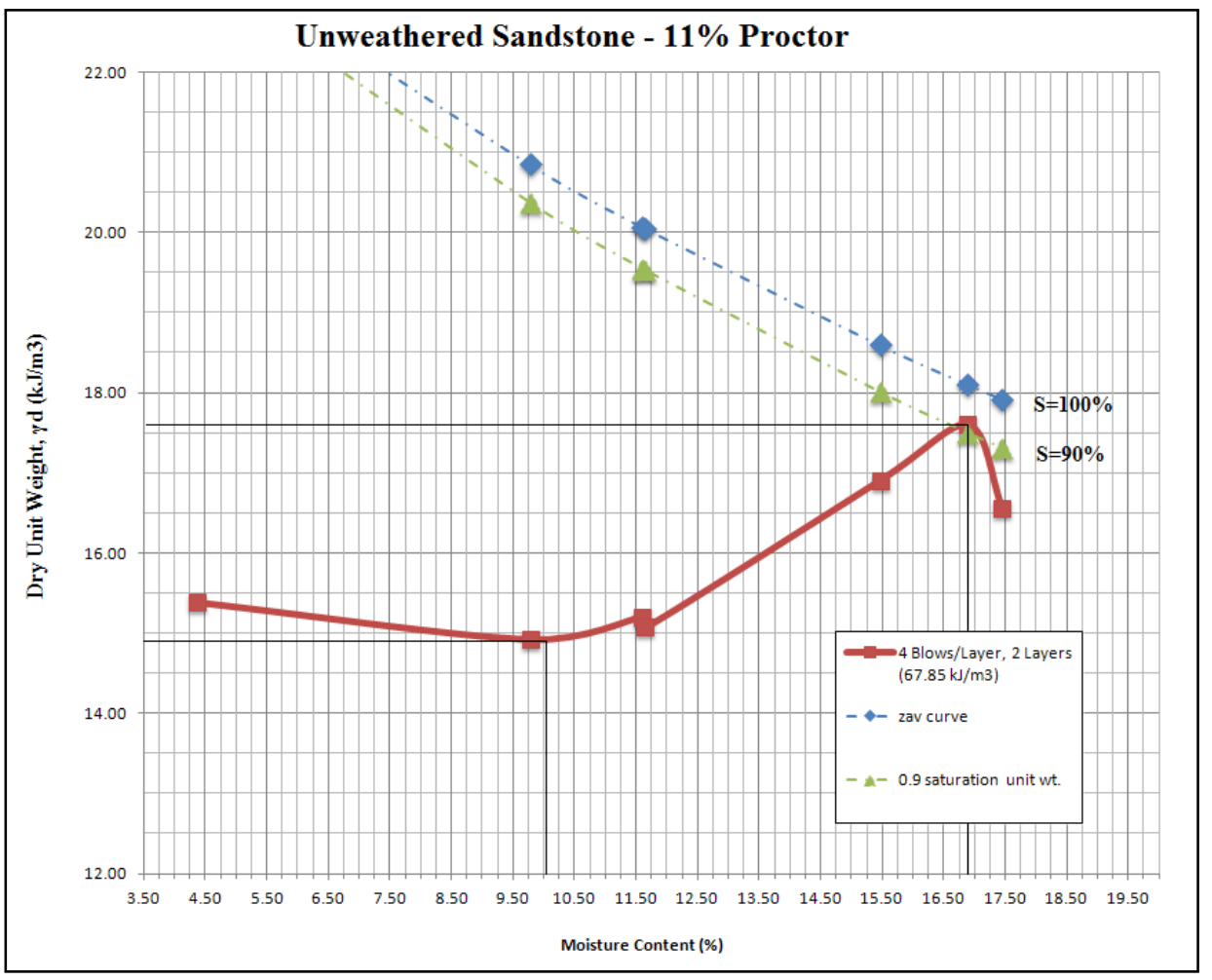

Figure $7.3 \quad 11 \%$ Proctor compaction curve with lines at $100 \%$ and $90 \%$ saturation.

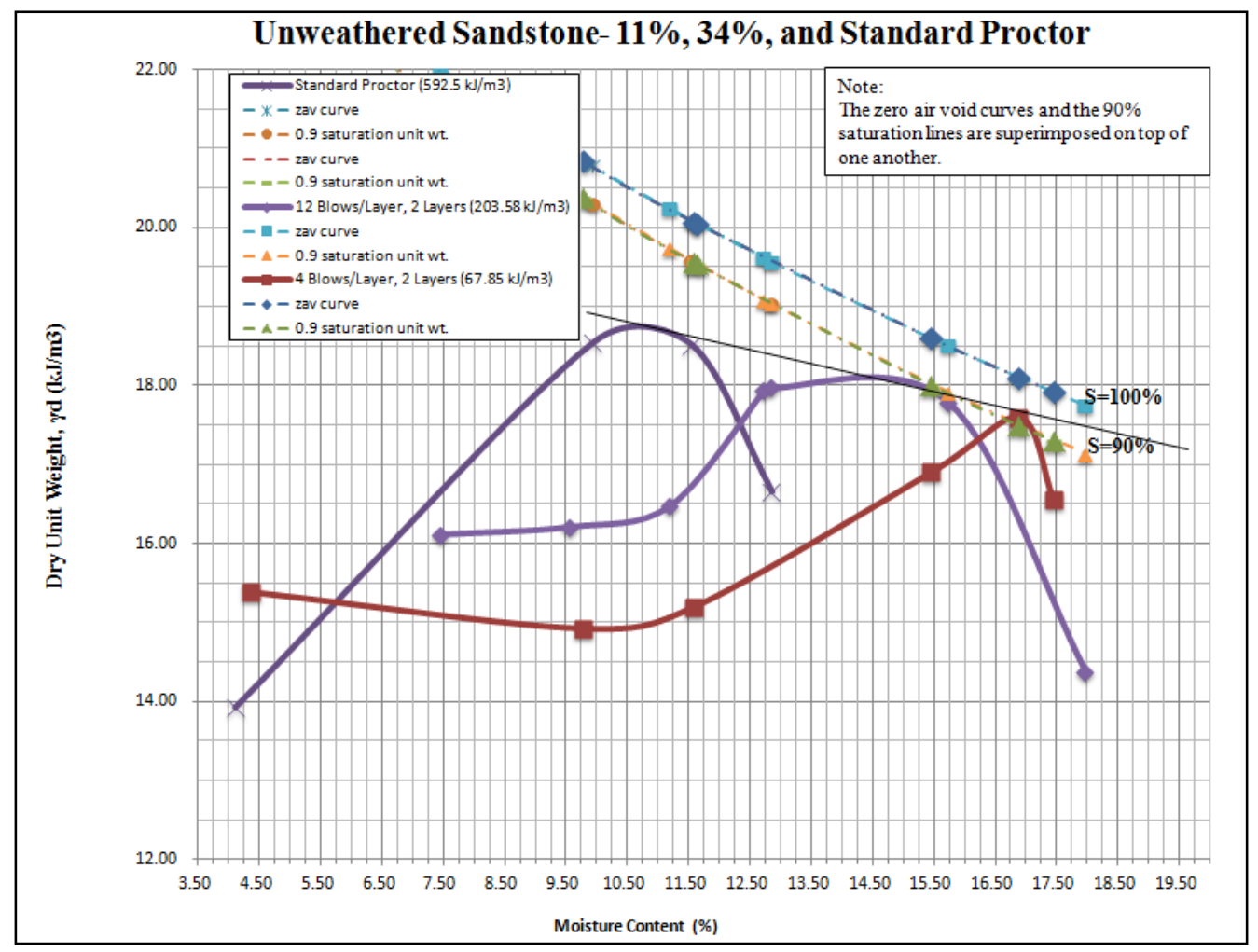

Figure 7.4 Compaction curve compilation 


\section{Discussion}

The compaction curves in Figure 7.4 show different behavior. The standard proctor curve is a typical bell shaped curve with an optimum dry unit weight of $18.75 \mathrm{kN} / \mathrm{m}^{3}$ at a moisture content of approximately $10.75 \%$. The $34 \%$ proctor curve resembles a transition between standard proctor and $11 \%$ proctor curves. The optimum dry density of the $34 \%$ proctor curve was 18.1 $\mathrm{kN} / \mathrm{m}^{3}$ at a moisture content of $14.50 \%$. The $11 \%$ proctor curve shows a compaction curve resembling a standard behavior for a well graded sand. The optimum dry density of the $11 \%$ proctor was at $17.6 \mathrm{kN} / \mathrm{m}^{3}$ with a moisture content of approximately $17.00 \%$. The minimum dry density of the $11 \%$ curve was at $10.50 \%$ moisture content at a value of $14.90 \mathrm{kN} / \mathrm{m}^{3}$. The compaction energy applied in these three scenarios varied from $592.5 \mathrm{~kJ} / \mathrm{m}^{3}$ (standard proctor), $203.6 \mathrm{~kJ} / \mathrm{m}^{3}$ ( $34 \%$ proctor), and $67.85 \mathrm{~kJ} / \mathrm{m}^{3}$ (11\% proctor). The optimum dry densities did not increase by much, only a difference of $1.15 \mathrm{kN} / \mathrm{m}^{3}$ between standard proctor and $11 \%$ proctor compaction. The corresponding moisture contents for these maximums varied from $10.75 \%$ (standard proctor) to $17.00 \%$ (11\% proctor) at a difference of $6.25 \%$. The material does not need a significant amount of compaction in order to achieve a high dry density, but it does need the accompanying moisture content to achieve it.

\subsection{Variability in Compaction}

After reducing the compaction data, it was found that some significant variability occurred for the $34 \%$ and $11 \%$ Proctor compaction effort testing. The variability is a result of a thick first lift in the compaction mold. At a low energy, some of the specimen could not experience the full effect of the compaction effort. The points lying off of the curve are the compaction points for $34 \%$ Proctor compaction effort permeability triplicate specimen testing and a direct shear specimen. The variability effects are shown in Figure 7.5 and Figure 7.6. 


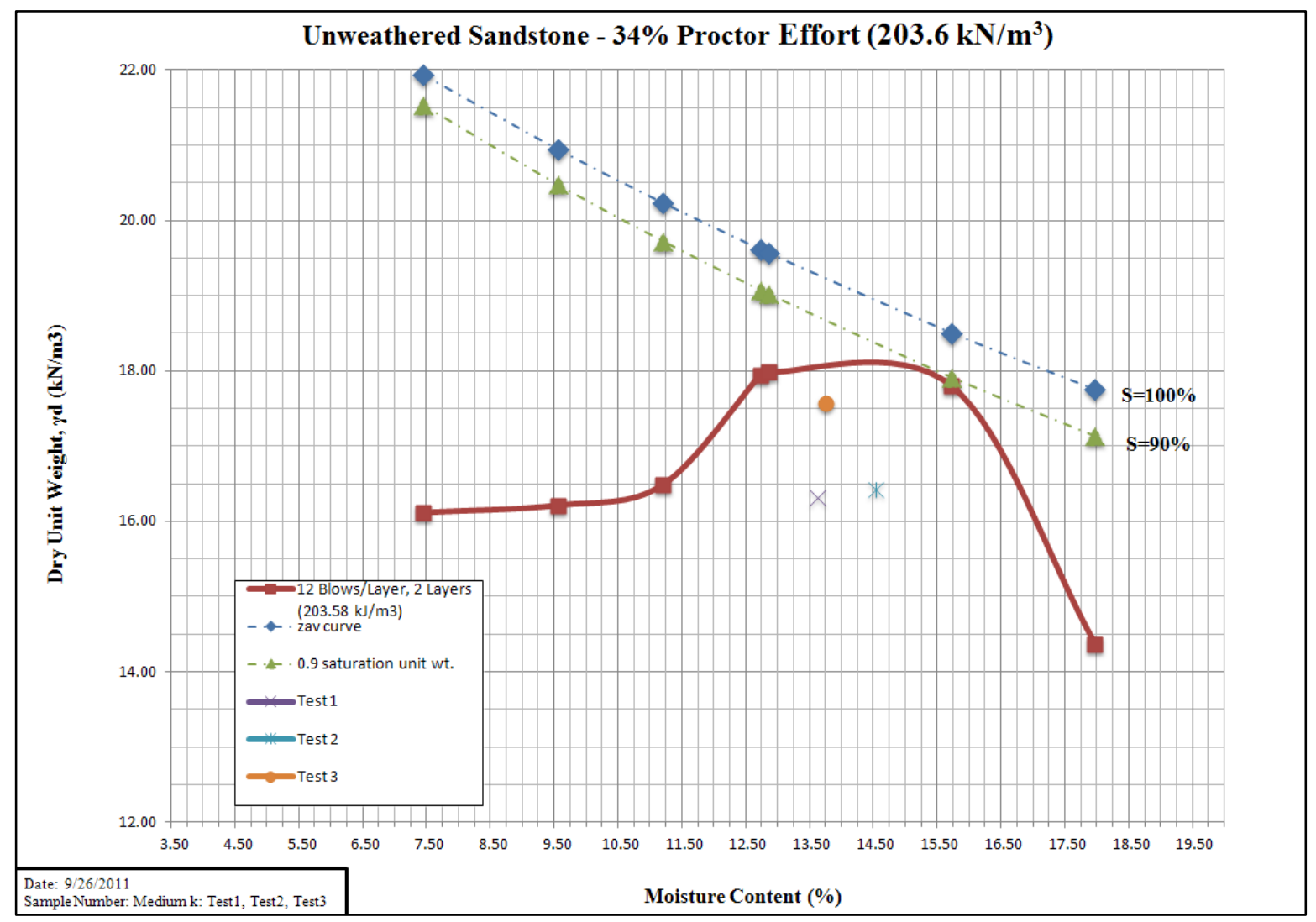

Figure $7.534 \%$ Proctor compaction energy $\left(203.6 \mathrm{~kJ} / \mathrm{m}^{3}\right)$ : Variability in dry density

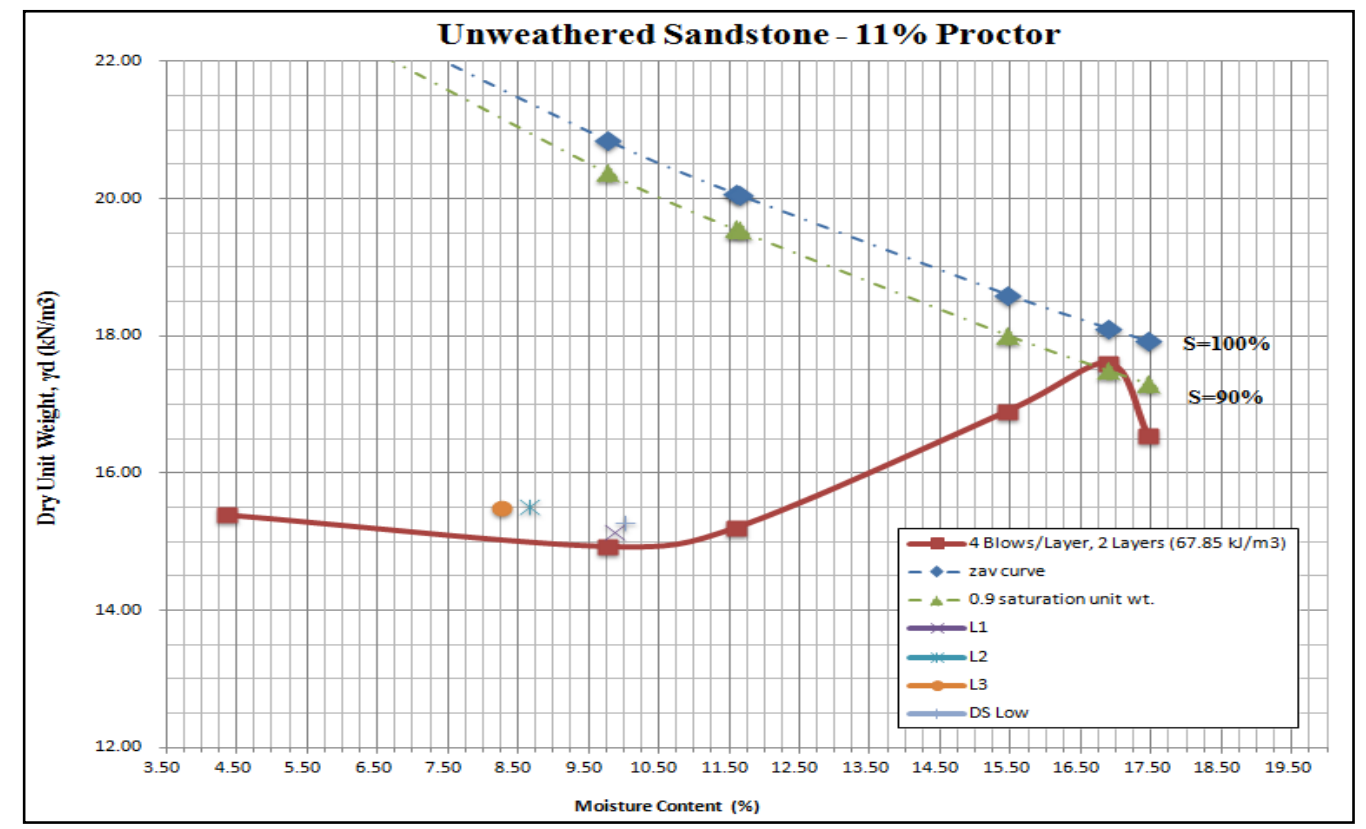

Figure $7.6 \quad 11 \%$ Proctor Compaction Energy $\left(67.85 \mathrm{~kJ} / \mathrm{m}^{3}\right)$ : Variability in dry density 


\section{8. $\quad$ Strength Testing}

The shear strength testing was performed on a GeoJac direct shear testing device. Each test was performed at a saturated, consolidated condition. The specimens were prepared as a standard proctor compaction sample, 34\% Proctor compaction effort sample, and an $11 \%$ Proctor compaction effort sample. The angle of internal friction $(\phi)$ was calculated using MohrCoulomb failure criterion concepts. The tests were performed on the gray unweathered well graded sand with silt material to determine the shear strength properties of the material under specified normal stress conditions. These stress conditions were determined by multiplying the optimum density of the soil by the depth of a valley fill at the Coal MAC site in Logan, WV. The initial stresses were adjusted based on the capabilities of the testing equipment. The maximum normal stresses and shear strains of the equipment capability were sought to investigate thoroughly the residual strength of the material.

\section{Unweathered Sandstone Overburden}

The strength testing phase was organized into three different test specimens with predetermined specified compaction energies which each had unique void ratios. The compaction energies were at a standard proctor effort of $592.5 \mathrm{~kJ} / \mathrm{m}^{3}$, a $65.64 \%$ reduced compaction effort at 203.6 $\mathrm{kJ} / \mathrm{m}^{3}$ or $34.36 \%$ of a standard proctor effort, and an even further reduced compaction effort at $11.45 \%$ of standard proctor equal to $67.85 \mathrm{~kJ} / \mathrm{m}^{3}$ or $88.55 \%$ reduced. These three compaction energies will be referred to as "34\% Proctor," "11\% Proctor," and Standard Proctor. The specimens were prepared to target the optimum dry density for their respective compaction energies. Each compacted specimen was extruded approximately one third the length of the compaction mold. The three layers were captured in a direct shear specimen ring. The testing was performed on a GeoJac $₫$ direct shear testing device. The software used to reduce the data was DigiShear ${ }^{\mathrm{TM}}$. Loading schedules were determined from analyzing a valley fill at a surface mine in Logan, West Virginia. After the normal stress conditions were determined, they were modified to not exceed the loading limitations of the testing devices. The tests were run at a saturated condition. The data and results for the testing are shown in this chapter. Figure 8.1 and Figure 8.2 show the valley fill under inspection for this testing in plan and profile view. 


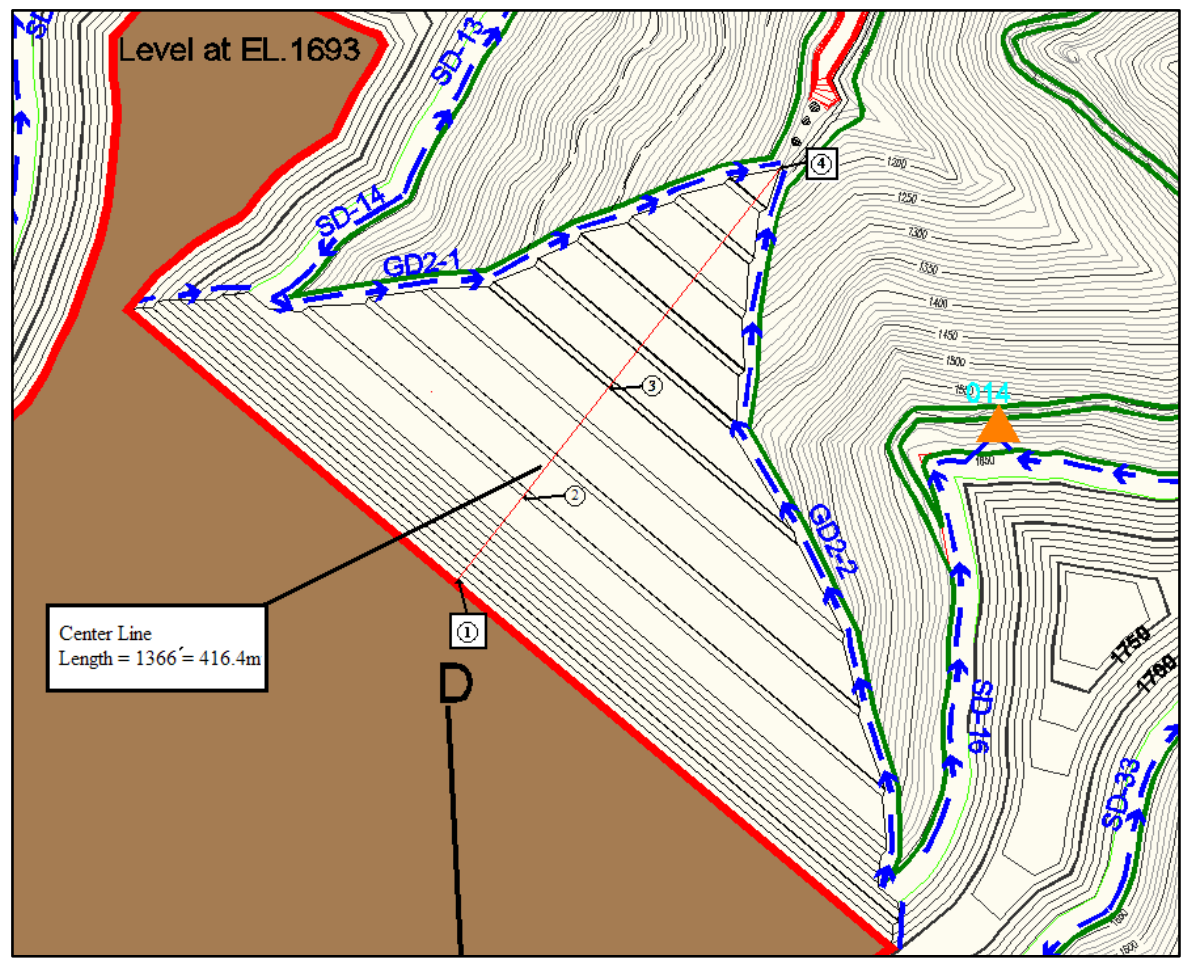

Figure 8.1 Shows the centerline and the points of evaluation on the valley fill under inspection in this section.

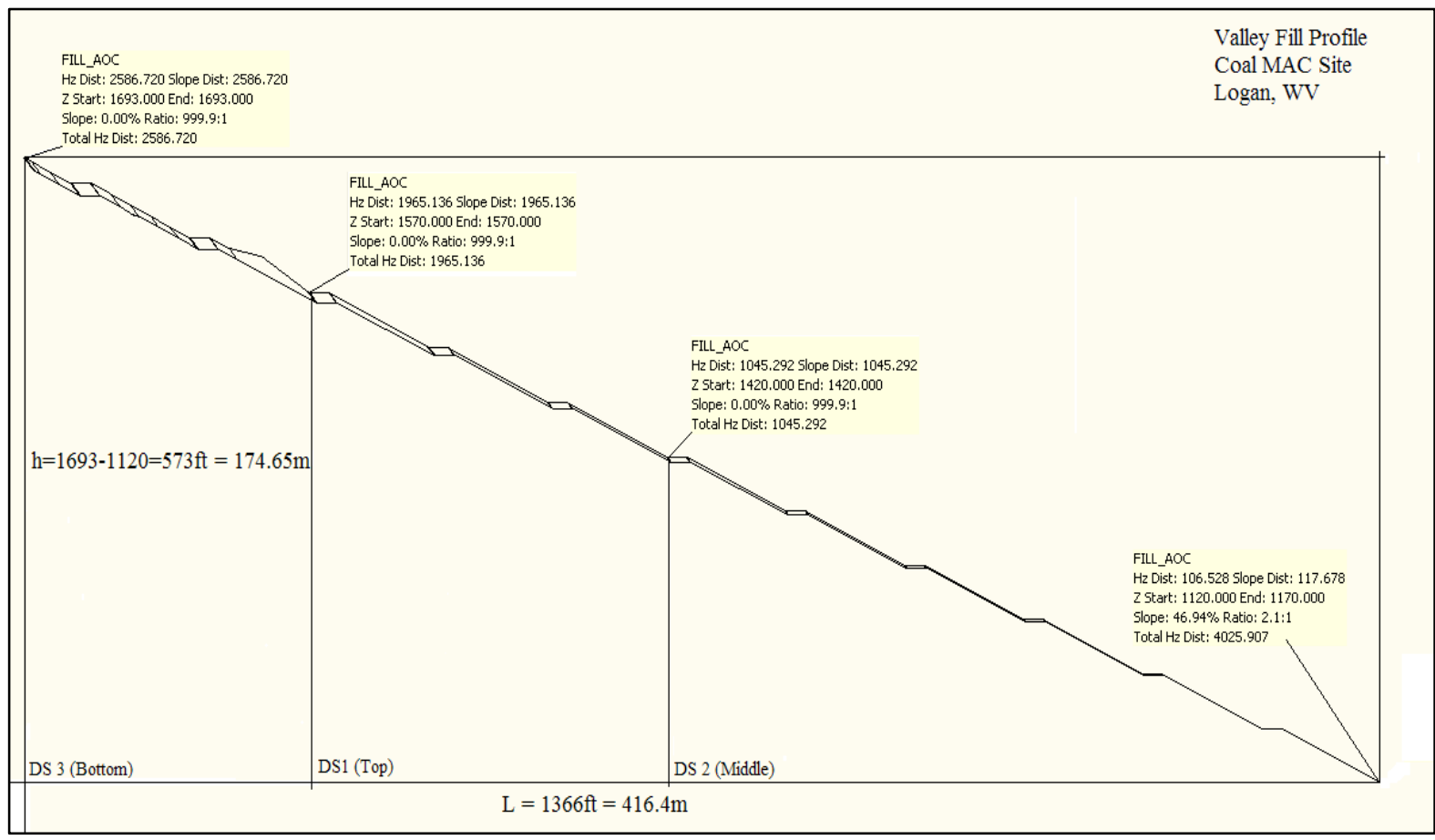

Figure 8.2 Slope profile of an AOC fill design illustrating determined stress evaluation points and slope dimensions. 
Table 8.1 Stress conditions for direct shear test depths (DS1, DS2, DS3)

\begin{tabular}{|c|c|r|r|r|}
\hline $\begin{array}{c}\text { Compaction } \\
\text { Condition }\end{array}$ & Test Points & $\begin{array}{c}\text { Dry Density, } \\
\gamma_{\mathrm{d}}\left[\mathrm{kN} / \mathrm{m}^{2}\right]\end{array}$ & $\begin{array}{c}\text { Depth, } \mathrm{d} \\
{[\mathrm{m}]}\end{array}$ & $\begin{array}{c}\text { Normal } \\
\text { Stress, } \sigma \\
\left(\gamma_{\mathrm{d}}^{*} \mathrm{~d}\right)[\mathrm{kPa}]\end{array}$ \\
\hline \multirow{3}{*}{$\begin{array}{c}\text { Standard } \\
\text { Proctor }\end{array}$} & 3 & 18.39 & 0.00 & 0.00 \\
\cline { 2 - 5 } & 2 & 18.39 & 97.02 & 1784.26 \\
\hline \multirow{3}{*}{$34 \%$ Proctor } & 1 & 18.39 & 145.54 & 2676.40 \\
\cline { 2 - 5 } & DS31 & 18.56 & 32.33 & 600.07 \\
\cline { 2 - 5 } & DS32 & 18.56 & 64.66 & 1200.14 \\
\hline \multirow{3}{*}{$11 \%$ Proctor } & DSL1 & 18.56 & 134.72 & 2500.32 \\
\cline { 2 - 5 } & DSL2 & 16.81 & 35.69 & 600.00 \\
\cline { 2 - 5 } & DSL3 & 16.81 & 71.39 & 1200.00 \\
\hline
\end{tabular}

The depths of the stress conditions varied as a result of equipment maximum loading. The $34 \%$ proctor sample dry density was in fact higher than the standard proctor sample. This was a function of climatic variability in the laboratory. Moisture content varied some throughout the testing, and the target dry densities were not fully achieved. For the standard proctor sample, the third point was made to be at the origin of the graph to demonstrate a zero cohesion condition. The maximum normal stress and shear strain conditions were sought to investigate the behavior of the residual strength of the unweathered sandstone. The objective of the residual strength investigation was to give insight into slope strength. 


\subsection{Standard Proctor $\left(592.5 \mathrm{~kJ} / \mathrm{m}^{3}\right)$}

A standard proctor compaction specimen was prepared and layer depths were each approximately $1 / 3$ of the height of the compaction mold. After compaction, the specimen was extruded from the compaction mold approximately one third at a time. The center of each layer was captured in a direct shear ring mold. The remaining material for each layer was used for grain size distribution analysis. Direct shearing tests were performed on each ring specimen. The stress conditions for consolidation were found by multiplying the optimum dry density of the unweathered sandstone fill by the depth of the valley fill profile shown in Figure 8.2. It was determined that an additional point could be assumed on the Mohr-Coulomb failure envelope at the origin $(0 \mathrm{kPa}, 0 \mathrm{kPa})$ since the material was classified as a well graded sand with silt and would have little cohesion. The consolidation stress conditions were at a normal stress of $1784.26 \mathrm{kPa}$ and $2676.40 \mathrm{kPa}$. The maximum shear stresses that occurred during the testing were $1029.95 \mathrm{kPa}$, and $1342.94 \mathrm{kPa}$, respectively. For DS1, the testing equipment reached its maximum loading capability before peak strength, but likely very near to it around a strain of approximately $7.5 \%$. The maximum shear stress that was read was taken to be the maximum. The testing was performed at a saturated condition. An apparent cohesion resulted from graphing a best fit line to the data points. The apparent cohesion is understood to be the result of the creation of a negative pore pressure in the specimen during the shearing phase of the testing. The differences of $\varphi$ ' are shown for a best fit line and where cohesion equals zero. The data and results are shown in Figure 8.3 through Figure 8.7, and Table 8.2. The compaction information for the sheared specimens is in Appendix V.

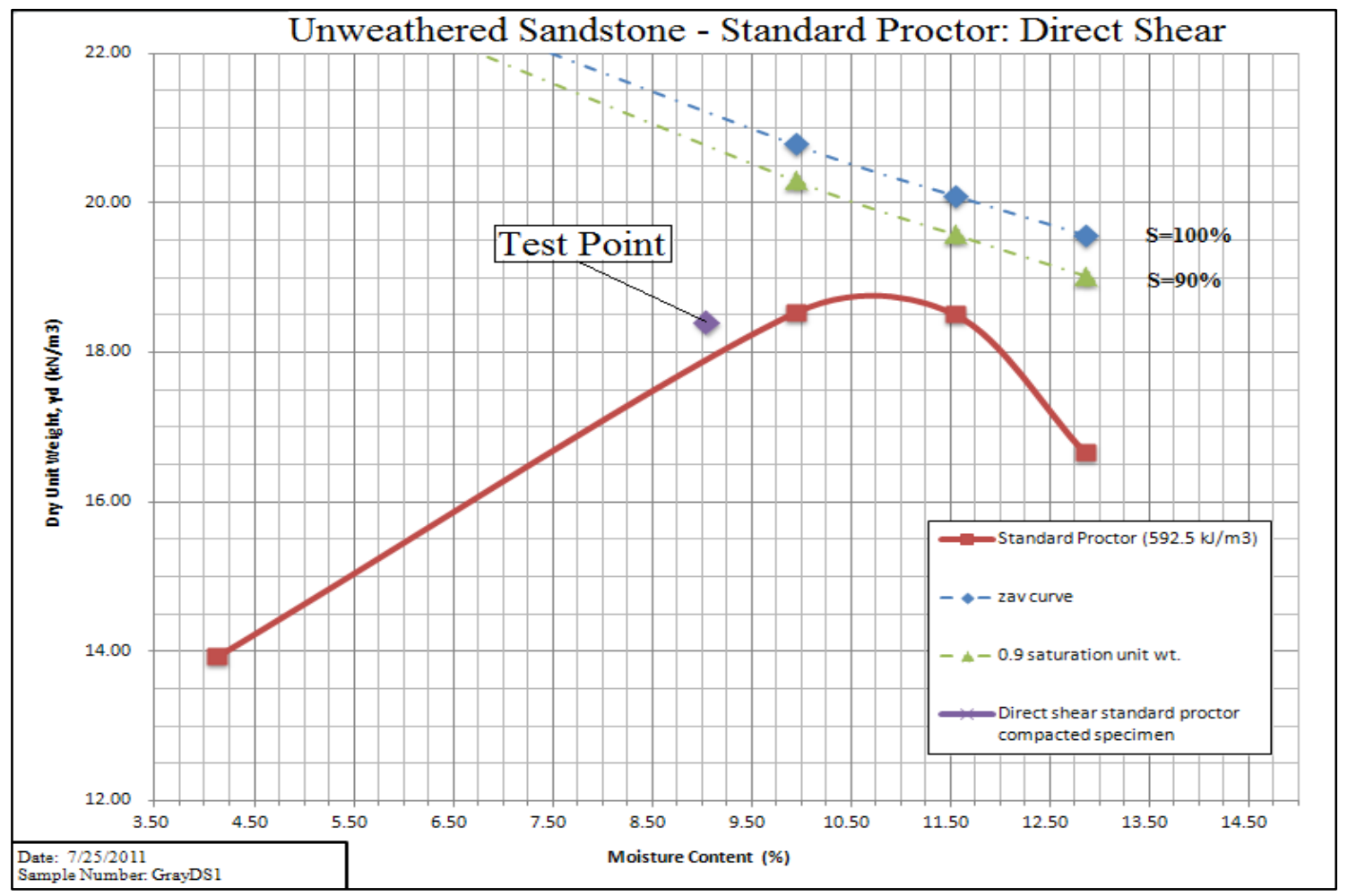

Figure 8.3

Comparison of the direct shear standard proctor compaction specimen and other standard proctor compaction data. 
Table 8.2 Direct shear peak data and calculated values

\begin{tabular}{|c|c|c|c|}
\hline Date & Sample & Compaction & Material \\
\hline $7 / 28 / 2011$ & GrayDS1 & Standard Proctor & Passing No. 4 \\
\hline Specimen Number & Max Shear Stress (ksf) & Max Shear Stress(psf) & Normal Stress (psf) \\
\hline 1 & 28.04 & 28044 & 55890 \\
\hline 2 & 21.51 & 21508 & 37260 \\
\hline 3 & 0 & 0 & 0 \\
\hline Specimen Number & Max Shear Stress(kPa) & Normal Stress (kPa) & \\
\hline 1 & 1342.94 & 2676.4 & \\
\hline 2 & 1029.95 & 1784.26 & \\
\hline 3 & 0 & 0 & \\
\hline $\mathrm{m}=$ & 0.51 & $\mathrm{~m}=$ & 0.53 \\
\hline$\phi_{\text {best fit }}($ degrees $)=$ & 27.14 & $\phi_{\mathrm{c}^{\prime}=0^{\prime}}($ degrees $)=$ & 27.7 \\
\hline$c^{\prime}(p s f)=$ & 602.57 & $\mathrm{c}^{\prime}(\mathrm{kPa})=$ & 0 \\
\hline$c^{\prime}(k P a)=$ & 28.86 & & \\
\hline
\end{tabular}

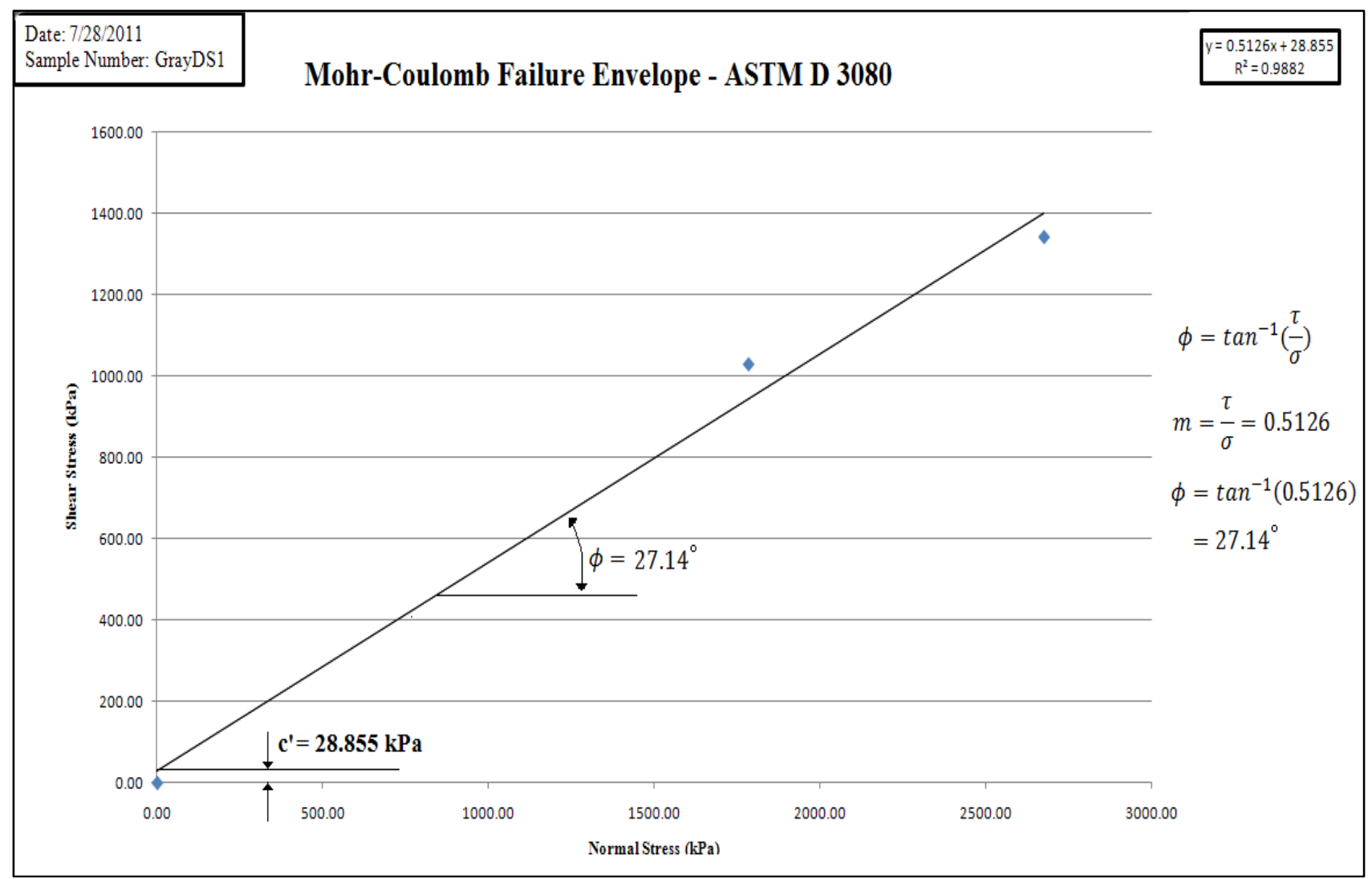

Figure 8.4 Shear stress versus normal stress plot of the standard proctor specimen 


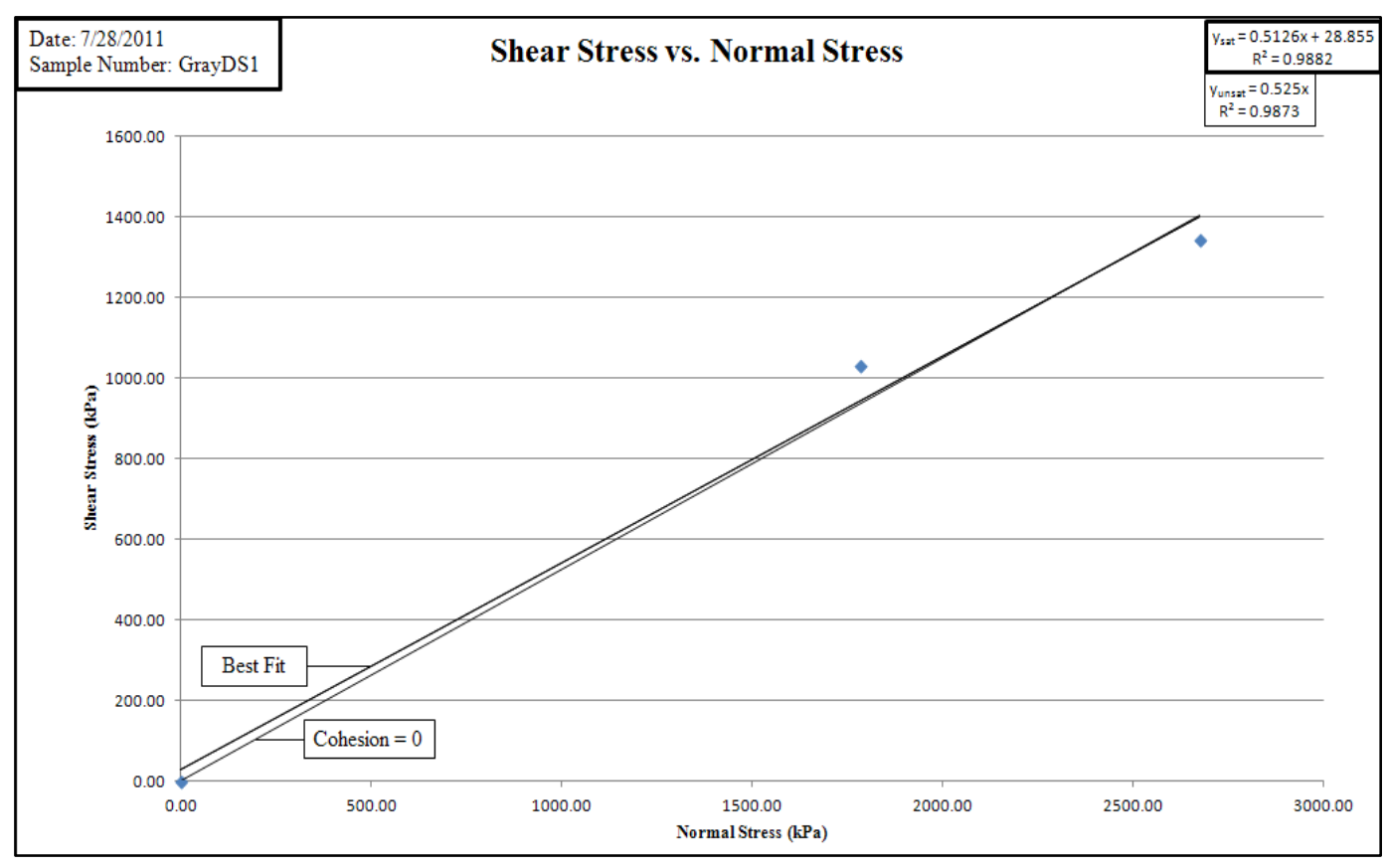

Figure 8.5 Shear stress versus normal stress saturated and unsaturated conditions of the standard proctor specimen

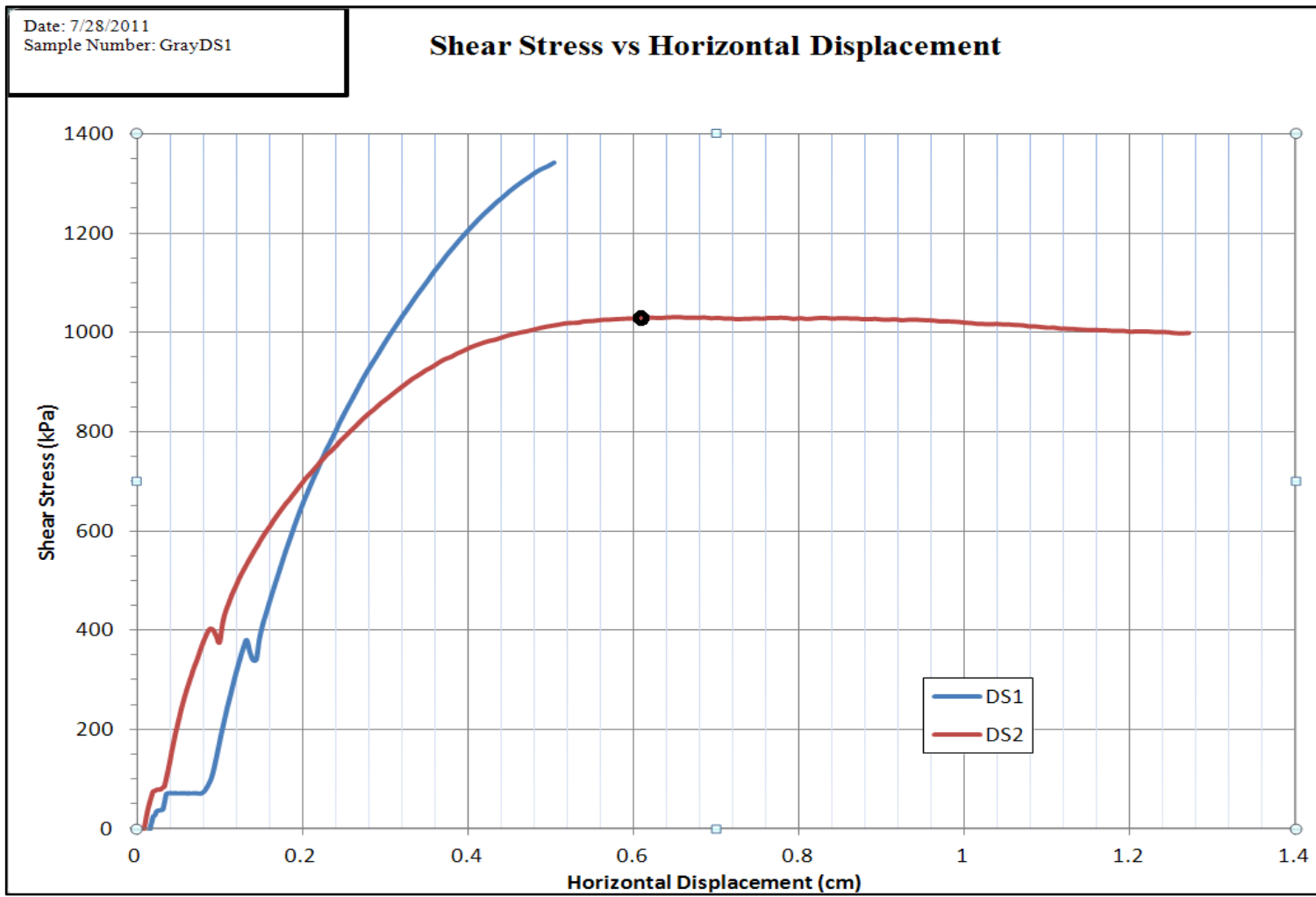

Figure 8.6 Shear stress versus horizontal displacement of test 1 (DS1) and test 2 (DS2). 


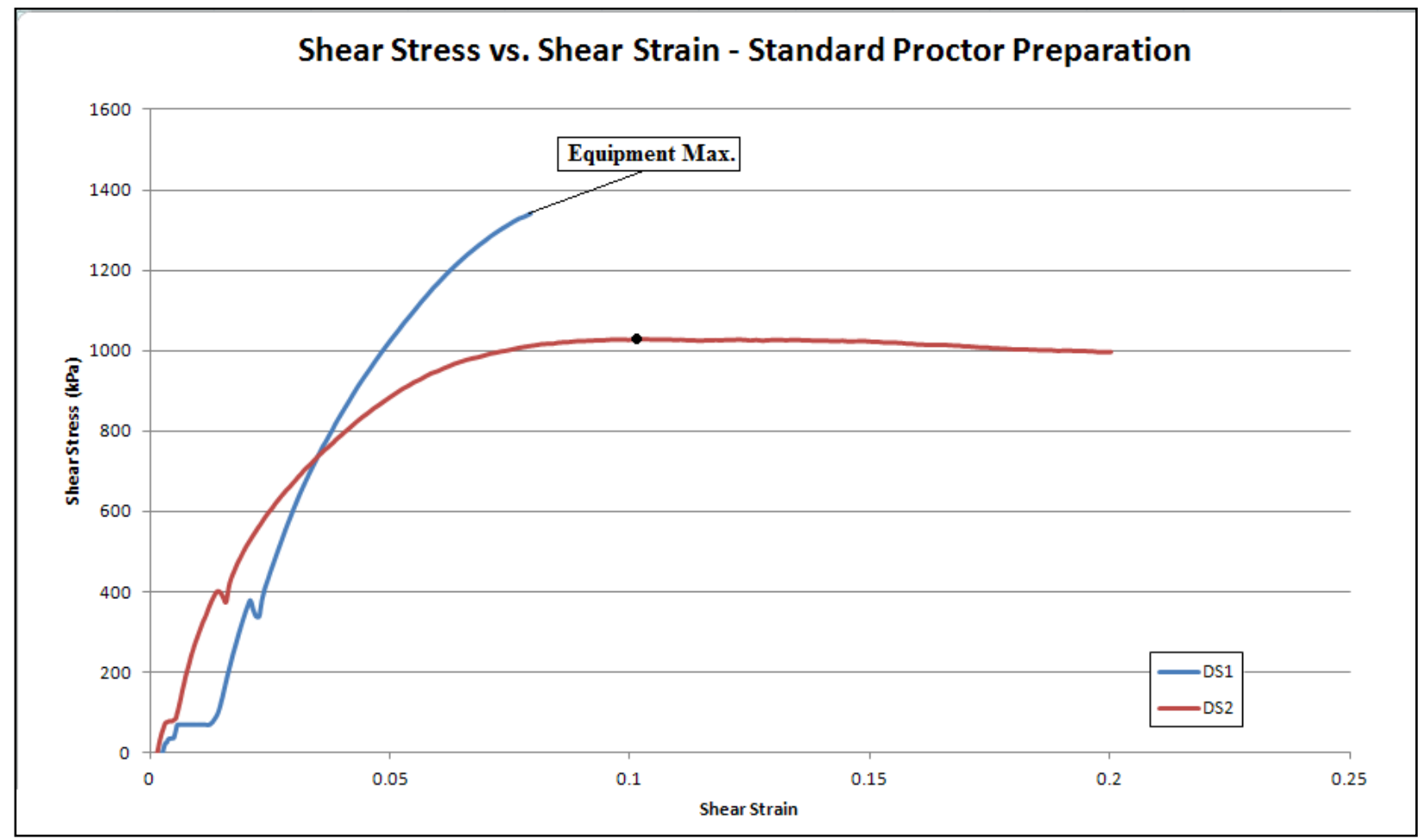

Figure 8.7 Shear stress versus shear strain of test 1 (DS1) and test 2 (DS2)

The jump on Figure 8.6 and Figure 8.7 represents a shear box set up error. The shearing pins used to separate the top and bottom of the shearing box 0.025 in were not adequately loosened. The result is the jump between the shear stress of 200 and $400 \mathrm{kPa}$ to overcome the friction caused by the pins on the shear box. The initial inconsistency of the curves also represents this error. The friction angle that was calculated using these data are consistent with the $34 \%$ and $11 \%$ proctor strength assessment data, however, its precision up to $0.2 \mathrm{~cm}$ displacement is approximate as a result of the error. 


\subsection{Proctor Compaction Energy at 34\%: 12 Blows/Layer, 2 Layers (203.6 $\mathrm{kJ} / \mathbf{m}^{3}$ )}

A specimen was prepared at 34\% Proctor with layer depths each approximately $1 / 3$ of the height of the compaction mold. After compaction, the specimen was extruded from the compaction mold approximately one third at a time. The center of each layer was captured in a direct shear ring mold. The remaining material for each layer was used for grain size distribution analysis. Direct shearing tests were performed on each ring specimen. The stress conditions for consolidation were found by multiplying the optimum dry density of the unweathered sandstone material by the depth of the valley fill profile at the points shown Figure 8.8. For this test, it was determined that a forth point could be assumed on the Mohr-Coulomb failure envelope at the origin $(0 \mathrm{kPa}, 0 \mathrm{kPa})$ since the material was classified as a well graded sand, has a low plasticity index, and therefore little cohesion. The consolidation stress conditions were at normal stresses of $600 \mathrm{kPa}, 1200 \mathrm{kPa}$, and $2500 \mathrm{kPa}$ for the top, middle, and bottom layers, respectively. The maximum shear stresses that occurred during the testing were $365.71 \mathrm{kPa}, 607.73 \mathrm{kPa}$, and $1078.41 \mathrm{kPa}$, respectively. The testing was performed at a saturated condition. An apparent cohesion resulted from graphing a best fit line to the data points. The apparent cohesion is understood to be the result of the creation of a negative pore pressure in the specimen during the shearing phase of the testing. The differences of $\varphi$ ' are shown for a best fit line and where the cohesion equals zero. The data and results are shown in Figure 8.8 through Figure 8.12 and Table 8.3. The compaction information for the sheared specimens is in Appendix V.

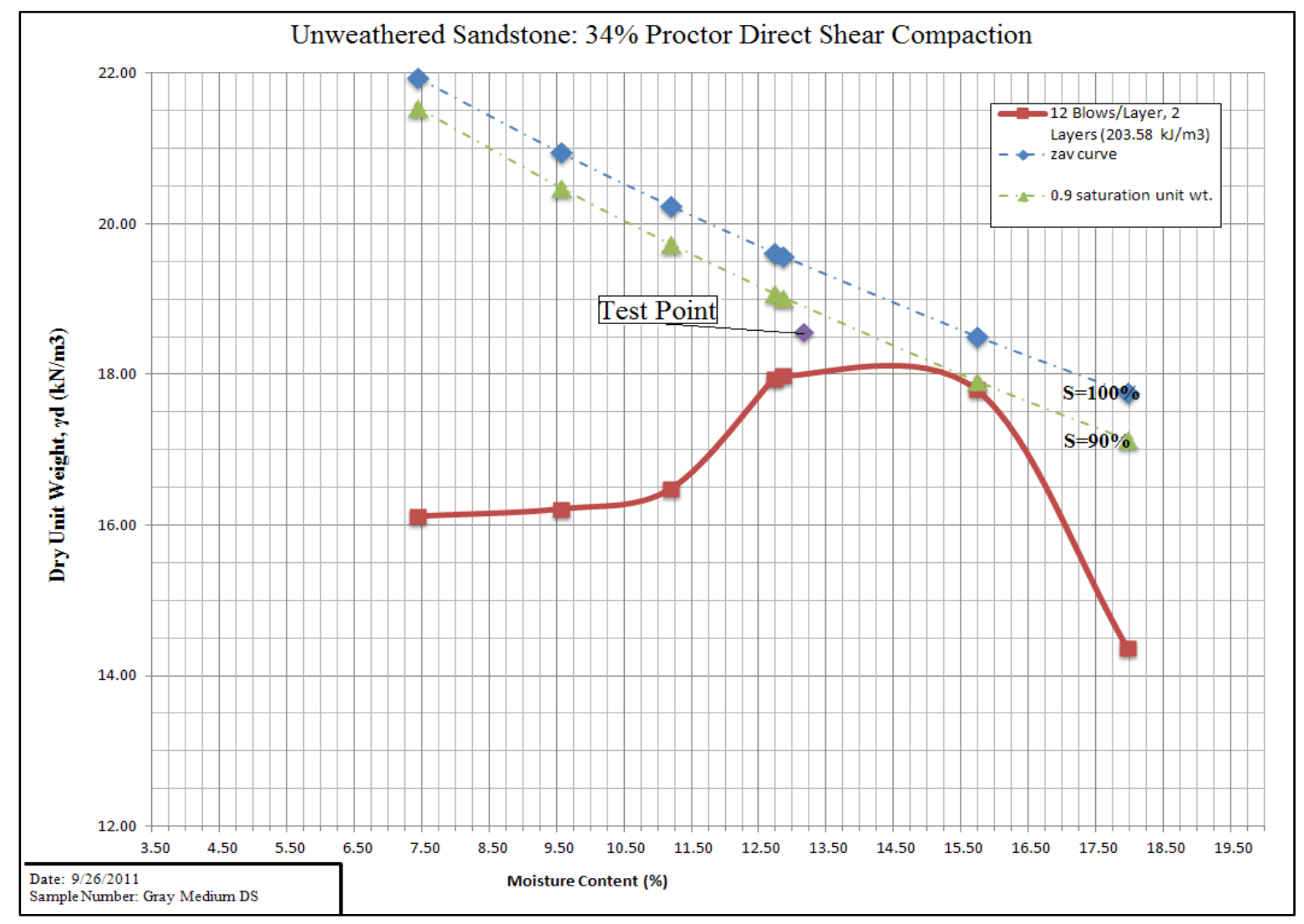

Figure 8.8 Comparison of the direct shear 34\% Proctor compaction specimen and other $34 \%$ Proctor compaction energy specimen data. 
Table 8.3 Direct shear peak data and calculated values

\begin{tabular}{|c|c|c|c|}
\hline Date & Sample & Compaction & Material \\
\hline $9 / 26 / 2011$ & $\begin{array}{l}\text { Gray M:DS31, } \\
\text { DS32, DS33 }\end{array}$ & $\begin{array}{c}12 \text { Blows/Layer, } 2 \\
\text { Layers }(203.6 \text { kJ/m3) }\end{array}$ & Passing No. 4 \\
\hline Specimen Number & $\begin{array}{c}\text { Max Shear Stress } \\
(\mathbf{k s f})\end{array}$ & Max Shear Stress(psf) & $\begin{array}{c}\text { Normal Stress } \\
(\mathrm{psf})\end{array}$ \\
\hline DS31 & 7.64 & 7637 & 12531 \\
\hline DS32 & 12.69 & 12691 & 25062 \\
\hline DS33 & 22.52 & 22520 & 52213 \\
\hline 4 & 0 & 0 & 0 \\
\hline Specimen Number & $\begin{array}{l}\text { Max Shear } \\
\text { Stress(kPa) }\end{array}$ & Normal Stress (kPa) & \\
\hline DS31 & 365.71 & 600.07 & \\
\hline DS32 & 607.73 & 1200.14 & \\
\hline DS33 & 1078.41 & 2500.32 & \\
\hline 4 & 0 & 0 & \\
\hline $\mathrm{m}=$ & 0.42 & $\mathrm{~m}=$ & 0.45 \\
\hline$\phi_{\text {best fit }}($ degrees $)=$ & 22.77 & $\phi_{\mathrm{c}^{\prime}=0^{\prime}}($ degrees $)=$ & 24.36 \\
\hline$c^{\prime}(k s f)=$ & 1287.42 & $c^{\prime}(\mathrm{kPa})=$ & 0 \\
\hline$c^{\prime}(\mathrm{kPa})=$ & 61.642 & & \\
\hline
\end{tabular}

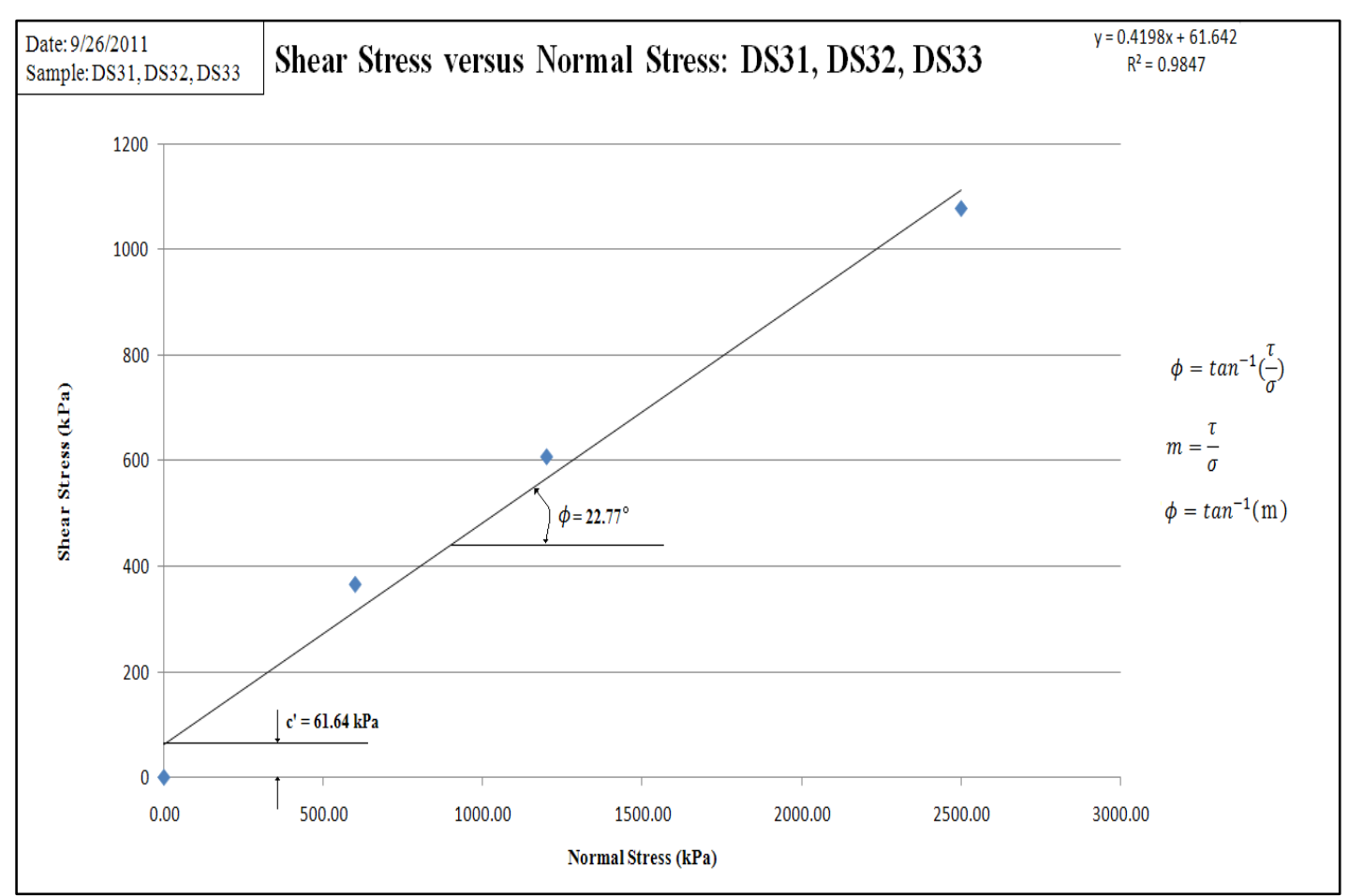

Figure 8.9 Shear stress versus normal stress plot of test 1 (DS31), test 2 (DS32), and test 3 (DS33) 


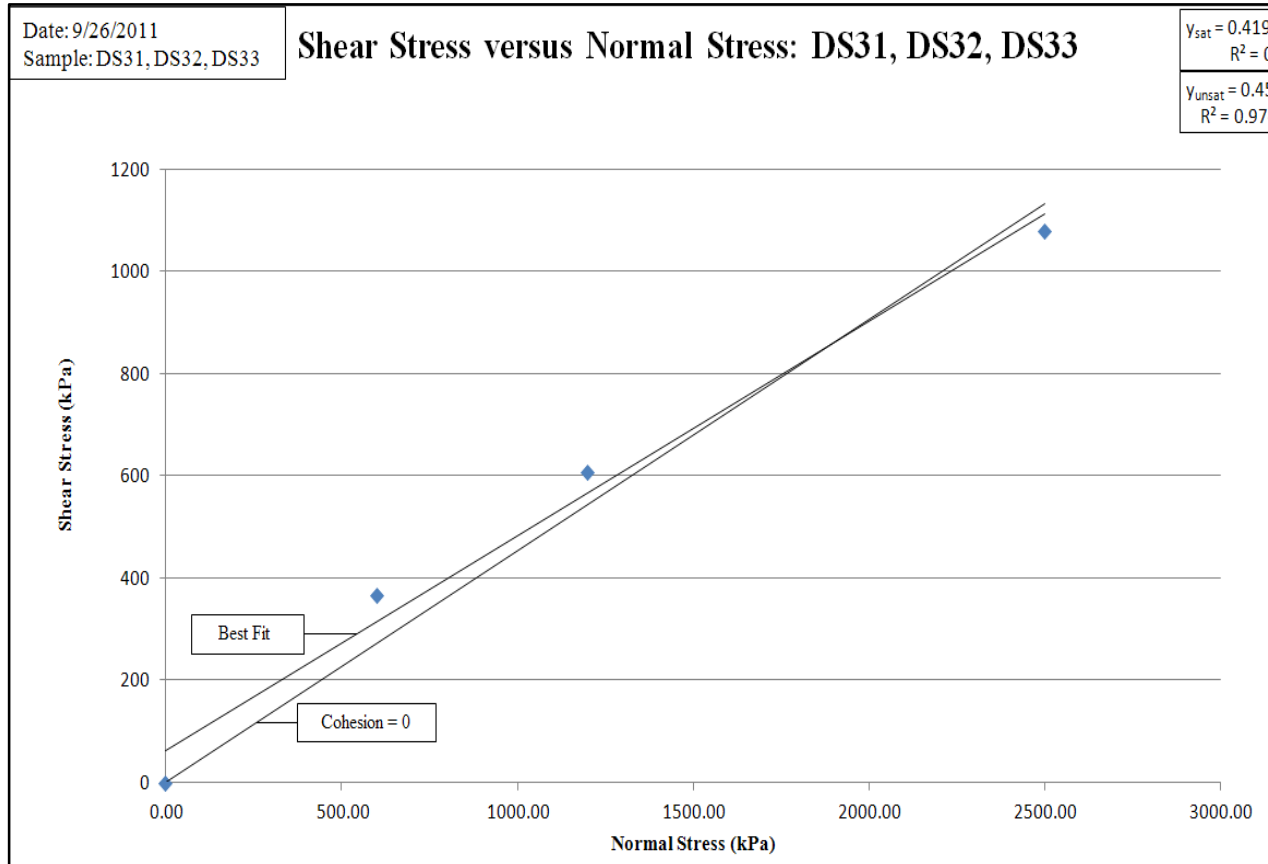

Figure 8.10 Shear stress versus normal stress saturated and unsaturated conditions of test 1 (DS31), test 2 (DS32), and test 3 (DS33)

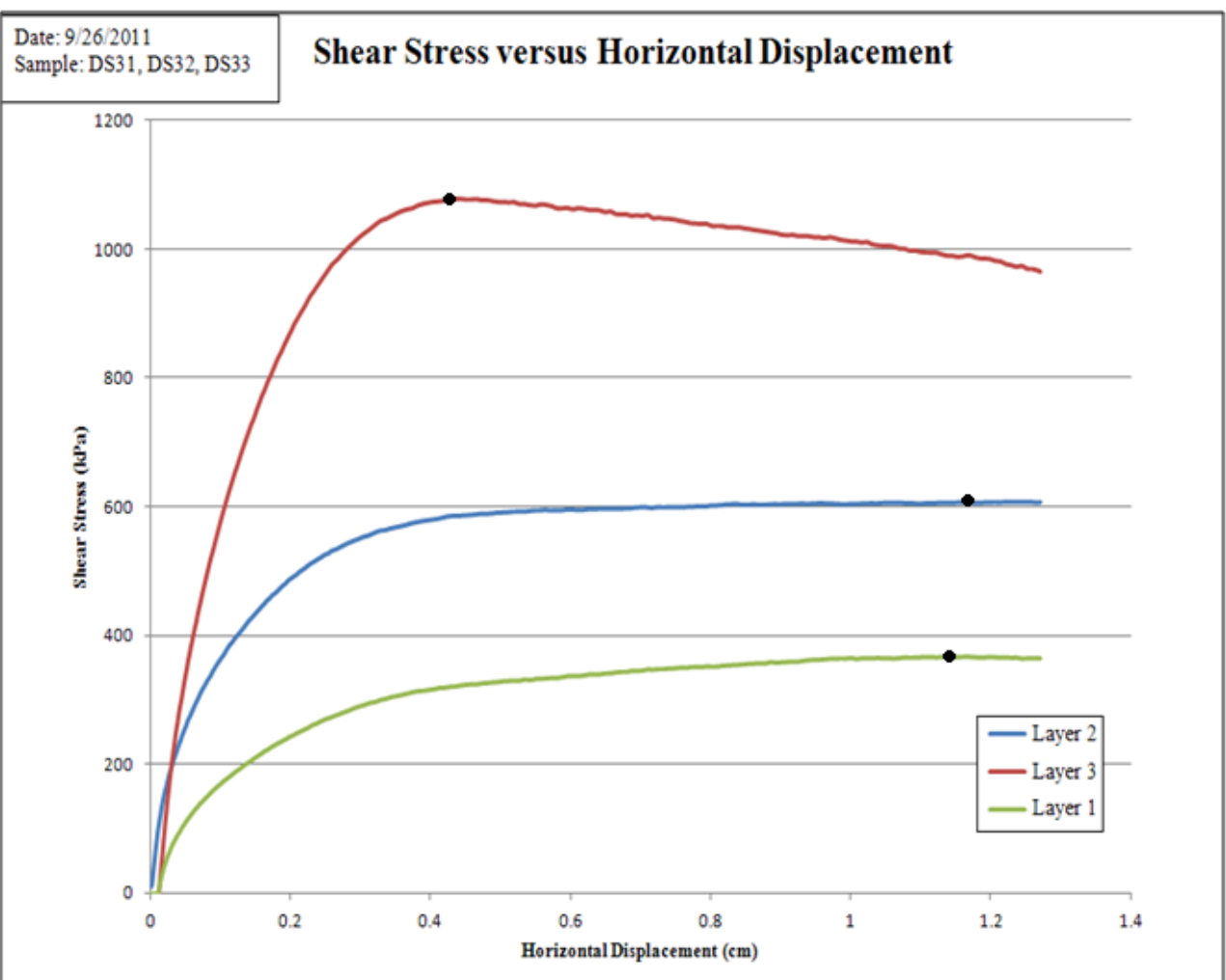

Figure 8.11 Shear stress versus horizontal displacement of layer 1, layer 2, and layer 3. 


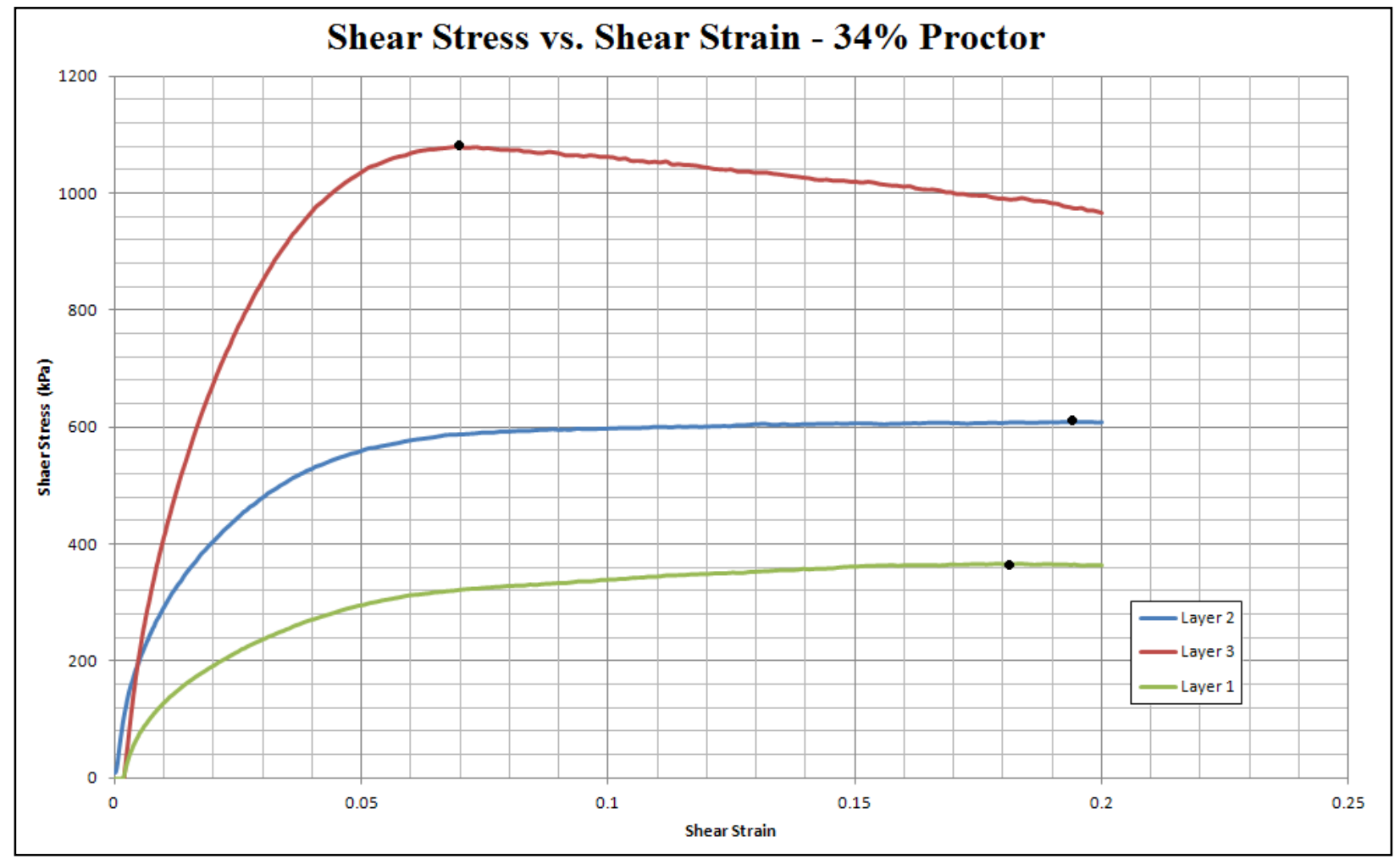

Figure 8.12 Shear stress versus shear strain of layer 1, layer 2, and layer 3. 


\subsection{Proctor Compaction Energy at 11\%: 4 Blows/Layer, 2 Layers (67.85 $\mathbf{k J} / \mathbf{m}^{3}$ )}

A specimen was prepared at the minimum dry density of the $11 \%$ Proctor compaction energy compaction curve. Layer depths were each approximately $1 / 3$ of the height of the compaction mold. After compaction, the specimen was extruded from the compaction mold approximately one third at a time. The center of each layer was captured in a direct shear ring mold. The remaining material for each layer was used for grain size distribution analysis. Direct shearing tests were performed on each ring specimen. The stress conditions for consolidation were found by multiplying the optimum dry density of the unweathered sandstone material by the depth of the valley fill profile at the points shown below. For this test, it was determined that a forth point could be assumed on the Mohr-Coulomb failure envelope at the origin $(0 \mathrm{kPa}, 0 \mathrm{kPa})$ since the material was classified as a well graded sand with silt, has a low plasticity index, and therefore little cohesion. The consolidation stress conditions were at normal stresses of $600 \mathrm{kPa}, 1200$ $\mathrm{kPa}$, and $2500 \mathrm{kPa}$ for the top, middle, and bottom layers, respectively. The maximum shear stresses that occurred during the testing were $314.19 \mathrm{kPa}, 595.62 \mathrm{kPa}$, and $1180.03 \mathrm{kPa}$, respectively. The testing was performed at a saturated condition. An apparent cohesion resulted from graphing a best fit line to the data points. The apparent cohesion is understood to be the result of the creation of a negative pore pressure in the specimen during the shearing phase of the testing. The differences of $\varphi^{\prime}$ are shown for a best fit line and where the cohesion equals zero. The data and results are shown in Figure 8.13 through Figure 8.17 and Table 8.4. The compaction information for the sheared specimens is in Appendix V.

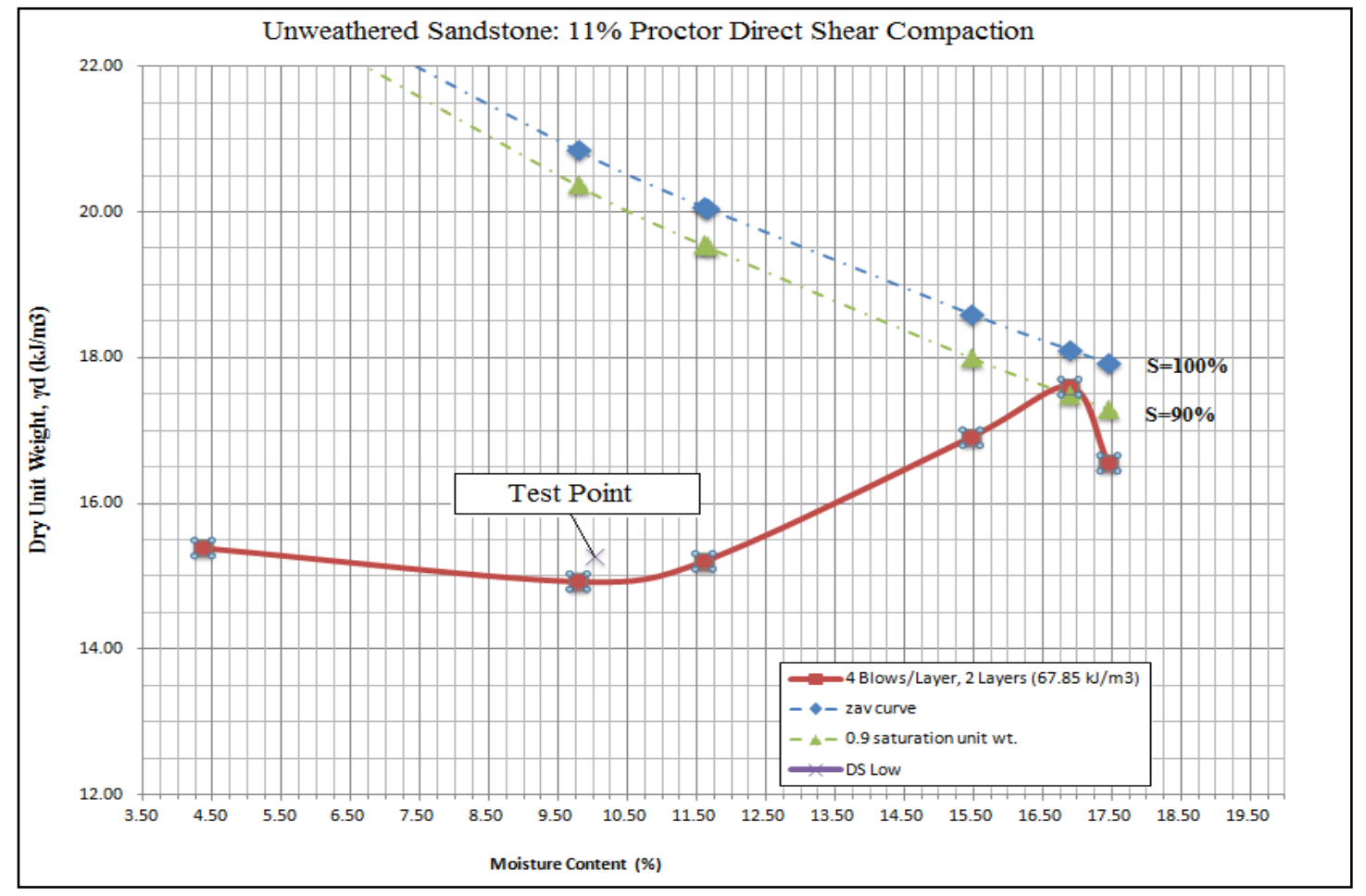

Figure 8.13 Comparison of the direct shear $11 \%$ Proctor compaction specimen and other $11 \%$ Proctor compaction data. 
Table 8.4 Direct shear peak data and calculated values

\begin{tabular}{|c|c|c|c|}
\hline Date & Sample & Compaction & Material \\
\hline $10 / 15 / 2011$ & $\begin{array}{l}\text { 11\% Proctor:DSL1, DSL2, } \\
\text { DSL3 }\end{array}$ & $\begin{array}{c}\text { Blows/Layer, } 2 \text { Layers (67.85 } \\
\left.\mathrm{kJ} / \mathrm{m}^{3}\right)\end{array}$ & Passing No. 4 \\
\hline $\begin{array}{l}\text { Specimen } \\
\text { Number }\end{array}$ & Max Shear Stress (ksf) & Max Shear Stress(psf) & $\begin{array}{c}\text { Normal Stress } \\
(\text { psf })\end{array}$ \\
\hline DSL1 & 6.56 & 6561 & 12531 \\
\hline DSL2 & 12.44 & 12438 & 25062 \\
\hline DSL3 & 24.64 & 24642 & 52213 \\
\hline 4 & 0 & 0 & 0 \\
\hline $\begin{array}{c}\text { Specimen } \\
\text { Number }\end{array}$ & Max Shear Stress(kPa) & Normal Stress (kPa) & \\
\hline DSL1 & 314.19 & 600 & \\
\hline DSL2 & 595.62 & 1200 & \\
\hline DSL3 & 1180.03 & 2500 & \\
\hline 4 & 0 & 0 & \\
\hline $\mathrm{m}=$ & 0.47 & $\mathrm{~m}=$ & 0.48 \\
\hline $\begin{array}{r}\phi_{\text {best fit }}{ }^{\prime}(\text { degrees }) \\
=\end{array}$ & 25.11 & $\phi_{\mathrm{c}^{\prime}=0}($ degrees $)=$ & 25.58 \\
\hline$c^{\prime}(\mathrm{ksf})=$ & 386.76 & $c^{\prime}(\mathrm{kPa})=$ & 0 \\
\hline$c^{\prime}(\mathrm{kPa})=$ & 18.52 & & \\
\hline
\end{tabular}

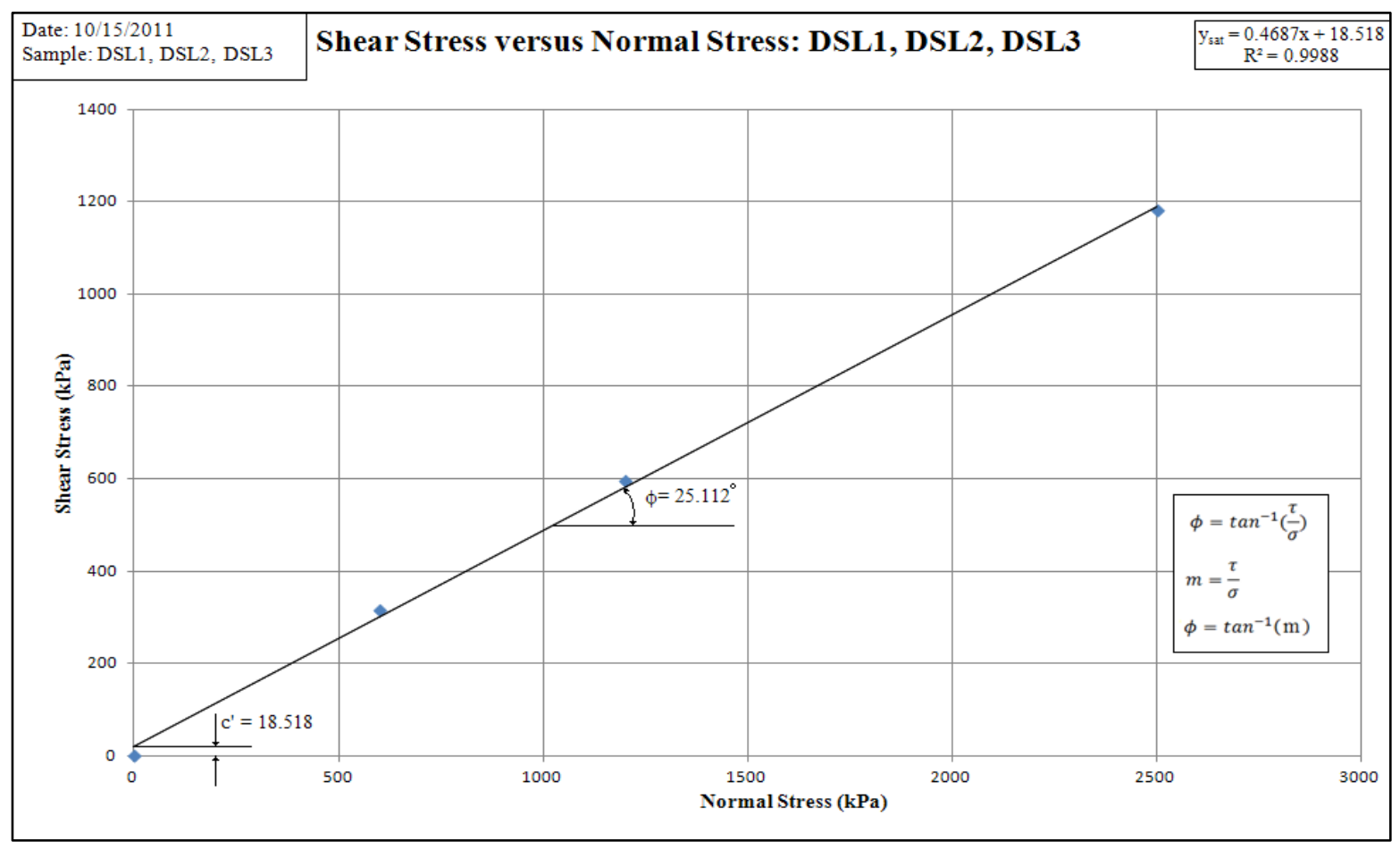

Figure 8.14 Shear stress versus normal stress plot of $11 \%$ Proctor compaction layer 1 , layer 2, and layer 3 


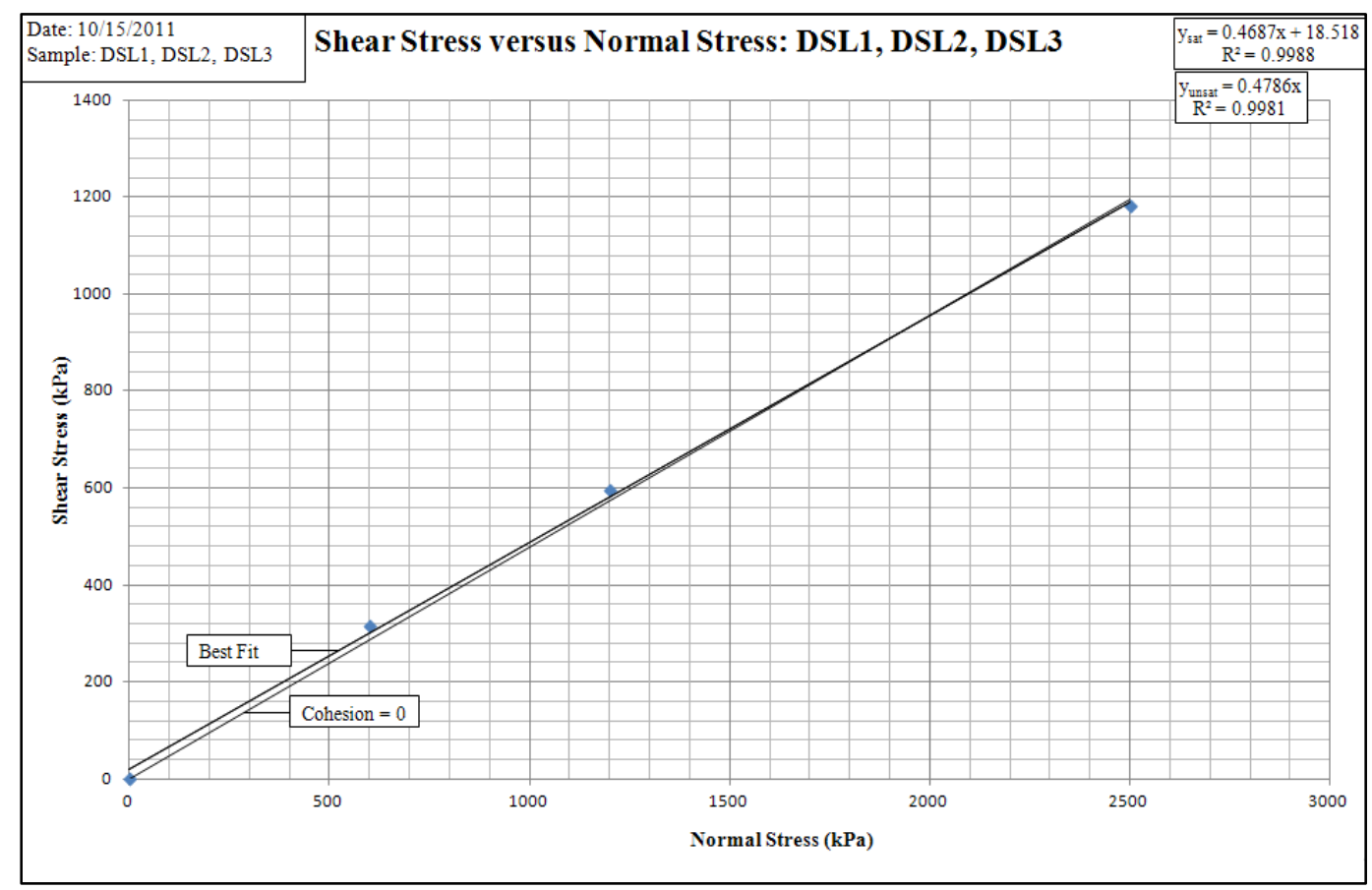

Figure 8.15 Shear stress versus normal stress saturated and unsaturated conditions of test 1 (DSL1), test 2 (DSL2), and test 3 (DSL3)

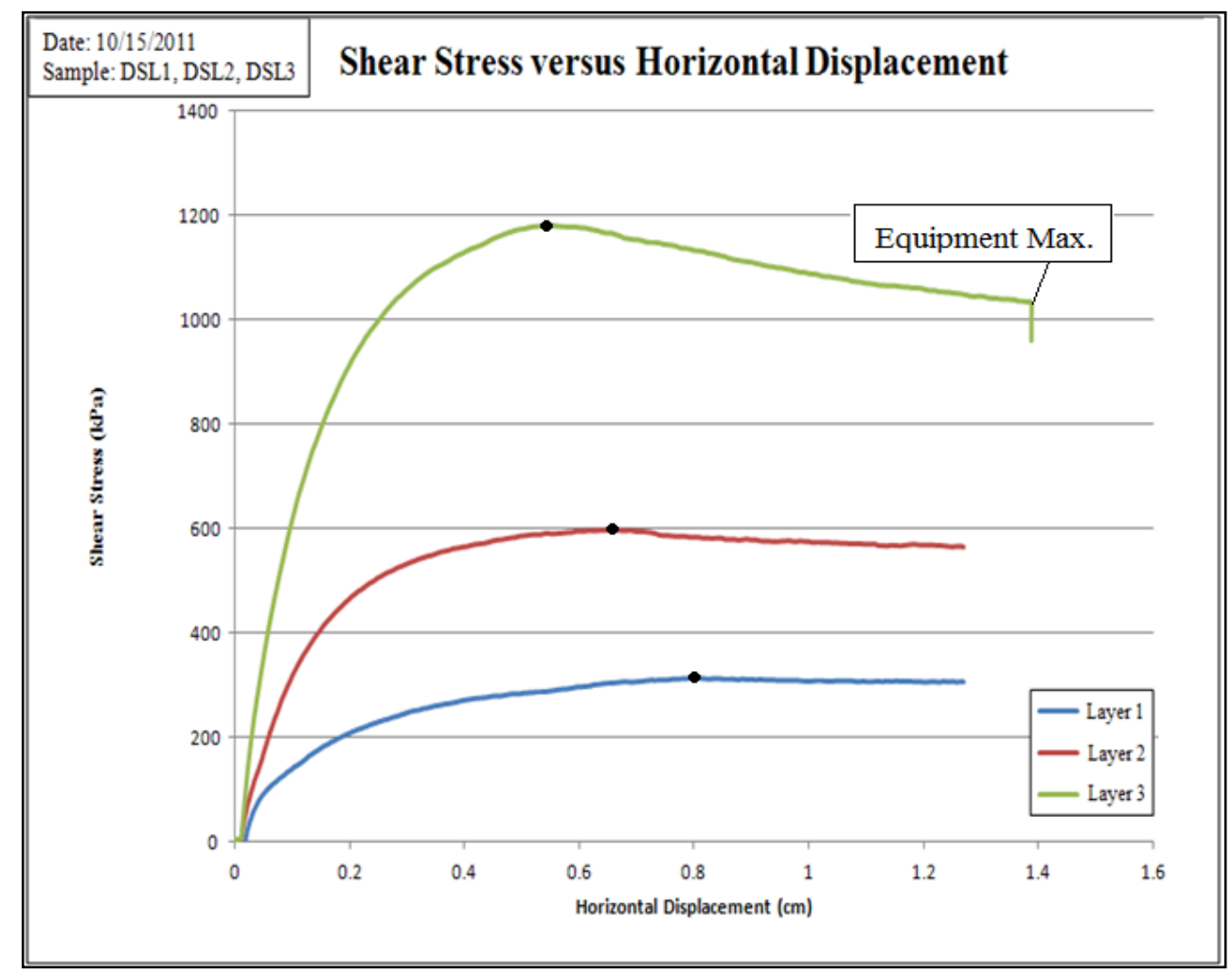

Figure 8.16 Shear stress versus horizontal displacement of layer 1, layer 2, and layer 3. 


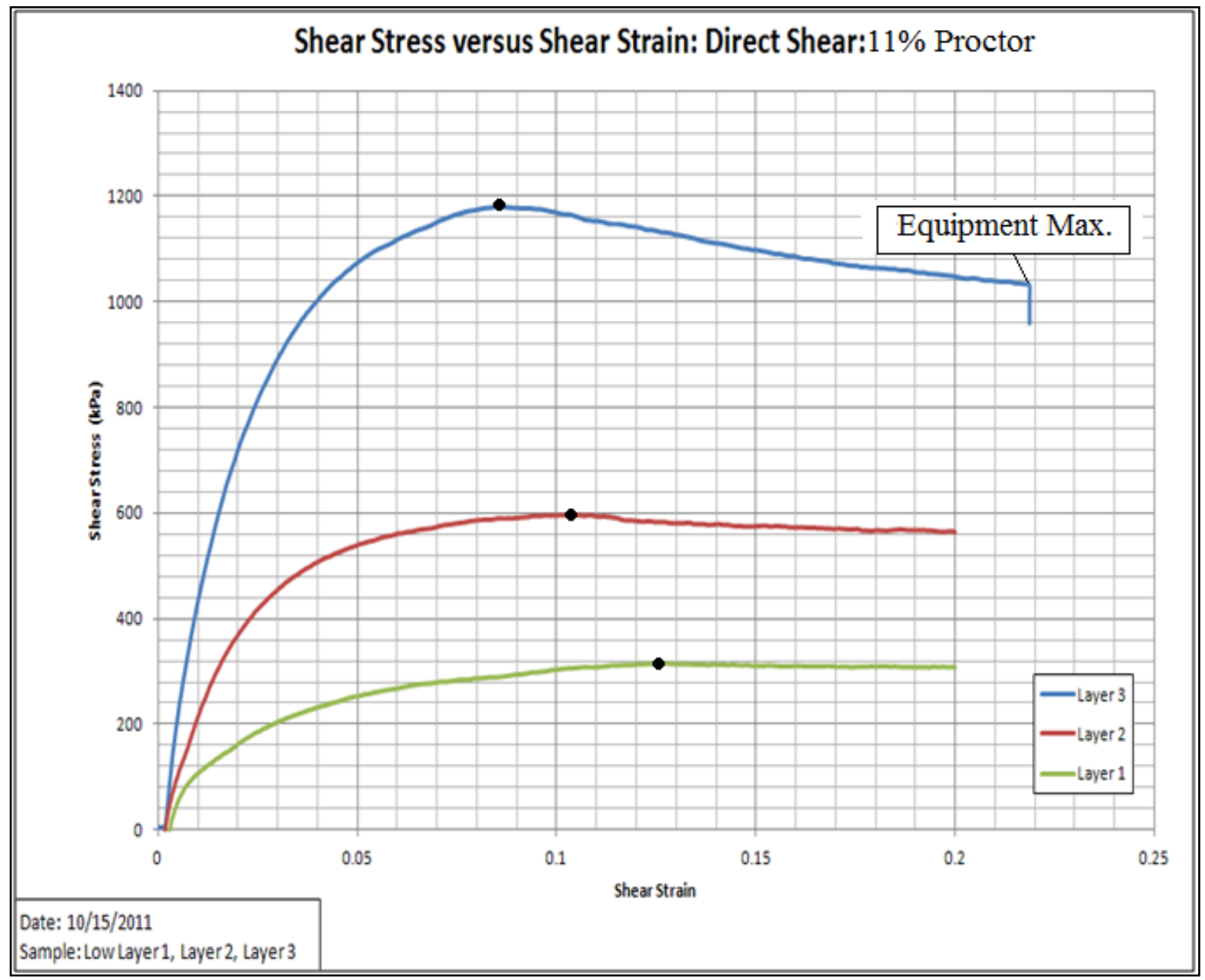

Figure 8.17 Shear stress versus shear strain 


\subsection{Strength Testing Results}

The results of the strength testing performed in sections 8.1-8.3 were useful to determine the input parameter " $\varphi$ " into GeoStudio ${ }^{\mathrm{TM}}$. The friction angle results are shown in Table 8.5.

Table 8.5 Friction angle results with shear stresses and normal stresses shown

\begin{tabular}{|c|c|c|c|c|c|}
\hline $\begin{array}{c}\text { Compaction } \\
\text { Condition }\end{array}$ & $\begin{array}{c}\text { Test } \\
\text { Points }\end{array}$ & $\begin{array}{c}\text { Normal } \\
\text { Stress, } \sigma \\
\left(\gamma_{\mathrm{d}} * \mathrm{~d}\right)[\mathrm{kPa}]\end{array}$ & $\begin{array}{c}\text { Shear } \\
\text { Stress, } \tau \\
{[\mathrm{kPa}]}\end{array}$ & $\begin{array}{c}\text { Friction Angle }, \\
\varphi \text { (Best fit) }\end{array}$ & $\begin{array}{c}\text { Friction Angle } \\
\varphi(\text { zero } \\
\text { cohesion) }\end{array}$ \\
\hline \multirow{3}{*}{$\begin{array}{l}\text { Standard } \\
\text { Proctor }\end{array}$} & 3 & 0.00 & 0.00 & \multirow{3}{*}{$27.14^{\mathrm{o}}$} & \multirow{3}{*}{$27.70^{\circ}$} \\
\hline & 2 & 1784.26 & 1029.95 & & \\
\hline & 1 & 2676.40 & 1342.94 & & \\
\hline \multirow{3}{*}{$\begin{array}{c}34 \% \\
\text { Proctor }\end{array}$} & DS31 & 600.07 & 365.71 & \multirow{3}{*}{$22.77^{\circ}$} & \multirow{3}{*}{$24.36^{\circ}$} \\
\hline & DS32 & 1200.14 & 607.73 & & \\
\hline & DS33 & 2500.32 & 1078.41 & & \\
\hline \multirow{3}{*}{$\begin{array}{c}11 \% \\
\text { Proctor }\end{array}$} & DSL1 & 600.00 & 314.19 & \multirow{3}{*}{$25.11^{\mathrm{o}}$} & \multirow{3}{*}{$25.58^{\circ}$} \\
\hline & DSL2 & 1200.00 & 595.62 & & \\
\hline & DSL3 & 2500.00 & 1180.03 & & \\
\hline
\end{tabular}

The target shear strain for each sample was $20 \%$. The shear strain curves revealed that much of the residual strength is retained within the sample. The reason the samples retained their strength is likely a result of the creation of the unweathered material. The geometry of the particles of the sample is angular. The material was blasted, unweathered sandstone. The angular nature of the material increases the friction between shear planes and resists displacement. This insight is beneficial when considering slope stability. Slopes constructed with this material should be strong and resistant to failure $(\mathrm{FS}<1)$. 


\section{Pre-Permeability Grain Size Distribution}

The compacted specimens were tested using standard proctor compaction energy $\left(592.5 \mathrm{~kJ} / \mathrm{m}^{3}\right)$, $34 \%$ Proctor compaction energy $\left(203.6 \mathrm{~kJ} / \mathrm{m}^{3}\right)$, and an $11 \%$ Proctor compaction energy $(67.85$ $\mathrm{kJ} / \mathrm{m}^{3}$ ). Sieve analysis was performed on the compacted specimens for the remainder of each of three layers from which the direct shear specimens were taken. The objective of the testing was to determine the volume of created fines in the three layers due to the compaction effort, and compare their distribution within the mold with the distribution of fines in the post-permeability specimens. The desired outcome was to understand the creation, movement, and variability of fine particles in the specimens at a pre-permeability condition and later compare the results to a post-permeability condition grain size distribution analysis. The concept is that the testing will emulate field compaction energies and fine particle creation. Therefore, it will be possible to understand how to construct a valley fill in order to reduce the creation and movement of fine particles to prevent suffusion and internal erosion and ultimately increase the durability and prolong the lifetime of the structure. The results of the testing are shown in this chapter (Chapter 9).

\subsection{Grain Size Distribution: Standard Proctor $\left(592.5 \mathrm{~kJ} / \mathrm{m}^{3}\right)$}

Grain size distribution testing was performed on three layers of a specimen that was prepared via standard proctor compaction. The specimen was used for direct shear testing, but the remainder of the soil per layer was used for grain size distribution testing. The third layer of the specimen could not be tested with our direct shear equipment because the second layer maxed out the load actuators on the GeoJac equipment. The normal stresses were intended to increase from the top layer to the bottom layer. Regardless, the grain size distribution analysis testing was performed on the third layer of the specimen. The layers varied very little in their gradations, as shown by the coefficient of variability for the uniformity coefficient at 0.068 , and the coefficient of variation for the coefficient of gradation at 0.116 . The specimen was oven dried prior to testing. The data are shown in Table 9.1, Table 9.2, Table 9.3, and Figure 9.1.

Table 9.1 Critical index values for the direct shear grain size distribution testing.

\begin{tabular}{|c|r|r|r|}
\hline \multicolumn{4}{|c|}{ Results } \\
\hline Critical Indices & $\begin{array}{c}\text { Layer } \\
\mathbf{1}\end{array}$ & $\begin{array}{c}\text { Layer } \\
\mathbf{2}\end{array}$ & $\begin{array}{c}\text { Layer } \\
\mathbf{3}\end{array}$ \\
\hline $\mathrm{D}_{90}$ & 3.75 & 3.30 & 3.80 \\
\hline $\mathrm{D}_{60}$ & 1.65 & 1.05 & 1.80 \\
\hline $\mathrm{D}_{50}$ & 1.15 & 0.69 & 1.35 \\
\hline $\mathrm{D}_{30}$ & 0.48 & 0.35 & 0.55 \\
\hline $\mathrm{D}_{25}$ & 0.40 & 0.29 & 0.44 \\
\hline $\mathrm{D}_{10}$ & 0.15 & 0.10 & 0.15 \\
\hline Uniformity Coefficient, $\mathbf{C}_{\mathbf{u}}$ & $\mathbf{1 1 . 0 0}$ & $\mathbf{1 0 . 5 0}$ & $\mathbf{1 2 . 0 0}$ \\
\hline Coefficient of Gradation, $\mathbf{C}_{\boldsymbol{c}}$ & $\mathbf{0 . 9 3}$ & $\mathbf{1 . 1 7}$ & $\mathbf{1 . 1 2}$ \\
\hline
\end{tabular}


Table 9.2 Uniformity coefficient statistics

\begin{tabular}{|l|c|}
\hline \multicolumn{2}{|c|}{ Uniformity Coefficient, $\mathbf{C}_{\mathbf{u}}$} \\
\hline Average Uniformity Coefficient & 11.167 \\
\hline Sample Standard Deviation (s) & 0.764 \\
\hline Coefficient of Variation (COV) & 0.068 \\
\hline
\end{tabular}

Table 9.3 Coefficient of gradation statistics

\begin{tabular}{|l|l|}
\hline \multicolumn{2}{|c|}{ Coefficient of Gradation, $\mathbf{C}_{\mathbf{c}}$} \\
\hline Average Coefficient of Gradation & 1.073 \\
\hline Sample Standard Deviation (s) & 0.125 \\
\hline Coefficient of Variation (COV) & 0.116 \\
\hline
\end{tabular}

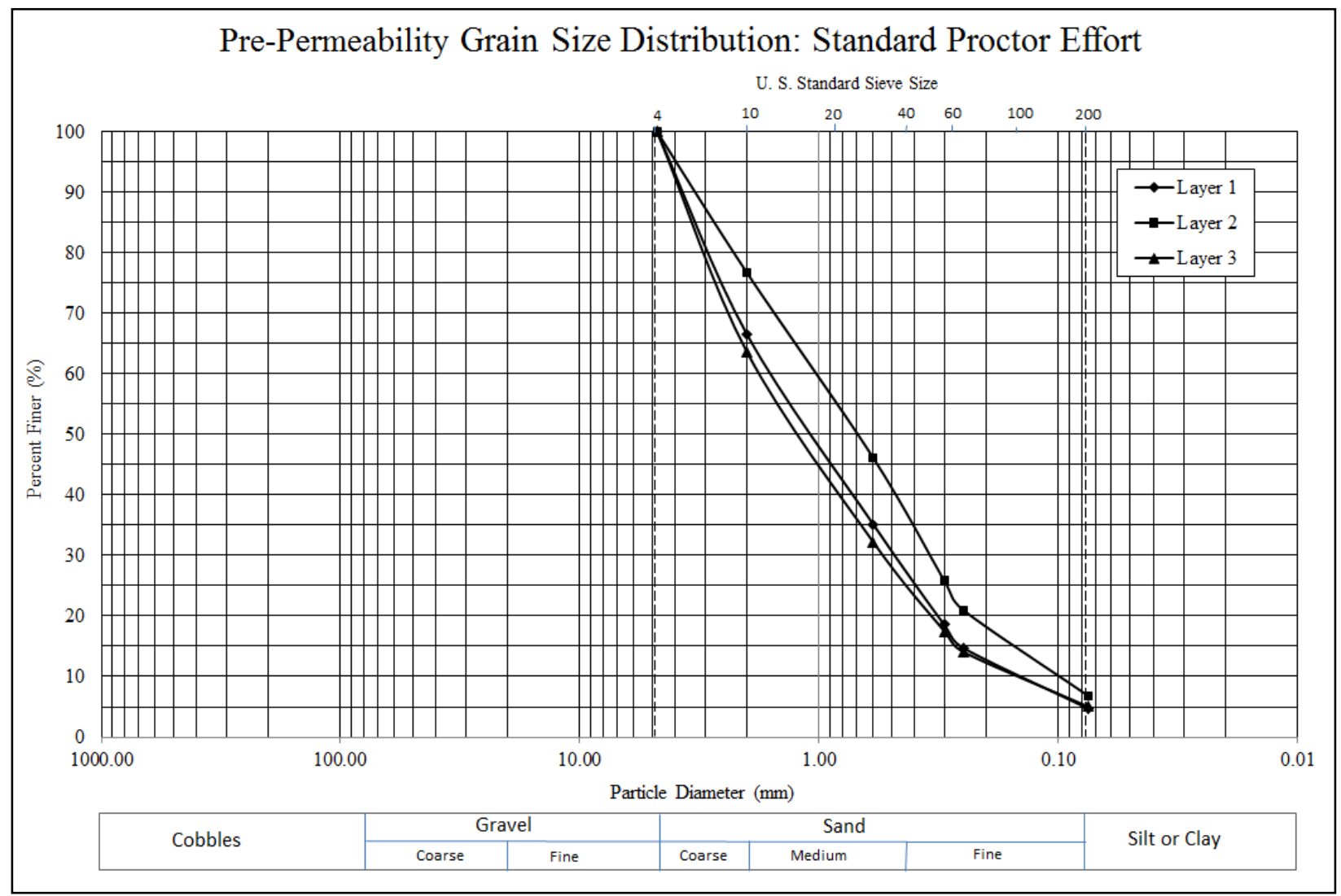

Figure 9.1 Grain size distribution of layer 1, layer 2, layer 3. 


\subsection{Grain Size Distribution: 34\% Proctor Compaction Energy $\left(203.6 \mathrm{~kJ} / \mathrm{m}^{3}\right)$}

Grain size distribution testing was performed on a 34\% Proctor specimen that was prepared for direct shear testing. The remainder of the soil for the 3 layers from which direct shear ring specimens were taken was used for the grain size distribution testing. The material was oven dried before testing. The three layers showed very little variability. The variability is shown by the coefficient of variability for the uniformity coefficient at 0.117 , and a coefficient of variability for the coefficient of gradation at 0.048. The data are shown in Table 9.4, Table 9.5, Table 9.6, and Figure 9.2.

Table 9.4 Critical index values for the direct shear grain size distribution testing.

\begin{tabular}{|c|r|r|r|}
\hline Results & Layer 1 & Layer 2 & Layer 3 \\
\hline $\mathrm{D}_{90}$ & 3.80 & 3.80 & 3.80 \\
\hline $\mathrm{D}_{60}$ & 1.80 & 1.70 & 1.70 \\
\hline $\mathrm{D}_{50}$ & 1.40 & 1.30 & 1.30 \\
\hline $\mathrm{D}_{30}$ & 0.69 & 0.58 & 0.56 \\
\hline $\mathrm{D}_{25}$ & 0.56 & 0.45 & 0.44 \\
\hline $\mathrm{D}_{15}$ & 0.28 & 0.22 & 0.24 \\
\hline $\mathrm{D}_{10}$ & 0.17 & 0.13 & 0.13 \\
\hline${\text { Uniformity Coefficient, } \mathrm{C}_{\mathrm{u}}}$ & 10.59 & 13.08 & 13.08 \\
\hline Coefficient of Gradation, $\mathrm{C}_{\mathrm{c}}$ & 1.56 & 1.52 & 1.42 \\
\hline
\end{tabular}

Table 9.5 Uniformity coefficient statistics

\begin{tabular}{|l|r|}
\hline \multicolumn{2}{|c|}{ Uniformity Coefficient, $\mathbf{C}_{\mathbf{u}}$} \\
\hline Average Uniformity Coefficient & 12.247 \\
\hline Sample Standard Deviation (s) & 1.437 \\
\hline Coefficient of Variation (COV) & 0.117 \\
\hline
\end{tabular}

Table 9.6 Coefficient of gradation statistics

\begin{tabular}{|l|l|}
\hline \multicolumn{2}{|c|}{ Coefficient of Gradation, $\mathbf{C}_{\boldsymbol{c}}$} \\
\hline Average Coefficient of Gradation & 1.499 \\
\hline Sample Standard Deviation (s) & 0.071 \\
\hline Coefficient of Variation (COV) & 0.048 \\
\hline
\end{tabular}




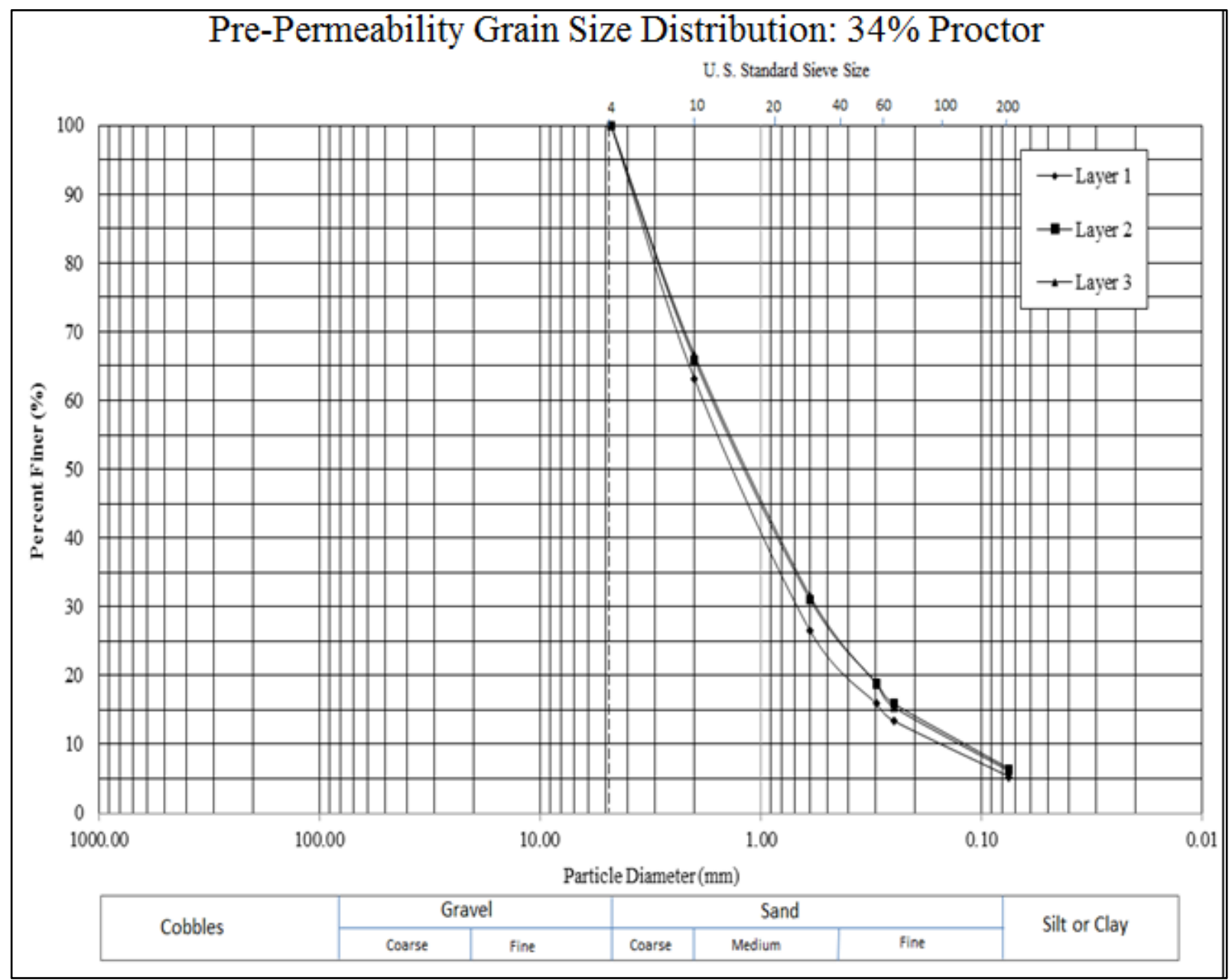

Figure 9.2 Grain size distribution of 34\% Proctor compaction effort: layer 1 (test 1), layer 2 (test 2), layer 3 (test 3 ) 


\subsection{Grain Size Distribution: $11 \%$ Proctor Compaction Energy $\left(67.85 \mathrm{~kJ} / \mathrm{m}^{3}\right)$}

Grain size distribution testing was performed on an $11 \%$ Proctor compaction energy specimen that was prepared for direct shear testing. The remainder of the soil for the 3 layers from which direct shear ring specimens were taken was used for the grain size distribution testing. The material was oven dried before testing. There was little variability in the data. The variability is expressed by the coefficient of variability. The coefficient of variability for the uniformity coefficient was 0.123 . The coefficient of variability for the coefficient of gradation was 0.170 . The data are shown in Table 9.7, Table 9.8, Table 9.9, and Figure 9.3.

Table 9.7 Critical index values for the direct shear grain size distribution testing.

\begin{tabular}{|c|r|r|r|}
\hline Results & Layer 1 & Layer 2 & Layer 3 \\
\hline $\mathrm{D}_{90}$ & 4.10 & 4.00 & 4.00 \\
\hline $\mathrm{D}_{60}$ & 2.70 & 2.60 & 2.40 \\
\hline $\mathrm{D}_{50}$ & 2.20 & 2.00 & 1.80 \\
\hline $\mathrm{D}_{30}$ & 1.20 & 0.98 & 0.90 \\
\hline $\mathrm{D}_{25}$ & 0.88 & 0.75 & 0.73 \\
\hline $\mathrm{D}_{15}$ & 0.51 & 0.39 & 0.41 \\
\hline $\mathrm{D}_{10}$ & 0.28 & 0.22 & 0.25 \\
\hline Uniformity Coefficient, $\mathrm{C}_{\mathrm{u}}$ & 9.64 & 11.82 & 9.60 \\
\hline Coefficient of Gradation, $\mathrm{C}_{\mathfrak{c}}$ & 1.90 & 1.68 & 1.35 \\
\hline
\end{tabular}

Table 9.8 Uniformity coefficient statistics

\begin{tabular}{|l|r|}
\hline \multicolumn{2}{|c|}{ Uniformity Coefficient, $\mathbf{C}_{\mathbf{u}}$} \\
\hline Average Uniformity Coefficient & 10.354 \\
\hline Sample Standard Deviation (s) & 1.268 \\
\hline Coefficient of Variation (COV) & 0.123 \\
\hline
\end{tabular}

Table 9.9 Coefficient of gradation statistics

\begin{tabular}{|l|l|}
\hline \multicolumn{2}{|c|}{ Coefficient of Gradation, $\mathbf{C}_{\boldsymbol{c}}$} \\
\hline Average Coefficient of Gradation & 1.645 \\
\hline Sample Standard Deviation (s) & 0.279 \\
\hline Coefficient of Variation (COV) & 0.170 \\
\hline
\end{tabular}




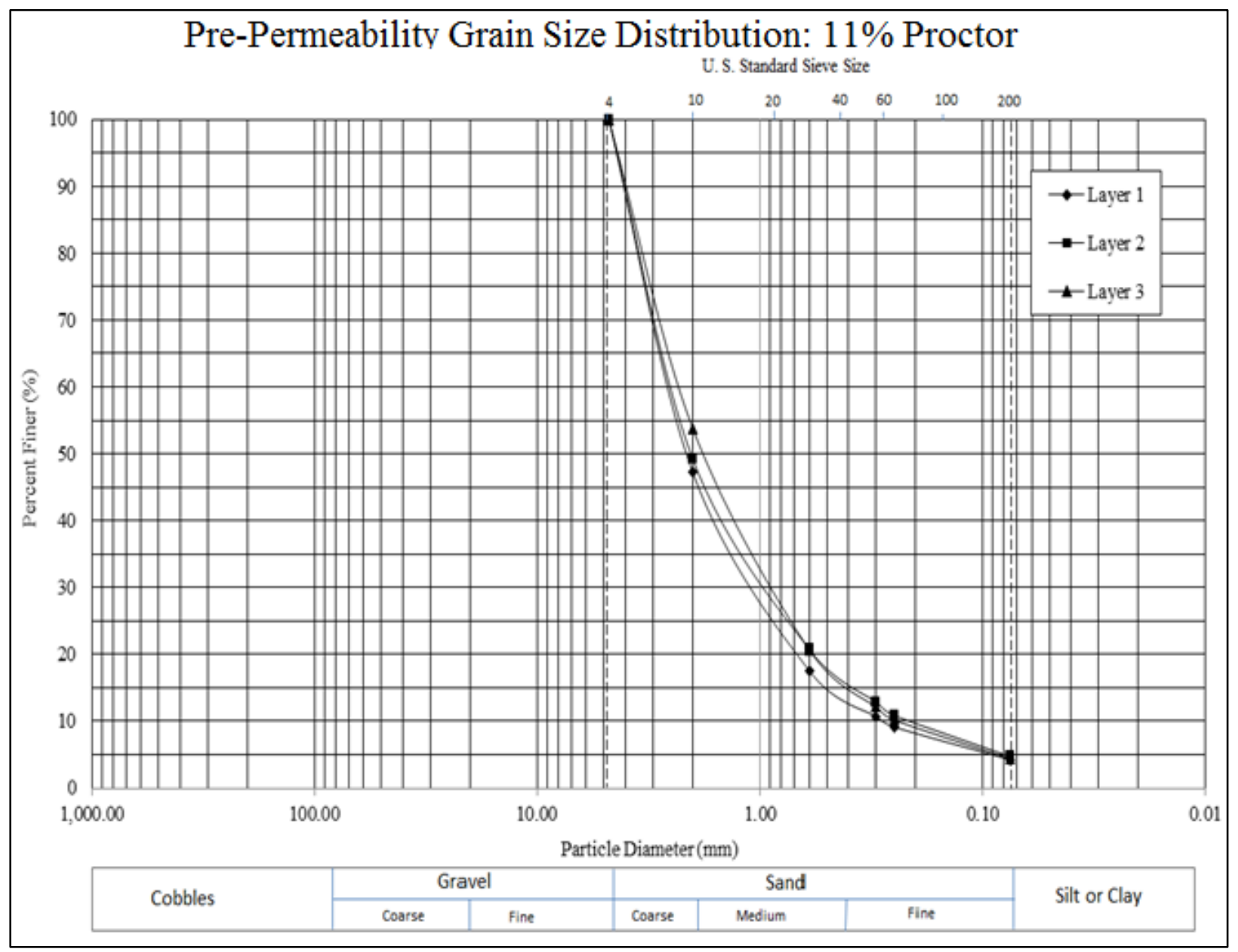

Figure 9.3 Grain size distribution of $11 \%$ Proctor compaction effort: layer 1, layer 2, layer 3 


\section{Hydraulic Conductivity}

Hydraulic conductivity testing was performed using the ASTM standard test method D 5856. The target compaction density was the maximum dry density of the unweathered sandstone overburden for the standard proctor compaction specimen, and the 34\% Proctor compaction specimen. The $11 \%$ Proctor compaction energy specimen was prepared for the minimum dry density to establish an upper limit for the hydraulic conductivity. The objective of the hydraulic conductivity testing was to determine the permeability of water through a test specimen at the maximum and minimum dry density of the material. Grain size distribution tests were performed on three approximately equal layers of the specimen after a gradient of $i=100$ for the standard proctor specimens, and a hydraulic gradient of $i=15$ for the $34 \%$ and $11 \%$ proctor specimens was permeated through each specimen for an adequate period of time, and the hydraulic conductivity had been determined. The high gradients were chosen to accelerate the testing process. The gradient of 100 was used on the standard proctor specimen as no hydraulic consolidation was expected, nor did it occur. The hydraulic gradient of 15 was chosen for the reduced proctor specimens to avoid hydraulic consolidation and accelerate the testing process as a low hydraulic conductivity was expected for the well graded sand with silt. The purpose of the grain size distribution testing was to track the movement of material particles, particularly the smaller diameter particles. The effort was meant to emulate field conditions replicating suffusion phenomena and internal erosion within an AOC valley fill. The results of the testing are shown in this chapter.

\subsection{Hydraulic Conductivity: Standard Proctor $\left(592.5 \mathrm{~kJ} / \mathrm{m}^{3}\right)$}

Hydraulic conductivity testing was performed on a standard proctor compaction effort (592.5 $\mathrm{kJ} / \mathrm{m}^{3}$ ) standard proctor specimen. The target dry density was at optimum for the standard proctor compaction effort test data. The optimum dry density for the standard proctor compaction effort specimen was $18.75 \mathrm{kN} / \mathrm{m}^{3}$. Triplicate testing was performed to ensure accuracy. The dry densities for tests 1,2 , and 3 were $18.14 \mathrm{kN} / \mathrm{m}^{3}, 18.15 \mathrm{kN} / \mathrm{m}^{3}$, and 18.30 $\mathrm{kN} / \mathrm{m}^{3}$ respectively. The objective of the testing was to determine the hydraulic conductivity in order to better understand the rate at which water would permeate through the material under inspection. The purpose of the testing was to determine the fine particle movement within the specimen under the influence of a hydraulic gradient $i=100$. After the hydraulic conductivity readings reached equilibrium, the hydraulic conductivity was determined and the specimen was extruded approximately one third at a time. The hydraulic conductivity was determined after the data had become stable. In these cases, the average of the last five data points was taken to be the hydraulic conductivity of the specimens. The layers were saved and oven dried. Grain size analysis was run on three layers of each specimen. The hydraulic conductivity data for the standard proctor compaction energy specimens are presented in this section (10.1). The hydraulic conductivity data is presented in Appendix I. 
Table 10.1 Hydraulic conductivty standard proctor compaction energy specimen data.

\begin{tabular}{|c|c|c|c|}
\hline Test Number & Test 1 & Test 2 & Test 3 \\
\hline Assumed moisture content $(\%)$ & 10.75 & 10.75 & 10.75 \\
\hline Mold Weight (g), $\mathbf{M}_{\mathrm{md}}$ & 614.90 & 616.62 & 618.11 \\
\hline Specimen+Mold Weight $(\mathrm{g}), \mathrm{M}_{\mathrm{t}}$ & 2454.57 & 2318.32 & 2416.29 \\
\hline Volume of Mold $\left(\mathrm{cm}^{3}\right), \mathrm{V}$ & 888.52 & 837.04 & 888.52 \\
\hline Specific Gravity of Soil, $\mathrm{G}_{\mathrm{s}}$ & 2.69 & 2.69 & 2.69 \\
\hline Unit Weight of Water @20 $\mathrm{C}\left(\mathrm{KN} / \mathrm{m}^{3}\right), ? \mathrm{w}$ & 9.79 & 9.79 & 9.79 \\
\hline Unit Weight of Water @20 ${ }^{\circ} \mathrm{C}\left(\mathrm{lb} / \mathrm{ft}^{3}\right), \gamma_{\mathrm{w}}$ & 62.34 & 62.34 & 62.34 \\
\hline Moist Unit Weight of Compacted Specimen $\left(\mathrm{g} / \mathrm{cm}^{3}\right), \gamma_{\mathrm{m}}$ & 2.07 & 2.03 & 2.02 \\
\hline Dry Unit Weight of Compacted Specimen $\left(\mathrm{g} / \mathrm{cm}^{3}\right), \gamma_{\mathrm{d}}$ & 1.85 & 1.85 & 1.87 \\
\hline Dry Unit Weight of Compacted Specimen $\left(K N / \mathrm{m}^{3}\right), \gamma_{d}$ & 18.14 & 18.15 & 18.30 \\
\hline Dry Unit Weight of Compacted Specimen $\left(\mathrm{lb} / \mathrm{ft}^{3}\right), \gamma_{\mathrm{d}}$ & 115.49 & 115.55 & 116.52 \\
\hline Dry Unit Weight at $S=1.0\left(\mathrm{KN} / \mathrm{m}^{3}\right), \gamma_{d}$ & 19.94 & 20.82 & 21.47 \\
\hline Dry Unit Weight at $S=0.9\left(\mathrm{KN} / \mathrm{m}^{3}\right), \gamma_{d}$ & 19.42 & 20.35 & 21.03 \\
\hline Dry Unit Weight at $\mathrm{S}=1.0\left(\mathrm{lb} / \mathrm{ft}^{3}\right), \gamma_{\mathrm{d}}$ & 126.98 & 132.59 & 136.70 \\
\hline Dry Unit Weight at $S=0.9\left(\mathrm{lb} / \mathrm{ft}^{3}\right), \gamma_{\mathrm{d}}$ & 123.65 & 129.57 & 133.95 \\
\hline Void Ratio, $\mathrm{e}=\left(\left(\mathrm{G}_{\mathrm{s}}^{*} \gamma_{\mathrm{w}}\right) / \gamma_{\mathrm{d}}\right)-1$ & 0.45 & 0.45 & 0.44 \\
\hline Degree of Saturation $(\%), \mathrm{S}=\mathrm{G}_{\mathrm{s}} *(\mathrm{w} / \mathrm{e})$ & 0.71 & 0.59 & 0.52 \\
\hline Saturated Water Content, $\mathrm{w}_{\text {sat }}(\%)$ & 16.80 & 16.78 & 16.33 \\
\hline Assumed moisture content $(\%)$ & 10.75 & 10.75 & 10.75 \\
\hline Container Mass (g), Mc & 30.40 & 30.55 & 30.52 \\
\hline Container+Moist Specimen Mass (g), Mcms & 70.12 & 58.00 & 69.62 \\
\hline Intial Container+Oven Dry Specimen Mass (g), Mcds & 65.89 & 55.54 & 66.58 \\
\hline Mass of Water $(\mathrm{g}), \mathrm{Mw}=\mathrm{Mcms}-\mathrm{Mcds}$ & 4.23 & 2.46 & 3.04 \\
\hline Mass of Solids (g), Ms= Mcds-Mc & 35.49 & 24.99 & 36.06 \\
\hline Water Content, $(\%) \mathrm{W}=(\mathrm{Mw} / \mathrm{Ms}) \times 100$ & 11.92 & 9.84 & 8.43 \\
\hline Compaction Energy $\mathrm{kJ} / \mathrm{m}^{3}\left(\mathrm{ft}-\mathrm{lb} / \mathrm{ft}^{3}\right)$ & \multicolumn{3}{|c|}{$592.50(12375)$} \\
\hline
\end{tabular}




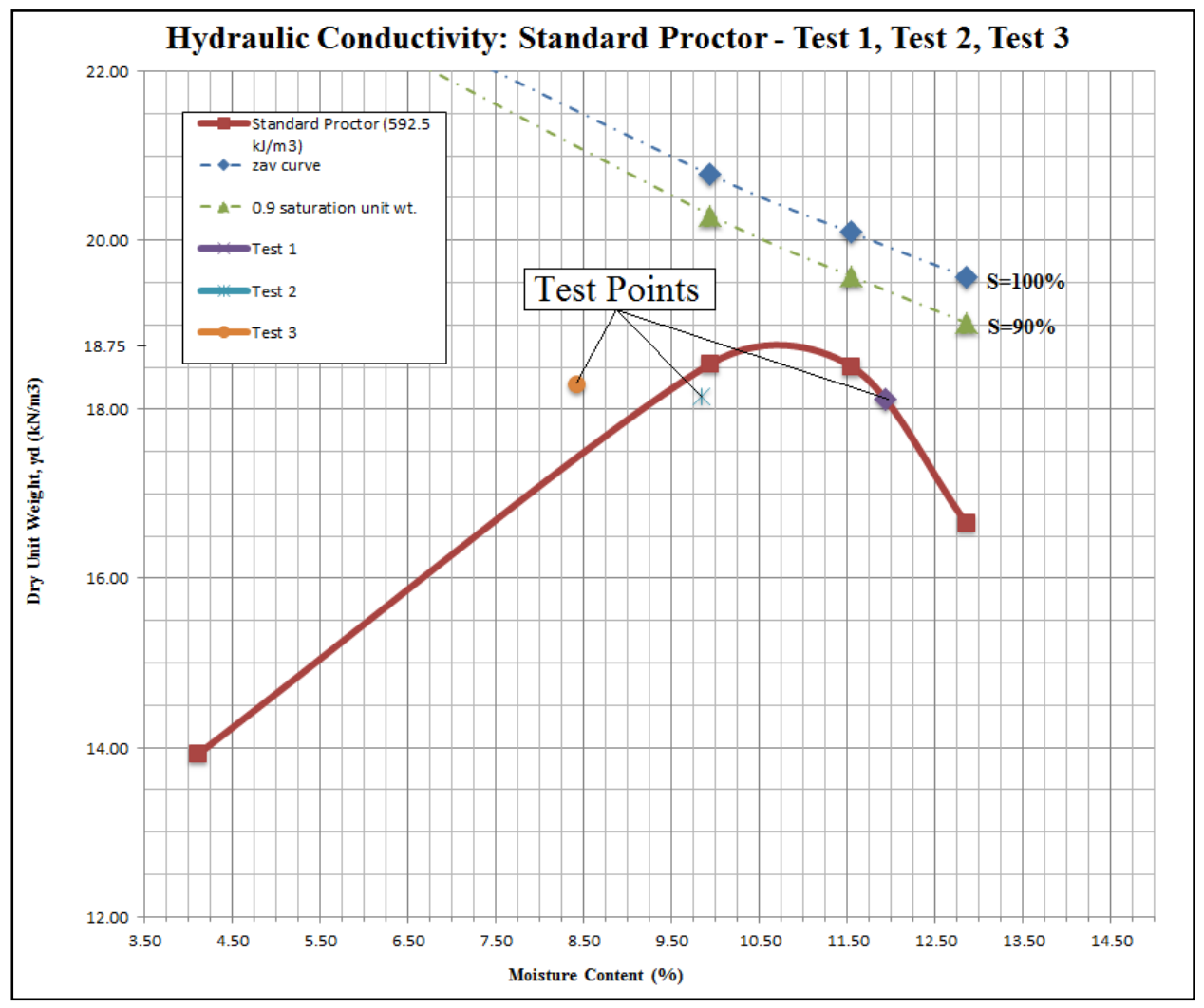

Figure 10.1 Comparison of the hydraulic conductivity standard proctor compaction energy specimen and other standard proctor compaction energy compaction data. 


\subsubsection{Test 1}

The target dry density for the specimen was at optimum for standard proctor at $18.75 \mathrm{kN} / \mathrm{m}^{3}$. The dry density of the specimen for test 1 was found to be $18.14 \mathrm{kN} / \mathrm{m}^{3}$. The void ratio (e) was 0.45 . The porosity (n) was 0.31 . The average hydraulic conductivity of the last 5 points of test 1 was found to be $1.14 \mathrm{E}-09 \mathrm{~m} / \mathrm{s}$ with a coefficient of variation of 0.073 . The low coefficient of variability implies that a stable filter was reach as a result of little variability within the specimen. One pore volume was calculated to be $276.35 \mathrm{~cm}^{3}$. It was calculated that 2.89 pore volumes were permeated through the specimen. Test 1 results are shown in Table 10.2 through Table 10.7, Figure 10.2, and Figure 10.3.

Table 10.2 Sample properties for the hydraulic conductivity specimen.

\begin{tabular}{|l|r|}
\hline \multicolumn{2}{|c|}{ Sample Properties } \\
\hline Molded Water Content, w (\%) & $11.92 \%$ \\
\hline Specific Gravity, $\mathrm{G}_{\mathrm{s}}$ & 2.69 \\
\hline Volume of specimen $\left(\mathrm{cm}^{3}\right), \mathrm{V}$ & 888.05 \\
\hline Unit Weight of Water, $\gamma_{\mathrm{w}}$ & 9.79 \\
\hline Target Dry Density $\left(\mathrm{kN} / \mathrm{m}^{3}\right), \gamma_{\mathrm{d}}$ & 18.75 \\
\hline Dry density $\left(\mathrm{lb} / \mathrm{ft}^{3}\right), \gamma_{\mathrm{d}}$ & 115.49 \\
\hline Dry density $\left(\mathrm{KN} / \mathrm{m}^{3}\right), \gamma_{\mathrm{d}}$ & 18.14 \\
\hline Void Ratio, e & 0.45 \\
\hline Porosity, $\mathrm{n}$ & 0.31 \\
\hline Pore Volume, $\left(\mathrm{cm}^{3}\right) \mathrm{Vp}$ & 276.35 \\
\hline Volume of Water Needed for Saturation (mL) & 295.34 \\
\hline Cylinder Water Level Change for Saturation (in) & $12 / 16$ \\
\hline Cylinder Water Level at Saturation (in) & $91 / 2$ \\
\hline
\end{tabular}


Table 10.3 Sample characteristics for the hydraulic conductivity specimen

\begin{tabular}{|l|r|}
\hline \multicolumn{2}{|c|}{ Sample Characteristics } \\
\hline Height of Sample $(\mathrm{cm})$ & 10.95 \\
\hline Diameter of Sample (cm) & 10.16 \\
\hline Area of Sample $\left(\mathrm{cm}^{2}\right)$ & 81.07 \\
\hline Volume of Sample $\left(\mathrm{cm}^{3}\right)$ & 888.05 \\
\hline Pressure (Inches water), P & 375 \\
\hline Applied Pressure (PSI), P & 16.48 \\
\hline Applied Pressure (kPa), P & 113.61 \\
\hline Area of Pressure Cylinder $\left(\mathrm{cm}^{2}\right)$ & 149.81 \\
\hline
\end{tabular}

Table 10.4 Sample preparation information

\begin{tabular}{|l|c|}
\hline \multicolumn{2}{|c|}{ Sample Preparation } \\
\hline Sample used for compaction & Passing No. 4 Sieve \\
\hline Density used for Compaction (\% target $\left.\gamma_{\mathrm{d}}\right)$ & $97 \%$ \\
\hline Corresponding Water Content & $11.92 \%$ (Dry Side) \\
\hline
\end{tabular}

Table 10.5 Hydraulic gradient calculation information

\begin{tabular}{|r|c|c|c|c|c|r|}
\hline \multicolumn{6}{|c|}{ Pressure calculation for a predetermined hydraulic gradient } \\
\hline $\mathrm{L}(\mathrm{ft})$ & $\mathrm{i}$ & $\gamma_{\mathrm{w}}\left(\mathrm{lb} / \mathrm{ft}^{3}\right)$ & $\mathrm{u}(\mathrm{psf})$ & $\mathrm{u}(\mathrm{psi})$ & $\mathrm{u}(\mathrm{kPa})$ & $\gamma_{\mathrm{w}}\left(\mathrm{kN} / \mathrm{m}^{3}\right)$ \\
\hline 0.38 & 100 & 62.4 & 2372.5 & 16.48 & 113.61 & 9.79 \\
\hline
\end{tabular}

Table 10.6 Equation Definitions

\begin{tabular}{|l|}
\hline Definitions: \\
\hline $\mathrm{i}=\mathrm{h} / \mathrm{L}:$ Hydraulic gradient (unitless) \\
\hline $\mathrm{h}=\mathrm{u} / \gamma_{\mathrm{w}}$ : Pressure head according to Bernoulli's equation \\
\hline $\mathrm{u}=$ Pressure $(\mathrm{psi})$ \\
\hline$\gamma_{\mathrm{w}}=62.4 \mathrm{lb} / \mathrm{ft}^{3}=9.79 \mathrm{kN} / \mathrm{m}^{3}:$ Unit weight of water \\
\hline $\mathrm{L}=$ Length of specimen (height of cylinder) $(\mathrm{cm}$ or in) \\
\hline
\end{tabular}


Table 10.7 Hydraulic conductivity results - Statistics (Last 5 data points)

\subsubsection{Test 2}

\begin{tabular}{|l|r|}
\hline \multicolumn{2}{|c|}{$k$ Results: Last 5 Points } \\
\hline Average Hydraulic Conductivity (m/s) & $1.14 \mathrm{E}-09$ \\
\hline Sample Standard Deviation (s) & $8.33 \mathrm{E}-11$ \\
\hline Coefficient of Variation (COV) & 0.073 \\
\hline
\end{tabular}

The target dry density for the specimen was at optimum for standard proctor at $18.75 \mathrm{kN} / \mathrm{m}^{3}$. The dry density of the specimen for test 2 was found to be $18.15 \mathrm{kN} / \mathrm{m}^{3}$. The void ratio (e) was 0.45 . The porosity (n) was 0.31 . The average hydraulic conductivity of the last 5 points of test 2 was found to be $5.81 \mathrm{E}-10 \mathrm{~m} / \mathrm{s}$ with a coefficient of variation of 0.243 . The low coefficient of variability implies that a stable filter was reach as a result of little variability within the specimen. One pore volume was calculated to be $260.01 \mathrm{~cm}^{3}$. It was calculated that 3.69 pore volumes were permeated through the specimen. Test 2 results are shown in Table 10.8 through Table 10.12, Figure 10.2, and Figure 10.3.

Table 10.8 Sample properties for the hydraulic conductivity specimen.

\begin{tabular}{|l|r|}
\hline \multicolumn{2}{|c|}{ Sample Properties } \\
\hline Molded Water Content, w (\%) & $11.92 \%$ \\
\hline Specific Gravity, $\mathrm{G}_{\mathrm{s}}$ & 2.69 \\
\hline Volume of specimen $\left(\mathrm{cm}^{3}\right), \mathrm{V}$ & 836.57 \\
\hline Unit Weight of Water, $\gamma_{\mathrm{w}}$ & 9.79 \\
\hline Target Dry Density $\left(\mathrm{kN} / \mathrm{m}^{3}\right), \gamma_{\mathrm{d}}$ & 18.75 \\
\hline Dry density $\left(\mathrm{lb} / \mathrm{ft}^{3}\right), \gamma_{\mathrm{d}}$ & 115.55 \\
\hline Dry density $\left(\mathrm{KN} / \mathrm{m}^{3}\right), \gamma_{\mathrm{d}}$ & 18.15 \\
\hline Void Ratio, e & 0.45 \\
\hline Porosity, $\mathrm{n}$ & 0.31 \\
\hline Pore Volume, $\left(\mathrm{cm}^{3}\right) \mathrm{Vp}$ & 260.01 \\
\hline Volume of Water Needed for Saturation (mL) & 277.55 \\
\hline Cylinder Water Level Change for Saturation (in) & $12 / 16$ \\
\hline Cylinder Water Level at Saturation (in) & $101 / 4$ \\
\hline
\end{tabular}


Table 10.9 Sample characteristics for the hydraulic conductivity specimen

\begin{tabular}{|l|r|}
\hline \multicolumn{2}{|c|}{ Sample Characteristics } \\
\hline Height of Sample $(\mathrm{cm})$ & 10.32 \\
\hline Diameter of Sample (cm) & 10.16 \\
\hline Area of Sample $\left(\mathrm{cm}^{2}\right)$ & 81.07 \\
\hline Volume of Sample $\left(\mathrm{cm}^{3}\right)$ & 836.57 \\
\hline Pressure (Inches water), P & 375 \\
\hline Applied Pressure (PSI), P & 16.48 \\
\hline Applied Pressure (kPa), P & 113.61 \\
\hline Area of Pressure Cylinder $\left(\mathrm{cm}^{2}\right)$ & 149.81 \\
\hline
\end{tabular}

Table 10.10 Sample preparation information

\begin{tabular}{|l|c|}
\hline \multicolumn{2}{|c|}{ Sample Preparation } \\
\hline Sample used for compaction & Passing No. 4 Sieve \\
\hline Density used for Compaction $\left(\%\right.$ target $\left.\gamma_{\mathrm{d}}\right)$ & $97 \%$ \\
\hline Corresponding Water Content & $9.84 \%$ (Dry Side) \\
\hline
\end{tabular}

Table 10.11 Hydraulic gradient calculation information

\begin{tabular}{|r|c|c|c|c|c|r|}
\hline \multicolumn{6}{|c|}{ Pressure calculation for a predetermined hydraulic gradient } \\
\hline $\mathrm{L}(\mathrm{ft})$ & $\mathrm{i}$ & $\gamma_{\mathrm{w}}\left(\mathrm{lb} / \mathrm{ft}^{3}\right)$ & $\mathrm{u}(\mathrm{psf})$ & $\mathrm{u}(\mathrm{psi})$ & $\mathrm{u}(\mathrm{kPa})$ & $\gamma_{\mathrm{w}}\left(\mathrm{kN} / \mathrm{m}^{3}\right)$ \\
\hline 0.38 & 100 & 62.4 & 2372.5 & 16.48 & 113.61 & 9.79 \\
\hline
\end{tabular}

Table 10.12 Hydraulic conductivity results - Statistics (Last 5 data points)

\begin{tabular}{|l|r|}
\hline \multicolumn{2}{|c|}{ k Results: Last 5 Points } \\
\hline Average Hydraulic Conductivity (m/s) & $5.81 \mathrm{E}-10$ \\
\hline Sample Standard Deviation (s) & $1.41 \mathrm{E}-10$ \\
\hline Coefficient of Variation (COV) & 0.243 \\
\hline
\end{tabular}




\subsubsection{Test 3}

The target dry density for the specimen was at optimum for standard proctor at $18.75 \mathrm{kN} / \mathrm{m}^{3}$. The dry density of the specimen for test 3 was found to be $18.30 \mathrm{kN} / \mathrm{m}^{3}$. The void ratio (e) was 0.44 . The porosity (n) was 0.31 . The average hydraulic conductivity of the last 5 points of test 3 was found to be $1.82 \mathrm{E}-09 \mathrm{~m} / \mathrm{s}$ with a coefficient of variation of 0.062 . The low coefficient of variability implies that a stable filter was reach as a result of little variability within the specimen. One pore volume was calculated to be $270.95 \mathrm{~cm}^{3}$. It was calculated that 18.46 pore volumes were permeated through the specimen. Test 3 results are shown in Table 10.13 through Table 10.17, Figure 10.2, and Figure 10.3.

Table 10.13 Sample properties for the hydraulic conductivity specimen

\begin{tabular}{|l|r|}
\hline \multicolumn{2}{|c|}{ Sample Properties } \\
\hline Molded Water Content, w (\%) & $8.43 \%$ \\
\hline Specific Gravity, $\mathrm{G}_{\mathrm{s}}$ & 2.69 \\
\hline Volume of specimen $\left(\mathrm{cm}^{3}\right), \mathrm{V}$ & 888.05 \\
\hline Unit Weight of Water, $\gamma_{\mathrm{w}}$ & 9.79 \\
\hline Target Dry Density $\left(\mathrm{kN} / \mathrm{m}^{3}\right), \gamma_{\mathrm{d}}$ & 18.75 \\
\hline Dry density $\left(\mathrm{lb} / \mathrm{ft}^{3}\right), \gamma_{\mathrm{d}}$ & 115.55 \\
\hline Dry density $\left(\mathrm{KN} / \mathrm{m}^{3}\right), \gamma_{\mathrm{d}}$ & 18.3 \\
\hline Void Ratio, e & 0.44 \\
\hline Porosity, $\mathrm{n}$ & 0.31 \\
\hline Pore Volume, $\left(\mathrm{cm}^{3}\right) \mathrm{Vp}$ & 270.95 \\
\hline Volume of Water Needed for Saturation (mL) & 315.06 \\
\hline Cylinder Water Level Change for Saturation (in) & $13 / 16$ \\
\hline Cylinder Water Level at Saturation (in) & 16 \\
\hline
\end{tabular}


Table 10.14 Sample characteristics for the hydraulic conductivity specimen.

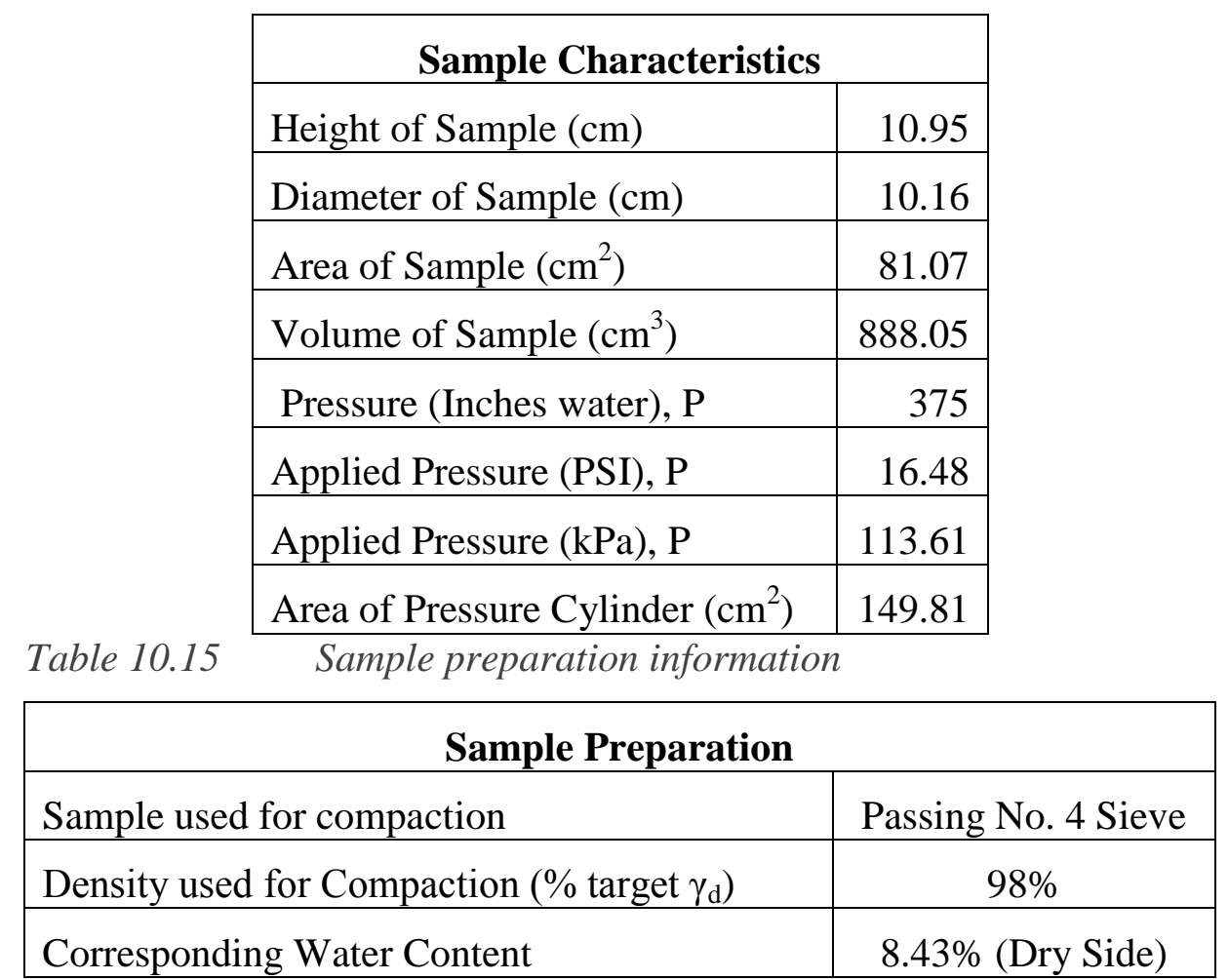

Table 10.16 Hydraulic gradient calculation information

\begin{tabular}{|r|c|r|r|r|r|r|}
\hline \multicolumn{7}{|c|}{ Pressure calculation for a predetermined hydraulic gradient } \\
\hline $\mathrm{L}(\mathrm{ft})$ & $\mathrm{i}$ & $\gamma_{\mathrm{w}}\left(\mathrm{lb} / \mathrm{ft}^{3}\right)$ & $\mathrm{u}(\mathrm{psf})$ & $\mathrm{u}(\mathrm{psi})$ & $\mathrm{u}(\mathrm{kPa})$ & $\gamma_{\mathrm{w}}\left(\mathrm{kN} / \mathrm{m}^{3}\right)$ \\
\hline 0.38 & 100 & 62.4 & 2372.5 & 16.48 & 113.61 & 9.79 \\
\hline
\end{tabular}


Table 10.17 Hydraulic conductivity results - Statistics (Last 5 data points)

\begin{tabular}{|l|r|}
\hline \multicolumn{2}{|c|}{ k Results: Last 5 Points } \\
\hline Average Hydraulic Conductivity (m/s) & $1.82 \mathrm{E}-09$ \\
\hline Sample Standard Deviation (s) & $1.13 \mathrm{E}-10$ \\
\hline Coefficient of Variation (COV) & 0.062 \\
\hline
\end{tabular}

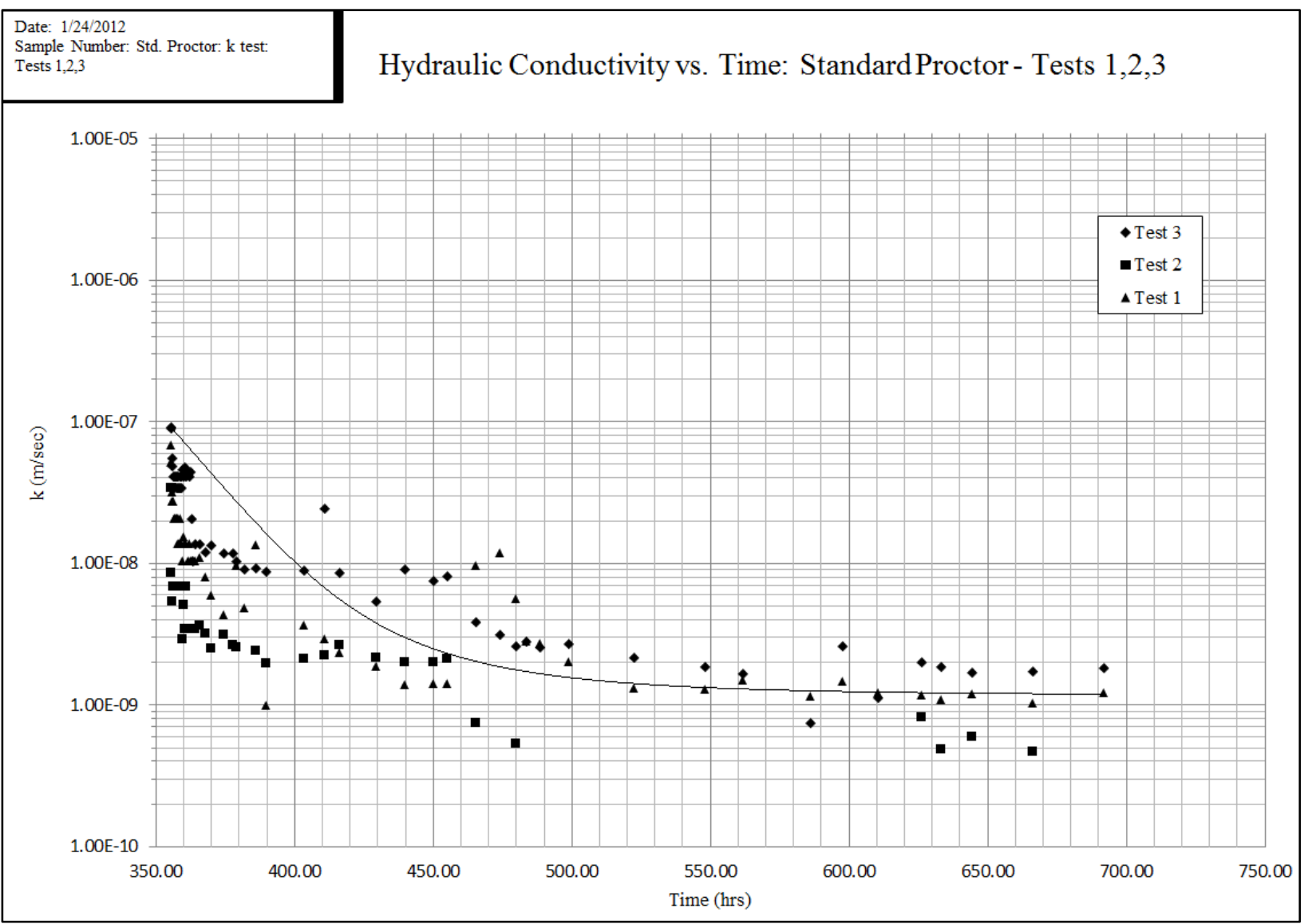

Figure 10.2 Hydraulic conductivity $(k)$ versus time. 


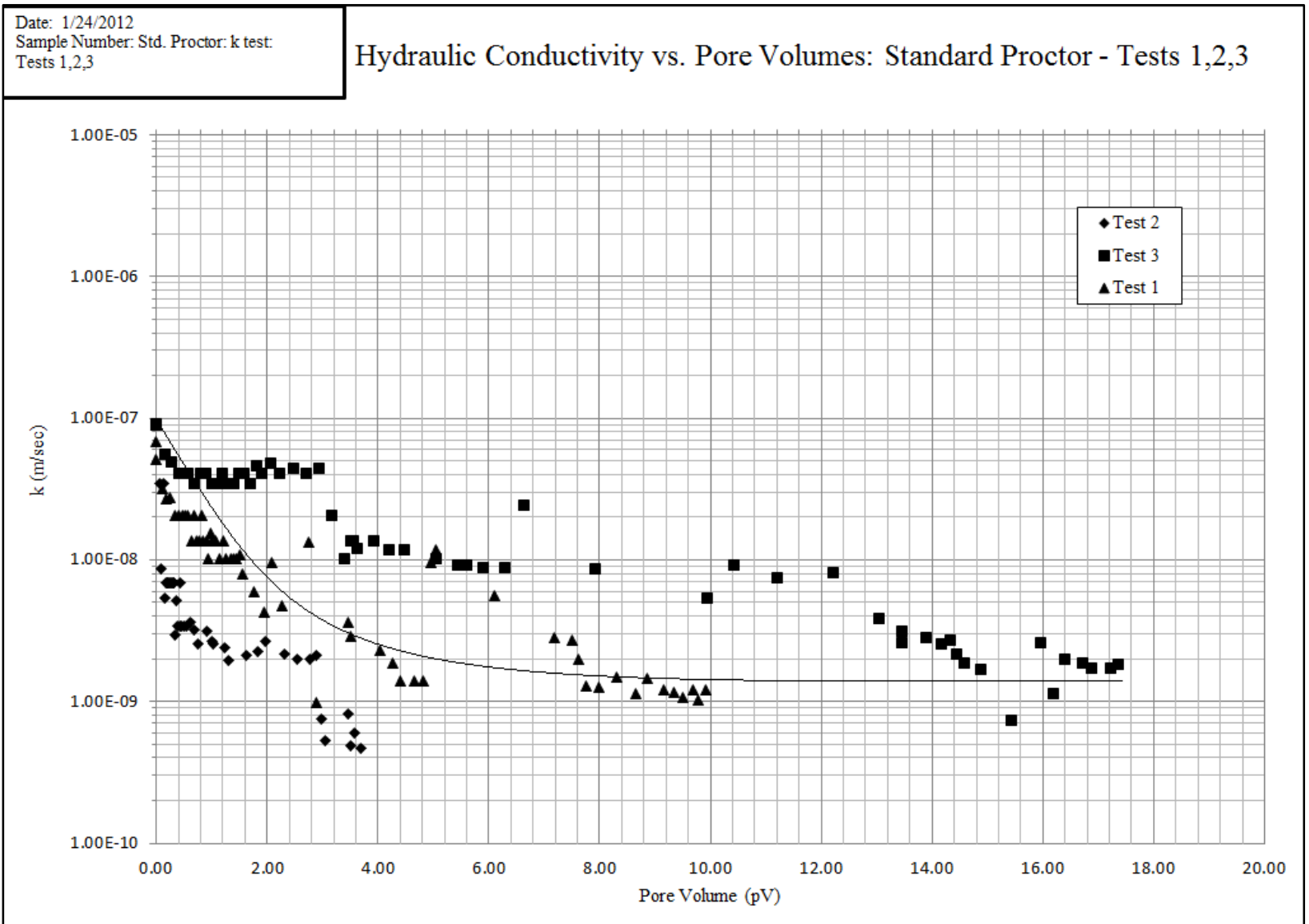

Figure 10.3 Hydraulic conductivity $(k)$ versus pore volumes $(p V)$.

Table 10.18 Summary values for tests 1, 2, and 3.

\begin{tabular}{|c|c|c|c|c|c|c|c|c|}
\hline & $\mathbf{i}$ & $\begin{array}{c}\gamma_{\text {std. proctor }} \\
\left(\mathbf{k N} / \mathbf{m}^{3}\right)\end{array}$ & $\gamma_{\text {optimum }}\left(\mathrm{kN} / \mathrm{m}^{3}\right)$ & $\mathbf{e}$ & $\mathbf{n}$ & $\mathbf{k}(\mathbf{m} / \mathbf{s})$ & s (for k) & $\mathrm{COV}$ \\
\hline Test 1 & 100 & 18.14 & 18.75 & 0.45 & 0.31 & $1.14 \mathrm{E}-09$ & 8.33E-11 & 0.073 \\
\hline Test 2 & 100 & 18.15 & 18.75 & 0.45 & 0.31 & $5.81 \mathrm{E}-10$ & $1.41 \mathrm{E}-10$ & 0.243 \\
\hline Test 3 & 100 & 18.30 & 18.75 & 0.44 & 0.31 & $1.82 \mathrm{E}-09$ & $1.13 \mathrm{E}-10$ & 0.062 \\
\hline Average & -- & 18.20 & -- & 0.45 & 0.31 & $1.18 \mathrm{E}-09$ & $1.12 \mathrm{E}-10$ & 0.126 \\
\hline
\end{tabular}




\subsection{Hydraulic Conductivity: $34 \%$ Proctor $\left(203.6 \mathrm{~kJ} / \mathrm{m}^{3}\right)$}

Hydraulic conductivity testing was performed on a $34 \%$ Proctor compaction effort $\left(203.6 \mathrm{~kJ} / \mathrm{m}^{3}\right)$ specimen. The target dry density was at optimum for this compaction effort test data. The optimum dry density for the specimen was $18.1 \mathrm{kN} / \mathrm{m}^{3}$. Triplicate testing was performed to ensure accuracy. The dry densities for tests 1,2 , and 3 were $16.32 \mathrm{kN} / \mathrm{m}^{3}, 16.44 \mathrm{kN} / \mathrm{m}^{3}$, and $17.61 \mathrm{kN} / \mathrm{m}^{3}$ respectively. The objective of the testing was to determine the hydraulic conductivity in order to better understand the rate at which water would permeate through the material under inspection. The purpose of the testing was to determine the fine particle movement within the specimen under the influence of a hydraulic gradient $i=15$. The hydraulic gradient of 15 was chosen for the $34 \%$ proctor specimens to avoid hydraulic consolidation and accelerate the testing process as a low hydraulic conductivity was expected for the well graded sand with silt. After the hydraulic conductivity readings reached equilibrium, the hydraulic conductivity was determined and the specimen was extruded approximately one third at a time. The hydraulic conductivity was determined after the data had become stable. In these cases, the average of the last five data points was taken to be the hydraulic conductivity of the specimens. The layers were saved and oven dried. Grain size analysis was run on three layers of each specimen. The hydraulic conductivity results are presented in this section (10.2). The hydraulic conductivity data is presented in Appendix I. 
Table 10.19

Hydraulic conductivity 34\% Proctor compaction energy specimen data.

\begin{tabular}{|c|c|c|c|}
\hline Test Number & Test 1 & Test 2 & Test 3 \\
\hline Assumed moisture content (\%) & 14.5 & 14.5 & 14.5 \\
\hline Mold Weight (g), $\mathrm{M}_{\mathrm{md}}$ & 613.79 & 615.98 & 617.2 \\
\hline Specimen Weight (g) & 1778.08 & 1803.46 & 1917.1 \\
\hline Specimen+Mold Weight $(\mathrm{g}), \mathrm{M}_{\mathrm{t}}$ & 2391.87 & 2419.44 & 2534.3 \\
\hline Volume of Mold $\left(\mathrm{cm}^{3}\right), \mathrm{V}$ & 940 & 940 & 940 \\
\hline Specific Gravity of Soil, $\mathrm{G}_{\mathrm{s}}$ & 2.69 & 2.69 & 2.69 \\
\hline Unit Weight of Water@20 $0^{\circ} \mathrm{C}\left(\mathrm{KN} / \mathrm{m}^{3}\right), \gamma_{\mathrm{w}}$ & 9.79 & 9.79 & 9.79 \\
\hline Unit Weight of Water @ $20^{\circ} \mathrm{C}\left(\mathrm{lb} / \mathrm{ft}^{3}\right), \gamma_{w}$ & 62.34 & 62.34 & 62.34 \\
\hline Moist Unit Weight of Compacted Specimen $\left(\mathrm{g} / \mathrm{cm}^{3}\right), \gamma_{\mathrm{m}}$ & 1.89 & 1.92 & 2.04 \\
\hline Dry Unit Weight of Compacted Specimen $\left(\mathrm{g} / \mathrm{cm}^{3}\right), \gamma_{d}$ & 1.66 & 1.67 & 1.79 \\
\hline Dry Unit Weight of Compacted Specimen $\left(\mathrm{KN} / \mathrm{m}^{3}\right), \gamma_{d}$ & 16.32 & 16.42 & 17.58 \\
\hline Dry Unit Weight of Compacted Specimen $\left(\mathrm{lb} / \mathrm{ft}^{3}\right), \gamma_{d}$ & 103.93 & 104.57 & 111.93 \\
\hline Dry Unit Weight at $\mathrm{S}=1.0\left(\mathrm{KN} / \mathrm{m}^{3}\right), \curlyvee_{\mathrm{d}}$ & 19.27 & 18.93 & 19.22 \\
\hline Dry Unit Weight at $\mathrm{S}=0.9\left(\mathrm{KN} / \mathrm{m}^{3}\right), \curlyvee_{d}$ & 18.71 & 18.36 & 18.66 \\
\hline Dry Unit Weight at $S=1.0\left(\mathrm{lb} / \mathrm{ft}^{3}\right), \gamma_{\mathrm{d}}$ & 122.71 & 120.53 & 122.4 \\
\hline Dry Unit Weight at $S=0.9\left(\mathrm{lb} / \mathrm{ft}^{3}\right), \gamma_{\mathrm{d}}$ & 119.16 & 116.88 & 118.83 \\
\hline Void Ratio, $e=\left(\left(\mathrm{G}_{\mathrm{s}}{ }^{*} \gamma_{\mathrm{w}}\right) / \gamma_{\mathrm{d}}\right)-1$ & 0.61 & 0.6 & 0.5 \\
\hline Degree of Saturation $(\%), S=\mathrm{G}_{\mathrm{s}}{ }^{*} \mathrm{w} / \mathrm{e}$ & 0.6 & 0.65 & 0.74 \\
\hline Saturated Water Content, $\mathrm{w}_{\mathrm{sat}}(\%)$ & 22.81 & 22.44 & 18.52 \\
\hline Assumed moisture content (\%) & 14.5 & 14.5 & 14.5 \\
\hline Container Mass (g), Mc & 18.85 & 22.01 & 17.4 \\
\hline Container+Moist Specimen Mass(g), Mcms & 66.63 & 83.67 & 74.62 \\
\hline Intial Container+Oven Dry Specimen Mass(g), Mcds & 60.9 & 75.84 & 67.7 \\
\hline Mass of Water $(\mathrm{g}), \mathrm{Mw}=\mathrm{Mcms}-\mathrm{Mcds}$ & 5.73 & 7.83 & 6.92 \\
\hline Mass of Solids (g), Ms= Mcds-Mc & 42.05 & 53.83 & 50.3 \\
\hline Water Content, \% W= (Mw/Ms $) \times 100$ & 13.63 & 14.55 & 13.76 \\
\hline
\end{tabular}




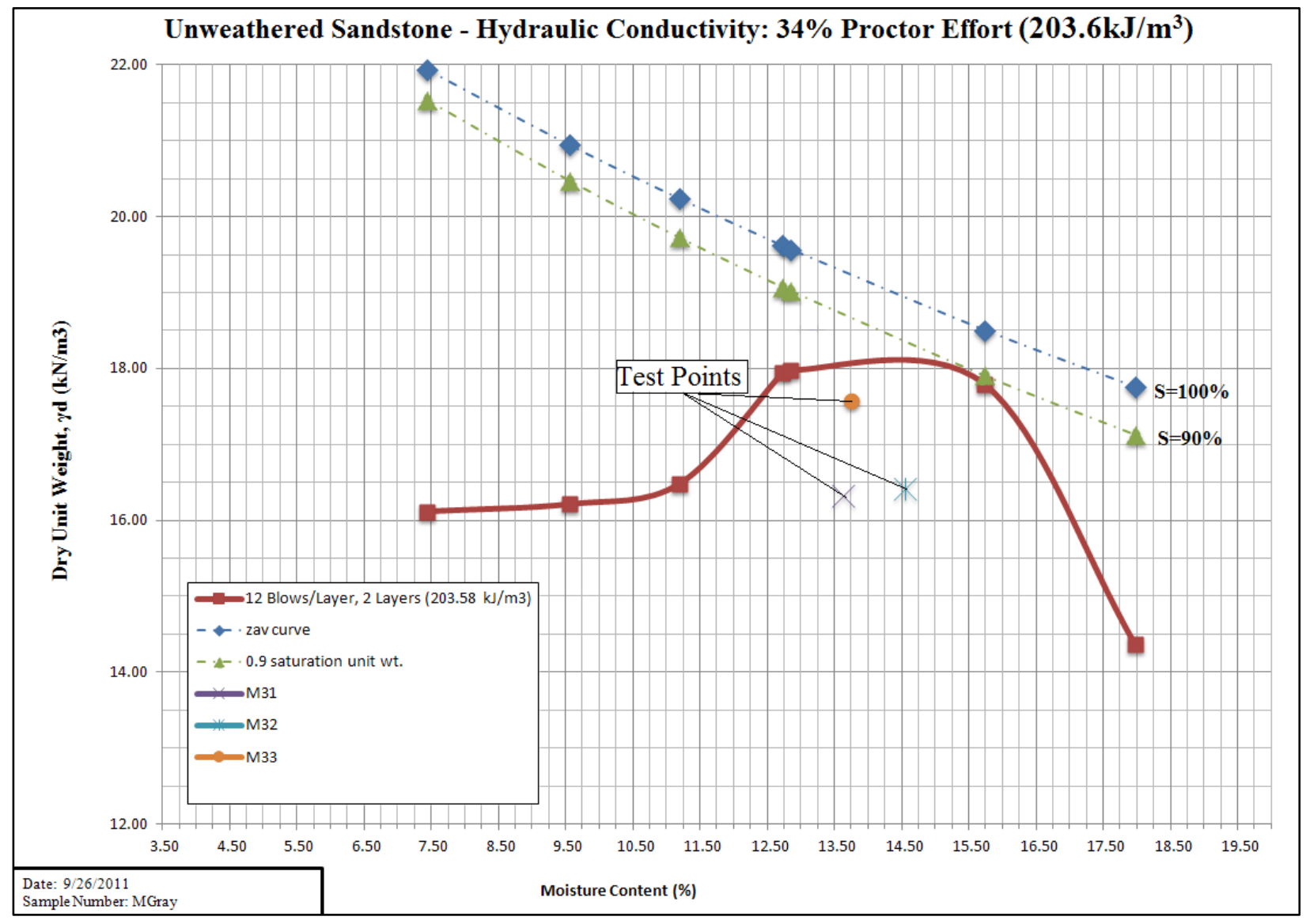

Figure 10.4 Comparison of the hydraulic conductivity 34\% Proctor compaction energy specimen and other $34 \%$ Proctor specimen compaction data. 


\subsubsection{Test 1}

The target dry density for the specimen was at optimum for $34 \%$ proctor at $18.1 \mathrm{kN} / \mathrm{m}^{3}$. The dry density of the specimen for test 1 was found to be $16.32 \mathrm{kN} / \mathrm{m}^{3}$. The void ratio (e) was 0.61 . The porosity (n) was 0.38 . The average hydraulic conductivity of the last 5 points of test 1 was found to be $2.02 \mathrm{E}-09 \mathrm{~m} / \mathrm{s}$ with a coefficient of variation of 0.09 . The low coefficient of variability implies that a stable filter was reach as a result of little variability within the specimen. The statistics are also shown for all of the test data to illustrate that the sample became a stable filter near the end of permeation. One pore volume was calculated to be 357.24 $\mathrm{cm}^{3}$. It was calculated that 1.79 pore volumes were permeated through the specimen. Test 1 results are shown in Table 10.20 through Table 10.26, Figure 10.5 and Figure 10.6.

Table 10.20 Sample characteristics for the hydraulic conductivity specimen

\begin{tabular}{|l|r|}
\hline \multicolumn{2}{|c|}{ Sample Characteristics } \\
\hline Height of Sample $(\mathrm{cm})$ & 11.59 \\
\hline Diameter of Sample $(\mathrm{cm})$ & 10.16 \\
\hline Area of Sample $\left(\mathrm{cm}^{2}\right)$ & 81.07 \\
\hline Volume of Sample $\left(\mathrm{cm}^{3}\right)$ & 939.54 \\
\hline Pressure (Inches water), P & 0.00 \\
\hline Applied Pressure (PSI), P & 2.37 \\
\hline Applied Pressure (kPa), P & 0.11 \\
\hline
\end{tabular}

Table 10.21 Sample properties for the hydraulic conductivity specimen

\begin{tabular}{|l|r|}
\hline \multicolumn{2}{|c|}{ Sample Properties } \\
\hline Molded Water Content, w $(\%)$ & 0.14 \\
\hline Specific Gravity, $\mathrm{G}_{\mathrm{s}}$ & 2.69 \\
\hline Volume of specimen $\left(\mathrm{cm}^{3}\right), \mathrm{V}$ & 939.54 \\
\hline Unit Weight of Water, $\gamma_{\mathrm{w}}$ & 9.79 \\
\hline Dry density $\left(\mathrm{lb} / \mathrm{ft}^{3}\right), \gamma_{\mathrm{d}}$ & 103.93 \\
\hline Dry density $\left(\mathrm{kN} / \mathrm{m}^{3}\right), \gamma_{\mathrm{d}}$ & 16.32 \\
\hline Void Ratio, e & 0.61 \\
\hline Porosity, $\mathrm{n}$ & 0.38 \\
\hline Pore Volume, $\left(\mathrm{cm}^{3}\right) \mathrm{Vp}$ & 357.24 \\
\hline
\end{tabular}


Table 10.22 Sample preparation information

\begin{tabular}{|l|c|}
\hline \multicolumn{2}{|c|}{ Sample Preparation } \\
\hline Sample used for compaction & Passing No. 4 Sieve \\
\hline Density used for Compaction & $90 \%$ max $\gamma_{\mathrm{d}}$ \\
\hline Corresponding Water Content & $13.63 \%$ (Dry Side) \\
\hline
\end{tabular}

Table 10.23 Hydraulic gradient calculation information

\begin{tabular}{|r|c|r|r|r|r|r|}
\hline \multicolumn{6}{|c|}{ Pressure calculation for a predetermined hydraulic gradient } \\
\hline $\mathrm{L}(\mathrm{ft})$ & $\mathrm{i}$ & $\gamma \mathrm{w}\left(\mathrm{lb} / \mathrm{ft}^{3}\right)$ & $\mathrm{u}(\mathrm{psf})$ & $\mathrm{u}(\mathrm{psi})$ & $\mathrm{u}(\mathrm{kPa})$ & $\gamma \mathrm{w}\left(\mathrm{kN} / \mathrm{m}^{3}\right)$ \\
\hline 0.38 & 15.00 & 62.40 & 355.88 & 2.47 & 17.04 & 9.79 \\
\hline
\end{tabular}

Table 10.24 Equation Definitions

\begin{tabular}{|l|}
\hline Definitions: \\
\hline $\mathrm{i}=\mathrm{h} / \mathrm{L}:$ Hydraulic gradient (unitless) \\
\hline $\mathrm{h}=\mathrm{u} / \gamma_{\mathrm{w}}:$ Pressure head according to Bernoulli's equation \\
\hline $\mathrm{u}=$ Pressure $(\mathrm{psi})$ \\
\hline$\gamma_{\mathrm{w}}=62.4 \mathrm{lb} / \mathrm{ft}^{3}=9.79 \mathrm{kN} / \mathrm{m}^{3}:$ Unit weight of water \\
\hline $\mathrm{L}=$ Length of specimen (height of cylinder) (cm or in) \\
\hline
\end{tabular}

Table 10.25 Hydraulic conductivity results - Statistics (All test 1 data)

\begin{tabular}{|l|r|}
\hline Average Hydraulic Conductivity (m/s): & $9.60 \mathrm{E}-08$ \\
\hline Sample Standard Deviation (s) & $4.92 \mathrm{E}-07$ \\
\hline Coefficient of Variation (COV) & 5.12 \\
\hline
\end{tabular}

Table 10.26 Hydraulic conductivity results - Statistics (Last 5 data points)

\begin{tabular}{|l|r|}
\hline Last 5 Points & \\
\hline Average Hydraulic Conductivity (m/s): & $2.02 \mathrm{E}-09$ \\
\hline Sample Standard Deviation (s) & $1.84 \mathrm{E}-10$ \\
\hline Coefficient of Variation (COV) & 0.09 \\
\hline
\end{tabular}




\subsubsection{Test 2}

The target dry density for the specimen was at optimum for $34 \%$ proctor at $18.1 \mathrm{kN} / \mathrm{m}^{3}$. The dry density of the specimen for test 2 was found to be $16.32 \mathrm{kN} / \mathrm{m}^{3}$. The void ratio (e) was 0.60 . The porosity (n) was 0.38 . The average hydraulic conductivity of the last 5 points of test 2 was found to be $1.69 \mathrm{E}-09 \mathrm{~m} / \mathrm{s}$ with a coefficient of variation of 0.21 . The low coefficient of variability implies that a stable filter was reach as a result of little variability within the specimen. The statistics are also shown for all of the test data to illustrate that the sample became a stable filter near the end of permeation. One pore volume was calculated to be 352.96 $\mathrm{cm}^{3}$. It was calculated that 0.751 pore volumes were permeated through the specimen. Test 2 results are shown in Table 10.27 through Table 10.32, Figure 10.5 and Figure 10.6.

Table 10.27 Sample characteristics for the hydraulic conductivity specimen

\begin{tabular}{|l|r|}
\hline \multicolumn{2}{|c|}{ Sample Characteristics } \\
\hline Height of Sample (cm) & 11.59 \\
\hline Diameter of Sample (cm) & 10.16 \\
\hline Area of Sample $\left(\mathrm{cm}^{2}\right)$ & 81.07 \\
\hline Volume of Sample $\left(\mathrm{cm}^{3}\right)$ & 939.54 \\
\hline Pressure (Inches water), P & 56.25 \\
\hline Applied Pressure (PSI), P & 2.37 \\
\hline Applied Pressure (kPa), P & 0.11 \\
\hline
\end{tabular}

Table 10.28 Sample properties for the hydraulic conductivity specimen

\begin{tabular}{|l|r|}
\hline \multicolumn{2}{|c|}{ Sample Properties } \\
\hline Molded Water Content, w (\%) & 0.15 \\
\hline Specific Gravity, $\mathrm{G}_{\mathrm{s}}$ & 2.69 \\
\hline Volume of specimen $\left(\mathrm{cm}^{3}\right), \mathrm{V}$ & 939.54 \\
\hline Unit Weight of Water, $\gamma_{\mathrm{w}}$ & 9.79 \\
\hline Dry density $\left(\mathrm{lb} / \mathrm{ft}^{3}\right), \gamma_{\mathrm{d}}$ & 104.69 \\
\hline Dry density $\left(\mathrm{kN} / \mathrm{m}^{3}\right), \gamma_{\mathrm{d}}$ & 16.44 \\
\hline Void Ratio, e & 0.60 \\
\hline Porosity, $\mathrm{n}$ & 0.38 \\
\hline Pore Volume, $\left(\mathrm{cm}^{3}\right) \mathrm{V}_{\mathrm{p}}$ & 352.96 \\
\hline
\end{tabular}


Table 10.29 Sample preparation information

\begin{tabular}{|l|l|}
\hline \multicolumn{2}{|c|}{ Sample Preparation } \\
\hline Sample used for Compaction & Passing No. 4 Sieve \\
\hline Density used for Compaction & $90 \% \max \gamma_{\mathrm{d}}$ \\
\hline Corresponding Water Content & $14.55 \%$ (Wet Side) \\
\hline
\end{tabular}

Table 10.30 Hydraulic gradient calculation information

\begin{tabular}{|c|c|c|c|c|c|c|}
\hline \multicolumn{10}{|c|}{$\begin{array}{c}\text { Pressure calculation for a predetermined } \\
\text { hydraulic gradient }\end{array}$} \\
\hline $\begin{array}{c}\mathbf{L} \\
(\mathbf{f t})\end{array}$ & $\mathbf{i}$ & $\begin{array}{c}\boldsymbol{\gamma}_{\mathbf{w}} \\
\left(\mathbf{l b} / \mathbf{f t}^{\mathbf{3}}\right)\end{array}$ & $\begin{array}{c}\mathbf{u} \\
(\mathbf{p s f})\end{array}$ & $\begin{array}{c}\mathbf{u} \\
(\mathbf{p s i})\end{array}$ & $\begin{array}{c}\mathbf{u} \\
(\mathbf{k P a})\end{array}$ & $\begin{array}{c}\boldsymbol{\gamma}_{\mathbf{w}} \\
\left(\mathbf{k N} / \mathbf{m}^{\mathbf{3}}\right)\end{array}$ \\
\hline 0.38 & 15 & 62.40 & 355.88 & 2.47 & 17.04 & 9.79 \\
\hline
\end{tabular}

Table 10.31 Hydraulic conductivity results - Statistics (All test 2 data)

\begin{tabular}{|l|r|}
\hline Average Hydraulic Conductivity $(\mathrm{m} / \mathrm{s}):$ & $1.80 \mathrm{E}-09$ \\
\hline Sample Standard Deviation (s) & $1.87 \mathrm{E}-09$ \\
\hline Coefficient of Variation (COV) & $1.04 \mathrm{E}+00$ \\
\hline
\end{tabular}

Table 10.32 Hydraulic conductivity results - Statistics (Last 5 data points)

\begin{tabular}{|l|r|}
\hline Last 5 Points & \\
\hline Average Hydraulic Conductivity $(\mathrm{m} / \mathrm{s}):$ & $1.69 \mathrm{E}-09$ \\
\hline Sample Standard Deviation $(\mathrm{s})$ & $3.52 \mathrm{E}-10$ \\
\hline Coefficient of Variation $(\mathrm{COV})$ & $2.08 \mathrm{E}-01$ \\
\hline
\end{tabular}




\subsubsection{Test 3}

The target dry density for the specimen was at optimum for $34 \%$ proctor at $18.1 \mathrm{kN} / \mathrm{m}^{3}$. The dry density of the specimen for test 3 was found to be $17.61 \mathrm{kN} / \mathrm{m}^{3}$. The void ratio (e) was 0.50 . The porosity (n) was 0.33 . The average hydraulic conductivity of the last 5 points of test 3 was found to be $3.31 \mathrm{E}-09 \mathrm{~m} / \mathrm{s}$ with a coefficient of variation of 0.07 . The low coefficient of variability implies that a stable filter was reach as a result of little variability within the specimen. The statistics are also shown for all of the test data to illustrate that the sample became a stable filter near the end of permeation. One pore volume was calculated to be 311.21 $\mathrm{cm}^{3}$. It was calculated that 2.22 pore volumes were permeated through the specimen. Test 3 results are shown in Table 10.33 through Table 10.38, Figure 10.5 and Figure 10.6.

Table 10.33 Sample characteristics for the hydraulic conductivity specimen

\begin{tabular}{|l|r|}
\hline \multicolumn{2}{|c|}{ Sample Characteristics } \\
\hline Height of Sample $(\mathrm{cm})$ & 11.59 \\
\hline Diameter of Sample (cm) & 10.16 \\
\hline Area of Sample $\left(\mathrm{cm}^{2}\right)$ & 81.07 \\
\hline Volume of Sample (cm $\left.{ }^{3}\right)$ & 939.54 \\
\hline Pressure (Inches water), P & 56.25 \\
\hline Applied Pressure (PSI), P & 2.37 \\
\hline Applied Pressure (kPa), P & 0.11 \\
\hline
\end{tabular}

Table 10.34 Sample properties for the hydraulic conductivity specimen

\begin{tabular}{|l|r|}
\hline \multicolumn{2}{|c|}{ Sample Properties } \\
\hline Molded Water Content, w (\%) & 14 \\
\hline Specific Gravity, $\mathrm{G}_{\mathrm{s}}$ & 2.69 \\
\hline Volume of specimen $\left(\mathrm{cm}^{3}\right), \mathrm{V}$ & 939.54 \\
\hline Unit Weight of Water, $\gamma_{\mathrm{w}}$ & 9.79 \\
\hline Dry density $\left(\mathrm{lb} / \mathrm{ft}^{3}\right), \gamma_{\mathrm{d}}$ & 112.12 \\
\hline Dry density $\left(\mathrm{kN} / \mathrm{m}^{3}\right), \gamma_{\mathrm{d}}$ & 17.61 \\
\hline Void Ratio, e & 0.50 \\
\hline Porosity, $\mathrm{n}$ & 0.33 \\
\hline Pore Volume, $\left(\mathrm{cm}^{3}\right) \mathrm{V}_{\mathrm{p}}$ & 311.21 \\
\hline
\end{tabular}


Table 10.35 Sample preparation information

\begin{tabular}{|l|l|}
\hline Sample Preparation & \\
\hline Sample used for Compaction & Passing No. 4 Sieve \\
\hline Density used for Compaction & $97 \% \max \gamma \mathrm{d}$ \\
\hline Corresponding Water Content & $13.76 \%$ (Dry Side) \\
\hline
\end{tabular}

Table 10.36 Hydraulic gradient calculation information

\begin{tabular}{|r|r|r|r|r|r|r|}
\hline \multicolumn{7}{|c|}{ Pressure calculation for a predetermined hydraulic gradient } \\
\hline $\mathbf{L}(\mathbf{f t})$ & $\mathbf{i}$ & $\boldsymbol{\gamma}_{\mathbf{w}}\left(\mathbf{l b} / \mathbf{f t}^{\mathbf{3}}\right)$ & $\mathbf{u}(\mathbf{p s f})$ & $\mathbf{u}(\mathbf{p s i})$ & $\mathbf{u}(\mathbf{k P a})$ & $\gamma_{\mathbf{w}}\left(\mathbf{k N} / \mathbf{m}^{\mathbf{3}}\right)$ \\
\hline 0.38 & 15 & 62.40 & 355.88 & 2.47 & 17.04 & 9.79 \\
\hline
\end{tabular}

Table 10.37 Hydraulic conductivity results - Statistics (All test 3 data)

\begin{tabular}{|l|l|}
\hline Average Hydraulic Conductivity (m/s): & $4.611 \mathrm{E}-09$ \\
\hline Sample Standard Deviation (s) & $2.650 \mathrm{E}-09$ \\
\hline Coefficient of Variation (COV) & $5.747 \mathrm{E}-01$ \\
\hline
\end{tabular}

Table 10.38 Hydraulic conductivity results - Statistics (Last 5 data points)

\begin{tabular}{|l|l|}
\hline \multicolumn{2}{|l|}{ Last 5 Points } \\
\hline Average Hydraulic Conductivity (m/s): & $3.313 \mathrm{E}-09$ \\
\hline Sample Standard Deviation (s) & $2.298 \mathrm{E}-10$ \\
\hline Coefficient of Variation (COV) & $6.936 \mathrm{E}-02$ \\
\hline
\end{tabular}




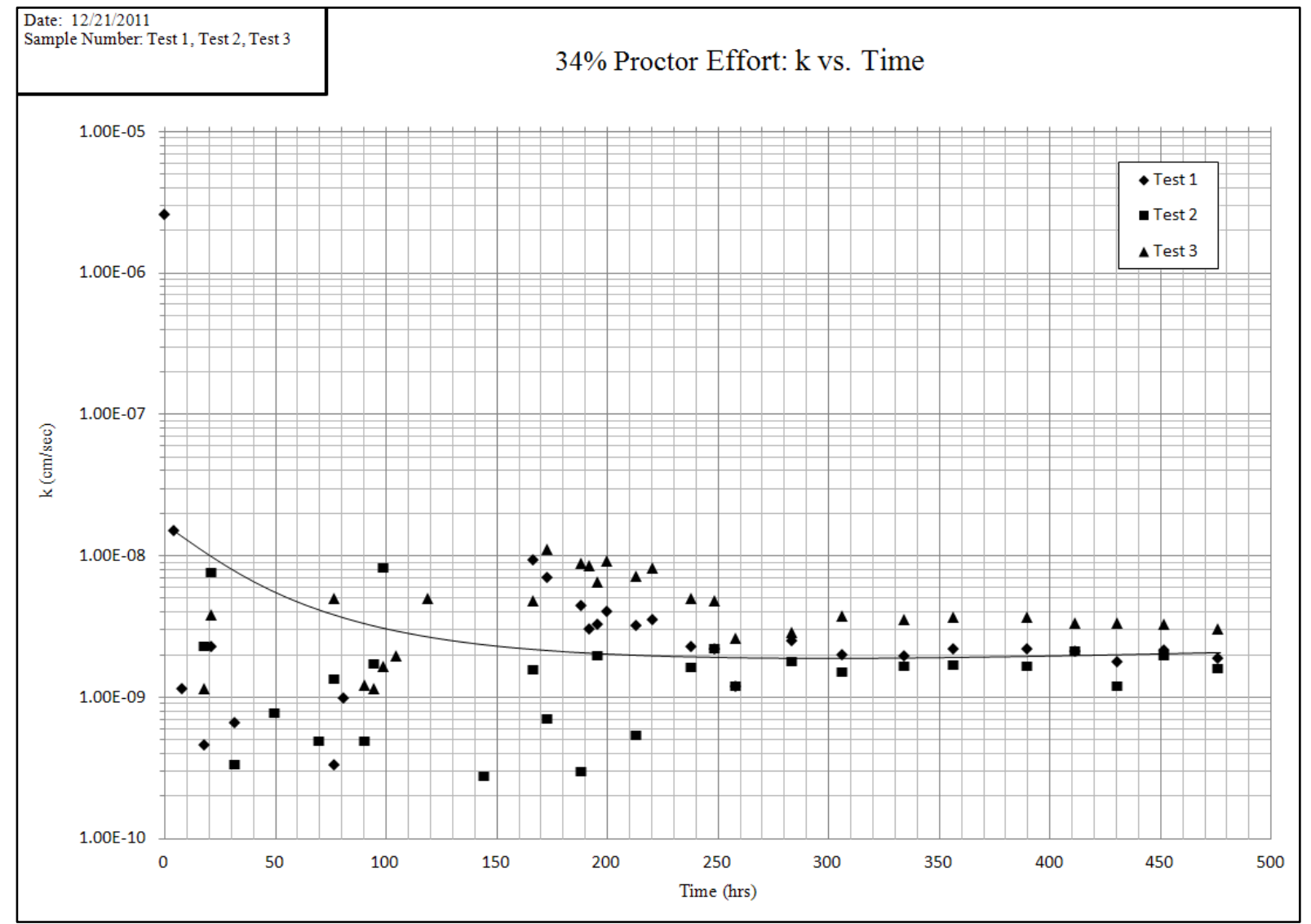

Figure 10.5 Hydraulic conductivity $(k)$ versus time.

Table 10.39 Summary values for tests 1, 2, and 3.

\begin{tabular}{|c|c|c|c|c|c|c|c|c|}
\hline & $\mathbf{i}$ & $\begin{array}{c}\gamma_{34 \% \text { Proctor }} \\
\left(\mathrm{kN} / \mathrm{m}^{3}\right)\end{array}$ & $\gamma_{\text {optimum }}\left(\mathrm{kN} / \mathrm{m}^{3}\right)$ & $\mathbf{e}$ & $\mathbf{n}$ & $\mathbf{k}(\mathbf{m} / \mathbf{s})$ & $\mathbf{s}($ for $\mathbf{k})$ & $\mathrm{COV}$ \\
\hline Test 1 & 15 & 16.32 & 18.1 & 0.61 & 0.38 & 2.02E-09 & $1.84 \mathrm{E}-10$ & 0.09 \\
\hline Test 2 & 15 & 16.44 & 18.1 & 0.60 & 0.38 & 1.69E-09 & $3.52 \mathrm{E}-10$ & 0.21 \\
\hline Test 3 & 15 & 17.61 & 18.1 & 0.50 & 0.33 & 3.31E-09 & $2.30 \mathrm{E}-10$ & 0.07 \\
\hline Average & -- & 16.79 & -- & 0.57 & 0.36 & 2.34E-09 & $2.55 \mathrm{E}-10$ & 0.12 \\
\hline
\end{tabular}




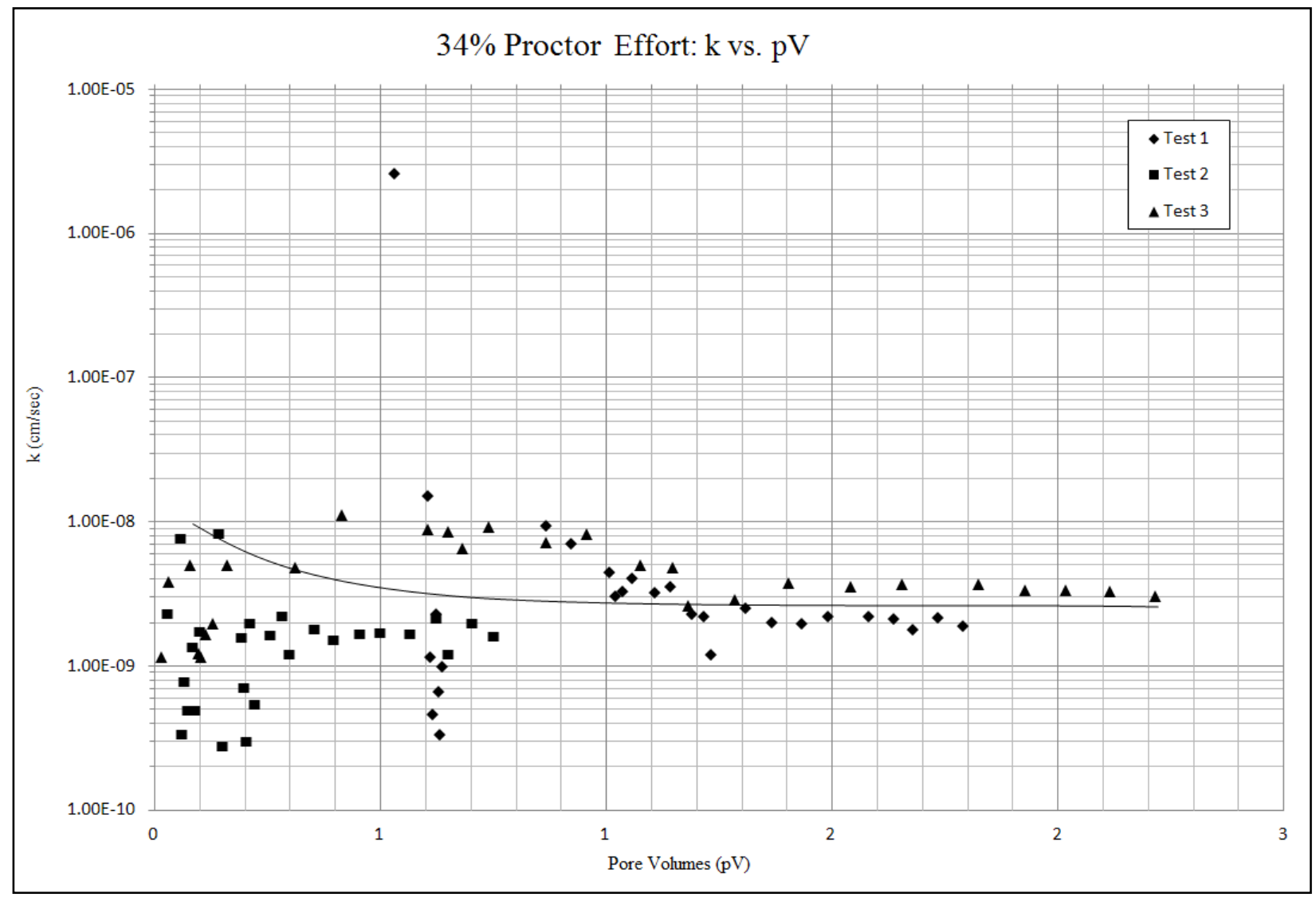

Figure 10.6 Hydraulic conductivity $(k)$ versus pore volumes $(p V)$. 


\subsection{Hydraulic Conductivity: $11 \%$ Proctor $\left(67.85 \mathrm{~kJ} / \mathrm{m}^{3}\right)$}

Hydraulic conductivity testing was performed on a $11 \%$ Proctor compaction effort $\left(67.85 \mathrm{~kJ} / \mathrm{m}^{3}\right)$ specimen. The target dry density was at the minimum for the $11 \%$ Proctor compaction effort test data. The minimum dry density for the $11 \%$ Proctor compaction effort specimen was 14.9 $\mathrm{kN} / \mathrm{m}^{3}$. Triplicate testing was performed to ensure accuracy. The dry densities for tests 1,2 , and 3 were $15.14 \mathrm{kN} / \mathrm{m}^{3}, 15.52 \mathrm{kN} / \mathrm{m}^{3}$, and $15.49 \mathrm{kN} / \mathrm{m}^{3}$ respectively. The objective of the testing was to determine the hydraulic conductivity in order to better understand the rate at which water would permeate through the material under inspection. The purpose of the testing was to determine the fine particle movement within the specimen under the influence of a hydraulic gradient $i=15$. The hydraulic gradient of 15 was chosen for the $11 \%$ proctor specimens to avoid hydraulic consolidation and accelerate the testing process as a low hydraulic conductivity was expected for the well graded sand with silt. After the hydraulic conductivity readings reached equilibrium, the hydraulic conductivity was determined and the specimen was extruded approximately one third at a time. The hydraulic conductivity was determined after the data had become stable. In these cases, the average of the last five data points was taken to be the hydraulic conductivity of the specimens. The layers were saved and oven dried. Grain size analysis was run on three layers of each specimen. The hydraulic conductivity data for the $11 \%$ Proctor compaction energy specimen are presented in this section (10.3). The hydraulic conductivity data is presented in Appendix I. 
Hydraulic conductivity $11 \%$ Proctor compaction energy specimen data.

\begin{tabular}{|c|c|c|c|}
\hline Test Number & Test 1 & Test 2 & Test 3 \\
\hline Assumed moisture content $(\%)$ & 10.5 & 10.5 & 10.5 \\
\hline Mold Weight(g), $M_{\mathrm{md}}$ & 614.74 & 616.56 & 617.67 \\
\hline Specimen Weight $(\mathrm{g})$ & 1595.5 & 1616.54 & 1608.18 \\
\hline Specimen+Mold Weight $(\mathrm{g}), \mathrm{M}_{\mathrm{t}}$ & 2210.24 & 2233.1 & 2225.85 \\
\hline Volume of $\operatorname{Mold}\left(\mathrm{cm}^{3}\right), V$ & 940 & 940 & 940 \\
\hline Specific Gravity of Soil, $\mathrm{G}_{\mathrm{s}}$ & 2.69 & 2.69 & 2.69 \\
\hline Unit Weight of Water @ $20^{\circ} \mathrm{C}\left(\mathrm{KN} / \mathrm{m}^{3}\right), \gamma_{w}$ & 9.79 & 9.79 & 9.79 \\
\hline Unit Weight of Water @ $20^{\circ} \mathrm{C}\left(\mathrm{lb} / \mathrm{ft}^{3}\right), \gamma_{w}$ & 62.34 & 62.34 & 62.34 \\
\hline $\begin{array}{l}\text { Moist Unit Weight of Compacted Specimen }\left(\mathrm{g} / \mathrm{cm}^{3}\right) \text {, } \\
\gamma_{\mathrm{m}}\end{array}$ & 1.7 & 1.72 & 1.71 \\
\hline Dry Unit Weight of Compacted Specimen $\left(\mathrm{g} / \mathrm{cm}^{3}\right), \gamma_{d}$ & 1.54 & 1.58 & 1.58 \\
\hline $\begin{array}{l}\text { Dry Unit Weight of Compacted Specimen }\left(\mathrm{kN} / \mathrm{m}^{3}\right) \text {, } \\
Y_{d}\end{array}$ & 15.14 & 15.52 & 15.49 \\
\hline Dry Unit Weight of Compacted Specimen $\left(\mathrm{lb} / \mathrm{ft}^{3}\right), \gamma_{d}$ & 96.44 & 98.8 & 98.65 \\
\hline Dry Unit Weight at $S=1.0\left(\mathrm{kN} / \mathrm{m}^{3}\right), \gamma_{d}$ & 20.81 & 21.36 & 21.55 \\
\hline Dry Unit Weight at $S=0.9\left(\mathrm{kN} / \mathrm{m}^{3}\right), \gamma_{d}$ & 20.33 & 20.92 & 21.12 \\
\hline Dry Unit Weight at $\mathrm{S}=1.0\left(\mathrm{lb} / \mathrm{ft}^{3}\right), \gamma_{\mathrm{d}}$ & 132.5 & 136.01 & 137.2 \\
\hline Dry Unit Weight at $\mathrm{S}=0.9\left(\mathrm{lb} / \mathrm{ft}^{3}\right), \gamma_{\mathrm{d}}$ & 129.48 & 133.21 & 134.48 \\
\hline Void Ratio, $e=\left(\left(\mathrm{Gs}^{*} \mathrm{~g}_{\mathrm{w}}\right) / \mathrm{g}_{\mathrm{d}}\right)-1$ & 0.74 & 0.7 & 0.7 \\
\hline Degree of Saturation $(\%), \mathrm{S}=\mathrm{Gs} * \mathrm{w} / \mathrm{e}$ & 0.36 & 0.33 & 0.32 \\
\hline Saturated Water content, $\mathrm{W}_{\text {sat }}(\%)$ & 27.47 & 25.92 & 26.02 \\
\hline Assumed moisture content $(\%)$ & 10.5 & 10.5 & 10.5 \\
\hline Container Mass $(\mathrm{g}), \mathrm{M}_{\mathrm{c}}$ & 30.65 & 30.47 & 30.56 \\
\hline Container+Moist Specimen Mass(g), $\mathrm{M}_{\mathrm{cms}}$ & 131 & 89.68 & 98.68 \\
\hline Intial Container+Oven Dry Specimen Mass $(\mathrm{g}), \mathrm{M}_{\mathrm{cds}}$ & 121.98 & 84.96 & 93.48 \\
\hline Mass of Water $(\mathrm{g}), \mathrm{M}_{\mathrm{w}}=\mathrm{M}_{\mathrm{cms}}-\mathrm{M}_{\mathrm{cds}}$ & 9.02 & 4.72 & 5.2 \\
\hline Mass of Solids $(\mathrm{g}), \mathrm{M}_{\mathrm{s}}=\mathrm{M}_{\mathrm{cds}}-\mathrm{M}_{\mathrm{c}}$ & 91.33 & 54.49 & 62.92 \\
\hline Water Content, \% W= $\left(M_{w} / M_{s}\right) \times 100$ & 9.88 & 8.66 & 8.26 \\
\hline
\end{tabular}




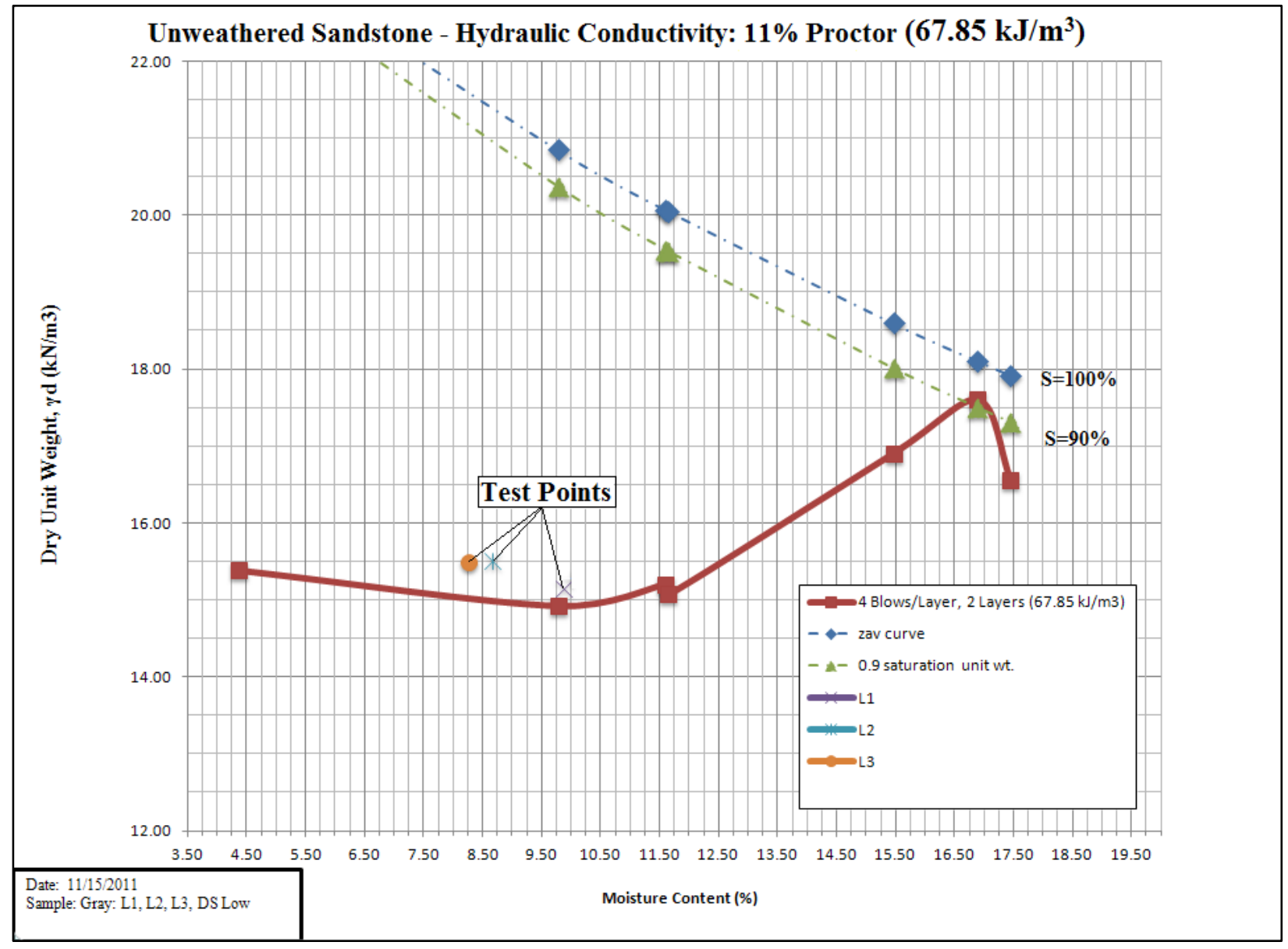

Figure 10.7 Comparison of the hydraulic conductivity 11\% Proctor compaction energy specimen and other $11 \%$ Proctor compaction energy compaction data. 


\subsubsection{Test 1}

The target dry density for the specimen was at minimum for $11 \%$ proctor at $14.90 \mathrm{kN} / \mathrm{m}^{3}$. The dry density of the specimen for test 1 was found to be $15.14 \mathrm{kN} / \mathrm{m}^{3}$. The void ratio (e) was 0.74 . The porosity (n) was 0.43 . The average hydraulic conductivity of the last 5 points of test 1 was found to be $1.89 \mathrm{E}-09 \mathrm{~m} / \mathrm{s}$ with a coefficient of variation of 0.125 . The low coefficient of variability implies that a stable filter was reach as a result of little variability within the specimen. The statistics are also shown for all of the test data to illustrate that the sample became a stable filter near the end of permeation. One pore volume was calculated to be 399.34 $\mathrm{cm}^{3}$. It was calculated that 1.10 pore volumes were permeated through the specimen. Test 1 results are shown in Table 10.41 through Table 10.46, Figure 10.8 and Figure 10.9.

Table 10.41 Sample characteristics for the hydraulic conductivity specimen

\begin{tabular}{|l|r|}
\hline \multicolumn{2}{|c|}{ Sample Characteristics } \\
\hline Height of Sample $(\mathrm{cm})$ & 11.59 \\
\hline Diameter of Sample (cm) & 10.16 \\
\hline Area of Sample $\left(\mathrm{cm}^{2}\right)$ & 81.07 \\
\hline Volume of Sample $\left(\mathrm{cm}^{3}\right)$ & 939.54 \\
\hline Pressure (Inches water), P & 56.25 \\
\hline Applied Pressure (PSI), P & 0.82 \\
\hline Applied Pressure (kPa), P & 0.04 \\
\hline
\end{tabular}

Table 10.42 Sample properties for the hydraulic conductivity specimen

\begin{tabular}{|l|r|}
\hline \multicolumn{2}{|c|}{ Sample Properties } \\
\hline Molded Water Content, w (\%) & $9.88 \%$ \\
\hline Specific Gravity, $\mathrm{G}_{\mathrm{s}}$ & 2.69 \\
\hline Volume of specimen $\left(\mathrm{cm}^{3}\right), \mathrm{V}$ & 939.54 \\
\hline Unit Weight of Water, $\gamma_{\mathrm{w}}$ & 9.79 \\
\hline Dry density $\left(\mathrm{lb} / \mathrm{ft}^{3}\right), \gamma_{\mathrm{d}}$ & 96.44 \\
\hline Dry density $\left(\mathrm{kN} / \mathrm{m}^{3}\right), \gamma_{\mathrm{d}}$ & 15.14 \\
\hline Void Ratio, e & 0.74 \\
\hline Porosity, $\mathrm{n}$ & 0.43 \\
\hline Pore Volume, $\left(\mathrm{cm}^{3}\right) \mathrm{V}_{\mathrm{p}}$ & 399.34 \\
\hline
\end{tabular}


Table 10.43 Sample preparation information

\begin{tabular}{|l|c|}
\hline \multicolumn{2}{|c|}{ Sample Preparation } \\
\hline Sample used for Compaction & Passing No. 4 Sieve \\
\hline Density used for Compaction & $101 \% \min \gamma_{\mathrm{d}}$ \\
\hline Corresponding Water Content & $9.88 \%$ (Dry Side) \\
\hline
\end{tabular}

Table 10.44 Hydraulic gradient calculation information

\begin{tabular}{|c|c|c|c|c|c|r|}
\hline \multicolumn{1}{|c|}{ Pressure calculation for a predetermined hydraulic gradient } \\
\hline $\mathrm{L}(\mathrm{ft})$ & $\mathrm{i}$ & $\gamma_{\mathrm{w}}\left(\mathrm{lb} / \mathrm{ft}^{3}\right)$ & $\mathrm{u}(\mathrm{psf})$ & $\mathrm{u}(\mathrm{psi})$ & $\mathrm{u}(\mathrm{kPa})$ & $\gamma_{\mathrm{w}}\left(\mathrm{kN} / \mathrm{m}^{3}\right)$ \\
\hline 0.38 & 15 & 62.4 & 355.88 & 2.47 & 17.04 & 9.79 \\
\hline
\end{tabular}

Table 10.45 Hydraulic conductivity results - Statistics (All test 1 data)

\begin{tabular}{|l|r|}
\hline Average Hydraulic Conductivity (m/s): & $1.41 \mathrm{E}-08$ \\
\hline Sample Standard Deviation (s) & $2.23 \mathrm{E}-08$ \\
\hline Coefficient of Variation (COV) & 1.577 \\
\hline
\end{tabular}

Table 10.46 Hydraulic conductivity results - Statistics (Last 5 data points)

\begin{tabular}{|l|r|}
\hline \multicolumn{2}{|c|}{ Last 5 Points } \\
\hline Average Hydraulic Conductivity $(\mathbf{m} / \mathbf{s})$ & $1.89 \mathrm{E}-09$ \\
\hline Sample Standard Deviation (s) & $2.37 \mathrm{E}-10$ \\
\hline Coefficient of Variation (COV) & 0.125 \\
\hline
\end{tabular}




\subsubsection{Test 2}

The target dry density for the specimen was at minimum for $11 \%$ proctor at $14.90 \mathrm{kN} / \mathrm{m}^{3}$. The dry density of the specimen for test 2 was found to be $15.52 \mathrm{kN} / \mathrm{m}^{3}$. The void ratio (e) was 0.70 . The porosity (n) was 0.41 . The average hydraulic conductivity of the last 5 points of test 2 was found to be $2.43 \mathrm{E}-09 \mathrm{~m} / \mathrm{s}$ with a coefficient of variation of 0.133 . The low coefficient of variability implies that a stable filter was reach as a result of little variability within the specimen. The statistics are also shown for all of the test data to illustrate that the sample became a stable filter near the end of permeation. One pore volume was calculated to be 385.79 $\mathrm{cm}^{3}$. It was calculated that 7.61 pore volumes were permeated through the specimen. Test 2 results are shown in Table 10.47 through Table 10.52, Figure 10.8 and Figure 10.9.

Table 10.47 Sample characteristics for the hydraulic conductivity specimen

\begin{tabular}{|l|r|}
\hline \multicolumn{2}{|c|}{ Sample Characteristics } \\
\hline Height of Sample $(\mathrm{cm})$ & 11.59 \\
\hline Diameter of Sample $(\mathrm{cm})$ & 10.16 \\
\hline Area of Sample $\left(\mathrm{cm}^{2}\right)$ & 81.07 \\
\hline Volume of Sample $\left(\mathrm{cm}^{3}\right)$ & 939.54 \\
\hline Pressure (Inches water), P & 56.25 \\
\hline Applied Pressure (PSI), P & 0.82 \\
\hline Applied Pressure (kPa), P & 0.04 \\
\hline
\end{tabular}

Table 10.48 Sample properties for the hydraulic conductivity specimen

\begin{tabular}{|l|r|}
\hline \multicolumn{2}{|c|}{ Sample Properties } \\
\hline Molded Water Content, w $(\%)$ & $8.66 \%$ \\
\hline Specific Gravity, Gs & 2.69 \\
\hline Volume of specimen $\left(\mathrm{cm}^{3}\right), \mathrm{V}$ & 939.54 \\
\hline Unit Weight of Water, $\gamma_{\mathrm{w}}$ & 9.79 \\
\hline Dry density $\left(\mathrm{lb} / \mathrm{ft}^{3}\right), \gamma_{\mathrm{d}}$ & 98.80 \\
\hline Dry density $\left(\mathrm{kN} / \mathrm{m}^{3}\right), \gamma_{\mathrm{d}}$ & 15.52 \\
\hline Void Ratio, e & 0.70 \\
\hline Porosity, $\mathrm{n}$ & 0.41 \\
\hline Pore Volume, $\left(\mathrm{cm}^{3}\right) \mathrm{V}_{\mathrm{p}}$ & 385.79 \\
\hline
\end{tabular}


Table 10.49 Sample preparation information

\begin{tabular}{|l|c|}
\hline \multicolumn{2}{|c|}{ Sample Preparation } \\
\hline Sample used for Compaction & Passing No. 4 Sieve \\
\hline Density used for Compaction & $104 \%$ min $\gamma_{d}$ \\
\hline Corresponding Water Content & $8.66 \%$ (Dry Side) \\
\hline
\end{tabular}

Table 10.50 Hydraulic gradient calculation information

\begin{tabular}{|c|c|c|c|c|c|r|}
\multicolumn{6}{|c|}{ Pressure calculation for a predetermined hydraulic gradient } \\
\hline $\mathrm{L}(\mathrm{ft})$ & $\mathrm{i}$ & $\gamma_{\mathrm{w}}\left(\mathrm{lb} / \mathrm{ft}^{3}\right)$ & $\mathrm{u}(\mathrm{psf})$ & $\mathrm{u}(\mathrm{psi})$ & $\mathrm{u}(\mathrm{kPa})$ & $\gamma_{\mathrm{w}}\left(\mathrm{kN} / \mathrm{m}^{3}\right)$ \\
\hline 0.38 & 15 & 62.4 & 355.88 & 2.47 & 17.04 & 9.79 \\
\hline
\end{tabular}

Table $10.51 \quad$ Hydraulic conductivity results - Statistics (All test 1 data)

\begin{tabular}{|l|r|}
\hline Average Hydraulic Conductivity (m/s): & $2.05 \mathrm{E}-07$ \\
\hline Sample Standard Deviation (s) & $3.88 \mathrm{E}-07$ \\
\hline Coefficient of Variation (COV) & 1.889 \\
\hline
\end{tabular}

Table 10.52 Hydraulic conductivity results - Statistics (Last 5 data points)

\begin{tabular}{|l|r|}
\hline \multicolumn{2}{|c|}{ Last 5 Points } \\
\hline Average Hydraulic Conductivity (m/s): & $2.43 \mathrm{E}-09$ \\
\hline Sample Standard Deviation (s) & $3.22 \mathrm{E}-10$ \\
\hline Coefficient of Variation (COV) & 0.133 \\
\hline
\end{tabular}




\subsubsection{Test 3}

The target dry density for the specimen was at minimum for $11 \%$ proctor at $14.90 \mathrm{kN} / \mathrm{m}^{3}$. The dry density of the specimen for test 3 was found to be $15.49 \mathrm{kN} / \mathrm{m}^{3}$. The void ratio (e) was 0.70 . The porosity (n) was 0.41 . The average hydraulic conductivity of the last 5 points of test 3 was found to be $3.60 \mathrm{E}-09 \mathrm{~m} / \mathrm{s}$ with a coefficient of variation of 0.121 . The low coefficient of variability implies that a stable filter was reach as a result of little variability within the specimen. The statistics are also shown for all of the test data to illustrate that the sample became a stable filter near the end of permeation. One pore volume was calculated to be 386.86 $\mathrm{cm}^{3}$. It was calculated that 9.04 pore volumes were permeated through the specimen. Test 3 results are shown in Table 10.53 through Table 10.58, Figure 10.8 and Figure 10.9.

Table 10.53 Sample characteristics for the hydraulic conductivity specimen

\begin{tabular}{|l|r|}
\hline \multicolumn{2}{|c|}{ Sample Characteristics } \\
\hline Height of Sample $(\mathrm{cm})$ & 11.59 \\
\hline Diameter of Sample $(\mathrm{cm})$ & 10.16 \\
\hline Area of Sample $\left(\mathrm{cm}^{2}\right)$ & 81.07 \\
\hline Volume of Sample $\left(\mathrm{cm}^{3}\right)$ & 939.54 \\
\hline Pressure (Inches water), P & 56.25 \\
\hline Applied Pressure (PSI), P & 0.82 \\
\hline Applied Pressure (kPa), P & 0.04 \\
\hline
\end{tabular}

Table 10.54 Sample properties for the hydraulic conductivity specimen

\begin{tabular}{|l|r|}
\hline \multicolumn{2}{|c|}{ Sample Properties } \\
\hline Molded Water Content, w $(\%)$ & $8.26 \%$ \\
\hline Specific Gravity, Gs & 2.69 \\
\hline Volume of specimen $\left(\mathrm{cm}^{3}\right), \mathrm{V}$ & 939.54 \\
\hline Unit Weight of Water, $\gamma_{\mathrm{w}}$ & 9.79 \\
\hline Dry density $\left(\mathrm{lb} / \mathrm{ft}^{3}\right), \gamma_{\mathrm{d}}$ & 98.65 \\
\hline Dry density $\left(\mathrm{kN} / \mathrm{m}^{3}\right), \gamma_{\mathrm{d}}$ & 15.49 \\
\hline Void Ratio, e & 0.70 \\
\hline Porosity, $\mathrm{n}$ & 0.41 \\
\hline Pore Volume, $\left(\mathrm{cm}^{3}\right) \mathrm{V}_{\mathrm{p}}$ & 386.86 \\
\hline
\end{tabular}


Table 10.55 Sample preparation information

\begin{tabular}{|l|c|}
\hline \multicolumn{2}{|c|}{ Sample Preparation } \\
\hline Sample used for comapaction & Passing No. 4 Sieve \\
\hline Density used for Comapaction & $104 \%$ min $\gamma_{d}$ \\
\hline Corresponding Water Content & $8.26 \%$ (Dry Side) \\
\hline
\end{tabular}

Table 10.56 Hydraulic gradient calculation information

\begin{tabular}{|c|c|c|c|c|c|r|}
\multicolumn{6}{|c|}{ Pressure calculation for a predetermined hydraulic gradient } \\
\hline $\mathrm{L}(\mathrm{ft})$ & $\mathrm{i}$ & $\gamma_{\mathrm{w}}\left(\mathrm{lb} / \mathrm{ft}^{3}\right)$ & $\mathrm{u}(\mathrm{psf})$ & $\mathrm{u}(\mathrm{psi})$ & $\mathrm{u}(\mathrm{kPa})$ & $\gamma_{\mathrm{w}}\left(\mathrm{kN} / \mathrm{m}^{3}\right)$ \\
\hline 0.38 & 15 & 62.4 & 355.88 & 2.47 & 17.04 & 9.79 \\
\hline
\end{tabular}

Table 10.57 Hydraulic conductivity results - Statistics (All test 1 data)

\begin{tabular}{|l|r|}
\hline Average Hydraulic Conductivity $(\mathrm{m} / \mathbf{s}):$ & $1.09 \mathrm{E}-07$ \\
\hline Sample Standard Deviation (s) & $1.86 \mathrm{E}-07$ \\
\hline Coefficient of Variation (COV) & 1.703 \\
\hline
\end{tabular}

Table 10.58 Hydraulic conductivity results - Statistics (Last 5 data points)

\begin{tabular}{|l|r|}
\hline \multicolumn{2}{|c|}{ Last 5 Points } \\
\hline Average Hydraulic Conductivity (m/s): & $3.60 \mathrm{E}-09$ \\
\hline Sample Standard Deviation (s) & $4.35 \mathrm{E}-10$ \\
\hline Coefficient of Variation (COV) & 0.121 \\
\hline
\end{tabular}




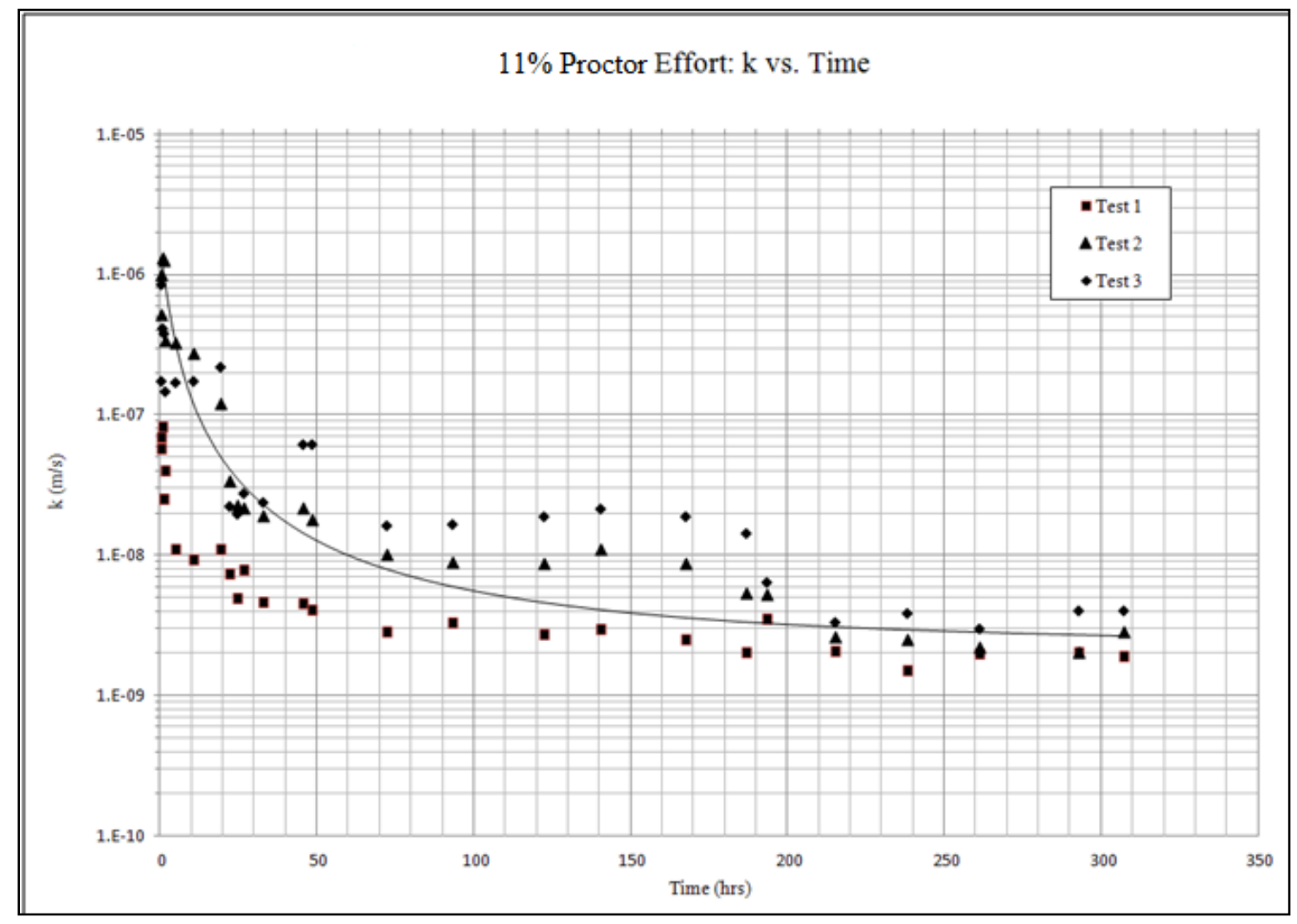

Figure $10.8 \quad$ Hydraulic conductivity $(k)$ versus time.

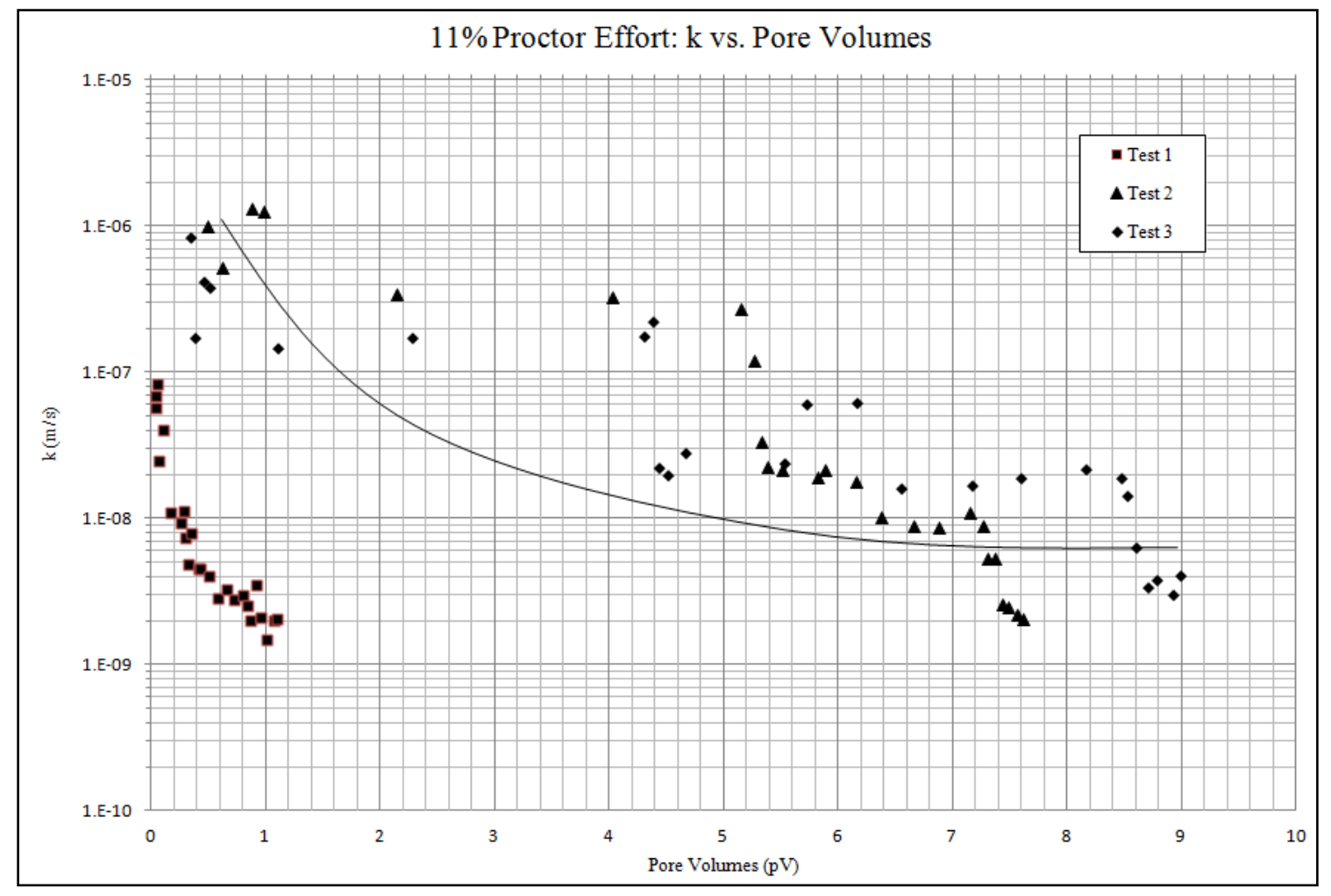

Figure 10.9 Hydraulic conductivity $(k)$ versus pore volumes $(p V)$. 
Table 10.59 Summary values for tests 1, 2, and 3.

\begin{tabular}{|c|c|c|c|c|c|c|c|c|}
\hline & $\mathbf{i}$ & $\begin{array}{c}\gamma_{11 \% \text { Proctor }} \\
\left(\mathbf{k N} / \mathbf{m}^{3}\right)\end{array}$ & $\gamma_{\text {minimum }}\left(\mathrm{kN} / \mathrm{m}^{3}\right)$ & $\mathbf{e}$ & $\mathbf{n}$ & $\mathbf{k}(\mathbf{m} / \mathbf{s})$ & $\mathbf{s}($ for $k)$ & $\mathrm{COV}$ \\
\hline Test 1 & 15 & 15.14 & 14.9 & 0.74 & 0.43 & 1.89E-09 & $2.37 \mathrm{E}-10$ & 0.13 \\
\hline Test 2 & 15 & 15.52 & 14.9 & 0.70 & 0.41 & $2.43 \mathrm{E}-09$ & $3.22 \mathrm{E}-10$ & 0.13 \\
\hline Test 3 & 15 & 15.49 & 14.9 & 0.70 & 0.41 & 3.60E-09 & $4.35 \mathrm{E}-10$ & 0.12 \\
\hline Average & -- & 15.38 & -- & 0.71 & 0.42 & $2.64 \mathrm{E}-09$ & $3.31 \mathrm{E}-10$ & 0.13 \\
\hline
\end{tabular}

\section{Discussion}

The hydraulic conductivity for each test performed for standard proctor, $34 \%$ proctor, and $11 \%$ proctor all remained in the order of $10^{-9} \mathrm{~m} / \mathrm{s}$. The neither the $34 \%$ proctor permeated specimens, nor the standard proctor specimens had hydraulic consolidation effects. Some hydraulic consolidation did occur for the $11 \%$ proctor specimens. The consolidation that occurred was the cause of the low hydraulic conductivity of the $11 \%$ proctor specimens. The soil structure could not retain its skeleton and void spaces collapsed under the hydraulic gradient of $i=15$. The standard proctor and $34 \%$ proctor specimens had low porosities in a range of $n=0.31$ to $n=0.38$ which resulted in low hydraulic conductivities. A summary table of the hydraulic conductivity results are shown in Table 10.60 below.

Table 10.60 Hydraulic conductivity summary

\begin{tabular}{|c|l|c|}
\hline & Test Number & $\mathbf{k}(\mathbf{m} / \mathbf{s})$ \\
\hline \multirow{3}{*}{ Standard Proctor } & Test 1 & $1.14 \mathrm{E}-09$ \\
\cline { 2 - 3 } & Test 2 & $5.81 \mathrm{E}-09$ \\
\cline { 2 - 3 } & Test 3 & $1.82 \mathrm{E}-09$ \\
\hline \multirow{3}{*}{$34 \%$ Proctor } & Test 1 & $2.02 \mathrm{E}-09$ \\
\cline { 2 - 3 } & Test 2 & $1.69 \mathrm{E}-09$ \\
\cline { 2 - 3 } & Test 3 & $3.31 \mathrm{E}-09$ \\
\hline \multirow{3}{*}{$11 \%$ Proctor } & Test 1 & $1.89 \mathrm{E}-09$ \\
\cline { 2 - 3 } & Test 2 & $2.43 \mathrm{E}-09$ \\
\cline { 2 - 3 } & Test 3 & $2.64 \mathrm{E}-09$ \\
\hline
\end{tabular}




\section{Post-Permeability Grain Size Distribution}

Triplicate testing was performed for three phases of hydraulic conductivity testing. The first phase was a triplicate testing of a standard proctor compacted specimen $\left(592.5 \mathrm{~kJ} / \mathrm{m}^{3}\right)$ with a hydraulic gradient of $i=100$. For the first phase, each specimen had a target density at the maximum dry density $\left(18.75 \mathrm{kN} / \mathrm{m}^{3}\right)$ of the determined proctor curve. The second phase was a triplicate testing of a $34 \%$ Proctor compacted specimen $\left(203.6 \mathrm{~kJ} / \mathrm{m}^{3}\right)$ with a hydraulic gradient of $\mathrm{i}=15$. For the second phase, each specimen had a target density at the maximum dry density $\left(18.1 \mathrm{kN} / \mathrm{m}^{3}\right)$ of the determined proctor curve. The third phase was a triplicate testing of a $11 \%$ Proctor compacted specimen $\left(67.85 \mathrm{~kJ} / \mathrm{m}^{3}\right)$ with a hydraulic gradient of $\mathrm{i}=15$. For the third phase, each specimen had a target density at the minimum dry density $\left(14.9 \mathrm{kN} / \mathrm{m}^{3}\right)$ of the determined proctor curve. One hydraulic conductivity specimen was chosen for each phase for grain size distribution testing. Three approximately equal layers were cut from the specimen after the hydraulic conductivity had been determined. A sieve analysis was performed on each of these layers. The objective of this testing was to determine the movement of the particles with an applied hydraulic gradient that was comparable to the conditions that the material would experience in the field. These results have implications on the stability or instability of earthen structures built from the unweathered sandstone under inspection. The results of the testing are shown in this chapter.

\subsection{Post-Permeability Grain Size Distribution: Standard Proctor $\left(592.5 \mathrm{~kJ} / \mathrm{m}^{3}\right)$}

Three approximately equal layers were cut from the standard proctor Test 1 hydraulic conductivity specimen in Chapter 10, section 10.1 for the standard proctor post-permeability grain size distribution testing. The layers were tested separately to determine whether or not their gradations varied. The sought after variation is a result of particle movement during permeation. Only the sand portion (passing \#4 sieve to \#200 sieve) was permeated and tested. The results of the sieve analysis yielded a coefficient of variation of 0.036 for the uniformity coefficient and a coefficient of variation of 0.044 for the coefficient of gradation. This low coefficient of variation implies that the samples had very little variation in their gradations. Additional information about the properties of this specimen can be found in Appendix I and section 10.1. The data for the sieve analysis is shown in Table 11.1, Table 11.2, Table 11.3, and Figure 11.1. 
Table 11.1 Critical index values for the hydraulic conductivity grain size distribution testing.

\begin{tabular}{|c|r|r|r|}
\hline Critical Indices & Layer 1 & Layer 2 & Layer 3 \\
\hline $\mathrm{D}_{90}$ & 3.90 & 4.00 & 4.00 \\
\hline $\mathrm{D}_{60}$ & 2.00 & 2.40 & 2.30 \\
\hline $\mathrm{D}_{50}$ & 1.60 & 1.80 & 1.75 \\
\hline $\mathrm{D}_{30}$ & 0.74 & 0.83 & 0.81 \\
\hline $\mathrm{D}_{25}$ & 0.60 & 0.65 & 0.65 \\
\hline $\mathrm{D}_{10}$ & 0.14 & 0.16 & 0.15 \\
\hline Uniformity Coefficient, $\mathbf{C}_{\mathbf{u}}$ & $\mathbf{1 4 . 2 9}$ & $\mathbf{1 5 . 0 0}$ & $\mathbf{1 5 . 3 3}$ \\
\hline Coefficient of Gradation, $\mathbf{C}_{\mathbf{c}}$ & $\mathbf{1 . 9 6}$ & $\mathbf{1 . 7 9}$ & $\mathbf{1 . 9 0}$ \\
\hline
\end{tabular}

Table 11.2 Uniformity coefficient statistics

\begin{tabular}{|l|r|}
\hline \multicolumn{2}{|l|}{ Uniformity Coefficient, $\mathbf{C}_{\mathbf{u}}$} \\
\hline Average Uniformity Coefficient & 14.873 \\
\hline Sample Standard Deviation (s) & 0.535 \\
\hline Coefficient of Variation (COV) & 0.036 \\
\hline
\end{tabular}

Table 11.3 Coefficient of gradation statistics

\begin{tabular}{|l|l|}
\hline Coefficient of Gradation, $\mathbf{C}_{\mathbf{c}}$ \\
\hline Average Coefficient of Gradation & 1.884 \\
\hline Sample Standard Deviation (s) & 0.082 \\
\hline Coefficient of Variation (COV) & 0.044 \\
\hline
\end{tabular}




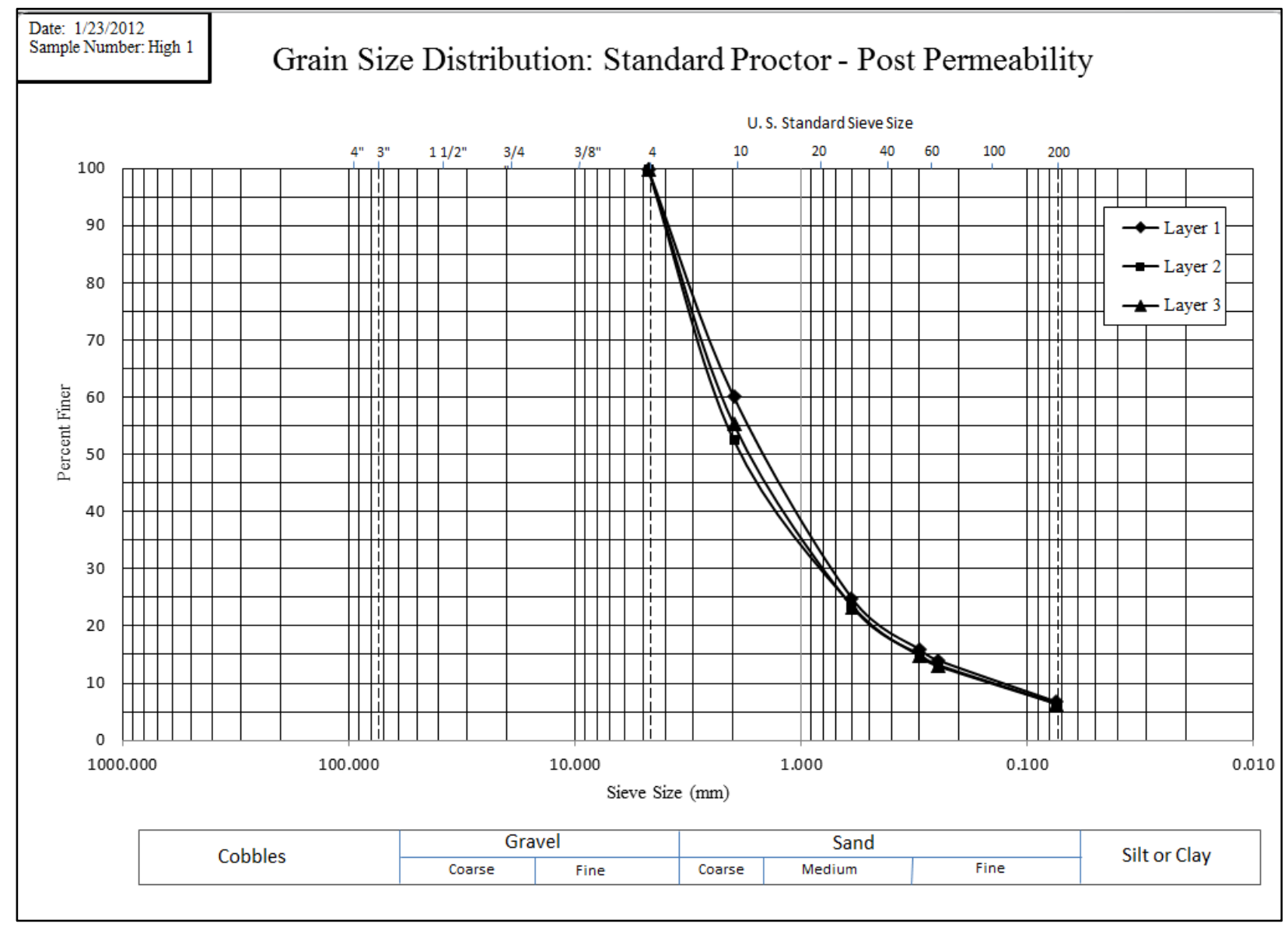

Figure 11.1 Grain size distribution of layer1, layer2, and layer3 of the hydraulic conductivity test specimen. 


\subsection{Post-Permeability Grain Size Distribution: $34 \%$ Proctor $\left(203.6 \mathrm{~kJ} / \mathrm{m}^{3}\right)$}

Three approximately equal layers were cut from the $34 \%$ proctor Test 1 hydraulic conductivity specimen in Chapter 10, section 10.2 for the standard proctor post-permeability grain size distribution testing. The layers were tested separately to determine whether or not their gradations varied. The sought after variation is a result of particle movement during permeation. Only the sand portion (passing \#4 sieve to \#200 sieve) was permeated and tested. The results of the sieve analysis yielded a coefficient of variation of 0.163 for the uniformity coefficient and a coefficient of variation of 0.050 for the coefficient of gradation. This low coefficient of variation implies that the samples had very little variation in their gradations. Additional information about the properties of this specimen can be found in Appendix I and section 10.2. The data for the sieve analysis is shown in Table 11.4, Table 11.5, Table 11.6, and Figure 11.2.

Table 11.4 Critical index values for the hydraulic conductivity grain size distribution testing.

\begin{tabular}{|c|r|r|r|}
\hline Critical Indices & Layer 1 & Layer 2 & Layer 3 \\
\hline $\mathrm{D}_{90}$ & 3.900 & 3.900 & 4.000 \\
\hline $\mathrm{D}_{60}$ & 2.100 & 2.200 & 2.400 \\
\hline $\mathrm{D}_{50}$ & 1.600 & 1.700 & 1.800 \\
\hline $\mathrm{D}_{30}$ & 0.660 & 0.700 & 0.880 \\
\hline $\mathrm{D}_{25}$ & 0.500 & 0.550 & 0.700 \\
\hline $\mathrm{D}_{15}$ & 0.230 & 0.260 & 0.350 \\
\hline $\mathrm{D}_{10}$ & 0.110 & 0.130 & 0.175 \\
\hline Uniformity Coefficient, $\mathbf{C}_{\mathbf{u}}$ & $\mathbf{1 9 . 0 9}$ & $\mathbf{1 6 . 9 2}$ & $\mathbf{1 3 . 7 1}$ \\
\hline Coefficient of Gradation, $\mathbf{C}_{\boldsymbol{c}}$ & $\mathbf{1 . 8 9}$ & $\mathbf{1 . 7 1}$ & $\mathbf{1 . 8 4}$ \\
\hline
\end{tabular}

Table 11.5 Uniformity coefficient statistics

\begin{tabular}{|c|r|}
\hline \multicolumn{2}{|c|}{ Uniformity Coefficient, $\mathbf{C}_{\mathbf{u}}$} \\
\hline Average Uniformity Coefficient & 16.576 \\
\hline Sample Standard Deviation (s) & 2.705 \\
\hline Coefficient of Variation (COV) & 0.163 \\
\hline
\end{tabular}


Table 11.6 Coefficient of gradation statistics

\begin{tabular}{|c|c|}
\hline \multicolumn{2}{|c|}{ Coefficient of Gradation, $\mathbf{C}_{\boldsymbol{c}}$} \\
\hline Average Coefficient of Gradation & 1.814 \\
\hline Sample Standard Deviation (s) & 0.090 \\
\hline Coefficient of Variation (COV) & 0.050 \\
\hline
\end{tabular}

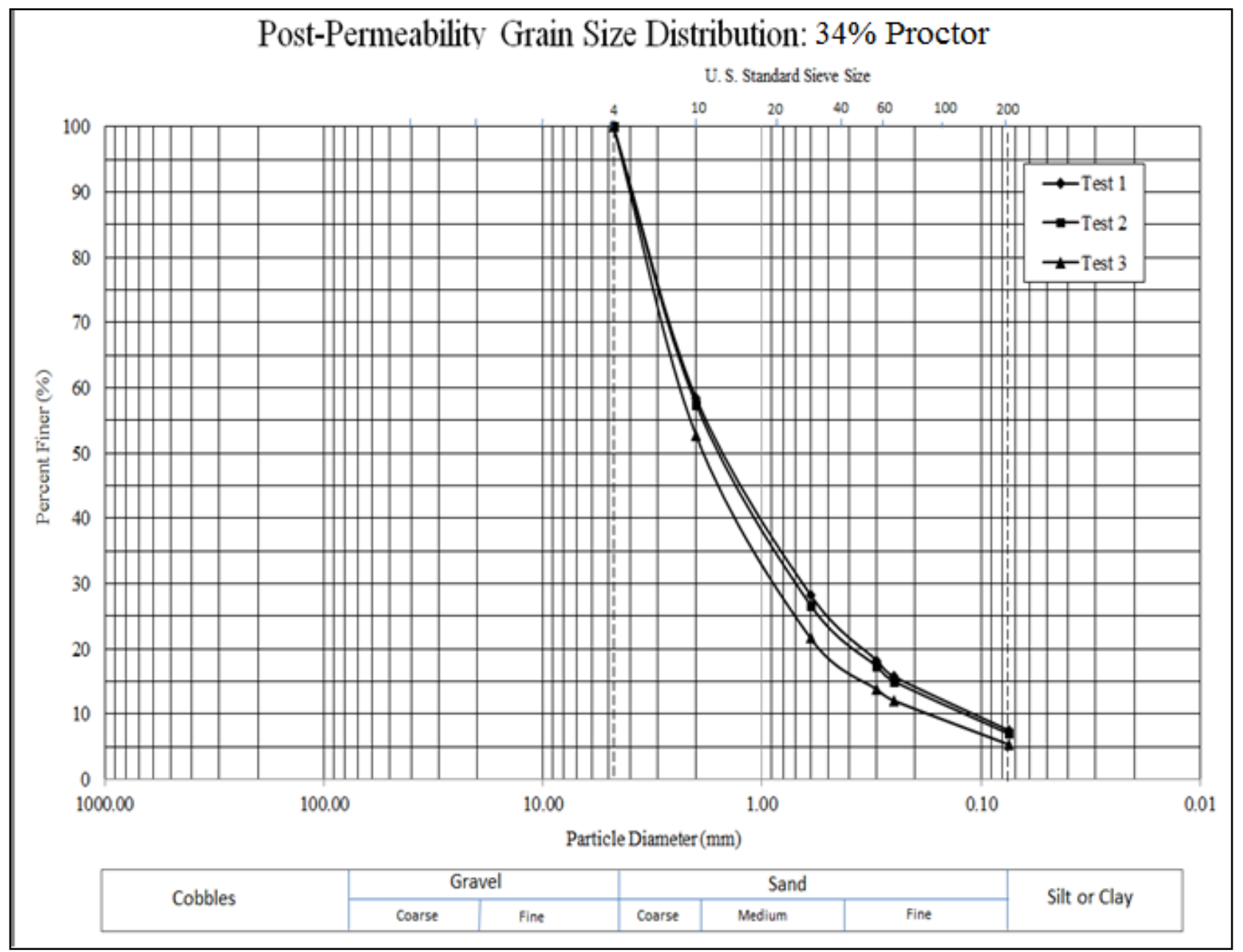

Figure 11.2 Grain size distribution of layer1, layer2, and layer3 of the hydraulic conductivity test specimen. 


\subsection{Post-Permeability Grain Size Distribution: $11 \%$ Proctor $\left(67.85 \mathrm{~kJ} / \mathrm{m}^{3}\right)$}

For $11 \%$ proctor hydraulic conductivity, a sieve analysis was performed for three permeated specimens with three layers each for additional precision in the testing. Test 1 , Test 2 , and Test 3 correspond to Tests 1, 2, and 3 in sections 10.3.1, 10.3.2, and 10.3.3, respectively. Compaction information, porosity (n), void ratio (e), and other properties of each specimen are given in each respective section as well as Appendix I. Three approximately equal layers were cut from the hydraulic conductivity specimen in Chapter 10 for the standard proctor post-permeability grain size distribution testing. The layers were tested separately to determine whether or not their gradations varied. The sought after variation is a result of particle movement during permeation. Only the sand portion (passing \#4 sieve to \#200 sieve) was permeated and tested. The results of this testing are shown in sections 11.3.1, 11.3.2, and 11.3.3.

\subsubsection{Post-Permeability Grain Size Distribution: 11\% Proctor - Test 1}

The results of this sieve analysis yielded a coefficient of variation of 0.096 for the uniformity coefficient and a coefficient of variation of 0.067 for the coefficient of gradation. This low coefficient of variation implies that the samples had very little variation in their gradations. The data for the sieve analysis is shown in Table 11.7, Table 11.8, Table 11.9, and Figure 11.3.

Table 11.7 Critical index values for the hydraulic conductivity grain size distribution testing

\begin{tabular}{|c|c|c|c|}
\hline \multicolumn{4}{|c|}{ Results } \\
\hline Critical Indices & Layer 1 & Layer 2 & Layer 3 \\
\hline $\mathrm{D}_{90}$ & 3.750 & 3.900 & 3.800 \\
\hline $\mathrm{D}_{60}$ & 1.750 & 2.000 & 1.900 \\
\hline $\mathrm{D}_{50}$ & 1.300 & 1.500 & 1.400 \\
\hline $\mathrm{D}_{30}$ & 0.590 & 0.630 & 0.650 \\
\hline $\mathrm{D}_{25}$ & 0.430 & 0.480 & 0.500 \\
\hline $\mathrm{D}_{15}$ & 0.180 & 0.210 & 0.240 \\
\hline $\mathrm{D}_{10}$ & 0.095 & 0.105 & 0.120 \\
\hline Uniformity Coefficient, $C_{u}$ & 18.42 & 19.05 & 15.83 \\
\hline Coefficient of Gradation, $\mathbf{C}_{\mathbf{c}}$ & 2.09 & 1.89 & 1.85 \\
\hline
\end{tabular}


Table 11.8 Uniformity coefficient statistics

\begin{tabular}{|l|r|}
\hline \multicolumn{2}{|c|}{ Uniformity Coefficient, $\mathbf{C}_{\mathbf{u}}$} \\
\hline Average Uniformity Coefficient & 17.767 \\
\hline Sample Standard Deviation (s) & 1.704 \\
\hline Coefficient of Variation (COV) & 0.096 \\
\hline
\end{tabular}

Table 11.9 Coefficient of gradation statistics

\begin{tabular}{|l|l|}
\hline \multicolumn{2}{|c|}{ Coefficient of Gradation, $\mathbf{C}_{\boldsymbol{c}}$} \\
\hline Average Coefficient of Gradation & 1.946 \\
\hline Sample Standard Deviation (s) & 0.130 \\
\hline Coefficient of Variation (COV) & 0.067 \\
\hline
\end{tabular}

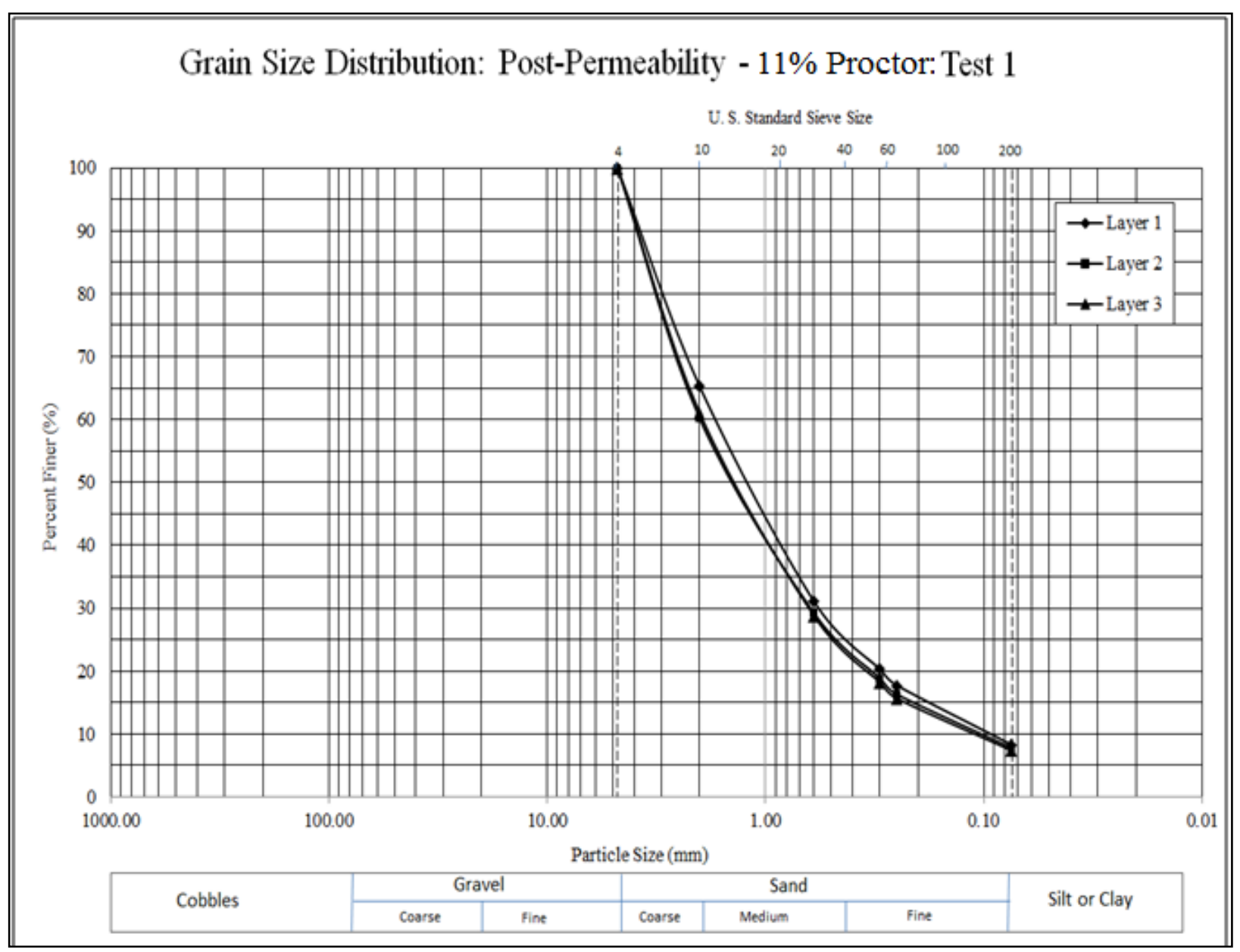

Figure 11.3 Grain size distribution of layer1, layer2, and layer3 of the hydraulic conductivity test specimen. 


\subsubsection{Post-Permeability Grain Size Distribution: 11\% Proctor - Test 2}

The results of this sieve analysis yielded a coefficient of variation of 0.065 for the uniformity coefficient and a coefficient of variation of 0.058 for the coefficient of gradation. This low coefficient of variation implies that the samples had very little variation in their gradations. The data for the sieve analysis is shown in Table 11.10, Table 11.11, Table 11.12, and Figure 11.4.

Table 11.10 Critical index values for the hydraulic conductivity grain size distribution testing.

\begin{tabular}{|c|r|r|r|}
\hline Critical Indices & \multicolumn{1}{|c|}{ Layer 1 } & Layer 2 & Layer 3 \\
\hline $\mathrm{D}_{90}$ & 3.800 & 3.800 & 3.900 \\
\hline $\mathrm{D}_{60}$ & 1.800 & 1.700 & 1.900 \\
\hline $\mathrm{D}_{50}$ & 1.400 & 1.400 & 1.450 \\
\hline $\mathrm{D}_{30}$ & 0.600 & 0.590 & 0.600 \\
\hline $\mathrm{D}_{25}$ & 0.470 & 0.450 & 0.480 \\
\hline $\mathrm{D}_{15}$ & 0.190 & 0.190 & 0.200 \\
\hline $\mathrm{D}_{10}$ & 0.094 & 0.100 & 0.100 \\
\hline Uniformity Coefficient, $\mathbf{C}_{\mathbf{u}}$ & $\mathbf{1 9 . 1 5}$ & $\mathbf{1 7 . 0 0}$ & $\mathbf{1 9 . 0 0}$ \\
\hline Coefficient of Gradation, $\mathbf{C}_{\mathbf{c}}$ & $\mathbf{2 . 1 3}$ & $\mathbf{2 . 0 5}$ & $\mathbf{1 . 8 9}$ \\
\hline
\end{tabular}

Table 11.11 Uniformity coefficient statistics

\begin{tabular}{|l|r|}
\hline \multicolumn{2}{|c|}{ Uniformity Coefficient, $\mathbf{C}_{\mathbf{u}}$} \\
\hline Average Uniformity Coefficient & 18.383 \\
\hline Sample Standard Deviation (s) & 1.200 \\
\hline Coefficient of Variation (COV) & 0.065 \\
\hline
\end{tabular}

Table 11.12 Coefficient of gradation statistics

\begin{tabular}{|l|l|}
\hline \multicolumn{2}{|c|}{ Coefficient of Gradation, $\mathbf{C}_{\mathbf{c}}$} \\
\hline Average Coefficient of Gradation & 2.023 \\
\hline Sample Standard Deviation (s) & 0.118 \\
\hline Coefficient of Variation (COV) & 0.058 \\
\hline
\end{tabular}




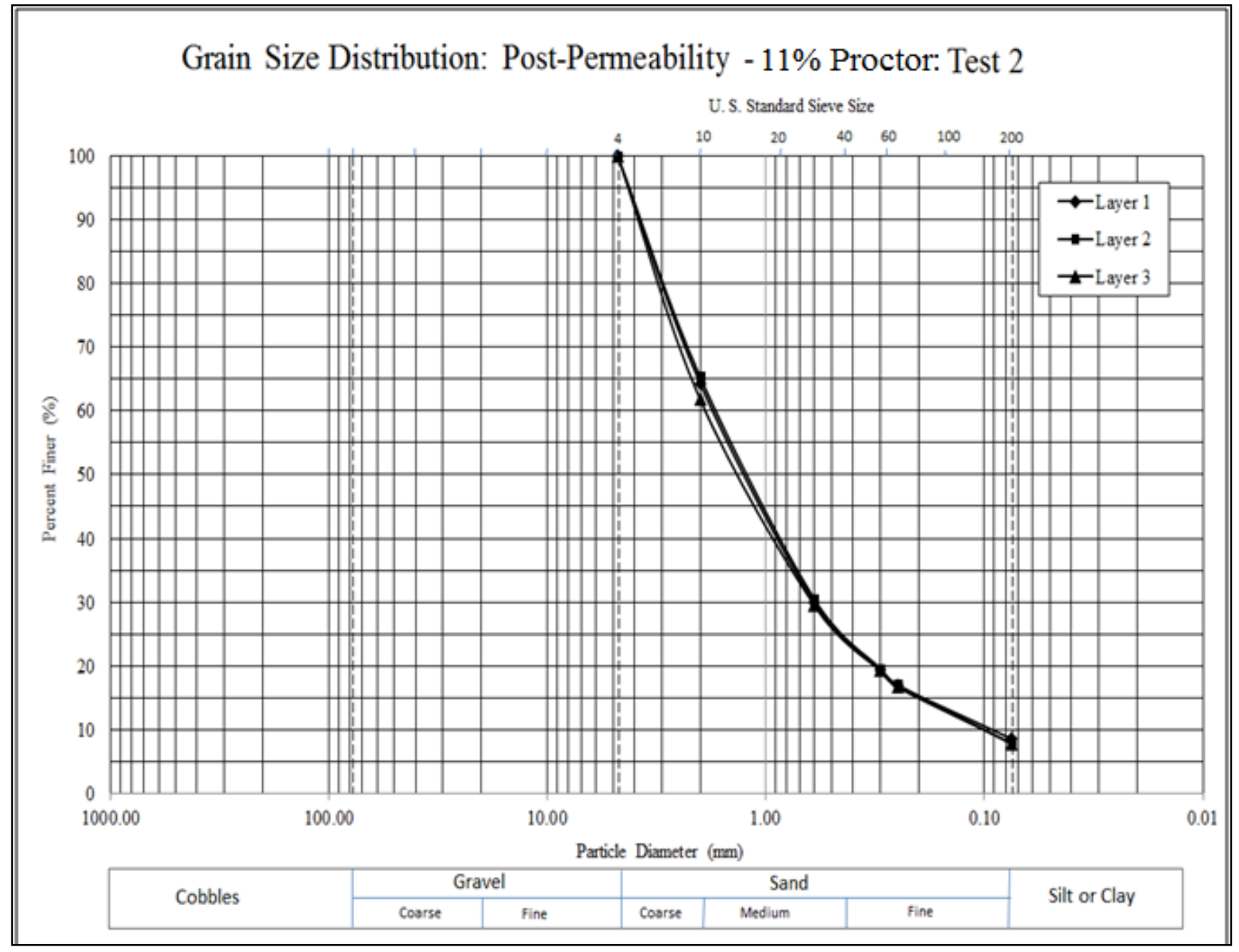

Figure 11.4 Grain size distribution of layer1, layer2, and layer3 of the hydraulic conductivity test specimen. 


\subsubsection{Post-Permeability Grain Size Distribution: 11\% Proctor - Test 3}

The results of this sieve analysis yielded a coefficient of variation of 0.121 for the uniformity coefficient and a coefficient of variation of 0.017 for the coefficient of gradation. This low coefficient of variation implies that the samples had very little variation in their gradations. The data for the sieve analysis is shown in Table 11.13, Table 11.14, Table 11.15, and Figure 11.5.

Table 11.13 Critical index values for the hydraulic conductivity grain size distribution testing.

\begin{tabular}{|c|r|r|r|}
\hline Critical Indices & Layer 1 & Layer 2 & Layer 3 \\
\hline $\mathrm{D}_{90}$ & 3.900 & 4.000 & 4.000 \\
\hline $\mathrm{D}_{60}$ & 1.900 & 2.200 & 2.400 \\
\hline $\mathrm{D}_{50}$ & 1.450 & 1.700 & 1.900 \\
\hline $\mathrm{D}_{30}$ & 0.650 & 0.680 & 0.800 \\
\hline $\mathrm{D}_{25}$ & 0.520 & 0.520 & 0.620 \\
\hline $\mathrm{D}_{15}$ & 0.240 & 0.220 & 0.280 \\
\hline $\mathrm{D}_{10}$ & 0.120 & 0.110 & 0.140 \\
\hline Uniformity Coefficient, $\mathbf{C}_{\mathbf{u}}$ & $\mathbf{1 5 . 8 3}$ & $\mathbf{2 0 . 0 0}$ & $\mathbf{1 7 . 1 4}$ \\
\hline Coefficient of Gradation, $\mathbf{C}_{\mathbf{c}}$ & $\mathbf{1 . 8 5}$ & $\mathbf{1 . 9 1}$ & $\mathbf{1 . 9 0}$ \\
\hline
\end{tabular}

Table 11.14 Uniformity coefficient statistics

\begin{tabular}{|l|r|}
\hline \multicolumn{2}{|c|}{ Uniformity Coefficient, $\mathbf{C}_{\mathbf{u}}$} \\
\hline Average Uniformity Coefficient & 17.659 \\
\hline Sample Standard Deviation (s) & 2.131 \\
\hline Coefficient of Variation (COV) & 0.121 \\
\hline
\end{tabular}

Table 11.15 Coefficient of gradation statistics

\begin{tabular}{|l|r|}
\hline \multicolumn{2}{|c|}{ Coefficient of Gradation, $\mathbf{C}_{\boldsymbol{c}}$} \\
\hline Average Coefficient of Gradation & 1.89 \\
\hline Sample Standard Deviation (s) & 0.032 \\
\hline Coefficient of Variation (COV) & 0.017 \\
\hline
\end{tabular}




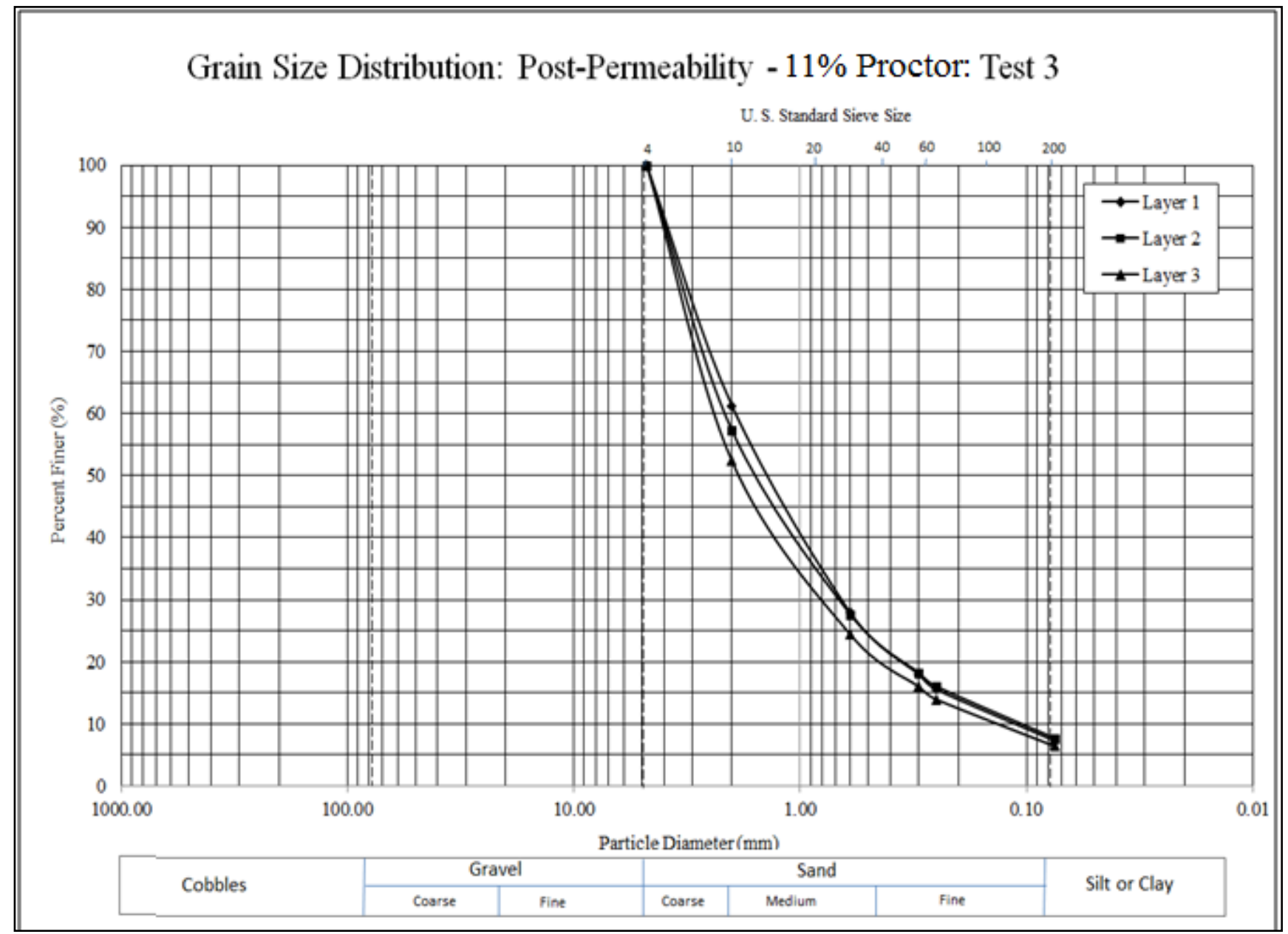

Figure 11.5 Grain size distribution of layer1, layer2, and layer3 of the hydraulic conductivity test specimen. 


\section{Grading Envelopes and Particle Transport}

\subsection{Introduction}

The term "grading envelope" refers to the range, or variation, of particle size with respect to the percent finer of the material being observed. Grading envelopes can be a result of a phenomenon called suffusion. Suffosion is defined as the transportation of soil particles over significant distances through constrictions within a soil matrix. If the constrictions are larger than the particle, then the particle has the potential to be transported, and sometimes exit the soil body it is encased within. It is understood that particle transport can clog a filter if a soil is regarded as unstable. Unstable soils are those which have significant particle movement, where the soil acting as a filter will become more porous due to a loss of fine particles. An increase in porosity and a potential increase in pore pressure at the toe of a slope due to an accumulation of fine particles, or clogging of the filter, can compromise the stability of a slope structure. This section compiles data accrued in the laboratory testing performed for this project. The purpose of the data is to illustrate the movement of soil particles under several imposed conditions, or lack thereof, to determine whether or not suffusion has the potential to be a significant concern in the stability modeling of the unweathered sandstone overburden under inspection. The data on the nine graphs below show the results of grain size distribution testing performed on layering of compacted specimens at three predetermined compaction energies. The energy levels are referred to as standard proctor at a compaction energy of $592.5 \mathrm{~kJ} / \mathrm{m}^{3}$, a $65.64 \%$ reduced from standard proctor effort or $34.36 \%$ of standard proctor or $203.6 \mathrm{~kJ} / \mathrm{m}^{3}$ ), and an even further reduced energy at $88.55 \%$ reduced equal to $67.85 \mathrm{~kJ} / \mathrm{m}^{3}$ or $11.45 \%$ of standard proctor energy. Three tests are shown per graph. The three tests are as received GSD, pre-permeability GSD, and post-permeability GSD. Layer 1, 2, and 3 are approximately one-third the length of the compacted specimen, and are top one-third, middle one-third, and bottom one-third, respectively.

\subsection{Standard Proctor GSD Results}

The figures below show graphs of superimposed grain size distributions. The grain size distributions illustrate the process of as received to a compaction to condition to a permeated condition. The item " $\Delta$ " in the figures means simply "the change in" for each maximum aggregation compared to the as received grain size distribution for the critical index shown. This value is expressed as a percent difference. Smaller values of " $\Delta$ " are lesser aggregation conditions, and larger values refer to larger changes in aggregation. The two graphs shown below illustrate some interesting phenomena. Let us consider the first illustration showing the grain size distribution of three layers of a compacted sample prepared as a standard proctor specimen alongside the original grain size distribution of the material. The material had $9.04 \%$ water content added to it. The material aggregated some, and was not particularly isotropic. The second illustration had $8.43 \%$ water content after distilled water was added to the sample, and it was compacted. The post-permeability grain size distribution became more aggregated after being permeated by 18.46 pore volumes. The material aggregation seems to be a function of the compaction energy and the water content. The compaction energy applied in the first illustration likely broke up the aggregation of the material, where the aggregation could reconvene in the hydraulic conductivity cell in the second illustration. The grain size distribution curves are illustrated in Figure 12.1. 


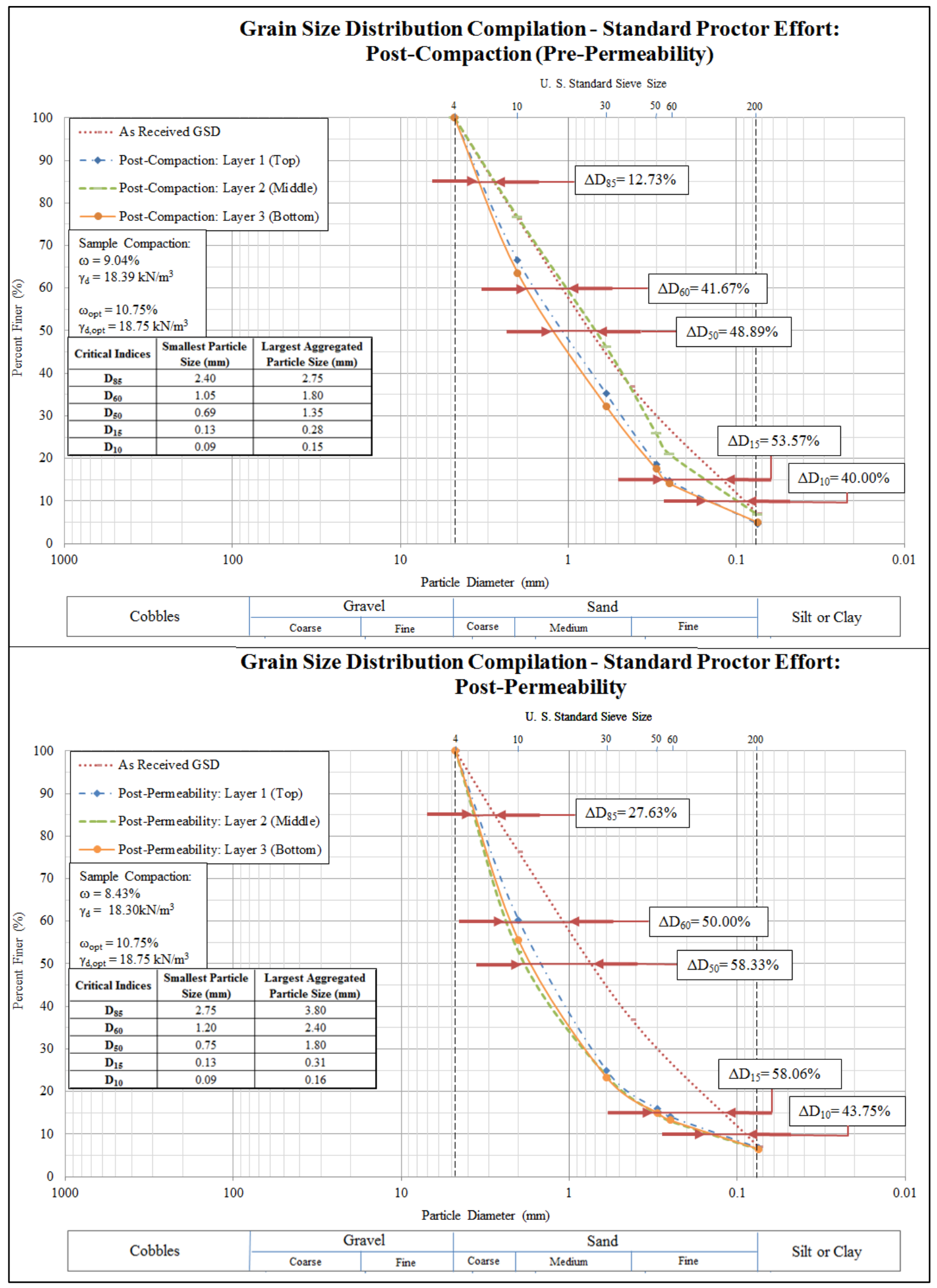

Figure 12.1. Standard Proctor grain size distribution compilation 


\subsection{Proctor Energy at $34 \%$ GSD Results}

The two illustrations below depict the variations in gradation for two samples of a well graded sand with silt material compared to the original gradation of the material. The first graph is at a pre-permeability or pre-permeability state, and the second is at a post-permeability state. Both samples had a target dry density at optimum of a set 34\% Proctor compaction effort of 203.6 $\mathrm{kJ} / \mathrm{m}^{3}$. The pre-permeability sample had a water content of $13.16 \%$. The post-permeability sample had a pre-permeated water content of $14 \%$. The permeated sample had 2.22 pore volumes run through it. The behavior of the material under these conditions seems to indicate that the compaction and added water increased the aggregation of the material. The permeation increased the aggregation more than the compaction alone. Similar behavior occurred in the standard proctor samples. The grain size distribution curves are illustrated in Figure 12.2. 


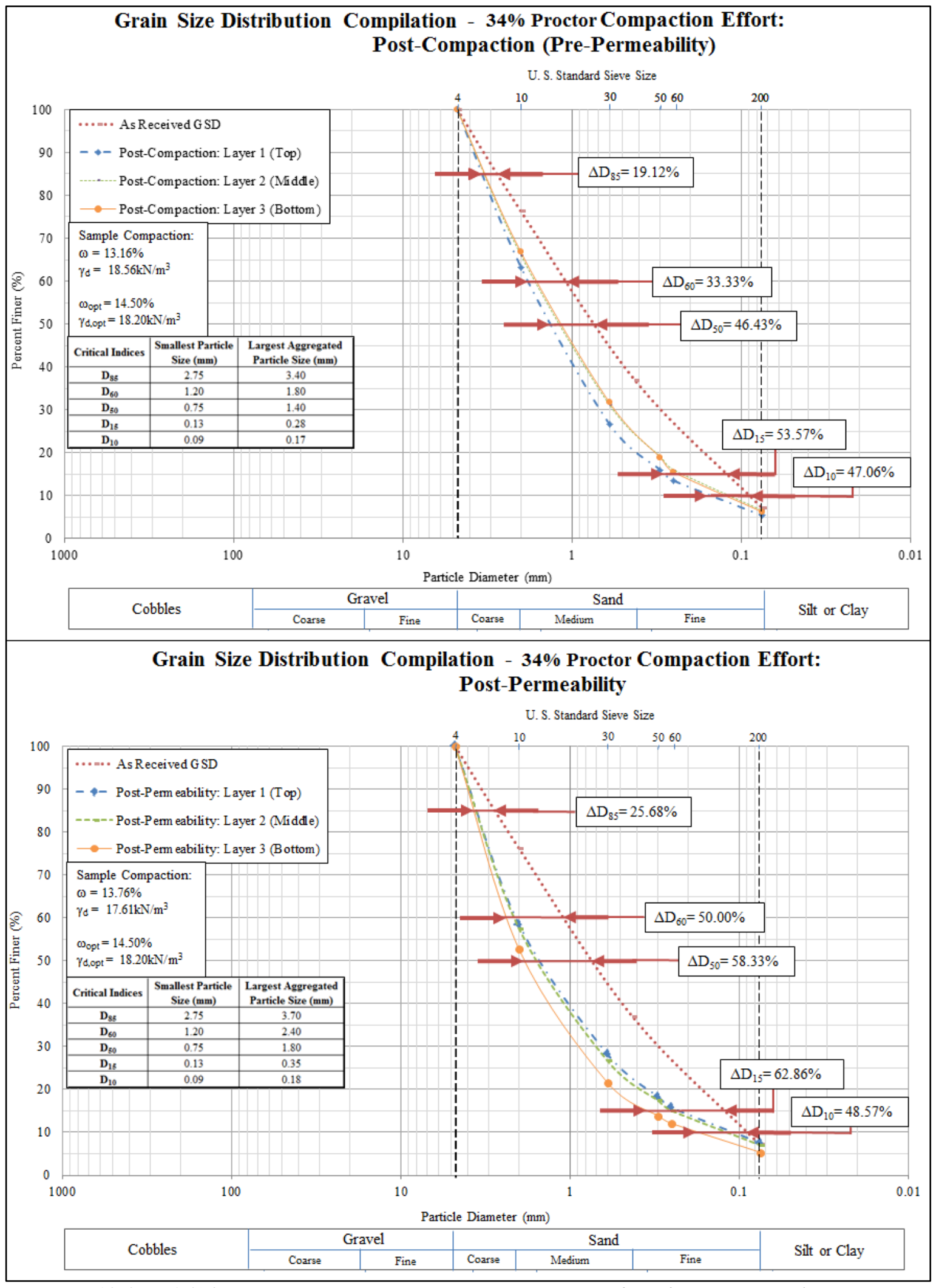

Figure 12.2. 34\% Proctor compaction energy grain size distribution compilation 


\subsection{Proctor Energy at $11 \%$ GSD Results}

The two illustrations below depict the variations in gradation for two samples of a well graded sand with silt material compared to the original gradation of the material. The first graph is at a pre-permeability or pre-permeability state, and the second is at a post-permeability state. Both samples had a target dry density at minimum of a set $11 \%$ Proctor compaction effort of $67.85 \mathrm{~kJ} / \mathrm{m}^{3}$. The pre-permeability sample had a water content of $10.02 \%$. The post-permeability sample had a pre-permeated water content of $8.26 \%$. The permeated sample had 9.04 pore volumes run through it. The behavior of the material under these conditions seems to indicate that the compaction and added water increased the aggregation of the material. The permeation decreased the aggregation from the compacted state aggregation. The grain size distribution curves are illustrated in Figure 12.3 


\section{Grain Size Distribution Compilation - 11\% Proctor Compaction Effort: Post-Compaction (Pre-Permeability)}

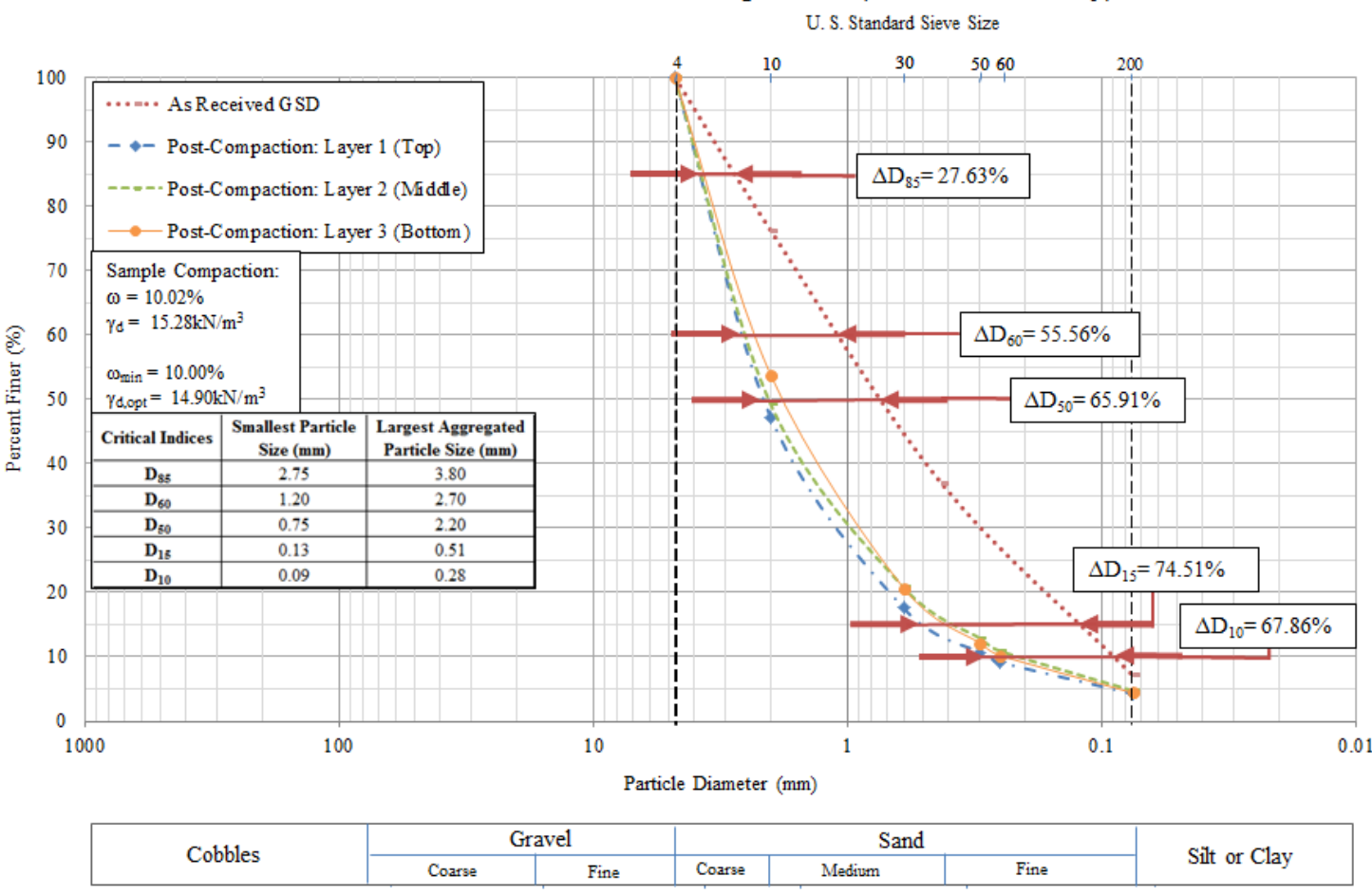

\section{Grain Size Distribution Compilation - 11\% Proctor Compaction}

Effort: Post-Permeability

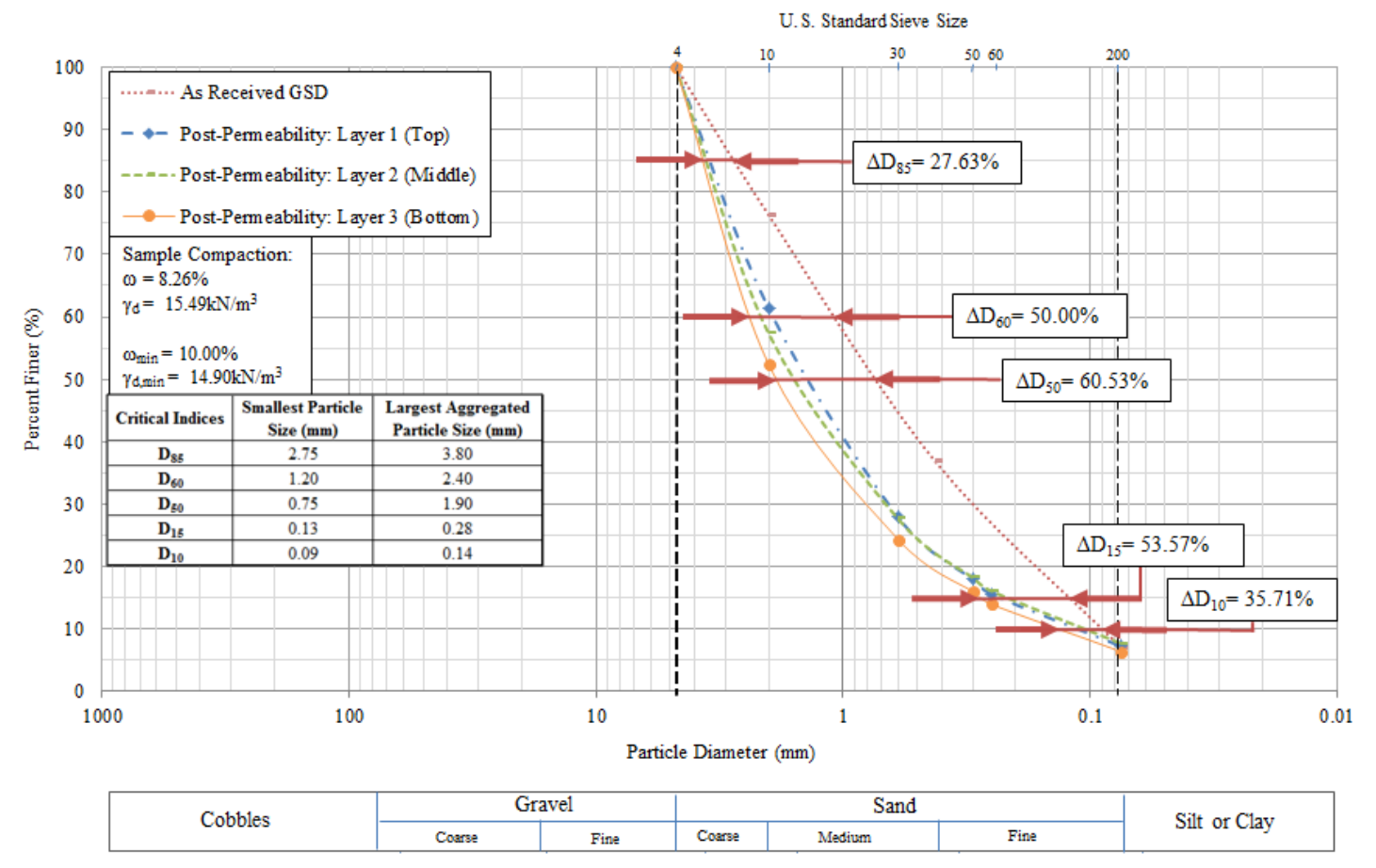

Figure 12.3. 11\% Proctor compaction energy grain size distribution compilation 


\subsection{Discussion}

Comparatively, taking into consideration all three compaction energies and the results shown above of the test scenarios performed it was found that particle movement varied significantly. The variation in gradation was a function of the moisture content added and the energy applied for preparation. The post-permeability results should be interpreted carefully as each specimen of different density varied in pore volume flux. The standard proctor specimens aggregated the most between $\mathrm{D}_{50}$ and $\mathrm{D}_{15}$ due to compaction, then aggregated more at a post-permeability condition. The 34\% Proctor compaction specimens showed similar results as standard proctor, aggregating more at a post-permeability condition. The $11 \%$ Proctor compaction specimen results were opposite 34\% Proctor compaction results and standard proctor compaction results. The $11 \%$ Proctor compaction specimen aggregated most at a pre-permeability condition, then became less aggregated at a post-permeability condition. The results indicate that the material reaches an aggregated equilibrium with very similar gradation after some pore volumes of water permeate through it. The results also imply that introducing a range of compaction energy can alter soil properties and have performance implications on earthen structures. Layered construction known as "lift construction" could assist in better quality control of the compaction energy applies to earthen structures to more precisely manage the aggregation phenomena. The amount of compaction energy for the $34 \%$ Proctor compaction and standard proctor samples seems to have broken up the aggregated particles, then when they were permeated, became more aggregated. After the permeation occurred, all three compaction energies approached a similar gradation, but diverged somewhat as the particle size decreased. The specimens began diverging in similarity around $40 \%$ finer. At $\mathrm{D}_{10}$ at a post-permeability condition, the $11 \%$ Proctor compaction energy compacted and permeated sample had the smallest particles, standard proctor had the next highest, and 34\% Proctor energy specimens had the largest particle size. Overall the $11 \%$ proctor pre-permeability condition had the most aggregated particles, likely due to little compaction energy applied to break apart aggregated particles. At $\mathrm{D}_{10}$ at a pre-permeability condition, the standard proctor sample had the smallest particles, then $34 \%$ proctor, and $11 \%$ Proctor energy samples had the largest aggregated particles. The item " $\Delta$ " in the figures means simply "the change in" for each maximum aggregation compared to the as received grain size distribution for the critical index shown. This value is expressed as a percent difference. Smaller values of " $\Delta$ " are lesser aggregation conditions, and larger values refer to larger changes in aggregation. Table 12.1 shows a summary of the delta values for Figure 12.1, Figure 12.2, and Figure 12.3. 
Table 12.1 Change in critical index summary table

\begin{tabular}{|c|c|c|c|c|c|}
\hline $\begin{array}{c}\text { Change in } \\
\text { Critical Indices } \\
{[\%]}\end{array}$ & $\begin{array}{c}\Delta \mathbf{D}_{85} \\
(\%)\end{array}$ & $\begin{array}{c}\Delta D_{60} \\
(\%)\end{array}$ & $\begin{array}{c}\Delta D_{50} \\
(\%)\end{array}$ & $\begin{array}{c}\Delta D_{15} \\
(\%)\end{array}$ & $\begin{array}{c}\Delta \mathbf{D}_{10} \\
(\%)\end{array}$ \\
\hline $\begin{array}{l}\text { Standard Proctor } \\
\text { Pre-Permeability }\end{array}$ & 12.73 & 41.67 & 48.89 & 53.57 & 40.00 \\
\hline $\begin{array}{c}\text { Standard Proctor } \\
\text { Post- } \\
\text { Permeability } \\
\end{array}$ & 27.63 & 50.00 & 58.33 & 58.06 & 43.75 \\
\hline $\begin{array}{c}34 \% \text { Proctor } \\
\text { Pre-Permeability }\end{array}$ & 19.12 & 33.33 & 46.43 & 53.57 & 47.06 \\
\hline $\begin{array}{c}34 \% \text { Proctor } \\
\text { Post- } \\
\text { Permeability }\end{array}$ & 25.68 & 50.00 & 58.33 & 62.86 & 48.57 \\
\hline $\begin{array}{c}11 \% \text { Proctor } \\
\text { Pre-Permeability }\end{array}$ & 27.63 & 55.56 & 65.91 & 74.51 & 67.86 \\
\hline $\begin{array}{l}11 \% \text { Proctor } \\
\text { Post- } \\
\text { Permeability }\end{array}$ & 27.63 & 50.00 & 60.53 & 53.57 & 35.71 \\
\hline
\end{tabular}




\section{Numerical Modeling}

\subsection{Introduction}

In order to establish adequate results for slope stability modeling, it is important to consider utilizing computer software. Computer software can be used to perform multiple analysis operations and can permit parametric studies of soil property sensitivity. For this project, the modeling software used for the earthwork designs were GeoStudio ${ }^{\mathrm{TM}}$ and GeoFluv ${ }^{\circledR}$. GeoStudio $^{\text {TM }}$ is an analysis tool for several earthwork functions. SLOPE/W, SIGMA/W and SEEP/W are the three modules of GeosStudio ${ }^{\mathrm{TM}}$ that were used for the modeling. The models that utilized SIGMA/W, SEEP/W, and SLOPE/W will be referred to as "cumulative analyses." SLOPE/W was the only module utilized on some models as a basic approach for comparison. This discussion will focus on targeted slope stability analysis of the earthwork designs that were produced by the GeoFluv® software as well as an AOC valley fill design.

\section{GeoStudio $^{\text {TM }}$}

GeoStudio is a finite element method analysis software that has the capacity to analyze slopes, earthen dams, and other earthwork structures. The results can be determined via probabilistic, sensitivity, seismic, or deterministic procedures for data input parameters. GeoStudio ${ }^{\mathrm{TM}}$ has several modules, all of which allow the user to view results via graphical representation which can be interpreted to look beyond the factor of safety. In SLOPE/W, the critical slice can be viewed to allow the user to determine methods of solution to the risk, or decide whether or not the risk is significant. Failure entry and exit points can be defined, as well as piezometric surfaces. There are many options available to the user, all of which can be explored to create more realistic scenarios for earth structure evaluation.

\section{General Limit Equilibrium Theory and Method}

The General Limit Equilibrium method commonly referred to as the "GLE method" uses statics equations to solve for a factor of safety. The GLE method of slope stability analysis was used for the modeling performed in this research. The following concepts for the equations were used as defined by GeoStudio SLOPE/W Engineering Methodology Book:

- The summation of forces in a vertical direction for each slice is used to compute the normal force at the base of the slice, $\mathrm{N}$.

- The summation of forces in a horizontal direction for each slice is used to compute the interslice normal force, $\mathrm{E}$. This equation is applied in an integration manner across the sliding mass (i.e., from left to right).

- The summation of moments about a common point for all slices. The equation can be rearranged and solved for the moment equilibrium factor of safety, $F_{m}$ (eqn. 1).

- The summation of forces in a horizontal direction for all slices, giving rise to a force equilibrium factor of safety, $\mathrm{F}_{\mathrm{f}}$ (eqn. 2).

$$
\begin{aligned}
& F_{m}=\frac{\sum\left(c^{\prime} \beta R+(N-u \beta) R \tan \left(\varphi^{\prime}\right)\right)}{\sum W x-\sum N f \pm \sum D d} \\
& F_{f}=\frac{\sum\left(c^{\prime} \beta \cos \alpha+(N-u \beta) \tan \varphi^{\prime} \cos \alpha\right)}{\sum N \sin \alpha-\sum D \cos \omega}
\end{aligned}
$$


where:

$c^{\prime}=$ effective cohesion

$\varphi^{\prime}=$ effective angle of friction

$\mathrm{u}=$ pore-water pressure

$\mathrm{N}=$ slice base normal force

$\mathrm{W}=$ slice weight

$\mathrm{D}=$ concentrated point load

$\beta, \mathrm{R}, \mathrm{x}, \mathrm{f}, \mathrm{d}, \omega=$ geometric parameters

$\alpha=$ inclination of slice base

In equation form, the base normal is defined as:

$$
N=\frac{W+\left(X_{R}-X_{L}\right)-\frac{\left(c^{\prime} \beta \sin \alpha+u \beta \sin \alpha \tan \varphi^{\prime}\right)}{F}}{\cos \alpha+\frac{\sin \alpha \tan \varphi^{\prime}}{F}}
$$

One of the most beneficial aspects of the GLE method is the option to vary a variety of interslice force conditions. The equations used for the GLE method gives the user the opportunity to use several methods of analysis. The limit equilibrium method of slices is based on the principles of statics. As a result, there are limitations to the general limit equilibrium method.. The missing physics of the limit equilibrium formulation is that there is a lack of a stress-strain constitutive relationship to ensure displacement compatibility.

SIGMA/W was used along with SEEP/W to yield more precise pore pressure and head conditions, with the intent of reducing the implications of the method's limitations, and producing accurate insitu stresses within the structures analyzed.

For the cumulative analysis, finite element models were produced with a global element size of $10 \mathrm{~m}$. The factor of safety or "stability factor" (S.F.) produced by a finite element stress method is defined as a ratio of the summation of the resisting shear force $S_{\mathrm{r}}$ along a failure plane to the summation of the mobilized shear force $S_{m}$ along a failure plane in the equation form:

$$
\begin{aligned}
& S . F .=\frac{\sum S_{r}}{\sum S_{m}} \\
& S_{r}=s \beta=\left(c^{\prime}+\left(\sigma_{n}-u_{a}\right) \tan \varphi^{\prime}+\left(u_{a}-u_{w}\right) \tan \varphi^{b}\right) \beta \\
& S_{m}=\tau_{m} \beta
\end{aligned}
$$

where:

$\mathrm{S}=$ effective shear strength of the soil at the base center of a slice

$\beta=$ base length of a slice

$\sigma_{\mathrm{n}}=$ normal stress at the base center of a slice

$\tau_{\mathrm{m}}=$ mobilized shear stress 
$\mathrm{u}_{\mathrm{a}}=$ pore-air pressure

$\mathrm{u}_{\mathrm{w}}=$ pore-water pressure

and,

$$
\text { Local S.F. }=\frac{S_{r}}{S_{m}}=\frac{s \beta}{\tau \beta}
$$

\section{Material Strength}

Geotechnical materials can be decribed in a legion of ways. One of the most common techniques to describe the strength of a geotechnical material is the Mohr-Coulomb model. The equation for this method is the following:

$$
\begin{aligned}
& \tau=c+\sigma_{n} \tan \varphi \\
& \sigma_{n}=\frac{N}{\beta}
\end{aligned}
$$

where:

$\tau=$ shear strength (i.e., shear at failure)

$\mathrm{c}=$ cohesion

$\sigma_{\mathrm{n}}=$ normal stress on shear plane

$\varphi=$ angle of internal friction (phi)

$\beta=$ the base length of each slice

$\mathrm{N}=$ the total normal force on the base of the slice

For all modeling, the input values were determined via geotechnical laboratory testing. Cohesion was taken to be zero as the gradation of the fill material under consideration was found to be sand with small volumes of fines. Details involving the internal friction angles produced for the range of stresses imposed and compaction energies performed for the specimen preparation can be found in Chapter 8 .

\section{Approach}

The approach taken for the modeling was analyze slopes in order to understand and assess the risk involved in the construction of a valley fill slope as well as several of the more critical cases generated GeoFluv ${ }^{\circledR}$ slopes. First, the models were calibrated to verify the stability analysis in the AOC design for the valley fill. The AOC valley fill design was then analyzed using deterministic and sensitivity methods. The methods were applied to four failure modes: face, toe, deep, and crest.

The entry and exit points of each case were input as a range of the surface area for a more realistic assessment. For each of the four failure modes, two piezometric conditions were addressed. The first piezometric condition considered that the slope drained to the durable rock underdrain. The second piezometric condition considered an elevated water table at a $50 \mathrm{ft}$ vertical displacement from the upper elevation along the underdrain. The second case considers that the rate of infiltration is greater than the rate of seepage. This condition could take place for 
several reasons, but we will consider that the rock underdrain could be clogged by small diameter particles.

A cumulative analysis was performed on the GeoFluv® valley fill alternative slope and the valley fill slope. The analysis included infiltration results over a 10 year period modeled in SEEP/W, insitu stress calculations performed in SIGMA/W, and deterministic and sensitivity slope stability analysis performed in SLOPE/W. The hydrologic infiltration information was modeled by considering practical hydraulic conductivity values for waste rock tailings. Piezometric lines locations were determined by utilizing the inspection of two conditions; condition 1 (or piez. 1) included a piezometric line at the top of the durable rock underdrain. Condition 2 (or piez. 2) included a piezometric line raised 50ft or $15.24 \mathrm{~m}$ above the underdrain to encapsulate a range of elevation for the water table and produce more accurate results. No piezometric line was needed for the cumulative analysis. SEEP/W produced areas of increased pore pressures and hydraulic head, and the analysis used those results in lieu of a piezometric line. All models used the results produced at the end of a 10 year infiltration period.

\section{Geometric Input}

The valley fill under inspection is the mass body by which the GeoFluv ${ }^{\circledR}$ designs were built upon. The geometry of the slope was taken from the AOC contour information as well as the profile elevations and distances shown in Figures 13.1 and 13.2. The fill is referred to as "Fill \#2." The figure below shows the profile that was emulated for the SLOPE/W designs. 


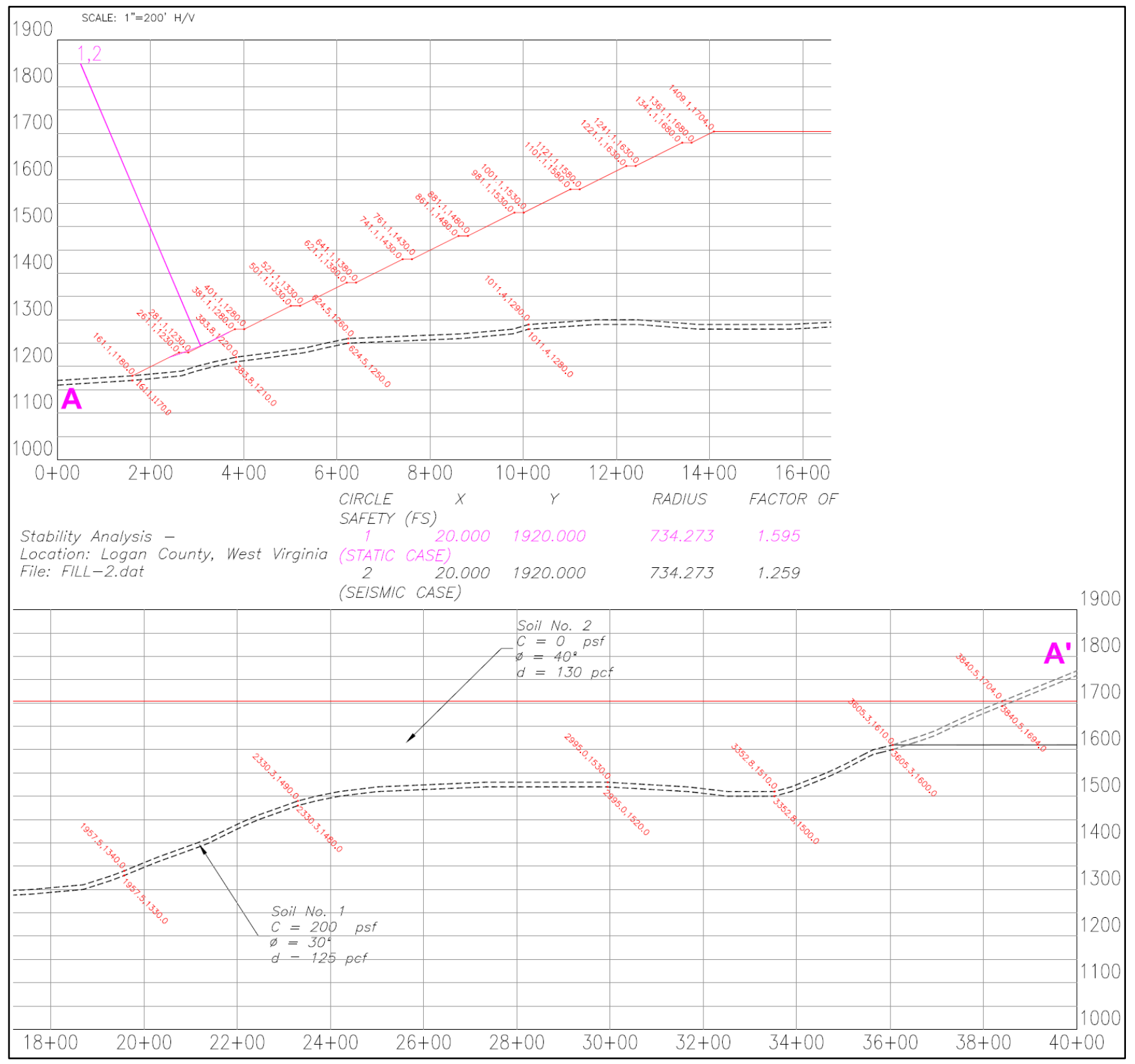

Figure 13.1. Slope profile used for valley fill modeling

Figure 13.2 shows the plan view with contour information for the proposed AOC valley fill design illustrated in Figure 13.1 (WVDEP, 2007). 


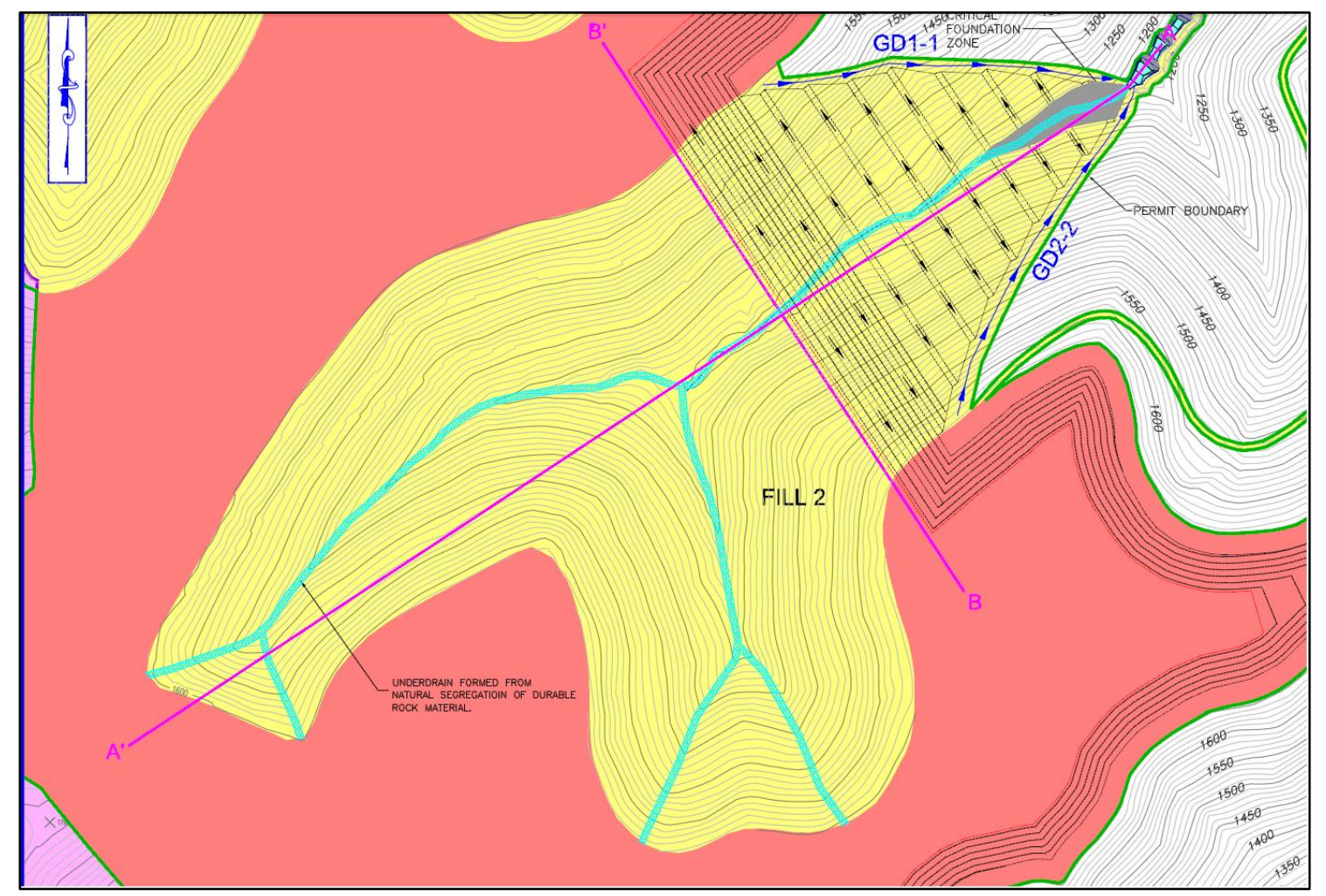

Figure 13.2. Valley fill plan view

The dimensions shown in Figure 13.1 and Figure 13.2 are in U.S. customary units. These files were taken from WVDEP permit File\#S500809. The models that were created used metric dimensions and metric laboratory soil property values for consistency within the scope of this research. Two types of soil are presented in Figure 13.1. The blasted overburden fill referred to as unweathered sandstone (Soil No. 2) is used in the design for the slope construction, with a $10 \mathrm{ft}$ thick durable rock underdrain constructed by gravity segregation of the end dumped unweathered sandstone material. The factors of safety shown in Figure 13.1 were developed using Bishop's Simplified Method, without taking into account any piezometric surface within the fill. This is a result of the assumption that the slope is entirely free draining. The assessment in Figure 13.1 identifies the friction angle $(\varphi)$ as $40^{\circ}$, the unit weight $\left(\gamma_{\mathrm{d}}\right)$ as $130 \mathrm{psf}$, and the cohesion (c) as $0 \mathrm{psf}$.

This blasted material is considered as unweathered sandstone and is modeled to act as sand within the fill with an associated cohesive input value of 0 psf. Soil No. 1 refers to a cohesive, weathered undisturbed material. This material contours the original valley bottom and creates a more impermeable layer to line the lower elevation of the underdrain. A labeled illustration of the GeoStudio ${ }^{\mathrm{TM}}$ modeled slope is shown in Figure 13.3. 


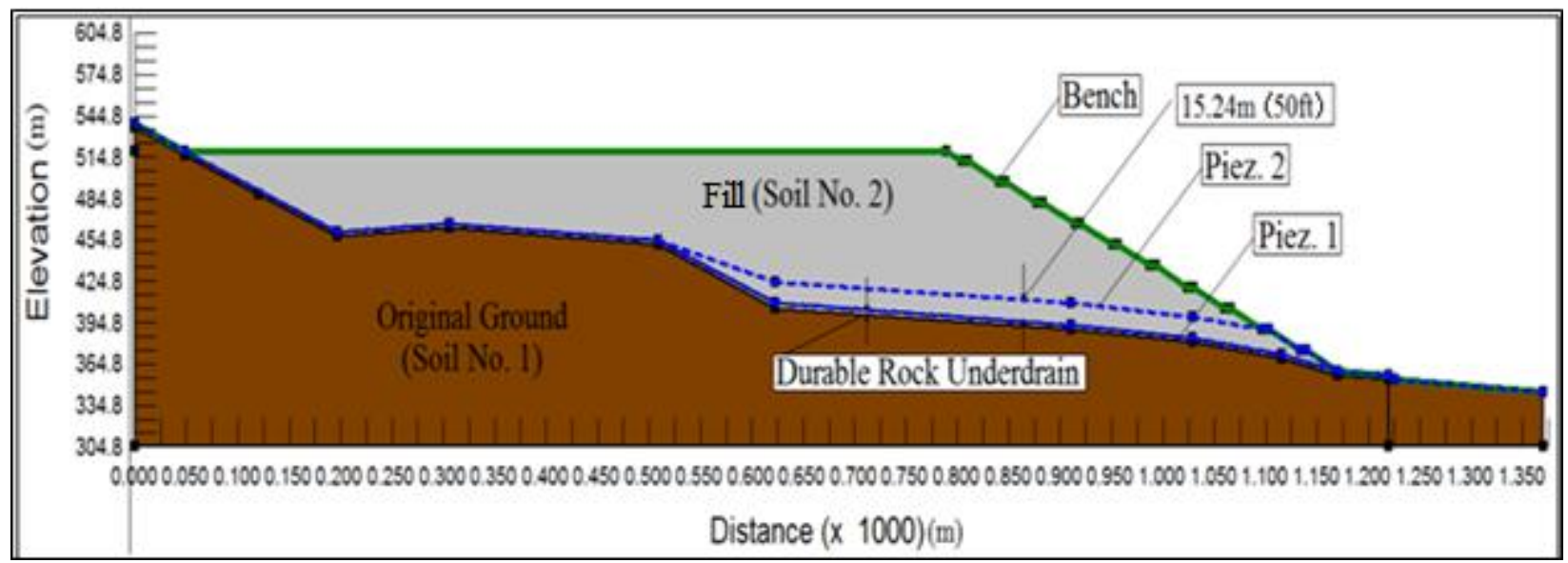

Figure 13.3. Actual modeled slope profile

\section{SEEP/W Analysis: Valley Fill}

Seepage was first modeled through a valley fill using "Approximate Original Contour" (AOC) design. The geometry of this fill was modeled under two cases. Case 1 used a drain that was modeled under a "saturated only" condition, and case 2 used a drain that was modeling under a "saturated/unsaturated" condition.

\section{Geometry}

The geometry for the profile view of the valley fill was taken from the fill cross-section details in the AOC valley fill design slope stability analysis. The information provided in Figure 13.1 was used for the coordinates of the AOC fill. Coordinates were given in U.S. customary units. These were converted to metric because distance in the model was measured in meters. The fill was modeled from an elevation of $304.8 \mathrm{~m}$ to $519.4 \mathrm{~m}$ with a length of $1370 \mathrm{~m}$. The face of the fill was modeled at an elevation of $359.7 \mathrm{~m}$ to $519.4 \mathrm{~m}$ and from a horizontal location of $789.7 \mathrm{~m}$ to $1170.1 \mathrm{~m}$. The curved line throughout the fill was a 10 foot core drain. The discharge pond of the fill was set at an elevation of $359.7 \mathrm{~m}$. An approximate global mesh size of $10 \mathrm{~m}$ was used to create 386 nodes and 352 elements. Because SEEP/W creates models in two dimensions, one profile slice was extracted from the entire fill to be modeled. SEEP/W then uses a profile thickness of $1 \mathrm{~m}$ to model the fill. The profile modeled followed the centerline of the fill as to include the core drain. A plan view of the fill is shown in Figure 13.2 with section A-A denoted as the profile that was used for the modeling.

\section{Materials}

The valley fill model consisted of three materials. These materials can be seen in Figure 13.4.

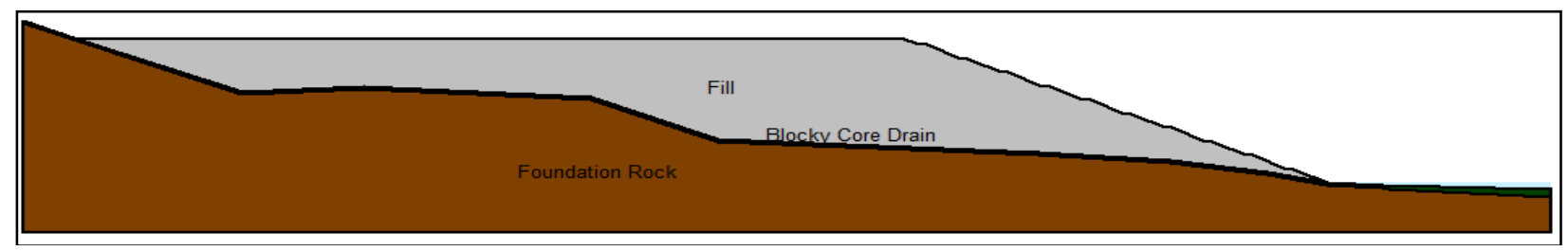

Figure 13.4. AOC fill materials 
The first material, named "Fill", was the top layer of the valley fill comprised of waste rock tailings from mining. It was modeled under a saturated/unsaturated condition, which required a function for hydraulic conductivity and an additional function for the material's water content. Hydraulic conductivity $(\mathrm{m} / \mathrm{s})$ was plotted versus pore water pressure $(\mathrm{kPa})$ by inputting a saturated hydraulic conductivity and using the Van Genuchten estimation method within $\mathrm{Seep} / \mathrm{W}$. A maximum suction was set at $0.01 \mathrm{kPa}$ and a minimum set at $1000 \mathrm{kPa}$ with 20 data points to produce a function. Hydraulic conductivity was chosen from a range values found from previous work done with waste rock tailings. These ranged from an unsaturated hydraulic conductivity of $1 \times 10^{\wedge}-5 \mathrm{~m} / \mathrm{s}$ (Abdelghani 2009) to a saturated hydraulic conductivity of $1 \times 10^{\wedge}-7$ $\mathrm{m} / \mathrm{s}$ (Aubertin et al 1996). These previously published values were chosen instead of the values determined from laboratory testing because they represented more realistic values. Laboratory testing calculates hydraulic conductivity based on optimum water content and compaction values, which are difficult to obtain in the field. Previously published values for hydraulic conductivity of waste rock tailings provided a more practical value to be used in numerical modeling. The function is shown in Figure 13.5.

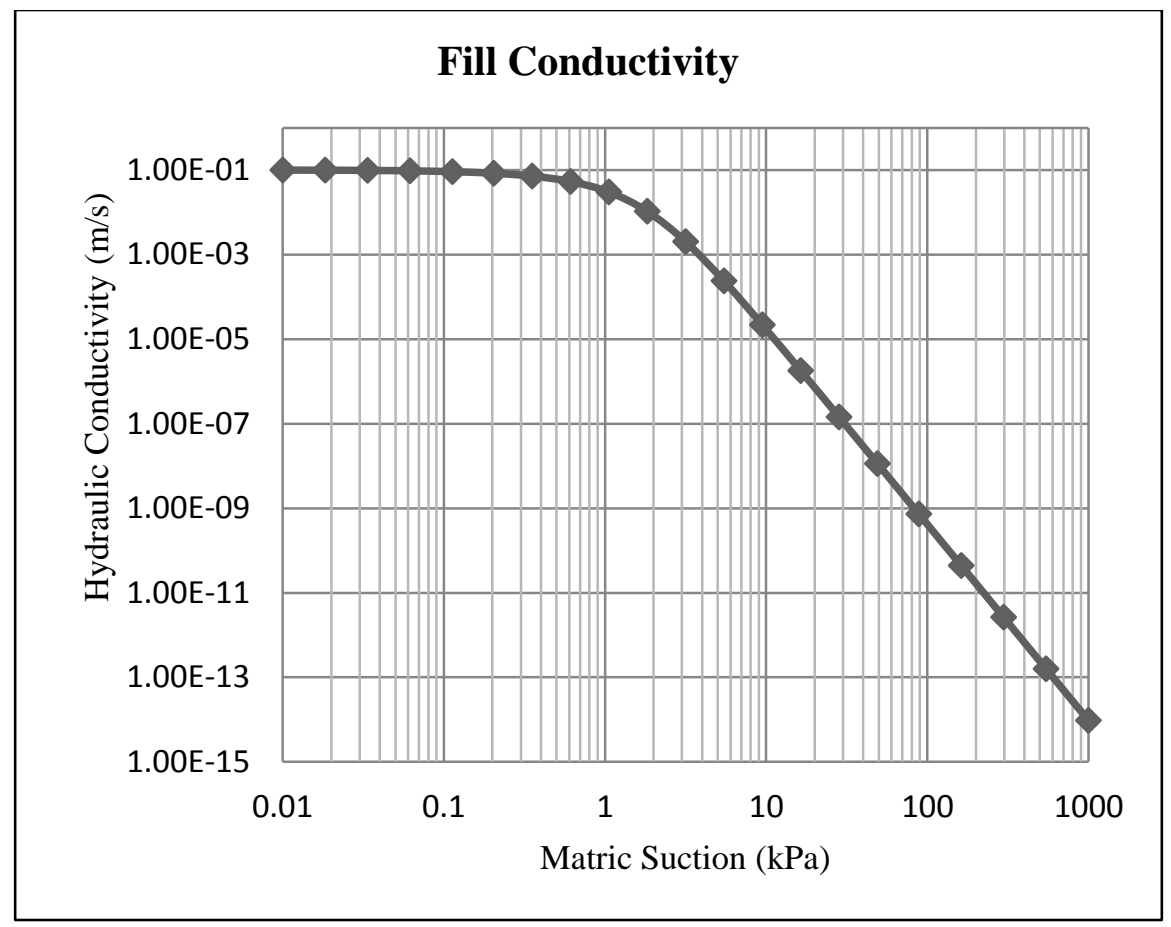

Figure 13.5. Fill conductivity function - AOC fill

This function was also compared to the function produced by Fredlund et. Al (1998) and found to be quite similar. The water content function was produced in a similar method. A saturated volumetric water content was input and the same parameters as the conductivity function were used to create a function. Gravel was chosen as the material type for this function. Saturated volumetric water content was taken to be $44 \%$, the value used by Fredlund et al (1998). This function is shown in Figure 13.6. 


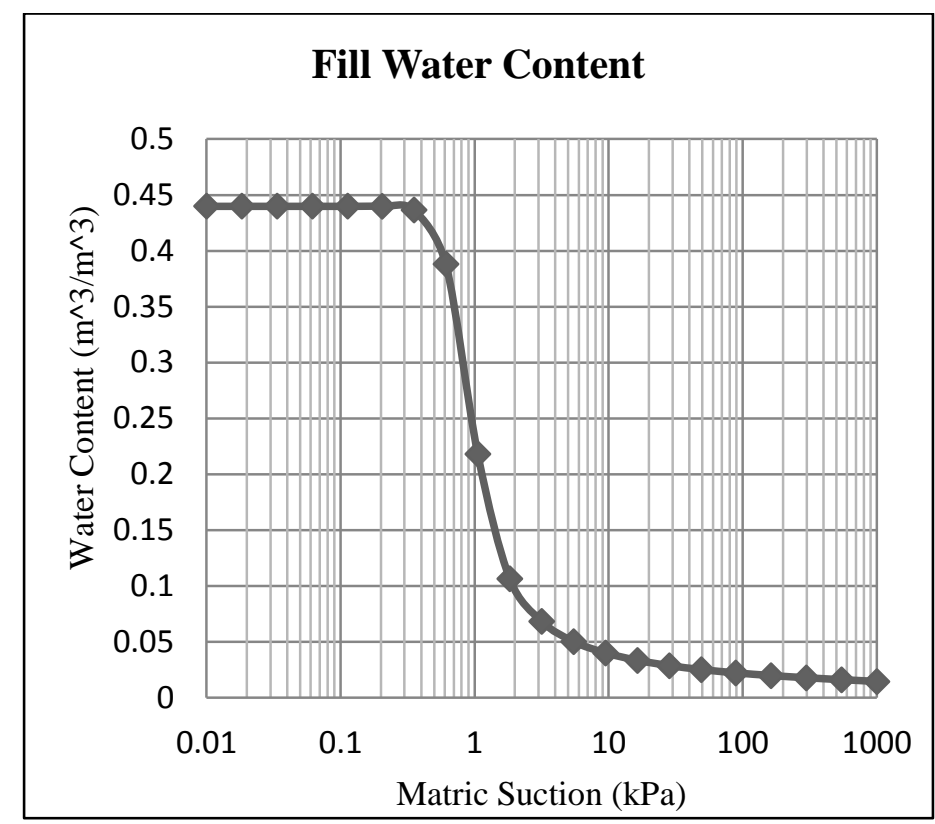

Figure 13.6. Fill water content function - AOC fill

The bottom layer of the valley fill, the "Foundation Rock" layer, was modeled in a saturated only condition with a very low hydraulic conductivity $\left(2 \times 10^{\wedge} 12 \mathrm{~m} / \mathrm{s}\right)$ to simulate an impermeable rock layer. Between the "Fill" layer and "Foundation Rock" layer, a 10-ft "Blocky Core Drain" material was placed. This layer was modeled under a saturated only condition with a constant hydraulic conductivity value of $0.1 \mathrm{~m} / \mathrm{s}$. This hydraulic conductivity was taken from the Das (2010) average value for gravel.

\section{Boundary Conditions}

Once materials were defined, boundary conditions were determined to fully define the model. A figure of the boundary conditions and their applied locations is shown in Figure 13.7.

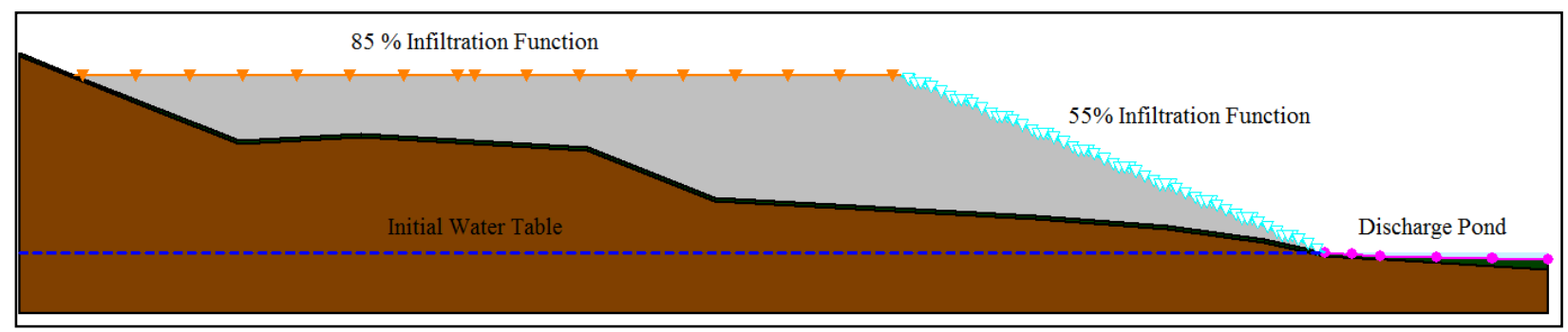

Figure 13.7. AOC fill boundary conditions

A step data point function for infiltration (unit flux vs. time) used the data points from the developed 10 year NOAA spreadsheet. The function developed from the $85 \%$ infiltration designation was applied to the top of the fill, and the function developed from the $55 \%$ infiltration designation was applied to the downstream sloped face of the fill. The $55 \%$ infiltration function boundary condition placed on the fill's downstream face was also analyzed as a potential seepage face. A constant head function was applied at the toe of the fill to model the discharge pond. The head value was input as the elevation of the discharge pond. Transient 
modeling with SEEP/W also requires inputting an initial water table. Water table was placed at a constant level through the foundation rock at the elevation of the discharge pond.

\section{SEEP/W Analysis: Geomorphic Fill}

In addition to the fill geometry from the permit file, a fill using geomorphic design principles was analyzed. This fill used an altered geometry but the same boundary conditions as the AOC fill. The profile was taken from the design contours produced by GeoFluv ${ }^{\circledR}$ and is shown in Figure 13.10.

\section{Geometry and Materials}

The same geometry for the "Foundation Rock" and "Blocky Core Drain" were used. Only the surface geometry of the "Fill" material was altered. The profile slope was taken from a geomorphic design using the Carlson Natural Regrade software. A plan view of the fill with the location of profile slice (black line) is shown in Figure 13.10. As in the AOC fill, the 2-D model uses a profile thickness of $1 \mathrm{~m}$. The same material properties were given to the three regions as in the AOC model. The two cases of modeling the drain in a saturated only condition and in an unsaturated/saturated condition were both modeled.

\section{Boundary Conditions}

The same boundary conditions were used to define this model as were used in the AOC model. For this case, however, the entire fill surface used the 55\% infiltration boundary condition because it is sloped for its entire length. The sloped fill surface was also analyzed as a potential seepage face. Due to the altered surface profile, the initial water table and discharge pond were modeled at a height of $353.57 \mathrm{~m}$, slightly lower than in the AOC fill. A figure showing the geomorphic profile with applied boundary conditions is illustrated in Figure 13.8 below.

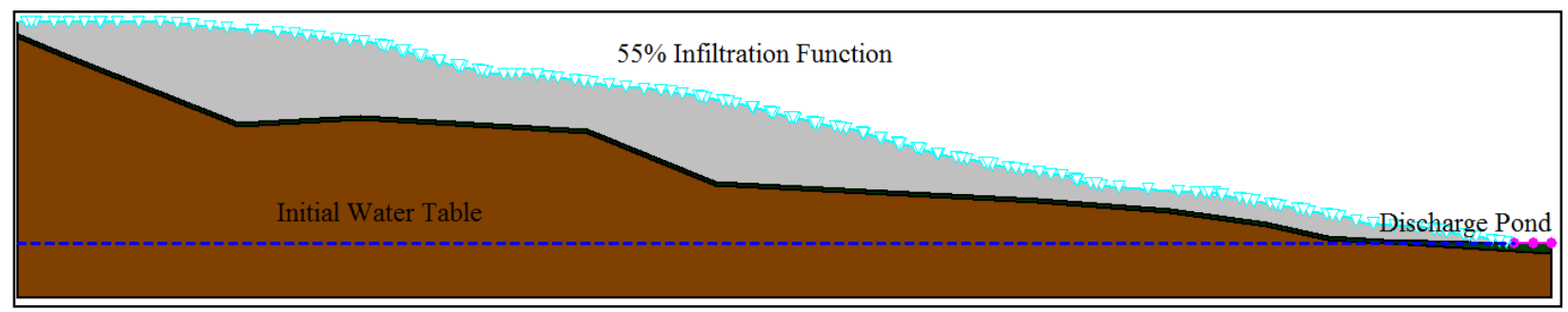

Figure 13.8. Geomorphic fill boundary conditions

\section{Sensitivity Analysis}

Sensitivity analysis is similar in comparison to probabilistic analysis. The difference is that instead of selecting variable parameters by a Monte Carlo simulation, the parameters are set with a mean value, a delta value, and a number of steps to set the range of sampling for each parameter. The delta value is input as equal steps from the mean input value for each property considered. Five steps of "delta" were used for each parameter in the sensitivity analysis. This analysis can be used to determine which parameter the design's stability is most sensitive. If the geometry and conditions happen to be more sensitive to a certain parameter, it means that small changes, or little variability, in the parameter can result in more significant result changes as compared to other parameters. It is valuable to know which parameter is the most critical. An example of a sensitivity output is shown in Figure 13.9. 


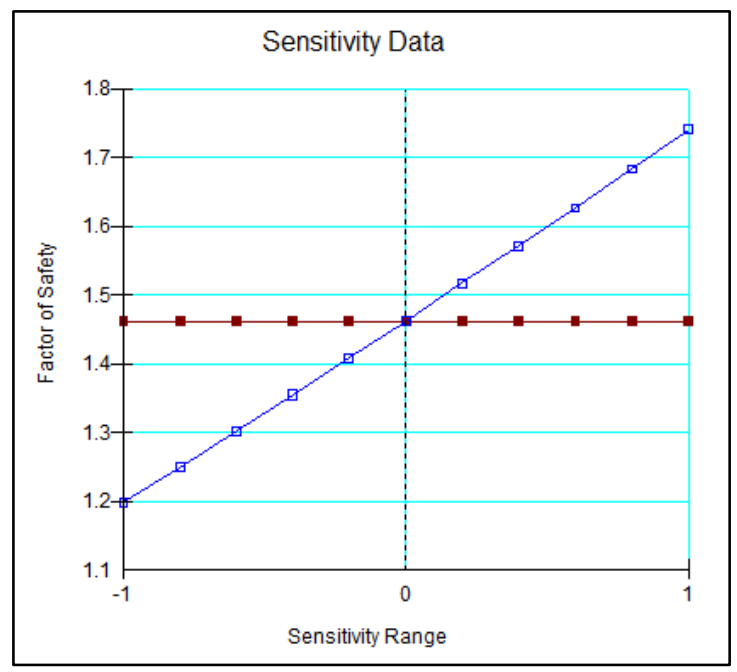

Figure 13.9. $\quad$ Sensitivity output example

This knowledge is important to determine the amount of risk involved in a specific earthwork design. The parameters taken into consideration for the sensitivity assessment were the friction angle $(\varphi)$ and the unit weight $\left(\gamma_{\mathrm{d}}\right)$. The range of values chosen for the sensitivity analysis was targeted to emulate the values that would exists in a realistic three dimensional anisotropic structure with significant spatial variability. The sensitivity input parameters and outputs are shown in section 13.2.

\section{Deterministic Analysis}

Deterministic analysis was performed on all slopes considered in order to give a range of factors of safety to more accurately assess the stability of each slope. The method was also used in order to validate the model geometry and conditions by calibrating the analysis performed on the AOC design, and to input the soil's researched geotechnical laboratory test values to compare the analysis. The AOC valley fill design assessment found the static factor of safety to be 1.592 as shown in Figure 13.1. The analysis performed for this research found the factor of safety to be approximately the same under the similar conditions, but using the GLE method in lieu of Bishop's simplified method. This assessment did not consider any elevated water table.

The values used for the fill material were a friction angle of $40^{\circ}$ and a unit weight of $130 \mathrm{pcf}$. The cohesion was set to a value of 0 psf, assuming that the material acts as cohesionless free draining sand.

\subsection{Data Input Parameters}

This data input information has been accumulated from geotechnical laboratory testing on an unweathered sandstone overburden. The details of the testing performed to obtain these laboratory values can be found in Chapters 5-12. This overburden material is the fill material in all slope models presented. A summary of the values and their associated statistics are shown in the following tables. The delta values are equal to one fifth of the range for the data. The delta values were used in the sensitivity analysis. Five steps from the mean value were assessed in the sensitivity analysis each equal to the addition of one delta value. A summary of the input parameters for the GeoStudio ${ }^{\mathrm{TM}}$ modules are shown in Table 13.1 through Table 13.7. 
Table 13.1. Laboratory friction angle values

\begin{tabular}{|c|c|c|c|c|c|c|c|c|}
\hline \multicolumn{9}{|c|}{$\varphi$ (From ALL DATA) } \\
\hline \multicolumn{3}{|c|}{$\begin{array}{c}11 \% \text { Proctor } \\
\text { Compaction Energy }\end{array}$} & \multicolumn{3}{|c|}{$\begin{array}{c}\text { 34\% Proctor } \\
\text { Compaction Energy }\end{array}$} & \multicolumn{3}{|c|}{$\begin{array}{c}\text { Standard Proctor } \\
\text { Compaction }\end{array}$} \\
\hline $\begin{array}{c}\text { Shear Stress } \\
(\mathbf{k P a})\end{array}$ & $\begin{array}{c}\text { Normal Stress } \\
(\mathbf{k P a})\end{array}$ & $\Phi^{\mathbf{0}}$ & $\begin{array}{c}\text { Shear } \\
\text { Stress } \\
\text { (kPa) }\end{array}$ & $\begin{array}{c}\text { Normal } \\
\text { Stress } \\
\text { (kPa) }\end{array}$ & $\Phi^{\mathbf{0}}$ & $\begin{array}{c}\text { Shear } \\
\text { Stress } \\
\text { (kPa) }\end{array}$ & $\begin{array}{c}\text { Normal } \\
\text { Stress } \\
\text { (kPa) }\end{array}$ & $\Phi^{\mathbf{0}}$ \\
\hline 314.19 & 600 & 27.64 & 365.71 & 600 & 31.36 & 1342.94 & 2676.40 & 26.65 \\
\hline 595.62 & 1200 & 26.39 & 607.73 & 1200 & 26.86 & 1029.95 & 1784.26 & 30.00 \\
\hline 1180.03 & 2500 & 25.27 & 1078.41 & 2500 & 23.33 & & & \\
\hline
\end{tabular}

Table 13.2. Laboratory friction angle statistics for sensitivity model input

\begin{tabular}{|r|r|}
\hline Mean: & $\mathbf{2 7 . 1 9}^{\mathbf{0}}$ \\
\hline Standard Deviation: & $\mathbf{2 . 5 4}$ \\
\hline Coefficient of Variation & $\mathbf{0 . 0 9}$ \\
\hline Ultimate Minimum: & $\mathbf{2 3 . 3 3 ^ { \circ }}$ \\
\hline Ultimate Maximum: & $\mathbf{3 1 . 3 6 ^ { \mathbf { 0 } }}$ \\
\hline Range: & 3.85 \\
\hline Delta: & 0.77 \\
\hline
\end{tabular}

Table 13.3. Laboratory dry unit weight $\left(\gamma_{d}\right)$ values at predetermined compaction energies

\begin{tabular}{|c|c|c|c|}
\hline \multirow{8}{*}{$\begin{array}{c}\gamma_{d}(\text { From ALL DATA }) \\
{\left[\mathrm{kN} / \mathbf{m}^{3}\right]}\end{array}$} & $\begin{array}{c}11 \% \\
\text { Proctor } \\
\text { Energy } \\
\end{array}$ & $\begin{array}{c}34 \% \\
\text { Proctor } \\
\text { Energy }\end{array}$ & $\begin{array}{c}\text { Standard } \\
\text { Proctor } \\
\end{array}$ \\
\hline & 15.39 & 16.11 & 16.65 \\
\hline & 16.90 & 16.21 & 18.51 \\
\hline & 15.20 & 16.48 & 18.54 \\
\hline & 14.93 & 17.98 & 13.92 \\
\hline & 15.07 & 17.94 & \\
\hline & 17.60 & 17.80 & \\
\hline & 16.55 & 14.37 & \\
\hline
\end{tabular}


Table 13.4. Laboratory dry unit weight $\left(\gamma_{d}\right)$ statistics for sensitivity model input

\begin{tabular}{|r|r|}
\hline Mean: & $16.45^{\circ}$ \\
\hline Standard Deviation: & 1.42 \\
\hline Coefficient of Variation & $\mathbf{0 . 0 9}$ \\
\hline Ultimate Minimum: & $\mathbf{1 4 . 9 3}^{\circ}$ \\
\hline Ultimate Maximum: & $\mathbf{1 8 . 7 5}^{\circ}$ \\
\hline Range: & 1.52 \\
\hline Delta: & 0.30 \\
\hline
\end{tabular}

Table 13.5. Deterministic SLOPE/W material input values

\begin{tabular}{|c|r|c|r|c|r|}
\hline \multicolumn{5}{|c|}{ SLOPE/W } \\
\hline \multicolumn{5}{|c|}{ Deterministic Inputs } \\
\hline \multicolumn{2}{|c|}{ Blasted Fill } & \multicolumn{2}{c|}{$\begin{array}{c}\text { Blocky Core } \\
\text { Drain }\end{array}$} & \multicolumn{2}{c|}{$\begin{array}{c}\text { Foundation } \\
\text { Rock }\end{array}$} \\
\hline$\gamma\left(\mathrm{kN} / \mathrm{m}^{3}\right)$ & 18.39 & $\gamma\left(\mathrm{kN} / \mathrm{m}^{3}\right)$ & 19.64 & $\gamma\left(\mathrm{kN} / \mathrm{m}^{3}\right)$ & 18.39 \\
\hline $\mathrm{c}(\mathrm{kPa})$ & 0 & $\mathrm{c}(\mathrm{kPa})$ & 9.58 & $\mathrm{c}(\mathrm{kPa})$ & 0 \\
\hline$\varphi$ & $27.7^{\circ}$ & $\varphi$ & $30^{\circ}$ & $\varphi$ & $27.7^{\circ}$ \\
\hline
\end{tabular}


Table 13.6. Sensitivity SLOPE/W material input values

\begin{tabular}{|c|c|r|}
\hline \multicolumn{3}{|c|}{ SLOPE/W } \\
\hline \multicolumn{3}{|c|}{ Sensitivity Inputs } \\
\hline $\begin{array}{c}\text { Unweathered } \\
\text { Sandstone Fill }\end{array}$ & $\begin{array}{c}\text { Slip Surface } \\
\text { Calculation Value }\end{array}$ & Mean \\
\hline$\gamma\left(\mathrm{kN} / \mathrm{m}^{3}\right)$ & 16.45 & 14.93 \\
\hline $\mathrm{c}(\mathrm{kPa})$ & 0.00 & 0.00 \\
\hline$\varphi$ & $27.19^{\circ}$ & $23.33^{\circ}$ \\
\hline \multicolumn{2}{|c|}{} \\
\hline Blocky Core Drain & 16.45 & 14.93 \\
\hline$\gamma\left(\mathrm{kN} / \mathrm{m}^{3}\right)$ & 0.00 & 0.00 \\
\hline $\mathrm{c}(\mathrm{kPa})$ & $27.19^{\circ}$ & $23.33^{\circ}$ \\
\hline$\varphi$ & 19.64 \\
\hline Foundation Rock & No Sensitivity Values \\
\hline$\gamma\left(\mathrm{kN} / \mathrm{m}^{3}\right)$ & 9.58 \\
\hline $\mathrm{c}(\mathrm{kPa})$ & $30.00^{\circ}$ \\
\hline$\varphi$ & \multicolumn{2}{|c|}{} \\
\hline
\end{tabular}

Table 13.7. SIGMA/W material input values

\begin{tabular}{|c|r|r|r|}
\hline \multicolumn{5}{|c|}{ SIGMA/W } \\
\hline & Elastic Modulus, kPa & Unit Weight, $\boldsymbol{\gamma}\left(\mathbf{k N} / \mathbf{m}^{3}\right)$ & Poisson's Ratio \\
\hline Blocky Core Drain & 29868 & 18.39 & 0.34 \\
\hline Foundation Rock & 1000000 & 26.48 & 0.38 \\
\hline Unweathered Fill & 29868 & 18.39 & 0.34 \\
\hline
\end{tabular}




\subsection{Stability Analysis: AOC Valley Fill Design}

The results of the limit equilibrium analysis yielded critical factors of safety found from the AOC valley fill (Fig. 13.3) deterministic SLOPE/W analysis are shown in the following tables. The two analysis methods shown below are deterministic and sensitivity each utilizing GLE theory. The failure modes assessed were: crest, toe, face, and deep foundation failures. The factor of safety (FS) results are shown in Table 13.8, Table 13.9, and Table 13.10. Two water table elevations were considered for each failure mode for precision:

- Piez. 1: Piezometric line at the top elevation of durable rock underdrain

- Piez. 2: Piezometric line at an elevated displacement (50ft or $15.24 \mathrm{~m}$ ) above the durable rock underdrain.

Table 13.8. Deterministic critical factors of safety (FOS) for selected scenarios using AOC valley fill input parameters

\begin{tabular}{|c|l|r|}
\hline \multicolumn{3}{|c|}{ AOC Valley Fill Design Values } \\
\hline \multicolumn{2}{|c|}{ Location } & Critical Deterministic FS \\
\hline \multirow{2}{*}{ Crest } & Piez. 1 & 2.84 \\
\cline { 2 - 3 } & Piez. 2 & 2.84 \\
\hline \multirow{2}{*}{ Toe } & Piez. 1 & 1.51 \\
\cline { 2 - 3 } & Piez. 2 & 0.91 \\
\hline \multirow{2}{*}{ Face } & Piez. 1 & 2.13 \\
\cline { 2 - 3 } & Piez. 2 & 2.13 \\
\hline \multirow{2}{*}{ Deep } & Piez. 1 & 1.54 \\
\cline { 2 - 3 } & Piez. 2 & 1.41 \\
\hline
\end{tabular}

Table 13.9. Deterministic critical factors of safety for selected scenarios using laboratory value

\begin{tabular}{|c|l|r|}
\hline \multicolumn{3}{|c|}{ Laboratory Values } \\
\hline \multicolumn{2}{|c|}{ Location } & Critical Deterministic FS \\
\hline \multirow{2}{*}{ Crest } & Piez. 1 & 1.78 \\
\cline { 2 - 4 } & Piez. 2 & 1.78 \\
\hline \multirow{2}{*}{ Toe } & Piez. 1 & 1.23 \\
\cline { 2 - 4 } & Piez. 2 & 0.5 \\
\hline \multirow{2}{*}{ Face } & Piez. 1 & 1.33 \\
\cline { 2 - 3 } & Piez. 2 & 1.33 \\
\hline \multirow{2}{*}{ Deep } & Piez. 1 & 1.37 \\
\cline { 2 - 3 } & Piez. 2 & 1.21 \\
\hline
\end{tabular}


Table 13.10. Sensitivity assessment: Critical factor of safety results for selected scenarios

\begin{tabular}{|c|c|c|c|c|c|}
\hline \multirow{2}{*}{\multicolumn{2}{|c|}{ Location }} & \multicolumn{4}{|c|}{ Critical Sensitivity Factor of Safety } \\
\hline & & \multirow{2}{*}{$\begin{array}{r}\text { Friction Angle, } \boldsymbol{\varphi} \\
19.475 \\
\end{array}$} & \multirow{2}{*}{$\begin{array}{r}\text { FS for } \boldsymbol{\varphi} \\
1.199 \\
\end{array}$} & \multirow{2}{*}{$\begin{array}{r}\text { Unit Wt., } \boldsymbol{\gamma}_{\mathbf{d}} \\
13.407\end{array}$} & \multirow{2}{*}{$\begin{array}{r}\mathbf{F S} \text { for } \boldsymbol{\gamma}_{\mathbf{d}} \\
1.462 \\
\end{array}$} \\
\hline Crect & Piez. 1 & & & & \\
\hline Chest & Piez. 2 & 19.475 & 1.199 & 13.407 & 1.462 \\
\hline \multirow{2}{*}{ Toe } & Piez. 1 & 19.475 & 0.815 & 13.407 & 0.979 \\
\hline & Piez. 2 & 19.475 & 0.223 & 13.407 & 0.198 \\
\hline \multirow{2}{*}{ Face } & Piez. 1 & 19.475 & 0.898 & 13.407 & 1.095 \\
\hline & Piez. 2 & 19.475 & 0.898 & 13.407 & 1.095 \\
\hline \multirow{2}{*}{ Deep } & Piez. 1 & 19.475 & 1.120 & 13.407 & 1.232 \\
\hline & Piez. 2 & 19.475 & 0.927 & 13.407 & 1.020 \\
\hline
\end{tabular}

\section{Discussion}

The critical factor of safety results show that for an elevated water table in the AOC design, the factor of safety decreases below the regulatory requirement for a static case of 1.5. If a failure plane is taken entirely in the saturated zone; the factor of safety becomes less than 1.0.

Furthermore, the soil's laboratory values found differ from the AOC soil values used from the DEP permit file. The test results show that the blasted overburden has a lower friction angle, as well as a lower unit weight. It can be determined; however, that if the AOC design remains at a drained condition, the factor of safety will remain above 1.0.

The durability of the valley fill structure may be dependent on the limitation of the particle transport within the structure itself. Less internal erosion of fine particles could yield a more durable structure. Future research in modeling of this slope will shed more light to the limitations and shortcomings of the scenarios shown. 


\subsection{Stability Analysis: Geomorphic Valley Fill Alternative}

Geomorphic design uses concepts derived from natural processes. Geomorphic landforms are designed with the intent of emulating a naturally occurring landform whose erosion potential is minimized. The minimized erosion potential is a function of drainage density. Drainage density is the ratio of the relationship between watershed area per channel length.

Some initial benefits can be observed when addressing geomorphic landform design from a slope stability, and earthen structure durability standpoint. Slope angles and lengths have the potential to be decreased. Smaller slopes give water runoff shorter distances to travel before being collected in a drainage channel. This analysis was performed to explore the stability capacity of the geomorphic landform design to be compared to the AOC valley fill design with regard to a factor of safety computed from GeoStudio ${ }^{\mathrm{TM}}$ by the general limit equilibrium (GLE) approach.

The geomorphic landform design shown in Figures 13.10 and 13.11 below was produced with GeoFluv ${ }^{\circledR}$ software. SLOPE/W was used for the slope stability analysis. The contours by which the profile dimensions were retrieved are shown in Figure 13.10. The geomorphic alternative dimensions were retrieved from a centerline cut at the identical dimensions as the valley fill centerline section A-A in Figure 13.2.

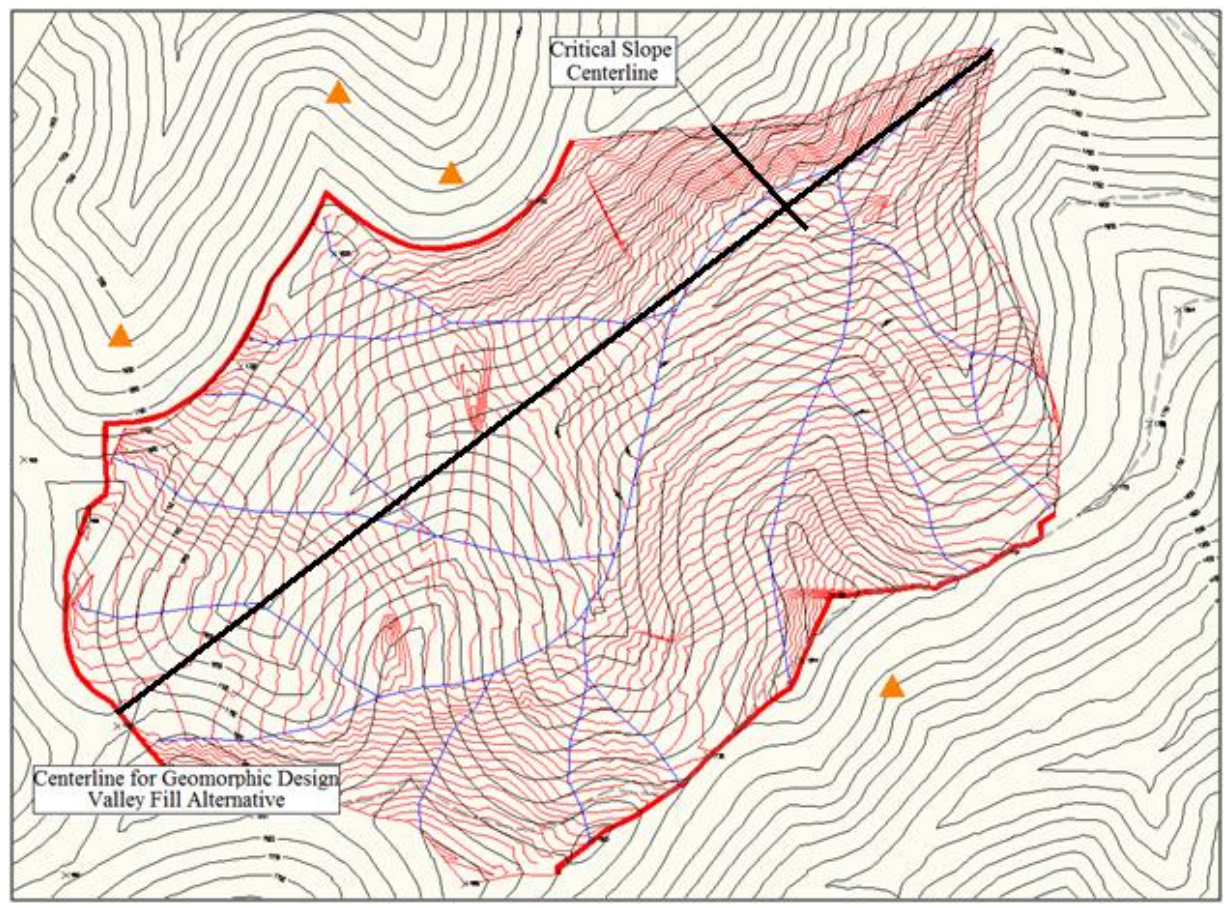

Figure 13.10. Geomorphic design contours superimposed on original ground contours 


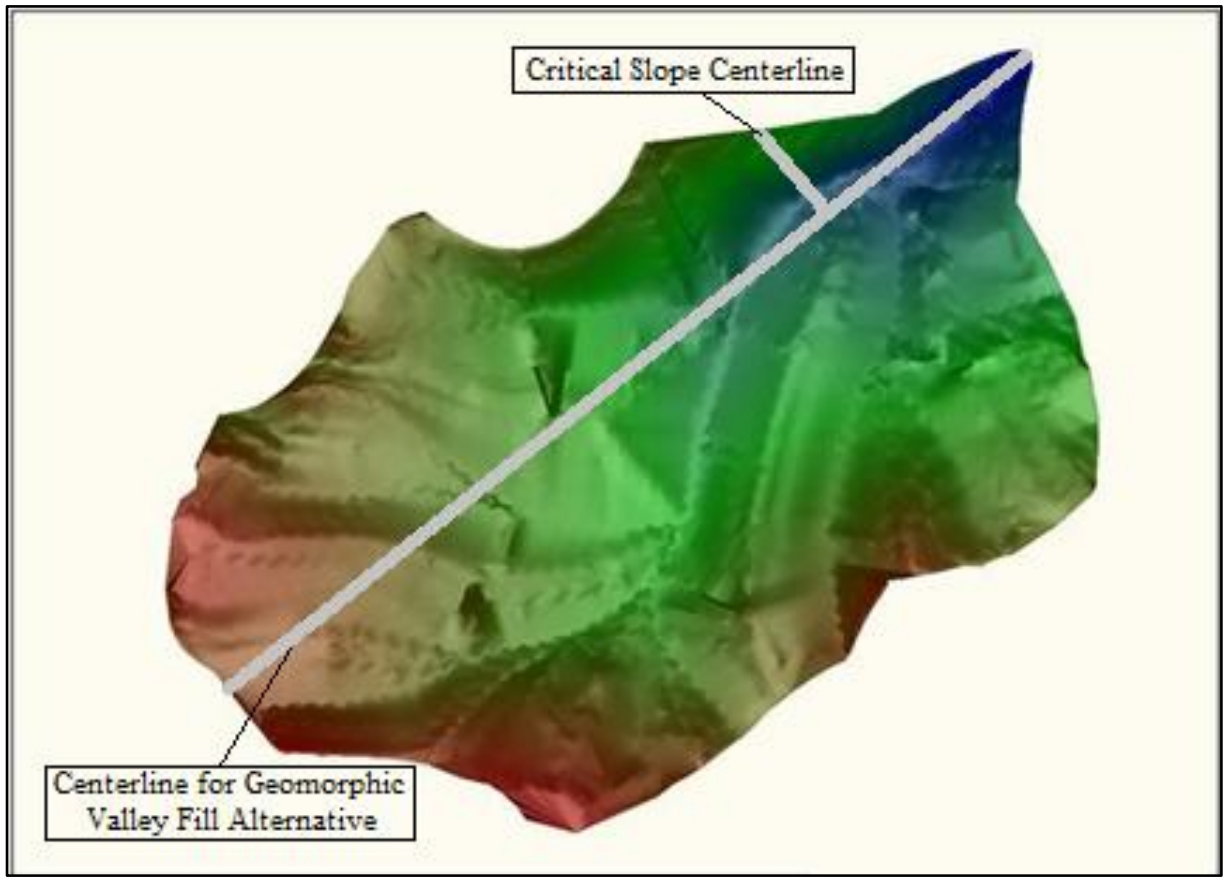

Figure 13.11. Geomorphic design surface generated from a triangulated irregular network (TIN)

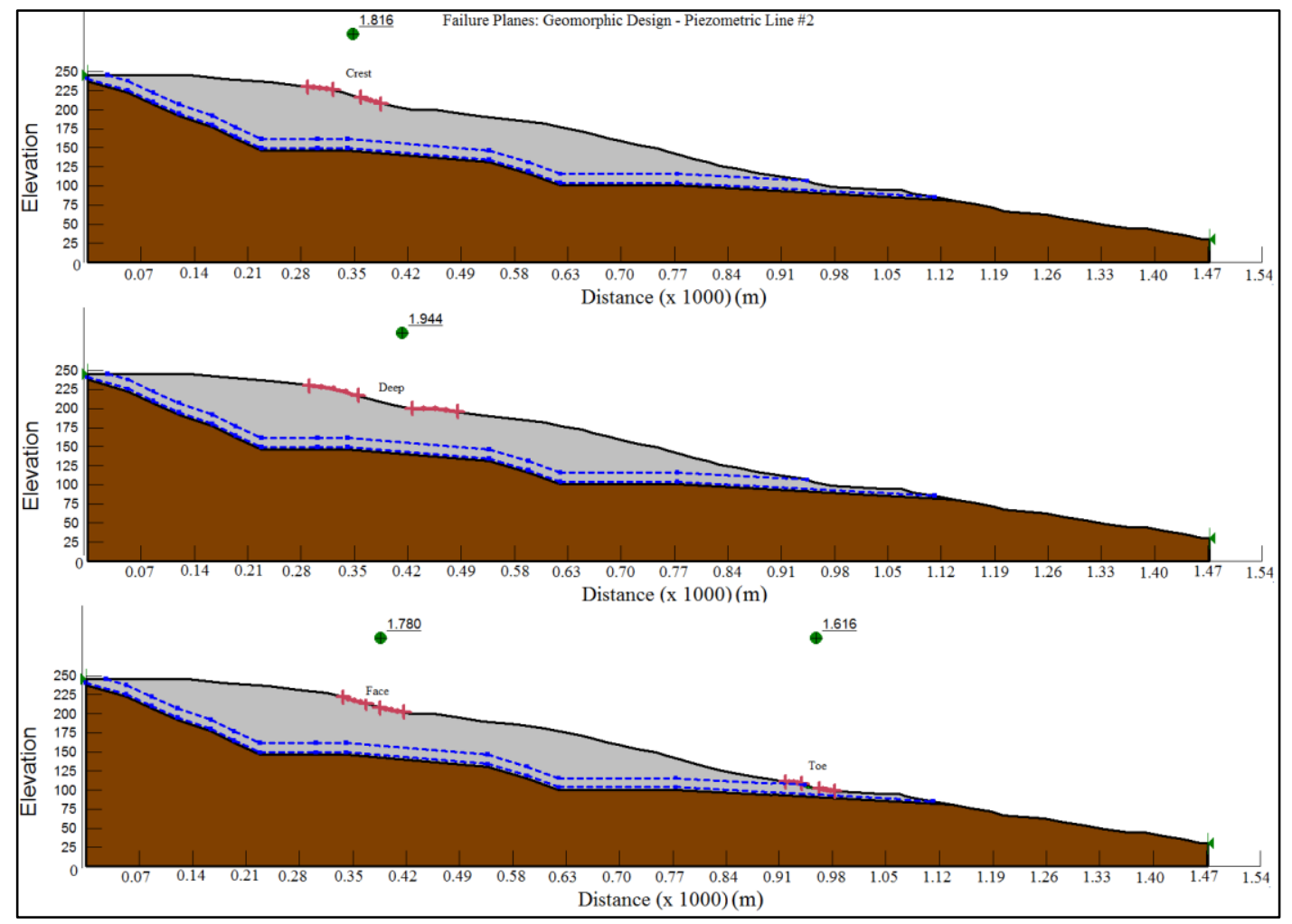

Figure 13.12. Geomorphic valley fill alternative failure planes along centerline shown in Fig. 13.10 


\section{Data Input Parameters}

The data that was input into the model to identify the geometry of the slope was taken from the AOC contours in and the geomorphic design contours in Figure 13.10. The material's geotechnical properties were input identically to the data used for the AOC modeling in section 13.3 for accurate comparison. The failure planes were determines such that the most critical areas would be analyzed. The critical areas were identified as the steepest areas along the slope. From a slope stability standpoint, the steep slopes would have the highest driving forces for slope failure. These areas should have the lowest factors of safety. Four locations were chosen for analysis as shown in Figure 13.12. Two piezometric scenarios were assessed separately. The piezometric lines were at a $10 \mathrm{ft}$ thickness along the bottom of the fill to emulate a saturated gravity segregated durable rock underdrain, and a $50 \mathrm{ft}(15.24 \mathrm{~m})$ elevated water table to emulate a more critical condition. Slope angles are shown in Table 13.23. A summary of the results for the deterministic and sensitivity factors of safety are shown in Table 13.11 and Table 13.12.

\section{Results}

Table 13.11. Deterministic critical factors of safety for two piezometric scenarios

\begin{tabular}{|c|l|r|}
\hline \multicolumn{3}{|c|}{ Laboratory Values } \\
\hline \multicolumn{2}{|c|}{ Location } & \multicolumn{1}{c|}{$\begin{array}{c}\text { Critical } \\
\text { Deterministic } \\
\text { Factor of Safety }\end{array}$} \\
\hline \multirow{2}{*}{ Crest } & Piez. 1 & 1.816 \\
\cline { 2 - 3 } & Piez. 2 & 1.816 \\
\hline \multirow{3}{*}{ Toe } & Piez. 1 & 1.822 \\
\cline { 2 - 3 } & Piez. 2 & 1.616 \\
\hline \multirow{3}{*}{ Face } & Piez. 1 & 1.780 \\
\cline { 2 - 3 } & Piez. 2 & 1.780 \\
\hline \multirow{3}{*}{ Deep } & Piez. 1 & 1.944 \\
\cline { 2 - 3 } & Piez. 2 & 1.944 \\
\hline
\end{tabular}


Table 13.12. Sensitivity critical factors of safety for two piezometric scenarios

\begin{tabular}{|c|c|c|c|c|c|c|}
\hline \multirow{2}{*}{\multicolumn{2}{|c|}{ Location }} & \multicolumn{5}{|c|}{ Critical Sensitivity Factors of Safety } \\
\hline & & \multirow{2}{*}{$\begin{array}{r}\text { Friction Angle, } \boldsymbol{\varphi}^{\mathbf{o}} \\
19.475\end{array}$} & \multirow{2}{*}{$\begin{array}{r}\text { FS for } \boldsymbol{\varphi} \\
1.223\end{array}$} & \multirow{2}{*}{$\begin{array}{r}\text { Unit Wt., } \boldsymbol{\gamma}_{\mathbf{d}} \\
13.407\end{array}$} & \multirow{2}{*}{$\begin{array}{r}\text { FS for } \gamma_{\mathbf{d}} \\
1.491\end{array}$} & \multirow{2}{*}{$\frac{\text { FS }}{1.776}$} \\
\hline & Piez. 1 & & & & & \\
\hline & Piez. 2 & 19.475 & 1.223 & 13.407 & 1.491 & 1.776 \\
\hline \multirow{2}{*}{ Toe } & Piez. 1 & 19.475 & 1.227 & 13.407 & 1.497 & 1.783 \\
\hline & Piez. 2 & 19.475 & 1.058 & 13.407 & 1.267 & 1.559 \\
\hline \multirow{2}{*}{ Face } & Piez. 1 & 19.475 & 1.199 & 13.407 & 1.462 & 1.741 \\
\hline & Piez. 2 & 19.475 & 1.199 & 13.407 & 1.462 & 1.741 \\
\hline \multirow{2}{*}{ Deep } & Piez. 1 & 19.475 & 1.309 & 13.407 & 1.597 & 1.902 \\
\hline & Piez. 2 & 19.475 & 1.309 & 13.407 & 1.597 & 1.902 \\
\hline
\end{tabular}




\subsection{Cumulative Analysis: AOC Valley Fill Design}

The modeling process undertaken for the valley fill under inspection in this section was for two scenarios. The first scenario run was for the durable rock underdrain to be initially dry or unsaturated. The second condition run was for the underdrain to be at an initially saturated state. The objective of the stability analysis performed for this valley fill profile geometry was intended to imitate more realistic in-field conditions. SEEP/W was first used to produce infiltration results over a 10 year period. The results from SEEP/W illustrated areas of storage, areas of increased hydraulic head, and elevated pore pressures. The results from this analysis were utilized as parent inputs to a SIGMA/W analysis. The SIGMA/W analysis, via finite element modeling techniques, calculated insitu stresses within the fill structure. The insitu stresses varied from previous piezometric head conditions by having spatially variable areas of increased total hydraulic head, as well as spatially variable areas of elevated pore pressures. Finally, the SIGMA/W results were used as parent input parameters for the finite element SLOPE/W analysis. The SLOPE/W analysis was run to produce factors of safety at several critical areas. The critical areas that were selected for failure plane entry and exit points were chosen to be identical to the valley fill modeling shown in section 13.3 for comparison. Slope profile with cumulative analysis results shown in Table 13.13 through Table 13.16, Figure 13.13, and Figure 13.14.

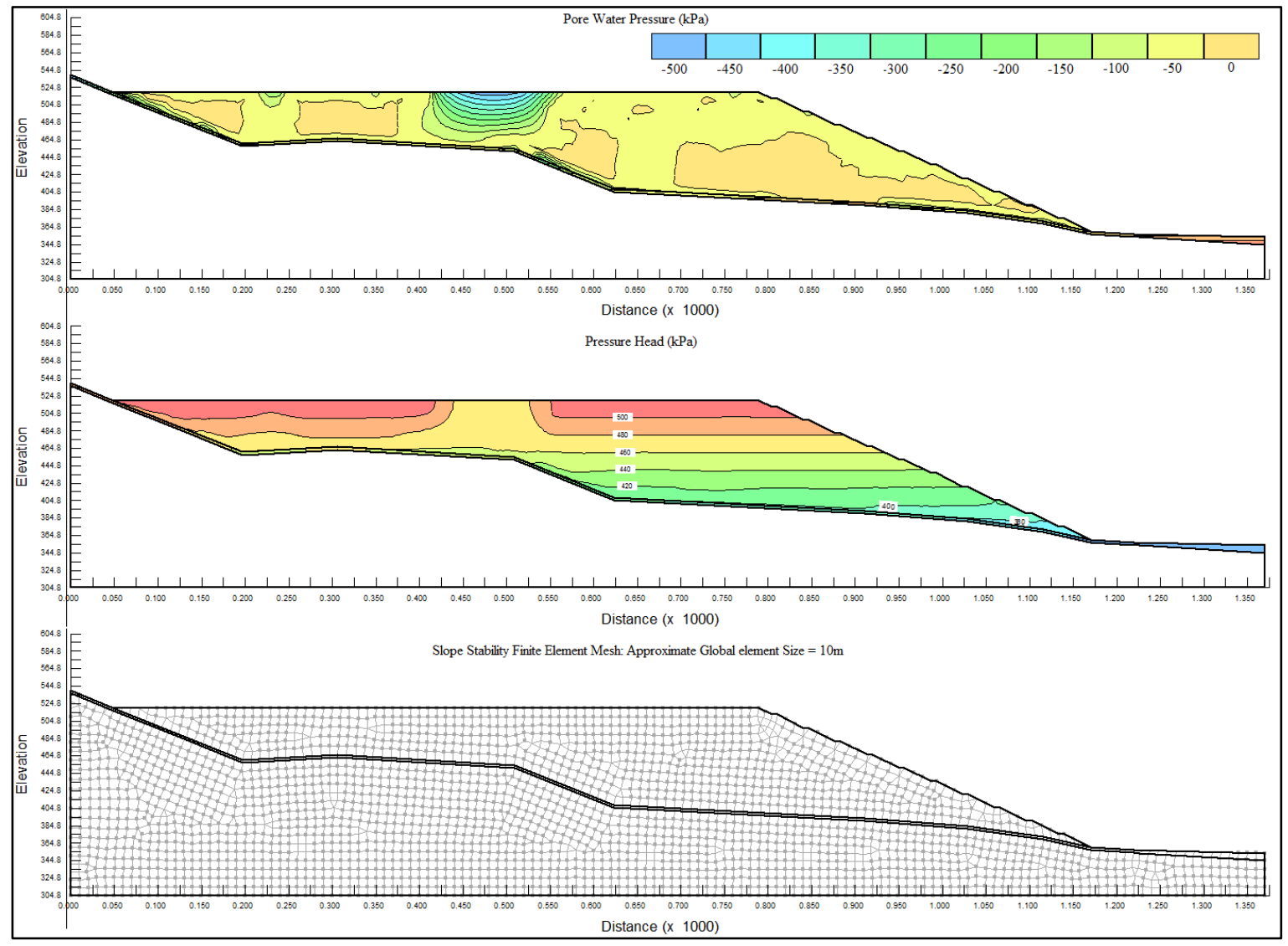

Figure 13.13. Valley fill diagrams of results from a cumulative analysis of SEEP/W, SIGMA/W, and SLOPE/W from GeoStudio ${ }^{\mathrm{TM}}$ 


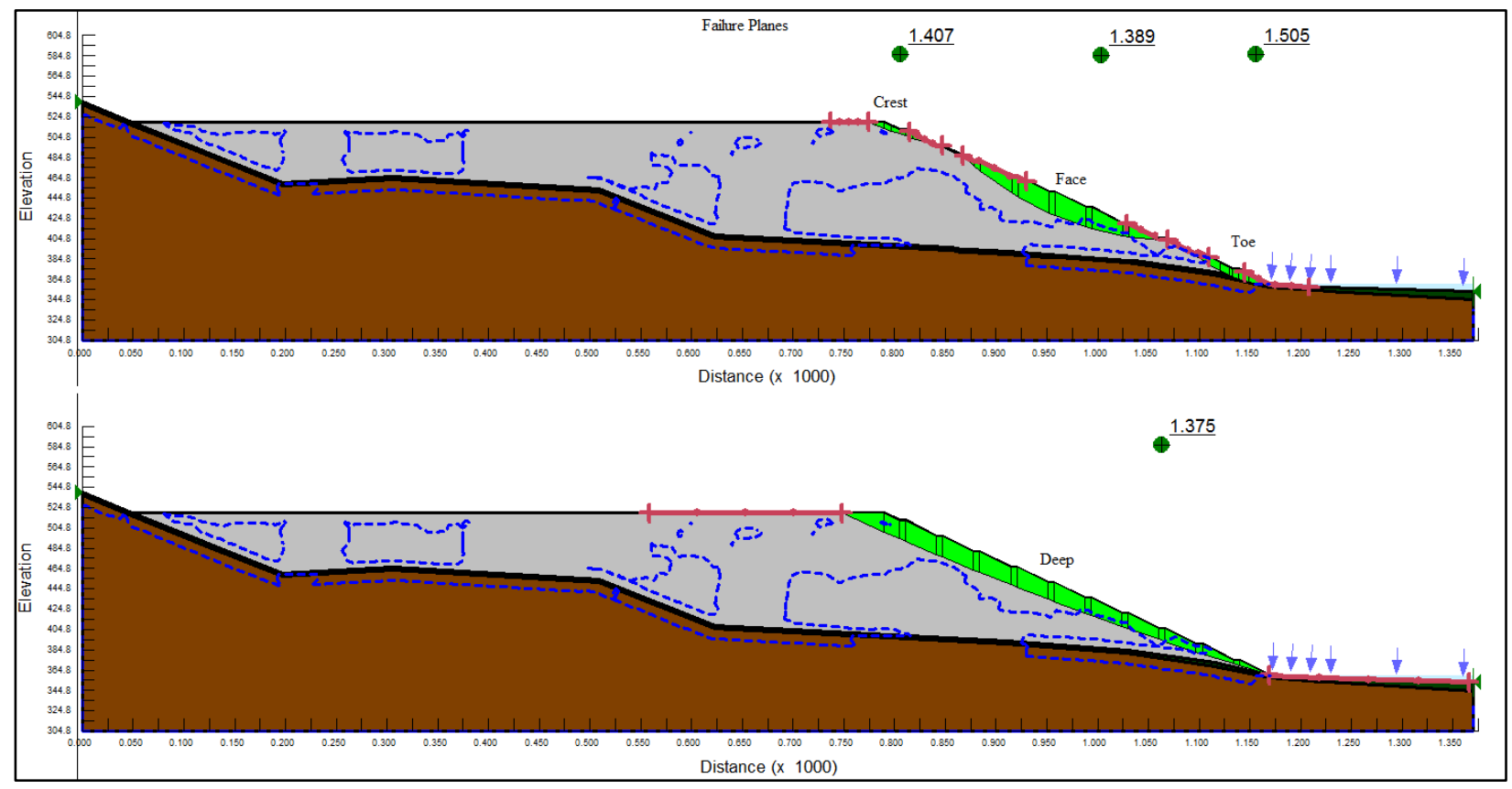

Figure 13.14. Failure entry and exit locations for saturated underdrain-Deterministic analysis results

\section{Data Input Parameters}

The geometry of this valley fill profile was taken from the image in Figure 13.1. The geometry is identical to the analysis described in section 13.3. The SEEP/W inputs are described in SEEP/W Analysis section in this chapter, or section 13.1. The SIGMA/W input parameters are shown in Table 13.7. The blocky underdrain material had its own unique hydraulic conductivity for the SEEP/W modeling, but had identical input parameters for strength, unit weight, and friction angle as the fill material. The original ground material was considered as a weak sandstone with an elastic modulus at the minimum for solid sandstone at $10^{6} \mathrm{kPa}$.

\section{Results}

Table 13.13. Deterministic factor of safety results: Saturated Underdrain

\begin{tabular}{|c|r|}
\hline \multicolumn{2}{|c|}{$\begin{array}{c}\text { Laboratory Values Valley Fill - } \\
\text { Saturated }\end{array}$} \\
\hline Location & $\begin{array}{c}\text { Critical } \\
\text { Deterministic } \\
\text { Factor of Safety }\end{array}$ \\
\hline Crest & 1.407 \\
\hline Toe & 1.505 \\
\hline Face & 1.389 \\
\hline Deep & 1.375 \\
\hline
\end{tabular}


Table 13.14. Deterministic factor of safety results: Unsaturated Underdrain

\begin{tabular}{|c|r|}
\hline \multicolumn{2}{|c|}{$\begin{array}{c}\text { Laboratory Values Valley Fill - } \\
\text { Unsaturated }\end{array}$} \\
\hline Location & $\begin{array}{c}|c| \\
\text { Critical } \\
\text { Deterministic } \\
\text { Factor of Safety }\end{array}$ \\
\hline Crest & 1.673 \\
\hline Toe & 1.246 \\
\hline Face & 1.365 \\
\hline Deep & 1.299 \\
\hline
\end{tabular}

Table 13.15. Sensitivity factor of safety results: Saturated Underdrain

\begin{tabular}{|c|r|r|c|}
\hline \multirow{2}{*}{ Location } & \multicolumn{3}{|c|}{ Sensitivity FS: Valley Fill - Saturated } \\
\cline { 2 - 4 } & Friction Angle, $\boldsymbol{\varphi}$ & $\begin{array}{c}\text { Unit Wt., } \\
\boldsymbol{\gamma}_{\mathbf{d}}\end{array}$ & FS \\
\hline Crest & 19.475 & 13.407 & 1.377 \\
\hline Toe & 19.475 & 13.407 & 1.472 \\
\hline Face & 19.475 & 13.407 & 1.359 \\
\hline Deep & 19.475 & 13.407 & 1.345 \\
\hline
\end{tabular}

Table 13.16. Sensitivity factor of safety results: Unsaturated underdrain

\begin{tabular}{|c|r|r|c|}
\hline \multirow{2}{*}{ Location } & \multicolumn{3}{|c|}{ Sensitivity FS: Valley Fill - Unsaturated } \\
\cline { 2 - 4 } & Friction Angle, $\boldsymbol{\varphi}$ & Unit Wt., $\boldsymbol{\gamma}_{\mathbf{d}}$ & \multicolumn{1}{|c|}{ FS } \\
\hline Crest & 19.475 & 13.407 & 1.637 \\
\hline Toe & 19.475 & 13.407 & 1.219 \\
\hline Face & 19.475 & 13.407 & 1.335 \\
\hline Deep & 19.475 & 13.407 & 1.271 \\
\hline
\end{tabular}




\subsection{Cumulative Analysis: Geomorphic Valley Fill Alternative}

The objective of the stability analysis performed for this geomorphic design valley fill alternative profile geometry was intended to imitate more realistic in-field conditions than utilizing SLOPE/W alone. The modeling process undertaken for the geomorphic design valley fill alternative under inspection in this section was for two scenarios. The first scenario run was for the durable rock underdrain to be initially dry (unsaturated). The second condition run was for the underdrain to initially be at a fully saturated state. The cumulative analysis procedure was identical to the analysis run on the AOC valley fill design in the previous section (section 13.5), except for the failure plane entry and exit selection. SEEP/W was first used to produce infiltration results over a 10 year period. The results from SEEP/W illustrated areas of ground water storage, areas of increased hydraulic head, and elevated pore pressures. The results from this analysis were utilized as parent inputs to a SIGMA/W analysis.

The SIGMA/W analysis, via finite element modeling techniques, calculated insitu stresses within the fill structure. The insitu stresses varied from previous piezometric head conditions by having spatially variable areas of increased total hydraulic head, as well as spatially variable areas of elevated pore pressures. Finally, the SIGMA/W results were used as parent input parameters for the finite element SLOPE/W analysis. The SLOPE/W analysis was run to produce factors of safety at several critical areas. The critical areas that were selected for failure plane entry and exit points were chosen by considering areas where pore pressures were highest. Other failure plane entry and exit locations were selected by keeping in mind general limit equilibrium concepts of driving forces and resisting forces (or moments). The failure plane entry and exit location selection also involved keeping in mind the sometimes significant effects that steep slope angles can have on the stability of an earthen structure. The slope profile with cumulative analysis results are shown in the following figures and tables along with identified failure planes.

Figure 13.15 shows output from (top to bottom) SLOPE/W, SIGMA/W, SEEP/W, then finally the finite element mesh with a global element size of $10 \mathrm{~m}$. SEEP/W analysis was performed first to calculate the water storage through hydraulic conductivity and water content functions. SIGMA/W was then utilized to calculate the insitu stresses caused by the water storage and unit weight. SLOPE/W was lastly utilized to calculate factors of safety at three critical locations. 


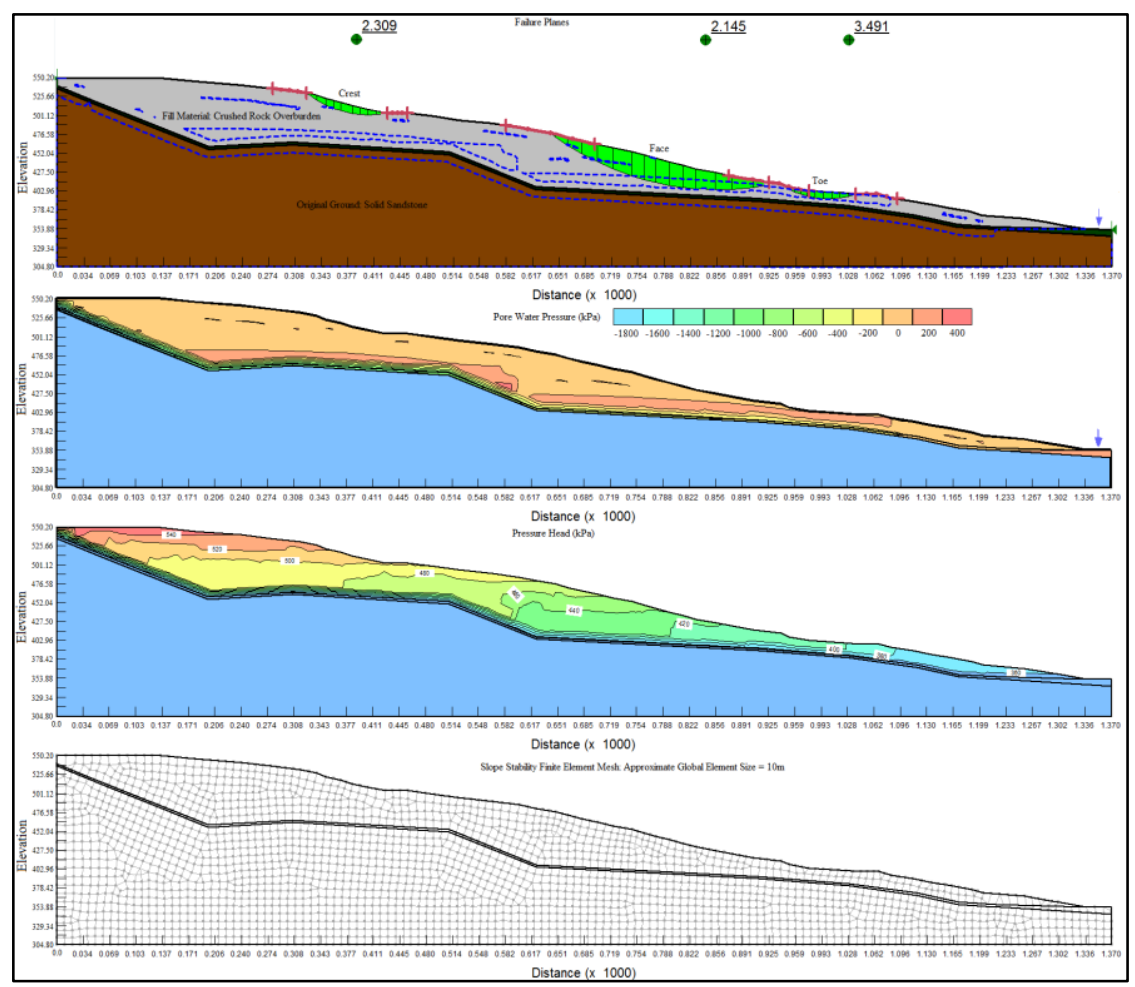

Figure 13.15. Geomorphic valley fill alternative cumulative analysis results for unsaturated underdrain conditions

\section{Data Input Parameters}

It is important to note that the profile geometry used for this model and the model described in section 13.10 vary slightly. The reason for this alteration is that the original ground input dimensions varied in discretization between the two illustrations in Figure 13.1 and Figure 13.10. Each geometry was chosen to be assessed in the manner laid out in this chapter. The SEEP/W inputs are described in SEEP/W Analysis section in this chapter, or section 13.1. The SIGMA/W input parameters are shown in Table 13.7. The blocky underdrain material had its own unique hydraulic conductivity for the SEEP/W modeling, but had identical input parameters for strength, unit weight, and friction angle as the fill material. The original ground material was considered as a weak sandstone with an elastic modulus at the minimum for solid sandstone at $10^{6} \mathrm{kPa}$. 


\section{Results}

Table 13.17. Deterministic critical factor of safety results for the geomorphic design valley fill alternative under an initial saturated underdrain condition

\begin{tabular}{|c|c|}
\hline \multicolumn{2}{|c|}{ Laboratory Values } \\
Geomorphic Design - Saturated \\
\hline Location & $\begin{array}{c}\text { Critical } \\
\text { Deterministic } \\
\text { FS }\end{array}$ \\
\hline Crest & 2.040 \\
\hline Toe & 2.144 \\
\hline Face & 2.242 \\
\hline
\end{tabular}

Table 13.18. Sensitivity critical factor of safety results for the geomorphic design valley fill alternative under an initial saturated undedrain condition

\begin{tabular}{|c|r|r|c|}
\hline \multicolumn{4}{|c|}{ Sensitivity: Geomorphic Design - Saturated } \\
\hline Location & Friction Angle, $\boldsymbol{\varphi}$ & Unit Wt., $\boldsymbol{\gamma}_{\mathbf{d}}$ & FS \\
\hline Crest & 19.475 & 13.407 & 1.997 \\
\hline Toe & 19.475 & 13.407 & 2.097 \\
\hline Face & 19.475 & 13.407 & 2.194 \\
\hline
\end{tabular}

Table 13.19. Deterministic critical factor of safety results for the geomorphic design valley fill alternative under an initial unsaturated underdrain condition

\begin{tabular}{|c|c|}
\hline \multicolumn{2}{|c|}{$\begin{array}{c}\text { Laboratory Values } \\
\text { Geomorphic Design - Unsaturated }\end{array}$} \\
\hline Location & $\begin{array}{c}\text { Critical } \\
\text { Deterministic } \\
\text { FS }\end{array}$ \\
\hline Crest & 2.309 \\
\hline Toe & 3.491 \\
\hline Face & 2.145 \\
\hline
\end{tabular}


Table 13.20. Sensitivity critical factor of safety results for the geomorphic design valley fill alternative under an initial unsaturated undedrain condition

\begin{tabular}{|c|r|r|c|}
\hline \multicolumn{4}{|c|}{ Sensitivity: Geomorphic Design - Unsaturated } \\
\hline Location & Friction Angle, $\boldsymbol{\varphi}$ & Unit Wt., $\boldsymbol{\gamma}_{\mathbf{d}}$ & \multicolumn{1}{c|}{ FS } \\
\hline Crest & 19.475 & 13.407 & 2.260 \\
\hline Toe & 19.475 & 13.407 & 3.416 \\
\hline Face & 19.475 & 13.407 & 2.099 \\
\hline
\end{tabular}

\subsection{Geomorphic Design Critical Slope Analysis}

This slope analysis was performed to illustrate areas of concern for the GeoFluv® geomorphic design process. The geometry for these slopes were taken directly from the labeled location in the design in Figure 13.10. Since GeoFluv® does not have a slope stability module or assessment of any kind to reinsure the durability of the output, excessively steep slopes sometimes result. These excessively steep slopes result because the GeoFluv ${ }^{\circledR}$ program bases the design on the hydraulic factors involving surface precipitation runoff. These hydraulic factors include stream type, and stream slope. This particular slope was in a narrow part of the design. When inspecting Figure 13.10, one notices that the main channel and the design boundary are close to one another in proximity; however, their individual elevations vary greatly. In response to this scenario, the design software "ties in" the two elevations in a very short distance, producing a steep slope. Two piezometric conditions were modeled for this slope. The results prove that this slope is too steep to meet the factor of safety requirement for AOC of 1.5. None of the 16 models that were run produced a factor of safety over 1.0. One promising insight is that within GeoFluv®, the designer can mitigate these types of problems by changing the number of drainage channels, shifting the slope of the drainage channel, or by altering cut and fill volumes in specific areas. Designer customization in any of these areas will affect the calculated factor of safety. If a designer can identify critical slope areas accurately, then the low factors of safety can be increased by altering the geometry of the landform. The factor of safety results are presented in Figure 13.16 and Table 13.21. 


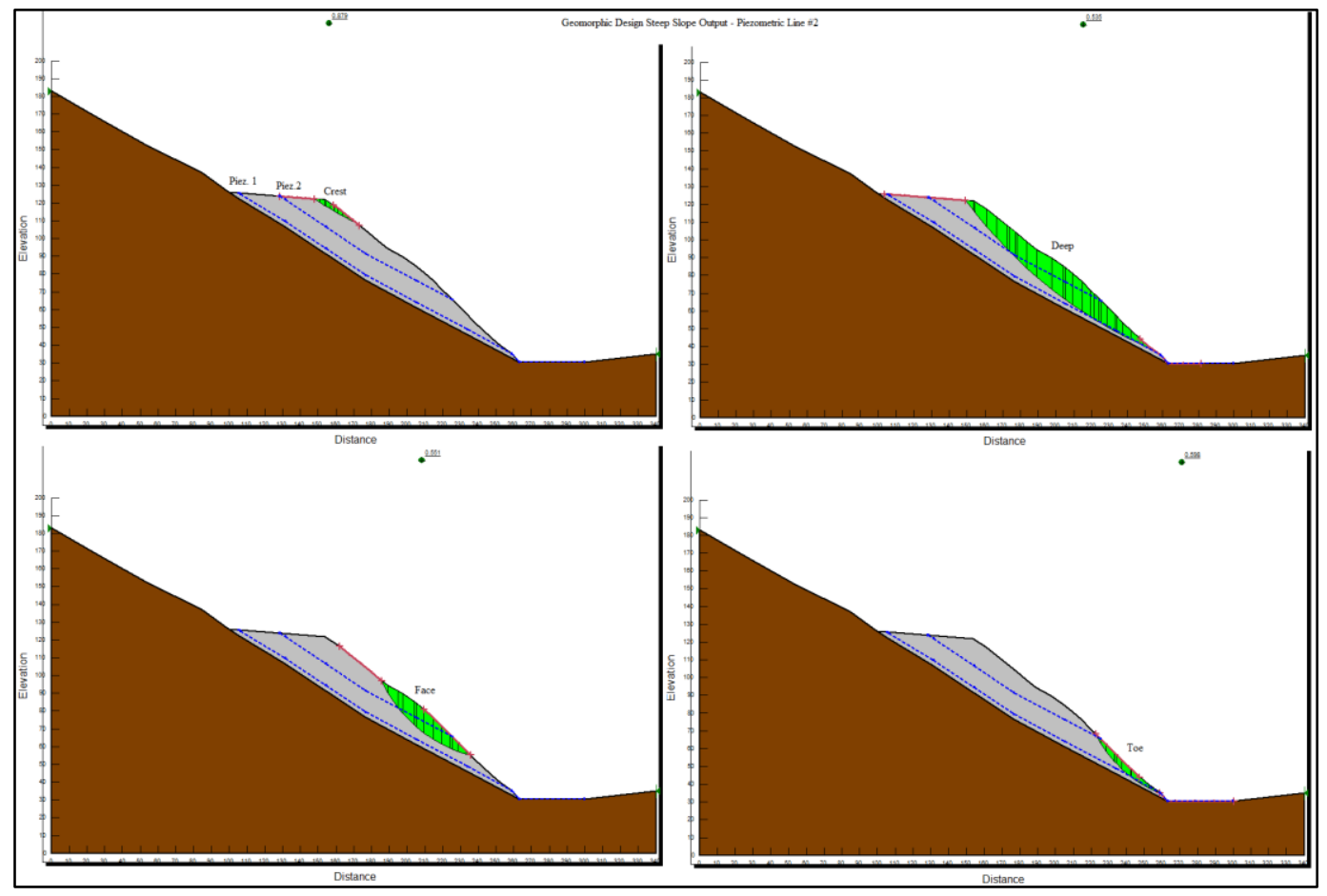

Figure 13.16. Critical slope profile with failure planes along centerline shown in Fig. 13.10. Pieziometric line \#2 enabled - Deterministic analysis visual results 


\section{Data Input Parameters}

The geometry of the model, as noted above, was retrieved from the AutoCad ${ }^{\mathrm{TM}}$ output contours of the original ground and the superimposed geomorphic design contours. The fill material and original ground material are defined identical to the previous models. The material's geotechnical properties were input according to Tables 13.1-13.7. The failure planes were determined such that the most critical areas would be analyzed along the fill surface. Two piezometric scenarios were assessed separately. The piezometric lines were at a 10ft thickness along the bottom of the fill to model a saturated gravity segregated durable rock underdrain, and a $50 \mathrm{ft}(15.24 \mathrm{~m})$ elevated water table to approximate a more critical condition. Tables summarizing the deterministic and sensitivity factors of safety are shown below in Table 13.21 and Table 13.22. Slope angles are shown in Table 13.23.

\section{Results}

Table 13.21. Sensitivity critical factor of safety results for the critical slope for two piezometric scenarios

\begin{tabular}{|c|l|r|r|r|r|c|}
\hline \multirow{2}{*}{ Location } & \multicolumn{5}{|c|}{ Critical Sensitivity Factor of Safety } \\
\cline { 2 - 8 } \multicolumn{2}{|c|}{ Crest } & Friction Angle, $\boldsymbol{\varphi}$ & FS for $\boldsymbol{\varphi}$ & Unit Wt., $\boldsymbol{\gamma}_{\mathbf{d}}$ & FS for $\boldsymbol{\gamma}_{\mathbf{d}}$ & \multicolumn{1}{c|}{ FS } \\
\hline \multirow{3}{*}{ Toe } & Piez. 1 & 19.475 & 0.611 & 13.407 & 0.745 & 0.887 \\
\cline { 2 - 8 } & Piez. 2 & 19.475 & 0.611 & 13.407 & 0.745 & 0.887 \\
\hline \multirow{3}{*}{ Face } & Piez. 1 & 19.475 & 0.227 & 13.407 & 0.220 & 0.363 \\
\cline { 2 - 8 } & Piez. 2 & 19.475 & 0.402 & 13.407 & 0.489 & 0.584 \\
\hline \multirow{3}{*}{ Deep } & Piez. 1 & 19.475 & 0.463 & 13.407 & 0.564 & 0.670 \\
\hline & Piez. 2 & 19.475 & 0.345 & 13.407 & 0.400 & 0.519 \\
\hline & Piez. 1 & 19.475 & 0.468 & 13.407 & 0.570 & 0.677 \\
\hline
\end{tabular}


Table 13.22. Deterministic critical factor of safety results for the critical slope for two piezometric scenarios

\begin{tabular}{|c|c|c|}
\hline \multicolumn{3}{|c|}{ Laboratory Values } \\
\hline \multicolumn{2}{|c|}{ Location } & $\begin{array}{l}\text { Critical Deterministic } \\
\text { Factor of Safety }\end{array}$ \\
\hline \multirow{2}{*}{ Crest } & Piez. 1 & 0.879 \\
\hline & \begin{tabular}{|l|} 
Piez. 2 \\
\end{tabular} & 0.879 \\
\hline \multirow{2}{*}{ Toe } & Piez. 1 & 0.409 \\
\hline & Piez. 2 & 0.598 \\
\hline \multirow{2}{*}{ Face } & Piez. 1 & 0.685 \\
\hline & Piez. 2 & 0.551 \\
\hline \multirow{2}{*}{ Deep } & Piez. 1 & 0.679 \\
\hline & Piez. 2 & 0.535 \\
\hline
\end{tabular}




\section{AOC Valley Fill and Geomorphic Alternative Profiles}

An additional assessment of the friction angle of the material was performed at a loose, as received condition. The friction angles were found through direct shear testing on GeoTac ${ }^{\mathrm{TM}}$ equipment. Figure 13.17 shows the direct shear information for an as received friction angle (phi). It was found that the friction angle for the cohesion case was $37.99^{\circ}$. The friction angle for the no cohesion case, or where the best fit line is forced through $(0,0)$ was $39.75^{\circ}$. The WVDEP permit File\#S500809 which was used to define the geometry of the AOC valley fill slope used a friction angle of $40^{\circ}$ for the slope stability analysis performed on the valley fill. An analysis was performed in order to attain factors of safety for the same failure locations as defined for the AOC valley fill and geomorphic landform design alternative in Section 13.3 and Section 13.4. The results are shown in Figure 13.18 and Figure 13.19.

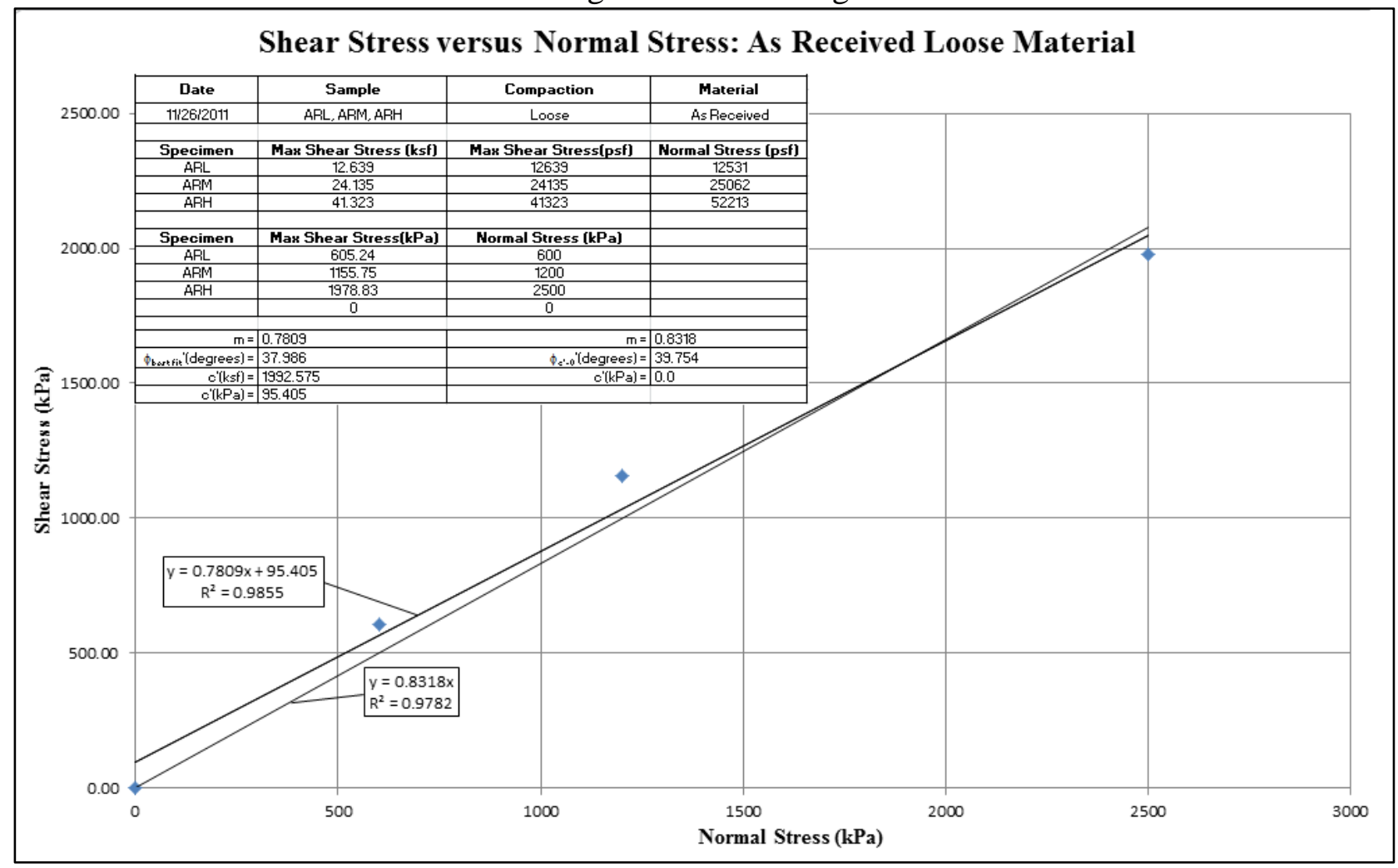

Figure 13.17. Direct shear information on as received testing 


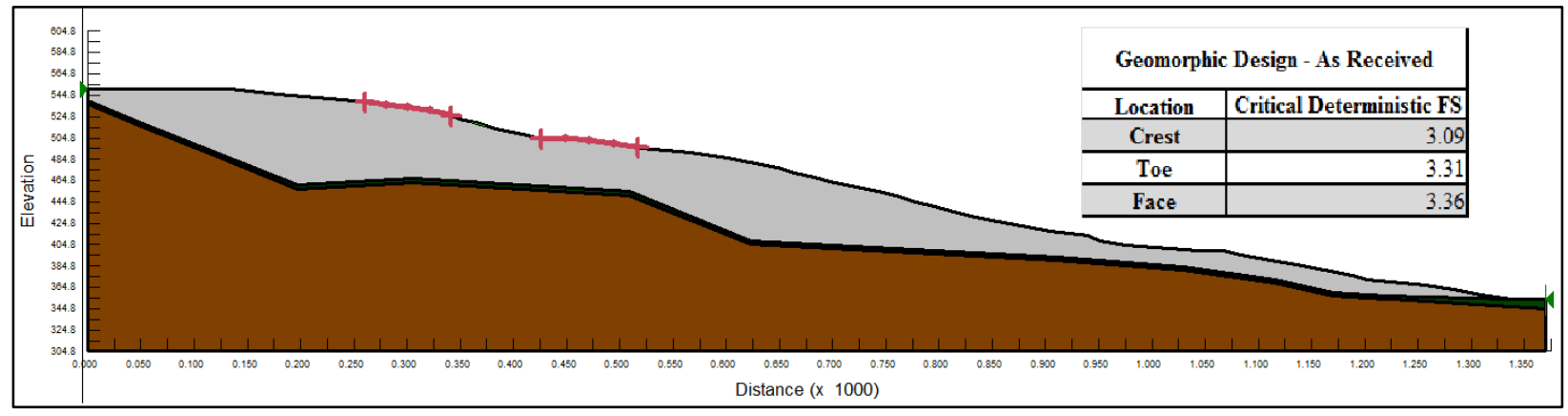

Figure 13.18. Geomorphic profile for as received models

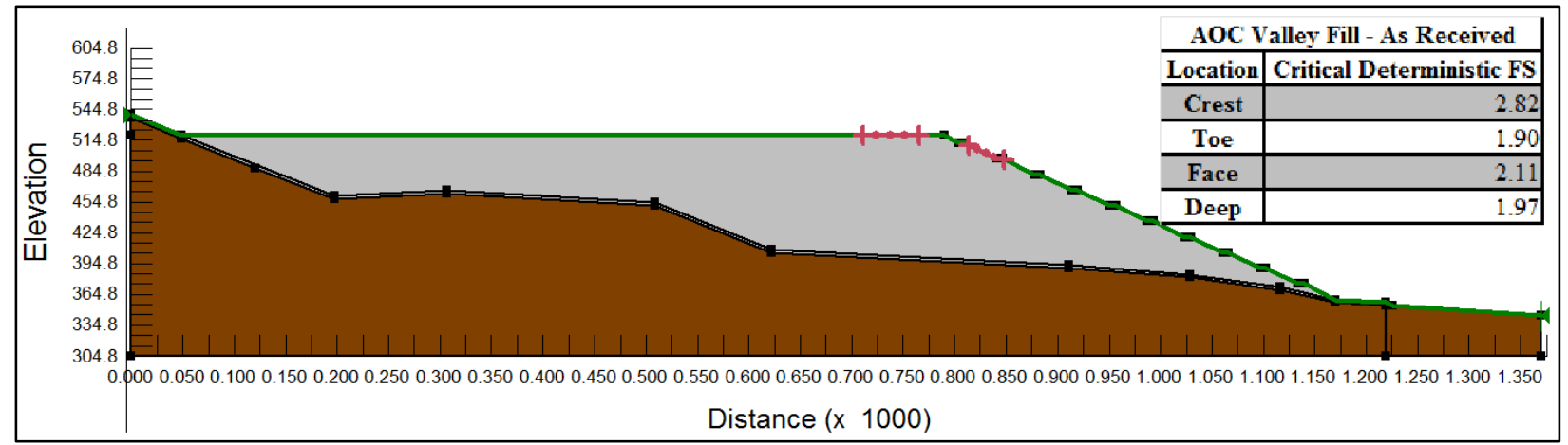

Figure 13.19. AOC valley fill profile for as received models

\section{Discussion}

The as received friction angle was modeled for the geomorphic and AOC valley fill profiles. It was found that the factors of safety increased significantly. The AOC factors of safety were all near 2.0 with a maximum of 2.82 and a minimum of 1.90 . The geomorphic valley fill alternative profile also had very high factors of safety which increased from all previous models. All factors of safety were above 3.0 for the geomorphic models. For the geomorphic models, the maximum factor of safety was 3.36, and a minimum of 3.09. Regulatory requirements enforce that a factor of safety of 1.5 must be met for all valley fill slope faces. With this friction angle input parameter at $39.75^{\circ}$, the factors of safety all greatly exceed the regulatory requirement. The material gradation considered as "as received" still had to be altered due to testing equipment limitations; however, the material passing the $3 / 8$ in. sieve was used. These high factors of safety imply that the previously shown input parameter for a friction angle of $27.7^{\circ}$ was rather conservative at a gradation of the material passing the \#4 sieve. Therefore, the factors of safety in Chapter 13 are conservative. 


\section{Summary and Comparison}

Five separate assessments were performed in the modules available in GeoStudio ${ }^{\mathrm{TM}}$ for comparison. Through this rigorous analysis, it was found that slope angles, phreatic elevations, and areas of increased pore pressures greatly affected the factors of safety that were yielded by GeoStudio $^{\mathrm{TM}}$ modules. The slope angles and associated coordinates for each failure plane assessed are shown in Table 13.23.

Table 13.23. Critical slip plane approximate exit point slope angles

\begin{tabular}{|c|c|c|c|c|c|c|c|}
\hline \multicolumn{8}{|c|}{ Slope Angles } \\
\hline & \multirow[t]{2}{*}{$\mathbf{x}(\mathbf{m})$} & \multirow[t]{2}{*}{$\mathbf{y}(\mathbf{m})$} & \multirow[t]{2}{*}{$\beta^{0}=\tan ^{-1}(y / x)$} & \multicolumn{2}{|c|}{ Top Left Coord. } & \multicolumn{2}{|c|}{$\begin{array}{c}\text { Bottom Right } \\
\text { Coord. }\end{array}$} \\
\hline & & & & $\mathbf{x}(\mathbf{m})$ & $\mathbf{y}(\mathbf{m})$ & $\mathbf{x}(\mathbf{m})$ & $\mathbf{y}(\mathbf{m})$ \\
\hline Valley Fill & 30.40 & 15.20 & 26.57 & 920.20 & 466.30 & 950.60 & 451.10 \\
\hline \multicolumn{8}{|c|}{ Geomorphic Alternative: Contour Profile } \\
\hline Face & 19.81 & 4.57 & 12.99 & 383.88 & 208.79 & 403.69 & 204.22 \\
\hline Toe & 25.05 & 4.57 & 10.34 & 950.76 & 103.63 & 975.81 & 99.06 \\
\hline Deep & 22.62 & 4.58 & 11.45 & 403.69 & 204.22 & 426.31 & 199.64 \\
\hline Crest & 18.96 & 4.57 & 13.55 & 349.49 & 217.93 & 368.45 & 213.36 \\
\hline \multicolumn{8}{|c|}{ Geomorphic Alternative: Plan Profile - Saturated } \\
\hline Face & 16.52 & 4.57 & 15.47 & 813.90 & 435.86 & 830.42 & 431.29 \\
\hline Toe & 14.39 & 4.57 & 17.63 & 1188.21 & 376.43 & 1202.60 & 371.86 \\
\hline Crest & 22.62 & 4.57 & $\mathbf{1 1 . 4 3}$ & 403.689 & 509.02 & 426.31 & 504.44 \\
\hline \multicolumn{8}{|c|}{ Geomorphic Alternative: Plan Profile - Unsaturated } \\
\hline Face & 35.48 & 4.57 & 7.34 & 904.86 & 417.58 & 940.33 & 413.00 \\
\hline Toe & 68.09 & 4.57 & 3.84 & 975.82 & 403.86 & 1043.91 & 399.29 \\
\hline Crest & 22.62 & 4.57 & 11.43 & 403.69 & 509.02 & 426.31 & 504.44 \\
\hline \multicolumn{8}{|c|}{ Geomorphic Critical Slope } \\
\hline Face & 4.74 & 4.57 & 43.95 & 228.62 & 62.48 & 233.36 & 57.91 \\
\hline Toe & 104.59 & 56.39 & 28.33 & 154.45 & 91.44 & 259.04 & 35.05 \\
\hline Deep & 6.48 & 4.57 & 35.19 & 252.56 & 39.62 & 259.04 & 35.05 \\
\hline Crest & 5.82 & 4.57 & 38.14 & 172.3 & 108.2 & 178.12 & 103.63 \\
\hline
\end{tabular}

The height of the piezometric line had a profound influence on the factors of safety. When an area was saturated, the factor of safety decreased, sometimes below 1.0 as in the piez. 2 toe scenario of the AOC valley fill design (Table 13.24). If the piezometric line was not elevated to the area of the selected failure plane, then the factor of safety remained unchanged.

Additionally, steeper slope angles decreased factors of safety. Two initial saturation conditions were modeled for the cumulative analysis. The saturation conditions were applied in SEEP/W, and SIGMA/W computed insitu stresses to be input into SLOPE/W for a factor of safety computation. The initial saturation condition of the gravity segregated durable rock underdrain was significant. The initial saturation altered the volume of water retained within the structure, 
and ultimately altered the factors of safety that resulted. Tables 13.24 and 13.25 show the factors of safety for both the saturated and unsaturated initial hydraulic condition. The factors of safety vary from one hydraulic condition to the next, but do not necessarily increase or decrease accordingly. The result is an effect of the varying areas of increased pore pressure. The result of the SEEP/W analysis produced outputs that accumulated water storage within each fill in different areas, which resulted in varying factors of safety. Both cumulative analysis that were run for the geomorphic design and the valley fill proved that the initial condition could vary the factor of safety. The change in the factor of safety was not always in favor of either condition from a structural standpoint. The significance of the initial saturation condition was that the water storage areas within the fill changed, and altered the factors of safety. It is important to note that the fills may be built in lifts or by end dumping. Sometimes when contractors build slopes, they cut into the original ground, and may use compaction equipment to help integrate the components of the structure. These considerations would likely alter the factors of safety. Additionally, spatial variability was only taken into account in these models as a sensitivity analysis. Field conditions of a slope structure would have a great deal of spatial variability both in compaction and in initial water content affecting soil strength and phreatic surface elevations.

By far, the cumulative analysis for the geomorphic valley fill alternative design yielded the highest factors of safety. Most cases produced factors of safety over 2.0. The most likely reason for these high factors of safety is that the geomorphic design has shallower slopes, and drains well. Geomorphic landform design can be utilized to reduce infiltration volumes by shortening runoff travel distances, increasing runoff water removal from a design site. A completed design should retain less water than the modeled results show because of vegetative cover and quick surface runoff. Both initial saturated and unsaturated conditions yielded high factors of safety. The failure locations were sought out to find the lowest factors of safety for the structure. The geomorphic stability analysis described in section 13.4 yielded high factors of safety (Table 13.25) also; however, the water tables were exaggerated. The profile described in section 13.4 still retains its structural integrity even when high volumes of water are being stored within it. None of the factors of safety even under the most critical circumstances tested yielded factors of safety under 1.0. Even though the original ground dimensions vary for the two profiles, the surface dimensions are identical except for the near the toe. The results prove that the geomorphic design can remain very stable under different conditions and geometries.

The weakest structure was by far the critical slope described in section 13.7. None of the factors of safety under any scenario analyzed yielded a factor of safety over 1.0. The factors of safety of this structure were expected to be low. The analysis of the critical slope was intended to illustrate that GeoFluv ${ }^{\circledR}$ does not consider slope stability, and can produce slopes that are not stable. As discussed in section 13.7, GeoFluv® does enable the designer to alter many components of the design to mitigate the slope stability problems that may occur due to rapid elevation changes.

The AOC design was typical with its bench cuts and planar slopes. Regulations require that slope factors of safety must remain above 1.5. The analysis performed showed that the design could withstand insitu loads and slope angle under most conditions analyzed. Elevated pore pressures tended to result at the toe of the slope, and decreased the factor of safety. The most critical scenario was a totally saturated toe which yielded a factor of safety of 0.50 as shown in the piez. 2 toe AOC valley fill design model summary in Table 13.24. 
The SEEP/W analysis yielded results that implied that the structure drained well for the AOC valley fill design. There were small areas of water storage accumulation and elevated pore water pressures, but nothing which caused the factor of safety to drop below 1.0 for the cumulative analysis. For the cumulative analysis, the lowest factor of safety for the AOC valley fill design was 1.22 at the toe of the slope at an initially unsaturated durable rock underdrain condition.

Geomorphic design decreases erosion potential and therefore decreases maintenance demands. The proposed AOC design would be adequate if it remained sufficiently drained. If particle transport can occur and alter toe pore pressures, it is possible that some small slope failure may occur. The gradations that were found in the fill material in Chapter 9 and Chapter 12 show that particle transport probably would not be a concern for the laboratory tested unweathered sandstone.

Table 13.24. AOC valley fill slope summary

\begin{tabular}{|c|c|c|c|c|}
\hline \multicolumn{5}{|c|}{ Slope Angles and Correlating Factors of Safety } \\
\hline $\begin{array}{l}\text { Failure } \\
\text { Plane }\end{array}$ & $\begin{array}{l}\text { Hydraulic } \\
\text { Condition }\end{array}$ & $\beta^{0}=\tan ^{-1}(y / x)$ & $\begin{array}{c}\text { Critical } \\
\text { Deterministic FS }\end{array}$ & $\begin{array}{c}\text { Critical Sensitivity } \\
\text { Factor of Safety }\end{array}$ \\
\hline \multicolumn{5}{|c|}{ AOC Valley Fill Design (Permit Values) } \\
\hline \multirow[b]{2}{*}{ Crest } & Piez. 1 & 26.57 & 2.84 & - \\
\hline & Piez. 2 & 26.57 & 2.84 & - \\
\hline \multirow[b]{2}{*}{ Toe } & Piez. 1 & 26.57 & 1.51 & - \\
\hline & Piez. 2 & 26.57 & 0.91 & - \\
\hline \multirow[b]{2}{*}{ Face } & Piez. 1 & 26.57 & 2.13 & - \\
\hline & Piez. 2 & 26.57 & 2.13 & - \\
\hline \multirow[b]{2}{*}{ Deep } & Piez. 1 & 26.57 & 1.54 & - \\
\hline & Piez. 2 & 26.57 & 1.41 & - \\
\hline \multicolumn{5}{|c|}{ AOC Valley Fill Design (Laboratory Values) } \\
\hline \multirow{2}{*}{ Face } & Piez. 1 & 26.57 & 1.78 & 1.74 \\
\hline & Piez. 2 & 26.57 & 1.78 & 1.74 \\
\hline \multirow{2}{*}{ Toe } & Piez. 1 & 26.57 & 1.23 & 1.20 \\
\hline & Piez. 2 & 26.57 & 0.50 & 0.40 \\
\hline \multirow{2}{*}{ Deep } & Piez. 1 & 26.57 & 1.33 & 1.31 \\
\hline & Piez. 2 & 26.57 & 1.33 & 1.31 \\
\hline \multirow{2}{*}{ Crest } & Piez. 1 & 26.57 & 1.37 & 1.35 \\
\hline & Piez. 2 & 26.57 & 1.21 & 1.18 \\
\hline \multicolumn{5}{|c|}{ Cumulative Analysis: AOC Valley Fill Design - Saturated } \\
\hline Crest & Saturated & 26.57 & 1.41 & 1.38 \\
\hline Toe & Saturated & 26.57 & 1.51 & 1.47 \\
\hline Face & Saturated & 26.57 & 1.39 & 1.36 \\
\hline Deep & Saturated & 26.57 & 1.38 & 1.35 \\
\hline \multicolumn{5}{|c|}{ Cumulative Analysis: AOC Valley Fill Design - Unsaturated } \\
\hline Crest & Unsaturated & 26.57 & 1.67 & 1.64 \\
\hline Toe & Unsaturated & 26.57 & 1.25 & 1.22 \\
\hline Face & Unsaturated & 26.57 & 1.37 & 1.34 \\
\hline Deep & Unsaturated & 26.57 & 1.30 & 1.27 \\
\hline
\end{tabular}


Table 13.25. Geomorphic valley fill alternative slope summary

\begin{tabular}{|c|c|c|c|c|}
\hline \multicolumn{5}{|c|}{ Slope Angles and Correlating Factors of Safety } \\
\hline $\begin{array}{l}\text { Failure } \\
\text { Plane }\end{array}$ & $\begin{array}{l}\text { Hydraulic } \\
\text { Condition }\end{array}$ & $\beta^{0}=\tan ^{-1}(y / x)$ & $\begin{array}{c}\text { Critical } \\
\text { Deterministic FS }\end{array}$ & $\begin{array}{l}\text { Critical Sensitivity } \\
\text { Factor of Safety }\end{array}$ \\
\hline \multicolumn{5}{|c|}{ Stability Analysis: Geomorphic Valley Fill Alternative } \\
\hline \multirow{2}{*}{ Face } & Piez. 1 & 12.99 & 1.82 & 1.78 \\
\hline & Piez. 2 & 12.99 & 1.82 & 1.78 \\
\hline \multirow{2}{*}{ Toe } & Piez. 1 & 10.34 & 1.82 & 1.78 \\
\hline & Piez. 2 & 10.34 & 1.62 & 1.56 \\
\hline \multirow{2}{*}{ Deep } & Piez. 1 & 11.45 & 1.78 & 1.74 \\
\hline & Piez. 2 & 11.45 & 1.78 & 1.74 \\
\hline \multirow{2}{*}{ Crest } & Piez. 1 & 13.55 & 1.94 & 1.90 \\
\hline & Piez. 2 & 13.55 & 1.94 & 1.90 \\
\hline \multicolumn{5}{|c|}{ Cumulative Analysis: Geomorphic Valley Fill Alternative - Saturated } \\
\hline Crest & Saturated & 11.43 & 2.04 & 2.00 \\
\hline Toe & Saturated & 17.63 & 2.14 & 2.10 \\
\hline Face & Saturated & 15.47 & 2.42 & 2.19 \\
\hline \multicolumn{5}{|c|}{ Cumulative Analysis: Geomorphic Valley Fill Alternative - Unsaturated } \\
\hline Crest & Unsaturated & 11.43 & 2.31 & 2.26 \\
\hline Toe & Unsaturated & 3.84 & 3.49 & 3.42 \\
\hline Face & Unsaturated & 7.34 & 2.15 & 2.10 \\
\hline \multicolumn{5}{|c|}{ Geomorphic Critical Slope } \\
\hline \multirow{2}{*}{ Face } & Piez. 1 & 43.95 & 0.88 & 0.89 \\
\hline & Piez. 2 & 43.95 & 0.88 & 0.89 \\
\hline \multirow{2}{*}{ Toe } & Piez. 1 & 28.33 & 0.41 & 0.36 \\
\hline & Piez. 2 & 28.33 & 0.60 & 0.58 \\
\hline \multirow{2}{*}{ Deep } & Piez. 1 & 35.19 & 0.69 & 0.67 \\
\hline & Piez. 2 & 35.19 & 0.55 & 0.52 \\
\hline \multirow{2}{*}{ Crest } & Piez. 1 & 38.14 & 0.68 & 0.68 \\
\hline & Piez. 2 & 38.14 & 0.54 & 0.51 \\
\hline
\end{tabular}




\section{Conclusions and Practical Significance}

The objective of this research was to sample and identify a surface mine spoil in southern West Virginia, characterize its associated physical properties as well as the strength aspects for appropriate input parameter key in into a slope stability software analysis tool to compare stability results of an AOC valley fill and a geomorphic landform design with regard to a factor of safety computed by the general limit equilibrium method. The significant conclusions of this research are as follows:

By rigorous analysis of the laboratory testing for the unweathered sandstone overburden material, the following conclusions were identified:

- The standard proctor curve is a typical bell shaped curve with an optimum dry unit weight of $18.75 \mathrm{kN} / \mathrm{m}^{3}$ at a moisture content of approximately $10.75 \%$. The $34 \%$ proctor curve resembles a transition between standard proctor and $11 \%$ proctor curves. The optimum dry density of the $34 \%$ proctor curve was $18.1 \mathrm{kN} / \mathrm{m}^{3}$ at a moisture content of $14.50 \%$. The $11 \%$ proctor curve shows a compaction curve resembling a standard behavior for a well graded sand. The optimum dry density of the $11 \%$ proctor was at $17.6 \mathrm{kN} / \mathrm{m}^{3}$ with a moisture content of approximately $17.00 \%$. The minimum dry density of the $11 \%$ curve was at $10.50 \%$ moisture content at a value of $14.90 \mathrm{kN} / \mathrm{m}^{3}$. The compaction energy applied in these three scenarios varied from $592.5 \mathrm{~kJ} / \mathrm{m}^{3}$ (standard proctor), $203.6 \mathrm{~kJ} / \mathrm{m}^{3}$ ( $34 \%$ proctor), and $67.85 \mathrm{~kJ} / \mathrm{m}^{3}$ (11\% proctor). The optimum dry densities did not increase by much, only a difference of $1.15 \mathrm{kN} / \mathrm{m}^{3}$ between standard proctor and $11 \%$ proctor compaction. The corresponding moisture contents for these maximums varied from $10.75 \%$ (standard proctor) to $17.00 \%$ (11\% proctor) at a difference of $6.25 \%$. By observation of the data, the material does not need a significant amount of compaction in order to achieve a high dry density, but it does need the accompanying moisture content to achieve it.

- The shear strain curves revealed that much of the residual strength is retained within the sample. The reason the samples retained their strength is likely a result of the creation of the unweathered material. The geometry of the particles of the sample is angular. The material was blasted, unweathered sandstone. The angular nature of the material increases the friction between shear planes and resists displacement. This insight is beneficial when considering slope stability. Slopes constructed with this material should be strong and resistant to failure $(\mathrm{FS}<1)$. Regulations require a factor of safety of 1.5 or greater.

- The hydraulic conductivity for each test performed for standard proctor, $34 \%$ proctor, and $11 \%$ proctor all remained in the order of $10^{-9} \mathrm{~m} / \mathrm{s}$. The neither the $34 \%$ proctor permeated specimens, nor the standard proctor specimens had hydraulic consolidation effects. Some hydraulic consolidation did occur for the $11 \%$ proctor specimens. The consolidation that occurred was the cause of the low hydraulic conductivity of the $11 \%$ proctor specimens. The soil structure could not retain its skeleton and void spaces collapsed under the hydraulic gradient of $i=15$. The standard proctor and $34 \%$ proctor specimens had low porosities in a range of $n=0.31$ to $n=0.38$ which resulted in low hydraulic conductivities. 
While observing the summary of the gradations produced by the as received grain size distribution, the pre-permeability test specimens, and the post-permeability specimens, the following conclusions were formed:

- Comparatively, taking into consideration all three compaction energies and the results shown above of the test scenarios performed it was found that particle movement varied significantly. The variation in gradation was a function of the moisture content added and the energy applied for preparation. The post-permeability results should be interpreted carefully as each specimen of different density varied in pore volume flux. The standard proctor specimens aggregated the most between $\mathrm{D}_{50}$ and $\mathrm{D}_{15}$ due to compaction, then aggregated more at a post-permeability condition. The $34 \%$ Proctor compaction specimens showed similar results as standard proctor, aggregating more at a post-permeability condition. The $11 \%$ Proctor compaction specimen results were opposite $34 \%$ Proctor compaction results and standard proctor compaction results. The 11\% Proctor compaction specimen aggregated most at a pre-permeability condition, then became less aggregated at a post-permeability condition.

- The results of the particle transport analysis indicate that the unweathered sandstone material reaches an aggregated equilibrium with very similar gradation after some pore volumes of water permeate through it. The results also imply that introducing a range of compaction energy can alter soil properties and have performance implications on earthen structures. Layered construction known as "lift construction" could assist in better quality control of the compaction energy applies to earthen structures to more precisely manage the aggregation phenomena. The amount of compaction energy for the $34 \%$ Proctor compaction and standard proctor samples seems to have broken up the aggregated particles, then when they were permeated, became more aggregated. After the permeation occurred, all three compaction energies approached a similar gradation, but diverged somewhat as the particle size decreased. The specimens began diverging in similarity around $40 \%$ finer.

- Through rigorous grain size distribution analysis of the pre and post-permeability test specimens, it was found that at a $\mathrm{D}_{10}$ post-permeability condition, the $11 \%$ Proctor compaction energy compacted and permeated sample had the smallest particles, standard proctor had the next highest, and 34\% Proctor energy specimens had the largest particle size. Overall the $11 \%$ proctor pre-permeability condition had the most aggregated particles, likely due to little compaction energy applied to break apart aggregated particles. At $\mathrm{D}_{10}$ at a prepermeability condition, the standard proctor sample had the smallest particles, then $34 \%$ proctor, and $11 \%$ Proctor energy samples had the largest aggregated particles.

The numerical modeling of the AOC valley fill design juxtaposed with the geomorphic landform design alternative, the following significant conclusions were drawn:

- The height of the piezometric line had a profound influence on the factors of safety. When an area was saturated, the factor of safety decreased, sometimes below 1.0 as in the piez. 2 toe scenario of the AOC valley fill design (Table 13.24). If the piezometric line was not elevated to the area of the selected failure plane, then the factor of safety remained unchanged. Steep slope angles also decreased the factors of safety. 
- Two initial saturation conditions were modeled for the cumulative analysis. The saturation conditions were applied in SEEP/W, and SIGMA/W computed insitu stresses to be input into SLOPE/W for a factor of safety computation. The initial saturation condition of the gravity segregated durable rock underdrain was significant. The initial saturation condition altered the volume of water retained within the structure, and ultimately altered the factors of safety that resulted.

- In the cumulative analysis, the change in the factor of safety was not always in favor of either saturation condition from a structural standpoint. The significance of the initial saturation condition was that the water storage areas within the fill changed, and altered the factors of safety. It is important to note that the fills may be built in lifts or by end dumping.

Sometimes when contractors build slopes, they cut into the original ground, and may use compaction equipment to help integrate the components of the structure. These considerations would likely alter the factors of safety.

- The cumulative analysis for the geomorphic valley fill alternative design yielded the highest factors of safety. Most cases produced factors of safety over 2.0. The most likely reason for these high factors of safety is that the geomorphic design has shallower slopes, and drains well. Geomorphic landform design can be utilized to reduce infiltration volumes by shortening runoff travel distances, increasing runoff water removal from a design site. A completed design should retain less water than the modeled results show because of vegetative cover and quick surface runoff.

- The geomorphic stability analysis described in section 13.4 yielded high factors of safety between 1.56 and 1.92 (Table 13.25) also; however, the water tables were exaggerated. The geomorphic profile described in section 13.4 still retains its structural integrity even when high volumes of water are being stored within it. None of the factors of safety even under the most critical circumstances tested yielded factors of safety under 1.0. The results prove that the geomorphic design can remain stable under extreme hydraulic conditions and varying geometries.

- The weakest structure assessed was by far the critical slope described in section 13.7. None of the factors of safety under any scenario analyzed yielded a factor of safety over 1.0. The factors of safety of this structure were expected to be low. The analysis of the critical slope was intended to illustrate that GeoFluv® does not consider slope stability, and can produce slopes that are not stable. As discussed in section 13.7, GeoFluv ${ }^{\circledR}$ does enable the designer to alter many components of the design to mitigate the slope stability problems that may occur due to rapid elevation changes.

- The analysis performed for the AOC valley fill design showed that the design could withstand insitu loads and slope angle under most conditions analyzed. Elevated pore pressures tended to result at the toe of the slope, and decreased the factor of safety. The most critical scenario was a totally saturated toe which yielded a factor of safety of 0.50 as shown in the piez. 2 toe AOC valley fill design model summary in Table 13.24. 
- In the cumulative analysis, the SEEP/W assessment yielded results that implied that the structure drained well for the AOC valley fill design. There were small areas of water storage accumulation and elevated pore water pressures, but nothing which caused the factor of safety to drop below 1.0. For the cumulative analysis, the lowest factor of safety for the AOC valley fill design was 1.22 at the toe of the slope at an initially unsaturated durable rock underdrain condition.

- The as received material (material passing the 3/8 in. sieve) achieved a friction angle of $39.75^{\circ}$, which implies that the factors of safety which were produced for the friction angle of $27.7^{\circ}$ were conservative. The as received AOC valley fill achieved a maximum factor of safety of 2.82, and a minimum factor of safety of 1.90. The as received geomorphic landform design achieved a maximum factor of safety of 3.36, and a minimum factor of safety of 3.09 .

The conclusions pointed to supporting the idea of the geomorphic design of valley fills having advantages over Approximate Original Contour design applied to valley fills from a slope stability perspective.

A geomorphic fill showed a distinct advantage in the durability of the earthen structure geometry addressed. To further analyze the comparison between a geomorphic and AOC fill, probabilistic analyses could be performed to more thoroughly account for spatial variability. Spatial variability was only taken into account in these models as a sensitivity analysis. Field conditions of a slope structure would have a great deal of spatial variability both in compaction and in initial water content affecting soil strength and phreatic surface elevations.

The AOC valley fill design would be adequate if it remained sufficiently drained. If particle transport can occur and alter toe pore pressures, it is possible that some small slope failure may occur. The gradations that were found in the fill material in Chapter 9 and Chapter 12 show that particle transport probably would not be a concern for the laboratory tested unweathered sandstone.

Geomorphic design decreases erosion potential and therefore decreases maintenance demands theoretically, however, in order to fully address this potential benefit of geomorphic landform design, a thorough cost analysis with regard to construction techniques in AOC and geomorphic landform design would need to be investigated.

With the very limited amount of work that has been done with geomorphic fills in the region of central Appalachia, this research has provided a sound initial analysis to compare with previously used design techniques. Further research must be done as a thorough cost analysis, and different overburden property stability analysis local to Appalachia in order to make a fully informed decision as to whether or not geomorphic design would be feasible to implement in the reclamation of surface mines in central Appalachia. 


\section{References}

Abdelghani, F.B., Simon, R., Aubertin, M, Molson, J. \& Therrien, R. (2009). "Use of the hydrogeosphere code to simulate water flow and contaminants transport through mining wastes disposed in a symmetric open pit within fractured rock." Proc. Tailings and Mine Waste. Taylor and Francis Group. Vail, CO. 601-611.

ASTM Designation D422. (2007). "Standard Test Method for Particle-Size Analysis of Soils." Annual Book of ASTM Standards, American Society of Testing Materials, Easton, MD.

ASTM Designation D698. (2007). "Standard Test Methods for Laboratory Compaction Characteristics of Soil Using Standard Effort (12400 ft-lbf/ $\left.\mathrm{ft}^{3}\left(600 \mathrm{KN}-\mathrm{m} / \mathrm{m}^{3}\right)\right)$." Annual Book of ASTM Standards, American Society of Testing Materials, Easton, MD.

ASTM Designation D854. (2007). "Standard Test Methods for Specific Gravity of Soil Solids by Water Pycnometer." Annual Book of ASTM Standards, American Society of Testing Materials, Easton, MD.

ASTM Designation D2216. (2007). "Standard Test Methods for Laboratory Determination of Water (Moisture) Content of Soil and Rock by Mass." Annual Book of ASTM Standards, American Society of Testing Materials, Easton, MD.

ASTM Designation D2487. (2010). "Standard Practice for Classification of Soils for Engineering Purposes (Unified Soil Classification System)." Annual Book of ASTM Standards, American Society of Testing Materials, Easton, MD.

ASTM Designation D3080. (2007). "Standard Test Methods for.Direct Shear Test of Soils Under Consolidated Drained Conditions." Annual Book of ASTM Standards, American Society of Testing Materials, Easton, MD

ASTM Designation D4318. (2007). "Standard Test Methods for Liquid Limit, Plastic Limit, and Plasticity Index of Soils." Annual Book of ASTM Standards, American Society of Testing Materials, Easton, MD

ASTM Designation D-5856. (2007). "Standard test Method for Measurement of Hydraulic Conductivity of Porous Material using a Rigid-Wall, Compaction-Mold Permeameter." Annual Book of ASTM Standards, American Society of Testing Materials, Easton, MD.

Aubertin, M., Bussierre, B. \& Chapuis, R. (1996). "Hydraulic conductivity of homogenized tailings from hard rock mines." Can. Geotech. J., 33: 470-482.

Bugosh, N. 2004. Computerizing the fluvial geomorphic approach to land reclamation. National Meeting of the American Society of Mining and Reclamation and The 25th West Virginia Surface Mine Drainage Task Force, April 18-24, 240-258.

Bugosh N. 2009. A summary of some land surface and water quality monitoring results for constructed GeoFluv ® landforms. Revitalizing the Environment: Proven Solutions and Innovative Approaches, National Meeting of the American Society of Mining and Reclamation, Billings, MT, May 30 - June 5, 153-175.

Das, Braja M. (2006). Principles of Geotechnical Engineering ( $7^{\text {th }}$ ed.). Canada: Nelson Education Ltd. 
Davis ED, Duffy RJ. 2009. King coal vs. reclamation: Federal regulation of mountaintop removal mining in Appalachia. Administration and Society, 41(6), 674692.

Eckels, R, Bugosh N. 2010. Natural approach to mined land reclamation. FIG Congress 2010.

Ferrari JR, Lookingbill TR, McCormick B, Townsend PA. 2009. Surface mining and reclamation effects on flood response of watersheds in the central Appalachian Plateau region. Water Resources Research, 45, W04407.

Fredlund, M.D., Wilson, G.W. \& Fredlund, D.G. (1998). “Estimation of hydraulic properties of an unsaturated soil using a knowledge-based system." Proc., Second Inter. Conf. on Unsat. Soils. Beiling, China.

GEO-SLOPE International Ltd. (2007). Stability Modeling with SLOPE/W 2007 Version. Calgary, Alberta, Canada.

H. Gercek. April 22, 2006. "Poisson's ratio values for rocks." Elsevier. International Journal of Rock Mechanics \& Mining Sciences 44 (2007) 1-13.

Hartman KJ, Kaller MD, Howell JW, Sweka JA. 2005. How much do valley fills influence headwater streams? Hydrobiologia, 532, 91-102.

Hasselman, M. 2002. Bragg v. W-Va. Coal Ass'n and the unfortunate limitation of citizen suits against the state in cooperative federalism regimes. Ecol. Law Quart. 29: 205-229.

Martin-Duque JF, Sanz MA, Bodoque JM, Lucia A, Martin-Moreno C. 2009. Restoring earth surface processes through landform design. A 13-year monitoring of a geomorphic reclamation model for quarries on slopes. Earth Surface Processes and Landforms, 35, 531-548.

Martin-Moreno C, Martin-Duque JF, Nicolau JM, Sanchez L, Ruiz R, Sanz MA, Lucia A, Zapico I. 2008. A geomorphic approach for the ecological restoration of kaolin mines at the Upper Tagus Natural Park (Spain). $6^{\text {th }}$ European Conference on Ecological Restoration, Ghent, Belgium, August 8-12.

Measles D., Bugosh N. 2007. Making and building a fluvial geomorphic reclamation design at an active dragline mine using the GeoFluv ${ }^{\circledR}$ design method. 30 Years of SMCRA and Beyond, National Meeting of the American Society of Mining and Reclamation, Gillette, WY, June 2-7, 2007, 449-456.

Michael PR, Superfesky MJ, Uranowski LJ. 2010. "Challenges to applying the geomorphic and stream reclamation methodologies to mountaintop mining and excess spoil fill construction in steep-slope topography (e.g. Central Appalachia)." 2010 National Meeting of the American Society of Mining and Reclamation, Pittsburgh, PA Bridging Reclamation, Science and the Community June 5 - 11, 2010. R.I. Barnhisel (Ed.) Published by ASMR, 3134 Montavesta Rd., Lexington, KY 40502.

National Oceanic and Atmospheric Administration. (2012). "Precipitation Frequency Data Server (PFDS)." Hydrometeorological Design Studies Center, $<$ http://hdsc.nws.noaa.gov> (Feb. 10, 2012). 
Pond GJ, Passmore ME, Borsuk FA, Reynolds L, Rose CJ. 2008. Downstream effects of mountaintop coal mining: comparing biological conditions using family- and genus-level macroinvertebrate bioassessment tools. J. N. Am. Benthol. Soc., 27(3), 717-737.

Robson M, Spotts R, Wade R, Erickson W. 2009. A case history: Limestone quarry reclamation using fluvial geomorphic design techniques.

Rosgen DL. 1994. A classification of natural rivers. Catena, 22, 169-199.

Rosgen, D. 1996. Applied River Morphology. Wildland Hydrology, Pagosa Springs, Colorado.

Superfesky, M., Michael P. (2007). "Excess Spoil Minimization and Fill Stability.” Proc., SME Annual Meeting, SME, Denver, CO, 1-13.

Toy TJ, Chuse WR. 2005. “ Topographic reconstruction: a geomorphic approach.” Ecological Engineering, 24, 29-35.

USEPA. 2005. Final Programmatic Environmental Impact Statement (PEIS) on Mountaintop Mining/Valley Fills in Appalachia (EPA 9-03-R-05002). U.S. Environmental Protection Agency. http://www.epa.gov/region03/mtntop/eis2005.htm

West Virginia Department of Environmental Protection, Division of Mining and Reclamation. (1999). Permit Handbook: AOC and excess spoil disposal.

West Virginia Department of Environmental Protection (WVDEP), Permit ID S500809. Pine Creek No. 2 Surface Mine (July 12, 2007). 


\section{Appendices}

\section{Appendix I - Hydraulic Conductivity Data Tables}

Hydraulic Conductivity: Test 1 - Standard Proctor Compaction $\left(592.5 \mathrm{~kJ} / \mathrm{m}^{3}\right)$

\begin{tabular}{|c|c|c|c|c|c|c|}
\hline \multirow{2}{*}{ Time } & \multirow{2}{*}{$\begin{array}{l}\text { Vol } \\
\text { (ml) }\end{array}$} & \multirow{2}{*}{$\underset{(\min )}{\Delta \mathrm{t}}$} & \multirow{2}{*}{$\begin{array}{c}\text { Time } \\
\text { (Seconds) } \\
\Delta \mathrm{t} \\
\end{array}$} & \multirow{2}{*}{$\begin{array}{c}\text { Cumulative } \\
\text { (Seconds) } \\
\Delta \mathrm{t}\end{array}$} & $\begin{array}{c}\text { Time } \\
\text { (Hours) }\end{array}$ & \multirow{2}{*}{$\begin{array}{c}\Delta \mathrm{t} \\
\text { (hours) }\end{array}$} \\
\hline & & & & & Cumulative & \\
\hline $\begin{array}{r}12 / 21 / 113: 00 \\
\text { PM } \\
\end{array}$ & 0 & 0 & 0 & 0 & 0 & 0 \\
\hline $\begin{array}{r}12: 45 \\
\text { PM } \\
\end{array}$ & 0 & 0 & 0 & 0 & 0 & 0 \\
\hline $\begin{array}{r}10: 16 \\
\text { AM } \\
\end{array}$ & 0 & 21316 & 1278960 & 1278960 & 355.27 & 355.27 \\
\hline $\begin{array}{r}10: 25 \\
\text { AM } \\
\end{array}$ & 30 & 21325 & 540 & 1279500 & 355.42 & 0.15 \\
\hline $\begin{array}{r}10: 33 \\
\mathrm{AM} \\
\end{array}$ & 50 & 21333 & 480 & 1279980 & 355.55 & 0.13 \\
\hline $\begin{array}{r}1 / 5 / 1210: 46 \\
\mathrm{AM} \\
\end{array}$ & 70 & 21346 & 780 & 1280760 & 355.77 & 0.22 \\
\hline $\begin{array}{r}1 / 5 / 1211: 05 \\
\mathrm{AM} \\
\end{array}$ & 95 & 21365 & 1140 & 1281900 & 356.08 & 0.32 \\
\hline $\begin{array}{r}11 / 5 / 1211: 20 \\
\mathrm{AM} \\
\end{array}$ & 115 & 21380 & 900 & 1282800 & 356.33 & 0.25 \\
\hline $\begin{array}{r}1 / 5 / 1211: 35 \\
\mathrm{AM} \\
\end{array}$ & 130 & 21395 & 900 & 1283700 & 356.58 & 0.25 \\
\hline $\begin{array}{r}1 / 5 / 1211: 50 \\
\mathrm{AM} \\
\end{array}$ & 145 & 21410 & 900 & 1284600 & 356.83 & 0.25 \\
\hline $\begin{array}{r}1 / 5 / 12 \text { 12:05 } \\
\text { PM } \\
\end{array}$ & 160 & 21425 & 900 & 1285500 & 357.08 & 0.25 \\
\hline $\begin{array}{r}1 / 5 / 12: 20 \\
\mathrm{PM} \\
\end{array}$ & 175 & 21440 & 900 & 1286400 & 357.33 & 0.25 \\
\hline $\begin{array}{r}1 / 5 / 1212: 35 \\
\mathrm{PM} \\
\end{array}$ & 190 & 21455 & 900 & 1287300 & 357.58 & 0.25 \\
\hline $\begin{array}{r}1 / 5 / 12: 50 \\
\mathrm{PM} \\
\end{array}$ & 200 & 21470 & 900 & 1288200 & 357.83 & 0.25 \\
\hline 1/5/12 1:05 PM & 215 & 21485 & 900 & 1289100 & 358.08 & 0.25 \\
\hline
\end{tabular}




\begin{tabular}{|c|c|c|c|c|c|c|}
\hline 1/5/12 1:20 PM & 225 & 21500 & 900 & 1290000 & 358.33 & 0.25 \\
\hline 1/5/12 1:35 PM & 235 & 21515 & 900 & 1290900 & 358.58 & 0.25 \\
\hline 1/5/12 1:50 PM & 250 & 21530 & 900 & 1291800 & 358.83 & 0.25 \\
\hline 1/5/12 2:05 PM & 260 & 21545 & 900 & 1292700 & 359.08 & 0.25 \\
\hline 1/5/12 2:20 PM & 270 & 21560 & 900 & 1293600 & 359.33 & 0.25 \\
\hline 1/5/12 2:40 PM & 280 & 21580 & 1200 & 1294800 & 359.67 & 0.33 \\
\hline 1/5/12 3:00 PM & 295 & 21600 & 1200 & 1296000 & 360.00 & 0.33 \\
\hline 1/5/12 3:30 PM & 315 & 21630 & 1800 & 1297800 & 360.50 & 0.50 \\
\hline 1/5/12 4:00 PM & 335 & 21660 & 1800 & 1299600 & 361.00 & 0.50 \\
\hline 1/5/12 4:30 PM & 350 & 21690 & 1800 & 1301400 & 361.50 & 0.50 \\
\hline 1/5/12 5:00 PM & 370 & 21720 & 1800 & 1303200 & 362.00 & 0.50 \\
\hline 1/5/12 5:30 PM & 385 & 21750 & 1800 & 1305000 & 362.50 & 0.50 \\
\hline 1/5/12 6:00 PM & 400 & 21780 & 1800 & 1306800 & 363.00 & 0.50 \\
\hline 1/5/12 6:30 PM & 415 & 21810 & 1800 & 1308600 & 363.50 & 0.50 \\
\hline 1/5/12 7:00 PM & 430 & 21840 & 1800 & 1310400 & 364.00 & 0.50 \\
\hline 1/5/12 8:53 PM & 490 & 21953 & 6780 & 1317180 & 365.88 & 1.88 \\
\hline $\begin{array}{r}\text { 1/5/12 11:02 } \\
\text { PM }\end{array}$ & 540 & 22082 & 7740 & 1324920 & 368.03 & 2.15 \\
\hline 1/6/12 1:04 AM & 575 & 22204 & 7320 & 1332240 & 370.07 & 2.03 \\
\hline 1/6/12 5:28 AM & 630 & 22468 & 15840 & 1348080 & 374.47 & 4.40 \\
\hline $\begin{array}{r}1 / 6 / 12 \text { 10:08 } \\
\text { AM }\end{array}$ & 760 & 22748 & 16800 & 1364880 & 379.13 & 4.67 \\
\hline 1/6/12 1:00 PM & 800 & 22920 & 10320 & 1375200 & 382.00 & 2.87 \\
\hline
\end{tabular}


Hydraulic Conductivity: Test 1 - Standard Proctor Compaction $\left(592.5 \mathrm{~kJ} / \mathrm{m}^{3}\right)$ : Continued

\begin{tabular}{|c|c|c|c|c|c|c|}
\hline \multirow[t]{2}{*}{ Time } & \multirow{2}{*}{$\begin{array}{l}\text { Vol } \\
(\mathrm{ml})\end{array}$} & \multirow{2}{*}{$\begin{array}{c}\Delta \mathrm{t} \\
(\min )\end{array}$} & \multirow{2}{*}{$\begin{array}{c}\text { Time } \\
\text { (Seconds) } \\
\Delta \mathrm{t} \\
\end{array}$} & \multirow{2}{*}{$\begin{array}{c}\text { Cumulative } \\
\text { (Seconds) } \\
\Delta \mathrm{t}\end{array}$} & $\begin{array}{c}\text { Time } \\
\text { (Hours) }\end{array}$ & \multirow{2}{*}{$\begin{array}{c}\Delta \mathrm{t} \\
\text { (hours) }\end{array}$} \\
\hline & & & & & Cumulative & \\
\hline 1/6/12 8:35 PM & 970 & 23375 & 12600 & 1402500 & 389.58 & 3.50 \\
\hline $\begin{array}{r}\text { 1/7/12 10:15 } \\
\text { AM }\end{array}$ & 1115 & 24195 & 49200 & 1451700 & 403.25 & 13.67 \\
\hline 1/7/12 5:55 PM & 1180 & 24655 & 27600 & 1479300 & 410.92 & 7.67 \\
\hline $\begin{array}{r}1 / 7 / 12 \text { 11:07 } \\
\text { PM }\end{array}$ & 1215 & 24967 & 18720 & 1498020 & 416.12 & 5.20 \\
\hline $\begin{array}{r}1 / 8 / 12 \text { 12:30 } \\
\text { PM }\end{array}$ & 1288 & 25770 & 48180 & 1546200 & 429.50 & 13.38 \\
\hline $\begin{array}{r}1 / 8 / 1210: 50 \\
\text { PM } \\
\end{array}$ & 1330 & 26390 & 37200 & 1583400 & 439.83 & 10.33 \\
\hline $\begin{array}{r}\text { 1/9/12 9:09 } \\
\text { AM } \\
\end{array}$ & 1372 & 27009 & 37140 & 1620540 & 450.15 & 10.32 \\
\hline 1/9/12 2:01 PM & 1392 & 27301 & 17520 & 1638060 & 455.02 & 4.87 \\
\hline $\begin{array}{r}1 / 10 / 1212: 30 \\
\text { AM } \\
\end{array}$ & 1685 & 27930 & 37740 & 1675800 & 465.50 & 10.48 \\
\hline $\begin{array}{r}1 / 10 / 129: 15 \\
\text { AM } \\
\end{array}$ & 1985 & 28455 & 31500 & 1707300 & 474.25 & 8.75 \\
\hline $\begin{array}{r}1 / 10 / 122: 45 \\
\text { PM } \\
\end{array}$ & 2075 & 28785 & 19800 & 1727100 & 479.75 & 5.50 \\
\hline $\begin{array}{r}1 / 10 / 126: 24 \\
\text { PM } \\
\end{array}$ & 2105 & 29004 & 13140 & 1740240 & 483.40 & 3.65 \\
\hline $\begin{array}{r}1 / 10 / 1211: 30 \\
\text { PM } \\
\end{array}$ & 2145 & 29310 & 18360 & 1758600 & 488.50 & 5.10 \\
\hline $\begin{array}{r}1 / 11 / 129: 50 \\
\text { AM } \\
\end{array}$ & 2205 & 29930 & 37200 & 1795800 & 498.83 & 10.33 \\
\hline $\begin{array}{r}1 / 12 / 129: 35 \\
\mathrm{AM} \\
\end{array}$ & 2295 & 31355 & 85500 & 1881300 & 522.58 & 23.75 \\
\hline $\begin{array}{r}1 / 13 / 1211: 12 \\
\text { AM } \\
\end{array}$ & 2390 & 32892 & 92220 & 1973520 & 548.20 & 25.62 \\
\hline $\begin{array}{r}1 / 14 / 12: 30 \\
\text { AM } \\
\end{array}$ & 2448 & 33690 & 47880 & 2021400 & 561.50 & 13.30 \\
\hline
\end{tabular}




\begin{tabular}{|c|c|c|c|c|c|c|}
\hline $\begin{array}{r}1 / 15 / 12 \text { 1:00 } \\
\text { AM }\end{array}$ & 2530 & 35160 & 88200 & 2109600 & 586.00 & 24.50 \\
\hline $\begin{array}{r}1 / 15 / 12 \text { 12:45 } \\
\text { PM }\end{array}$ & 2580 & 35865 & 42300 & 2151900 & 597.75 & 11.75 \\
\hline $\begin{array}{r}1 / 16 / 121: 30 \\
\text { AM } \\
\end{array}$ & 2625 & 36630 & 45900 & 2197800 & 610.50 & 12.75 \\
\hline $\begin{array}{r}1 / 16 / 12 \text { 5:00 } \\
\text { PM }\end{array}$ & 2678 & 37560 & 55800 & 2253600 & 626.00 & 15.50 \\
\hline $\begin{array}{r}1 / 17 / 12 \text { 12:00 } \\
\text { AM } \\
\end{array}$ & 2700 & 37980 & 25200 & 2278800 & 633.00 & 7.00 \\
\hline $\begin{array}{r}1 / 17 / 1211: 25 \\
\text { AM } \\
\end{array}$ & 2740 & 38665 & 41100 & 2319900 & 644.42 & 11.42 \\
\hline $\begin{array}{r}1 / 18 / 129: 15 \\
\mathrm{AM} \\
\end{array}$ & 2805 & 39975 & 78600 & 2398500 & 666.25 & 21.83 \\
\hline $\begin{array}{r}1 / 19 / 12 \text { 10:45 } \\
\text { AM }\end{array}$ & 2895 & 41505 & 91800 & 2490300 & 691.75 & 25.50 \\
\hline
\end{tabular}


Hydraulic Conductivity: Test 1 - Standard Proctor Compaction $\left(592.5 \mathrm{~kJ} / \mathrm{m}^{3}\right)$ : Continued

\begin{tabular}{|c|c|c|c|c|c|c|c|c|c|c|c|}
\hline $\begin{array}{c}\Delta \mathrm{V}^{3} \\
\left(\mathrm{~cm}^{3}\right)\end{array}$ & $\mathrm{i}$ & $\begin{array}{l}\text { Area } \\
\left(\mathrm{cm}^{2}\right)\end{array}$ & $\begin{array}{c}\mathrm{q}_{\mathrm{in}} \\
\left(\mathrm{cm}^{3} / \mathrm{sec}\right)\end{array}$ & $\begin{array}{c}\text { qout } \\
\left(\mathrm{cm}^{3} / \mathrm{sec}\right)\end{array}$ & $\begin{array}{c}\mathrm{k} \\
(\mathrm{cm} / \mathrm{sec})\end{array}$ & $\mathrm{k}(\mathrm{m} / \mathrm{sec})$ & $\begin{array}{l}\text { Height } \\
\text { of } \\
\text { Water } \\
(\mathrm{cm}) \\
\end{array}$ & $\begin{array}{c}\text { Height } \\
\text { of } \\
\text { Water } \\
\text { (in) } \\
\end{array}$ & $\begin{array}{l}\text { Time } \\
\text { Step }\end{array}$ & $\mathrm{N}_{\mathrm{PV}}$ & $\begin{array}{c}\text { Qin (mL) } \\
\text { Cumulative }\end{array}$ \\
\hline 0 & 100 & 81.07 & 0 & 0 & 0 & $0.00 \mathrm{E}+00$ & 26.04 & 10.25 & 0 & 0 & 0 \\
\hline 0 & 100 & 81.07 & 0 & 0 & 0 & $0.00 \mathrm{E}+00$ & 25.08 & 9.88 & 1 & 0 & 0 \\
\hline 0 & 100 & 81.07 & $3.80 \mathrm{E}-05$ & $0.00 \mathrm{E}+00$ & $0.00 \mathrm{E}+00$ & $0.00 \mathrm{E}+00$ & 23.18 & 9.13 & 2 & 0 & 0 \\
\hline 30 & 100 & 81.07 & $4.50 \mathrm{E}-02$ & $5.56 \mathrm{E}-02$ & $6.85 \mathrm{E}-06$ & $6.85 \mathrm{E}-08$ & 22.86 & 9.00 & 3 & 0.11 & 30 \\
\hline 20 & 100 & 81.07 & $5.07 \mathrm{E}-02$ & 4.17E-02 & 5.14E-06 & $5.14 \mathrm{E}-08$ & 22.70 & 8.94 & 4 & 0.18 & 50 \\
\hline 20 & 100 & 81.07 & $3.12 \mathrm{E}-02$ & $2.56 \mathrm{E}-02$ & $3.16 \mathrm{E}-06$ & $3.16 \mathrm{E}-08$ & 22.54 & 8.88 & 5 & 0.25 & 70 \\
\hline 25 & 100 & 81.07 & $0.00 \mathrm{E}+00$ & $2.19 \mathrm{E}-02$ & $2.70 \mathrm{E}-06$ & $2.70 \mathrm{E}-08$ & 22.38 & 8.81 & 6 & 0.34 & 95 \\
\hline 20 & 100 & 81.07 & $2.70 \mathrm{E}-02$ & $2.22 \mathrm{E}-02$ & $2.74 \mathrm{E}-06$ & $2.74 \mathrm{E}-08$ & 22.38 & 8.81 & 7 & 0.42 & 115 \\
\hline 15 & 100 & 81.07 & $2.70 \mathrm{E}-02$ & $1.67 \mathrm{E}-02$ & $2.06 \mathrm{E}-06$ & $2.06 \mathrm{E}-08$ & 22.23 & 8.75 & 8 & 0.47 & 130 \\
\hline 15 & 100 & 81.07 & $2.70 \mathrm{E}-02$ & $1.67 \mathrm{E}-02$ & $2.06 \mathrm{E}-06$ & $2.06 \mathrm{E}-08$ & 22.07 & 8.69 & 9 & 0.52 & 145 \\
\hline 15 & 100 & 81.07 & $0.00 \mathrm{E}+00$ & $1.67 \mathrm{E}-02$ & $2.06 \mathrm{E}-06$ & $2.06 \mathrm{E}-08$ & 21.91 & 8.63 & 10 & 0.58 & 160 \\
\hline 15 & 100 & 81.07 & $0.00 \mathrm{E}+00$ & $1.67 \mathrm{E}-02$ & $2.06 \mathrm{E}-06$ & $2.06 \mathrm{E}-08$ & 21.91 & 8.63 & 11 & 0.63 & 175 \\
\hline 15 & 100 & 81.07 & $2.70 \mathrm{E}-02$ & $1.67 \mathrm{E}-02$ & $2.06 \mathrm{E}-06$ & $2.06 \mathrm{E}-08$ & 21.91 & 8.63 & 12 & 0.69 & 190 \\
\hline 10 & 100 & 81.07 & $2.70 \mathrm{E}-02$ & $1.11 \mathrm{E}-02$ & $1.37 \mathrm{E}-06$ & $1.37 \mathrm{E}-08$ & 21.75 & 8.56 & 13 & 0.72 & 200 \\
\hline 15 & 100 & 81.07 & $0.00 \mathrm{E}+00$ & $1.67 \mathrm{E}-02$ & $2.06 \mathrm{E}-06$ & $2.06 \mathrm{E}-08$ & 21.59 & 8.50 & 14 & 0.78 & 215 \\
\hline 10 & 100 & 81.07 & $0.00 \mathrm{E}+00$ & $1.11 \mathrm{E}-02$ & $1.37 \mathrm{E}-06$ & $1.37 \mathrm{E}-08$ & 21.59 & 8.50 & 15 & 0.81 & 225 \\
\hline 10 & 100 & 81.07 & $2.70 \mathrm{E}-02$ & $1.11 \mathrm{E}-02$ & $1.37 \mathrm{E}-06$ & $1.37 \mathrm{E}-08$ & 21.59 & 8.50 & 16 & 0.85 & 235 \\
\hline 15 & 100 & 81.07 & $2.70 \mathrm{E}-02$ & $1.67 \mathrm{E}-02$ & $2.06 \mathrm{E}-06$ & $2.06 \mathrm{E}-08$ & 21.43 & 8.44 & 17 & 0.90 & 250 \\
\hline 10 & 100 & 81.07 & $0.00 \mathrm{E}+00$ & $1.11 \mathrm{E}-02$ & $1.37 \mathrm{E}-06$ & $1.37 \mathrm{E}-08$ & 21.27 & 8.38 & 18 & 0.94 & 260 \\
\hline 10 & 100 & 81.07 & $0.00 \mathrm{E}+00$ & $1.11 \mathrm{E}-02$ & $1.37 \mathrm{E}-06$ & $1.37 \mathrm{E}-08$ & 21.27 & 8.38 & 19 & 0.98 & 270 \\
\hline 10 & 100 & 81.07 & $2.03 \mathrm{E}-02$ & $8.33 \mathrm{E}-03$ & $1.03 \mathrm{E}-06$ & $1.03 \mathrm{E}-08$ & 21.27 & 8.38 & 20 & 1.01 & 280 \\
\hline 15 & 100 & 81.07 & $0.00 \mathrm{E}+00$ & $1.25 \mathrm{E}-02$ & $1.54 \mathrm{E}-06$ & $1.54 \mathrm{E}-08$ & 21.11 & 8.31 & 21 & 1.07 & 295 \\
\hline 20 & 100 & 81.07 & $1.35 \mathrm{E}-02$ & $1.11 \mathrm{E}-02$ & $1.37 \mathrm{E}-06$ & $1.37 \mathrm{E}-08$ & 21.11 & 8.31 & 22 & 1.14 & 315 \\
\hline 20 & 100 & 81.07 & $1.35 \mathrm{E}-02$ & $1.11 \mathrm{E}-02$ & $1.37 \mathrm{E}-06$ & $1.37 \mathrm{E}-08$ & 20.96 & 8.25 & 23 & 1.21 & 335 \\
\hline 15 & 100 & 81.07 & $1.35 \mathrm{E}-02$ & 8.33E-03 & $1.03 \mathrm{E}-06$ & $1.03 \mathrm{E}-08$ & 20.80 & 8.19 & 24 & 1.27 & 350 \\
\hline 20 & 100 & 81.07 & $1.35 \mathrm{E}-02$ & $1.11 \mathrm{E}-02$ & $1.37 \mathrm{E}-06$ & $1.37 \mathrm{E}-08$ & 20.64 & 8.13 & 25 & 1.34 & 370 \\
\hline
\end{tabular}




\begin{tabular}{|r|r|r|r|r|r|r|r|r|r|r|r|}
\hline 15 & 100 & 81.07 & $1.35 \mathrm{E}-02$ & $8.33 \mathrm{E}-03$ & $1.03 \mathrm{E}-06$ & $1.03 \mathrm{E}-08$ & 20.48 & 8.06 & 26 & 1.39 & 385 \\
\hline 15 & 100 & 81.07 & $0.00 \mathrm{E}+00$ & $8.33 \mathrm{E}-03$ & $1.03 \mathrm{E}-06$ & $1.03 \mathrm{E}-08$ & 20.32 & 8.00 & 27 & 1.45 & 400 \\
\hline 15 & 100 & 81.07 & $0.00 \mathrm{E}+00$ & $8.33 \mathrm{E}-03$ & $1.03 \mathrm{E}-06$ & $1.03 \mathrm{E}-08$ & 20.32 & 8.00 & 28 & 1.50 & 415 \\
\hline 15 & 100 & 81.07 & $4.05 \mathrm{E}-02$ & $8.33 \mathrm{E}-03$ & $1.03 \mathrm{E}-06$ & $1.03 \mathrm{E}-08$ & 20.32 & 8.00 & 29 & 1.56 & 430 \\
\hline 60 & 100 & 81.07 & $7.17 \mathrm{E}-03$ & $8.85 \mathrm{E}-03$ & $1.09 \mathrm{E}-06$ & $1.09 \mathrm{E}-08$ & 19.84 & 7.81 & 30 & 1.77 & 490 \\
\hline 50 & 100 & 81.07 & $6.28 \mathrm{E}-03$ & $6.46 \mathrm{E}-03$ & $7.97 \mathrm{E}-07$ & $7.97 \mathrm{E}-09$ & 19.53 & 7.69 & 31 & 1.95 & 540 \\
\hline 35 & 100 & 81.07 & $9.97 \mathrm{E}-03$ & $4.78 \mathrm{E}-03$ & $5.90 \mathrm{E}-07$ & $5.90 \mathrm{E}-09$ & 19.21 & 7.56 & 32 & 2.08 & 575 \\
\hline 55 & 100 & 81.07 & $3.07 \mathrm{E}-03$ & $3.47 \mathrm{E}-03$ & $4.28 \mathrm{E}-07$ & $4.28 \mathrm{E}-09$ & 18.73 & 7.38 & 33 & 2.28 & 630 \\
\hline 130 & 100 & 81.07 & $5.79 \mathrm{E}-03$ & $7.74 \mathrm{E}-03$ & $9.54 \mathrm{E}-07$ & $9.54 \mathrm{E}-09$ & 18.42 & 7.25 & 34 & 2.75 & 760 \\
\hline 40 & 100 & 81.07 & $4.71 \mathrm{E}-03$ & $3.88 \mathrm{E}-03$ & $4.78 \mathrm{E}-07$ & $4.78 \mathrm{E}-09$ & 17.78 & 7.00 & 35 & 2.89 & 800 \\
\hline
\end{tabular}




\begin{tabular}{|c|c|c|c|c|c|c|c|c|c|c|c|}
\hline $\begin{array}{c}\Delta \mathrm{V} \\
\left(\mathrm{cm}^{3}\right)\end{array}$ & $\mathrm{i}$ & $\begin{array}{l}\text { Area } \\
\left(\mathrm{cm}^{2}\right)\end{array}$ & $\begin{array}{c}\mathrm{q}_{\mathrm{in}} \\
\left(\mathrm{cm}^{3} / \mathrm{sec}\right)\end{array}$ & $\begin{array}{c}\text { qout } \\
\left(\mathrm{cm}^{3} / \mathrm{sec}\right)\end{array}$ & $\begin{array}{c}\mathrm{k} \\
(\mathrm{cm} / \mathrm{sec})\end{array}$ & $\begin{array}{c}\mathrm{k} \\
(\mathrm{m} / \mathrm{sec})\end{array}$ & $\begin{array}{l}\text { Height of } \\
\text { Water } \\
(\mathrm{cm})\end{array}$ & $\begin{array}{c}\text { Height } \\
\text { of Water } \\
\text { (in) }\end{array}$ & $\begin{array}{l}\text { Time } \\
\text { Step }\end{array}$ & $\mathrm{N}_{\mathrm{PV}}$ & $\begin{array}{c}\text { Qin (mL) } \\
\text { Cumulative }\end{array}$ \\
\hline 160 & 100 & 81.07 & $3.31 \mathrm{E}-03$ & $1.09 \mathrm{E}-02$ & $\begin{array}{r}1.34 \mathrm{E}- \\
06 \\
\end{array}$ & $\begin{array}{r}1.34 \mathrm{E}- \\
08 \\
\end{array}$ & 17.46 & 6.88 & 36 & 3.47 & 960 \\
\hline 10 & 100 & 81.07 & $9.65 \mathrm{E}-03$ & 7.94E-04 & $\begin{array}{r}9.79 \mathrm{E}- \\
08 \\
\end{array}$ & $\begin{array}{r}9.79 \mathrm{E}- \\
10 \\
\end{array}$ & 17.15 & 6.75 & 37 & 3.51 & 970 \\
\hline 145 & 100 & 81.07 & $1.48 \mathrm{E}-03$ & $2.95 \mathrm{E}-03$ & $\begin{array}{r}3.64 \mathrm{E}- \\
07\end{array}$ & $\begin{array}{r}3.64 \mathrm{E}- \\
09\end{array}$ & 16.35 & 6.44 & 38 & 4.03 & 1115 \\
\hline 65 & 100 & 81.07 & 8.81E-04 & $2.36 \mathrm{E}-03$ & $\begin{array}{r}2.90 \mathrm{E}- \\
07 \\
\end{array}$ & $\begin{array}{r}2.90 \mathrm{E}- \\
09 \\
\end{array}$ & 15.88 & 6.25 & 39 & 4.27 & 1180 \\
\hline 35 & 100 & 81.07 & $5.20 \mathrm{E}-03$ & $1.87 \mathrm{E}-03$ & $\begin{array}{r}2.31 \mathrm{E}- \\
07 \\
\end{array}$ & $\begin{array}{r}2.31 \mathrm{E}- \\
09 \\
\end{array}$ & 15.72 & 6.19 & 40 & 4.40 & 1215 \\
\hline 73 & 100 & 81.07 & $1.01 \mathrm{E}-03$ & $1.52 \mathrm{E}-03$ & $\begin{array}{r}1.87 \mathrm{E}- \\
07 \\
\end{array}$ & $\begin{array}{r}1.87 \mathrm{E}- \\
09 \\
\end{array}$ & 15.08 & 5.94 & 41 & 4.66 & 1288 \\
\hline 42 & 100 & 81.07 & $6.54 \mathrm{E}-04$ & $1.13 \mathrm{E}-03$ & $\begin{array}{r}1.39 \mathrm{E}- \\
07 \\
\end{array}$ & $\begin{array}{r}1.39 \mathrm{E}- \\
09 \\
\end{array}$ & 14.76 & 5.81 & 42 & 4.81 & 1330 \\
\hline 42 & 100 & 81.07 & $3.27 \mathrm{E}-03$ & $1.13 \mathrm{E}-03$ & $\begin{array}{r}1.39 \mathrm{E}- \\
07 \\
\end{array}$ & $\begin{array}{r}1.39 \mathrm{E}- \\
09 \\
\end{array}$ & 14.61 & 5.75 & 43 & 4.96 & 1372 \\
\hline 20 & 100 & 81.07 & 1.67E-02 & $1.14 \mathrm{E}-03$ & $\begin{array}{r}1.41 \mathrm{E}- \\
07 \\
\end{array}$ & $\begin{array}{r}1.41 \mathrm{E}- \\
09 \\
\end{array}$ & 13.81 & 5.44 & 44 & 5.04 & 1392 \\
\hline 293 & 100 & 81.07 & 7.73E-03 & $7.76 \mathrm{E}-03$ & $\begin{array}{r}9.58 \mathrm{E}- \\
07 \\
\end{array}$ & $\begin{array}{r}9.58 \mathrm{E}- \\
09 \\
\end{array}$ & 11.91 & 4.69 & 45 & 6.10 & 1685 \\
\hline 300 & 100 & 81.07 & $3.86 \mathrm{E}-03$ & $9.52 \mathrm{E}-03$ & $\begin{array}{r}1.17 \mathrm{E}- \\
06 \\
\end{array}$ & $\begin{array}{r}1.17 \mathrm{E}- \\
08 \\
\end{array}$ & 10.00 & 3.94 & 46 & 7.18 & 1985 \\
\hline 90 & 100 & 81.07 & $1.23 \mathrm{E}-03$ & $4.55 \mathrm{E}-03$ & $\begin{array}{r}5.61 \mathrm{E}- \\
07 \\
\end{array}$ & $\begin{array}{r}5.61 \mathrm{E}- \\
09 \\
\end{array}$ & 9.21 & 3.63 & 47 & 7.51 & 2075 \\
\hline 30 & 100 & 81.07 & $3.70 \mathrm{E}-03$ & $2.28 \mathrm{E}-03$ & $\begin{array}{r}2.82 \mathrm{E}- \\
07 \\
\end{array}$ & $\begin{array}{r}2.82 \mathrm{E}- \\
09 \\
\end{array}$ & 9.05 & 3.56 & 48 & 7.62 & 2105 \\
\hline 40 & 100 & 81.07 & $2.65 \mathrm{E}-03$ & $2.18 \mathrm{E}-03$ & $\begin{array}{r}2.69 \mathrm{E}- \\
07 \\
\end{array}$ & $\begin{array}{r}2.69 \mathrm{E}- \\
09 \\
\end{array}$ & 8.73 & 3.44 & 49 & 7.76 & 2145 \\
\hline 60 & 100 & 81.07 & $2.62 \mathrm{E}-03$ & $1.61 \mathrm{E}-03$ & $\begin{array}{r}1.99 \mathrm{E}- \\
07 \\
\end{array}$ & $\begin{array}{r}1.99 \mathrm{E}- \\
09 \\
\end{array}$ & 8.41 & 3.31 & 50 & 7.98 & 2205 \\
\hline 90 & 100 & 81.07 & $1.42 \mathrm{E}-03$ & $1.05 \mathrm{E}-03$ & $\begin{array}{r}1.30 \mathrm{E}- \\
07\end{array}$ & $\begin{array}{r}1.30 \mathrm{E}- \\
09\end{array}$ & 7.78 & 3.06 & 51 & 8.30 & 2295 \\
\hline
\end{tabular}




\begin{tabular}{|c|c|c|c|c|c|c|c|c|c|c|c|}
\hline 95 & 100 & 81.07 & $\begin{array}{r}-1.21 \mathrm{E}- \\
02 \\
\end{array}$ & $1.03 \mathrm{E}-03$ & $\begin{array}{r}1.27 \mathrm{E}- \\
07 \\
\end{array}$ & $\begin{array}{r}1.27 \mathrm{E}- \\
09 \\
\end{array}$ & 6.99 & 2.75 & 52 & 8.65 & 2390 \\
\hline 58 & 100 & 81.07 & $2.64 \mathrm{E}-02$ & $1.21 \mathrm{E}-03$ & $\begin{array}{r}1.49 \mathrm{E}- \\
07 \\
\end{array}$ & $\begin{array}{r}1.49 \mathrm{E}- \\
09 \\
\end{array}$ & 14.29 & 5.63 & 53 & 8.86 & 2448 \\
\hline 82 & 100 & 81.07 & $5.51 \mathrm{E}-04$ & $9.30 \mathrm{E}-04$ & $\begin{array}{r}1.15 \mathrm{E}- \\
07 \\
\end{array}$ & $\begin{array}{r}1.15 \mathrm{E}- \\
09 \\
\end{array}$ & 6.03 & 2.38 & 54 & 9.16 & 2530 \\
\hline 50 & 100 & 81.07 & $1.15 \mathrm{E}-03$ & $1.18 \mathrm{E}-03$ & $\begin{array}{r}1.46 \mathrm{E}- \\
07 \\
\end{array}$ & $\begin{array}{r}1.46 \mathrm{E}- \\
09 \\
\end{array}$ & 5.72 & 2.25 & 55 & 9.34 & 2580 \\
\hline 45 & 100 & 81.07 & $1.06 \mathrm{E}-03$ & $9.80 \mathrm{E}-04$ & $\begin{array}{r}1.21 \mathrm{E}- \\
07 \\
\end{array}$ & $\begin{array}{r}1.21 \mathrm{E}- \\
09 \\
\end{array}$ & 5.40 & 2.13 & 56 & 9.50 & 2625 \\
\hline 53 & 100 & 81.07 & 4.36E-04 & $9.50 \mathrm{E}-04$ & $\begin{array}{r}1.17 \mathrm{E}- \\
07\end{array}$ & $\begin{array}{r}1.17 \mathrm{E}- \\
09\end{array}$ & 5.08 & 2.00 & 57 & 9.69 & 2678 \\
\hline 22 & 100 & 81.07 & $9.65 \mathrm{E}-04$ & $8.73 \mathrm{E}-04$ & $\begin{array}{r}1.08 \mathrm{E}- \\
07\end{array}$ & $\begin{array}{r}1.08 \mathrm{E}- \\
09\end{array}$ & 4.92 & 1.94 & 58 & 9.77 & 2700 \\
\hline 40 & 100 & 81.07 & $1.18 \mathrm{E}-03$ & $9.73 \mathrm{E}-04$ & $\begin{array}{r}1.20 \mathrm{E}- \\
07\end{array}$ & $\begin{array}{r}1.20 \mathrm{E}- \\
09\end{array}$ & 4.76 & 1.88 & 59 & 9.91 & 2740 \\
\hline 65 & 100 & 81.07 & $8.66 \mathrm{E}-03$ & $8.27 \mathrm{E}-04$ & $\begin{array}{r}1.02 \mathrm{E}- \\
07\end{array}$ & $\begin{array}{r}1.02 \mathrm{E}- \\
09\end{array}$ & 4.45 & 1.75 & 60 & 10.15 & 2805 \\
\hline 90 & 100 & 81.07 & $6.36 \mathrm{E}-03$ & $9.80 \mathrm{E}-04$ & $\begin{array}{r}1.21 \mathrm{E}- \\
07\end{array}$ & $\begin{array}{r}1.21 \mathrm{E}- \\
09\end{array}$ & 3.81 & 1.50 & 61 & 10.48 & 2895 \\
\hline
\end{tabular}


Hydraulic Conductivity: Test 2 - Standard Proctor Compaction $\left(592.5 \mathrm{~kJ} / \mathrm{m}^{3}\right)$

\begin{tabular}{|c|c|c|c|c|c|c|}
\hline \multirow[t]{2}{*}{ Time } & \multirow{2}{*}{$\begin{array}{l}\text { Vol } \\
(\mathrm{ml})\end{array}$} & \multirow{2}{*}{$\begin{array}{c}\Delta \mathrm{t} \\
(\min )\end{array}$} & \multirow{2}{*}{$\begin{array}{c}\text { Time } \\
\text { (Seconds) } \\
\Delta \mathrm{t}\end{array}$} & \multirow{2}{*}{$\begin{array}{l}\text { Cumulative } \\
\text { (Seconds) } \Delta t\end{array}$} & $\begin{array}{c}\text { Time } \\
\text { (Hours) }\end{array}$ & \multirow{2}{*}{$\begin{array}{c}\Delta \mathrm{t} \\
\text { (hours) }\end{array}$} \\
\hline & & & & & Cumulative & \\
\hline $\begin{array}{r}12 / 21 / 113: 00 \\
\text { PM }\end{array}$ & 0 & 0 & 0 & 0 & 0 & 0 \\
\hline $\begin{array}{r}1 / 3 / 1212: 35 \\
\text { AM } \\
\end{array}$ & 0 & 17855 & 1071300 & 1071300 & 297.58 & 297.58 \\
\hline $\begin{array}{r}1 / 5 / 12 \text { 10:16 } \\
\text { AM } \\
\end{array}$ & 0 & 21316 & 207660 & 1278960 & 355.27 & 57.68 \\
\hline $\begin{array}{r}1 / 5 / 1210: 25 \\
\text { AM }\end{array}$ & 15 & 21325 & 540 & 1279500 & 355.42 & 0.15 \\
\hline $\begin{array}{r}1 / 5 / 1210: 37 \\
\mathrm{AM} \\
\end{array}$ & 20 & 21337 & 720 & 1280220 & 355.62 & 0.20 \\
\hline $\begin{array}{r}1 / 5 / 1210: 46 \\
\mathrm{AM} \\
\end{array}$ & 35 & 21346 & 540 & 1280760 & 355.77 & 0.15 \\
\hline $\begin{array}{r}1 / 5 / 1211: 05 \\
\text { AM }\end{array}$ & 40 & 21365 & 1140 & 1281900 & 356.08 & 0.32 \\
\hline $\begin{array}{r}1 / 5 / 1211: 20 \\
\text { AM } \\
\end{array}$ & 45 & 21380 & 900 & 1282800 & 356.33 & 0.25 \\
\hline $\begin{array}{r}1 / 5 / 1211: 35 \\
\text { AM }\end{array}$ & 50 & 21395 & 900 & 1283700 & 356.58 & 0.25 \\
\hline $\begin{array}{r}1 / 5 / 1211: 50 \\
\text { AM } \\
\end{array}$ & 55 & 21410 & 900 & 1284600 & 356.83 & 0.25 \\
\hline $\begin{array}{r}1 / 5 / 12 \text { 12:05 } \\
\text { PM } \\
\end{array}$ & 60 & 21425 & 900 & 1285500 & 357.08 & 0.25 \\
\hline $\begin{array}{r}1 / 5 / 1212: 20 \\
\text { PM }\end{array}$ & 60 & 21440 & 900 & 1286400 & 357.33 & 0.25 \\
\hline $\begin{array}{r}1 / 5 / 1212: 35 \\
\text { PM } \\
\end{array}$ & 65 & 21455 & 900 & 1287300 & 357.58 & 0.25 \\
\hline $\begin{array}{r}1 / 5 / 1212: 50 \\
\text { PM } \\
\end{array}$ & 70 & 21470 & 900 & 1288200 & 357.83 & 0.25 \\
\hline 1/5/12 1:05 PM & 70 & 21485 & 900 & 1289100 & 358.08 & 0.25 \\
\hline 1/5/12 1:20 PM & 75 & 21500 & 900 & 1290000 & 358.33 & 0.25 \\
\hline 1/5/12 1:35 PM & 75 & 21515 & 900 & 1290900 & 358.58 & 0.25 \\
\hline
\end{tabular}




\begin{tabular}{|r|r|r|r|r|r|r|}
\hline $1 / 5 / 121: 50 \mathrm{PM}$ & 80 & 21530 & 900 & 1291800 & 358.83 & 0.25 \\
\hline $1 / 5 / 12$ 2:05 PM & 85 & 21545 & 900 & 1292700 & 359.08 & 0.25 \\
\hline $1 / 5 / 122: 40 \mathrm{PM}$ & 90 & 21580 & 2100 & 1294800 & 359.67 & 0.58 \\
\hline $1 / 5 / 123: 00 \mathrm{PM}$ & 95 & 21600 & 1200 & 1296000 & 360.00 & 0.33 \\
\hline $1 / 5 / 123: 30 \mathrm{PM}$ & 100 & 21630 & 1800 & 1297800 & 360.50 & 0.50 \\
\hline $1 / 5 / 124: 00 \mathrm{PM}$ & 110 & 21660 & 1800 & 1299600 & 361.00 & 0.50 \\
\hline $1 / 5 / 124: 30 \mathrm{PM}$ & 115 & 21690 & 1800 & 1301400 & 361.50 & 0.50 \\
\hline $1 / 5 / 125: 00 \mathrm{PM}$ & 120 & 21720 & 1800 & 1303200 & 362.00 & 0.50 \\
\hline $1 / 5 / 126: 00 \mathrm{PM}$ & 130 & 21780 & 3600 & 1306800 & 363.00 & 1.00 \\
\hline $1 / 5 / 127: 00 \mathrm{PM}$ & 140 & 21840 & 3600 & 1310400 & 364.00 & 1.00 \\
\hline $1 / 5 / 128: 53 \mathrm{PM}$ & 160 & 21953 & 6780 & 1317180 & 365.88 & 1.88 \\
\hline $1 / 5 / 1211: 02$ & 180 & 22082 & 7740 & 1324920 & 368.03 & 2.15 \\
\hline $\mathrm{PM}$ & 185 & 22204 & 7320 & 1332240 & 370.07 & 2.03 \\
\hline $1 / 6 / 121: 04 \mathrm{AM}$ & 195 & 15840 & 1348080 & 374.47 & 4.40 \\
\hline $1 / 6 / 125: 28 \mathrm{AM}$ & 235 & 22468 & 11520 & 1359600 & 377.67 & 3.20 \\
\hline $1 / 6 / 128: 40 \mathrm{AM}$ & 260 & 22660 & 4800 & 1364400 & 379.00 & 1.33 \\
\hline $1 / 6 / 1210: 00$ & 270 & 22740 & 25500 & 1389900 & 386.08 & 7.08 \\
\hline AM & 320 & 23165 & & & & \\
\hline $1 / 6 / 125: 05 \mathrm{PM}$ & 1300 & & & \\
\hline
\end{tabular}


Hydraulic Conductivity: Test 2 - Standard Proctor Compaction $\left(592.5 \mathrm{~kJ} / \mathrm{m}^{3}\right):$ Continued

\begin{tabular}{|c|c|c|c|c|c|c|}
\hline \multirow[t]{2}{*}{ Time } & \multirow{2}{*}{$\begin{array}{l}\text { Vol } \\
(\mathrm{ml})\end{array}$} & \multirow{2}{*}{$\begin{array}{c}\Delta \mathrm{t} \\
(\min )\end{array}$} & \multirow{2}{*}{$\begin{array}{c}\text { Time } \\
\text { (Seconds) } \\
\Delta \mathrm{t}\end{array}$} & \multirow{2}{*}{$\begin{array}{l}\text { Cumulative } \\
\text { (Seconds) } \Delta \mathrm{t}\end{array}$} & $\begin{array}{c}\text { Time } \\
\text { (Hours) }\end{array}$ & \multirow{2}{*}{$\begin{array}{c}\Delta \mathrm{t} \\
\text { (hours) }\end{array}$} \\
\hline & & & & & Cumulative & \\
\hline 1/6/12 8:35 PM & 340 & 23375 & 12600 & 1402500 & 389.58 & 3.50 \\
\hline $\begin{array}{r}1 / 7 / 12 \text { 10:15 } \\
\text { AM }\end{array}$ & 425 & 24195 & 49200 & 1451700 & 403.25 & 13.67 \\
\hline 1/7/12 5:55 PM & 475 & 24655 & 27600 & 1479300 & 410.92 & 7.67 \\
\hline $\begin{array}{r}1 / 7 / 12 \text { 11:05 } \\
\text { PM }\end{array}$ & 515 & 24965 & 18600 & 1497900 & 416.08 & 5.17 \\
\hline $\begin{array}{r}1 / 8 / 12 \text { 12:30 } \\
\text { PM }\end{array}$ & 600 & 25770 & 48300 & 1546200 & 429.50 & 13.42 \\
\hline $\begin{array}{r}1 / 8 / 1210: 50 \\
\text { PM }\end{array}$ & 660 & 26390 & 37200 & 1583400 & 439.83 & 10.33 \\
\hline 1/9/12 9:09 AM & 720 & 27009 & 37140 & 1620540 & 450.15 & 10.32 \\
\hline 1/9/12 2:01 PM & 750 & 27301 & 17520 & 1638060 & 455.02 & 4.87 \\
\hline $\begin{array}{r}1 / 10 / 12: 30 \\
\text { AM } \\
\end{array}$ & 773 & 27930 & 37740 & 1675800 & 465.50 & 10.48 \\
\hline $\begin{array}{r}1 / 10 / 12 \text { 2:45 } \\
\text { PM }\end{array}$ & 795 & 28785 & 51300 & 1727100 & 479.75 & 14.25 \\
\hline $\begin{array}{r}1 / 16 / 125: 00 \\
\text { PM } \\
\end{array}$ & 900 & 37560 & 55800 & 2253600 & 626.00 & 15.50 \\
\hline $\begin{array}{r}\text { 1/17/12 12:00 } \\
\text { AM } \\
\end{array}$ & 910 & 37980 & 25200 & 2278800 & 633.00 & 7.00 \\
\hline $\begin{array}{r}1 / 17 / 121: 25 \\
\text { AM } \\
\end{array}$ & 930 & 38665 & 41100 & 2319900 & 644.42 & 11.42 \\
\hline $\begin{array}{r}1 / 18 / 129: 15 \\
\text { AM }\end{array}$ & 960 & 39975 & 78600 & 2398500 & 666.25 & 21.83 \\
\hline
\end{tabular}


Hydraulic Conductivity: Test 2 - Standard Proctor Compaction $\left(592.5 \mathrm{~kJ} / \mathrm{m}^{3}\right)$ : Continued

\begin{tabular}{|c|c|c|c|c|c|c|c|c|c|c|c|}
\hline $\begin{array}{c}\Delta \mathrm{V} \\
\left(\mathrm{cm}^{3}\right)\end{array}$ & $\mathrm{i}$ & $\begin{array}{l}\text { Area } \\
\left(\mathrm{cm}^{2}\right)\end{array}$ & $\begin{array}{c}\mathrm{q}_{\text {in }} \\
\left(\mathrm{cm}^{3} / \mathrm{sec}\right)\end{array}$ & $\begin{array}{c}\text { qout }^{3} \\
\left(\mathrm{~cm}^{3} / \mathrm{sec}\right)\end{array}$ & $\begin{array}{c}\mathrm{k} \\
(\mathrm{cm} / \mathrm{sec})\end{array}$ & $\mathrm{k}(\mathrm{m} / \mathrm{sec})$ & $\begin{array}{l}\text { Height } \\
\text { of } \\
\text { Water } \\
(\mathrm{cm}) \\
\end{array}$ & $\begin{array}{l}\text { Height } \\
\text { of } \\
\text { Water } \\
\text { (in) }\end{array}$ & $\begin{array}{l}\text { Time } \\
\text { Step }\end{array}$ & $\mathrm{N}_{\mathrm{PV}}$ & $\begin{array}{c}\text { Qin (mL) } \\
\text { Cumulative }\end{array}$ \\
\hline 0 & 100 & 81.07 & 0 & 0 & 0 & $0.00 \mathrm{E}+00$ & 27.94 & 11.00 & 1 & 0 & 0 \\
\hline 0 & 100 & 81.07 & $1.14 \mathrm{E}-03$ & $0.00 \mathrm{E}+00$ & $0.00 \mathrm{E}+00$ & $0.00 \mathrm{E}+00$ & 26.83 & 10.56 & 2 & 0.00 & 0 \\
\hline 0 & 100 & 81.07 & $\begin{array}{r}-3.51 \mathrm{E}- \\
04 \\
\end{array}$ & $0.00 \mathrm{E}+00$ & $0.00 \mathrm{E}+00$ & $0.00 \mathrm{E}+00$ & 18.89 & 7.44 & 3 & 0.00 & 0 \\
\hline 15 & 100 & 81.07 & $4.50 \mathrm{E}-02$ & $2.78 \mathrm{E}-02$ & $3.43 \mathrm{E}-06$ & $3.43 \mathrm{E}-08$ & 19.37 & 7.63 & 4 & 0.06 & 15 \\
\hline 5 & 100 & 81.07 & $0.00 \mathrm{E}+00$ & $6.94 \mathrm{E}-03$ & $8.57 \mathrm{E}-07$ & 8.57E-09 & 19.21 & 7.56 & 5 & 0.08 & 20 \\
\hline 15 & 100 & 81.07 & $0.00 \mathrm{E}+00$ & $2.78 \mathrm{E}-02$ & $3.43 \mathrm{E}-06$ & $3.43 \mathrm{E}-08$ & 19.21 & 7.56 & 6 & 0.13 & 35 \\
\hline 5 & 100 & 81.07 & $0.00 \mathrm{E}+00$ & 4.39E-03 & $5.41 \mathrm{E}-07$ & $5.41 \mathrm{E}-09$ & 19.21 & 7.56 & 7 & 0.15 & 40 \\
\hline 5 & 100 & 81.07 & $2.70 \mathrm{E}-02$ & $5.56 \mathrm{E}-03$ & $6.85 \mathrm{E}-07$ & $6.85 \mathrm{E}-09$ & 19.21 & 7.56 & 8 & 0.17 & 45 \\
\hline 5 & 100 & 81.07 & $0.00 \mathrm{E}+00$ & $5.56 \mathrm{E}-03$ & $6.85 \mathrm{E}-07$ & $6.85 \mathrm{E}-09$ & 19.05 & 7.50 & 9 & 0.19 & 50 \\
\hline 5 & 100 & 81.07 & $0.00 \mathrm{E}+00$ & $5.56 \mathrm{E}-03$ & $6.85 \mathrm{E}-07$ & $6.85 \mathrm{E}-09$ & 19.05 & 7.50 & 10 & 0.21 & 55 \\
\hline 5 & 100 & 81.07 & $0.00 \mathrm{E}+00$ & $5.56 \mathrm{E}-03$ & $6.85 \mathrm{E}-07$ & $6.85 \mathrm{E}-09$ & 19.05 & 7.50 & 11 & 0.23 & 60 \\
\hline 0 & 100 & 81.07 & $0.00 \mathrm{E}+00$ & $0.00 \mathrm{E}+00$ & $0.00 \mathrm{E}+00$ & $0.00 \mathrm{E}+00$ & 19.05 & 7.50 & 12 & 0.23 & 60 \\
\hline 5 & 100 & 81.07 & $0.00 \mathrm{E}+00$ & $5.56 \mathrm{E}-03$ & $6.85 \mathrm{E}-07$ & $6.85 \mathrm{E}-09$ & 19.05 & 7.50 & 13 & 0.25 & 65 \\
\hline 5 & 100 & 81.07 & $0.00 \mathrm{E}+00$ & $5.56 \mathrm{E}-03$ & $6.85 \mathrm{E}-07$ & $6.85 \mathrm{E}-09$ & 19.05 & 7.50 & 14 & 0.27 & 70 \\
\hline 0 & 100 & 81.07 & $0.00 \mathrm{E}+00$ & $0.00 \mathrm{E}+00$ & $0.00 \mathrm{E}+00$ & $0.00 \mathrm{E}+00$ & 19.05 & 7.50 & 15 & 0.27 & 70 \\
\hline 5 & 100 & 81.07 & $2.70 \mathrm{E}-02$ & $5.56 \mathrm{E}-03$ & $6.85 \mathrm{E}-07$ & $6.85 \mathrm{E}-09$ & 19.05 & 7.50 & 16 & 0.29 & 75 \\
\hline 0 & 100 & 81.07 & $0.00 \mathrm{E}+00$ & $0.00 \mathrm{E}+00$ & $0.00 \mathrm{E}+00$ & $0.00 \mathrm{E}+00$ & 18.89 & 7.44 & 17 & 0.29 & 75 \\
\hline 5 & 100 & 81.07 & $0.00 \mathrm{E}+00$ & $5.56 \mathrm{E}-03$ & $6.85 \mathrm{E}-07$ & $6.85 \mathrm{E}-09$ & 18.89 & 7.44 & 18 & 0.31 & 80 \\
\hline 5 & 100 & 81.07 & $0.00 \mathrm{E}+00$ & $5.56 \mathrm{E}-03$ & $6.85 \mathrm{E}-07$ & $6.85 \mathrm{E}-09$ & 18.89 & 7.44 & 19 & 0.33 & 85 \\
\hline 5 & 100 & 81.07 & $0.00 \mathrm{E}+00$ & $2.38 \mathrm{E}-03$ & $2.94 \mathrm{E}-07$ & $2.94 \mathrm{E}-09$ & 18.89 & 7.44 & 20 & 0.35 & 90 \\
\hline 5 & 100 & 81.07 & $0.00 \mathrm{E}+00$ & 4.17E-03 & $5.14 \mathrm{E}-07$ & $5.14 \mathrm{E}-09$ & 18.89 & 7.44 & 21 & 0.37 & 95 \\
\hline 5 & 100 & 81.07 & $0.00 \mathrm{E}+00$ & $2.78 \mathrm{E}-03$ & $3.43 \mathrm{E}-07$ & $3.43 \mathrm{E}-09$ & 18.89 & 7.44 & 22 & 0.38 & 100 \\
\hline 10 & 100 & 81.07 & $1.35 \mathrm{E}-02$ & $5.56 \mathrm{E}-03$ & $6.85 \mathrm{E}-07$ & $6.85 \mathrm{E}-09$ & 18.89 & 7.44 & 23 & 0.42 & 110 \\
\hline 5 & 100 & 81.07 & $0.00 \mathrm{E}+00$ & $2.78 \mathrm{E}-03$ & $3.43 \mathrm{E}-07$ & 3.43E-09 & 18.73 & 7.38 & 24 & 0.44 & 115 \\
\hline 5 & 100 & 81.07 & $1.35 \mathrm{E}-02$ & $2.78 \mathrm{E}-03$ & $3.43 \mathrm{E}-07$ & $3.43 \mathrm{E}-09$ & 18.73 & 7.38 & 25 & 0.46 & 120 \\
\hline 10 & 100 & 81.07 & $0.00 \mathrm{E}+00$ & $2.78 \mathrm{E}-03$ & $3.43 \mathrm{E}-07$ & 3.43E-09 & 18.57 & 7.31 & 26 & 0.50 & 130 \\
\hline
\end{tabular}




\begin{tabular}{|r|r|r|r|r|r|r|r|r|r|r|r|}
10 & 100 & 81.07 & $6.76 \mathrm{E}-03$ & $2.78 \mathrm{E}-03$ & $3.43 \mathrm{E}-07$ & $3.43 \mathrm{E}-09$ & 18.57 & 7.31 & 27 & 0.54 & 140 \\
\hline 20 & 100 & 81.07 & $3.59 \mathrm{E}-03$ & $2.95 \mathrm{E}-03$ & $3.64 \mathrm{E}-07$ & $3.64 \mathrm{E}-09$ & 18.42 & 7.25 & 28 & 0.62 & 160 \\
\hline 20 & 100 & 81.07 & $0.00 \mathrm{E}+00$ & $2.58 \mathrm{E}-03$ & $3.19 \mathrm{E}-07$ & $3.19 \mathrm{E}-09$ & 18.26 & 7.19 & 29 & 0.69 & 180 \\
\hline 15 & 100 & 81.07 & $0.00 \mathrm{E}+00$ & $2.05 \mathrm{E}-03$ & $2.53 \mathrm{E}-07$ & $2.53 \mathrm{E}-09$ & 18.26 & 7.19 & 31 & 0.75 & 195 \\
\hline 40 & 100 & 81.07 & $4.61 \mathrm{E}-03$ & $2.53 \mathrm{E}-03$ & $3.11 \mathrm{E}-07$ & $3.11 \mathrm{E}-09$ & 18.26 & 7.19 & 32 & 0.90 & 235 \\
\hline 25 & 100 & 81.07 & $0.00 \mathrm{E}+00$ & $2.17 \mathrm{E}-03$ & $2.68 \mathrm{E}-07$ & $2.68 \mathrm{E}-09$ & 17.78 & 7.00 & 33 & 1.00 & 260 \\
\hline 10 & 100 & 81.07 & $1.01 \mathrm{E}-02$ & $2.08 \mathrm{E}-03$ & $2.57 \mathrm{E}-07$ & $2.57 \mathrm{E}-09$ & 17.78 & 7.00 & 34 & 1.04 & 270 \\
\hline 50 & 100 & 81.07 & $9.54 \mathrm{E}-04$ & $1.96 \mathrm{E}-03$ & $2.42 \mathrm{E}-07$ & $2.42 \mathrm{E}-09$ & 17.46 & 6.88 & 35 & 1.23 & 320 \\
\hline
\end{tabular}


Hydraulic Conductivity: Test 2 - Standard Proctor Compaction $\left(592.5 \mathrm{~kJ} / \mathrm{m}^{3}\right)$ : Continued

\begin{tabular}{|c|c|c|c|c|c|c|c|c|c|c|c|}
\hline $\begin{array}{c}\Delta \mathrm{V}^{3} \\
\left(\mathrm{~cm}^{3}\right)\end{array}$ & $\mathrm{i}$ & $\begin{array}{l}\text { Area } \\
\left(\mathrm{cm}^{2}\right)\end{array}$ & $\begin{array}{c}\mathrm{q}_{\mathrm{in}} \\
\left(\mathrm{cm}^{3} / \mathrm{sec}\right)\end{array}$ & $\begin{array}{c}\text { qout } \\
\left(\mathrm{cm}^{3} / \mathrm{sec}\right)\end{array}$ & $\begin{array}{c}\mathrm{k} \\
(\mathrm{cm} / \mathrm{sec})\end{array}$ & $\begin{array}{c}\mathrm{k} \\
(\mathrm{m} / \mathrm{sec})\end{array}$ & $\begin{array}{c}\text { Height of } \\
\text { Water } \\
(\mathrm{cm})\end{array}$ & $\begin{array}{l}\text { Height } \\
\text { of Water } \\
\text { (in) }\end{array}$ & $\begin{array}{l}\text { Time } \\
\text { Step }\end{array}$ & $\mathrm{N}_{\mathrm{PV}}$ & $\begin{array}{c}\text { Qin (mL) } \\
\text { Cumulative }\end{array}$ \\
\hline 20 & 100 & 81.07 & 7.72E-03 & $1.59 \mathrm{E}-03$ & $\begin{array}{r}1.96 \mathrm{E}- \\
07 \\
\end{array}$ & $\begin{array}{r}1.96 \mathrm{E}- \\
09 \\
\end{array}$ & 17.30 & 6.81 & 36 & 1.31 & 340 \\
\hline 85 & 100 & 81.07 & 9.89E-04 & $1.73 \mathrm{E}-03$ & $\begin{array}{r}2.13 \mathrm{E}- \\
07 \\
\end{array}$ & $\begin{array}{r}2.13 \mathrm{E}- \\
09 \\
\end{array}$ & 16.67 & 6.56 & 37 & 1.63 & 425 \\
\hline 50 & 100 & 81.07 & $1.76 \mathrm{E}-03$ & $1.81 \mathrm{E}-03$ & $\begin{array}{r}2.23 \mathrm{E}- \\
07 \\
\end{array}$ & $\begin{array}{r}2.23 \mathrm{E}- \\
09 \\
\end{array}$ & 16.35 & 6.44 & 38 & 1.83 & 475 \\
\hline 40 & 100 & 81.07 & $3.92 \mathrm{E}-03$ & $2.15 \mathrm{E}-03$ & $\begin{array}{r}2.65 \mathrm{E}- \\
07\end{array}$ & $\begin{array}{r}2.65 \mathrm{E}- \\
09\end{array}$ & 16.03 & 6.31 & 39 & 1.98 & 515 \\
\hline 85 & 100 & 81.07 & 2.01E-03 & $1.76 \mathrm{E}-03$ & $\begin{array}{r}2.17 \mathrm{E}- \\
07 \\
\end{array}$ & $\begin{array}{r}2.17 \mathrm{E}- \\
09 \\
\end{array}$ & 15.56 & 6.13 & 40 & 2.31 & 600 \\
\hline 60 & 100 & 81.07 & $6.54 \mathrm{E}-04$ & $1.61 \mathrm{E}-03$ & $\begin{array}{r}1.99 \mathrm{E}- \\
07\end{array}$ & $\begin{array}{r}1.99 \mathrm{E}- \\
09\end{array}$ & 14.92 & 5.88 & 41 & 2.54 & 660 \\
\hline 60 & 100 & 81.07 & $1.96 \mathrm{E}-03$ & $1.62 \mathrm{E}-03$ & $\begin{array}{r}1.99 \mathrm{E}- \\
07\end{array}$ & $\begin{array}{r}1.99 \mathrm{E}- \\
09\end{array}$ & 14.76 & 5.81 & 42 & 2.77 & 720 \\
\hline 30 & 100 & 81.07 & $0.00 \mathrm{E}+00$ & $1.71 \mathrm{E}-03$ & $\begin{array}{r}2.11 \mathrm{E}- \\
07 \\
\end{array}$ & $\begin{array}{r}2.11 \mathrm{E}- \\
09 \\
\end{array}$ & 14.29 & 5.63 & 43 & 2.88 & 750 \\
\hline 23 & 100 & 81.07 & 1.29E-03 & 6.09E-04 & $\begin{array}{r}7.52 \mathrm{E}- \\
08 \\
\end{array}$ & $\begin{array}{r}7.52 \mathrm{E}- \\
10 \\
\end{array}$ & 14.29 & 5.63 & 44 & 2.97 & 773 \\
\hline 22 & 100 & 81.07 & 4.74E-04 & 4.29E-04 & $\begin{array}{r}5.29 \mathrm{E}- \\
08 \\
\end{array}$ & $\begin{array}{r}5.29 \mathrm{E}- \\
10 \\
\end{array}$ & 13.97 & 5.50 & 45 & 3.06 & 795 \\
\hline 37 & 100 & 81.07 & 4.36E-04 & $6.63 \mathrm{E}-04$ & $\begin{array}{r}8.18 \mathrm{E}- \\
08 \\
\end{array}$ & $\begin{array}{r}8.18 \mathrm{E}- \\
10 \\
\end{array}$ & 13.02 & 5.13 & 51 & 3.46 & 900 \\
\hline 10 & 100 & 81.07 & $0.00 \mathrm{E}+00$ & 3.97E-04 & $\begin{array}{r}4.89 \mathrm{E}- \\
08 \\
\end{array}$ & $\begin{array}{r}4.89 \mathrm{E}- \\
10 \\
\end{array}$ & 12.86 & 5.06 & 52 & 3.50 & 910 \\
\hline 20 & 100 & 81.07 & $4.79 \mathrm{E}-02$ & 4.87E-04 & $\begin{array}{r}6.00 \mathrm{E}- \\
08 \\
\end{array}$ & $\begin{array}{r}6.00 \mathrm{E}- \\
10 \\
\end{array}$ & 12.86 & 5.06 & 53 & 3.58 & 930 \\
\hline 30 & 100 & 81.07 & $2.48 \mathrm{E}-02$ & $3.82 \mathrm{E}-04$ & $\begin{array}{r}4.71 \mathrm{E}- \\
08 \\
\end{array}$ & $\begin{array}{r}4.71 \mathrm{E}- \\
10 \\
\end{array}$ & 12.70 & 5.00 & 54 & 3.69 & 960 \\
\hline
\end{tabular}


Hydraulic Conductivity: Test 3- Standard Proctor Compaction $\left(592.5 \mathrm{~kJ} / \mathrm{m}^{3}\right)$

\begin{tabular}{|c|c|c|c|c|c|c|}
\hline \multirow[t]{2}{*}{ Time } & \multirow{2}{*}{$\begin{array}{l}\text { Vol } \\
(\mathrm{ml})\end{array}$} & \multirow{2}{*}{$\begin{array}{c}\Delta \mathrm{t} \\
(\mathrm{min})\end{array}$} & \multirow{2}{*}{$\begin{array}{c}\text { Time } \\
\text { (Seconds) } \\
\Delta \mathrm{t}\end{array}$} & \multirow{2}{*}{$\begin{array}{c}\text { Cumulative } \\
\text { (Seconds) } \\
\Delta \mathrm{t}\end{array}$} & $\begin{array}{c}\text { Time } \\
\text { (Hours) }\end{array}$ & \multirow{2}{*}{$\begin{array}{c}\Delta \mathrm{t} \\
\text { (hours) }\end{array}$} \\
\hline & & & & & Cumulative & \\
\hline $\begin{array}{r}12 / 21 / 113: 00 \\
\text { PM } \\
\end{array}$ & 0 & 0 & 0 & 0 & 0 & 0 \\
\hline $\begin{array}{r}1 / 3 / 12 \text { 12:45 } \\
\text { PM }\end{array}$ & 0 & 18585 & 1115100 & 1115100 & 309.75 & 309.75 \\
\hline $\begin{array}{r}1 / 5 / 12 \text { 10:16 } \\
\text { AM } \\
\end{array}$ & 0 & 21316 & 163860 & 1278960 & 355.27 & 45.52 \\
\hline $\begin{array}{r}1 / 5 / 12 \text { 10:25 } \\
\text { AM }\end{array}$ & 40 & 21325 & 540 & 1279500 & 355.42 & 0.15 \\
\hline $\begin{array}{r}1 / 5 / 1210: 33 \\
\text { AM } \\
\end{array}$ & 75 & 21333 & 480 & 1279980 & 355.55 & 0.13 \\
\hline $\begin{array}{r}1 / 5 / 12 \text { 10:46 } \\
\mathrm{AM} \\
\end{array}$ & 110 & 21346 & 780 & 1280760 & 355.77 & 0.22 \\
\hline $\begin{array}{r}1 / 5 / 12 \text { 11:05 } \\
\text { AM } \\
\end{array}$ & 155 & 21365 & 1140 & 1281900 & 356.08 & 0.32 \\
\hline $\begin{array}{r}11: 20 \\
\text { AM }\end{array}$ & 185 & 21380 & 900 & 1282800 & 356.33 & 0.25 \\
\hline $\begin{array}{r}1 / 5 / 1211: 35 \\
\text { AM } \\
\end{array}$ & 215 & 21395 & 900 & 1283700 & 356.58 & 0.25 \\
\hline $\begin{array}{r}1 / 5 / 1211: 50 \\
\text { AM } \\
\end{array}$ & 240 & 21410 & 900 & 1284600 & 356.83 & 0.25 \\
\hline $\begin{array}{r}1 / 5 / 12 \text { 12:05 } \\
\text { PM }\end{array}$ & 270 & 21425 & 900 & 1285500 & 357.08 & 0.25 \\
\hline $\begin{array}{r}1 / 5 / 12: 20 \\
\text { PM } \\
\end{array}$ & 300 & 21440 & 900 & 1286400 & 357.33 & 0.25 \\
\hline $\begin{array}{r}1 / 5 / 12 \text { 12:35 } \\
\text { PM } \\
\end{array}$ & 325 & 21455 & 900 & 1287300 & 357.58 & 0.25 \\
\hline $\begin{array}{r}1 / 5 / 12 \text { 12:50 } \\
\text { PM }\end{array}$ & 350 & 21470 & 900 & 1288200 & 357.83 & 0.25 \\
\hline 1/5/12 1:05 PM & 380 & 21485 & 900 & 1289100 & 358.08 & 0.25 \\
\hline 1/5/12 1:20 PM & 405 & 21500 & 900 & 1290000 & 358.33 & 0.25 \\
\hline 1/5/12 1:35 PM & 430 & 21515 & 900 & 1290900 & 358.58 & 0.25 \\
\hline
\end{tabular}




\begin{tabular}{|r|r|r|r|r|r|r|}
\hline $1 / 5 / 121: 50 \mathrm{PM}$ & 460 & 21530 & 900 & 1291800 & 358.83 & 0.25 \\
\hline $1 / 5 / 122: 05 \mathrm{PM}$ & 490 & 21545 & 900 & 1292700 & 359.08 & 0.25 \\
\hline $1 / 5 / 122: 20 \mathrm{PM}$ & 515 & 21560 & 900 & 1293600 & 359.33 & 0.25 \\
\hline $1 / 5 / 122: 40 \mathrm{PM}$ & 560 & 21580 & 1200 & 1294800 & 359.67 & 0.33 \\
\hline $1 / 5 / 123: 00 \mathrm{PM}$ & 600 & 21600 & 1200 & 1296000 & 360.00 & 0.33 \\
\hline $1 / 5 / 123: 30 \mathrm{PM}$ & 670 & 21630 & 1800 & 1297800 & 360.50 & 0.50 \\
\hline $1 / 5 / 124: 00 \mathrm{PM}$ & 730 & 21660 & 1800 & 1299600 & 361.00 & 0.50 \\
\hline $1 / 5 / 124: 30 \mathrm{PM}$ & 795 & 21690 & 1800 & 1301400 & 361.50 & 0.50 \\
\hline $1 / 5 / 125: 00 \mathrm{PM}$ & 855 & 21720 & 1800 & 1303200 & 362.00 & 0.50 \\
\hline $1 / 5 / 125: 30 \mathrm{PM}$ & 920 & 21750 & 1800 & 1305000 & 362.50 & 0.50 \\
\hline $1 / 5 / 126: 00 \mathrm{PM}$ & 950 & 21780 & 1800 & 1306800 & 363.00 & 0.50 \\
\hline $1 / 5 / 126: 30 \mathrm{PM}$ & 965 & 21810 & 1800 & 1308600 & 363.50 & 0.50 \\
\hline $1 / 5 / 127: 00 \mathrm{PM}$ & 985 & 21840 & 1800 & 1310400 & 364.00 & 0.50 \\
\hline $1 / 5 / 128: 53 \mathrm{PM}$ & 1060 & 21953 & 6780 & 1317180 & 365.88 & 1.88 \\
\hline $1 / 5 / 1211: 02$ & 1135 & 22082 & 7740 & 1324920 & 368.03 & 2.15 \\
\hline $1 / 6 / 121: 04 \mathrm{AM}$ & 1215 & 22204 & 7320 & 1332240 & 370.07 & 2.03 \\
\hline $1 / 6 / 125: 28 \mathrm{AM}$ & 1365 & 22468 & 15840 & 1348080 & 374.47 & 4.40 \\
\hline $1 / 6 / 128: 40 \mathrm{AM}$ & 1475 & 22660 & 11520 & 1359600 & 377.67 & 3.20 \\
\hline
\end{tabular}


Hydraulic Conductivity: Test 3-Standard Proctor Compaction $\left(592.5 \mathrm{~kJ} / \mathrm{m}^{3}\right)$ : Continued

\begin{tabular}{|c|c|c|c|c|c|c|}
\hline \multirow{2}{*}{ Time } & \multirow{2}{*}{$\begin{array}{l}\text { Vol } \\
(\mathrm{ml})\end{array}$} & \multirow{2}{*}{$\begin{array}{c}\Delta \mathrm{t} \\
(\min )\end{array}$} & \multirow{2}{*}{$\begin{array}{c}\text { Time } \\
\text { (Seconds) } \\
\Delta \mathrm{t}\end{array}$} & \multirow{2}{*}{$\begin{array}{c}\text { Cumulative } \\
\text { (Seconds) } \\
\Delta \mathrm{t}\end{array}$} & $\begin{array}{c}\text { Time } \\
\text { (Hours) }\end{array}$ & \multirow{2}{*}{$\begin{array}{c}\Delta \mathrm{t} \\
\text { (hours) }\end{array}$} \\
\hline & & & & & Cumulative & \\
\hline $\begin{array}{r}1 / 6 / 12 \text { 10:00 } \\
\text { AM }\end{array}$ & 1515 & 22740 & 4800 & 1364400 & 379.00 & 1.33 \\
\hline 1/6/12 1:00 PM & 1595 & 22920 & 10800 & 1375200 & 382.00 & 3.00 \\
\hline 1/6/12 5:05 PM & 1705 & 23165 & 14700 & 1389900 & 386.08 & 4.08 \\
\hline 1/6/12 8:35 PM & 1795 & 23375 & 12600 & 1402500 & 389.58 & 3.50 \\
\hline $\begin{array}{r}1 / 7 / 12 \text { 10:15 } \\
\text { AM } \\
\end{array}$ & 2148 & 24195 & 49200 & 1451700 & 403.25 & 13.67 \\
\hline 1/7/12 5:55 PM & 2693 & 24655 & 27600 & 1479300 & 410.92 & 7.67 \\
\hline $\begin{array}{r}1 / 7 / 1211: 07 \\
\text { PM } \\
\end{array}$ & 2823 & 24967 & 18720 & 1498020 & 416.12 & 5.20 \\
\hline $\begin{array}{r}1 / 8 / 1212: 30 \\
\text { PM } \\
\end{array}$ & 3033 & 25770 & 48180 & 1546200 & 429.50 & 13.38 \\
\hline $\begin{array}{r}1 / 8 / 1210: 50 \\
\text { PM } \\
\end{array}$ & 3308 & 26390 & 37200 & 1583400 & 439.83 & 10.33 \\
\hline 1/9/12 9:09 AM & 3533 & 27009 & 37140 & 1620540 & 450.15 & 10.32 \\
\hline 1/9/12 2:01 PM & 3648 & 27301 & 17520 & 1638060 & 455.02 & 4.87 \\
\hline $\begin{array}{r}1 / 10 / 1212: 30 \\
\text { AM } \\
\end{array}$ & 3761 & 27930 & 36000 & 1675800 & 465.50 & 10.00 \\
\hline $\begin{array}{r}1 / 10 / 129: 15 \\
\mathrm{AM} \\
\end{array}$ & 3841 & 28455 & 31500 & 1707300 & 474.25 & 8.75 \\
\hline $\begin{array}{r}1 / 10 / 122: 45 \\
\mathrm{PM} \\
\end{array}$ & 3883 & 28785 & 19800 & 1727100 & 479.75 & 5.50 \\
\hline $\begin{array}{r}1 / 10 / 126: 24 \\
\text { PM } \\
\end{array}$ & 3913 & 29004 & 13140 & 1740240 & 483.40 & 3.65 \\
\hline $\begin{array}{r}1 / 10 / 1211: 30 \\
\text { PM } \\
\end{array}$ & 3951 & 29310 & 18360 & 1758600 & 488.50 & 5.10 \\
\hline $\begin{array}{r}1 / 11 / 129: 50 \\
\text { AM } \\
\end{array}$ & 4033 & 29930 & 37200 & 1795800 & 498.83 & 10.33 \\
\hline $\begin{array}{r}1 / 12 / 129: 30 \\
\mathrm{AM} \\
\end{array}$ & 4183 & 31350 & 85200 & 1881000 & 522.50 & 23.67 \\
\hline $1 / 13 / 1211: 12$ & 4323 & 32892 & 92520 & 1973520 & 548.20 & 25.70 \\
\hline
\end{tabular}




\begin{tabular}{|r|r|r|r|r|r|r|} 
& & & & & \\
\hline AM & & & & & & \\
AM & 4388 & 33690 & 47880 & 2021400 & 561.50 & 13.30 \\
\hline $1 / 14 / 12$ 12:30 $1: 00$ & & & & & & \\
AM & 4441 & 35160 & 88200 & 2109600 & 586.00 & 24.50 \\
\hline $1 / 15 / 1212: 45$ & & & & & & \\
PM & 4531 & 35865 & 42300 & 2151900 & 597.75 & 11.75 \\
\hline $1 / 16 / 121: 30$ & & & & & & \\
AM & 4573 & 36630 & 45900 & 2197800 & 610.50 & 12.75 \\
\hline $1 / 16 / 125: 00$ & & & & & & \\
PM & 4663 & 37560 & 55800 & 2253600 & 626.00 & 15.50 \\
\hline $1 / 17 / 1212: 00$ & & & & & & \\
AM & 4701 & 37980 & 25200 & 2278800 & 633.00 & 7.00 \\
\hline $1 / 17 / 1211: 25$ & & & & & & \\
$\mathrm{AM}$ & 4758 & 38665 & 41100 & 2319900 & 644.42 & 11.42 \\
\hline $1 / 18 / 129: 15$ & & & & & & \\
$\mathrm{AM}$ & 4868 & 39975 & 78600 & 2398500 & 666.25 & 21.83 \\
\hline $1 / 19 / 1210: 45$ & & & & & & \\
$\mathrm{AM}$ & 5003 & 41505 & 91800 & 2490300 & 691.75 & 25.50 \\
\hline
\end{tabular}


Hydraulic Conductivity: Test 3-Standard Proctor Compaction $\left(592.5 \mathrm{~kJ} / \mathrm{m}^{3}\right)$ : Continued

\begin{tabular}{|c|c|c|c|c|c|c|c|c|c|c|c|}
\hline $\begin{array}{c}\Delta \mathrm{V}^{3} \\
\left(\mathrm{~cm}^{3}\right)\end{array}$ & $\mathrm{i}$ & $\begin{array}{l}\text { Area } \\
\left(\mathrm{cm}^{2}\right)\end{array}$ & $\begin{array}{c}\mathrm{q}_{\mathrm{in}} \\
\left(\mathrm{cm}^{3} / \mathrm{sec}\right)\end{array}$ & $\begin{array}{c}\mathrm{q}_{\text {out }} \\
\left(\mathrm{cm}^{3} / \mathrm{sec}\right)\end{array}$ & $\begin{array}{c}\mathrm{k} \\
(\mathrm{cm} / \mathrm{sec})\end{array}$ & $\mathrm{k}(\mathrm{m} / \mathrm{sec})$ & $\begin{array}{l}\text { Height } \\
\text { of } \\
\text { Water } \\
(\mathrm{cm})\end{array}$ & $\begin{array}{l}\text { Height } \\
\text { of } \\
\text { Water } \\
\text { (in) } \\
\end{array}$ & $\begin{array}{l}\text { Time } \\
\text { Step }\end{array}$ & $\mathrm{N}_{\mathrm{PV}}$ & $\begin{array}{c}\text { Qin (mL) } \\
\text { Cumulative }\end{array}$ \\
\hline 0 & 100 & 81.07 & 0 & 0 & 0 & $0.00 \mathrm{E}+00$ & 42.70 & 16.81 & 1 & 0 & 0 \\
\hline 0 & 100 & 81.07 & $1.96 \mathrm{E}-04$ & $0.00 \mathrm{E}+00$ & $0.00 \mathrm{E}+00$ & $0.00 \mathrm{E}+00$ & 41.43 & 16.31 & 2 & 0.00 & 0 \\
\hline 0 & 100 & 81.07 & $2.97 \mathrm{E}-04$ & $0.00 \mathrm{E}+00$ & $0.00 \mathrm{E}+00$ & $0.00 \mathrm{E}+00$ & 40.01 & 15.75 & 3 & 0.00 & 0 \\
\hline 40 & 100 & 81.07 & $9.01 \mathrm{E}-02$ & $7.41 \mathrm{E}-02$ & $9.14 \mathrm{E}-06$ & $9.14 \mathrm{E}-08$ & 39.69 & 15.63 & 4 & 0.15 & 40 \\
\hline 35 & 100 & 81.07 & 5.07E-02 & 7.29E-02 & 8.99E-06 & 8.99E-08 & 39.37 & 15.50 & 5 & 0.28 & 75 \\
\hline 35 & 100 & 81.07 & $9.35 \mathrm{E}-02$ & 4.49E-02 & 5.53E-06 & 5.53E-08 & 39.21 & 15.44 & 6 & 0.41 & 110 \\
\hline 45 & 100 & 81.07 & $0.00 \mathrm{E}+00$ & $3.95 \mathrm{E}-02$ & 4.87E-06 & 4.87E-08 & 38.74 & 15.25 & 7 & 0.57 & 155 \\
\hline 30 & 100 & 81.07 & $2.70 \mathrm{E}-02$ & $3.33 \mathrm{E}-02$ & $4.11 \mathrm{E}-06$ & 4.11E-08 & 38.74 & 15.25 & 8 & 0.68 & 185 \\
\hline 30 & 100 & 81.07 & $5.40 \mathrm{E}-02$ & 3.33E-02 & $4.11 \mathrm{E}-06$ & $4.11 \mathrm{E}-08$ & 38.58 & 15.19 & 9 & 0.79 & 215 \\
\hline 25 & 100 & 81.07 & $2.70 \mathrm{E}-02$ & $2.78 \mathrm{E}-02$ & $3.43 \mathrm{E}-06$ & 3.43E-08 & 38.26 & 15.06 & 10 & 0.89 & 240 \\
\hline 30 & 100 & 81.07 & $2.70 \mathrm{E}-02$ & $3.33 \mathrm{E}-02$ & $4.11 \mathrm{E}-06$ & $4.11 \mathrm{E}-08$ & 38.10 & 15.00 & 11 & 1.00 & 270 \\
\hline 30 & 100 & 81.07 & $2.70 \mathrm{E}-02$ & 3.33E-02 & $4.11 \mathrm{E}-06$ & $4.11 \mathrm{E}-08$ & 37.94 & 14.94 & 12 & 1.11 & 300 \\
\hline 25 & 100 & 81.07 & $5.40 \mathrm{E}-02$ & $2.78 \mathrm{E}-02$ & $3.43 \mathrm{E}-06$ & $3.43 \mathrm{E}-08$ & 37.78 & 14.88 & 13 & 1.20 & 325 \\
\hline 25 & 100 & 81.07 & $0.00 \mathrm{E}+00$ & $2.78 \mathrm{E}-02$ & $3.43 \mathrm{E}-06$ & $3.43 \mathrm{E}-08$ & 37.47 & 14.75 & 14 & 1.29 & 350 \\
\hline 30 & 100 & 81.07 & $5.40 \mathrm{E}-02$ & $3.33 \mathrm{E}-02$ & $4.11 \mathrm{E}-06$ & $4.11 \mathrm{E}-08$ & 37.47 & 14.75 & 15 & 1.40 & 380 \\
\hline 25 & 100 & 81.07 & $0.00 \mathrm{E}+00$ & $2.78 \mathrm{E}-02$ & $3.43 \mathrm{E}-06$ & $3.43 \mathrm{E}-08$ & 37.15 & 14.63 & 16 & 1.49 & 405 \\
\hline 25 & 100 & 81.07 & $5.40 \mathrm{E}-02$ & $2.78 \mathrm{E}-02$ & $3.43 \mathrm{E}-06$ & $3.43 \mathrm{E}-08$ & 37.15 & 14.63 & 17 & 1.59 & 430 \\
\hline 30 & 100 & 81.07 & $0.00 \mathrm{E}+00$ & $3.33 \mathrm{E}-02$ & $4.11 \mathrm{E}-06$ & 4.11E-08 & 36.83 & 14.50 & 18 & 1.70 & 460 \\
\hline 30 & 100 & 81.07 & $5.40 \mathrm{E}-02$ & $3.33 \mathrm{E}-02$ & $4.11 \mathrm{E}-06$ & 4.11E-08 & 36.83 & 14.50 & 19 & 1.81 & 490 \\
\hline 25 & 100 & 81.07 & $5.40 \mathrm{E}-02$ & $2.78 \mathrm{E}-02$ & $3.43 \mathrm{E}-06$ & 3.43E-08 & 36.51 & 14.38 & 20 & 1.90 & 515 \\
\hline 45 & 100 & 81.07 & $2.03 \mathrm{E}-02$ & $3.75 \mathrm{E}-02$ & 4.63E-06 & 4.63E-08 & 36.20 & 14.25 & 21 & 2.07 & 560 \\
\hline 40 & 100 & 81.07 & $4.05 \mathrm{E}-02$ & $3.33 \mathrm{E}-02$ & $4.11 \mathrm{E}-06$ & 4.11E-08 & 36.04 & 14.19 & 22 & 2.21 & 600 \\
\hline 70 & 100 & 81.07 & 4.05E-02 & $3.89 \mathrm{E}-02$ & $4.80 \mathrm{E}-06$ & 4.80E-08 & 35.72 & 14.06 & 23 & 2.47 & 670 \\
\hline 60 & 100 & 81.07 & 4.05E-02 & $3.33 \mathrm{E}-02$ & 4.11E-06 & 4.11E-08 & 35.24 & 13.88 & 24 & 2.69 & 730 \\
\hline 65 & 100 & 81.07 & $4.05 \mathrm{E}-02$ & $3.61 \mathrm{E}-02$ & $4.45 \mathrm{E}-06$ & $4.45 \mathrm{E}-08$ & 34.77 & 13.69 & 25 & 2.93 & 795 \\
\hline 60 & 100 & 81.07 & $2.70 \mathrm{E}-02$ & $3.33 \mathrm{E}-02$ & 4.11E-06 & 4.11E-08 & 34.29 & 13.50 & 26 & 3.16 & 855 \\
\hline
\end{tabular}




\begin{tabular}{|r|r|r|r|r|r|r|r|r|r|r|r|}
65 & 100 & 81.07 & $1.35 \mathrm{E}-02$ & $3.61 \mathrm{E}-02$ & $4.45 \mathrm{E}-06$ & $4.45 \mathrm{E}-08$ & 33.97 & 13.38 & 27 & 3.40 & 920 \\
\hline 30 & 100 & 81.07 & $1.35 \mathrm{E}-02$ & $1.67 \mathrm{E}-02$ & $2.06 \mathrm{E}-06$ & $2.06 \mathrm{E}-08$ & 33.81 & 13.31 & 28 & 3.51 & 950 \\
\hline 15 & 100 & 81.07 & $1.35 \mathrm{E}-02$ & $8.33 \mathrm{E}-03$ & $1.03 \mathrm{E}-06$ & $1.03 \mathrm{E}-08$ & 33.66 & 13.25 & 29 & 3.56 & 965 \\
\hline 20 & 100 & 81.07 & $4.05 \mathrm{E}-02$ & $1.11 \mathrm{E}-02$ & $1.37 \mathrm{E}-06$ & $1.37 \mathrm{E}-08$ & 33.50 & 13.19 & 30 & 3.64 & 985 \\
\hline 75 & 100 & 81.07 & $1.08 \mathrm{E}-02$ & $1.11 \mathrm{E}-02$ & $1.36 \mathrm{E}-06$ & $1.36 \mathrm{E}-08$ & 33.02 & 13.00 & 31 & 3.91 & 1060 \\
\hline 75 & 100 & 81.07 & $9.43 \mathrm{E}-03$ & $9.69 \mathrm{E}-03$ & $1.20 \mathrm{E}-06$ & $1.20 \mathrm{E}-08$ & 32.54 & 12.81 & 32 & 4.19 & 1135 \\
\hline 80 & 100 & 81.07 & $1.99 \mathrm{E}-02$ & $1.09 \mathrm{E}-02$ & $1.35 \mathrm{E}-06$ & $1.35 \mathrm{E}-08$ & 32.07 & 12.63 & 33 & 4.48 & 1215 \\
\hline 150 & 100 & 81.07 & $7.68 \mathrm{E}-03$ & $9.47 \mathrm{E}-03$ & $1.17 \mathrm{E}-06$ & $1.17 \mathrm{E}-08$ & 31.12 & 12.25 & 34 & 5.04 & 1365 \\
\hline 110 & 100 & 81.07 & $4.22 \mathrm{E}-03$ & $9.55 \mathrm{E}-03$ & $1.18 \mathrm{E}-06$ & $1.18 \mathrm{E}-08$ & 30.32 & 11.94 & 35 & 5.44 & 1475 \\
\hline
\end{tabular}


Hydraulic Conductivity: Test 3- Standard Proctor Compaction $\left(592.5 \mathrm{~kJ} / \mathrm{m}^{3}\right)$ : Continued

\begin{tabular}{|c|c|c|c|c|c|c|c|c|c|c|c|}
\hline $\begin{array}{c}\Delta \mathrm{V}^{3} \\
\left(\mathrm{~cm}^{3}\right)\end{array}$ & $\mathrm{i}$ & $\begin{array}{l}\text { Area } \\
\left(\mathrm{cm}^{2}\right)\end{array}$ & $\begin{array}{c}\mathrm{q}_{\mathrm{in}} \\
\left(\mathrm{cm}^{3} / \mathrm{sec}\right)\end{array}$ & $\begin{array}{c}\text { qout } \\
\left(\mathrm{cm}^{3} / \mathrm{sec}\right)\end{array}$ & $\begin{array}{c}\mathrm{k} \\
(\mathrm{cm} / \mathrm{sec})\end{array}$ & $\begin{array}{c}\mathrm{k} \\
(\mathrm{m} / \mathrm{sec})\end{array}$ & $\begin{array}{l}\text { Height } \\
\text { of Water } \\
\quad(\mathrm{cm})\end{array}$ & $\begin{array}{l}\text { Height } \\
\text { of } \\
\text { Water } \\
\text { (in) } \\
\end{array}$ & $\begin{array}{l}\text { Time } \\
\text { Step }\end{array}$ & $\mathrm{N}_{\mathrm{PV}}$ & $\begin{array}{c}\text { Qin (mL) } \\
\text { Cumulative }\end{array}$ \\
\hline 40 & 100 & 81.07 & $1.52 \mathrm{E}-02$ & 8.33E-03 & $\begin{array}{r}1.03 \mathrm{E}- \\
06 \\
\end{array}$ & $\begin{array}{r}1.03 \mathrm{E}- \\
08 \\
\end{array}$ & 30.00 & 11.81 & 36 & 5.59 & 1515 \\
\hline 80 & 100 & 81.07 & $9.01 \mathrm{E}-03$ & $7.41 \mathrm{E}-03$ & $\begin{array}{r}9.14 \mathrm{E}- \\
07\end{array}$ & $\begin{array}{r}9.14 \mathrm{E}- \\
09\end{array}$ & 29.53 & 11.63 & 37 & 5.89 & 1595 \\
\hline 110 & 100 & 81.07 & $6.62 \mathrm{E}-03$ & $7.48 \mathrm{E}-03$ & $\begin{array}{r}9.23 \mathrm{E}- \\
07\end{array}$ & $\begin{array}{r}9.23 \mathrm{E}- \\
09 \\
\end{array}$ & 28.89 & 11.38 & 38 & 6.29 & 1705 \\
\hline 90 & 100 & 81.07 & $2.70 \mathrm{E}-02$ & 7.14E-03 & $\begin{array}{r}8.81 \mathrm{E}- \\
07\end{array}$ & $\begin{array}{r}8.81 \mathrm{E}- \\
09\end{array}$ & 28.26 & 11.13 & 39 & 6.62 & 1795 \\
\hline 353 & 100 & 81.07 & $3.95 \mathrm{E}-03$ & 7.17E-03 & $\begin{array}{r}8.85 \mathrm{E}- \\
07 \\
\end{array}$ & $\begin{array}{r}8.85 \mathrm{E}- \\
09 \\
\end{array}$ & 26.04 & 10.25 & 40 & 7.93 & 2148 \\
\hline 545 & 100 & 81.07 & $5.29 \mathrm{E}-03$ & $1.97 \mathrm{E}-02$ & $\begin{array}{r}2.44 \mathrm{E}- \\
06\end{array}$ & $\begin{array}{r}2.44 \mathrm{E}- \\
08\end{array}$ & 24.77 & 9.75 & 41 & 9.94 & 2693 \\
\hline 130 & 100 & 81.07 & $1.69 \mathrm{E}-02$ & $6.94 \mathrm{E}-03$ & $\begin{array}{r}8.57 \mathrm{E}- \\
07 \\
\end{array}$ & $\begin{array}{r}8.57 \mathrm{E}- \\
09 \\
\end{array}$ & 23.81 & 9.38 & 42 & 10.42 & 2823 \\
\hline 210 & 100 & 81.07 & $1.51 \mathrm{E}-03$ & $4.36 \mathrm{E}-03$ & $\begin{array}{r}5.38 \mathrm{E}- \\
07 \\
\end{array}$ & $\begin{array}{r}5.38 \mathrm{E}- \\
09 \\
\end{array}$ & 21.75 & 8.56 & 43 & 11.19 & 3033 \\
\hline 275 & 100 & 81.07 & $9.81 \mathrm{E}-03$ & 7.39E-03 & $\begin{array}{r}9.12 \mathrm{E}- \\
07 \\
\end{array}$ & $\begin{array}{r}9.12 \mathrm{E}- \\
09 \\
\end{array}$ & 21.27 & 8.38 & 44 & 12.21 & 3308 \\
\hline 225 & 100 & 81.07 & $3.27 \mathrm{E}-03$ & $6.06 \mathrm{E}-03$ & $\begin{array}{r}7.47 \mathrm{E}- \\
07 \\
\end{array}$ & $\begin{array}{r}7.47 \mathrm{E}- \\
09 \\
\end{array}$ & 18.89 & 7.44 & 45 & 13.04 & 3533 \\
\hline 115 & 100 & 81.07 & $0.00 \mathrm{E}+00$ & $6.56 \mathrm{E}-03$ & $\begin{array}{r}8.10 \mathrm{E}- \\
07 \\
\end{array}$ & $\begin{array}{r}8.10 \mathrm{E}- \\
09 \\
\end{array}$ & 18.10 & 7.13 & 46 & 13.46 & 3648 \\
\hline 113 & 100 & 81.07 & $1.35 \mathrm{E}-03$ & $3.14 \mathrm{E}-03$ & $\begin{array}{r}3.87 \mathrm{E}- \\
07 \\
\end{array}$ & $\begin{array}{r}3.87 \mathrm{E}- \\
09 \\
\end{array}$ & 17.15 & 6.75 & 48 & 13.88 & 3761 \\
\hline 80 & 100 & 81.07 & $1.54 \mathrm{E}-03$ & $2.54 \mathrm{E}-03$ & $\begin{array}{r}3.13 \mathrm{E}- \\
07 \\
\end{array}$ & $\begin{array}{r}3.13 \mathrm{E}- \\
09 \\
\end{array}$ & 16.83 & 6.63 & 49 & 14.18 & 3841 \\
\hline 42 & 100 & 81.07 & $1.23 \mathrm{E}-03$ & $2.12 \mathrm{E}-03$ & $\begin{array}{r}2.62 \mathrm{E}- \\
07 \\
\end{array}$ & $\begin{array}{r}2.62 \mathrm{E}- \\
09 \\
\end{array}$ & 16.51 & 6.50 & 50 & 14.33 & 3883 \\
\hline 30 & 100 & 81.07 & $3.70 \mathrm{E}-03$ & $2.28 \mathrm{E}-03$ & $\begin{array}{r}2.82 \mathrm{E}- \\
07\end{array}$ & $\begin{array}{r}2.82 \mathrm{E}- \\
09\end{array}$ & 16.35 & 6.44 & 51 & 14.44 & 3913 \\
\hline 38 & 100 & 81.07 & $3.97 \mathrm{E}-03$ & $2.07 \mathrm{E}-03$ & $\begin{array}{r}2.55 \mathrm{E}- \\
07 \\
\end{array}$ & $\begin{array}{r}2.55 \mathrm{E}- \\
09\end{array}$ & 16.03 & 6.31 & 52 & 14.58 & 3951 \\
\hline
\end{tabular}




\begin{tabular}{|c|c|c|c|c|c|c|c|c|c|c|c|}
\hline 82 & 100 & 81.07 & $4.58 \mathrm{E}-03$ & $2.20 \mathrm{E}-03$ & $\begin{array}{r}2.72 \mathrm{E}- \\
07\end{array}$ & $\begin{array}{r}2.72 \mathrm{E}- \\
09\end{array}$ & 15.56 & 6.13 & 53 & 14.88 & 4033 \\
\hline 150 & 100 & 81.07 & $1.71 \mathrm{E}-03$ & $1.76 \mathrm{E}-03$ & $\begin{array}{r}2.17 \mathrm{E}- \\
07 \\
\end{array}$ & $\begin{array}{r}2.17 \mathrm{E}- \\
09 \\
\end{array}$ & 14.45 & 5.69 & 54 & 15.44 & 4183 \\
\hline 140 & 100 & 81.07 & $1.05 \mathrm{E}-03$ & $1.51 \mathrm{E}-03$ & $\begin{array}{r}1.87 \mathrm{E}- \\
07 \\
\end{array}$ & $\begin{array}{r}1.87 \mathrm{E}- \\
09 \\
\end{array}$ & 13.49 & 5.31 & 55 & 15.95 & 4323 \\
\hline 65 & 100 & 81.07 & $2.54 \mathrm{E}-03$ & $1.36 \mathrm{E}-03$ & $\begin{array}{r}1.67 \mathrm{E}- \\
07 \\
\end{array}$ & $\begin{array}{r}1.67 \mathrm{E}- \\
09 \\
\end{array}$ & 12.86 & 5.06 & 56 & 16.19 & 4388 \\
\hline 53 & 100 & 81.07 & $5.51 \mathrm{E}-04$ & 6.01E-04 & $\begin{array}{r}7.41 \mathrm{E}- \\
08 \\
\end{array}$ & $\begin{array}{r}7.41 \mathrm{E}- \\
10 \\
\end{array}$ & 12.07 & 4.75 & 57 & 16.39 & 4441 \\
\hline 90 & 100 & 81.07 & $1.15 \mathrm{E}-03$ & $2.13 \mathrm{E}-03$ & $\begin{array}{r}2.62 \mathrm{E}- \\
07 \\
\end{array}$ & $\begin{array}{r}2.62 \mathrm{E}- \\
09 \\
\end{array}$ & 11.75 & 4.63 & 58 & 16.72 & 4531 \\
\hline 42 & 100 & 81.07 & $2.12 \mathrm{E}-03$ & $9.15 \mathrm{E}-04$ & $\begin{array}{r}1.13 \mathrm{E}- \\
07\end{array}$ & $\begin{array}{r}1.13 \mathrm{E}- \\
09 \\
\end{array}$ & 11.43 & 4.50 & 59 & 16.88 & 4573 \\
\hline 90 & 100 & 81.07 & 4.36E-04 & $1.61 \mathrm{E}-03$ & $\begin{array}{r}1.99 \mathrm{E}- \\
07\end{array}$ & $\begin{array}{r}1.99 \mathrm{E}- \\
09\end{array}$ & 10.80 & 4.25 & 60 & 17.21 & 4663 \\
\hline 38 & 100 & 81.07 & $9.65 \mathrm{E}-04$ & $1.51 \mathrm{E}-03$ & $\begin{array}{r}1.86 \mathrm{E}- \\
07\end{array}$ & $\begin{array}{r}1.86 \mathrm{E}- \\
09\end{array}$ & 10.64 & 4.19 & 61 & 17.35 & 4701 \\
\hline 57 & 100 & 81.07 & $3.91 \mathrm{E}-02$ & $1.39 \mathrm{E}-03$ & $\begin{array}{r}1.71 \mathrm{E}- \\
07 \\
\end{array}$ & $\begin{array}{r}1.71 \mathrm{E}- \\
09 \\
\end{array}$ & 10.48 & 4.13 & 62 & 17.56 & 4758 \\
\hline 110 & 100 & 81.07 & $1.92 \mathrm{E}-02$ & $1.40 \mathrm{E}-03$ & $\begin{array}{r}1.73 \mathrm{E}- \\
07\end{array}$ & $\begin{array}{r}1.73 \mathrm{E}- \\
09\end{array}$ & 9.84 & 3.88 & 63 & 17.97 & 4868 \\
\hline 135 & 100 & 81.07 & $1.48 \mathrm{E}-02$ & $1.47 \mathrm{E}-03$ & $\begin{array}{r}1.81 \mathrm{E}- \\
07\end{array}$ & $\begin{array}{r}1.81 \mathrm{E}- \\
09\end{array}$ & 8.89 & 3.50 & 64 & 18.46 & 5003 \\
\hline
\end{tabular}


Hydraulic Conductivity: Test $1-34 \%$ Proctor Compaction $\left(203.6 \mathrm{~kJ} / \mathrm{m}^{3}\right)$

\begin{tabular}{|c|c|c|c|c|c|c|}
\hline \multirow{2}{*}{ Time } & \multirow{2}{*}{$\operatorname{Vol}(\mathrm{ml})$} & \multirow{2}{*}{$\Delta \mathrm{t}(\min )$} & \multirow{2}{*}{$\begin{array}{c}\text { Time } \\
\text { (Seconds) } \Delta t\end{array}$} & \multirow{2}{*}{ Cumulative } & Time (Hours) & \multirow{2}{*}{$\begin{array}{c}\Delta \mathrm{t} \\
\text { (hours) }\end{array}$} \\
\hline & & & & & Cumulative & \\
\hline 9/22/11 4:22 PM & 0.00 & 0.00 & 0.00 & 0.00 & 0.00 & 0.00 \\
\hline 9/22/11 4:32 PM & 190.00 & 10.00 & 600.00 & 600.00 & 0.17 & 0.17 \\
\hline 9/22/11 8:30 PM & 216.00 & 248.00 & 14280.00 & 14880.00 & 4.13 & 3.97 \\
\hline 9/23/11 12:30 AM & 218.00 & 488.00 & 14400.00 & 29280.00 & 8.13 & 4.00 \\
\hline 9/23/11 10:30 AM & 220.00 & 1088.00 & 36000.00 & 65280.00 & 18.13 & 10.00 \\
\hline 9/23/11 1:30 PM & 223.00 & 1268.00 & 10800.00 & 76080.00 & 21.13 & 3.00 \\
\hline 9/23/11 5:05 PM & 223.00 & 1483.00 & 12900.00 & 88980.00 & 24.72 & 3.58 \\
\hline 9/24/11 12:00 AM & 225.00 & 1898.00 & 24900.00 & 113880.00 & 31.63 & 6.92 \\
\hline 9/24/11 12:00 PM & 225.00 & 2618.00 & 43200.00 & 157080.00 & 43.63 & 12.00 \\
\hline 9/24/11 6:00 PM & 225.00 & 2978.00 & 21600.00 & 178680.00 & 49.63 & 6.00 \\
\hline 9/25/11 12:00 AM & 225.00 & 3338.00 & 21600.00 & 200280.00 & 55.63 & 6.00 \\
\hline 9/25/11 2:00 PM & 225.00 & 4178.00 & 50400.00 & 250680.00 & 69.63 & 14.00 \\
\hline 9/25/11 8:50 PM & 226.00 & 4588.00 & 24600.00 & 275280.00 & 76.47 & 6.83 \\
\hline 9/26/11 1:30 AM & 228.00 & 4868.00 & 16800.00 & 292080.00 & 81.13 & 4.67 \\
\hline 9/26/11 11:00 AM & 228.00 & 5438.00 & 34200.00 & 326280.00 & 90.63 & 9.50 \\
\hline 9/26/11 3:00 PM & 228.00 & 5678.00 & 14400.00 & 340680.00 & 94.63 & 4.00 \\
\hline 9/26/11 7:10 PM & 228.00 & 5928.00 & 15000.00 & 355680.00 & 98.80 & 4.17 \\
\hline 9/27/11 1:00 AM & 228.00 & 6278.00 & 21000.00 & 376680.00 & 104.63 & 5.83 \\
\hline 9/27/11 11:00 AM & 228.00 & 6878.00 & 36000.00 & 412680.00 & 114.63 & 10.00 \\
\hline 9/27/11 3:35 PM & 228.00 & 7153.00 & 16500.00 & 429180.00 & 119.22 & 4.58 \\
\hline 9/28/11 4:30 PM & 220.00 & 8648.00 & 89700.00 & 518880.00 & 144.13 & 24.92 \\
\hline 9/29/11 2:45 PM & 310.00 & 9983.00 & 80100.00 & 598980.00 & 166.38 & 22.25 \\
\hline 9/29/11 9:20 PM & 330.00 & 10378.00 & 23700.00 & 622680.00 & 172.97 & 6.58 \\
\hline 9/30/11 12:45 PM & 360.00 & 11303.00 & 55500.00 & 678180.00 & 188.38 & 15.42 \\
\hline 9/30/11 4:30 PM & 365.00 & 11528.00 & 13500.00 & 691680.00 & 192.13 & 3.75 \\
\hline 9/30/11 8:00 PM & 370.00 & 11738.00 & 12600.00 & 704280.00 & 195.63 & 3.50 \\
\hline 10/1/11 12:30 AM & 378.00 & 12008.00 & 16200.00 & 720480.00 & 200.13 & 4.50 \\
\hline 10/1/11 1:15 PM & 396.00 & 12773.00 & 45900.00 & 766380.00 & 212.88 & 12.75 \\
\hline 10/1/11 9:02 PM & 408.00 & 13240.00 & 28020.00 & 794400.00 & 220.67 & 7.78 \\
\hline 10/2/11 2:10 PM & 425.00 & 14268.00 & 61680.00 & 856080.00 & 237.80 & 17.13 \\
\hline
\end{tabular}




\begin{tabular}{|l|l|l|l|l|l|l|} 
10/3/11 12:40 AM & 435.00 & 14898.00 & 37800.00 & 893880.00 & 248.30 & 10.50 \\
\hline 10/3/11 10:20 AM & 440.00 & 15478.00 & 34800.00 & 928680.00 & 257.97 & 9.67 \\
\hline 10/4/11 12:00 PM & 468.00 & 17018.00 & 92400.00 & 1021080.00 & 283.63 & 25.67 \\
\hline $10 / 5 / 1110: 45 \mathrm{AM}$ & 488.00 & 18383.00 & 81900.00 & 1102980.00 & 306.38 & 22.75 \\
\hline $10 / 6 / 112: 45 \mathrm{PM}$ & 512.00 & 20063.00 & 100800.00 & 1203780.00 & 334.38 & 28.00 \\
\hline $10 / 7 / 1112: 45 \mathrm{PM}$ & 533.00 & 21383.00 & 79200.00 & 1282980.00 & 356.38 & 22.00 \\
\hline $10 / 8 / 1110: 00 \mathrm{PM}$ & 565.00 & 23378.00 & 119700.00 & 1402680.00 & 389.63 & 33.25 \\
\hline $10 / 9 / 117: 45 \mathrm{PM}$ & 585.00 & 24683.00 & 78300.00 & 1480980.00 & 411.38 & 21.75 \\
\hline $10 / 10 / 113: 00 \mathrm{PM}$ & 600.00 & 25838.00 & 69300.00 & 1550280.00 & 430.63 & 19.25 \\
\hline $10 / 11 / 1112: 10 \mathrm{PM}$ & 620.00 & 27108.00 & 76200.00 & 1626480.00 & 451.80 & 21.17 \\
\hline $10 / 12 / 1112: 30 \mathrm{PM}$ & 640.00 & 28568.00 & 87600.00 & 1714080.00 & 476.13 & 24.33 \\
\hline
\end{tabular}




\begin{tabular}{|c|c|c|c|c|c|c|c|c|c|c|c|}
\hline$\Delta \mathrm{V}\left(\mathrm{cm}^{3}\right)$ & $\mathrm{i}$ & $\begin{array}{l}\text { Area } \\
\left(\mathrm{cm}^{2}\right)\end{array}$ & $\begin{array}{c}\mathrm{q}_{\mathrm{in}} \\
\left(\mathrm{cm}^{3} / \mathrm{sec}\right)\end{array}$ & $\begin{array}{c}\text { qout } \\
\left(\mathrm{cm}^{3} / \mathrm{sec}\right)\end{array}$ & $\begin{array}{c}\mathrm{k} \\
(\mathrm{cm} / \mathrm{sec})\end{array}$ & $\mathrm{k}(\mathrm{m} / \mathrm{sec})$ & $\begin{array}{l}\text { Height } \\
\text { of } \\
\text { Water } \\
(\mathrm{cm})\end{array}$ & $\begin{array}{l}\text { Height } \\
\text { of } \\
\text { Water } \\
\text { (in) }\end{array}$ & $\begin{array}{l}\text { Time } \\
\text { Step }\end{array}$ & $\mathrm{N}_{\mathrm{PV}}$ & $\begin{array}{c}\text { Qin (mL) } \\
\text { Cumulative }\end{array}$ \\
\hline 0.00 & 15 & 81.07 & 0.00 & 0.00 & 0.00 & $0.000 \mathrm{E}+00$ & 23.65 & 9.31 & 1.00 & 0.00 & 0 \\
\hline 190.00 & 15 & 81.07 & 0.08 & 0.32 & 0.00 & 2.604E-06 & 22.23 & 8.75 & 2.00 & 0.53 & 190 \\
\hline 26.00 & 15 & 81.07 & 0.00 & 0.00 & 0.00 & $1.497 \mathrm{E}-08$ & 21.91 & 8.63 & 3.00 & 0.60 & 216 \\
\hline 2.00 & 15 & 81.07 & 0.00 & 0.00 & 0.00 & $1.142 \mathrm{E}-09$ & 21.91 & 8.63 & 4.00 & 0.61 & 218 \\
\hline 2.00 & 15 & 81.07 & 0.00 & 0.00 & 0.00 & $4.568 \mathrm{E}-10$ & 21.59 & 8.50 & 5.00 & 0.62 & 220 \\
\hline 3.00 & 15 & 81.07 & 0.00 & 0.00 & 0.00 & 2.284E-09 & 21.59 & 8.50 & 6.00 & 0.62 & 223 \\
\hline 0.00 & 15 & 81.07 & 0.00 & 0.00 & 0.00 & $0.000 \mathrm{E}+00$ & 21.59 & 8.50 & 7.00 & 0.62 & 223 \\
\hline 2.00 & 15 & 81.07 & 0.00 & 0.00 & 0.00 & $6.605 \mathrm{E}-10$ & 21.59 & 8.50 & 8.00 & 0.63 & 225 \\
\hline 0.00 & 15 & 81.07 & 0.00 & 0.00 & 0.00 & $0.000 \mathrm{E}+00$ & 21.59 & 8.50 & 9.00 & 0.63 & 225 \\
\hline 0.00 & 15 & 81.07 & 0.00 & 0.00 & 0.00 & $0.000 \mathrm{E}+00$ & 21.59 & 8.50 & 10.00 & 0.63 & 225 \\
\hline 0.00 & 15 & 81.07 & 0.00 & 0.00 & 0.00 & $0.000 \mathrm{E}+00$ & 21.59 & 8.50 & 11.00 & 0.63 & 225 \\
\hline 0.00 & 15 & 81.07 & 0.00 & 0.00 & 0.00 & $0.000 \mathrm{E}+00$ & 21.59 & 8.50 & 12.00 & 0.63 & 225 \\
\hline 1.00 & 15 & 81.07 & 0.00 & 0.00 & 0.00 & $3.343 \mathrm{E}-10$ & 21.43 & 8.44 & 13.00 & 0.63 & 226 \\
\hline 2.00 & 15 & 81.07 & 0.00 & 0.00 & 0.00 & 9.789E-10 & 21.43 & 8.44 & 14.00 & 0.64 & 228 \\
\hline 0.00 & 15 & 81.07 & 0.00 & 0.00 & 0.00 & $0.000 \mathrm{E}+00$ & 21.43 & 8.44 & 15.00 & 0.64 & 228 \\
\hline 0.00 & 15 & 81.07 & 0.00 & 0.00 & 0.00 & $0.000 \mathrm{E}+00$ & 21.43 & 8.44 & 16.00 & 0.64 & 228 \\
\hline 0.00 & 15 & 81.07 & 0.00 & 0.00 & 0.00 & $0.000 \mathrm{E}+00$ & 21.43 & 8.44 & 17.00 & 0.64 & 228 \\
\hline 0.00 & 15 & 81.07 & 0.00 & 0.00 & 0.00 & $0.000 \mathrm{E}+00$ & 21.43 & 8.44 & 18.00 & 0.64 & 228 \\
\hline 0.00 & 15 & 81.07 & 0.00 & 0.00 & 0.00 & $0.000 \mathrm{E}+00$ & 21.27 & 8.38 & 19.00 & 0.64 & 228 \\
\hline 0.00 & 15 & 81.07 & 0.00 & 0.00 & 0.00 & $0.000 \mathrm{E}+00$ & 21.27 & 8.38 & 20.00 & 0.64 & 228 \\
\hline-8.00 & 15 & 81.07 & 0.00 & 0.00 & 0.00 & $\begin{array}{r}-7.334 \mathrm{E}- \\
10 \\
\end{array}$ & 21.27 & 8.38 & 21.00 & 0.62 & 220 \\
\hline 90.00 & 15 & 81.07 & 0.00 & 0.00 & 0.00 & $9.239 \mathrm{E}-09$ & 20.64 & 8.13 & 22.00 & 0.87 & 310 \\
\hline 20.00 & 15 & 81.07 & 0.00 & 0.00 & 0.00 & 6.939E-09 & 20.48 & 8.06 & 23.00 & 0.92 & 330 \\
\hline 30.00 & 15 & 81.07 & 0.00 & 0.00 & 0.00 & 4.445E-09 & 20.32 & 8.00 & 24.00 & 1.01 & 360 \\
\hline 5.00 & 15 & 81.07 & 0.00 & 0.00 & 0.00 & $3.046 \mathrm{E}-09$ & 20.16 & 7.94 & 25.00 & 1.02 & 365 \\
\hline 5.00 & 15 & 81.07 & 0.00 & 0.00 & 0.00 & $3.263 \mathrm{E}-09$ & 20.16 & 7.94 & 26.00 & 1.04 & 370 \\
\hline 8.00 & 15 & 81.07 & 0.00 & 0.00 & 0.00 & 4.061E-09 & 20.16 & 7.94 & 27.00 & 1.06 & 378 \\
\hline
\end{tabular}




\begin{tabular}{|r|r|l|l|l|l|l|l|l|l|l|l|}
18.00 & 15 & 81.07 & 0.00 & 0.00 & 0.00 & $3.225 \mathrm{E}-09$ & 20.00 & 7.88 & 28.00 & 1.11 & 396 \\
\hline 12.00 & 15 & 81.07 & 0.00 & 0.00 & 0.00 & $3.522 \mathrm{E}-09$ & 20.00 & 7.88 & 29.00 & 1.14 & 408 \\
\hline 17.00 & 15 & 81.07 & 0.00 & 0.00 & 0.00 & $2.266 \mathrm{E}-09$ & 19.69 & 7.75 & 30.00 & 1.19 & 425 \\
\hline 10.00 & 15 & 81.07 & 0.00 & 0.00 & 0.00 & $2.175 \mathrm{E}-09$ & 19.69 & 7.75 & 31.00 & 1.22 & 435 \\
\hline 5.00 & 15 & 81.07 & 0.00 & 0.00 & 0.00 & $1.181 \mathrm{E}-09$ & 19.69 & 7.75 & 32.00 & 1.23 & 440 \\
\hline 28.00 & 15 & 81.07 & 0.00 & 0.00 & 0.00 & $2.492 \mathrm{E}-09$ & 19.37 & 7.63 & 33.00 & 1.31 & 468 \\
\hline 20.00 & 15 & 81.07 & 0.00 & 0.00 & 0.00 & $2.008 \mathrm{E}-09$ & 19.37 & 7.63 & 34.00 & 1.37 & 488 \\
\hline 24.00 & 15 & 81.07 & 0.00 & 0.00 & 0.00 & $1.958 \mathrm{E}-09$ & 19.05 & 7.50 & 35.00 & 1.43 & 512 \\
\hline 21.00 & 15 & 81.07 & 0.00 & 0.00 & 0.00 & $2.180 \mathrm{E}-09$ & 19.05 & 7.50 & 36.00 & 1.49 & 533 \\
\hline 32.00 & 15 & 81.07 & 0.00 & 0.00 & 0.00 & $2.198 \mathrm{E}-09$ & 18.73 & 7.38 & 37.00 & 1.58 & 565 \\
\hline 20.00 & 15 & 81.07 & 0.00 & 0.00 & 0.00 & $2.100 \mathrm{E}-09$ & 18.73 & 7.38 & 38.00 & 1.64 & 585 \\
\hline 15.00 & 15 & 81.07 & 0.00 & 0.00 & 0.00 & $1.780 \mathrm{E}-09$ & 18.57 & 7.31 & 39.00 & 1.68 & 600 \\
\hline 20.00 & 15 & 81.07 & 0.00 & 0.00 & 0.00 & $2.158 \mathrm{E}-09$ & 18.42 & 7.25 & 40.00 & 1.74 & 620 \\
\hline 20.00 & 15 & 81.07 & 0.03 & 0.00 & 0.00 & $1.877 \mathrm{E}-09$ & 18.26 & 7.19 & 41.00 & 1.79 & 640 \\
\hline
\end{tabular}

Back pressure saturation was attempted on September 28 at 4:30 p.m. for a duration of 22 hours and 15 minutes. The effort was an attempt to remove additional air trapped in the specimen. 
Hydraulic Conductivity: Test $2-34 \%$ Proctor Compaction $\left(203.6 \mathrm{~kJ} / \mathrm{m}^{3}\right)$

Sample - GrayPermM32: Test Started on 9/22/2011 at 4:22:00 p.m.

\begin{tabular}{|c|c|c|c|c|c|c|c|c|}
\hline \multirow{2}{*}{ Time } & \multirow{2}{*}{$\begin{array}{r}\text { Vol } \\
(\mathrm{ml}) \\
\end{array}$} & \multirow{2}{*}{$\begin{array}{c}\Delta \mathrm{t} \\
(\mathrm{min})\end{array}$} & \multicolumn{2}{|c|}{ Time (Seconds) } & \multicolumn{2}{|c|}{ Time (Hours) } & \multirow{2}{*}{$\begin{array}{c}\Delta V^{3} \\
\left(\mathrm{~cm}^{3}\right)\end{array}$} & \multirow{2}{*}{$\mathrm{i}$} \\
\hline & & & $\Delta \mathrm{t}$ & Cumulative & Cumulative & $\Delta \mathrm{t}$ & & \\
\hline 9/22/11 4:22 PM & 0 & 0 & 0 & 0 & 0.00 & 0.00 & 0 & 15 \\
\hline 9/22/11 4:32 PM & 0 & 10 & 600 & 600 & 0.17 & 0.17 & 0 & 15 \\
\hline 9/22/11 8:30 PM & 0 & 248 & 14280 & 14880 & 4.13 & 3.97 & 0 & 15 \\
\hline 9/23/11 12:30 AM & 0 & 488 & 14400 & 29280 & 8.13 & 4.00 & 0 & 15 \\
\hline 9/23/11 10:30 AM & 10 & 1088 & 36000 & 65280 & 18.13 & 10.00 & 10 & 15 \\
\hline 9/23/11 1:30 PM & 20 & 1268 & 10800 & 76080 & 21.13 & 3.00 & 10 & 15 \\
\hline 9/23/11 5:05 PM & 20 & 1483 & 12900 & 88980 & 24.72 & 3.58 & 0 & 15 \\
\hline 9/24/11 12:00 AM & 21 & 1898 & 24900 & 113880 & 31.63 & 6.92 & 1 & 15 \\
\hline 9/24/11 12:00 PM & 21 & 2618 & 43200 & 157080 & 43.63 & 12.00 & 0 & 15 \\
\hline 9/24/11 6:00 PM & 23 & 2978 & 21600 & 178680 & 49.63 & 6.00 & 2 & 15 \\
\hline 9/25/11 12:00 AM & 23 & 3338 & 21600 & 200280 & 55.63 & 6.00 & 0 & 15 \\
\hline 9/25/11 2:00 PM & 26 & 4178 & 50400 & 250680 & 69.63 & 14.00 & 3 & 15 \\
\hline 9/25/11 8:50 PM & 30 & 4588 & 24600 & 275280 & 76.47 & 6.83 & 4 & 15 \\
\hline 9/26/11 1:30 AM & 30 & 4868 & 16800 & 292080 & 81.13 & 4.67 & 0 & 15 \\
\hline 9/26/11 11:00 AM & 32 & 5438 & 34200 & 326280 & 90.63 & 9.50 & 2 & 15 \\
\hline 9/26/11 3:00 PM & 35 & 5678 & 14400 & 340680 & 94.63 & 4.00 & 3 & 15 \\
\hline 9/26/11 7:10 PM & 50 & 5928 & 15000 & 355680 & 98.80 & 4.17 & 15 & 15 \\
\hline 9/27/11 1:00 AM & 50 & 6278 & 21000 & 376680 & 104.63 & 5.83 & 0 & 15 \\
\hline 9/27/11 11:00 AM & 50 & 6878 & 36000 & 412680 & 114.63 & 10.00 & 0 & 15 \\
\hline 9/27/11 3:35 PM & 50 & 7153 & 16500 & 429180 & 119.22 & 4.58 & 0 & 15 \\
\hline 9/28/11 4:30 PM & 53 & 8648 & 89700 & 518880 & 144.13 & 24.92 & 3 & 15 \\
\hline 9/29/11 2:45 PM & 68 & 9983 & 80100 & 598980 & 166.38 & 22.25 & 15 & 15 \\
\hline 9/29/11 9:20 PM & 70 & 10378 & 23700 & 622680 & 172.97 & 6.58 & 2 & 15 \\
\hline 9/30/11 12:45 PM & 72 & 11303 & 55500 & 678180 & 188.38 & 15.42 & 2 & 15 \\
\hline 9/30/11 4:30 PM & 72 & 11528 & 13500 & 691680 & 192.13 & 3.75 & 0 & 15 \\
\hline 9/30/11 8:00 PM & 75 & 11738 & 12600 & 704280 & 195.63 & 3.50 & 3 & 15 \\
\hline 10/1/11 12:30 AM & 75 & 12008 & 16200 & 720480 & 200.13 & 4.50 & 0 & 15 \\
\hline
\end{tabular}




\begin{tabular}{|r|c|c|c|c|c|c|c|c|}
\hline $10 / 1 / 11 ~ 1: 15 ~ P M$ & 78 & 12773 & 45900 & 766380 & 212.88 & 12.75 & 3 & 15 \\
\hline $10 / 1 / 119: 02 \mathrm{PM}$ & 78 & 13240 & 28020 & 794400 & 220.67 & 7.78 & 0 & 15 \\
\hline $10 / 2 / 112: 10 \mathrm{PM}$ & 90 & 14268 & 61680 & 856080 & 237.80 & 17.13 & 12 & 15 \\
\hline $10 / 3 / 1112: 40 \mathrm{AM}$ & 100 & 14898 & 37800 & 893880 & 248.30 & 10.50 & 10 & 15 \\
\hline $10 / 3 / 1110: 20 \mathrm{AM}$ & 105 & 15478 & 34800 & 928680 & 257.97 & 9.67 & 5 & 15 \\
\hline $10 / 4 / 1112: 00 \mathrm{PM}$ & 125 & 17018 & 92400 & 1021080 & 283.63 & 25.67 & 20 & 15 \\
\hline $10 / 5 / 1110: 45 \mathrm{AM}$ & 140 & 18383 & 81900 & 1102980 & 306.38 & 22.75 & 15 & 15 \\
\hline $10 / 6 / 112: 45 \mathrm{PM}$ & 160 & 20063 & 100800 & 1203780 & 334.38 & 28.00 & 20 & 15 \\
\hline $10 / 7 / 1112: 45 \mathrm{PM}$ & 176 & 21383 & 79200 & 1282980 & 356.38 & 22.00 & 16 & 15 \\
\hline $10 / 8 / 1110: 00 \mathrm{PM}$ & 200 & 23378 & 119700 & 1402680 & 389.63 & 33.25 & 24 & 15 \\
\hline $10 / 9 / 117: 45 \mathrm{PM}$ & 220 & 24683 & 78300 & 1480980 & 411.38 & 21.75 & 20 & 15 \\
\hline $10 / 10 / 113: 00 \mathrm{PM}$ & 230 & 25838 & 69300 & 1550280 & 430.63 & 19.25 & 10 & 15 \\
\hline $10 / 11 / 1112: 10 \mathrm{PM}$ & 248 & 27108 & 76200 & 1626480 & 451.80 & 21.17 & 18 & 15 \\
\hline $10 / 12 / 1112: 30 \mathrm{PM}$ & 265 & 28568 & 87600 & 1714080 & 476.13 & 24.33 & 17 & 15 \\
\hline
\end{tabular}




\begin{tabular}{|c|c|c|c|c|c|c|c|c|c|}
\hline $\begin{array}{l}\text { Area } \\
\left(\mathrm{cm}^{2}\right)\end{array}$ & $\begin{array}{c}\text { qin } \\
\left(\mathrm{cm}^{3} / \mathrm{sec}\right)\end{array}$ & $\begin{array}{c}\text { qout } \\
\left(\mathrm{cm}^{3} / \mathrm{sec}\right)\end{array}$ & $\begin{array}{c}\mathrm{k} \\
(\mathrm{cm} / \mathrm{sec})\end{array}$ & $\mathrm{k}(\mathrm{m} / \mathrm{sec})$ & $\begin{array}{c}\text { Height of } \\
\text { Water } \\
(\mathrm{cm})\end{array}$ & $\begin{array}{l}\text { Height } \\
\text { of Water } \\
\text { (in) }\end{array}$ & $\begin{array}{l}\text { Time } \\
\text { Step }\end{array}$ & $\mathrm{N}_{\mathrm{PV}}$ & $\begin{array}{l}\text { Qin (mL) } \\
\text { Cumulative }\end{array}$ \\
\hline 81.07 & $0.000 \mathrm{E}+00$ & $0.000 \mathrm{E}+00$ & $0.00 \mathrm{E}+00$ & $0.00 \mathrm{E}+00$ & 28.89 & 11.38 & 1 & 0.000 & 0 \\
\hline 81.07 & 8.107E-02 & $0.000 \mathrm{E}+00$ & $0.00 \mathrm{E}+00$ & $0.00 \mathrm{E}+00$ & 28.89 & 11.38 & 2 & 0.000 & 0 \\
\hline 81.07 & $0.000 \mathrm{E}+00$ & $0.000 \mathrm{E}+00$ & $0.00 \mathrm{E}+00$ & $0.00 \mathrm{E}+00$ & 28.58 & 11.25 & 3 & 0.000 & 0 \\
\hline 81.07 & $3.378 \mathrm{E}-03$ & $0.000 \mathrm{E}+00$ & $0.00 \mathrm{E}+00$ & $0.00 \mathrm{E}+00$ & 28.58 & 11.25 & 4 & 0.000 & 0 \\
\hline 81.07 & $0.000 \mathrm{E}+00$ & $2.778 \mathrm{E}-04$ & $2.28 \mathrm{E}-07$ & $2.28 \mathrm{E}-09$ & 28.26 & 11.13 & 5 & 0.028 & 10 \\
\hline 81.07 & $2.252 \mathrm{E}-03$ & $9.259 \mathrm{E}-04$ & 7.61E-07 & 7.61E-09 & 28.26 & 11.13 & 6 & 0.057 & 20 \\
\hline 81.07 & $0.000 \mathrm{E}+00$ & $0.000 \mathrm{E}+00$ & $0.00 \mathrm{E}+00$ & $0.00 \mathrm{E}+00$ & 28.10 & 11.06 & 7 & 0.057 & 20 \\
\hline 81.07 & $0.000 \mathrm{E}+00$ & $4.016 \mathrm{E}-05$ & $3.30 \mathrm{E}-08$ & $3.30 \mathrm{E}-10$ & 28.10 & 11.06 & 8 & 0.059 & 21 \\
\hline 81.07 & $0.000 \mathrm{E}+00$ & $0.000 \mathrm{E}+00$ & $0.00 \mathrm{E}+00$ & $0.00 \mathrm{E}+00$ & 28.10 & 11.06 & 9 & 0.059 & 21 \\
\hline 81.07 & $0.000 \mathrm{E}+00$ & $9.259 \mathrm{E}-05$ & 7.61E-08 & 7.61E-10 & 28.10 & 11.06 & 10 & 0.065 & 23 \\
\hline 81.07 & $0.000 \mathrm{E}+00$ & $0.000 \mathrm{E}+00$ & $0.00 \mathrm{E}+00$ & $0.00 \mathrm{E}+00$ & 28.10 & 11.06 & 11 & 0.065 & 23 \\
\hline 81.07 & $4.826 \mathrm{E}-04$ & $5.952 \mathrm{E}-05$ & 4.89E-08 & $4.89 \mathrm{E}-10$ & 28.10 & 11.06 & 12 & 0.074 & 26 \\
\hline 81.07 & $0.000 \mathrm{E}+00$ & $1.626 \mathrm{E}-04$ & $1.34 \mathrm{E}-07$ & $1.34 \mathrm{E}-09$ & 27.94 & 11.00 & 13 & 0.085 & 30 \\
\hline 81.07 & $0.000 \mathrm{E}+00$ & $0.000 \mathrm{E}+00$ & $0.00 \mathrm{E}+00$ & $0.00 \mathrm{E}+00$ & 27.94 & 11.00 & 14 & 0.085 & 30 \\
\hline 81.07 & $0.000 \mathrm{E}+00$ & $5.848 \mathrm{E}-05$ & 4.81E-08 & $4.81 \mathrm{E}-10$ & 27.94 & 11.00 & 15 & 0.091 & 32 \\
\hline 81.07 & $1.689 \mathrm{E}-03$ & $2.083 \mathrm{E}-04$ & $1.71 \mathrm{E}-07$ & $1.71 \mathrm{E}-09$ & 27.94 & 11.00 & 16 & 0.099 & 35 \\
\hline 81.07 & $0.000 \mathrm{E}+00$ & $1.000 \mathrm{E}-03$ & $8.22 \mathrm{E}-07$ & 8.22E-09 & 27.78 & 10.94 & 17 & 0.142 & 50 \\
\hline 81.07 & $0.000 \mathrm{E}+00$ & $0.000 \mathrm{E}+00$ & $0.00 \mathrm{E}+00$ & $0.00 \mathrm{E}+00$ & 27.78 & 10.94 & 18 & 0.142 & 50 \\
\hline 81.07 & $0.000 \mathrm{E}+00$ & $0.000 \mathrm{E}+00$ & $0.00 \mathrm{E}+00$ & $0.00 \mathrm{E}+00$ & 27.78 & 10.94 & 19 & 0.142 & 50 \\
\hline 81.07 & $1.327 \mathrm{E}-02$ & $0.000 \mathrm{E}+00$ & $0.00 \mathrm{E}+00$ & $0.00 \mathrm{E}+00$ & 27.78 & 10.94 & 20 & 0.142 & 50 \\
\hline 81.07 & $2.711 \mathrm{E}-04$ & $3.344 \mathrm{E}-05$ & $2.75 \mathrm{E}-08$ & $2.75 \mathrm{E}-10$ & 26.35 & 10.38 & 21 & 0.150 & 53 \\
\hline 81.07 & $0.000 \mathrm{E}+00$ & $1.873 \mathrm{E}-04$ & $1.54 \mathrm{E}-07$ & $1.54 \mathrm{E}-09$ & 26.19 & 10.31 & 22 & 0.193 & 68 \\
\hline 81.07 & $0.000 \mathrm{E}+00$ & 8.439E-05 & $6.94 \mathrm{E}-08$ & $6.94 \mathrm{E}-10$ & 26.19 & 10.31 & 23 & 0.198 & 70 \\
\hline 81.07 & $0.000 \mathrm{E}+00$ & $3.604 \mathrm{E}-05$ & $2.96 \mathrm{E}-08$ & $2.96 \mathrm{E}-10$ & 26.19 & 10.31 & 24 & 0.204 & 72 \\
\hline 81.07 & $0.000 \mathrm{E}+00$ & $0.000 \mathrm{E}+00$ & $0.00 \mathrm{E}+00$ & $0.00 \mathrm{E}+00$ & 26.19 & 10.31 & 25 & 0.204 & 72 \\
\hline 81.07 & $0.000 \mathrm{E}+00$ & $2.381 \mathrm{E}-04$ & $1.96 \mathrm{E}-07$ & $1.96 \mathrm{E}-09$ & 26.19 & 10.31 & 26 & 0.212 & 75 \\
\hline 81.07 & $0.000 \mathrm{E}+00$ & $0.000 \mathrm{E}+00$ & $0.00 \mathrm{E}+00$ & $0.00 \mathrm{E}+00$ & 26.19 & 10.31 & 27 & 0.212 & 75 \\
\hline 81.07 & $0.000 \mathrm{E}+00$ & $6.536 \mathrm{E}-05$ & $5.37 \mathrm{E}-08$ & $5.37 \mathrm{E}-10$ & 26.19 & 10.31 & 28 & 0.221 & 78 \\
\hline 81.07 & $8.680 \mathrm{E}-04$ & $0.000 \mathrm{E}+00$ & $0.00 \mathrm{E}+00$ & $0.00 \mathrm{E}+00$ & 26.19 & 10.31 & 29 & 0.221 & 78 \\
\hline 81.07 & $3.943 \mathrm{E}-04$ & $1.946 \mathrm{E}-04$ & $1.60 \mathrm{E}-07$ & $1.60 \mathrm{E}-09$ & 26.04 & 10.25 & 30 & 0.255 & 90 \\
\hline 81.07 & $0.000 \mathrm{E}+00$ & $2.646 \mathrm{E}-04$ & $2.18 \mathrm{E}-07$ & $2.18 \mathrm{E}-09$ & 25.88 & 10.19 & 31 & 0.283 & 100 \\
\hline
\end{tabular}




\begin{tabular}{|l|l|l|l|l|l|l|l|l|l|}
81.07 & $6.989 \mathrm{E}-04$ & $1.437 \mathrm{E}-04$ & $1.18 \mathrm{E}-07$ & $1.18 \mathrm{E}-09$ & 25.88 & 10.19 & 32 & 0.297 & 105 \\
\hline 81.07 & $2.632 \mathrm{E}-04$ & $2.165 \mathrm{E}-04$ & $1.78 \mathrm{E}-07$ & $1.78 \mathrm{E}-09$ & 25.72 & 10.13 & 33 & 0.354 & 125 \\
\hline 81.07 & $2.970 \mathrm{E}-04$ & $1.832 \mathrm{E}-04$ & $1.51 \mathrm{E}-07$ & $1.51 \mathrm{E}-09$ & 25.56 & 10.06 & 34 & 0.397 & 140 \\
\hline 81.07 & $2.413 \mathrm{E}-04$ & $1.984 \mathrm{E}-04$ & $1.63 \mathrm{E}-07$ & $1.63 \mathrm{E}-09$ & 25.40 & 10.00 & 35 & 0.453 & 160 \\
\hline 81.07 & $3.071 \mathrm{E}-04$ & $2.020 \mathrm{E}-04$ & $1.66 \mathrm{E}-07$ & $1.66 \mathrm{E}-09$ & 25.24 & 9.94 & 36 & 0.499 & 176 \\
\hline 81.07 & $2.032 \mathrm{E}-04$ & $2.005 \mathrm{E}-04$ & $1.65 \mathrm{E}-07$ & $1.65 \mathrm{E}-09$ & 25.08 & 9.88 & 37 & 0.567 & 200 \\
\hline 81.07 & $0.000 \mathrm{E}+00$ & $2.554 \mathrm{E}-04$ & $2.10 \mathrm{E}-07$ & $2.10 \mathrm{E}-09$ & 24.92 & 9.81 & 38 & 0.623 & 220 \\
\hline 81.07 & $3.509 \mathrm{E}-04$ & $1.443 \mathrm{E}-04$ & $1.19 \mathrm{E}-07$ & $1.19 \mathrm{E}-09$ & 24.92 & 9.81 & 39 & 0.652 & 230 \\
\hline 81.07 & $3.192 \mathrm{E}-04$ & $2.362 \mathrm{E}-04$ & $1.94 \mathrm{E}-07$ & $1.94 \mathrm{E}-09$ & 24.77 & 9.75 & 40 & 0.703 & 248 \\
\hline 81.07 & $4.303 \mathrm{E}-02$ & $1.941 \mathrm{E}-04$ & $1.60 \mathrm{E}-07$ & $1.60 \mathrm{E}-09$ & 24.61 & 9.69 & 41 & 0.751 & 265 \\
\hline
\end{tabular}


Hydraulic Conductivity: Test 3 - 34\% Proctor Compaction $\left(203.6 \mathrm{~kJ} / \mathrm{m}^{3}\right)$

\begin{tabular}{|c|c|c|c|c|c|c|c|c|c|}
\hline \multirow{2}{*}{ Time } & \multirow{2}{*}{$\begin{array}{l}\text { Vol } \\
(\mathrm{ml})\end{array}$} & \multirow{2}{*}{$\begin{array}{c}\Delta \mathrm{t} \\
(\mathrm{min})\end{array}$} & \multicolumn{2}{|c|}{ Time (Seconds) } & \multicolumn{2}{|c|}{ Time (Hours) } & \multirow{2}{*}{$\begin{array}{c}\Delta \mathrm{V} \\
\left(\mathrm{cm}^{3}\right)\end{array}$} & \multirow{2}{*}{$\mathrm{i}$} & \multirow{2}{*}{ Area $\left(\mathrm{cm}^{2}\right)$} \\
\hline & & & $\Delta \mathrm{t}$ & Cumulative & Cumulative & $\Delta \mathrm{t}$ & & & \\
\hline 9/22/11 4:22 PM & 0 & 0 & 0 & 0 & 0.00 & 0.00 & 0 & 15 & 81.07 \\
\hline 9/22/11 4:32 PM & 0 & 10 & 600 & 600 & 0.17 & 0.17 & 0 & 15 & 81.07 \\
\hline 9/22/11 8:30 PM & 0 & 248 & 14280 & 14880 & 4.13 & 3.97 & 0 & 15 & 81.07 \\
\hline 9/23/11 12:30 AM & 0 & 488 & 14400 & 29280 & 8.13 & 4.00 & 0 & 15 & 81.07 \\
\hline 9/23/11 10:30 AM & 5 & 1088 & 36000 & 65280 & 18.13 & 10.00 & 5 & 15 & 81.07 \\
\hline 9/23/11 1:30 PM & 10 & 1268 & 10800 & 76080 & 21.13 & 3.00 & 5 & 15 & 81.07 \\
\hline 9/23/11 5:05 PM & 10 & 1483 & 12900 & 88980 & 24.72 & 3.58 & 0 & 15 & 81.07 \\
\hline 9/24/11 12:00 AM & 10 & 1898 & 24900 & 113880 & 31.63 & 6.92 & 0 & 15 & 81.07 \\
\hline 9/24/11 12:00 PM & 10 & 2618 & 43200 & 157080 & 43.63 & 12.00 & 0 & 15 & 81.07 \\
\hline 9/24/11 6:00 PM & 10 & 2978 & 21600 & 178680 & 49.63 & 6.00 & 0 & 15 & 81.07 \\
\hline 9/25/11 12:00 AM & 10 & 3338 & 21600 & 200280 & 55.63 & 6.00 & 0 & 15 & 81.07 \\
\hline 9/25/11 2:00 PM & 10 & 4178 & 50400 & 250680 & 69.63 & 14.00 & 0 & 15 & 81.07 \\
\hline 9/25/11 8:50 PM & 25 & 4588 & 24600 & 275280 & 76.47 & 6.83 & 15 & 15 & 81.07 \\
\hline 9/26/11 1:30 AM & 25 & 4868 & 16800 & 292080 & 81.13 & 4.67 & 0 & 15 & 81.07 \\
\hline 9/26/11 11:00 AM & 30 & 5438 & 34200 & 326280 & 90.63 & 9.50 & 5 & 15 & 81.07 \\
\hline 9/26/11 3:00 PM & 32 & 5678 & 14400 & 340680 & 94.63 & 4.00 & 2 & 15 & 81.07 \\
\hline 9/26/11 7:10 PM & 35 & 5928 & 15000 & 355680 & 98.80 & 4.17 & 3 & 15 & 81.07 \\
\hline 9/27/11 1:00 AM & 40 & 6278 & 21000 & 376680 & 104.63 & 5.83 & 5 & 15 & 81.07 \\
\hline 9/27/11 11:00 AM & 40 & 6878 & 36000 & 412680 & 114.63 & 10.00 & 0 & 15 & 81.07 \\
\hline 9/27/11 3:35 PM & 50 & 7153 & 16500 & 429180 & 119.22 & 4.58 & 10 & 15 & 81.07 \\
\hline 9/28/11 4:30 PM & 50 & 8648 & 89700 & 518880 & 144.13 & 24.92 & 0 & 15 & 81.07 \\
\hline 9/29/11 2:45 PM & 97 & 9983 & 80100 & 598980 & 166.38 & 22.25 & 47 & 15 & 81.07 \\
\hline 9/29/11 9:20 PM & 129 & 10378 & 23700 & 622680 & 172.97 & 6.58 & 32 & 15 & 81.07 \\
\hline 9/30/11 12:45 PM & 188 & 11303 & 55500 & 678180 & 188.38 & 15.42 & 59 & 15 & 81.07 \\
\hline 9/30/11 4:30 PM & 202 & 11528 & 13500 & 691680 & 192.13 & 3.75 & 14 & 15 & 81.07 \\
\hline 9/30/11 8:00 PM & 212 & 11738 & 12600 & 704280 & 195.63 & 3.50 & 10 & 15 & 81.07 \\
\hline 10/1/11 12:30 AM & 230 & 12008 & 16200 & 720480 & 200.13 & 4.50 & 18 & 15 & 81.07 \\
\hline 10/1/11 1:15 PM & 270 & 12773 & 45900 & 766380 & 212.88 & 12.75 & 40 & 15 & 81.07 \\
\hline 10/1/11 9:02 PM & 298 & 13240 & 28020 & 794400 & 220.67 & 7.78 & 28 & 15 & 81.07 \\
\hline
\end{tabular}




\begin{tabular}{|r|r|r|r|r|r|r|r|r|r|} 
10/2/11 2:10 PM & 335 & 14268 & 61680 & 856080 & 237.80 & 17.13 & 37 & 15 & 81.07 \\
\hline $10 / 3 / 1112: 40 \mathrm{AM}$ & 357 & 14898 & 37800 & 893880 & 248.30 & 10.50 & 22 & 15 & 81.07 \\
\hline $10 / 3 / 1110: 20 \mathrm{AM}$ & 368 & 15478 & 34800 & 928680 & 257.97 & 9.67 & 11 & 15 & 81.07 \\
\hline $10 / 4 / 1112: 00 \mathrm{PM}$ & 400 & 17018 & 92400 & 1021080 & 283.63 & 25.67 & 32 & 15 & 81.07 \\
\hline $10 / 5 / 1110: 45 \mathrm{AM}$ & 437 & 18383 & 81900 & 1102980 & 306.38 & 22.75 & 37 & 15 & 81.07 \\
\hline $10 / 6 / 112: 45 \mathrm{PM}$ & 480 & 20063 & $1 \mathrm{E}+05$ & 1203780 & 334.38 & 28.00 & 43 & 15 & 81.07 \\
\hline $10 / 7 / 1112: 45 \mathrm{PM}$ & 515 & 21383 & 79200 & 1282980 & 356.38 & 22.00 & 35 & 15 & 81.07 \\
\hline $10 / 8 / 1110: 00 \mathrm{PM}$ & 568 & 23378 & $1 \mathrm{E}+05$ & 1402680 & 389.63 & 33.25 & 53 & 15 & 81.07 \\
\hline $10 / 9 / 117: 45 \mathrm{PM}$ & 600 & 24683 & 78300 & 1480980 & 411.38 & 21.75 & 32 & 15 & 81.07 \\
\hline $10 / 10 / 113: 00 \mathrm{PM}$ & 628 & 25838 & 69300 & 1550280 & 430.63 & 19.25 & 28 & 15 & 81.07 \\
\hline $10 / 11 / 1112: 10 \mathrm{PM}$ & 658 & 27108 & 76200 & 1626480 & 451.80 & 21.17 & 30 & 15 & 81.07 \\
\hline $10 / 12 / 1112: 30 \mathrm{PM}$ & 690 & 28568 & 87600 & 1714080 & 476.13 & 24.33 & 32 & 15 & 81.07 \\
\hline
\end{tabular}




\begin{tabular}{|c|c|c|c|c|c|c|c|c|}
\hline $\begin{array}{c}\text { qin } \\
\left(\mathrm{cm}^{3} / \mathrm{sec}\right)\end{array}$ & $\begin{array}{c}\text { qout } \\
\left(\mathrm{cm}^{3} / \mathrm{sec}\right)\end{array}$ & $\mathrm{k}(\mathrm{cm} / \mathrm{sec})$ & $\mathrm{k}(\mathrm{m} / \mathrm{sec})$ & $\begin{array}{c}\text { Height of } \\
\text { Water }(\mathrm{cm})\end{array}$ & $\begin{array}{l}\text { Height of } \\
\text { Water } \\
\text { (in) }\end{array}$ & $\begin{array}{l}\text { Time } \\
\text { Step }\end{array}$ & $\mathrm{N}_{\mathrm{PV}}$ & $\begin{array}{c}\mathrm{Q}_{\text {in }}(\mathrm{mL}) \\
\text { Cumulative }\end{array}$ \\
\hline $0.00 \mathrm{E}+00$ & $0.00 \mathrm{E}+00$ & $0.00 \mathrm{E}+00$ & $0.00 \mathrm{E}+00$ & 29.37 & 11.56 & 1 & 0.00 & 0 \\
\hline $0.00 \mathrm{E}+00$ & $0.00 \mathrm{E}+00$ & $0.00 \mathrm{E}+00$ & $0.00 \mathrm{E}+00$ & 29.21 & 11.50 & 2 & 0.00 & 0 \\
\hline $0.00 \mathrm{E}+00$ & $0.00 \mathrm{E}+00$ & $0.00 \mathrm{E}+00$ & $0.00 \mathrm{E}+00$ & 29.21 & 11.50 & 3 & 0.00 & 0 \\
\hline $6.76 \mathrm{E}-03$ & $0.00 \mathrm{E}+00$ & $0.00 \mathrm{E}+00$ & $0.00 \mathrm{E}+00$ & 29.21 & 11.50 & 4 & 0.00 & 0 \\
\hline $0.00 \mathrm{E}+00$ & 1.39E-04 & $1.14 \mathrm{E}-07$ & 1.14E-09 & 28.58 & 11.25 & 5 & 0.02 & 5 \\
\hline $2.25 \mathrm{E}-03$ & 4.63E-04 & $3.81 \mathrm{E}-07$ & $3.81 \mathrm{E}-09$ & 28.58 & 11.25 & 6 & 0.03 & 10 \\
\hline $0.00 \mathrm{E}+00$ & $0.00 \mathrm{E}+00$ & $0.00 \mathrm{E}+00$ & $0.00 \mathrm{E}+00$ & 28.42 & 11.19 & 7 & 0.03 & 10 \\
\hline $0.00 \mathrm{E}+00$ & $0.00 \mathrm{E}+00$ & $0.00 \mathrm{E}+00$ & $0.00 \mathrm{E}+00$ & 28.42 & 11.19 & 8 & 0.03 & 10 \\
\hline $0.00 \mathrm{E}+00$ & $0.00 \mathrm{E}+00$ & $0.00 \mathrm{E}+00$ & $0.00 \mathrm{E}+00$ & 28.42 & 11.19 & 9 & 0.03 & 10 \\
\hline $0.00 \mathrm{E}+00$ & $0.00 \mathrm{E}+00$ & $0.00 \mathrm{E}+00$ & $0.00 \mathrm{E}+00$ & 28.42 & 11.19 & 10 & 0.03 & 10 \\
\hline $0.00 \mathrm{E}+00$ & $0.00 \mathrm{E}+00$ & $0.00 \mathrm{E}+00$ & $0.00 \mathrm{E}+00$ & 28.42 & 11.19 & 11 & 0.03 & 10 \\
\hline $9.65 \mathrm{E}-04$ & $0.00 \mathrm{E}+00$ & $0.00 \mathrm{E}+00$ & $0.00 \mathrm{E}+00$ & 28.42 & 11.19 & 12 & 0.03 & 10 \\
\hline $0.00 \mathrm{E}+00$ & $6.10 \mathrm{E}-04$ & $5.01 \mathrm{E}-07$ & 5.01E-09 & 28.10 & 11.06 & 13 & 0.08 & 25 \\
\hline $0.00 \mathrm{E}+00$ & $0.00 \mathrm{E}+00$ & $0.00 \mathrm{E}+00$ & $0.00 \mathrm{E}+00$ & 28.10 & 11.06 & 14 & 0.08 & 25 \\
\hline $0.00 \mathrm{E}+00$ & $1.46 \mathrm{E}-04$ & $1.20 \mathrm{E}-07$ & $1.20 \mathrm{E}-09$ & 28.10 & 11.06 & 15 & 0.10 & 30 \\
\hline $1.69 \mathrm{E}-03$ & 1.39E-04 & $1.14 \mathrm{E}-07$ & $1.14 \mathrm{E}-09$ & 28.10 & 11.06 & 16 & 0.10 & 32 \\
\hline $0.00 \mathrm{E}+00$ & $2.00 \mathrm{E}-04$ & $1.64 \mathrm{E}-07$ & 1.64E-09 & 27.94 & 11.00 & 17 & 0.11 & 35 \\
\hline $0.00 \mathrm{E}+00$ & $2.38 \mathrm{E}-04$ & $1.96 \mathrm{E}-07$ & $1.96 \mathrm{E}-09$ & 27.94 & 11.00 & 18 & 0.13 & 40 \\
\hline $0.00 \mathrm{E}+00$ & $0.00 \mathrm{E}+00$ & $0.00 \mathrm{E}+00$ & $0.00 \mathrm{E}+00$ & 27.94 & 11.00 & 19 & 0.13 & 40 \\
\hline $2.95 \mathrm{E}-03$ & 6.06E-04 & $4.98 \mathrm{E}-07$ & 4.98E-09 & 27.94 & 11.00 & 20 & 0.16 & 50 \\
\hline $2.98 \mathrm{E}-03$ & $0.00 \mathrm{E}+00$ & $0.00 \mathrm{E}+00$ & $0.00 \mathrm{E}+00$ & 27.62 & 10.88 & 21 & 0.16 & 50 \\
\hline $3.04 \mathrm{E}-04$ & 5.87E-04 & $4.82 \mathrm{E}-07$ & 4.82E-09 & 25.88 & 10.19 & 22 & 0.31 & 97 \\
\hline $3.08 \mathrm{E}-03$ & $1.35 \mathrm{E}-03$ & $1.11 \mathrm{E}-06$ & $1.11 \mathrm{E}-08$ & 25.72 & 10.13 & 23 & 0.41 & 129 \\
\hline $4.38 \mathrm{E}-04$ & $1.06 \mathrm{E}-03$ & $8.74 \mathrm{E}-07$ & 8.74E-09 & 25.24 & 9.94 & 24 & 0.60 & 188 \\
\hline $0.00 \mathrm{E}+00$ & $1.04 \mathrm{E}-03$ & $8.53 \mathrm{E}-07$ & 8.53E-09 & 25.08 & 9.88 & 25 & 0.65 & 202 \\
\hline $1.93 \mathrm{E}-03$ & 7.94E-04 & $6.53 \mathrm{E}-07$ & $6.53 \mathrm{E}-09$ & 25.08 & 9.88 & 26 & 0.68 & 212 \\
\hline $1.50 \mathrm{E}-03$ & $1.11 \mathrm{E}-03$ & $9.14 \mathrm{E}-07$ & $9.14 \mathrm{E}-09$ & 24.92 & 9.81 & 27 & 0.74 & 230 \\
\hline $5.30 \mathrm{E}-04$ & 8.71E-04 & 7.17E-07 & 7.17E-09 & 24.77 & 9.75 & 28 & 0.87 & 270 \\
\hline $2.60 \mathrm{E}-03$ & 9.99E-04 & 8.22E-07 & 8.22E-09 & 24.61 & 9.69 & 29 & 0.96 & 298 \\
\hline $0.00 \mathrm{E}+00$ & $6.00 \mathrm{E}-04$ & 4.93E-07 & 4.93E-09 & 24.13 & 9.50 & 30 & 1.08 & 335 \\
\hline $6.43 \mathrm{E}-04$ & $5.82 \mathrm{E}-04$ & 4.79E-07 & 4.79E-09 & 24.13 & 9.50 & 31 & 1.15 & 357 \\
\hline
\end{tabular}




\begin{tabular}{|l|l|l|l|l|l|l|l|l|}
$1.40 \mathrm{E}-03$ & $3.16 \mathrm{E}-04$ & $2.60 \mathrm{E}-07$ & $2.60 \mathrm{E}-09$ & 23.97 & 9.44 & 32 & 1.18 & 368 \\
\hline $5.26 \mathrm{E}-04$ & $3.46 \mathrm{E}-04$ & $2.85 \mathrm{E}-07$ & $2.85 \mathrm{E}-09$ & 23.65 & 9.31 & 33 & 1.29 & 400 \\
\hline $5.94 \mathrm{E}-04$ & $4.52 \mathrm{E}-04$ & $3.71 \mathrm{E}-07$ & $3.71 \mathrm{E}-09$ & 23.34 & 9.19 & 34 & 1.40 & 437 \\
\hline $2.41 \mathrm{E}-04$ & $4.27 \mathrm{E}-04$ & $3.51 \mathrm{E}-07$ & $3.51 \mathrm{E}-09$ & 23.02 & 9.06 & 35 & 1.54 & 480 \\
\hline $9.21 \mathrm{E}-04$ & $4.42 \mathrm{E}-04$ & $3.63 \mathrm{E}-07$ & $3.63 \mathrm{E}-09$ & 22.86 & 9.00 & 36 & 1.65 & 515 \\
\hline $2.03 \mathrm{E}-04$ & $4.43 \mathrm{E}-04$ & $3.64 \mathrm{E}-07$ & $3.64 \mathrm{E}-09$ & 22.38 & 8.81 & 37 & 1.83 & 568 \\
\hline $3.11 \mathrm{E}-04$ & $4.09 \mathrm{E}-04$ & $3.36 \mathrm{E}-07$ & $3.36 \mathrm{E}-09$ & 22.23 & 8.75 & 38 & 1.93 & 600 \\
\hline $3.51 \mathrm{E}-04$ & $4.04 \mathrm{E}-04$ & $3.32 \mathrm{E}-07$ & $3.32 \mathrm{E}-09$ & 22.07 & 8.69 & 39 & 2.02 & 628 \\
\hline $6.38 \mathrm{E}-04$ & $3.94 \mathrm{E}-04$ & $3.24 \mathrm{E}-07$ & $3.24 \mathrm{E}-09$ & 21.91 & 8.63 & 40 & 2.11 & 658 \\
\hline $3.78 \mathrm{E}-02$ & $3.65 \mathrm{E}-04$ & $3.00 \mathrm{E}-07$ & $3.00 \mathrm{E}-09$ & 21.59 & 8.50 & 41 & 2.22 & 690 \\
\hline
\end{tabular}


Hydraulic Conductivity: Test $1-11 \%$ Proctor Compaction $\left(67.85 \mathrm{~kJ} / \mathrm{m}^{3}\right)$

\begin{tabular}{|c|c|c|c|c|c|c|c|c|c|}
\hline \multicolumn{9}{|c|}{ Sample - GrayPermL1: Test Started on 10/18/2011 at 2:40:00 p.m. } & \multirow{3}{*}{$\begin{array}{l}\text { Area } \\
\left(\mathrm{cm}^{2}\right)\end{array}$} \\
\hline \multirow{2}{*}{ Time } & \multirow{2}{*}{ Vol(ml) } & \multirow{2}{*}{$\Delta t$ (min) } & \multicolumn{2}{|c|}{ Time (Seconds) } & \multicolumn{2}{|c|}{ Time (Hours) } & \multirow{2}{*}{$\Delta \mathbf{V}\left(\mathbf{c m}^{3}\right)$} & \multirow{2}{*}{$\mathbf{i}$} & \\
\hline & & & $\Delta t$ & Cumulative & Cumulative & $\Delta \mathbf{t}$ & & & \\
\hline 10/18/11 2:40 PM & 0 & 0.00 & 0 & 0 & 0.00 & 0 & 0 & 15 & 81.07 \\
\hline 10/18/11 3:00 PM & 10 & 20.00 & 1200 & 1200 & 0.33 & 0.33 & 10 & 15 & 81.07 \\
\hline 10/18/11 3:12 PM & 15 & 32.00 & 720 & 1920 & 0.53 & 0.20 & 5 & 15 & 81.07 \\
\hline 10/18/11 3:27 PM & 18 & 47.00 & 900 & 2820 & 0.78 & 0.25 & 3 & 5 & 81.07 \\
\hline 10/18/11 4:00 PM & 20 & 80.00 & 1980 & 4800 & 1.33 & 0.55 & 2 & 5 & 81.07 \\
\hline 10/18/11 4:17 PM & 25 & 97.00 & 1020 & 5820 & 1.62 & 0.28 & 5 & 15 & 81.07 \\
\hline 10/18/11 7:24 PM & 40 & 284.00 & 11220 & 17040 & 4.73 & 3.12 & 15 & 15 & 81.07 \\
\hline 10/19/11 1:30 AM & 65 & 650.00 & 21960 & 39000 & 10.83 & 6.10 & 25 & 15 & 81.07 \\
\hline 10/19/11 9:45 AM & 105 & 1145.00 & 29700 & 68700 & 19.08 & 8.25 & 40 & 15 & 81.07 \\
\hline 10/19/11 12:50 PM & 115 & 1330.00 & 11100 & 79800 & 22.17 & 3.08 & 10 & 15 & 81.07 \\
\hline 10/19/11 3:10 PM & 120 & 1470.00 & 8400 & 88200 & 24.50 & 2.33 & 5 & 15 & 81.07 \\
\hline 10/19/11 5:30 PM & 128 & 1610.00 & 8400 & 96600 & 26.83 & 2.33 & 8 & 15 & 81.07 \\
\hline 10/19/11 11:30 PM & 140 & 1970.00 & 21600 & 118200 & 32.83 & 6.00 & 12 & 15 & 81.07 \\
\hline 10/20/11 12:10 PM & 165 & 2730.00 & 45600 & 163800 & 45.50 & 12.67 & 25 & 15 & 81.07 \\
\hline 10/20/11 3:00 PM & 170 & 2900.00 & 10200 & 174000 & 48.33 & 2.83 & 5 & 15 & 81.07 \\
\hline 10/21/11 3:00 PM & 200 & 4340.00 & 86400 & 260400 & 72.33 & 24.00 & 30 & 15 & 81.07 \\
\hline 10/22/11 12:00 PM & 230 & 5600.00 & 75600 & 336000 & 93.33 & 21.00 & 30 & 15 & 81.07 \\
\hline 10/23/11 5:10 PM & 265 & 7350.00 & 105000 & 441000 & 122.50 & 29.17 & 35 & 15 & 81.07 \\
\hline 10/24/11 10:55 AM & 288 & 8415.00 & 63900 & 504900 & 140.25 & 17.75 & 23 & 15 & 81.07 \\
\hline 10/25/11 2:15 PM & 318 & 10055.00 & 98400 & 603300 & 167.58 & 27.33 & 30 & 15 & 81.07 \\
\hline 10/26/11 9:30 AM & 335 & 11210.00 & 69300 & 672600 & 186.83 & 19.25 & 17 & 15 & 81.07 \\
\hline 10/26/11 4:00 PM & 345 & 11600.00 & 23400 & 696000 & 193.33 & 6.50 & 10 & 15 & 81.07 \\
\hline 10/27/11 2:00 PM & 365 & 12920.00 & 79200 & 775200 & 215.33 & 22.00 & 20 & 15 & 81.07 \\
\hline 10/28/11 1:00 PM & 380 & 14300.00 & 82800 & 858000 & 238.33 & 23.00 & 15 & 15 & 81.07 \\
\hline 10/29/11 12:00 PM & 400 & 15680.00 & 82800 & 940800 & 261.33 & 23.00 & 20 & 15 & 81.07 \\
\hline 10/30/11 7:30 PM & 428 & 17570.00 & 113400 & 1054200 & 292.83 & 31.50 & 28 & 15 & 81.07 \\
\hline 10/31/11 10:00 AM & 440 & 18440.00 & 52200 & 1106400 & 307.33 & 14.50 & 12 & 15 & 81.07 \\
\hline
\end{tabular}




\begin{tabular}{|c|c|c|c|c|c|c|c|c|}
\hline $\begin{array}{c}\mathbf{q}_{\text {in }} \\
\left(\mathrm{cm}^{3} / \mathrm{sec}\right)\end{array}$ & $\begin{array}{c}\mathbf{q}_{\text {out }} \\
\left(\mathrm{cm}^{3} / \mathrm{sec}\right)\end{array}$ & k $(\mathbf{c m} / \mathrm{sec})$ & $\begin{array}{c}\mathbf{k} \\
(\mathrm{m} / \mathrm{sec})\end{array}$ & $\begin{array}{c}\text { Height of } \\
\text { Water } \\
(\mathbf{c m})\end{array}$ & $\begin{array}{l}\text { Height of } \\
\text { Water } \\
\text { (in) }\end{array}$ & $\begin{array}{l}\text { Time } \\
\text { Step }\end{array}$ & $\mathbf{N}_{\mathbf{P V}}$ & $\begin{array}{c}\mathbf{Q}_{\text {in }}(\mathrm{mL}) \\
\text { Cumulative }\end{array}$ \\
\hline 0 & 0 & 0.00 & 0.00 & 30.32 & 11.938 & 1 & 0.00 & 0 \\
\hline 2.03E-02 & 8.33E-03 & $6.85 \mathrm{E}-06$ & $6.85 \mathrm{E}-08$ & 30.16 & 11.875 & 2 & 0.03 & 10 \\
\hline $0.00 \mathrm{E}+00$ & $6.94 \mathrm{E}-03$ & $5.71 \mathrm{E}-06$ & $5.71 \mathrm{E}-08$ & 30.00 & 11.813 & 3 & 0.04 & 15 \\
\hline $2.70 \mathrm{E}-02$ & 3.33E-03 & 8.22E-06 & $8.22 \mathrm{E}-08$ & 30.00 & 11.813 & 4 & 0.05 & 18 \\
\hline $0.00 \mathrm{E}+00$ & $1.01 \mathrm{E}-03$ & $2.49 \mathrm{E}-06$ & $2.49 \mathrm{E}-08$ & 29.85 & 11.750 & 5 & 0.05 & 20 \\
\hline $0.00 \mathrm{E}+00$ & $4.90 \mathrm{E}-03$ & 4.03E-06 & 4.03E-08 & 29.85 & 11.750 & 6 & 0.06 & 25 \\
\hline 4.34E-03 & $1.34 \mathrm{E}-03$ & $1.10 \mathrm{E}-06$ & $1.10 \mathrm{E}-08$ & 29.85 & 11.750 & 7 & 0.10 & 40 \\
\hline $1.11 \mathrm{E}-03$ & $1.14 \mathrm{E}-03$ & $9.36 \mathrm{E}-07$ & $9.36 \mathrm{E}-09$ & 29.53 & 11.625 & 8 & 0.16 & 65 \\
\hline $8.19 \mathrm{E}-04$ & $1.35 \mathrm{E}-03$ & $1.11 \mathrm{E}-06$ & $1.11 \mathrm{E}-08$ & 29.37 & 11.563 & 9 & 0.26 & 105 \\
\hline $0.00 \mathrm{E}+00$ & 9.01E-04 & $7.41 \mathrm{E}-07$ & 7.41E-09 & 29.21 & 11.500 & 10 & 0.29 & 115 \\
\hline $0.00 \mathrm{E}+00$ & $5.95 \mathrm{E}-04$ & 4.89E-07 & 4.89E-09 & 29.21 & 11.500 & 11 & 0.30 & 120 \\
\hline $5.79 \mathrm{E}-03$ & $9.52 \mathrm{E}-04$ & 7.83E-07 & 7.83E-09 & 29.21 & 11.500 & 12 & 0.32 & 128 \\
\hline $1.13 \mathrm{E}-03$ & $5.56 \mathrm{E}-04$ & $4.57 \mathrm{E}-07$ & $4.57 \mathrm{E}-09$ & 28.89 & 11.375 & 13 & 0.35 & 140 \\
\hline $0.00 \mathrm{E}+00$ & $5.48 \mathrm{E}-04$ & $4.51 \mathrm{E}-07$ & 4.51E-09 & 28.73 & 11.313 & 14 & 0.41 & 165 \\
\hline$-2.38 \mathrm{E}-03$ & $4.90 \mathrm{E}-04$ & 4.03E-07 & 4.03E-09 & 28.73 & 11.313 & 15 & 0.43 & 170 \\
\hline $8.44 \mathrm{E}-04$ & $3.47 \mathrm{E}-04$ & $2.86 \mathrm{E}-07$ & $2.86 \mathrm{E}-09$ & 28.89 & 11.375 & 16 & 0.50 & 200 \\
\hline $6.43 \mathrm{E}-04$ & 3.97E-04 & $3.26 \mathrm{E}-07$ & $3.26 \mathrm{E}-09$ & 28.42 & 11.188 & 17 & 0.58 & 230 \\
\hline 2.32E-04 & 3.33E-04 & $2.74 \mathrm{E}-07$ & $2.74 \mathrm{E}-09$ & 28.10 & 11.063 & 18 & 0.66 & 265 \\
\hline 7.61E-04 & $3.60 \mathrm{E}-04$ & $2.96 \mathrm{E}-07$ & $2.96 \mathrm{E}-09$ & 27.94 & 11.000 & 19 & 0.72 & 288 \\
\hline $2.47 \mathrm{E}-04$ & $3.05 \mathrm{E}-04$ & $2.51 \mathrm{E}-07$ & $2.51 \mathrm{E}-09$ & 27.62 & 10.875 & 20 & 0.80 & 318 \\
\hline $3.51 \mathrm{E}-04$ & $2.45 \mathrm{E}-04$ & $2.02 \mathrm{E}-07$ & $2.02 \mathrm{E}-09$ & 27.46 & 10.813 & 21 & 0.84 & 335 \\
\hline $1.04 \mathrm{E}-03$ & 4.27E-04 & $3.51 \mathrm{E}-07$ & $3.51 \mathrm{E}-09$ & 27.31 & 10.750 & 22 & 0.86 & 345 \\
\hline $3.07 \mathrm{E}-04$ & $2.53 \mathrm{E}-04$ & $2.08 \mathrm{E}-07$ & $2.08 \mathrm{E}-09$ & 27.15 & 10.688 & 23 & 0.91 & 365 \\
\hline $2.94 \mathrm{E}-04$ & $1.81 \mathrm{E}-04$ & $1.49 \mathrm{E}-07$ & $1.49 \mathrm{E}-09$ & 26.99 & 10.625 & 24 & 0.95 & 380 \\
\hline $2.94 \mathrm{E}-04$ & $2.42 \mathrm{E}-04$ & $1.99 \mathrm{E}-07$ & 1.99E-09 & 26.83 & 10.563 & 25 & 1.00 & 400 \\
\hline $4.29 \mathrm{E}-04$ & $2.47 \mathrm{E}-04$ & $2.03 \mathrm{E}-07$ & $2.03 \mathrm{E}-09$ & 26.67 & 10.500 & 26 & 1.07 & 428 \\
\hline 7.73E-02 & $2.30 \mathrm{E}-04$ & $1.89 \mathrm{E}-07$ & $1.89 \mathrm{E}-09$ & 26.35 & 10.375 & 27 & 1.10 & 440 \\
\hline
\end{tabular}


Hydraulic Conductivity: Test $2-11 \%$ Proctor Compaction $\left(67.85 \mathrm{~kJ} / \mathrm{m}^{3}\right)$

\begin{tabular}{|c|c|c|c|c|c|c|c|c|c|}
\hline \multicolumn{9}{|c|}{ Sample - GrayPermL2: Test Started on 10/18/2011 at 2:40:00 p.m. } & \multirow{3}{*}{$\begin{array}{l}\text { Area } \\
\left(\mathbf{c m}^{2}\right)\end{array}$} \\
\hline \multirow{2}{*}{ Time } & \multirow{2}{*}{$\operatorname{Vol}(\mathbf{m l})$} & \multirow{2}{*}{$\Delta t(\min )$} & \multicolumn{2}{|c|}{ Time (Seconds) } & \multicolumn{2}{|c|}{ Time (Hours) } & \multirow{2}{*}{$\begin{array}{c}\Delta \mathrm{V} \\
\left(\mathrm{cm}^{3}\right)\end{array}$} & \multirow{2}{*}{$\mathbf{i}$} & \\
\hline & & & $\Delta \mathbf{t}$ & Cumulative & Cumulative & $\Delta \mathbf{t}$ & & & \\
\hline 10/18/11 2:40 PM & 0 & 0.00 & 0 & 0 & 0.00 & 0 & 0 & 15 & 81.07 \\
\hline 10/18/11 3:00 PM & 145 & 20.00 & 1200 & 1200 & 0.33 & 0.33 & 145 & 15 & 81.07 \\
\hline 10/18/11 3:12 PM & 190 & 32.00 & 720 & 1920 & 0.53 & 0.20 & 45 & 15 & 81.07 \\
\hline 10/18/11 3:27 PM & 238 & 47.00 & 900 & 2820 & 0.78 & 0.25 & 48 & 5 & 81.07 \\
\hline 10/18/11 4:00 PM & 338 & 80.00 & 1980 & 4800 & 1.33 & 0.55 & 100 & 5 & 81.07 \\
\hline 10/18/11 4:17 PM & 380 & 97.00 & 1020 & 5820 & 1.62 & 0.28 & 42 & 15 & 81.07 \\
\hline 10/18/11 7:24 PM & 825 & 284.00 & 11220 & 17040 & 4.73 & 3.12 & 445 & 15 & 81.07 \\
\hline 10/19/11 1:30 AM & 1555 & 650.00 & 21960 & 39000 & 10.83 & 6.10 & 730 & 15 & 81.07 \\
\hline 10/19/11 9:45 AM & 1988 & 1145.00 & 29700 & 68700 & 19.08 & 8.25 & 433 & 15 & 81.07 \\
\hline 10/19/11 12:50 PM & 2033 & 1330.00 & 11100 & 79800 & 22.17 & 3.08 & 45 & 15 & 81.07 \\
\hline 10/19/11 3:10 PM & 2056 & 1470.00 & 8400 & 88200 & 24.50 & 2.33 & 23 & 15 & 81.07 \\
\hline 10/19/11 5:30 PM & 2078 & 1610.00 & 8400 & 96600 & 26.83 & 2.33 & 22 & 15 & 81.07 \\
\hline 10/19/11 11:30 PM & 2128 & 1970.00 & 21600 & 118200 & 32.83 & 6.00 & 50 & 15 & 81.07 \\
\hline $10 / 20 / 111$ & 2248 & 2730.00 & 45600 & 163800 & 45.50 & 12.67 & 120 & 15 & 81.07 \\
\hline 10/20/11 3:00 PM & 2270 & 2900.00 & 10200 & 174000 & 48.33 & 2.83 & 22 & 15 & 81.07 \\
\hline 10/21/11 3:00 PM & 2376 & 4340.00 & 86400 & 260400 & 72.33 & 24.00 & 106 & 15 & 81.07 \\
\hline 10/22/11 12:00 PM & 2458 & 5600.00 & 75600 & 336000 & 93.33 & 21.00 & 82 & 15 & 81.07 \\
\hline 10/23/11 5:10 PM & 2568 & 7350.00 & 105000 & 441000 & 122.50 & 29.17 & 110 & 15 & 81.07 \\
\hline 10/24/11 10:55 AM & 2653 & 8415.00 & 63900 & 504900 & 140.25 & 17.75 & 85 & 15 & 81.07 \\
\hline 10/25/11 2:15 PM & 2758 & 10055.00 & 98400 & 603300 & 167.58 & 27.33 & 105 & 15 & 81.07 \\
\hline 10/26/11 9:30 AM & 2803 & 11210.00 & 69300 & 672600 & 186.83 & 19.25 & 45 & 15 & 81.07 \\
\hline 10/26/11 4:00 PM & 2818 & 11600.00 & 23400 & 696000 & 193.33 & 6.50 & 15 & 15 & 81.07 \\
\hline 10/27/11 2:00 PM & 2843 & 12920.00 & 79200 & 775200 & 215.33 & 22.00 & 25 & 15 & 81.07 \\
\hline 10/28/11 1:00 PM & 2868 & 14300.00 & 82800 & 858000 & 238.33 & 23.00 & 25 & 15 & 81.07 \\
\hline 10/29/11 12:00 PM & 2890 & 15680.00 & 82800 & 940800 & 261.33 & 23.00 & 22 & 15 & 81.07 \\
\hline 10/30/11 7:30 PM & 2918 & 17570.00 & 113400 & 1054200 & 292.83 & 31.50 & 28 & 15 & 81.07 \\
\hline 10/31/11 10:00 AM & 2936 & 18440.00 & 52200 & 1106400 & 307.33 & 14.50 & 18 & 15 & 81.07 \\
\hline
\end{tabular}




\begin{tabular}{|c|c|c|c|c|c|c|c|c|}
\hline $\begin{array}{c}\mathbf{q}_{\text {in }} \\
\left(\mathrm{cm}^{3} / \mathrm{sec}\right)\end{array}$ & $\begin{array}{c}\mathbf{q}_{\text {out }} \\
\left(\mathrm{cm}^{3} / \mathrm{sec}\right)\end{array}$ & $\begin{array}{c}\mathbf{k} \\
(\mathrm{cm} / \mathrm{sec})\end{array}$ & $\begin{array}{c}\mathbf{k} \\
(\mathbf{m} / \mathbf{s e c})\end{array}$ & $\begin{array}{c}\text { Height of } \\
\text { Water } \\
(\mathrm{cm})\end{array}$ & $\begin{array}{l}\text { Height of } \\
\text { Water } \\
\text { (in) }\end{array}$ & $\begin{array}{l}\text { Time } \\
\text { Step }\end{array}$ & $\mathbf{N}_{\mathbf{P V}}$ & $\begin{array}{c}\mathbf{Q}_{\text {in }}(\mathbf{m L}) \\
\text { Cumulative }\end{array}$ \\
\hline 0 & 0 & 0.00 & 0.00 & 30.16 & 11.875 & 1 & 0.00 & 0 \\
\hline 4.05E-02 & $1.21 \mathrm{E}-01$ & $9.94 \mathrm{E}-05$ & 9.94E-07 & 29.21 & 11.500 & 2 & 0.38 & 145 \\
\hline $6.76 \mathrm{E}-02$ & $6.25 \mathrm{E}-02$ & $5.14 \mathrm{E}-05$ & $5.14 \mathrm{E}-07$ & 28.89 & 11.375 & 3 & 0.49 & 190 \\
\hline $1.35 \mathrm{E}-01$ & 5.33E-02 & $1.32 \mathrm{E}-04$ & $1.32 \mathrm{E}-06$ & 28.58 & 11.250 & 4 & 0.62 & 238 \\
\hline $1.23 \mathrm{E}-02$ & $5.05 \mathrm{E}-02$ & $1.25 \mathrm{E}-04$ & $1.25 \mathrm{E}-06$ & 27.78 & 10.938 & 5 & 0.88 & 338 \\
\hline 4.29E-01 & 4.12E-02 & 3.39E-05 & $3.39 \mathrm{E}-07$ & 27.62 & 10.875 & 6 & 0.99 & 380 \\
\hline 6.72E-02 & $3.97 \mathrm{E}-02$ & $3.26 \mathrm{E}-05$ & $3.26 \mathrm{E}-07$ & 24.77 & 9.750 & 7 & 2.14 & 825 \\
\hline 3.99E-02 & 3.32E-02 & $2.73 \mathrm{E}-05$ & $2.73 \mathrm{E}-07$ & 19.84 & 7.813 & 8 & 4.03 & 1555 \\
\hline $1.64 \mathrm{E}-03$ & $1.46 \mathrm{E}-02$ & $1.20 \mathrm{E}-05$ & $1.20 \mathrm{E}-07$ & 14.13 & 5.563 & 9 & 5.15 & 1988 \\
\hline $2.19 \mathrm{E}-03$ & 4.05E-03 & $3.33 \mathrm{E}-06$ & $3.33 \mathrm{E}-08$ & 13.81 & 5.438 & 10 & 5.27 & 2033 \\
\hline $0.00 \mathrm{E}+00$ & $2.74 \mathrm{E}-03$ & $2.25 \mathrm{E}-06$ & $2.25 \mathrm{E}-08$ & 13.65 & 5.375 & 11 & 5.33 & 2056 \\
\hline 8.69E-03 & 2.62E-03 & $2.15 \mathrm{E}-06$ & $2.15 \mathrm{E}-08$ & 13.65 & 5.375 & 12 & 5.39 & 2078 \\
\hline$-1.24 \mathrm{E}-02$ & $2.31 \mathrm{E}-03$ & $1.90 \mathrm{E}-06$ & $1.90 \mathrm{E}-08$ & 13.18 & 5.188 & 13 & 5.52 & 2128 \\
\hline $9.07 \mathrm{E}-03$ & $2.63 \mathrm{E}-03$ & $2.16 \mathrm{E}-06$ & $2.16 \mathrm{E}-08$ & 14.92 & 5.875 & 14 & 5.83 & 2248 \\
\hline $1.19 \mathrm{E}-02$ & $2.16 \mathrm{E}-03$ & $1.77 \mathrm{E}-06$ & $1.77 \mathrm{E}-08$ & 12.22 & 4.813 & 15 & 5.88 & 2270 \\
\hline $8.44 \mathrm{E}-04$ & $1.23 \mathrm{E}-03$ & $1.01 \mathrm{E}-06$ & $1.01 \mathrm{E}-08$ & 11.43 & 4.500 & 16 & 6.16 & 2376 \\
\hline $1.61 \mathrm{E}-03$ & $1.08 \mathrm{E}-03$ & 8.92E-07 & 8.92E-09 & 10.95 & 4.313 & 17 & 6.37 & 2458 \\
\hline $9.27 \mathrm{E}-04$ & $1.05 \mathrm{E}-03$ & 8.61E-07 & 8.61E-09 & 10.16 & 4.000 & 18 & 6.66 & 2568 \\
\hline $1.52 \mathrm{E}-03$ & $1.33 \mathrm{E}-03$ & $1.09 \mathrm{E}-06$ & 1.09E-08 & 9.53 & 3.750 & 19 & 6.88 & 2653 \\
\hline $4.94 \mathrm{E}-04$ & $1.07 \mathrm{E}-03$ & 8.77E-07 & 8.77E-09 & 8.89 & 3.500 & 20 & 7.15 & 2758 \\
\hline $3.51 \mathrm{E}-04$ & $6.49 \mathrm{E}-04$ & $5.34 \mathrm{E}-07$ & 5.34E-09 & 8.57 & 3.375 & 21 & 7.27 & 2803 \\
\hline $0.00 \mathrm{E}+00$ & $6.41 \mathrm{E}-04$ & $5.27 \mathrm{E}-07$ & 5.27E-09 & 8.41 & 3.313 & 22 & 7.30 & 2818 \\
\hline $6.14 \mathrm{E}-04$ & $3.16 \mathrm{E}-04$ & $2.60 \mathrm{E}-07$ & $2.60 \mathrm{E}-09$ & 8.41 & 3.313 & 23 & 7.37 & 2843 \\
\hline $2.94 \mathrm{E}-04$ & $3.02 \mathrm{E}-04$ & $2.48 \mathrm{E}-07$ & $2.48 \mathrm{E}-09$ & 8.10 & 3.188 & 24 & 7.43 & 2868 \\
\hline $5.87 \mathrm{E}-04$ & $2.66 \mathrm{E}-04$ & $2.18 \mathrm{E}-07$ & 2.18E-09 & 7.94 & 3.125 & 25 & 7.49 & 2890 \\
\hline $0.00 \mathrm{E}+00$ & $2.47 \mathrm{E}-04$ & $2.03 \mathrm{E}-07$ & 2.03E-09 & 7.62 & 3.000 & 26 & 7.56 & 2918 \\
\hline $2.24 \mathrm{E}-02$ & $3.45 \mathrm{E}-04$ & $2.84 \mathrm{E}-07$ & 2.84E-09 & 7.62 & 3.000 & 27 & 7.61 & 2936 \\
\hline
\end{tabular}


Hydraulic Conductivity: Test $3-11 \%$ Proctor Compaction $\left(67.85 \mathrm{~kJ} / \mathrm{m}^{3}\right)$

\begin{tabular}{|c|c|c|c|c|c|c|c|c|c|}
\hline \multicolumn{9}{|c|}{ Sample - GrayPermL3: Test Started on 10/18/2011 at 2:40:00 p.m. } & \multirow{3}{*}{$\begin{array}{l}\text { Area } \\
\left(\mathrm{cm}^{2}\right)\end{array}$} \\
\hline \multirow{2}{*}{ Time } & \multirow{2}{*}{$\operatorname{Vol}(\mathbf{m l})$} & \multirow{2}{*}{$\Delta t(\min )$} & \multicolumn{2}{|c|}{ Time (Seconds) } & \multicolumn{2}{|c|}{ Time (Hours) } & \multirow{2}{*}{$\begin{array}{c}\Delta V^{3} \\
\left(\mathrm{~cm}^{3}\right)\end{array}$} & \multirow{2}{*}{$\mathbf{i}$} & \\
\hline & & & $\Delta \mathbf{t}$ & Cumulative & Cumulative & $\Delta \mathbf{t}$ & & & \\
\hline 10/18/11 2:40 PM & 0 & 0.00 & 0 & 0 & 0.00 & 0 & 0 & 15 & 81.07 \\
\hline 10/18/11 3:00 PM & 122 & 20.00 & 1200 & 1200 & 0.33 & 0.33 & 122 & 15 & 81.07 \\
\hline 10/18/11 3:12 PM & 137 & 32.00 & 720 & 1920 & 0.53 & 0.20 & 15 & 15 & 81.07 \\
\hline 10/18/11 3:27 PM & 152 & 47.00 & 900 & 2820 & 0.78 & 0.25 & 15 & 5 & 81.07 \\
\hline 10/18/11 4:00 PM & 182 & 80.00 & 1980 & 4800 & 1.33 & 0.55 & 30 & 5 & 81.07 \\
\hline 10/18/11 4:17 PM & 200 & 97.00 & 1020 & 5820 & 1.62 & 0.28 & 18 & 15 & 81.07 \\
\hline 10/18/11 7:24 PM & 430 & 284.00 & 11220 & 17040 & 4.73 & 3.12 & 230 & 15 & 81.07 \\
\hline 10/19/11 1:30 AM & 890 & 650.00 & 21960 & 39000 & 10.83 & 6.10 & 460 & 15 & 81.07 \\
\hline 10/19/11 9:45 AM & 1678 & 1145.00 & 29700 & 68700 & 19.08 & 8.25 & 788 & 15 & 81.07 \\
\hline 10/19/11 12:50 PM & 1708 & 1330.00 & 11100 & 79800 & 22.17 & 3.08 & 30 & 15 & 81.07 \\
\hline 10/19/11 3: & 1728 & 1470.00 & 8400 & 88200 & 24.50 & 2.33 & 20 & 15 & 81.07 \\
\hline 10/19/11 5:30 PM & 1756 & 1610.00 & 8400 & 96600 & 26.83 & 2.33 & 28 & 15 & 81.07 \\
\hline 10/19/11 11:30 PM & 1818 & 1970.00 & 21600 & 118200 & 32.83 & 6.00 & 62 & 15 & 81.07 \\
\hline 10/20/11 12:10 PM & 2153 & 2730.00 & 45600 & 163800 & 45.50 & 12.67 & 335 & 15 & 81.07 \\
\hline 10/20/11 3:00 PM & 2228 & 2900.00 & 10200 & 000 & 48.33 & 2.83 & 75 & 15 & 81.07 \\
\hline 10/21/11 3:00 PM & 2396 & 4340.00 & 86400 & 260400 & 72.33 & 24.00 & 168 & 15 & 81.07 \\
\hline 10/22/11 12:00 PM & 2548 & 5600.00 & 75600 & 336000 & 93.33 & 21.00 & 152 & 15 & 81.07 \\
\hline 10/23/11 5:10 PM & 2788 & 7350.00 & 105000 & 441000 & 122.50 & 29.17 & 240 & 15 & 81.07 \\
\hline 10/24/11 10:55 AM & 2953 & 8415.00 & 63900 & 504900 & 140.25 & 17.75 & 165 & 15 & 81.07 \\
\hline 10/25/11 2:15 PM & 3178 & 10055.00 & 98400 & 603300 & 167.58 & 27.33 & 225 & 15 & 81.07 \\
\hline 10/26/11 9:30 AM & 3298 & 11210.00 & 69300 & 672600 & 186.83 & 19.25 & 120 & 15 & 81.07 \\
\hline 10/26/11 4:00 PM & 3316 & 11600.00 & 23400 & 696000 & 193.33 & 6.50 & 18 & 15 & 81.07 \\
\hline 10/27/11 2:00 PM & 3348 & 12920.00 & 79200 & 775200 & 215.33 & 22.00 & 32 & 15 & 81.07 \\
\hline 10/28/11 1:00 PM & 3386 & 14300.00 & 82800 & 858000 & 238.33 & 23.00 & 38 & 15 & 81.07 \\
\hline 10/29/11 12:00 PM & 3416 & 15680.00 & 82800 & 940800 & 261.33 & 23.00 & 30 & 15 & 81.07 \\
\hline 10/30/11 7:30 PM & 3471 & 17570.00 & 113400 & 1054200 & 292.83 & 31.50 & 55 & 15 & 81.07 \\
\hline 10/31/11 10:00 AM & 3496 & 18440.00 & 52200 & 1106400 & 307.33 & 14.50 & 25 & 15 & 81.07 \\
\hline
\end{tabular}




\begin{tabular}{|c|c|c|c|c|c|c|c|c|}
\hline $\begin{array}{c}\mathbf{q}_{\text {in }} \\
\left(\mathrm{cm}^{3} / \mathrm{sec}\right)\end{array}$ & $\begin{array}{c}\mathbf{q}_{\text {out }} \\
\left(\mathrm{cm}^{3} / \mathrm{sec}\right)\end{array}$ & $\begin{array}{c}\mathbf{k} \\
(\mathrm{cm} / \mathrm{sec})\end{array}$ & $\mathbf{k}(\mathbf{m} / \mathbf{s e c})$ & $\begin{array}{c}\text { Height of } \\
\text { Water } \\
(\mathbf{c m})\end{array}$ & $\begin{array}{l}\text { Height of } \\
\text { Water } \\
\text { (in) }\end{array}$ & $\begin{array}{l}\text { Time } \\
\text { Step }\end{array}$ & $\mathbf{N}_{\mathbf{P V}}$ & $\begin{array}{c}\mathbf{Q}_{\text {in }}(\mathbf{m L}) \\
\text { Cumulative }\end{array}$ \\
\hline 0 & 0 & 0.00 & 0.00 & 26.51 & 10.438 & 1 & 0.00 & 0 \\
\hline $2.03 \mathrm{E}-02$ & $1.02 \mathrm{E}-01$ & $8.36 \mathrm{E}-05$ & $8.36 \mathrm{E}-07$ & 26.35 & 10.375 & 2 & 0.32 & 122 \\
\hline $0.00 \mathrm{E}+00$ & $2.08 \mathrm{E}-02$ & $1.71 \mathrm{E}-05$ & $1.71 \mathrm{E}-07$ & 26.19 & 10.313 & 3 & 0.35 & 137 \\
\hline $5.40 \mathrm{E}-02$ & 1.67E-02 & 4.11E-05 & 4.11E-07 & 26.19 & 10.313 & 4 & 0.39 & 152 \\
\hline $1.23 \mathrm{E}-02$ & $1.52 \mathrm{E}-02$ & $3.74 \mathrm{E}-05$ & $3.74 \mathrm{E}-07$ & 25.88 & 10.188 & 5 & 0.47 & 182 \\
\hline $1.91 \mathrm{E}-01$ & $1.76 \mathrm{E}-02$ & $1.45 \mathrm{E}-05$ & $1.45 \mathrm{E}-07$ & 25.72 & 10.125 & 6 & 0.52 & 200 \\
\hline 4.34E-02 & $2.05 \mathrm{E}-02$ & $1.69 \mathrm{E}-05$ & $1.69 \mathrm{E}-07$ & 24.45 & 9.625 & 7 & 1.11 & 430 \\
\hline $3.21 \mathrm{E}-02$ & $2.09 \mathrm{E}-02$ & $1.72 \mathrm{E}-05$ & $1.72 \mathrm{E}-07$ & 21.27 & 8.375 & 8 & 2.30 & 890 \\
\hline $1.64 \mathrm{E}-03$ & $2.65 \mathrm{E}-02$ & $2.18 \mathrm{E}-05$ & $2.18 \mathrm{E}-07$ & 16.67 & 6.563 & 9 & 4.34 & 1678 \\
\hline 2.19E-03 & $2.70 \mathrm{E}-03$ & $2.22 \mathrm{E}-06$ & $2.22 \mathrm{E}-08$ & 16.35 & 6.438 & 10 & 4.42 & 1708 \\
\hline $2.90 \mathrm{E}-03$ & $2.38 \mathrm{E}-03$ & $1.96 \mathrm{E}-06$ & $1.96 \mathrm{E}-08$ & 16.19 & 6.375 & 11 & 4.47 & 1728 \\
\hline 8.69E-03 & $3.33 \mathrm{E}-03$ & $2.74 \mathrm{E}-06$ & $2.74 \mathrm{E}-08$ & 16.03 & 6.313 & 12 & 4.54 & 1756 \\
\hline $1.46 \mathrm{E}-02$ & $2.87 \mathrm{E}-03$ & $2.36 \mathrm{E}-06$ & $2.36 \mathrm{E}-08$ & 15.56 & 6.125 & 13 & 4.70 & 1818 \\
\hline $1.60 \mathrm{E}-03$ & $7.35 \mathrm{E}-03$ & $6.04 \mathrm{E}-06$ & $6.04 \mathrm{E}-08$ & 13.49 & 5.313 & 14 & 5.57 & 2153 \\
\hline $1.67 \mathrm{E}-02$ & 7.35E-03 & $6.05 \mathrm{E}-06$ & $6.05 \mathrm{E}-08$ & 13.02 & 5.125 & 15 & 5.76 & 2228 \\
\hline 1.69E-03 & 1.94E-03 & $1.60 \mathrm{E}-06$ & $1.60 \mathrm{E}-08$ & 11.91 & 4.688 & 16 & 6.19 & 2396 \\
\hline $2.90 \mathrm{E}-03$ & $2.01 \mathrm{E}-03$ & $1.65 \mathrm{E}-06$ & $1.65 \mathrm{E}-08$ & 10.95 & 4.313 & 17 & 6.59 & 2548 \\
\hline $1.85 \mathrm{E}-03$ & $2.29 \mathrm{E}-03$ & $1.88 \mathrm{E}-06$ & $1.88 \mathrm{E}-08$ & 9.53 & 3.750 & 18 & 7.21 & 2788 \\
\hline $3.81 \mathrm{E}-03$ & $2.58 \mathrm{E}-03$ & $2.12 \mathrm{E}-06$ & $2.12 \mathrm{E}-08$ & 8.26 & 3.250 & 19 & 7.63 & 2953 \\
\hline 9.89E-04 & $2.29 \mathrm{E}-03$ & $1.88 \mathrm{E}-06$ & $1.88 \mathrm{E}-08$ & 6.67 & 2.625 & 20 & 8.21 & 3178 \\
\hline 7.02E-04 & $1.73 \mathrm{E}-03$ & $1.42 \mathrm{E}-06$ & $1.42 \mathrm{E}-08$ & 6.03 & 2.375 & 21 & 8.53 & 3298 \\
\hline $1.04 \mathrm{E}-03$ & 7.69E-04 & $6.33 \mathrm{E}-07$ & $6.33 \mathrm{E}-09$ & 5.72 & 2.250 & 22 & 8.57 & 3316 \\
\hline $9.21 \mathrm{E}-04$ & 4.04E-04 & $3.32 \mathrm{E}-07$ & $3.32 \mathrm{E}-09$ & 5.56 & 2.188 & 23 & 8.65 & 3348 \\
\hline 2.94E-04 & 4.59E-04 & $3.77 \mathrm{E}-07$ & $3.77 \mathrm{E}-09$ & 5.08 & 2.000 & 24 & 8.75 & 3386 \\
\hline $5.87 \mathrm{E}-04$ & $3.62 \mathrm{E}-04$ & $2.98 \mathrm{E}-07$ & $2.98 \mathrm{E}-09$ & 4.92 & 1.938 & 25 & 8.83 & 3416 \\
\hline $2.14 \mathrm{E}-04$ & 4.85E-04 & $3.99 \mathrm{E}-07$ & 3.99E-09 & 4.60 & 1.813 & 26 & 8.97 & 3471 \\
\hline $1.30 \mathrm{E}-02$ & 4.79E-04 & $3.94 \mathrm{E}-07$ & 3.94E-09 & 4.45 & 1.750 & 27 & 9.04 & 3496 \\
\hline
\end{tabular}




\section{Appendix II - Compaction Data}

Standard Proctor Compaction $\left(592.5 \mathrm{~kJ} / \mathrm{m}^{3}\right)$

\begin{tabular}{|c|c|c|c|c|}
\hline Compaction Energy $\mathrm{kJ} / \mathrm{m}^{3}\left(\mathrm{ft}-\mathrm{lb} / \mathrm{ft}^{3}\right)$ & 592.5( & 2375) & & \\
\hline Test Number & 1 & 2 & 3 & 4 \\
\hline Assumed moisture content $(\%)$ & 14.00 & 11.00 & 8.00 & 6.00 \\
\hline Mold Weight (g), $M_{m d}$ & 2044.62 & 2044.62 & 2044.62 & 2044.62 \\
\hline Specimen+Mold Weight $(\mathrm{g}), \mathrm{M}_{\mathrm{t}}$ & 3846.50 & 4024.33 & 3998.61 & 3434.61 \\
\hline Volume of Mold $\left(\mathrm{cm}^{3}\right), \mathrm{V}$ & 940.00 & 940.00 & 940.00 & 940.00 \\
\hline Specific Gravity of Soil, $\mathrm{G}_{\mathrm{s}}$ & 2.69 & 2.69 & 2.69 & 2.69 \\
\hline Unit Weight of Water @ $20^{\circ} \mathrm{C}\left(\mathrm{KN} / \mathrm{m}^{3}\right), \gamma_{\mathrm{w}}$ & 9.79 & 9.79 & 9.79 & 9.79 \\
\hline Unit Weight of Water @ $20^{\circ} \mathrm{C}\left(\mathrm{lb} / \mathrm{ft}^{3}\right), \gamma_{\mathrm{w}}$ & 62.34 & 62.34 & 62.34 & 62.34 \\
\hline Moist Unit Weight of Compacted Specimen $\left(\mathrm{g} / \mathrm{cm}^{3}\right), \gamma_{\mathrm{m}}$ & 1.92 & 2.11 & 2.08 & 1.48 \\
\hline Dry Unit Weight of Compacted Specimen $\left(\mathrm{g} / \mathrm{cm}^{3}\right), \gamma_{\mathrm{d}}$ & 1.70 & 1.89 & 1.89 & 1.42 \\
\hline Dry Unit Weight of Compacted Specimen $\left(K N / m^{3}\right), \gamma_{d}$ & 16.65 & 18.51 & 18.54 & 13.92 \\
\hline Dry Unit Weight of Compacted Specimen $\left(\mathrm{lb} / \mathrm{ft}^{3}\right), \gamma_{\mathrm{d}}$ & 106.04 & 117.87 & 118.04 & 88.67 \\
\hline Dry Unit Weight at $S=1.0\left(K N / \mathrm{m}^{3}\right), \gamma_{d}$ & 19.57 & 20.09 & 20.78 & 23.71 \\
\hline Dry Unit Weight at $S=0.9\left(\mathrm{KN} / \mathrm{m}^{3}\right), \gamma_{d}$ & 19.03 & 19.58 & 20.30 & 23.45 \\
\hline Dry Unit Weight at $\mathrm{S}=1.0(\mathrm{lb} / \mathrm{ft} 3), \gamma \mathrm{d}$ & 124.61 & 127.96 & 132.32 & 150.98 \\
\hline Dry Unit Weight at $\mathrm{S}=0.9\left(\mathrm{lb} / \mathrm{ft}^{3}\right), \gamma_{\mathrm{d}}$ & 121.15 & 124.68 & 129.29 & 149.32 \\
\hline Void Ratio, $e=\left(\left(\mathrm{G}_{\mathrm{s}} * \gamma_{\mathrm{w}}\right) / \gamma_{\mathrm{d}}\right)-1$ & 0.58 & 0.42 & 0.42 & 0.89 \\
\hline Degree of Saturation $(\%), \mathrm{S}=\mathrm{G}_{\mathrm{s}} * \mathrm{w} / \mathrm{e}$ & 0.59 & 0.73 & 0.64 & 0.12 \\
\hline Saturated Water Content, $\mathrm{w}_{\text {sat }}(\%)$ & 21.62 & 15.71 & 15.64 & 33.14 \\
\hline
\end{tabular}

\begin{tabular}{|c|c|c|c|c|}
\hline \multicolumn{5}{|l|}{ Moisture Content: } \\
\hline Test Number & 1 & 2 & 3 & 4 \\
\hline Assumed moisture content $(\%)$ & 14.00 & 11.00 & 8.00 & 6.00 \\
\hline Container Mass $(\mathrm{g}), \mathrm{M}_{\mathrm{c}}$ & 30.03 & 17.27 & 30.55 & 18.84 \\
\hline Container+Moist Specimen Mass (g), $\mathbf{M}_{\mathrm{cms}}$ & 90.43 & 70.70 & 77.78 & 41.60 \\
\hline Intial Container+Oven Dry Specimen Mass $(\mathrm{g}), \mathrm{M}_{\mathrm{cds}}$ & 83.55 & 65.17 & 73.51 & 40.70 \\
\hline Mass of Water $(\mathrm{g}), \mathrm{M}_{\mathrm{w}}=\mathrm{M}_{\mathrm{cms}}-\mathrm{M}_{\mathrm{cds}}$ & 6.88 & 5.53 & 4.27 & 0.90 \\
\hline Mass of Solids $(\mathrm{g}), \mathrm{M}_{\mathrm{s}}=\mathrm{M}_{\mathrm{cds}}-\mathrm{M}_{\mathrm{c}}$ & 53.52 & 47.90 & 42.96 & 21.86 \\
\hline
\end{tabular}




\begin{tabular}{|l|r|r|r|r|} 
Water Content, $\mathrm{w}=\left(\mathrm{M}_{\mathrm{w}} / \mathrm{M}_{\mathrm{s}}\right) \times 100(\%)$ & 12.86 & 11.54 & 9.94 & 4.12 \\
\hline
\end{tabular}


$34 \%$ Proctor Compaction Energy: $\left(203.6 \mathrm{~kJ} / \mathrm{m}^{3}\right)$

\begin{tabular}{|c|c|c|c|c|c|c|c|}
\hline Compaction Energy kJ/m $\mathrm{m}^{3}\left(\mathrm{ft}-\mathrm{lb} / \mathrm{ft}^{3}\right)$ & & $3.6(425$ & & & & & \\
\hline Test Number & 1 & 2 & 3 & 4 & 5 & 6 & 7 \\
\hline Assumed moisture content $(\%)$ & 3.00 & 6.00 & 9.00 & 14.00 & 12.00 & 15.00 & 12.00 \\
\hline Mold Weight (g), $\mathrm{M}_{\mathrm{md}}$ & 1985.84 & 1985.84 & 1985.84 & 1985.84 & 1985.84 & 1985.84 & 1985.84 \\
\hline Specimen Weight (g) & 1660.06 & 1703.00 & 1757.33 & 1945.49 & 1939.41 & 1974.56 & 1625.31 \\
\hline Specimen+Mold Weight $(\mathrm{g}), \mathrm{M}_{\mathrm{t}}$ & 3645.90 & 3688.84 & 3743.17 & 3931.33 & 3925.25 & 3960.40 & 3611.15 \\
\hline Volume of Mold $\left(\mathrm{cm}^{3}\right), \mathrm{V}$ & 940.00 & 940.00 & 940.00 & 940.00 & 940.00 & 940.00 & 940.00 \\
\hline Specific Gravity of Soil, $\mathrm{G}_{\mathrm{s}}$ & 2.69 & 2.69 & 2.69 & 2.69 & 2.69 & 2.69 & 2.69 \\
\hline $\begin{array}{l}\text { Unit Weight of Water @ } 20^{\circ} \mathrm{C} \\
\left(\mathrm{KN} / \mathrm{m}^{3}\right), \gamma_{\mathrm{w}}\end{array}$ & 9.79 & 9.79 & 9.79 & 9.79 & 9.79 & 9.79 & 9.79 \\
\hline $\begin{array}{l}\text { Unit Weight of Water@ } 20^{\circ} \mathrm{C}\left(\mathrm{lb} / \mathrm{ft}^{3}\right) \text {, } \\
\gamma_{\mathrm{w}}\end{array}$ & 62.34 & 62.34 & 62.34 & 62.34 & 62.34 & 62.34 & 62.34 \\
\hline $\begin{array}{l}\text { Moist Unit Weight of Compacted } \\
\text { Specimen }\left(\mathrm{g} / \mathrm{cm}^{3}\right), \gamma_{\mathrm{m}}\end{array}$ & 1.77 & 1.81 & 1.87 & 2.07 & 2.06 & 2.10 & 1.73 \\
\hline $\begin{array}{l}\text { Dry Unit Weight of Compacted } \\
\text { Specimen }\left(\mathrm{g} / \mathrm{cm}^{3}\right), \gamma_{d}\end{array}$ & 1.64 & 1.65 & 1.68 & 1.83 & 1.83 & 1.82 & 1.47 \\
\hline $\begin{array}{l}\text { Dry Unit Weight of Compacted } \\
\text { Specimen }\left(\mathrm{KN} / \mathrm{m}^{3}\right), \gamma_{d}\end{array}$ & 16.11 & 16.21 & 16.48 & $\mathbf{1 7 . 9 8}$ & 17.94 & $\mathbf{1 7 . 8 0}$ & 14.37 \\
\hline $\begin{array}{l}\text { Dry Unit Weight of Compacted } \\
\text { Specimen }\left(\mathrm{lb} / \mathrm{ft}^{3}\right), \gamma_{d}\end{array}$ & 102.61 & 103.23 & 104.96 & 114.49 & 114.26 & 113.32 & 91.50 \\
\hline $\begin{array}{l}\text { Dry Unit Weight at } S=1.0 \\
\left(K N / \mathbf{m}^{3}\right), \gamma_{d}\end{array}$ & 21.94 & 20.95 & 20.24 & 19.57 & 19.62 & 18.51 & 17.75 \\
\hline $\begin{array}{l}\text { Dry Unit Weight at } S=0.9 \\
\left(K N / \mathbf{m}^{3}\right), Y_{d}\end{array}$ & 21.54 & 20.48 & 19.73 & 19.03 & 19.08 & 17.91 & 17.13 \\
\hline Dry Unit Weight at $S=1.0\left(\mathrm{lb} / \mathrm{ft}^{3}\right), \vee_{\mathrm{d}}$ & 139.72 & 133.38 & 128.87 & 124.61 & 124.92 & 117.84 & 113.05 \\
\hline Dry Unit Weight at $S=0.9\left(1 \mathrm{~b} / \mathrm{ft}^{3}\right), \gamma_{d}$ & 137.17 & 130.41 & 125.63 & 121.15 & 121.48 & 114.07 & 109.10 \\
\hline Void Ratio, $\mathrm{e}=\left(\left(\mathrm{G}_{\mathrm{s}} * \gamma_{\mathrm{w}}\right) / \gamma_{\mathrm{d}}\right)-1$ & 0.63 & 0.62 & 0.60 & 0.46 & 0.47 & 0.48 & 0.83 \\
\hline Degree of Saturation $(\%), \mathrm{S}=\mathrm{G}_{\mathrm{s}} * \mathrm{w} / \mathrm{e}$ & 0.32 & 0.41 & 0.50 & 0.74 & 0.73 & 0.88 & 0.58 \\
\hline Saturated Water Content, $\mathrm{w}_{\text {sat }}(\%)$ & 23.58 & 23.22 & 22.22 & 17.28 & 17.39 & 17.84 & 30.96 \\
\hline
\end{tabular}




\begin{tabular}{|l|r|r|r|r|r|r|r|}
\hline Moisture Content: & & & & & & & \\
\hline \multicolumn{1}{|c|}{ Test Number } & \multicolumn{1}{|c|}{1} & \multicolumn{1}{c|}{2} & \multicolumn{1}{c|}{3} & \multicolumn{1}{c|}{4} & \multicolumn{1}{c|}{5} & \multicolumn{1}{c|}{6} & 7 \\
\hline Assumed moisture content (\%) & 3.00 & 6.00 & 9.00 & 14.00 & 12.00 & 14.00 & 12.00 \\
\hline Container Mass (g), $\mathrm{M}_{\mathrm{c}}$ & 16.74 & 30.45 & 30.69 & 18.73 & 17.40 & 22.00 & 30.11 \\
\hline Container+Moist Specimen Mass (g), $\mathrm{M}_{\mathrm{cms}}$ & 68.55 & 128.84 & 128.77 & 78.87 & 85.68 & 99.55 & 131.87 \\
\hline $\begin{array}{l}\text { Intial Container+Oven Dry Specimen Mass (g), } \\
\mathrm{M}_{\mathrm{cds}}\end{array}$ & 64.96 & 120.25 & 118.89 & 72.02 & 77.97 & 89.01 & 116.37 \\
\hline Mass of Water $(\mathrm{g}), \mathrm{M}_{\mathrm{w}}=\mathrm{M}_{\mathrm{cms}}-\mathrm{M}_{\mathrm{cds}}$ & 3.59 & 8.59 & 9.88 & 6.85 & 7.71 & 10.54 & 15.50 \\
\hline Mass of Solids $(\mathrm{g}), \mathrm{M}_{\mathrm{s}}=\mathrm{M}_{\mathrm{cds}} \mathrm{M}_{\mathcal{c}}$ & 48.22 & 89.80 & 88.20 & 53.29 & 60.57 & 67.01 & 86.26 \\
\hline Water Content, $(\boldsymbol{\%}) \mathbf{W}=\left(\mathbf{M}_{\mathrm{w}} / \mathbf{M}_{\mathbf{s}}\right) \mathbf{x 1 0 0}$ & $\mathbf{7 . 4 5}$ & $\mathbf{9 . 5 7}$ & $\mathbf{1 1 . 2 0}$ & $\mathbf{1 2 . 8 5}$ & $\mathbf{1 2 . 7 3}$ & $\mathbf{1 5 . 7 3}$ & $\mathbf{1 7 . 9 7}$ \\
\hline
\end{tabular}


$11 \%$ Proctor Compaction Energy: $\left(67.85 \mathrm{~kJ} / \mathrm{m}^{3}\right)$

\begin{tabular}{|c|c|c|c|c|c|c|c|}
\hline Compaction Energy $\mathrm{kJ} / \mathrm{m}^{3}\left(\mathrm{ft}-\mathrm{lb} / \mathrm{ft}^{3}\right)$ & 67.85 & 1417) & & & & & \\
\hline Test Number & 1 & 2 & 3 & 4 & 5 & 6 & 7 \\
\hline Assumed moisture content $(\%)$ & 3.00 & 9.00 & 8.00 & 12.00 & 6.00 & 12.00 & 17.00 \\
\hline Mold Weight (g), $\mathrm{M}_{\mathrm{md}}$ & 1985.84 & 1985.84 & 1985.84 & 1985.84 & 1985.84 & 1985.84 & 1985.84 \\
\hline Specimen Weight $(\mathrm{g})$ & 1539.63 & 1871.31 & 1626.85 & 1571.22 & 1613.3 & 1972.17 & 1864 \\
\hline Specimen+Mold Weight $(\mathrm{g}), \mathrm{M}_{\mathrm{t}}$ & 3525.47 & 3857.15 & 3612.69 & 3557.06 & 3599.14 & 3958.01 & 3849.84 \\
\hline Volume of Mold $\left(\mathrm{cm}^{3}\right), \mathrm{V}$ & 940.00 & 940.00 & 940.00 & 940.00 & 940.00 & 940.00 & 940.00 \\
\hline Specific Gravity of Soil, $\mathrm{G}_{\mathrm{s}}$ & 2.69 & 2.69 & 2.69 & 2.69 & 2.69 & 2.69 & 2.69 \\
\hline Unit Weight of Water@ $20^{\circ} \mathrm{C}\left(\mathrm{KN} / \mathrm{m}^{3}\right), \gamma_{w}$ & 9.79 & 9.79 & 9.79 & 9.79 & 9.79 & 9.79 & 9.79 \\
\hline Unit Weight of Water @ $20^{\circ} \mathrm{C}\left(\mathrm{lb} / \mathrm{ft}^{3}\right), \gamma_{w}$ & 62.34 & 62.34 & 62.34 & 62.34 & 62.34 & 62.34 & 62.34 \\
\hline $\begin{array}{l}\text { Moist Unit Weight of Compacted Specimen } \\
\left(\mathrm{g} / \mathrm{cm}^{3}\right), \gamma_{\mathrm{m}}\end{array}$ & 1.64 & 1.99 & 1.73 & 1.67 & 1.72 & 2.10 & 1.98 \\
\hline $\begin{array}{l}\text { Dry Unit Weight of Compacted Specimen } \\
\left(\mathrm{g} / \mathrm{cm}^{3}\right), \gamma_{\mathrm{d}}\end{array}$ & 1.57 & 1.72 & 1.55 & 1.52 & 1.54 & 1.79 & 1.69 \\
\hline $\begin{array}{l}\text { Dry Unit Weight of Compacted Specimen } \\
\left(\mathrm{KN} / \mathrm{m}^{3}\right), \gamma_{d}\end{array}$ & 15.39 & 16.90 & 15.20 & 14.93 & 15.07 & 17.60 & 16.55 \\
\hline $\begin{array}{l}\text { Dry Unit Weight of Compacted Specimen } \\
\left(\mathrm{lb} / \mathrm{ft}^{3}\right), \gamma_{\mathrm{d}}\end{array}$ & 97.98 & 107.64 & 96.82 & 95.05 & 95.97 & 112.05 & 105.40 \\
\hline Dry Unit Weight at $S=1.0\left(K N / \mathrm{m}^{3}\right), \gamma_{d}$ & 23.57 & 18.60 & 20.07 & 20.85 & 20.05 & 18.11 & 17.92 \\
\hline Dry Unit Weight at $S=0.9\left(\mathrm{KN} / \mathrm{m}^{3}\right), \gamma_{d}$ & 23.30 & 18.01 & 19.55 & 20.38 & 19.53 & 17.50 & 17.31 \\
\hline Dry Unit Weight at $\mathrm{S}=1.0\left(\mathrm{lb} / \mathrm{ft}^{3}\right), \gamma_{d}$ & 150.09 & 118.43 & 127.81 & 132.76 & 127.68 & 115.31 & 114.12 \\
\hline Dry Unit Weight at $S=0.9\left(\mathrm{lb} / \mathrm{ft}^{3}\right), \gamma_{d}$ & 148.36 & 114.68 & 124.52 & 129.75 & 124.38 & 111.44 & 110.20 \\
\hline Void Ratio, $e=\left(\left(\mathrm{G}_{\mathrm{s}}{ }^{*} \gamma_{\mathrm{w}}\right) / \gamma_{\mathrm{d}}\right)-1$ & 0.71 & 0.56 & 0.73 & 0.76 & 0.75 & 0.50 & 0.59 \\
\hline Degree of Saturation $(\%), \mathrm{S}=\mathrm{G}_{\mathrm{s}}{ }^{*} \mathrm{w} / \mathrm{e}$ & 0.16 & 0.75 & 0.43 & 0.34 & 0.42 & 0.92 & 0.79 \\
\hline Saturated Water Content, $\mathrm{w}_{\text {sat }}(\%)$ & 26.45 & 20.74 & 27.22 & 28.41 & 27.79 & 18.46 & 21.97 \\
\hline
\end{tabular}




\begin{tabular}{|c|c|c|c|c|c|c|c|}
\hline Moisture Content: & & & & & & & \\
\hline Test Number & 1 & 2 & 3 & 4 & 5 & 6 & 7 \\
\hline Assumed moisture content $(\%)$ & 3.00 & 9.00 & 8.00 & 12.00 & 6.00 & 12.00 & 17.00 \\
\hline Container Mass $(\mathrm{g}), \mathrm{M}_{\mathrm{c}}$ & 17.42 & 18.86 & 18.84 & 17.42 & 18.77 & 30.59 & 30 \\
\hline Container+Moist Specimen Mass (g), $\mathrm{M}_{\mathrm{cms}}$ & 71.98 & 84.78 & 100.32 & 102.02 & 83.17 & 155.85 & 85.92 \\
\hline $\begin{array}{l}\text { Intial Container+Oven Dry Specimen Mass } \\
(\mathrm{g}), \mathrm{M}_{\mathrm{cds}}\end{array}$ & 69.70 & 75.95 & 91.85 & 94.48 & 76.45 & 137.75 & 77.61 \\
\hline Mass of Water $(\mathrm{g}), \mathrm{M}_{\mathrm{w}}=\mathrm{M}_{\mathrm{cms}}-\mathrm{M}_{\mathrm{cds}}$ & 2.28 & 8.83 & 8.47 & 7.54 & 6.72 & 18.10 & 8.31 \\
\hline Mass of Solids $(\mathrm{g}), \mathrm{M}_{\mathrm{s}}=\mathrm{M}_{\mathrm{cds}}-\mathrm{M}_{\mathrm{c}}$ & 52.28 & 57.09 & 73.01 & 77.06 & 57.68 & 107.16 & 47.61 \\
\hline Water Content, $(\%) W=\left(M_{w} / M_{s}\right) \times 100$ & 4.36 & 15.47 & 11.60 & 9.78 & 11.65 & 16.89 & $\mathbf{1 7 . 4 5}$ \\
\hline
\end{tabular}


Appendix III - Grain Size Distribution Testing Data

Post-Permeability Grain Size Distribution Data

Standard Proctor Effort - Sieve analysis data for layer 1 and layer 2

\begin{tabular}{|c|c|c|c|c|c|c|c|c|c|c|c|c|c|}
\hline \multicolumn{14}{|c|}{ Sieve Analysis } \\
\hline \multirow[t]{2}{*}{$\begin{array}{c}\text { Sieve } \\
\text { No. }\end{array}$} & \multirow[t]{2}{*}{$\begin{array}{c}\text { Particle } \\
\text { dia. }(\mathbf{m m})\end{array}$} & \multicolumn{2}{|c|}{ Empty Pan } & \multicolumn{2}{|c|}{$\begin{array}{c}\text { Wt. } \\
\text { Retained+pan }\end{array}$} & \multicolumn{2}{|c|}{ Wt. Retained } & \multicolumn{2}{|c|}{$\%$ Retained } & \multicolumn{2}{|c|}{ Cumulative \% } & \multicolumn{2}{|c|}{ Percent Finer } \\
\hline & & $\begin{array}{l}\text { Layer } \\
1\end{array}$ & $\begin{array}{l}\text { Layer } \\
2\end{array}$ & $\begin{array}{l}\text { Layer } \\
1\end{array}$ & $\begin{array}{l}\text { Layer } \\
2 \\
\end{array}$ & $\begin{array}{l}\text { Layer } \\
1\end{array}$ & $\begin{array}{l}\text { Layer } \\
2\end{array}$ & Layer 1 & Layer 2 & Layer 1 & Layer 2 & $\begin{array}{l}\text { Layer } \\
1\end{array}$ & $\begin{array}{l}\text { Layer } \\
2\end{array}$ \\
\hline 2" & 50.80 & 775.71 & 775.71 & 775.71 & 775.71 & 0.00 & 0.00 & 0.00 & 0.00 & 0.00 & 0.00 & 100.00 & 100.00 \\
\hline No. 4 & 4.76 & 557.13 & 557.13 & 557.13 & 557.13 & 0.00 & 0.00 & 0.00 & 0.00 & 0.00 & 0.00 & 100.00 & 100.00 \\
\hline No. 10 & 2.00 & 469.11 & 469.11 & 680.54 & 768.01 & 211.43 & 298.90 & 39.74 & 47.31 & 39.74 & 47.31 & 60.26 & 52.69 \\
\hline No.30 & 0.60 & 396.30 & 396.30 & 584.04 & 579.53 & 187.74 & 183.23 & 35.29 & 29.00 & 75.03 & 76.31 & 24.97 & 23.69 \\
\hline No. 50 & 0.30 & 370.07 & 370.07 & 418.28 & 426.73 & 48.21 & 56.66 & 9.06 & 8.97 & 84.10 & 85.28 & 15.90 & 14.72 \\
\hline No.60 & 0.25 & 317.98 & 317.98 & 327.81 & 328.64 & 9.83 & 10.66 & 1.85 & 1.69 & 85.94 & 86.96 & 14.06 & 13.04 \\
\hline No.200 & 0.08 & 293.88 & 293.88 & 332.48 & 335.74 & 38.60 & 41.86 & 7.26 & 6.63 & 93.20 & 93.59 & 6.80 & 6.41 \\
\hline \multirow[t]{3}{*}{ Pan } & & 369.66 & 369.66 & 405.53 & 406.74 & 35.87 & 37.08 & 6.74 & 5.87 & 99.94 & 99.46 & 0.06 & 0.54 \\
\hline & & & & & Total & 531.68 & 628.39 & 99.94 & 99.46 & & & & \\
\hline & & $\begin{array}{l}\text { Layer } \\
1\end{array}$ & $\begin{array}{l}\text { Layer } \\
2 \\
\end{array}$ & $\begin{array}{l}\text { Layer } \\
3 \\
\end{array}$ & & & & & & & & & \\
\hline \multicolumn{2}{|c|}{ Mass of Sample } & 531.98 & 631.81 & 489.78 & & & & & & & & & \\
\hline \multicolumn{2}{|c|}{ Mass Loss $(\%)$} & 0.06 & 0.54 & 0.00 & & & & & & & & & \\
\hline
\end{tabular}


Standard Proctor Effort - Sieve analysis data for layer 3

\begin{tabular}{|c|c|c|c|c|c|c|c|}
\hline \multicolumn{8}{|c|}{ Sieve Analysis } \\
\hline Sieve No. & $\begin{array}{c}\text { Particle } \\
\text { dia. }(\mathbf{m m})\end{array}$ & $\begin{array}{c}\text { Empty } \\
\text { Pan }\end{array}$ & $\begin{array}{c}\text { Wt. } \\
\text { Retained+pan }\end{array}$ & Wt. Retained & $\begin{array}{c}\% \\
\text { Retained }\end{array}$ & $\begin{array}{c}\text { Cumulative } \\
\%\end{array}$ & $\begin{array}{c}\text { Percent } \\
\text { Finer }\end{array}$ \\
\hline & & $\begin{array}{c}\text { Layer } \\
3 \\
\end{array}$ & Layer 3 & Layer 3 & Layer 3 & Layer 3 & $\begin{array}{c}\text { Layer } \\
\mathbf{3} \\
\end{array}$ \\
\hline $2 "$ & 50.80 & 775.71 & 775.71 & 0.00 & 0.00 & 0.00 & 100.00 \\
\hline No. 4 & 4.76 & 557.13 & 557.13 & 0.00 & 0.00 & 0.00 & 100.00 \\
\hline No. 10 & 2.00 & 469.11 & 687.10 & 217.99 & 44.51 & 44.51 & 55.49 \\
\hline No.30 & 0.60 & 396.30 & 553.63 & 157.33 & 32.12 & 76.63 & 23.37 \\
\hline No. 50 & 0.30 & 370.07 & 411.06 & 40.99 & 8.37 & 85.00 & 15.00 \\
\hline No.60 & 0.25 & 317.98 & 326.60 & 8.62 & 1.76 & 86.76 & 13.24 \\
\hline No.200 & 0.08 & 293.88 & 326.84 & 32.96 & 6.73 & 93.49 & 6.51 \\
\hline \multirow[t]{2}{*}{ Pan } & & 369.66 & 401.56 & 31.90 & 6.51 & 100.00 & 0.00 \\
\hline & & & Total & 489.79 & 100.00 & & \\
\hline
\end{tabular}


Sieve Analysis

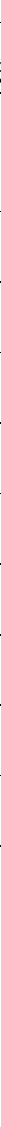


11\% Proctor Compaction Effort - Test 1

Analysis

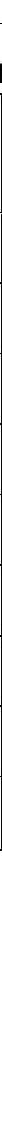


$11 \%$ Proctor Compaction Effort - Test 2

Sieve Analysis

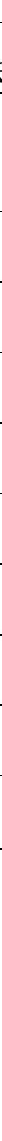


Sieve Analysis

\begin{tabular}{|c|c|c|c|c|c|c|c|c|c|c|c|c|c|c|c|c|c|}
\hline \multicolumn{18}{|c|}{ Sieve Analysis } \\
\hline \multirow{2}{*}{$\begin{array}{c}\text { Particle } \\
\text { dia. } \\
(\mathbf{m m})\end{array}$} & \multicolumn{3}{|c|}{ Empty Pan } & \multicolumn{3}{|c|}{ Wt Retained+pan } & \multicolumn{3}{|c|}{ Wt Retained } & \multicolumn{3}{|c|}{$\%$ Retained } & \multicolumn{3}{|c|}{ Cumulative \% } & \multicolumn{2}{|c|}{ Percent $F$} \\
\hline & \begin{tabular}{|l} 
Layer \\
1
\end{tabular} & $\begin{array}{l}\text { Layer } \\
2\end{array}$ & $\begin{array}{l}\text { Layer } \\
3\end{array}$ & $\begin{array}{l}\text { Layer } \\
1\end{array}$ & $\begin{array}{l}\text { Layer } \\
2\end{array}$ & $\begin{array}{l}\text { Layer } \\
3\end{array}$ & $\begin{array}{l}\text { Layer } \\
1\end{array}$ & $\begin{array}{l}\text { Layer } \\
2\end{array}$ & $\begin{array}{l}\text { Layer } \\
3\end{array}$ & $\begin{array}{l}\text { Layer } \\
1\end{array}$ & $\begin{array}{l}\text { Layer } \\
2\end{array}$ & $\begin{array}{l}\text { Layer } \\
3\end{array}$ & $\begin{array}{l}\text { Layer } \\
1\end{array}$ & $\begin{array}{l}\text { Layer } \\
2\end{array}$ & $\begin{array}{l}\text { Layer } \\
3\end{array}$ & $\begin{array}{l}\text { Layer } \\
1\end{array}$ & $\begin{array}{l}\text { Layer } \\
2\end{array}$ \\
\hline 50.8 & 775.73 & 775.73 & 775.73 & 775.73 & 775.73 & 775.73 & 0 & 0 & 0 & 0.00 & 0.00 & 0.00 & 0.00 & 0.00 & 0.00 & 100.00 & 10 \\
\hline 4.76 & 557.2 & 557.2 & 557.2 & 557.2 & 557.2 & 557.2 & 0 & 0 & 0 & 0.00 & 0.00 & 0.00 & 0.00 & 0.00 & 0.00 & 100.00 & 100.0 \\
\hline 2.00 & 479.19 & 479.23 & 479.26 & 647.7 & 693.04 & 677.5 & 168.51 & 213.81 & 198.24 & 38.73 & 42.72 & 47.67 & 38.73 & 42.72 & 47.67 & 61.27 & 57.2 \\
\hline 0.39 & 481.98 & 482.17 & 482.24 & 626.92 & 630.48 & 598.4 & 144.94 & 148.31 & 116.16 & 33.31 & 29.63 & 27.93 & 72.05 & 72.35 & 75.60 & 27.95 & 27.6 \\
\hline 0.30 & 370.93 & 370.96 & 370.92 & 414.12 & 417.82 & 405.7 & 43.19 & 46.86 & 34.78 & 9.93 & 9.36 & 8.36 & 81.97 & 81.72 & 83.96 & 18.03 & 18.2 \\
\hline 0.25 & 367.15 & 367.1 & 367.03 & 377.85 & 378.20 & 375.67 & 10.7 & 11.1 & 8.64 & 2.46 & 2.22 & 2.08 & 84.43 & 83.93 & 86.04 & 15.57 & $16.0^{\prime}$ \\
\hline 0.08 & 337.94 & 337.97 & 338 & 374.02 & 379.76 & 369.35 & 36.08 & 41.79 & 31.35 & 8.29 & 8.35 & 7.54 & 92.73 & 92.28 & 93.58 & 7.27 & 7.7 \\
\hline & 370.94 & 370.89 & 370.85 & 402.67 & 409.82 & 397.53 & 31.73 & 38.93 & 26.68 & 7.29 & 7.78 & 6.42 & 100.02 & 100.06 & 100.00 & -0.02 & -0.0 \\
\hline & & & & & & Total & 435.15 & 500.8 & 415.85 & 100.02 & 100.06 & 100.00 & & & & & \\
\hline & \begin{tabular}{|l} 
Layer \\
1 \\
\end{tabular} & $\begin{array}{l}\text { Layer } \\
2 \\
\end{array}$ & $\begin{array}{l}\text { Layer } \\
3\end{array}$ & & & & & & & & & & & & & & \\
\hline Sample & 435.06 & 500.49 & 415.87 & & & & & & & & & & & & & & \\
\hline $\operatorname{oss}(\%)$ & -0.02 & -0.06 & 0.00 & & & & & & & & & & & & & & \\
\hline
\end{tabular}




\section{Pre-Permeability Grain Size Distribution Data}

Standard Proctor Compaction Effort - Sieve analysis data for layer 1 and laver 2

\begin{tabular}{|c|c|c|c|c|c|c|c|c|c|c|c|c|c|}
\hline \multirow[t]{2}{*}{$\begin{array}{l}\text { Sieve } \\
\text { No. }\end{array}$} & \multirow[t]{2}{*}{$\begin{array}{l}\text { Particle dia. } \\
(\mathrm{mm})\end{array}$} & \multicolumn{2}{|c|}{ Empty Pan } & \multicolumn{2}{|c|}{ Wt Retained+pan } & \multicolumn{2}{|c|}{ Wt Retained } & \multicolumn{2}{|c|}{$\%$ Retained } & \multicolumn{2}{|c|}{ Cumulative $\%$} & \multicolumn{2}{|c|}{ Percent Finer } \\
\hline & & Layer 1 & Layer 2 & Layer 1 & Layer 2 & Layer 1 & Layer 2 & Layer 1 & Layer2 & Layer 1 & Layer2 & Layer 1 & Layer2 \\
\hline & & & & & & 0 & 0 & 0 & 0 & 0 & 0 & 100 & 100 \\
\hline $2^{\prime \prime}$ & 50.80 & 637.46 & 637.46 & 637.46 & 637.46 & 0 & 0 & 0 & 0 & 0 & 0 & 100 & 100 \\
\hline No. 4 & 4.760 & 556.79 & 556.7 & 556.79 & 556.7 & 0 & 0 & 0 & 0 & 0 & 0 & 100 & 100 \\
\hline No. 10 & 2.000 & 468.86 & 468.78 & 631.62 & 546.41 & 162.76 & 77.63 & 33.53 & 23.34 & 33.53 & 23.34 & 66.47 & 76.66 \\
\hline No. 30 & 0.595 & 409.52 & 409.38 & 561.44 & 510.89 & 151.92 & 101.51 & 31.3 & 30.52 & 64.83 & 53.86 & 35.17 & 46.14 \\
\hline No. 50 & 0.300 & 370.72 & 370.66 & 451.42 & 438.17 & 80.7 & 67.51 & 16.63 & 20.3 & 81.46 & 74.16 & 18.54 & 25.84 \\
\hline No. 60 & 0.250 & 366.81 & 366.87 & 385.25 & 383.01 & 18.44 & 16.14 & 3.8 & 4.85 & 85.26 & 79.01 & 14.74 & 20.99 \\
\hline No. 200 & 0.075 & 335.07 & 334.96 & 383.89 & 382.17 & 48.82 & 47.21 & 10.06 & 14.19 & 95.31 & 93.2 & 4.69 & 6.8 \\
\hline Pan & & 371.62 & 371.73 & 395.12 & 396.68 & 23.5 & 24.95 & 4.84 & 7.5 & 100.15 & 100.7 & -0.15 & -0.7 \\
\hline & & & & & Total & 486.14 & 334.95 & 100.15 & 100.7 & & & & \\
\hline
\end{tabular}


Standard Proctor Compaction Effort - Sieve analysis data for layer 3

\begin{tabular}{|c|c|c|c|c|c|c|c|c|}
\hline \multirow[t]{3}{*}{ No. } & \multicolumn{2}{|c|}{$\begin{array}{l}\text { Particle dia. } \\
(\mathrm{mm})\end{array}$} & $\begin{array}{l}\text { Empty } \\
\text { Pan } \\
\end{array}$ & $\begin{array}{l}\text { Wt } \\
\text { Retained+pan }\end{array}$ & $\begin{array}{l}\text { Wt } \\
\text { Retained }\end{array}$ & $\begin{array}{l}\% \\
\text { Retained } \\
\end{array}$ & $\begin{array}{l}\text { Cumulative } \\
\%\end{array}$ & $\begin{array}{l}\text { Percent } \\
\text { Finer }\end{array}$ \\
\hline & & & Layer 3 & Layer 3 & Layer 3 & Layer 3 & Layer 3 & Layer 3 \\
\hline & & & & & 0 & 0 & 0 & 100 \\
\hline $2 "$ & & 50.800 & 637.46 & 637.46 & 0 & 0 & 0 & 100 \\
\hline No. 4 & & 4.760 & 556.82 & 556.82 & 0 & 0 & 0 & 100 \\
\hline No. 10 & & 2.000 & 468.77 & 571.22 & 102.45 & 36.45 & 36.45 & 63.55 \\
\hline No. 30 & & 0.595 & 409.53 & 497.56 & 88.03 & 31.32 & 67.76 & 32.24 \\
\hline No. 50 & & 0.300 & 370.61 & 412.06 & 41.45 & 14.75 & 82.51 & 17.49 \\
\hline No. 60 & & 0.250 & 366.91 & 376.47 & 9.56 & 3.4 & 85.91 & 14.09 \\
\hline No. 200 & & 0.075 & 334.92 & 360.41 & 25.49 & 9.07 & 94.98 & 5.02 \\
\hline \multirow[t]{3}{*}{ Pan } & & & 371.69 & 386.66 & 14.97 & 5.33 & 100.3 & -0.3 \\
\hline & & & & Total & 281.95 & 100.3 & & \\
\hline & & Layer 1 & Layer 2 & Layer 3 & & & & \\
\hline \multicolumn{2}{|c|}{ Mass of Sample } & 485.39 & 332.61 & 281.10 & & & & \\
\hline \multicolumn{2}{|c|}{ Mass Loss $(\%)$} & -0.15 & -0.70 & -0.30 & & & & \\
\hline
\end{tabular}


$34 \%$ Proctor Compaction Effort - Sieve analysis data for layer 1 and layer 2

\begin{tabular}{|c|c|c|c|c|c|c|c|c|c|c|c|c|c|}
\hline \multicolumn{14}{|c|}{ Sieve Analysis } \\
\hline \multirow{2}{*}{$\begin{array}{c}\text { Sieve } \\
\text { No. }\end{array}$} & \multirow{2}{*}{$\begin{array}{c}\text { Particle } \\
\text { dia. }(\mathbf{m m})\end{array}$} & \multicolumn{2}{|c|}{ Empty Pan } & \multicolumn{2}{|c|}{$\begin{array}{c}\text { Wt. } \\
\text { Retained+pan }\end{array}$} & \multicolumn{2}{|c|}{ Wt. Retained } & \multicolumn{2}{|c|}{$\%$ Retained } & \multicolumn{2}{|c|}{ Cumulative \% } & \multicolumn{2}{|c|}{ Percent Finer } \\
\hline & & $\begin{array}{l}\text { Layer } \\
1\end{array}$ & \begin{tabular}{|l} 
Layer \\
2 \\
\end{tabular} & $\begin{array}{l}\text { Layer } \\
1\end{array}$ & $\begin{array}{l}\text { Layer } \\
2\end{array}$ & $\begin{array}{l}\text { Layer } \\
1\end{array}$ & $\begin{array}{l}\text { Layer } \\
2 \\
\end{array}$ & Layer 1 & Layer 2 & Layer 1 & Layer 2 & $\begin{array}{l}\text { Layer } \\
1\end{array}$ & $\begin{array}{l}\text { Layer } \\
2\end{array}$ \\
\hline $2^{\prime \prime}$ & 50.80 & 775.71 & 775.71 & 775.71 & 775.71 & 0 & 0 & 0 & 0 & 0 & 0 & 100 & 100 \\
\hline No. 4 & 4.76 & 557.43 & 557.43 & 557.43 & 557.43 & 0 & 0 & 0 & 0 & 0 & 0 & 100 & 100 \\
\hline No. 10 & 2.00 & 479.26 & 479.26 & 586.59 & 575.84 & 107.33 & 96.58 & 36.78 & 34.00 & 36.78 & 34.00 & 63.22 & 66.00 \\
\hline No.30 & 0.60 & 481.97 & 481.97 & 588.68 & 580.94 & 106.71 & 98.97 & 36.57 & 34.84 & 73.34 & 68.83 & 26.66 & 31.17 \\
\hline No. 50 & 0.30 & 370.89 & 370.95 & 402.09 & 405.43 & 31.2 & 34.48 & 10.69 & 12.14 & 84.04 & 80.97 & 15.96 & 19.03 \\
\hline No.60 & 0.25 & 367.06 & 367.09 & 374.34 & 375.76 & 7.28 & 8.67 & 2.49 & 3.05 & 86.53 & 84.02 & 13.47 & 15.98 \\
\hline No.200 & 0.08 & 338.03 & 338.03 & 361.75 & 364.91 & 23.72 & 26.88 & 8.13 & 9.46 & 94.66 & 93.48 & 5.34 & 6.52 \\
\hline \multirow[t]{2}{*}{ Pan } & & 370.9 & 370.91 & 388.55 & 392.06 & 17.65 & 21.15 & 6.05 & 7.44 & 100.71 & 100.93 & -0.71 & -0.93 \\
\hline & & & & & Total & 293.89 & 286.73 & 100.71 & 100.93 & & & & \\
\hline & & $\begin{array}{l}\text { Layer } \\
1\end{array}$ & \begin{tabular}{|l} 
Layer \\
2
\end{tabular} & $\begin{array}{l}\text { Layer } \\
\mathbf{3} \\
\end{array}$ & & & & & & & & & \\
\hline Mass of & mple & 291.83 & 284.09 & 535.42 & & & & & & & & & \\
\hline Mass Lo & & -0.71 & -0.93 & -0.97 & & & & & & & & & \\
\hline
\end{tabular}


34\% Proctor Compaction Effort - Sieve analysis data for layer 3

\begin{tabular}{|c|c|c|c|c|c|c|c|}
\hline \multicolumn{8}{|c|}{ Sieve Analysis } \\
\hline $\begin{array}{l}\text { Sieve } \\
\text { No. }\end{array}$ & $\begin{array}{c}\text { Particle } \\
\text { dia. } \\
(\mathrm{mm})\end{array}$ & $\begin{array}{l}\text { Empty } \\
\text { Pan }\end{array}$ & $\begin{array}{c}\text { Wt. } \\
\text { Retained+pan }\end{array}$ & $\begin{array}{c}\text { Wt. } \\
\text { Retained }\end{array}$ & $\begin{array}{c}\% \\
\text { Retained }\end{array}$ & $\underset{\%}{\text { Cumulative }}$ & $\begin{array}{l}\text { Percent } \\
\text { Finer }\end{array}$ \\
\hline & & Layer 3 & Layer 3 & Layer 3 & Layer 3 & Layer 3 & Layer 3 \\
\hline $2^{\prime \prime}$ & 50.80 & 775.71 & 775.71 & 0 & 0 & 0 & 100 \\
\hline No. 4 & 4.76 & 557.43 & 557.43 & 0 & 0 & 0 & 100 \\
\hline No. 10 & 2.00 & 479.26 & 657.49 & 178.23 & 33.29 & 33.29 & 66.71 \\
\hline No.30 & 0.60 & 482.09 & 669.48 & 187.39 & 35.00 & 68.29 & 31.71 \\
\hline No. 50 & 0.30 & 370.94 & 440.01 & 69.07 & 12.90 & 81.19 & 18.81 \\
\hline No.60 & 0.25 & 367.04 & 384.94 & 17.9 & 3.34 & 84.53 & 15.47 \\
\hline No.200 & 0.08 & 338.02 & 387.83 & 49.81 & 9.30 & 93.83 & 6.17 \\
\hline \multirow[t]{2}{*}{ Pan } & & 370.95 & 409.14 & 38.19 & 7.13 & 100.97 & -0.97 \\
\hline & & & Total & 540.59 & 100.97 & & \\
\hline
\end{tabular}


$11 \%$ Proctor Compaction Effort - Sieve analysis data for layer 1 and layer 2

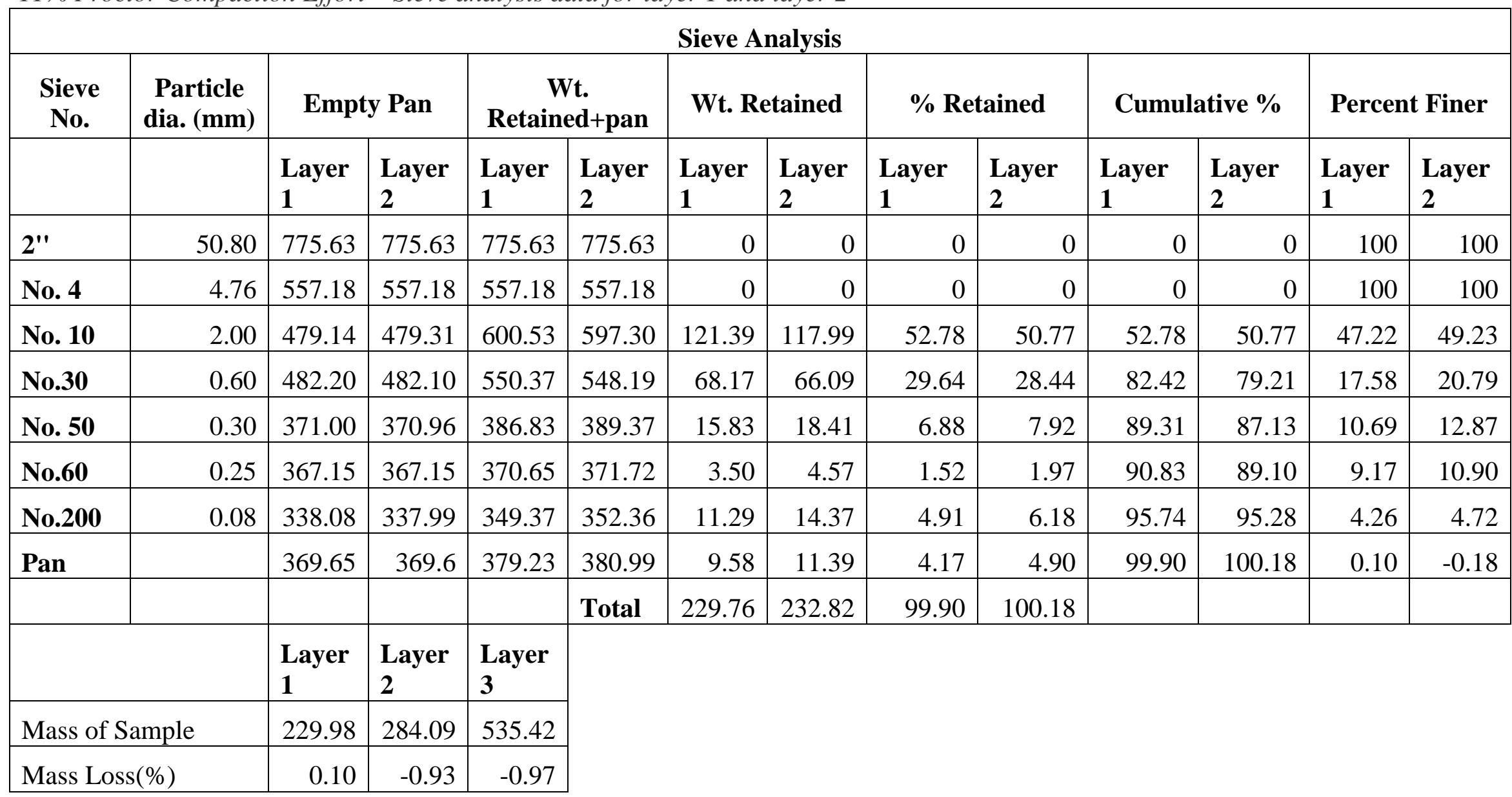


$11 \%$ Proctor Compaction Effort - Sieve analysis data for layer 3

\begin{tabular}{|c|c|c|c|c|c|c|c|}
\hline \multicolumn{8}{|c|}{ Sieve Analysis } \\
\hline Sieve No. & $\begin{array}{c}\text { Particle } \\
\text { dia. }(\mathbf{m m})\end{array}$ & $\begin{array}{c}\text { Empty } \\
\text { Pan }\end{array}$ & $\begin{array}{c}\text { Wt. } \\
\text { Retained+pan }\end{array}$ & $\begin{array}{c}\text { Wt. } \\
\text { Retained }\end{array}$ & $\begin{array}{c}\% \\
\text { Retained }\end{array}$ & $\underset{\%}{\text { Cumulative }}$ & $\begin{array}{c}\text { Percent } \\
\text { Finer }\end{array}$ \\
\hline & & Layer 3 & Layer 3 & Layer 3 & Layer 3 & Layer 3 & Layer 3 \\
\hline $2^{\prime \prime}$ & 50.80 & 775.63 & 775.63 & 0 & 0 & 0 & 100 \\
\hline No. 4 & 4.76 & 557.18 & 557.18 & 0 & 0 & 0 & 100 \\
\hline No. 10 & 2.00 & 479.30 & 604.95 & 125.65 & 46.21 & 46.21 & 53.80 \\
\hline No.30 & 0.60 & 482.04 & 572.07 & 90.03 & 33.11 & 79.31 & 20.69 \\
\hline No. 50 & 0.30 & 370.96 & 394.28 & 23.32 & 8.58 & 87.89 & 12.11 \\
\hline No.60 & 0.25 & 367.07 & 372.22 & 5.15 & 1.89 & 89.78 & 10.22 \\
\hline No.200 & 0.075 & 338.04 & 353.88 & 15.84 & 5.82 & 95.61 & 4.39 \\
\hline \multirow[t]{2}{*}{ Pan } & & 369.67 & 381.82 & 12.15 & 4.47 & 100.07 & -0.07 \\
\hline & & & Total & 272.14 & 100.07 & & \\
\hline
\end{tabular}




\section{As-Received Grain Size Distribution Data: Weathered Sandstone Material}

As Received Grain Size Distribution: Weathered Sandstone Material: Test 1, Test 2

\begin{tabular}{|l|r|r|r|r|r|}
\hline $\begin{array}{c}\text { Sieve } \\
\text { No. }\end{array}$ & $\begin{array}{c}\text { Particle dia. } \\
(\mathbf{m m})\end{array}$ & \multicolumn{2}{c|}{ Cumulative \% } & \multicolumn{2}{c|}{ Percent Finer } \\
\hline & & \multicolumn{1}{|c|}{ Test 1 } & \multicolumn{1}{c|}{ Test 2 } & Test 1 & Test 2 \\
\hline 2" & 50.8 & 0 & 0 & 100 & 100 \\
\hline 1" & 25.4 & 7.29 & 15.04 & 92.71 & 84.96 \\
\hline 3/4" & 19.05 & 18.27 & 17.95 & 81.73 & 82.05 \\
\hline 3/8" & 9.5 & 37.24 & 30.42 & 62.76 & 69.58 \\
\hline No. 4 & 4.76 & 55.99 & 51.7 & 44.01 & 48.3 \\
\hline No. 10 & 2 & 70.08 & 68.04 & 29.92 & 31.96 \\
\hline No. 40 & 0.43 & 84.42 & 86.76 & 15.58 & 13.24 \\
\hline No. 200 & 0.08 & 96.13 & 97.87 & 3.87 & 2.13 \\
\hline Pan & & 99.72 & 99.77 & 0.28 & 0.23 \\
\hline & & & & & \\
\hline
\end{tabular}

\begin{tabular}{|c|c|c|c|c|c|c|c|}
\hline \multicolumn{2}{|c|}{ Empty Pan } & \multicolumn{2}{|c|}{$\begin{array}{c}\text { Wt } \\
\text { Retained+pan } \\
\end{array}$} & \multicolumn{2}{|c|}{ Wt Retained } & \multicolumn{2}{|c|}{$\%$ Retained } \\
\hline Test 1 & Test 2 & Test 1 & Test 2 & Test 1 & Test 2 & Test 1 & Test 2 \\
\hline 638.02 & 638.02 & 638.02 & 638.02 & 0 & 0 & 0 & 0 \\
\hline 584.26 & 584.22 & 620.73 & 659.4 & 36.47 & 75.18 & 7.29 & 15.04 \\
\hline 587.77 & 587.8 & 642.66 & 602.37 & 54.89 & 14.57 & 10.98 & 2.91 \\
\hline 556.02 & 555.83 & 650.86 & 618.2 & 94.84 & 62.37 & 18.97 & 12.47 \\
\hline 517.72 & 585.78 & 611.47 & 692.18 & 93.75 & 106.4 & 18.75 & 21.28 \\
\hline 472.55 & 472.51 & 543 & 554.2 & 70.45 & 81.69 & 14.09 & 16.34 \\
\hline 375.02 & 374.98 & 446.74 & 468.58 & 71.72 & 93.6 & 14.34 & 18.72 \\
\hline 337.9 & 337.93 & 396.45 & 393.45 & 58.55 & 55.52 & 11.71 & 11.1 \\
\hline 371.84 & 372.52 & 389.75 & 382.03 & 17.91 & 9.51 & 3.58 & 1.9 \\
\hline & & & Total & 498.58 & 498.84 & 99.72 & 99.77 \\
\hline
\end{tabular}




\section{As-Received Grain Size Distribution Data: Unweathered Sandstone Overburden}

As Received Grain Size Distribution: Unweathered Sandstone Overburden: Test 1, Test 2

\begin{tabular}{|l|r|r|r|r|r|}
\hline & \multicolumn{2}{|c|}{$\begin{array}{c}\text { Particle dia. } \\
\text { Sieve No. }\end{array}$} & \multicolumn{2}{c|}{ Cumulative \% } & \multicolumn{2}{c|}{ Percent Finer } \\
\hline & & Test 1 & Test 2 & Test 1 & Test 2 \\
\hline 2" & 50.8 & 0 & 0 & 100 & 100 \\
\hline $1 "$ & 25.4 & 0 & 0 & 100 & 100 \\
\hline $3 / 4 "$ & 19.05 & 1.11 & 7.14 & 98.89 & 92.86 \\
\hline $3 / 8 "$ & 9.5 & 14.24 & 20.4 & 85.76 & 79.6 \\
\hline No. 4 & 4.76 & 28.83 & 32.19 & 71.17 & 67.81 \\
\hline No. 10 & 2 & 45.73 & 46.62 & 54.27 & 53.38 \\
\hline No. 40 & 0.43 & 73.73 & 74.03 & 26.27 & 25.97 \\
\hline No. 200 & 0.08 & 94.97 & 95.38 & 5.03 & 4.62 \\
\hline Pan & & 99.88 & 99.91 & 0.12 & 0.09 \\
\hline & & & & & \\
\hline
\end{tabular}

\begin{tabular}{|c|c|c|c|c|c|c|c|}
\hline \multicolumn{2}{|c|}{ Empty Pan } & \multicolumn{2}{|c|}{$\begin{array}{c}\text { Wt } \\
\text { Retained+pan } \\
\end{array}$} & \multicolumn{2}{|c|}{ Wt Retained } & \multicolumn{2}{|c|}{$\%$ Retained } \\
\hline Test 1 & Test 2 & Test 1 & Test 2 & Test 1 & Test 2 & Test 1 & Test 2 \\
\hline 638.02 & 638.02 & 638.02 & 638.02 & 0 & 0 & 0 & 0 \\
\hline 584.36 & 584.4 & 584.36 & 584.4 & 0 & 0 & 0 & 0 \\
\hline 587.78 & 587.83 & 593.31 & 623.53 & 5.53 & 35.7 & 1.11 & 7.14 \\
\hline 555.97 & 556.05 & 621.65 & 622.34 & 65.68 & 66.29 & 13.14 & 13.26 \\
\hline 517.73 & 517.68 & 590.68 & 576.62 & 72.95 & 58.94 & 14.59 & 11.79 \\
\hline 472.58 & 472.5 & 557.05 & 544.68 & 84.47 & 72.18 & 16.89 & 14.44 \\
\hline 375.07 & 374.97 & 515.11 & 512 & 140.04 & 137.03 & 28.01 & 27.41 \\
\hline 337.93 & 337.92 & 444.1 & 444.66 & 106.17 & 106.74 & 21.23 & 21.35 \\
\hline \multirow[t]{2}{*}{371.87} & 371.81 & 396.44 & 394.46 & 24.57 & 22.65 & 4.91 & 4.53 \\
\hline & & & Total & 499.41 & 499.53 & 99.88 & 99.91 \\
\hline
\end{tabular}

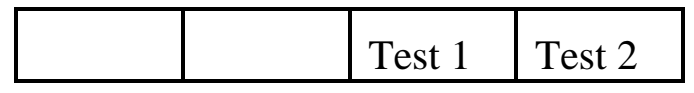




\begin{tabular}{|c|r|r|}
\hline Mass of Sample & 500 & 500 \\
\hline Mass Loss $(\%)$ & 0.12 & 0.09 \\
\hline
\end{tabular}


Appendix IV - Specific Gravity and Atterberg Limit Data

Weathered Sandstone - Specific Gravity - Test 1 Data

\begin{tabular}{|l|r|r|r|}
\hline \multicolumn{1}{|c|}{ Test Number } & \multicolumn{1}{c|}{1} & \multicolumn{1}{c|}{2} & \multicolumn{1}{c|}{3} \\
\hline Temperature, $\mathrm{T}\left({ }^{\mathrm{o}} \mathrm{C}\right)$ & 22.5 & 22.5 & 22.5 \\
\hline Density of Water, $\rho_{\mathrm{w}}(\mathrm{g} / \mathrm{ML})$ & 0.99766 & 0.99766 & 0.99766 \\
\hline Temperature Coefficient, K & 0.99945 & 0.99945 & 0.99945 \\
\hline Volume of Pycnometer, $\mathrm{V}_{\mathrm{p}}(\mathrm{mL})$ & 500 & 500 & 500 \\
\hline Wt. of Pycnometer, $\mathrm{M}_{\mathrm{p}}(\mathrm{g})$ & 166.15 & 167.96 & 160.61 \\
\hline Sample+Pycnomter+Water, $\mathrm{M}_{\mathrm{pws}, \mathrm{t}}(\mathrm{g})$ & 693.76 & 695.76 & 687.47 \\
\hline Pycnometer+Water, $\mathrm{M}_{\mathrm{pw}, \mathrm{t}}(\mathrm{g})$ & 664.35 & 666.04 & 657.59 \\
\hline Dry Sample Mass, $\mathrm{M}_{\mathrm{s}}(\mathrm{g})$ & 46.09 & 46.09 & 46.09 \\
\hline Wt. of Sample $(\mathrm{g})$ & $\mathbf{5 0 . 0 0}$ & 50.00 & 50.00 \\
\hline Specific Gravity of soil solids, $\mathrm{G}_{\mathrm{t}}$ & $\mathbf{2 . 7 6}$ & $\mathbf{2 . 8 2}$ & $\mathbf{2 . 8 4}$ \\
\hline Specific Gravity at Test Temp., $\mathrm{G}_{\mathrm{tt}}$ & $\mathbf{2 . 7 6}$ & $\mathbf{2 . 8 1}$ & $\mathbf{2 . 8 4}$ \\
\hline
\end{tabular}

Specific gravity test 1 results

\begin{tabular}{|l|r|}
\hline \multicolumn{1}{|c|}{ Test Number } & 1 \\
\hline Empty Container, $\mathbf{M}_{\mathrm{c},}(\mathrm{g})$ & 30.00 \\
\hline Container + Wet Sample, $\mathbf{M}_{\mathrm{cms}},(\mathrm{g})$ & 86.48 \\
\hline Container + Dry Sample, $\mathrm{M}_{\mathrm{cds}},(\mathrm{g})$ & 82.66 \\
\hline Moisture content w $(\boldsymbol{\%})$ & $\mathbf{7 . 2 5}$ \\
\hline Average Moisture Content $(\boldsymbol{\%}):$ & $\mathbf{7 . 8 1}$ \\
\hline
\end{tabular}

Water content for determining the dry mass of the test specimen. 
Weathered Sandstone - Specific Gravity - Test 2 Data

\begin{tabular}{|l|r|r|r|}
\hline \multicolumn{1}{|c|}{ Test Number } & \multicolumn{1}{c|}{1} & \multicolumn{1}{c|}{2} & \multicolumn{1}{c|}{3} \\
\hline Temperature, $\mathrm{T}\left({ }^{\circ} \mathrm{C}\right)$ & 22.00 & 22.00 & 22.00 \\
\hline Density of Water, $\rho_{\mathrm{w}, \mathrm{t}}(\mathrm{g} / \mathrm{ML})$ & 0.99777 & 0.99777 & 0.99777 \\
\hline Temperature Coefficient, $\mathrm{K}$ & 0.99957 & 0.99957 & 0.99957 \\
\hline Volume of Pycnometer, $\mathrm{V}_{\mathrm{p}}(\mathrm{mL})$ & 500.00 & 500.00 & 500.00 \\
\hline Wt. of Pycnometer, $\mathrm{M}_{\mathrm{p}}(\mathrm{g})$ & 168.09 & 168.29 & 160.72 \\
\hline Sample+Pycnomter+Water, $\mathrm{M}_{\mathrm{pws}, \mathrm{t}}(\mathrm{g})$ & 693.51 & 695.3 & 687.21 \\
\hline Pycnometer+Water, $\mathrm{M}_{\mathrm{pw}, \mathrm{t}}(\mathrm{g})$ & 664.23 & 666.06 & 657.92 \\
\hline Dry Sample Mass, $\mathrm{M}_{\mathrm{s}}(\mathrm{g})$ & 45.97 & 45.97 & 45.97 \\
\hline Wt. of Sample $(\mathrm{g})$ & 50.00 & 50.00 & 50.00 \\
\hline Specific Gravity of soil solids, $\mathrm{G}_{\mathrm{t}}$ & $\mathbf{2 . 7 5}$ & $\mathbf{2 . 7 5}$ & $\mathbf{2 . 7 6}$ \\
\hline Specific Gravity at Test Temp., $\mathrm{G}_{\mathrm{tt}}$ & $\mathbf{2 . 7 5}$ & $\mathbf{2 . 7 5}$ & $\mathbf{2 . 7 6}$ \\
\hline
\end{tabular}

Specific gravity test 2 results

\begin{tabular}{|l|r|r|r|}
\hline \multicolumn{1}{|c|}{ Test Number } & \multicolumn{1}{c|}{1} & \multicolumn{1}{c|}{2} & \multicolumn{1}{c|}{3} \\
\hline Empty Container, $\mathbf{M}_{\mathrm{c},}(\mathrm{g})$ & 17.41 & 17.3 & 18.77 \\
\hline Container + Wet Sample, $\mathrm{M}_{\mathrm{cms}},(\mathrm{g})$ & 73.92 & 80.97 & 80.85 \\
\hline Container + Dry Sample, $\mathrm{M}_{\mathrm{cds}},(\mathrm{g})$ & 69.63 & 76.29 & 76.22 \\
\hline Moisture content w (\%) & $\mathbf{8 . 2 2}$ & $\mathbf{7 . 9 3}$ & $\mathbf{8 . 0 6}$ \\
\hline Average Moisture Content (\%): & $\mathbf{8 . 0 7}$ & \multicolumn{2}{|c}{} \\
\cline { 1 - 3 } & &
\end{tabular}

Water content for determining the dry mass of the test specimen 
Weathered Sandstone - Atterberg Limit Data

\begin{tabular}{|l|r|r|r|}
\hline \multicolumn{4}{|c|}{ Liquid Limit Test } \\
\hline \multicolumn{1}{|c|}{ Test Number } & \multicolumn{1}{c|}{1} & \multicolumn{1}{c|}{3} & \multicolumn{1}{c|}{5} \\
\hline Empty Container (g) & 16.87 & 17.44 & 30.68 \\
\hline Container + Wet Sample (g) & 28.12 & 29.4 & 43.81 \\
\hline Container + Dry Sample (g) & 25.95 & 26.93 & 41.04 \\
\hline Moisture content, w (\%) & $\mathbf{2 3 . 9}$ & $\mathbf{2 6 . 0 3}$ & $\mathbf{2 6 . 7 4}$ \\
\hline Weight of Water (g) & 2.17 & 2.47 & 2.77 \\
\hline Number of Blows: & 38 & 26 & 19 \\
\hline
\end{tabular}

Liquid Limit test results

\begin{tabular}{|l|c|c|c|}
\hline \multicolumn{4}{|c|}{ Plastic Limit Test } \\
\hline \multicolumn{1}{|c|}{ Test Number } & 2 & 4 & 6 \\
\hline Empty Container (g) & 16.81 & 30.54 & 30.41 \\
\hline Container + Wet Sample (g) & 20.36 & 32.31 & 33.87 \\
\hline Container + Dry Sample (g) & 19.73 & 31.98 & 33.23 \\
\hline Moisture content, w (\%) & $\mathbf{2 1 . 5 8}$ & $\mathbf{2 2 . 9 2}$ & $\mathbf{2 2 . 7}$ \\
\hline Weight of Water (g) & 0.63 & 0.33 & 0.64 \\
\hline
\end{tabular}

Plastic Limit test results 
Unweathered Sandstone - Specific Gravity Data

\begin{tabular}{|c|c|c|c|c|c|c|}
\hline Test Number & 1 & 2 & 3 & 4 & 5 & 6 \\
\hline Temperature, $\mathbf{T}\left({ }^{\circ} \mathrm{C}\right)$ & 22.00 & 22.00 & 22.00 & 22.00 & 22.00 & 22.00 \\
\hline Density of Water, $\rho_{w}(g / m L)$ & 0.99777 & 0.99777 & 0.99777 & 0.99777 & 0.99777 & 0.99777 \\
\hline Temperature Coefficient, $\mathrm{K}$ & 0.99957 & 0.99957 & 0.99957 & 0.99957 & 0.99957 & 0.99957 \\
\hline Volume of Pycnometer, $V_{p}(\mathrm{~mL})$ & 500.00 & 500.00 & 500.00 & 500.00 & 500.00 & 500.00 \\
\hline Wt. of Pycnometer, $M_{p}(g)$ & 167.27 & 169.04 & 160.62 & 159.74 & 152.74 & 154.85 \\
\hline Sample+Pycnomter+Water, $M_{\mathrm{pws}, \mathrm{t}}(\mathrm{g})$ & 694.88 & 696.16 & 688.03 & 688.90 & 681.95 & 683.68 \\
\hline Pycnometer+Water, $M_{\mathrm{pw}, \mathrm{t}}(\mathrm{g})$ & 663.42 & 666.03 & 657.71 & 657.82 & 650.84 & 653.13 \\
\hline Dry Sample Mass, $M_{s}(g)$ & 48.58 & 48.55 & 48.69 & 49.42 & 49.38 & 49.34 \\
\hline Wt. of Sample (g) & 50.00 & 50.00 & 50.00 & 50.00 & 50.00 & 50.00 \\
\hline Specific Gravity of soil solids, $\mathbf{G}_{\mathbf{t}}$ & 2.84 & 2.64 & 2.65 & 2.69 & 2.70 & 2.63 \\
\hline Specific Gravity at Test Temp., $\mathbf{G}_{t t}$ & 2.84 & 2.63 & 2.65 & 2.69 & 2.70 & 2.62 \\
\hline
\end{tabular}

Specific gravity test results

\begin{tabular}{|l|r|r|r|r|r|c|}
\hline Test Number & \multicolumn{1}{|c|}{1} & \multicolumn{1}{c|}{2} & \multicolumn{1}{c|}{3} & \multicolumn{1}{c|}{4} & \multicolumn{1}{c|}{5} & \multicolumn{1}{c|}{6} \\
\hline Empty Container, $\mathbf{M}_{\mathbf{c}}, \mathbf{( g )}$ & 16.89 & 21.79 & 30.03 & 30.47 & 16.76 & 16.84 \\
\hline Container + Wet Sample, $\mathbf{M}_{\mathbf{c m s}}, \mathbf{( g )}$ & 70.86 & 74.82 & 100.21 & 159.29 & 87.45 & 90.81 \\
\hline Container + Dry Sample, $\mathbf{M}_{\mathbf{c d s}}, \mathbf{( g )}$ & 69.37 & 73.33 & 98.42 & 157.82 & 86.58 & 89.85 \\
\hline Moisture content w (\%) & 2.84 & 2.89 & 2.62 & 1.15 & 1.25 & 1.31 \\
\hline Average Moisture Content (\%): & 2.01 & & & & & \\
\hline
\end{tabular}

Moisture content for specific gravity test calculations 
Unweathered Sandstone - Atterberg Limit Data - Test 1

\begin{tabular}{|l|r|r|r|}
\hline \multicolumn{4}{|c|}{ Liquid Limit Test } \\
\hline \multicolumn{1}{|c|}{ Test Number } & \multicolumn{1}{c|}{1} & \multicolumn{1}{c|}{5} & \multicolumn{1}{c|}{3} \\
\hline Empty Container (g) & 18.80 & 30.28 & 16.90 \\
\hline Container + Wet Sample (g) & 32.55 & 45.46 & 35.71 \\
\hline Container + Dry Sample (g) & 30.25 & 43.01 & 33.00 \\
\hline Moisture content, w (\%) & $\mathbf{2 0 . 0 9}$ & $\mathbf{1 9 . 2 5}$ & $\mathbf{1 6 . 8 3}$ \\
\hline Weight of Water (g) & 2.30 & 2.45 & 2.71 \\
\hline Number of Blows: & 16 & 26 & 39 \\
\hline
\end{tabular}

Liquid Limit Results

\begin{tabular}{|l|r|r|r|}
\hline \multicolumn{4}{|c|}{ Plastic Limit Test } \\
\hline \multicolumn{1}{|c|}{ Test Number } & \multicolumn{1}{c|}{2} & \multicolumn{1}{c|}{4} & \multicolumn{1}{c|}{6} \\
\hline Empty Container (g) & 17.4 & 30.46 & 16.9 \\
\hline Container + Wet Sample (g) & 20.1 & 36.29 & 20.3 \\
\hline Container + Dry Sample (g) & 19.71 & 35.51 & 19.82 \\
\hline Moisture content, w (\%) & $\mathbf{1 6 . 8 8}$ & $\mathbf{1 5 . 4 5}$ & $\mathbf{1 6 . 4 4}$ \\
\hline Weight of Water (g) & 0.39 & 0.78 & 0.48 \\
\hline
\end{tabular}

Plastic Limit Results

Unweathered Sandstone - Atterberg Limit Data - Test 2

\begin{tabular}{|l|r|r|r|r|}
\hline \multicolumn{5}{|c|}{ Liquid Limit Test } \\
\hline \multicolumn{1}{|c|}{ Test Number } & \multicolumn{1}{c|}{1} & \multicolumn{1}{c|}{3} & \multicolumn{1}{c|}{5} & \multicolumn{1}{c|}{7} \\
\hline Empty Container (g) & 18.8 & 16.9 & 30.28 & 17.45 \\
\hline Container + Wet Sample (g) & 30.65 & 32.69 & 39.02 & 32.05 \\
\hline Container + Dry Sample (g) & 28.66 & 30.16 & 37.66 & 29.53 \\
\hline Moisture content w (\%) & $\mathbf{2 0 . 1 8}$ & $\mathbf{1 9 . 0 8}$ & $\mathbf{1 8 . 4 3}$ & $\mathbf{2 0 . 8 6}$ \\
\hline Weight of Water (g) & 1.99 & 2.53 & 1.36 & 2.52 \\
\hline Number of Blows: & 17 & 25 & 32 & 15 \\
\hline
\end{tabular}

Liquid Limit Results 


\begin{tabular}{|l|r|c|c|c|}
\hline \multicolumn{5}{|c|}{ Plastic Limit Test } \\
\hline \multicolumn{1}{|c|}{ Test Number } & \multicolumn{1}{c|}{2} & \multicolumn{1}{c|}{4} & \multicolumn{1}{c|}{6} & \multicolumn{1}{c|}{8} \\
\hline Empty Container (g) & 17.4 & 30.46 & 16.9 & 16.87 \\
\hline Container + Wet Sample (g) & 18.82 & 35.48 & 18.44 & 19.61 \\
\hline Container + Dry Sample (g) & 18.62 & 34.74 & 18.22 & 19.24 \\
\hline Moisture content w (\%) & $\mathbf{1 6 . 3 9}$ & $\mathbf{1 7 . 2 9}$ & $\mathbf{1 6 . 6 7}$ & $\mathbf{1 5 . 6 1}$ \\
\hline Weight of Water (g) & 0.2 & 0.74 & 0.22 & 0.37 \\
\hline
\end{tabular}

Plastic Limit Results 


\section{Appendix V - Direct Shear Data}

Unweathered Sandstone - Direct Shear Standard Proctor Compaction Data

\begin{tabular}{|c|c|}
\hline Test Number & DS Specimen \\
\hline Assumed moisture content (\%) & 10.75 \\
\hline Mold Weight (g), $\mathrm{M}_{\mathrm{md}}$ & 2042.22 \\
\hline Specimen+Mold Weight $(\mathrm{g}), \mathrm{M}_{\mathrm{t}}$ & 3965.00 \\
\hline Volume of Mold $\left(\mathrm{cm}^{3}\right), \mathrm{V}$ & 940.00 \\
\hline Specific Gravity of Soil, $\mathrm{G}_{\mathrm{s}}$ & 2.69 \\
\hline Unit Weight of Water@20 $@\left(\mathrm{KN} / \mathrm{m}^{3}\right), \gamma_{\mathrm{w}}$ & 9.79 \\
\hline Unit Weight of Water @ $20^{\circ} \mathrm{C}\left(\mathrm{lb} / \mathrm{ft}^{3}\right), \gamma_{\mathrm{w}}$ & 62.34 \\
\hline Moist Unit Weight of Compacted Specimen $\left(\mathrm{g} / \mathrm{cm}^{3}\right), \gamma_{\mathrm{m}}$ & 2.05 \\
\hline Dry Unit Weight of Compacted Specimen $\left(\mathrm{g} / \mathrm{cm}^{3}\right), \gamma_{d}$ & 1.88 \\
\hline Dry Unit Weight of Compacted Specimen $\left(K N / \mathrm{m}^{3}\right), \gamma_{d}$ & 18.39 \\
\hline Dry Unit Weight of Compacted Specimen $\left(\mathrm{lb} / \mathrm{ft}^{3}\right), \gamma_{\mathrm{d}}$ & 117.11 \\
\hline Dry Unit Weight at $S=1.0\left(K N / \mathrm{m}^{3}\right), \gamma_{d}$ & 21.18 \\
\hline Dry Unit Weight at $S=0.9\left(\mathrm{KN} / \mathrm{m}^{3}\right), \gamma_{d}$ & 20.73 \\
\hline Dry Unit Weight at $\mathrm{S}=1.0\left(\mathrm{lb} / \mathrm{ft}^{3}\right), \gamma_{\mathrm{d}}$ & 134.88 \\
\hline Dry Unit Weight at $S=0.9\left(\mathrm{lb} / \mathrm{ft}^{3}\right), \gamma_{\mathrm{d}}$ & 132.01 \\
\hline Void Ratio, $\mathrm{e}=\left(\left(\mathrm{Gs} * \gamma_{\mathrm{w}}\right) / \gamma_{\mathrm{d}}\right)-1$ & 0.43 \\
\hline Degree of Saturation $(\%), \mathrm{S}=\mathrm{G}_{\mathrm{s}} * \mathrm{w} / \mathrm{e}$ & 0.56 \\
\hline Saturated Water Content, $\mathrm{w}_{\text {sat }}(\%)$ & 16.06 \\
\hline Compaction Energy $\mathrm{kJ} / \mathrm{m}^{3}\left(\mathrm{ft}-\mathrm{lb} / \mathrm{ft}^{3}\right)$ & $592.5(12375)$ \\
\hline Assumed moisture content $(\%)$ & 10.75 \\
\hline Container Mass (g), Mc & 209.89 \\
\hline Container+Moist Specimen Mass (g), Mcms & 572.58 \\
\hline Intial Container+Oven Dry Specimen Mass (g), Mcds & 542.50 \\
\hline Mass of Water $(\mathrm{g}), \mathrm{Mw}=\mathrm{Mcms}-\mathrm{Mcds}$ & 30.08 \\
\hline Mass of Solids (g), Ms= Mcds-Mc & 332.61 \\
\hline Water Content, $(\%) \mathrm{W}=(\mathrm{Mw} / \mathrm{Ms}) \times 100$ & 9.04 \\
\hline
\end{tabular}


Unweathered Sandstone - Direct Shear 34\% Proctor Compaction Data

\begin{tabular}{|c|c|}
\hline Test Number & $\begin{array}{l}\text { 34\% Proctor Energy: } \\
\text { DS }\end{array}$ \\
\hline Assumed moisture content (\%) & 14.5 \\
\hline Mold Weight (g), $\mathrm{M}_{\mathrm{md}}$ & 1985.84 \\
\hline Specimen Weight $(\mathrm{g})$ & 1625.31 \\
\hline Specimen+Mold Weight $(\mathrm{g}), \mathrm{M}_{\mathrm{t}}$ & 4000 \\
\hline Volume of Mold $\left(\mathrm{cm}^{3}\right), \mathrm{V}$ & 940 \\
\hline Specific Gravity of Soil, $\mathrm{G}_{\mathrm{s}}$ & 2.69 \\
\hline Unit Weight of Water @ $20^{\circ} \mathrm{C}\left(\mathrm{KN} / \mathrm{m}^{3}\right), \gamma_{\mathrm{w}}$ & 9.79 \\
\hline Unit Weight of Water@ $20^{\circ} \mathrm{C}\left(\mathrm{lb} / \mathrm{ft}^{3}\right), \gamma_{w}$ & 62.34 \\
\hline Moist Unit Weight of Compacted Specimen $\left(\mathrm{g} / \mathrm{cm}^{3}\right), \gamma_{\mathrm{m}}$ & 2.14 \\
\hline Dry Unit Weight of Compacted Specimen $\left(\mathrm{g} / \mathrm{cm}^{3}\right), \gamma_{d}$ & 1.89 \\
\hline $\begin{array}{l}\text { Dry Unit Weight of Compacted Specimen }\left(\mathrm{KN} / \mathrm{m}^{3}\right) \text {, } \\
Y_{d}\end{array}$ & 18.56 \\
\hline Dry Unit Weight of Compacted Specimen $\left(\mathrm{lb} / \mathrm{ft}^{3}\right), \mathrm{Yd}_{\mathrm{d}}$ & 118.21 \\
\hline Dry Unit Weight at $S=1.0\left(\mathrm{KN} / \mathrm{m}^{3}\right), \gamma_{d}$ & 19.45 \\
\hline Dry Unit Weight at $S=0.9\left(\mathrm{KN} / \mathrm{m}^{3}\right), \gamma_{d}$ & 18.9 \\
\hline Dry Unit Weight at $S=1.0\left(\mathrm{lb} / \mathrm{ft}^{3}\right), \gamma_{d}$ & 123.85 \\
\hline Dry Unit Weight at $S=0.9\left(\mathrm{lb} / \mathrm{ft}^{3}\right), \gamma_{d}$ & 120.35 \\
\hline Void Ratio, $\mathrm{e}=\left(\left(\mathrm{G}_{\mathrm{s}}{ }^{*} \gamma_{\mathrm{w}}\right) / \gamma_{\mathrm{d}}\right)-1$ & 0.42 \\
\hline Degree of Saturation (\%), $\mathrm{S}=\mathrm{G}_{\mathrm{s}}{ }^{*} \mathrm{w} / \mathrm{e}$ & 0.85 \\
\hline Saturated Water Content, $\mathrm{w}_{\text {sat }}(\%)$ & 15.56 \\
\hline Compaction Energy $\mathrm{kJ} / \mathrm{m}^{3}\left(\mathrm{ft}-\mathrm{lb} / \mathrm{ft}^{3}\right)$ & $203.6(4252)$ \\
\hline Assumed moisture content (\%) & 14.5 \\
\hline Container Mass(g), Mc & 17.43 \\
\hline Container+Moist Specimen Mass(g), Mcms & 77.61 \\
\hline Intial Container+Oven Dry Specimen Mass(g), Mcds & 70.61 \\
\hline Mass of Water $(\mathrm{g}), \mathrm{Mw}=$ Mcms-Mcds & 7 \\
\hline Mass of Solids $(\mathrm{g}), \mathrm{Ms}=$ Mcds-Mc & 53.18 \\
\hline Water Content, \% W= (Mw/Ms) $\times 100$ & 13.16 \\
\hline
\end{tabular}


Unweathered Sandstone - Direct Shear 11\% Proctor Compaction Data

\begin{tabular}{|c|c|}
\hline Test Number & $\begin{array}{c}11 \% \text { Proctor } \\
\text { DS }\end{array}$ \\
\hline Assumed moisture content $(\%)$ & 10.50 \\
\hline Mold Weight (g), $\mathrm{M}_{\mathrm{md}}$ & 1988.11 \\
\hline Specimen Weight $(\mathrm{g})$ & 1611.89 \\
\hline Specimen+Mold Weight $(\mathrm{g}), \mathrm{M}_{\mathrm{t}}$ & 3600.00 \\
\hline Volume of Mold $\left(\mathrm{cm}^{3}\right), \mathrm{V}$ & 940.00 \\
\hline Specific Gravity of Soil, $\mathrm{G}_{\mathrm{s}}$ & 2.69 \\
\hline Unit Weight of Water@20ㄷ $\left(\mathrm{KN} / \mathrm{m}^{3}\right), \gamma_{\mathrm{w}}$ & 9.79 \\
\hline Unit Weight of Water@20 $\mathrm{C}\left(\mathrm{lb} / \mathrm{ft}^{3}\right), \gamma_{w}$ & 62.34 \\
\hline Moist Unit Weight of Compacted Specimen $\left(\mathrm{g} / \mathrm{cm}^{3}\right), \gamma_{\mathrm{m}}$ & 1.71 \\
\hline Dry Unit Weight of Compacted Specimen $\left(\mathrm{g} / \mathrm{cm}^{3}\right), \gamma_{\mathrm{d}}$ & 1.71 \\
\hline Dry Unit Weight of Compacted Specimen $\left(\mathrm{KN} / \mathrm{m}^{3}\right), \gamma_{d}$ & 16.81 \\
\hline Dry Unit Weight of Compacted Specimen $\left(\mathrm{lb} / \mathrm{ft}^{3}\right), \gamma_{d}$ & 107.05 \\
\hline Dry Unit Weight at $S=1.0\left(K N / \mathrm{m}^{3}\right), Y_{d}$ & 26.34 \\
\hline Dry Unit Weight at $S=0.9\left(K N / \mathrm{m}^{3}\right), \gamma_{d}$ & 26.34 \\
\hline Dry Unit Weight at $S=1.0\left(\mathrm{lb} / \mathrm{ft}^{3}\right), \gamma_{\mathrm{d}}$ & 167.70 \\
\hline Dry Unit Weight at $S=0.9\left(\mathrm{lb} / \mathrm{ft}^{3}\right), \gamma_{\mathrm{d}}$ & 167.70 \\
\hline Void Ratio, $e=\left(\left(\mathrm{G}_{\mathrm{s}} * \gamma_{\mathrm{w}}\right) / \gamma_{\mathrm{d}}\right)-1$ & 0.57 \\
\hline Degree of Saturation $(\%), \mathrm{S}=\mathrm{G}_{\mathrm{s}}{ }^{*} \mathrm{w} / \mathrm{e}$ & 0.00 \\
\hline Saturated Water Content, $\mathrm{w}_{\text {sat }}(\%)$ & 21.06 \\
\hline Compaction Energy $\mathrm{kJ} / \mathrm{m}^{3}\left(\mathrm{ft}-\mathrm{lb} / \mathrm{ft}^{3}\right)$ & $67.85(1417)$ \\
\hline Assumed moisture content $(\%)$ & 10.50 \\
\hline Container Mass(g), Mc & 30.44 \\
\hline Container+Moist Specimen Mass(g), Mcms & 127.07 \\
\hline Intial Container+Oven Dry Specimen Mass(g), Mcds & 118.27 \\
\hline Mass of Water $(\mathrm{g}), \mathrm{Mw}=$ Mcms-Mcds & 8.80 \\
\hline Mass of Solids(g), Ms= Mcds-Mc & 87.83 \\
\hline Water Content, $\% \mathrm{~W}=(\mathrm{Mw} / \mathrm{Ms}) \times 100$ & 10.02 \\
\hline
\end{tabular}

